\title{
GEOLOGÍA Y GÉNESIS DE LOS DEPÓSITOS BARÍTICO-POLIMETÁLICOS (Ba-Fe-Pb-Cu-Zn-Mn) DEL ÁREA DE COLIPILLI, SECTOR CENTRO-OCCIDENTAL DE LA CUENCA NEUQUINA
}

Lic. Melisa Ariana Salvioli

Directores:

Dra. Mabel E. Lanfranchini

Dr. Raúl E. de Barrio

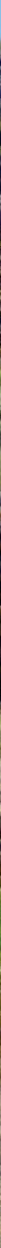


En la portada:

Labor principal de la mina San Eduardo, Colipilli, Neuquén. 


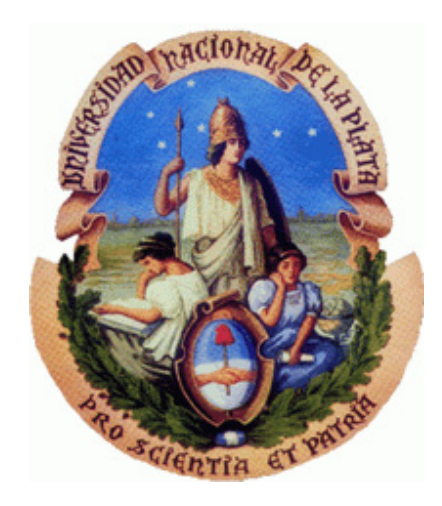

\section{GEOLOGÍA Y GÉNESIS DE LOS DEPÓSITOS BARÍTICO- POLIMETÁLICOS (Ba-Fe-Pb-Cu-Zn-Mn) DEL ÁREA DE COLIPILLI, SECTOR CENTRO - OCCIDENTAL DE LA CUENCA NEUQUINA}

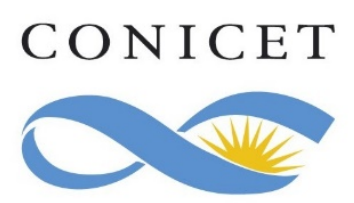

Lic. Melisa Ariana Salvioli

Directores:

Dra. Mabel E. Lanfranchini

Dr. Raúl E. de Barrio

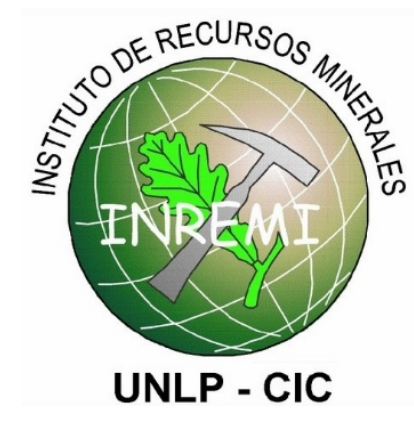

La Plata, 2017 
Lic. Melisa Ariana Salvioli

Consejo Nacional de Investigaciones Científicas y Técnicas (CONICET)

Instituto de Recursos Minerales (INREMI, UNLP-CICBA)

Calle 64 esquina 120, s/n, 1er piso

C.P. 1900, La Plata, Provincia de Buenos Aires, Argentina

Tel. /Fax: (+54 221) 4225648 (Interno 25)

E-mail: melisa_salvioli@hotmail.com.ar 
... a mi querido abuelo Fredy, por su fe en mí y compañía amorosa 


\section{ÍNDICE}

Página

Agradecimientos

Resumen $\quad$ V

$\begin{array}{lll}\text { Abstract } & \text { IX }\end{array}$

CAPÍTULO 1: OBJETIVOS, METODOLOGÍA DE TRABAJO, DESCRIPCIÓN DEL ÁREA DE ESTUDIO

Introducción $\quad 2$

Objetivos 2

Estructura de la Tesis $\quad 3$

Métodos de investigación $\quad 5$

Descripción del área de estudio 13

Trabajos citados en el texto 15

CAPÍTULO 2: GEOLOGÍA REGIONAL 16

$\begin{array}{ll}\text { Introducción } & 17\end{array}$

Antecedentes Estratigráficos $\quad 18$

$\begin{array}{lr}\text { Estratigrafía de la Cuenca Neuquina } & \mathbf{2 0}\end{array}$

Estratigrafía de Unidades Magmáticas

Antecedentes Metalogenéticos $\quad 45$

Trabajos citados en el texto $\quad 46$

CAPÍTULO 3: MARCO TECTÓNICO

Introducción $\quad \mathbf{5 8}$

Faja Plegada y Corrida del Agrio $\quad 58$

Evolución Tectónica $\quad 63$

Trabajos citados en el texto

CAPÍTULO 4: EL MAGMATISMO CRETÁCICO SUPERIOR-TERCIARIO 67

$\begin{array}{lc}\text { Introducción } & \mathbf{6 8}\end{array}$

Geología de las unidades magmáticas

Petrografía

Características Geoquímicas $\quad 79$

Discusión y Conclusiones parciales $\quad 89$

Trabajos citados en el texto 
CAPÍTULO 5: GEOLOGÍA DE LAS MINERALIZACIONES BARÍTICO-POLIMETÁLICAS 93

$\begin{array}{ll}\text { Introducción } & 94\end{array}$

$\begin{array}{ll}\text { Estratigrafía local } & 94\end{array}$

Mineralizaciones barítico-polimetálicas $\quad 98$

A-Depósitos de baritina con sulfuros

$\begin{array}{ll}\text { B-Mineralizaciones de óxidos de hierro } & 113\end{array}$

$\begin{array}{ll}\text { Texturas asociadas a las mineralizaciones } & 117\end{array}$

$\begin{array}{ll}\text { Control litoestratigráfico y estructural } & 127\end{array}$

$\begin{array}{ll}\text { Discusión y Conclusiones parciales } & 128\end{array}$

$\begin{array}{ll}\text { Trabajos citados en el texto } & 131\end{array}$

CAPÍTULO 6: GEOQUÍMICA MINERAL 134

$\begin{array}{ll}\text { Introducción } & 135\end{array}$

Métodos analíticos $\quad 135$

Determinaciones microanalíticas en sulfatos $\quad 136$

Determinaciones microanalíticas en sulfuros y sulfosales $\quad 140$

Determinaciones microanalíticas en óxidos de hierro 143

Discusión y Conclusiones parciales $\quad 146$

$\begin{array}{ll}\text { Trabajos citados en el texto } & 159\end{array}$

CAPÍTULO 7: FLUIDOS MINERALIZANTES 161

INCLUSIONES FLUIDAS

$\begin{array}{ll}\text { Introducción } & 162\end{array}$

Petrografía de inclusiones fluidas con luz trasmitida 162

$\begin{array}{ll}\text { Fluorescencia con luz UV en inclusiones fluidas } & 165\end{array}$

Microtermometría en inclusiones fluidas $\quad 166$

$\begin{array}{ll}\text { Discusión y Conclusiones parciales } & 174\end{array}$

ISÓTOPOS ESTABLES

$\begin{array}{ll}\text { Introducción } & 179\end{array}$

$\begin{array}{ll}\text { Resultados: } & 179\end{array}$

$\begin{array}{lr}\text {-En sulfatos y sulfuros } & 179\end{array}$

$\begin{array}{ll}-E n \text { magnetitas } & 183\end{array}$

$\begin{array}{ll}\text { Discusión y Conclusiones parciales } & 184\end{array}$

$\begin{array}{ll}\text { Trabajos citados en el texto } & 188\end{array}$ 
CAPÍTULO 8: MODELO GENÉTICO Y CONCLUSIONES FINALES 192

Introducción $\quad 193$

Modelo Genético $\quad 195$

$\begin{array}{ll}\text { Conclusiones finales } & 201\end{array}$

$\begin{array}{ll}\text { Trabajos citados en el texto } & 204\end{array}$

$\begin{array}{ll}\text { ANEXOS } & 207\end{array}$

Anexo 1: Coordenadas geográficas de las rocas ígneas analizadas petrográficamente 208

Anexo 2: Mapa geológico del área de estudio $\quad 210$

Anexo 3: Análisis de baritina por microsonda electrónica 212

Anexo 4: Análisis de sulfuros por microsonda electrónica 239

Anexo 5: Análisis de galena por microsonda electrónica 247

Anexo 6: Análisis de magnetita por microsonda electrónica 256 


\section{Agradecimientos}

La realización y ejecución de esta Tesis fue posible gracias a la Universidad Nacional de La Plata (UNLP, FCNyM) quien me permitió seguir formándome como profesional, al Consejo Nacional de Investigaciones Científicas y Técnicas (CONICET) por haberme otorgado una Beca Interna Doctoral, al financiamiento de los proyectos PIP0285 (CONICET), 11N540 y 11N692 (UNLP-FCNyM), a la Society of Economic Geologists (SEG) por haberme otorgado dos becas de apoyo económico y a la ayuda de numerosas personas.

Deseo expresar mi más profundo agradecimiento a mis queridos directores, los Dres. Mabel E. Lanfranchini y Raúl E. de Barrio, por su amistad, compañía y paciencia a lo largo de todo este camino. Su interés, dedicación y disposición permanente me ayudaron a crecer tanto en lo académico y profesional como en lo personal. Del mismo modo, quiero agradecer al Dr. Isidoro B. Schalamuk por permitirme formar parte del Instituto de Recursos Minerales (INREMI), como así también a todos mis compañeros del instituto que de alguna u otra forma me ayudaron a desarrollar esta Tesis.

Este trabajo de investigación no habría sido posible sin el permiso otorgado por la comunidad mapuche del área de Colipilli; mi agradecimiento permanente hacia los Caciques Pedro S. y Juan A. Huayquillán por su amabilidad y cordialidad en cada una de nuestras visitas. A su vez, deseo agradecer al Dr. Clemente Recio Hernández (Universidad de Salamanca, España), Dr. Agustín Martín-Izard (Universidad de Oviedo, España), Dr. Fernando Colombo (Universidad Nacional de Córdoba, Argentina), Dra. Nora N. Cesaretti (Departamento de Geología, UNS) y Dra. Graciela R. Mas (Departamento de Geología, UNS) por haberme facilitado los equipos y resultados analíticos.

Además deseo expresar especial agradecimiento al Dr. Ricardo O. Etcheverry por haber sido director de la Beca Interna Doctoral y estar siempre presente y bien predispuesto a ayudarme, al Lic. Juan Carlos Danieli por su buena predisposición en ayudarme siempre y por su amabilidad y generosidad con que nos recibió todas las veces que lo visitamos, al Lic. Juan Carlos Gómez por su gran ayuda en el procesamiento de imágenes satelitales, a la Dra. Nora N. Cesaretti por lo mucho que aprendí de ella y por su guía en el estudio de las inclusiones fluidas, al Dr. Rodrigo I. Escobar por haberme ayudado durante los trabajos de campo y de gabinete, al Dr. Carlos A. Ballivián Justiniano por brindarme su ayuda de gabinete y compañía desinteresadamente, a la alumna Micaela Colavita por su optimismo y por su muy valiosa ayuda en la confección de varias figuras, a la Lic. Marcela V. Curci por su buena predisposición en ayudarme en el mapeo de las inclusiones fluidas, al Lic. Miguel A. Del Blanco por estar siempre predispuesto a ayudarme en los estudios petro-calcográficos, a la Arq. Adriana González de 
Ganganelli por la elaboración de numerosos dibujos, al Lic. Joaquín Nigro por estar siempre bien predispuesto a ayudarme en las tareas de mapeo con el programa GIS, al DCV. Esteban M. Luna por su colaboración en la parte gráfica, al Sr. José Luis Molina por la realización de numerosos cortes delgados, a la Srita. Marcela Pené por su amabilidad constante y buena predisposición en las tareas administrativas, a la Dra. María Florencia Lajoinie y Lic. Manuela E. Benítez por su compañía diaria.

De la misma forma quiero agradecer a mi amado esposo, mi compañero de la vida, Matías A. Sirini por haber estado incondicionalmente en cada momento de esta etapa. Su alegría, amor y palabras, ayudaron a que mí día a día sea más bello y especial. Asimismo, quiero agradecer profundamente a mis padres amorosos y bondadosos, Ana Ruth y Gustavo, como así también a mis queridos hermanos, Marco y Ailén, por creer en mí y estar siempre. Finalmente, mi más sincero agradecimiento a mis queridos abuelos Fredy, Elvy y Hugo por su compañía tan cariñosa.

Finalmente, deseo agradecer muy especialmente a los jurados, los Dres. Nora N. Cesaretti, Pablo R. Leal e Isidoro B. Schalamuk, por su lectura crítica y constructiva, por todas sus observaciones y comentarios los cuales han mejorado la calidad del presente trabajo de investigación.

Melisa A. Salvioli 


\section{Resumen}

En el sector centro-occidental de la provincia del Neuquén, en la región de Colipilli, se sitúa un conjunto de mineralizaciones barítico-polimetálicas asociadas esencialmente a la secuencia sedimentaria del Cretácico Temprano. Forma parte de una amplia provincia metalogenética que se extiende desde el río Diamante, en la provincia de Mendoza, hasta el sur del Neuquén.

El esquema estratigráfico regional del área investigada presenta una sucesión sedimentaria que va desde el Jurásico Tardío al Cretácico Temprano donde se pueden distinguir fundamentalmente unidades que conforman una alternancia de ciclos sedimentarios marinos y continentales. La sucesión se inicia con el Grupo Mendoza integrado por las Formaciones Vaca Muerta (pelitas y calizas marinas, Tithoniano-Valanginiano Temprano), Mulichinco (areniscas marino-continentales, Valanginiano) y Agrio (Valanginiano TempranoBarremiano); esta última constituida por los Miembros Pilmatué (pelitas y calizas marinas), Avilé (areniscas continentales) y Agua de la Mula (pelitas y calizas marinas). Por encima, continúa la secuencia eocretácica con el Grupo Bajada del Agrio (Grupo Rayoso) integrado por las Formaciones Huitrín (Barremiano-Aptiano) y Rayoso (Albiano-Cenomaniano Inferior). La Formación Huitrín está compuesta por los Miembros Chorreado, Troncoso Inferior, Troncoso Superior, La Tosca y Salina. Estas unidades representan eventos marinos, continentales neríticos y evaporíticos, que trasuntan una compleja historia evolutiva con cambios extremos en las condiciones ambientales. Completa la secuencia cretácica inferior la mencionada Formación Rayoso que agrupa esencialmente areniscas que responden a un ambiente fluvial.

Gran desarrollo presenta en el área el magmatismo diorítico-andesítico del Cretácico Tardío-Paleoceno denominado Grupo Naunauco. En él, se destacan netamente dos facies: una plutónica, la Formación Colipilli, constituida por cuerpos hipabisales tales como diques, filones capa y stocks, y la facies volcánica, representada por las lavas andesíticas de la Formación Cayanta.

Todo el conjunto ha sido sometido a una fuerte tectónica compresional que ha generado la Faja Plegada y Corrida del Agrio (FPyCA) asociada a corrimientos y plegamientos, de rumbo general N-S y que se caracteriza por presentar una historia de deformación multiepisódica conformándose dos zonas: una externa, donde las estructuras son principalmente de "piel fina" y una zona interna con predominio de estructuras de "piel gruesa" producto de la inversión del basamento. 
El Grupo Naunauco representa un magmatismo calco-alcalino, asociado a un ambiente de arco magmático continental que se generó en niveles de emplazamiento somero con aureolas de contacto de muy escaso desarrollo.

Las mineralizaciones barítico-polimetálicas asociadas a la secuencia Cretácica Temprano del área de Colipilli involucran elementos metalotécticos que han sido determinantes para la formación de los depósitos. Por un lado presentan un fuerte control litoestratigráfico, vinculado a facies carbonáticas y a silicoclásticas del Cretácico Temprano, y por otro, un control estructural producto de los distintos eventos de deformación que sufrió la secuencia sedimentaria mesozoica.

La mineralización barítico-polimetálica se aloja mayoritariamente en las facies carbonáticas de tipo grainstone oolítico y mudstone del Miembro Chorreado, en las arenosas finas silicoclásticas pertenecientes al Miembro Troncoso Inferior y carbonáticas de tipo boundstone desarrolladas en el Miembro Troncoso Superior de la Formación Huitrín. Dichas litologías son porosas y permeables, por lo que constituyeron canales muy propicios para la circulación de los fluidos mineralizantes. Por otra parte, las yacencias vetiformes afectan a las Formaciones Vaca Muerta, Mulichinco y Agrio como así también a las magmatitas del Grupo Naunauco, en especial en las superficies de discontinuidad existentes entre éstas y las sedimentitas.

Los depósitos minerales se muestran esencialmente de dos maneras:

1) mantos y vetas estratiformes, encajados mayoritariamente en unidades correspondientes a la Formación Huitrín.

La mineralogía predominante consiste en baritina, con textura cebrada y/o brechosa, y en menor proporción óxidos-hidróxidos de hierro con sulfuros de $\mathrm{Pb}$ subordinados.

Por otra parte, emplazados en horizontes calcáreos finos del Miembro Chorreado de la Formación Huitrín se presentan niveles mantiformes de magnetita.

2) Vetas discordantes que rellenan fracturas y zonas de brechamiento que se alojan en las sedimentitas de las Formaciones Vaca Muerta, Mulichinco, Agrio y Huitrín y en las dioritoandesitas de la Formación Colipilli. La paragénesis mineral está representada mayoritariamente por baritina espática, de grano grueso acompañada de óxidos-hidróxidos de hierro con proporciones minoritarias de galena, y en sectores restringidos, como en mina San Eduardo, por esfalerita, calcopirita, tetraedrita y pirita.

Los depósitos minerales estudiados, fueron a su vez agrupados desde el punto de vista paragenético en: 1) mineralizaciones de baritina con sulfuros, 2) mineralizaciones de óxidos de hierro, donde los procesos mineralizantes predominantes fueron relleno y reemplazo, respectivamente. 
El primer grupo de mineralizaciones se distribuye fundamentalmente en tres sectores: a) área de las minas San Eduardo y La Bienvenida, b) área de las minas La Bruja y Julio César y c) área de las minas Carlita-La Esperanza.

Las mineralizaciones de óxidos de hierro estudiadas fueron mina Augusta y un depósito de Fe situado en el cerro Naunauco, cercano a la mina Manuel Belgrano. En ambos casos la mena está representada por magnetita. Los procesos de reemplazo metasomático han sido predominantes en ambas mineralizaciones.

Las texturas de las mineralizaciones barítico-polimetálicas están representadas esencialmente por dos morfologías bien diferenciadas: textura cebrada y textura brechosa, ésta última desarrollada en varias fases. Por su parte en las mineralizaciones de hierro, la textura predominante es la maciza. Es de señalar, que en mina Augusta se produjo el hallazgo de magnetita laminar, mushketovita, que representa la segunda mención de esta variedad pseudomórfica de magnetita en Argentina.

Los análisis mineraloquímicos por microsonda electrónica revelaron que las baritinas de las diferentes localidades y yacencias del área de Colipilli conforman un conjunto mineral homogéneo con una marcada aproximación al extremo de Ba de la serie isomorfa, siendo clasificadas como baritinas s.s y celestobaritinas. Los contenidos de $\mathrm{BaO}$ fluctúan entre 61,46 y $67,30 \%$ en peso, los de $\mathrm{SrO}$ entre 0,11 y $3,59 \%$ en peso y de $\mathrm{CaO}$ entre 0 y $0,10 \%$ en peso. Se observa en los contenidos de Sr una cierta tendencia a disminuir en las morfologías vetiformes respecto de las estratiformes. Los sulfuros analizados revelan en general valores normales, destacándose el bajo contenido de $\mathrm{Fe}$ en muchos de los granos de esfalerita analizados.

Los estudios microtermométricos de inclusiones fluidas realizados en esquirlas de cristales de baritina permitieron reconocer que se clasifican en monofásicas de tipo L (líquido) y bifásicas de tipo $\mathrm{L}+\mathrm{B}$ (burbuja) y $\mathrm{L}+\mathrm{S}$ (sólido), y minoritariamente multifásicas $\mathrm{L}+\mathrm{B}+\mathrm{S}$, $\mathrm{L}+\mathrm{B}+\mathrm{S} 1+\mathrm{S} 2, \mathrm{~S} 1+\mathrm{S} 2+\mathrm{S} 3$, en tamaños de entre 20 y $30 \mu \mathrm{m}$ hasta $50 \mu \mathrm{m}$.

El análisis por fluorescencia de luz ultravioleta posibilitó reconocer la presencia de hidrocarburos, del tipo ciclohexano, y en algunos casos muy posiblemente metano. En las yacencias estratiformes, durante el calentamiento de las inclusiones bifásicas, la gran mayoría de las burbujas mostraron un movimiento browniano y homogeneizaron a líquido entre $156,2^{\circ}$ y $176,0^{\circ} \mathrm{C}$, con un valor promedio de $162,2^{\circ} \mathrm{C}$. Por su parte, en las morfologías vetiformes las temperaturas de homogeneización variaron entre $163,0^{\circ}$ y $280,6^{\circ} \mathrm{C}$, con un valor promedio de $241{ }^{\circ} \mathrm{C}$. Las salinidades calculadas fueron entre 0,2 y $7,2 \%$, y entre 0,5 y $8,3 \%$ en peso equiv. de $\mathrm{NaCl}$ para las IF de mantos y vetas, respectivamente. 
Los estudios de isótopos estables en $\mathrm{S}$ y $\mathrm{O}$ fueron ejecutados en baritinas, sulfuros y magnetitas. Los valores isotópicos de $\delta^{18} \mathrm{O}_{\mathrm{SMOW}}$ y $\delta^{34} \mathrm{~S}_{\mathrm{CDT}}$ en baritina se encuentran entre $+10,4 \%$ y $+17,0 \%$ y entre $+15,3 \%$ y $+23,4 \%$, respectivamente, mientras que las determinaciones isotópicas realizadas en galena arrojaron valores marcadamente negativos de $\delta^{34} \mathrm{~S}_{\mathrm{CDT}}$ entre $-10,6 \%$ y $-18,6 \%$, sin encontrarse grandes diferencias entre las yacencias mantiformes y las vetiformes.

Los valores $\delta^{18} \mathrm{O}_{\text {SMOW }}$ de las magnetitas de rocas ígneas varían entre un mínimo de 3,3 y un máximo de 6,4. Diferentes son los valores determinados en las mineralizaciones de Fe, Augusta y Naunauco, que alcanzaron a 2,9 y 9,1, respectivamente.

Finalmente, respecto del modelo genético al cual se ha arribado en la presente investigación se puede sostener que en la región de Colipilli se ha implantado un significativo conjunto de sistemas hidrotermales con abundancia de $\mathrm{Ba}$ y metales subordinados $(\mathrm{Pb}-\mathrm{Fe}-\mathrm{Zn}$ $\mathrm{Cu}$ ) vinculados espacialmente a la extendida secuencia eocretácica y a destacados cuerpos intrusivos cretácico-terciarios. El estudio metalogenético de las mineralizaciones permitió considerar y establecer que la formación de los depósitos minerales estuvo acompañada inicialmente por la circulación de fluidos hidrotermales (aguas formacionales calentadas), la migración-expulsión de hidrocarburos y una actividad tectonomagmática que afectó el área de Colipilli. Las características estratigráficas, mineralógicas y texturales de los depósitos en el sector de mina La Bienvenida, son similares a los depósitos MVT subtipo Laisvall, mientras que los rasgos geológicos observados en las mineralizaciones estratiformes de mina San Eduardo parecen asimilarse a una tipología MVT al estilo de los depósitos del Noreste de México. Por otra parte, las sucesivas reactivaciones estructurales, desarrollaron un ambiente favorable para la removilización de las mineralizaciones y la formación de depósitos vetiformes que se alojaron en discontinuidades estratigráficas y en fajas de cizalla con la generación de estructuras brechosas y en mucha menor medida bandeadas.

La fuente de procedencia del Ba muy posiblemente estuvo vinculada a la lixiviación de la pila sedimentaria en especial de las unidades silicoclásticas de las formaciones continentales con feldespatos en rocas tipo "red beds". Las secuencias evaporíticas podrían haber sido la fuente de salmueras sulfuradas capaces de transportar los elementos metálicos (hierro, plomo, cobre) y proveer el azufre. Las pelitas negras tipo "black shales" pudieron convertirse en la fuente con contenidos anómalos de metales.

La fase de deformación de la FPyCA ocurrida durante el Mioceno puede ser que haya favorecido la reactivación de estructuras mineralizadas y los nuevos pulsos de la actividad ígnea (magmatismo Huantraico) haber propiciado un nuevo episodio de removilización y relleno de los depósitos minerales de la región de Colipilli. 


\begin{abstract}
Geology and genesis of barite-polymetallic (Ba-Fe-Pb-Cu-Zn-Mn) deposits from the Colipilli area, central-western sector of the Neuquén basin (Argentina).
\end{abstract}

$\mathrm{Ba}-\mathrm{Fe}-\mathrm{Pb}-\mathrm{Zn}-\mathrm{Cu}$ ore deposits are placed in the Colipilli area, central-western sector of the Neuquén province. These mineralizations are associated essentially with the Lower Cretaceous sedimentary sequence and are part of a metallogenic regional district which extends from the Diamante River in the Mendoza province to the south of the Neuquén Province.

The regional geological setting shows a sedimentary sequence of Upper Jurassic to Lower Cretaceous age with an alternation of marine and continental cycles. The oldest unit is the Mendoza Group formed by the Vaca Muerta Formation (marine pelites and limestones, Early Tithonian-Valanginian), Mulichinco Formation (continental sandstones, Valanginian) and Agrio Formation (Early Valanginian-Barremian). This last unit is comprised of three Members: Pilmatué (marine pelites and limestones). Avilé (continental sandstones) and Agua de la Mula (marine pelites and limestones). Above, the sequence continues with the Bajada del Agrio Group (Rayoso Group) constituted by the Huitrín and Rayoso Formations. The Huitrín Formation (Barremian-Aptian) has five members: Chorreado, Lower Troncoso, Upper Troncoso, La Tosca and Salina. These units represent marine and continental events which reflect a complex evolutionary history with extreme changes in the environmental conditions. The Rayoso Formation (Lower AlbianCenomanian) which is essentially formed by sandstones of continental environment, completes the lower Cretaceous sequence.

The dioritic-andesitic magmatism of the Naunauco Group (Upper CretaceousPaleocen) is well developed in the studied region. It comprises two units: the Colipilli Formation, composed of hypabissal bodies such as dykes, sills and stocks, and the Cayanta Formation, represented by andesitic lavas.

The whole sequence has been subjected to strong compressional tectonics that generated the Faja Plegada y Corrida del Agrio (FPyCA) region. It is associated with thrusts and folds, of general N-S strike and has multiepisodic deformation phases that conform two 
zones: an external one, where the structures are mainly of "thin skin" and an internal zone with predominance of "thick skin" structures product of the basement inversion.

The Naunauco Group represents a calc-alkaline magmatism, related to a continental volcanic arc environment that was generated at shallow depths. The dioritic-andesitic plutons produced contact aureoles of very poor development.

The $\mathrm{Ba}-\mathrm{Fe}-\mathrm{Pb}-\mathrm{Zn}-\mathrm{Cu}$ ore deposits associated with the Lower Cretaceous sequence of the Colipilli area involve some metallotetic elements that were essential for the genesis of these mineralizations. These deposits show a strong lithostratigraphic control linked to carbonaceous and minor siliciclastic lithologies. In addition, they show a structural control resulting from the different deformation events that underwent the Mesozoic sedimentary sequence.

The Ba-polymetallic mineralizations are mostly located in the oolitic grainstones and mudstones of the Chorreado Member, in the fine siliciclastic sandstones of the Lower Troncoso Member, and in the boundstones of the Upper Troncoso Member, all of which belong to the Huitrín Formation. These lithologies are very porous and permeable; therefore, they constitute favorable channels for the circulation of mineralizing fluids. Furthermore, the vein deposits are placed in the Vaca Muerta, Mulichinco and Agrio Formations as well as into the discontinuity surfaces between the andesitic bodies and the sedimentary rocks.

Mineralizations are essentially from two types:

1) mantles and stratiform veins, mostly embedded in the Huitrín Formation.

The main mineralogy consists of abundant barite, and minor iron oxide-hydroxide minerals with subordinate $\mathrm{Pb}, \mathrm{Zn}$ and $\mathrm{Fe}$ sulfides. The predominant textures are zebra and breccia types.

In addition, the Chorreado Member of the Huitrín Formation shows stratiform beds of magnetite located in mudstones with massive texture generated by replacement processes.

2) Discordant veins that fill fractures and breccia zones which are hosted in the Vaca Muerta, Mulichinco, Agrio and Huitrín Formations and in the diorites-andesites of the Colipilli Formation. The mineral paragenesis is represented mainly by sparry coarse barite, accompanied by iron oxides-hydroxides with minor proportions of galena, and in restricted sectors (i.e. San Eduardo mine) with significant amounts of sphalerite, chalcopyrite, tetrahedrite and pyrite. 
The ore deposits were classified from a paragenetic point of view in: 1) barite mineralizations with sulfides, 2) iron oxide (magnetite) mineralizations, where the predominant mineralizing processes were filling and replacement, respectively.

The first group of mineralizations is mainly distributed in three sectors. a) San Eduardo and La Bienvenida mines area; b) La Bruja and Julio César mines area; and c) Carlita-La Esperanza mines area.

The studied iron oxide mineralizations were the Augusta mine and an iron deposit located at the Naunauco hill, near the Manuel Belgrano mine. In both cases the ore is represented by magnetite. Metasomatic replacement processes have been predominant in both mineralizations.

The textures of the barite-polymetallic mineralizations are represented essentially by two types: zebra and breccia, the latter developed in several phases. The predominant texture in the iron mineralizations is massive. It is noteworthy that in the Augusta mine there was a discovery of lamellar magnetite, mushketovite, which represent the second mention of this pseudomorphic variety of magnetite in Argentina.

Mineralochemical studies by electron microprobe analyses have revealed that the barites of the different localities and areas of the Colipilli area constitute an homogeneous mineral assemblage with a manifest approach to the $\mathrm{Ba}$ end of the isomorphic series, being classified as barites s.s and Sr-barites. The contents of $\mathrm{BaO}$ range from 61.46 to $67.30 \%$, $\mathrm{SrO}$ from 0.11 to $3.59 \%$ and $\mathrm{CaO}$ from 0 to $0.10 \%$. There is a certain tendency to a $\mathrm{Sr}$ content decrease in the veins respect the stratiform ones. The sulfide analyses reveal normal values, with a low content of $\mathrm{Fe}$ in many of the sphalerite grains.

The FI microthermometric studies made in barite crystal fragments showed that they are classified as $\mathrm{L}+\mathrm{B}$ (bubble) and $\mathrm{L}+\mathrm{S}$ (solid) type $\mathrm{L}$ (liquid) and biphasic $(\mathrm{L}+\mathrm{S})+\mathrm{S}, \mathrm{L}$ $+\mathrm{B}+\mathrm{S} 1+\mathrm{S} 2, \mathrm{~S} 1+\mathrm{S} 2+\mathrm{S} 3$. Their sizes vary between 20 and $30 \mu \mathrm{m}$, up to an exceptional maximum of $50 \mu \mathrm{m}$.

Fluorescence UV light analysis allows the recognition of the presence of cyclohexane hydrocarbons, and in some cases perhaps methane. During the heating of the biphasic inclusions in the stratiform mineralizations, the great majority of the bubbles showed a Brownian movement and homogenized to a liquid between $156.2^{\circ} \mathrm{C}$ and $176.0^{\circ} \mathrm{C}$, with $162.2{ }^{\circ} \mathrm{C}$ in average. In addition, in the vetiform types the homogenization temperatures vary between $163.0^{\circ} \mathrm{C}$ and $280.6{ }^{\circ} \mathrm{C}$, with $241^{\circ} \mathrm{C}$ in average. The calculated salinities were between 0.2 and $7.2 \%$, and between 0.5 and $8.3 \%$ weight equiv. $\mathrm{NaCl}$ for the stratiform and vein type FI, respectively. 
Stable isotope studies on $\mathrm{S}$ and $\mathrm{O}$ were performed on barites, sulfides and magnetites. The isotopic values of $\delta^{18} \mathrm{O}_{\mathrm{SMOW}}$ and $\delta^{34} \mathrm{~S}_{\mathrm{CDT}}$ in barite are between $+10.4 \%$ and $+17.0 \%$ and between $+15.3 \%$ and $+23.4 \%$, respectively, whereas the isotopic data in galena showed highly negative values of $\delta^{34} \mathrm{~S}_{\mathrm{CDT}}$ between $-10.6 \%$ and $-18.6 \%$, without any significant differences between the stratiform and the vetiform mineralization types.

The $\delta^{18} \mathrm{O}_{\text {SMOw }}$ values of the magnetite of igneous rocks vary between a minimum of 3.3 and a maximum of 6.4. Different values were determined in the mineralizations of Fe, Augusta and Naunauco, which reached 2.9 and 9.1, respectively.

Finally, regarding the genetic model of the $\mathrm{Ba}-\mathrm{Fe}-\mathrm{Pb}-\mathrm{Zn}-\mathrm{Cu}$ ore deposits of the Colipilli region, it can be argued that significant hydrothermal systems are spatially associated to the Early Cretaceous sedimentary sequence and the Upper CretaceousPaleocen magmatic bodies. The metallogenetic investigation permitted to consider and establish a model in which its formation was initially accompanied by the circulation of hydrothermal fluids (heated formational waters), migration-expulsion of hydrocarbons and a concomitant tectonomagmatic activity that affected the Colipilli area. The stratigraphic, mineralogical and textural characteristics of the ore deposits at La Bienvenida mine sector are similar to those of MVT deposits, Laisvall subtype. Besides, the geological features observed in the stratiform mineralizations of the San Eduardo mine seem to be assimilate to a MVT typology such as the Ba-Sr deposits of Northeast Mexico. Moreover, successive structural reactivations developed a favorable environment for the removal of mineralizations and the formation of vetiform deposits that were placed in stratigraphic discontinuities and in shear bands with the generation of breccias structures and to a much lesser extent bundles.

The Ba provenance was very possibly relate to the leaching of the sedimentary pile, especially from the rocks with feldspar of the continental siliciclastic formations ("red beds"). The evaporitic sequences may have been the source of sulfurous brines capable of transporting the metallic elements (iron, lead, copper) and providing sulfur. The black shales could have become a source with anomalous metal contents.

The deformation phase of the FPyCA occurred during the Miocene may have favored the reactivation of previous mineralized structures and the new pulses of the igneous activity (Huantraico magmatism) may have contributed favoring a new episode of remobilization and filling processes in the mineral deposits of the Colipilli region. 


\title{
Capítulo 1
}

\author{
OBJETIVOS \\ METODOLOGÍA DE TRABAJO \\ DESCRIPCIÓN DEL ÁREA DE ESTUDIO
}




\section{Introducción}

El presente trabajo fue desarrollado para ser presentado como Tesis Doctoral en la Facultad de Ciencias Naturales y Museo de la Universidad Nacional de La Plata. Abarca el estudio de la geología y la génesis de las mineralizaciones barítico-polimetálicas (Ba-Fe$\mathrm{Pb}-\mathrm{Cu}-\mathrm{Zn}-\mathrm{Mn}$ ) ubicadas en el área de Colipilli, sector occidental de la Cuenca Neuquina, en la provincia del Neuquén (Fig.1.1).

La importante actividad exploratoria de combustibles fósiles, que ha tenido y tiene la Cuenca Neuquina, la convierte en una de las cuencas sedimentarias más estudiadas y mejor conocidas de la Argentina. También, a mediados del siglo XX, fueron motivo de explotación yacimientos de baritina y celestina a los cuales se asocian en algunos sectores mineralizaciones metalíferas.

Las mineralizaciones presentes en la región de Colipilli forman parte de una amplia provincia metalogenética que se extiende desde el río Diamante, en la provincia de Mendoza, hasta el sur del Neuquén (Llambías y Malvicini 1978). Hasta el presente son escasas las investigaciones en las que se han empleado técnicas analíticas modernas (fluorescencia y microtermometría en inclusiones fluidas, análisis de isótopos estables, geoquímica, entre otras) que permitan clarificar los procesos mineralogenéticos sucedidos en estos depósitos minerales. También son pocas las contribuciones que han tratado de explicar el rol que desempeñó el magmatismo cretácico-terciario, presente en el área de estudio, en la génesis de los depósitos barítico-polimetálicos (Ba-Fe-Pb-Cu-Zn-Mn).

\section{Objetivos}

El objetivo general de este trabajo consistió en la caracterización geológica integral del área del distrito polimetálico Colipilli, mediante análisis mineralógicos, estructurales, petrológicos, geoquímicos y sedimentológicos generales, sustentados en datos concretos que permitieron explicar la génesis de las mineralizaciones estudiadas y el desarrollo de un modelo metalogenético integrando los resultados obtenidos.

Por su parte, los objetivos específicos planteados para la realización de este trabajo de investigación fueron:

- Análisis detallado de la estratigrafía del área con una caracterización litológica de cada una de las unidades sedimentarias y magmáticas que están fuertemente vinculadas a los depósitos minerales. 


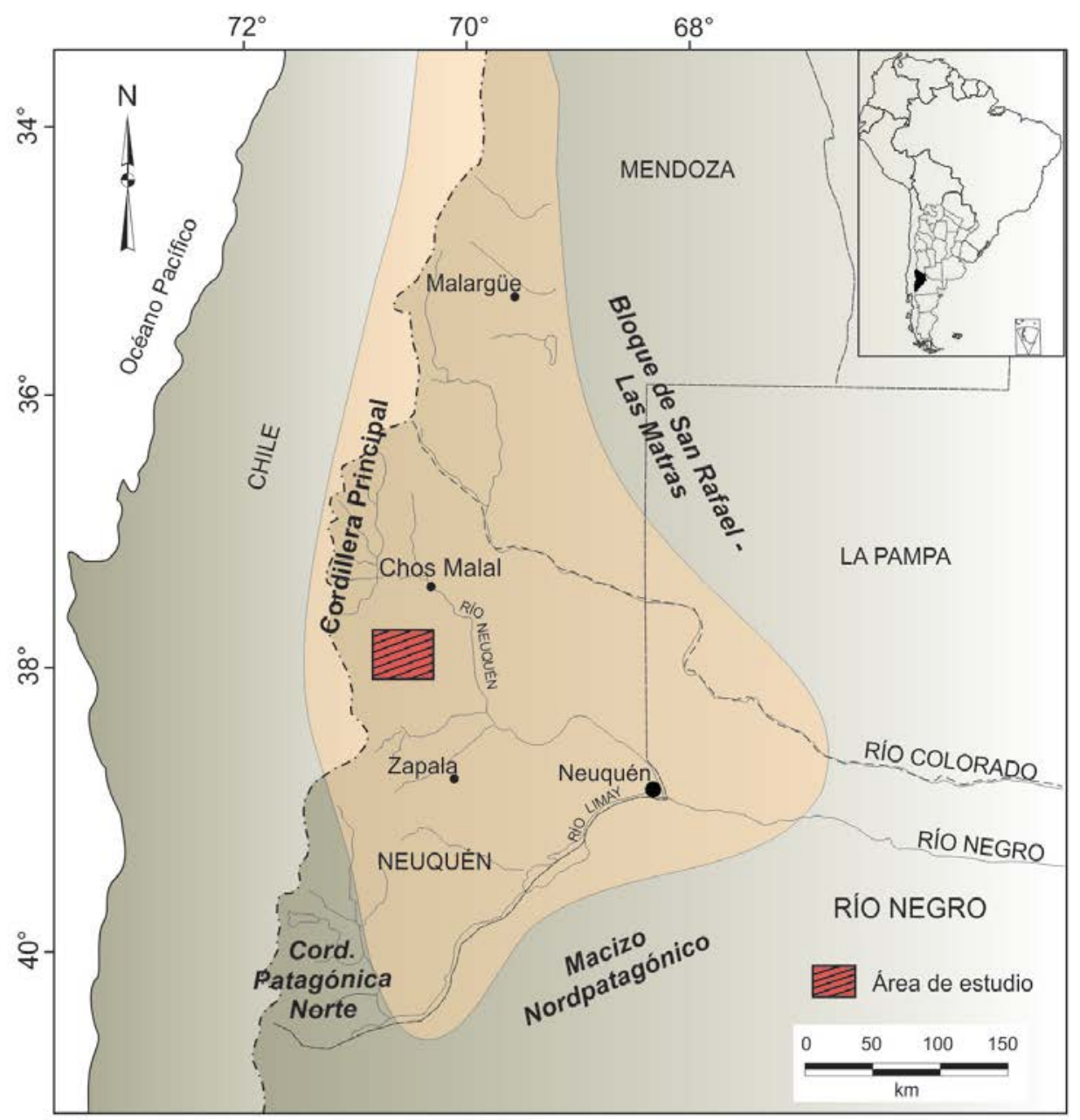

Figura 1.1: Mapa de la Cuenca Neuquina, con sus límites geológicos.

- Caracterización geológica y geoquímica de las rocas sedimentarias y magmáticas y de los depósitos minerales que afloran en el área de estudio.

- Definición de estructuras, su vinculación con la tectónica regional y la relación que tienen con los depósitos minerales.

- Caracterización de los fluidos vinculados a los procesos genéticos de las mineralizaciones, con la identificación de los procesos físico-químicos que intervinieron en la formación de los depósitos.

- Definición de guías metalotécticas a nivel local y regional.

- Divulgación de los resultados a través de publicaciones en revistas periódicas y reuniones científicas específicas. 


\section{Estructura de la tesis}

El presente trabajo de investigación se encuentra organizado en ocho capítulos que muestran en orden cronológico las tareas desarrolladas. Al final de cada uno de los capítulos se detalla la lista de los trabajos citados en el texto.

En el capítulo 1, de carácter introductorio, se expresan los objetivos de la presente Tesis Doctoral y se detallan las distintas metodologías empleadas para la obtención, procesamiento y análisis de los datos; finalmente se describe, de manera general, el área de estudio. En el capítulo 2 se presenta la geología de la región, caracterizándose las unidades sedimentarias, ígneas y los principales rasgos de estructuras deformacionales. El análisis de la geología local del área de Colipilli, en la que se exponen las estructuras de deformación, son tratadas en el capítulo 3.

El capítulo 4 presenta el estudio realizado sobre el magmatismo existente en el área de investigación. Se realiza una caracterización petrológica y geoquímica de las diferentes unidades ígneas.

En el capitulo 5 se abordan detalladamente las mineralizaciones baritopolimetálicas ( $\mathrm{Ba}-\mathrm{Fe}-\mathrm{Pb}-\mathrm{Cu}-\mathrm{Zn})$ presentes en cada uno de los sectores investigados. Se describen los principales afloramientos y los rasgos sedimentarios asociados a la mineralización. Se analizan los controles metalotécticos que influyeron en el transporte y precipitación de los fluidos mineralizantes. También se hace un estudio detallado de las texturas de mineralización. Asimismo, se exponen los análisis geoquímicos de las mineralizaciones.

El análisis de la naturaleza de los fluidos mineralizantes que condujeron a la generación de los depósitos minerales se expone en los capítulos 6 y 7. Se exponen las determinaciones microanalíticas por microsonda electrónica de las diferentes especies minerales estudiadas y se exhiben los resultados obtenidos a partir de la fluorescencia y microtermometría de inclusiones fluidas. Además, se presentan los resultados de análisis de isótopos estables $\left({ }^{34} \mathrm{~S} /{ }^{32} \mathrm{~S}\right.$ y $\left.{ }^{18} \mathrm{O} /{ }^{16} \mathrm{O}\right)$ en baritina, galena y magnetita de distintos sectores representativos de la zona de estudio, hecho que nos permitió determinar el origen de algunos elementos formadores de estos minerales.

En el último capítulo se realiza una discusión sobre los aspectos genéticos de los depósitos acompañada de un modelo genético integral, en el que se consideran los elementos metalotécticos que controlaron la formación de los depósitos y se propone un 
esquema evolutivo-paragenético con los diferentes procesos que sucedieron durante la formación del depósito. Finalmente, se exponen las principales consideraciones finales y conclusiones a las que se han arribado en la presente Tesis Doctoral.

\section{Métodos de Investigación}

A fin de cumplir con todos los objetivos propuestos en esta tesis, los métodos utilizados han sido:

\section{Tratamiento de imágenes satelitales y confección cartográfica}

Se confeccionó un mapa base, a partir del procesamiento de imágenes satelitales (principalmente ASTER y LANDSAT), cartas geológicas (Hoja Geológica 3769-31, Chorriaca 1:100.000 y Carta Geológica-Económica Chos Malal, 1:200.000), mapas geológicos (Llambías y Malvicini 1978 y Llambías y Rapela 1989) y detalles de la zona con Google Earth (Fig.1.2). En el tratamiento de las imágenes satelitales se identificaron los distintos afloramientos que luego fueron analizados y mapeados en el campo. Las cartas geológicas fueron escaneadas y geo-referenciadas en coordenadas Gauss Krüger con datum WGS84 Faja 2 y se rectificaron para eliminar la deformación cónica utilizando un programa de procesamiento digital de imágenes. La geo-referenciación se realizó mediante puntos de control como cruces de rutas, lagunas y resaltos topográficos. Con todo lo anterior se realizó un mosaico digital a escala 1:100.000. Este producto final se exportó a un SIG (Sistema de Información Geográfica) donde se confeccionó el mapa geológico del área, que integró la información aportada por autores que trabajaron previamente en la zona junto con la información nueva producto de este trabajo, superponiendo en distintas capas la información de los datos geológicos y estructurales. Este mapa se utilizó en el campo como base del levantamiento geológico para realizar el estudio y mapeo de detalle de los sectores de interés. Finalmente la edición del mapa se realizó a través de una herramienta informática de diseño gráfico (ArcMap versión 10.0). 


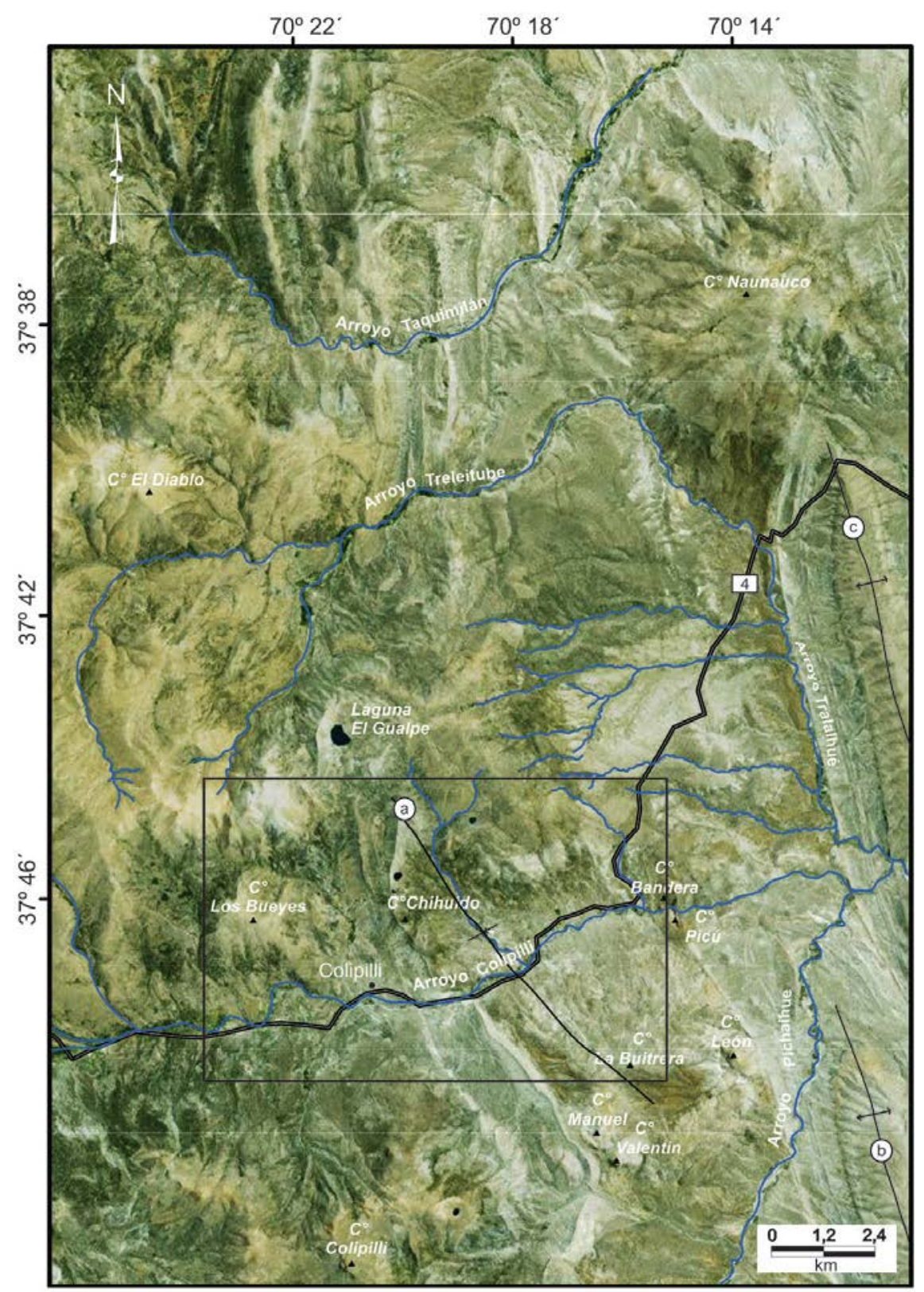

Figura 1.2: Ubicación del área de estudio en imagen satelital Landsat con los principales cerros, estructuras y arroyos. a- sinclinal de Colipilli; b- anticlinal de la sierra de Chorriaca; c- anticlinal de la Loma de Naunauco.

\section{Trabajo de Campo}

Uno de los meses climáticamente más favorables para efectuar las campañas al área de Colipilli fue diciembre. Se ejecutaron tres campañas de veinte días cada una en los años 2012, 2013 у 2014.

Se realizó el reconocimiento de las diversas unidades litológicas y principales estructuras mineralizadas del área de trabajo. Se mapearon los afloramientos de rocas sedimentarias e ígneas utilizando el mapa base para volcar la información. También, se 
realizaron perfiles estratigráficos detallados especialmente en los sectores donde se identificaron diferentes paragénesis minerales. A partir de estas tareas se llevó a cabo el muestreo litológico y geoquímico de las diferentes unidades relevadas. Además, se efectuó la toma de muestras minerales para estudios isotópicos y microtermométricos. En simultáneo, se tomaron datos de carácter estructural: rumbo e inclinación de planos estratigráficos y de fallas así como de ejes de pliegues, etc.

Finalmente, se logró un mapa geológico de las unidades sedimentarias e ígneas aflorantes en la zona, a escala 1:100.000, con algunos sectores de detalle a escala 1:10.000 $-1: 5.000$.

\section{Estudios de Gabinete y Laboratorio}

\section{-Confección de una base de datos bibliográficos:}

Se efectuó una recopilación y análisis del material bibliográfico, especialmente estratigráfico, mineralógico, geocronológico, geotectónico y cartográfico a los fines de construir una base digital de datos.

\section{-Petrografía:}

Se estudió un total de 100 secciones delgadas que incluyeron muestras de las mineralizaciones y de las rocas sedimentarias e ígneas del área con la finalidad de analizar su mineralogía, texturas y estructuras para su posterior caracterización y clasificación. El laboratorio del INREMI cuenta con un microscopio petro-calcográfico marca Nikon modelo Optiphot-POL y un microscopio petrográfico Nikon modelo Eclipse E400-POL.

Los estudios mineralógicos y petrográficos han sido complementados con datos obtenidos a partir de una serie de técnicas instrumentales y analíticas, que se detallan a continuación:

\section{-Análisis por microsonda electrónica:}

Mediante el análisis por microsonda electrónica (EPMA) se obtuvo la composición química de diferentes especies minerales entre las que se pueden citar baritina, galena, esfalerita, calcopirita, tetraedrita y magnetita provenientes de distintos depósitos minerales que permitió la reconstrucción de sus fórmulas estequiométricas; esto permtió comprobar sus variaciones composicionales. Los estudios de las baritinas, galenas, calcopiritas y tetraedritas se realizaron con una microsonda electrónica marca Cameca, modelo Camebax 
SX 100, en el laboratorio de microanálisis del Servicio de Ciencia y Técnica "El Cristo" de la Universidad de Oviedo, España (Fig.1.3a) y en el Departament de Cristallografía, Mineralogia i Diposits Minerals, Universitat de Barcelona, España. Los análisis se realizaron con aceleración de corriente $20 \mathrm{kv}$ e intensidad de corriente de $20 \mathrm{nA}$ y diámetro de haz de electrones entre 1 y $2 \mu \mathrm{m}$ utilizando patrones naturales certificados por MAC (Micro Analysis Consultants Ltd., Reino Unido). Por su parte, la determinación de la composición química de las magnetitas se efectuó en una microsonda electrónica marca JEOL, modelo Superprobe JXA-8230, en el Laboratorio de Análisis de Materiales por Rayos X (LAMARX) de la Universidad Nacional de Córdoba, Argentina (Fig.1.3b). Las condiciones analíticas fueron las siguientes: aceleración de corriente $15 \mathrm{kv}$ e intensidad de corriente entre 10 y 20 nA y diámetro de haz de electrones entre 1 y $2 \mu \mathrm{m}$. Los estándares naturales utilizados fueron: forsterita y rodonita para $\mathrm{Si}$, hornblenda para $\mathrm{Ca}$, ilmenita para $\mathrm{Ti}$, anortita para $\mathrm{Al}, \mathrm{ScVO}_{4}$ para $\mathrm{Sc}$, vanadinita para $\mathrm{V}$, cromita para $\mathrm{Cr}$, fayalita, hematita para $\mathrm{Fe}$, rodonita para $\mathrm{Mn}$, cobalto metálico (puro) para $\mathrm{Co}$, niquelina para $\mathrm{Ni}, \mathrm{ZnO}$ para $\mathrm{Zn}, \mathrm{MgO}$ para $\mathrm{Mg}$, wollastonita, calcita para Ca y ortosa para $\mathrm{K}$.
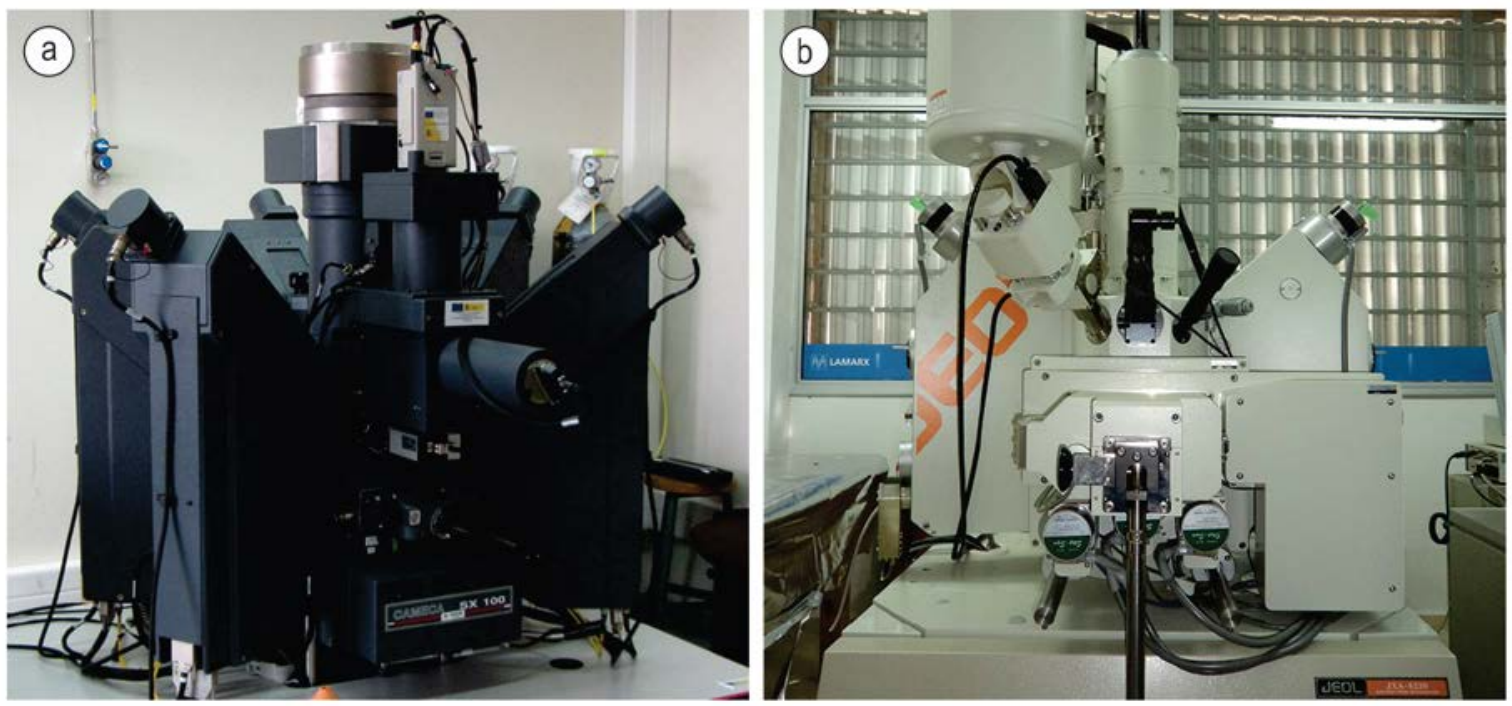

Figura 1.3: a- Microsonda electrónica del Laboratorio de microanálisis del Servicio de Ciencia y Técnica "El Cristo" de la Universidad de Oviedo, España. b- Microsonda electrónica del Laboratorio de Análisis de Materiales por Rayos X (LAMARX) de la Universidad de Córdoba. 


\section{-Difracción de rayos $X$ :}

Los análisis de espectros obtenidos por difracción de rayos X (DRX) se efectuaron mediante un difractómetro Philips PW1710, radiación CuKa $(\lambda=1,5378 \mathrm{~nm})$, con velocidad de barrido $60^{\circ} / \mathrm{h}$, en el Museo de La Plata (FCNyM, UNLP). Se analizaron óxidos, sulfatos $\mathrm{y}$ arcillas.

\section{-Geoquímica de roca total:}

Se determinó la composición química de la mineralización y de las rocas ígneas del área mediante la cuantificación de elementos mayoritarios, minoritarios, trazas y tierras raras. Sobre la base de los estudios petrográficos, se seleccionaron muestras representativas de cada tipo litológico identificado. Parte de estas muestras fueron trituradas y pulverizadas a malla 200 en un molino Herzog equipado con cámaras de molienda de anillos de carburo de tungsteno, para ser analizadas geoquímicamente en el Laboratorio ALS Patagonia S.A. (Argentina), y las muestras de mineralización y rocas ígneas en los laboratorios AcmeLabs (Canadá). Las primeras fueron analizadas con las rutinas analíticas ME-MS41 y Au-ICP22. El contenido de cada elemento se comprobó a partir del análisis por espectrometría de emisión atómica con plasma acoplado inductivamente (ICP-AES). Los patrones utilizados fueron GBM306-12, GBM398-4c, GLG305-3, GPP-02, MG-12, MRGeo08, OREAS-134b y PK2. Las rutinas analíticas empleadas para las rocas ígneas fueron LF 302 y LF 100 EXT. La concentración de cada elemento se determinó mediante el análisis por espectrometría de masas con plasma acoplado inductivamente (ICP-MS). Los patrones utilizados fueron OREAS-45EA, SO-18, DS10, GS311-1 y GS910-4. La pérdida por ignición (LOI) se determinó por calcinación de una fracción de la muestra y medición de la pérdida de peso.

Los resultados obtenidos fueron graficados en distintos diagramas binarios y ternarios, ampliamente utilizados en la bibliografía geológica, con el fin de realizar diferentes clasificaciones geoquímicas. Para clasificar las rocas ígneas se realizó el recálculo de los elementos mayoritarios al 100\% en base anhidra. Estos datos fueron comparados con rocas ígneas de áreas vecinas. 


\section{-Inclusiones fluidas:}

El análisis de inclusiones fluidas, permitió establecer la presencia o ausencia de compuestos orgánicos, salinidad, temperatura y composición de los fluidos que interactuaron con las rocas portadoras de las mineralizaciones. La fluorescencia de inclusiones fluidas se realizó con anterioridad a los ensayos microtermométricos con la finalidad de establecer si estas inclusiones contenían compuestos orgánicos que pudiesen distorsionar los resultados de los ensayos microtermométricos. La fluorescencia es la respuesta, en luz visible, de las inclusiones orgánicas expuestas a la luz ultravioleta (UV). La luz que incide provoca la luminiscencia del material, debido a que los compuestos orgánicos poseen la propiedad de fluorescer cuando son expuestos a esta fuente lumínica. La petrografía de luz ultravioleta fue realizada en el Laboratorio de Luminiscencia del Departamento de Geología de la Universidad Nacional del Sur (UNS), el cual está equipado con un microscopio petrográfico Nikon Eclipse 50iPOL con objetivos de 5x, 10x, 50x y 100x, integrado con una lámpara de mercurio de 100W (halógena) como fuente de iluminación UV, luz verde y azul (Fig.1.4a). Seguidamente se realizaron mediciones microtermométricas en las inclusiones fluidas acuosas hospedadas en baritinas que fueron cuidadosamente mapeadas y clasificadas de acuerdo a los criterios de Roedder (1984) y Nash (1976). Estas mediciones fueron realizadas en esquirlas de baritina en lugar de secciones bipulidas para minimizar la posible deformación de las inclusiones o pérdida de fases por efectos mecánicos. Los estudios termométricos de las inclusiones fluidas se realizaron en el Departamento de Geología de la UNS, en una platina de calentamiento/enfriamiento Linkam MDS 600 (Fig.1.4b), que permite operar entre: $-196^{\circ} \mathrm{C}$ y $600^{\circ} \mathrm{C}$. El proceso de calentamiento/enfriamiento es ejecutado y controlado automáticamente mediante "rampas" o también puede ser controlado de forma manual. Las rampas constituyen las tasas $\left({ }^{\circ} \mathrm{C} / \mathrm{min}\right)$ a la que se desea calentar o enfriar el sistema. Todas las muestras fueron inicialmente enfriadas hasta $-120^{\circ} \mathrm{C}$, y posteriormente, mientras el sistema se recuperaba lentamente, se midieron las temperaturas de la primera fusión (Tfi) y de fusión final del hielo (Tff) (Roedder, 1984). Se determinó la salinidad (\% en peso equiv. de $\mathrm{NaCl}$ ) utilizando la ecuación de Bodnar (1993). Luego se continuó con la rutina de calentamiento para determinar las temperaturas de homogeneización (Th). A partir de dichas temperaturas, se pudo calcular la densidad $\left(\mathrm{g} / \mathrm{cm}^{3}\right)$ y presión de entrampamiento (bares) del fluido. 

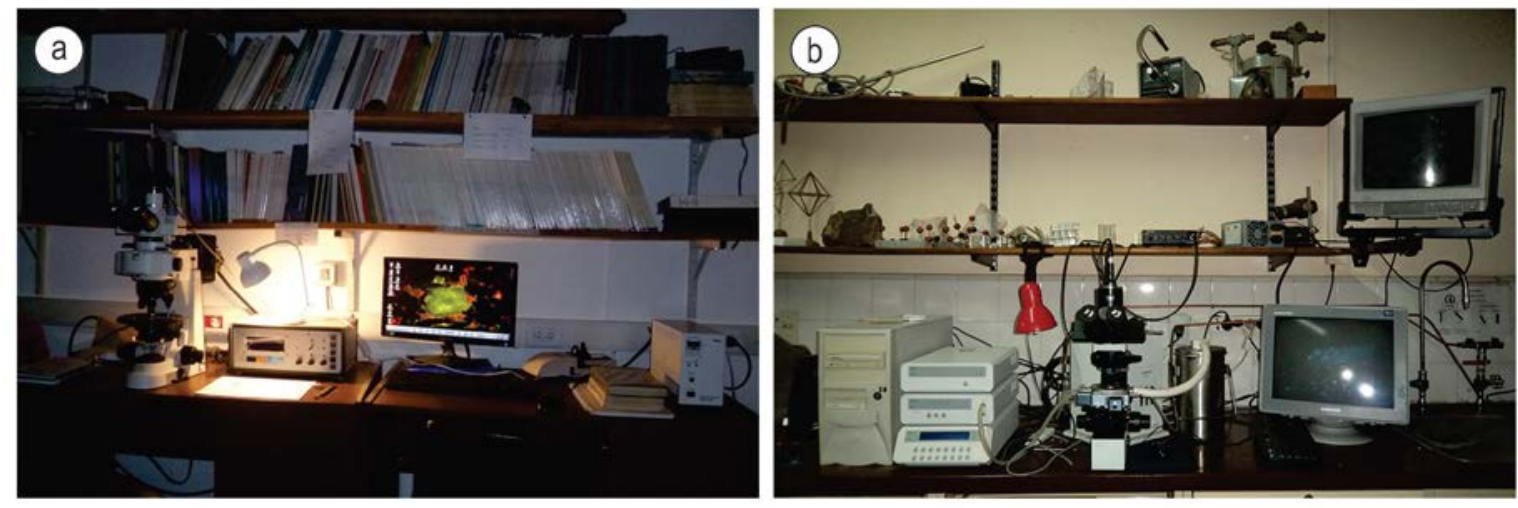

Figura 1.4: Laboratorios para ensayos de inclusiones fluidas del Departamento de Geología de la Universidad del Sur. a- Microscopio petrográfico Nikon eclipse 50i POL integrado con una lámpara de mercurio como fuente de iluminación UV con el fin de realizar lecturas de fluorescencia. b- Platina de calentamiento/enfriamiento Linkam MDS 600 para estudios microtermométricos.

\section{-Isótopos estables:}

Para definir la naturaleza y procedencia de los fluidos mineralizantes que actuaron en el área de estudio se realizaron análisis de isótopos estables ( $\mathrm{O}$ y $\mathrm{S})$ en muestras de la mineralización barito-polimetálica (baritina, galena) así como en minerales de las rocas ígneas y mineralizaciones de Fe (magnetita).
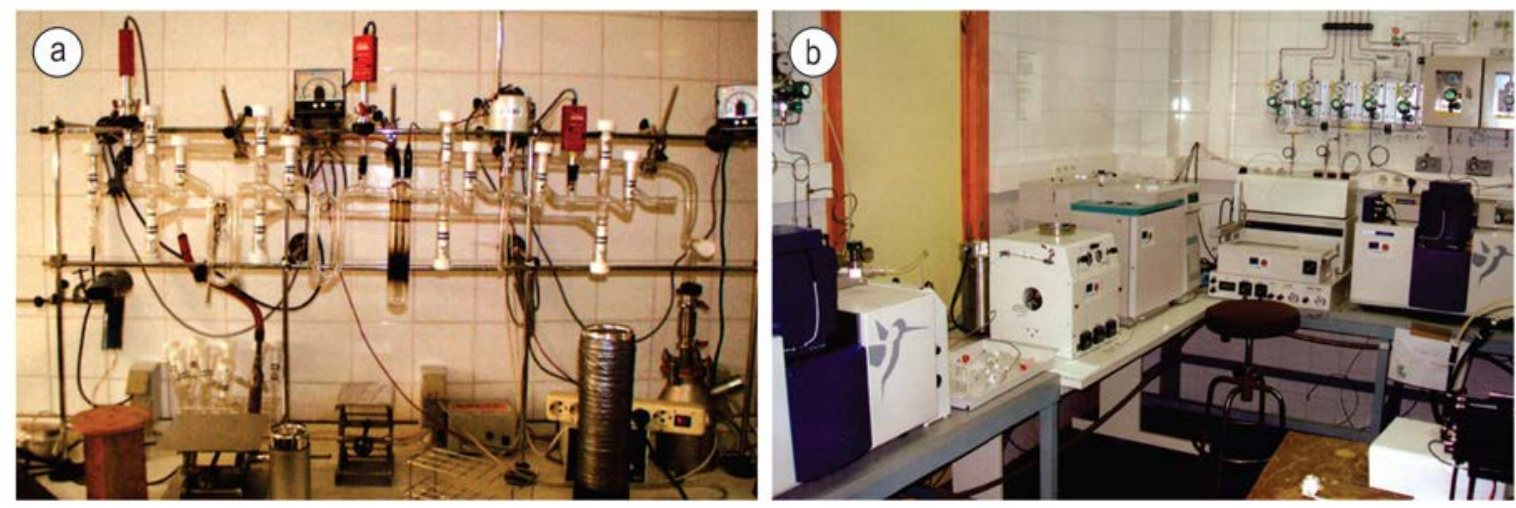

Figura 1.5: a-b: Laboratorios del Servicio de Isótopos Estables de la Universidad de Salamanca.

Las determinaciones isotópicas se realizaron en el Servicio de Isótopos Estables de la Universidad de Salamanca (España) (Fig.1.5) mediante la utilización de un espectrómetro de masas de fuente gaseosa, modelo SIRA-II, fabricado por VG-Isotech, equipado con "cold finger", para análisis de muestras pequeñas y sistema múltiple de admisión de muestras. Los cristales de cada uno de los minerales analizados fueron separados y concentrados en forma manual bajo lupa binocular para su posterior 
tratamiento. Las determinaciones de las relaciones isotópicas ${ }^{34} \mathrm{~S} /{ }^{32} \mathrm{~S}$ se efectuaron por métodos espectroscópicos sobre $\mathrm{SO}_{2}$ obtenido en una línea de alto vacío por combustión en horno tubular a $1070{ }^{\circ} \mathrm{C}$ (en sulfuros) y $1150{ }^{\circ} \mathrm{C}$ (en sulfatos, con $\mathrm{SiO}_{2}$ como catalizador). Los procedimientos ejecutados para la combustión de las muestras fueron realizados de acuerdo a Robinson y Kusakabe (1975) para sulfuros y Coleman y Moore (1978) para sulfatos. La extracción de $\mathrm{CO}_{2}$ de las calcitas se realizó mediante reacción con $\mathrm{H}_{3} \mathrm{PO}_{4}$ al $103 \%$ a $25^{\circ} \mathrm{C}$ durante 12 horas. Las relaciones isotópicas se expresan a través de la notación convencional como valor delta por mil ( $\delta \%$ ), con un error analítico de $\pm 0,2$ por mil para $\delta^{13} \mathrm{C}$ y $\delta^{18} \mathrm{O}$ y $\pm 0,27$ por mil para el $\delta^{34} \mathrm{~S}$. Los resultados están dados con relación al estándar SMOW (Standard Mean Ocean Water) para el $\delta^{18} \mathrm{O}$, con relación al estándar PDB (Belemnitella Americana, de la Formación Peedee, Cretácico de Carolina del Sur, USA) para el $\delta^{13} \mathrm{C}$ y con relación al estándar CDT (Troilita del meteorito del Cañón del Diablo, USA) para el $\delta^{34} \mathrm{~S}$. La información obtenida fue analizada y se volcó en distintos diagramas que permitieron interpretar su origen. 


\section{Descripción del área de estudio}

\section{Descripción geográfica}

El área de estudio se encuentra ubicada en el sector occidental de la Cuenca Neuquina, provincia del Neuquén, en la porción sudoccidental de la Argentina (Fig.1.1) y se extiende aproximadamente entre los paralelos $37^{\circ} 32^{\prime}$ y $37^{\circ} 50^{\prime}$ de latitud sur y los meridianos $70^{\circ} 10^{\prime}$ y $70^{\circ} 26^{\prime}$ de longitud oeste (Fig.1.2). La comarca motivo de estudio pertenece al Departamento de Norquín y se encuentra a $60 \mathrm{~km}$ al sur de la ciudad de Chos Malal y a $130 \mathrm{Km}$ del límite con la provincia de Mendoza. Los límites naturales principales de la zona de estudio son el cerro Naunauco al noreste, el cerro Diablo al Noroeste y el arroyo Colipilli al sur (Fig.1.2).

\section{Oro-hidrografia, rasgos climáticos y biota}

El sector de estudio forma parte, desde el punto de vista orográfico, de la precordillera andina. El relieve de la región se caracteriza por un paisaje serrano con fuertes desniveles conformado por sierras como las de Chorriaca y de Naunauco (Fig.1.2), que presentan cumbres redondeadas y pendientes con inclinación marcada que son el reflejo de una serie de pliegues anticlinales y sinclinales aproximadamente paralelos que afecta a sedimentitas mesozoicas y en menor medida cenozoicas. La secuencia sedimentaria se encuentra intruida por cuerpos de rocas ígneas que constituyen diversos cerros entre los que se destacan los cerros Naunauco y de Los Bueyes por tener las mayores alturas (2.051 msnm y $2.229 \mathrm{msnm}$, respectivamente) y otros de menor altura, que no superan los 1.300 y 1.500 msnm como los cerros Chihuido, León, Picú, Bandera, Manuel y Valentín (Fig.1.2). También cabe mencionar el cerro La Buitrera que se encuentra en el campo de lavas ubicado al sur del arroyo Colipilli, que se caracteriza por la amplia superficie que abarca y su relieve áspero producto de erosión fluvial sobre las rocas ígneas.

Entre los principales cursos fluviales permanentes se destacan los arroyos Colipilli y Pichaihue (Fig.1.2), cuyos rumbos generales son ENE y SE respectivamente. Estos cursos de agua se unen conformando el arroyo Pichi Neuquén, que es uno de los tributarios del río Neuquén, el río más importante del norte de la provincia. Otros cursos de agua permanentes a semipermanentes recorren el área, entre ellos se distinguen los arroyos 
Treleitube, Taquimilán y Tralalhué (Fig.1.2). Además, la zona presenta una gran cantidad de arroyos con regímenes efímeros.

El clima es seco y cálido en verano y frío y húmedo en invierno. Los vientos son moderados a fuertes, lo que constituye un factor adicional de aridez; provienen del sector oeste y noroeste y su época de mayor intensidad es entre los meses de noviembre y marzo. Como en toda zona árida, las precipitaciones son escasas y se registran especialmente en la época invernal.

Debido a que la vegetación depende principalmente del clima y de las condiciones edáficas, es de tipo xerófila, es decir con adaptaciones para resistir períodos de sequía, áfila, por lo general de color verde grisáceo y con raíces de gran desarrollo para aprovechar al máximo el agua de lluvias esporádicas. El tipo más característico de vegetación es el de meseta sobre suelo pedregoso, a veces desnudo, expuesto a los intensos rayos solares y además sometido a temperaturas muy bajas en época invernal. Este está constituido por arbustos bajos no mayores de 1,5 $\mathrm{m}$ de altura, muy espinosos.

Neuquén posee una gran variedad de mamíferos, aves, reptiles y peces. En la parte occidental de la provincia son típicas las especies nativas como las liebres, zorrinos, mulitas, zorros grises y pumas.

\section{Población y Economía}

En el sector de estudio la población es escasa y dispersa. La única concentración urbana es la de Colipilli donde se asienta una reserva mapuche que pertenece a la comunidad Huayquillán.

La actividad económica de la región es reducida y está restringida esencialmente a la cría de ganado caprino y en menor medida vacuno y ovino. Actualmente no se encuentran emprendimientos mineros en actividad. Entre los minerales industriales, la baritina constituyó el recurso más importante de la comarca. Si bien la actividad petrolera es intensa en la Cuenca Neuquina, en esta región los pozos exploratorios realizados no han descubierto acumulaciones de interés económico. 


\section{Trabajos citados en el texto}

Bodnar, R.J. 1993. Revised equation and table for determining the freezing point depression of $\mathrm{H}_{2} \mathrm{O}-\mathrm{NaCl}$ solutions. Geochimica et Cosmochimica Acta, 57: 683-684.

Coleman, M.L. y Moore, M.P. 1978. Direct reduction of sulfates to sulfur dioxide for isotopic analysis. Analytical Chemistry, 50: 1594-1595.

Leanza, H.A., Repol, D., Hugo, C.H. y Sruoga, P. 2006. Hoja Geológica 3769-31, Chorriaca, Provincia del Neuquén. Instituto de Geología y Recursos Minerales. Servicio Geológico Minero Argentino, Boletín 354, 93 p. Buenos Aires.

Llambías, E.J. y Malvicini, L. 1978. Geología, petrología y metalogénesis del área de Colipilli, provincia del Neuquén, República Argentina. Revista de la Asociación Geológica Argentina, 33: 257-276. Buenos Aires.

Nash, J.T. 1976. Fluid inclusion petrology-data from porphyry copper deposits and application to exploration. U. S. Geological Survey, Professional Paper 907-D: 16 p.

Robinson, B.W. y Kusakabe, M. 1975. Quantitative preparation of sulfur dioxide for ${ }^{34} \mathrm{~S} /{ }^{32} \mathrm{~S}$ analyses from sulfides by combustion with cuprous oxide. Analytical Chemistry 47:11791181.

Roedder, E. 1984. Fluid Inclusions. Mineralogical Society of America. Reviews in Mineralogy, 12, $644 \mathrm{p}$. 


\section{Capítulo 2}

GEOLOGÍA REGIONAL 


\section{Introducción}

La Cuenca Neuquina abarca geográficamente casi la totalidad de la provincia del Neuquén, el sector occidental de las provincias de Río Negro y La Pampa, y la parte suroccidental de la provincia de Mendoza. Geológicamente, los límites noreste y sureste son el bloque de San Rafael-Las Matras y el Macizo Nordpatagónico respectivamente, mientras que su límite occidental es el arco volcánico formado en la cordillera andina. Se trata de una cuenca de retroarco (Ramos 1978; Vergani et al., 1995) de más de 160.000 $\mathrm{km}^{2}$, de forma aproximadamente triangular. Las principales unidades morfoestructurales de la cuenca son las siguientes: 1) Cordillera Principal; 2) Faja Plegada y Corrida del Agrio; 3) Dorsal de Huincul; 4) Dorso de los Chihuidos; 5) Engolfamiento Neuquino y 6) Fosa de Loncopué (Fig.2.1).

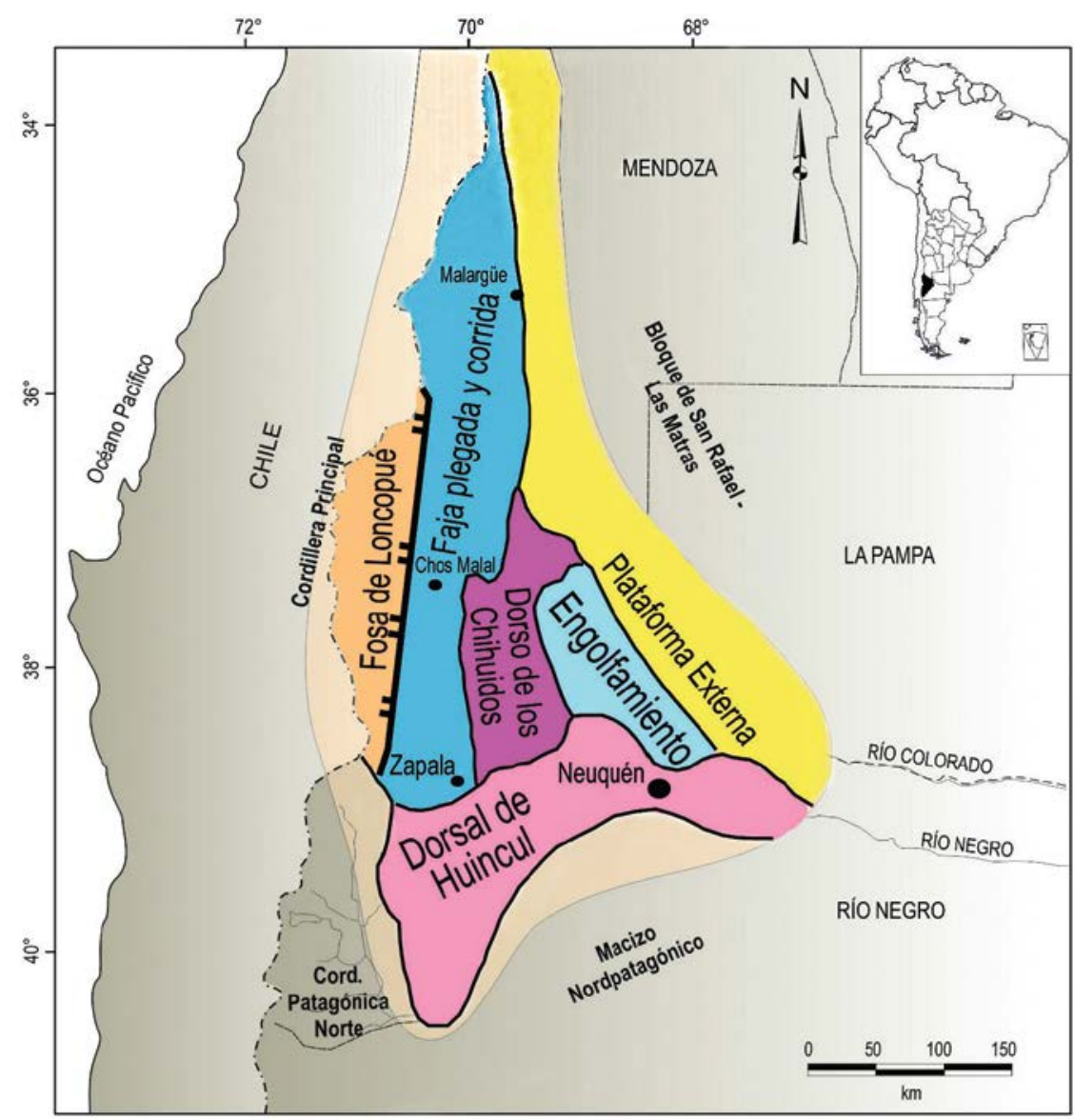

Figura 2.1: Límites y unidades morfoestructurales de la Cuenca Neuquina. Modificado de Giusiano y Bouhier (2009).

El relleno sedimentario tuvo lugar principalmente durante el Jurásico y el Cretácico, con una sucesión predominantemente clástica que alcanza los $7.000 \mathrm{~m}$ de potencia (Vergani et al., 1995). La sedimentación en la Cuenca Neuquina está representada 
por sucesivos ciclos de acumulaciones marinas y continentales mesozoicas que se iniciaron con los depósitos del Ciclo Precuyano y continuaron con los depósitos de los Grupos Cuyo, Lotena, Mendoza, Rayoso y Neuquén (Legarreta y Gulisano 1989).

En el sector centro-occidental de la cuenca, aproximadamente entre la localidad de Zapala y el río Diamante (de la provincia de Mendoza), se agrupan en una faja de rumbo norte-sur, numerosos depósitos de baritina y celestina, algunos de los cuales presentan asociadas concentraciones metalíferas ( $\mathrm{Fe}>\mathrm{Pb}>\mathrm{Cu}-\mathrm{Zn}-\mathrm{Mn})$ (Fig.2.2).

El presente capítulo tiene por finalidad brindar una descripción general de la estratigrafía regional de la Cuenca Neuquina, incluyendo los antecedentes de las unidades magmáticas presentes y a su vez, se describen los antecedentes de las mineralizaciones barito-celestínicas de la Cuenca Neuquina.

\section{Antecedentes estratigráficos}

Unas de las primeras contribuciones al conocimiento geológico de la Cuenca Neuquina fueron realizadas por Bodenbender (1889, 1891, 1892), pionero en la Argentina en desarrollar estudios estratigráfico-paleontológicos sistemáticos. Sin embargo, fueron los trabajos de Keidel $(1913,1917,1925)$ que aportaron importantes consideraciones sobre la estratigrafía y estructuración en la cuenca. Weaver (1927, 1931), otro gran estudioso de la Cuenca Neuquina, nominó varias unidades estratigráficas del Jurásico-Cretácico, reconstruyó la evolución de la cordillera andina en la región de Neuquén y llegó a reconocer la primera transgresión atlántica cretácica. Posteriormente, Groeber (1946) realizó, interpretó y propuso la separación de las secuencias estratigráficas en ciclos, todos éstos asociados a diversos eventos tectónicos. El detallado análisis estratigráfico le permitió definir tres grandes ciclos de sedimentación: Jurásico (HettangianoKimmeridgiano), Ándico (Tithoniano-Coniaciano) y Riográndico (Santoniano-Daniano) separados por discontinuidades o cambios en el régimen de sedimentación. A su vez los dividió en unidades de menor escala o subciclos: Cuyano y Loteniano-Chacayano para el Jurásico; Mendociano, Huitriniano y Diamantiano para el Ándico y Neuqueniano y Malalhueyano para el Riográndico.

El nuevo esquema sobre estratigrafía secuencial y la introducción de conceptos como secuencia depositacional (Mitchum et al., 1977, Legarreta y Gulisano, 1989) posibilitaron analizar la historia de acumulación sedimentaria de la cuenca desde el punto de vista secuencial. Esto permitió subdividirla en unidades de distintos órdenes: 


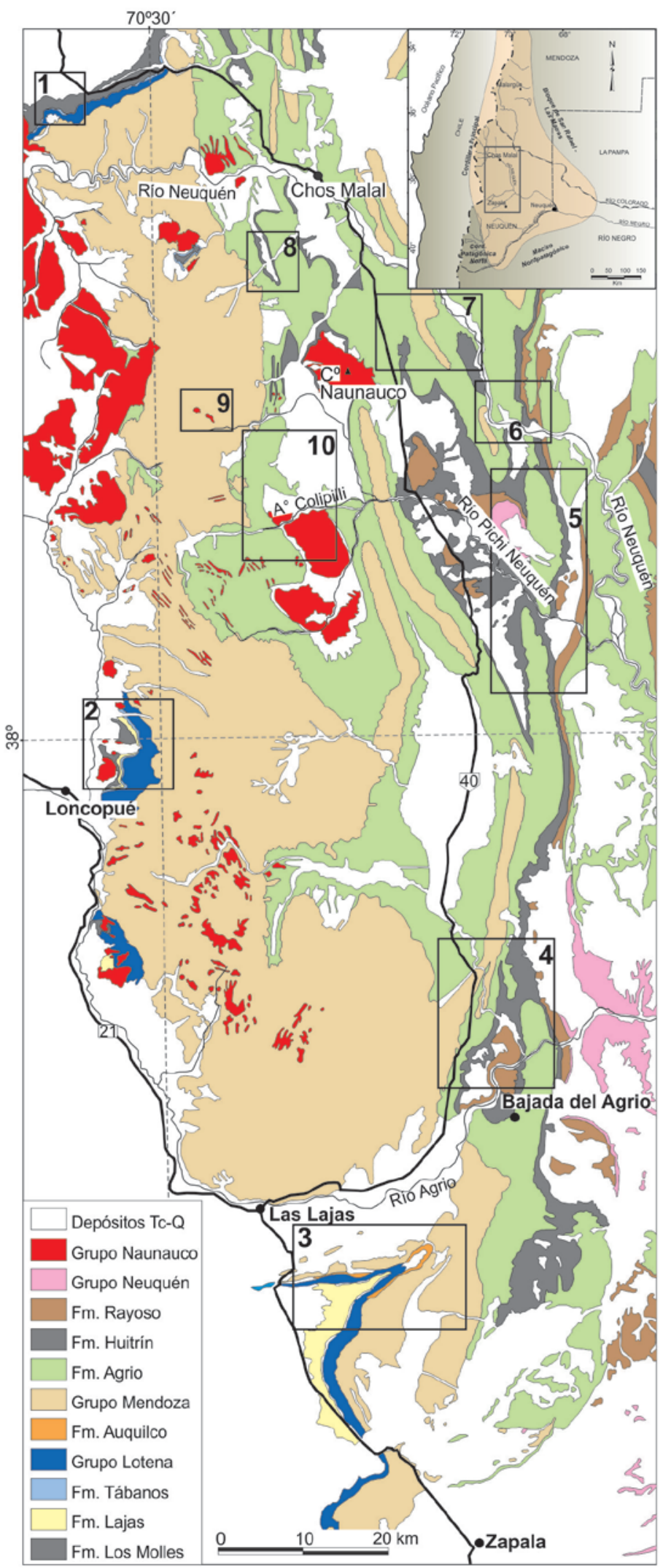

Figura 2.2: Principales distritos con depósitos de baritina y celestina en la provincia del Neuquén. 1- mina Arroyo Nuevo; 2-área de Loncopué; 3- Distrito Mallín Quemado; 4- Distrito Bajada del Agrio; 5- Cordón del Salado y Grupo Continental; 6- Barda Klein; 7- Distrito Naunauco; 8Distrito Taquimilán; 9- área cerro El Diablo; 10- distrito Colipilli. 
Secuencias Depositacionales, Mesosecuencias y Supersecuencias englobadas en la Megasecuencia Neuquina. En esta Megasecuencia (Triásico Superior-Terciario Inferior) se diferenciaron tres Supersecuencias: Inferior (Triásico Superior-Oxfordiano), Media (Kimmeridgiano-Cenomaniano Medio) y Superior (Cenomaniano Medio-Paleoceno Superior), las cuales coinciden parcialmente con los ciclos ya mencionados de Groeber (1946) (Cuadro 2.1). A su vez, cada Supersecuencia está compuesta por Mesosecuencias cuyo ordenamiento de unidades y el rango temporal que abarcan, serían el resultado de cambios relativos del nivel del mar asimilables a ciclos eustáticos de segundo orden que actuaron a lo largo de los diferentes estadios de la historia de subsidencia de la cuenca (Legarreta y Gulisano 1989).

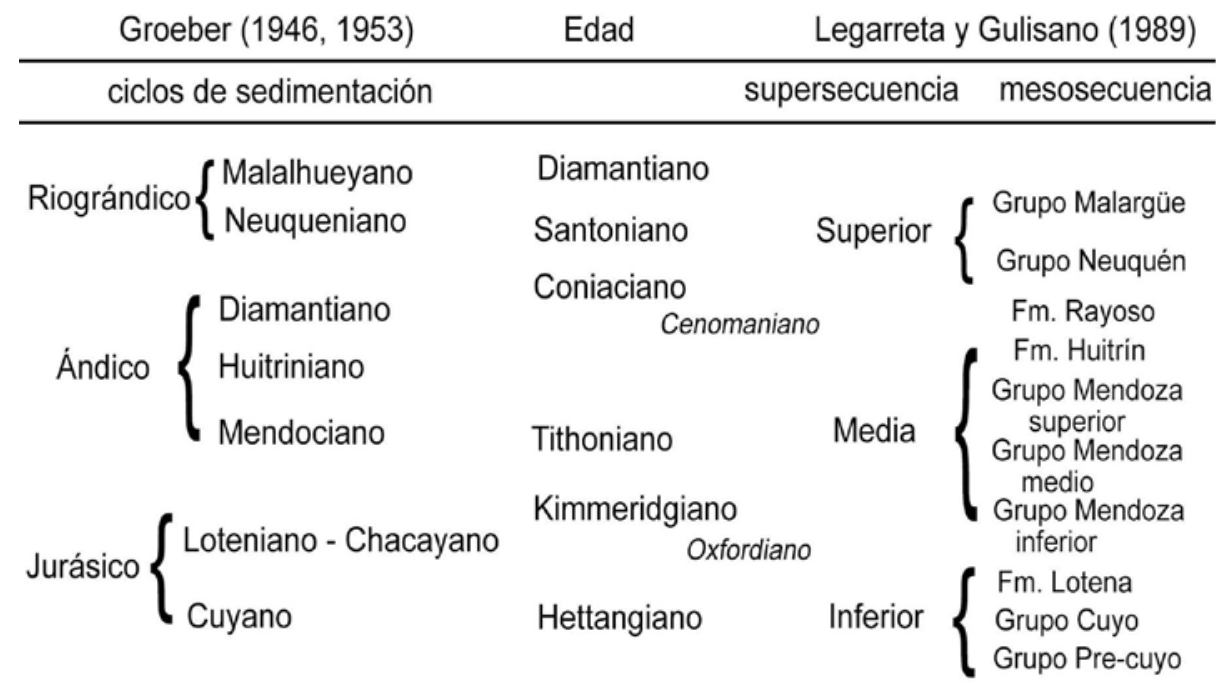

Cuadro 2.1: Equivalencias entre los ciclos de sedimentación propuestos por Groeber $(1946,1953)$ y las Supersecuencias y Mesosecuencias planteadas por Legarreta y Gulisano (1989).

\section{Estratigrafía de la Cuenca Neuquina}

La Cuenca Neuquina constituyó un amplio depocentro de acumulación sedimentaria durante el Triásico Tardío, Jurásico, Cretácico y parte del Cenozoico. Su relleno incluye sedimentos silicoclásticos, carbonáticos y evaporíticos (marinos $\mathrm{y}$ continentales) que se acumularon progresivamente bajo diferentes regímenes tectónicos (Legarreta y Gulisano, 1989; Howell et al., 2005). La evolución tectónica de la cuenca registra una compleja historia que incluye una etapa de sinrift (Triásico Tardío-Jurásico Temprano) seguida por un largo período de subsidencia termal (Jurásico Temprano a Cretácico Temprano) y una etapa de compresión-cuenca de antepaís (Cretácico TardíoCenozoico) (Vergani et al., 1995; Franzese y Spalletti 2001; Howell et al., 2005). 
Seguidamente, se detallarán los Grupos y Formaciones que forman el basamento y la cubierta sedimentaria de la cuenca, considerando el ambiente tectosedimentario en el que fueron depositados. Las edades de las discordancias regionales fueron tomadas de Leanza (2009), (Fig.2.3).

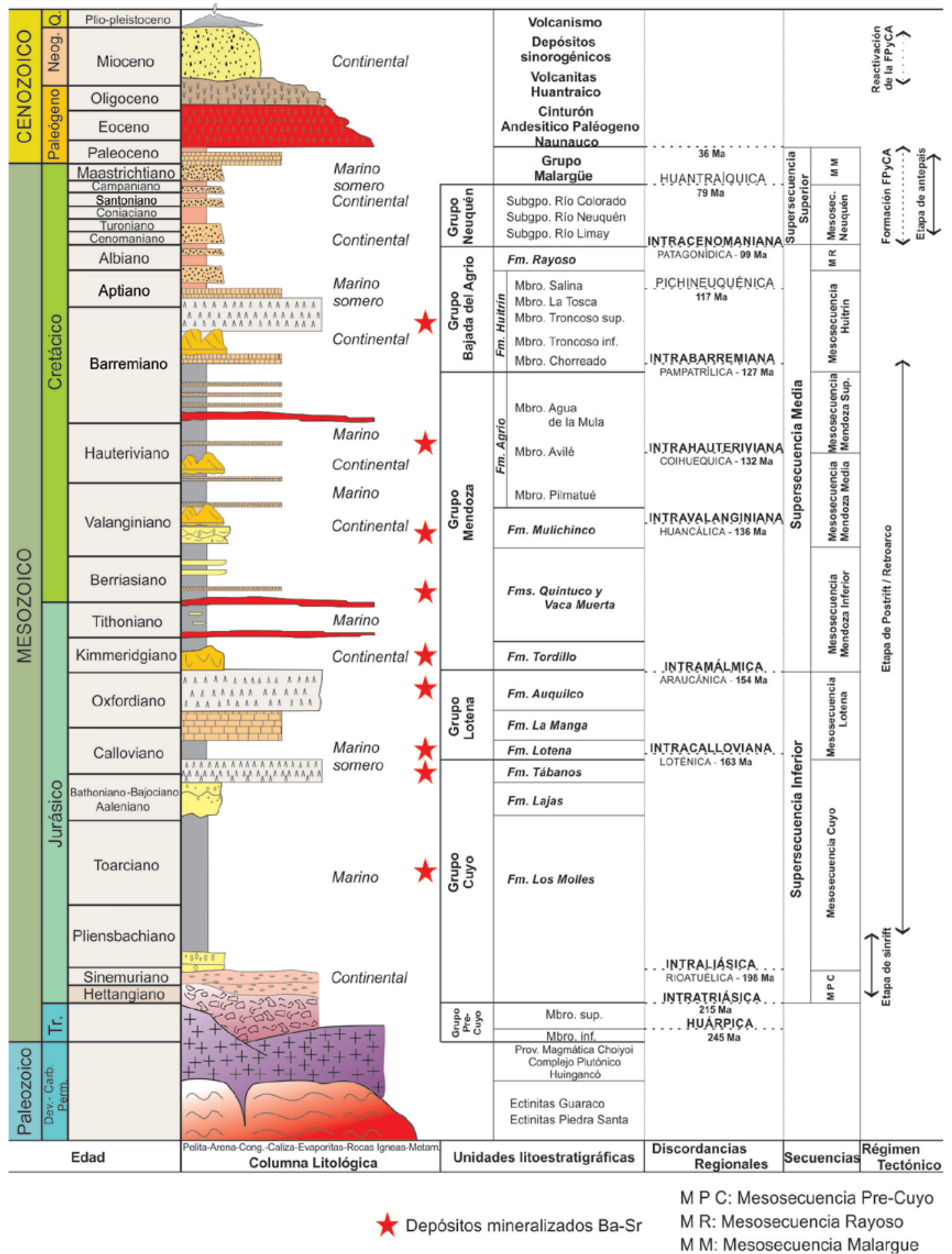

Figura 2.3: Columna cronoestratigráfica regional de la Cuenca Neuquina indicando los principales depósitos mineralizados de Ba-Sr. Modificado de Arregui et al. (2011) y Escobar (2016). 


\section{BASAMENTO}

Los afloramientos más antiguos llamados en forma amplia "basamento" de la Cuenca Neuquina consisten en rocas ígneas y metamórficas que afloran de manera aislada principalmente en el sector sur de la cuenca, con reducidos asomos en la región norte (Cingolani et al., 2011) (Fig.2.4). Las mayores exposiciones, correspondientes al sector sur de la cuenca, constan de rocas metamórficas de bajo grado, asignables a la facies de esquistos verdes agrupadas en la unidad Ectinita Piedra Santa (Digregorio y Uliana 1980). Los afloramientos de la región norte de la cuenca están compuestos por pizarras y esquistos también en facies de esquistos verdes que han sido denominados Ectinita Guaraco Norte (Zappettini et al., 1987).

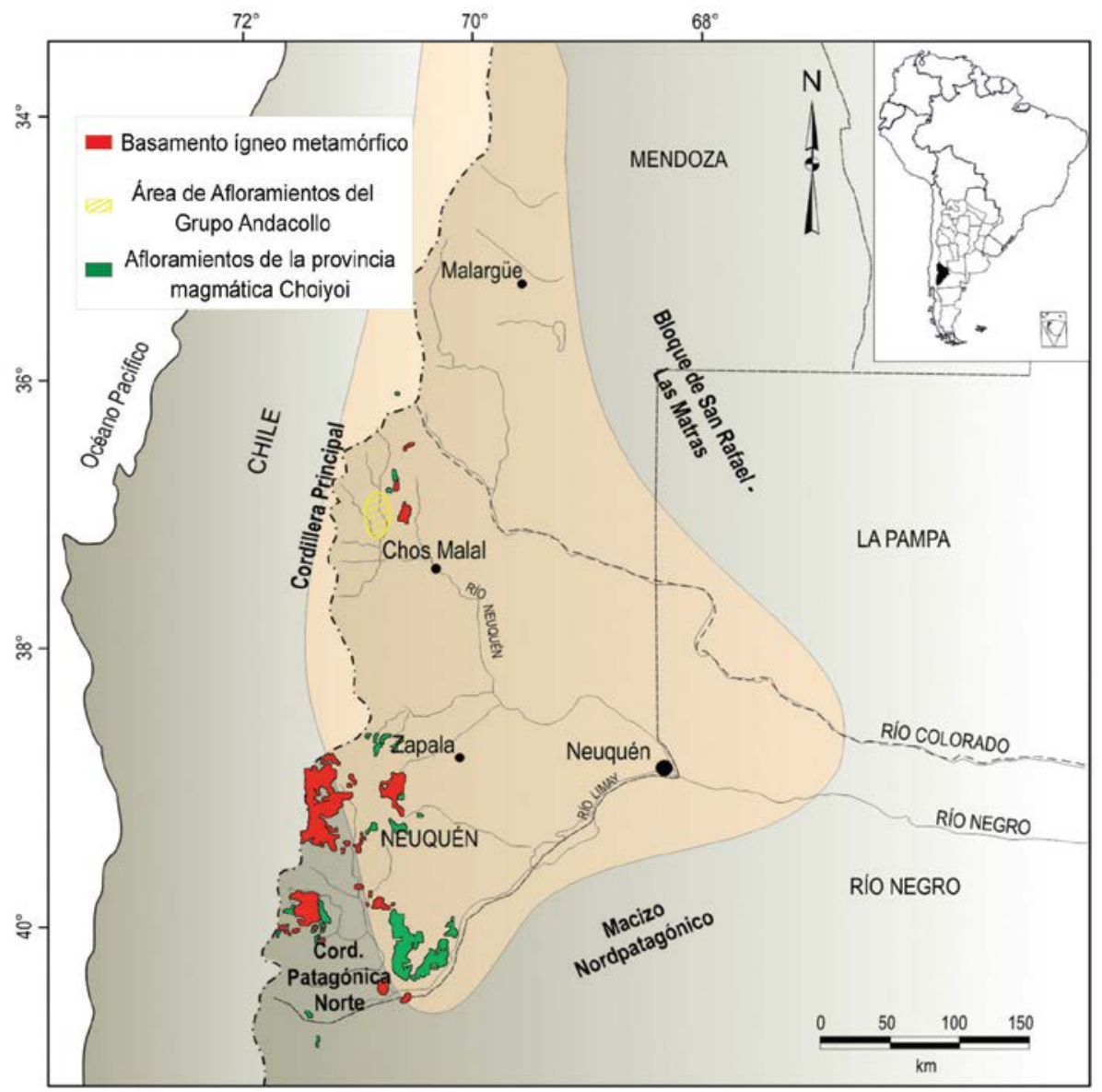

Figura 2.4: Distribución de los afloramientos que conforman el basamento de la Cuenca Neuquina. Modificado de Cingolani et al. (2011), Danieli et al. (2011) y Llambías y Sato (2011).

El Grupo Andacollo (Paleozoico Tardío) es considerado como parte del basamento Gondwánico (Danieli et al., 2011). Aflora en el área de la Cordillera del Viento (norte del Neuquén) (Fig.2.4) y está compuesto por sedimentitas marinas, rocas volcánicas y volcaniclásticas. Estas rocas presentan intensa deformación por haber sido afectadas por la 
fase diastrófica Sanrafaélica y por estar intruídas por el magmatismo ocurrido en el ciclo Gondwánico (Carbonífero-Triásico Temprano). Durante dicho ciclo se desarrolló una intensa actividad magmática, que por su gran extensión $\left(>500.000 \mathrm{~km}^{2}\right)$, fue considerada como provincia magmática Choiyoi (Kay et al., 1989). Estas rocas ígneas, de composición mesosilícica a silícica, también conforman el basamento de la Cuenca Neuquina y afloran como reducidos bloques exhumados en la Cordillera del Viento, en las Sierras ChacaicoChachil y en el Cerro Granito (integrante de la Dorsal de Huincul) (Llambías y Sato 2011) (Fig.2.4). La fase diastrófica Huárpica generó una superficie de erosión de magnitud regional marcando un cambio en el régimen tectónico de la región. Dicha superficie fue fracturada durante la extensión del Triásico Superior. Esta etapa de rifting dio origen a la Cuenca Neuquina.

\section{Relleno Sedimentario de la Cuenca Neuquina (Jurásico-Cretácico)}

La Cuenca Neuquina fue originada en el Triásico Superior como resultado de una extensión intracontinental (Franzese y Spalletti 2001). Uliana et al. (1989) relacionaron el inicio de la cuenca con el desmembramiento del supercontinente Gondwana. Los procesos extensionales de intraplaca, durante el Triásico Superior y el Jurásico Temprano, generaron un conjunto de rifts profundos y alargados constituyendo depocentros con geometría de hemigraben como los rifts de la Cuenca Neuquina (Vergani et al., 1995; Franzese y Spalletti 2001).

\section{GRUPO PRE-CUYO}

Este término fue definido para agrupar a un conjunto de depósitos de naturaleza continental comprendido entre el basamento y la primera ingresión marina jurásica (Gulisano 1981). El Pre-cuyano incluye a una serie de Formaciones que no se manifiestan en el área de estudio, denominadas: Remoredo, Arroyo Malo, Llantenes Chihuido, Cordillera del Viento, Milla Michicó, Lapa, Sañico, Paso Flores, Ñireco, entre otras (Cuadro 2.2). Esta etapa se caracterizó por el desarrollo de profundos depocentros aislados limitados por fallas normales, los cuales fueron rellenados con secuencias piroclásticas, volcánicas y epiclásticas constituyendo el relleno inicial de la Cuenca Neuquina. Estas secuencias se registran en los depósitos de sinrift y se encuentran limitadas por las discordancias Huárpica (215 Ma) e Intraliásica o Rioatuélica (198 Ma) con espesores de 
hasta $1.000 \mathrm{~m}$ (Legarreta y Gulisano 1989; Leanza 2009). Esta última discordancia marca la finalización de la etapa de rifting y el comienzo de la ingresión Cuyana.

\begin{tabular}{|c|c|c|c|c|c|c|c|}
\hline & Edad & Río Atuel & $\begin{array}{c}\text { Sierra de } \\
\text { Reyes }\end{array}$ & $\begin{array}{l}\text { Chos } \\
\text { Malal }\end{array}$ & Oeste & $\begin{array}{l}\text { Río } \\
\text { Limay }\end{array}$ & Este \\
\hline \multirow{3}{*}{$\begin{array}{l}\text { 옥 } \\
\text { U } \\
\text { 을 } \\
\text { 닌 }\end{array}$} & $\begin{array}{c}\text { Pliensbachiano } \\
\text { Toarciano }\end{array}$ & $\begin{array}{l}\text { Fm. Tres } \\
\text { Esquinas }\end{array}$ & $\begin{array}{c}\text { Fm. Bardas } \\
\text { Blancas }\end{array}$ & $\begin{array}{c}\text { Fm. Los } \\
\text { Molles }\end{array}$ & $\begin{array}{c}\text { Fms. } \\
\text { Los Molles } \\
\text { Chachil }\end{array}$ & \multirow{3}{*}{$\begin{array}{l}\text { Fm. } \\
\text { Piedra } \\
\text { del } \\
\text { Águila }\end{array}$} & $\begin{array}{l}\text { Fm. } \\
\text { P. Rosada } \\
\text { Lajas }\end{array}$ \\
\hline & \multirow{2}{*}{$\begin{array}{r}\text { Hettangiano } \\
\text { Sinemuriano }\end{array}$} & $\begin{array}{c}\text { Fm. } \\
\text { P. Araya }\end{array}$ & & \multirow[t]{2}{*}{$\begin{array}{c}\text { Fm. La } \\
\text { Primavera }\end{array}$} & & & \multirow[t]{2}{*}{$\begin{array}{l}\text { Fm. Puesto } \\
\text { Kauffman }\end{array}$} \\
\hline & & $\begin{array}{c}\text { Fm. } \\
\text { El Freno }\end{array}$ & & & & & \\
\hline \multirow{3}{*}{ 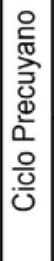 } & $\begin{array}{l}\text { Hettangiano } \\
\text { Sinemuriano }\end{array}$ & & $\begin{array}{c}\text { Fm. } \\
\text { Remoredo }\end{array}$ & & & $\begin{array}{l}\text { Fm. } \\
\text { Sañico }\end{array}$ & \multirow{3}{*}{$\begin{array}{l}\text { Fms. } \\
\text { P. Morada } \\
\text { Barda Alta } \\
\text { Medanito? }\end{array}$} \\
\hline & \multirow{2}{*}{$\begin{array}{l}\text { Triásico } \\
\text { Superior }\end{array}$} & \multirow{2}{*}{$\begin{array}{c}\text { Fm. Arroyo } \\
\text { Malo }\end{array}$} & \multirow{2}{*}{$\begin{array}{l}\text { Fm. Llantenes } \\
\text { Chihuido }\end{array}$} & $\begin{array}{c}\text { Fm. Milla } \\
\text { Michicó }\end{array}$ & Fm. Lapa & \multirow{2}{*}{$\begin{array}{c}\text { Fm. Paso } \\
\text { Flores }\end{array}$} & \\
\hline & & & & $\begin{array}{l}\text { Fm.Cordillera } \\
\text { del Viento }\end{array}$ & Fm. Ñireco & & \\
\hline
\end{tabular}

Cuadro 2.2: Cuadro litoestratigráfico de las unidades de los Grupos Precuyano y Cuyo. Modificado de Gulisano y Gutiérrez Pleimling (1994), Franzese y Spalletti (2001) y Leanza et al. (2005).

\section{Depósitos vinculados al estadio de subsidencia térmica-postrift}

Con posterioridad a la finalización del rifting, se desarrolló la transición a una etapa de postrift con subsidencia termal (SAG). Simultáneamente aconteció la primera transgresión marina y la amalgamación gradual de los depocentros que conformaron una sola depresión (Vergani et al., 1995). Por todo esto, dichos depósitos constituyen una de las fases evolutivas más importantes de la cuenca.

La sedimentación inicialmente estuvo fuertemente influenciada por la topografía heredada de los sistemas de sinrift. Con posterioridad, se depositaron extensas y potentes sucesiones que representan complejas series de ciclos transgresivo-regresivos de diferente magnitud (Howell et al., 2005). La caída del nivel de base en respuesta a un aumento del nivel marino global y a la subsidencia térmica (Legarreta y Uliana 1996), generó una transgresión marina diacrónica en toda la cuenca (Gulisano 1981), comenzando en el Hettangiano en el norte y en el Pliensbachiano en el sur (Legarreta y Uliana 1996). Con esta transgresión comenzó un período de sedimentación marina que dominó los ambientes depositacionales sucedidos durante el Jurásico e inicio del Cretácico, depositándose más de $4.000 \mathrm{~m}$ de sedimentos. Las secuencias depositacionales que integran el postrift están constituidas por los Grupos Cuyo, Lotena y Mendoza (Howell et al., 2005). Para ese 
entonces, el arco magmático Andino se presentaba desarrollado y la cuenca se encontraba conectada al océano proto-Pacífico a través de separaciones que existían en dicho arco (Spalletti et al., 2000).

\section{GRUPO CUYO}

La denominación de Grupo Cuyo fue propuesta por Dellapé et al. (1978). Su base y techo están marcadas por las discordancias Intraliásica o Rioatuélica (198 Ma) e Intracalloviana o Loténica (163 Ma), respectivamente. Posteriormente, los trabajos de Gulisano et al. (1984a y b) y Legarreta y Gulisano (1989), entre otros, han contribuido a la división de este intervalo estratigráfico.

El Grupo Cuyo no aflora en el área de estudio; corresponde al primer ciclo sedimentario marino que se depositó en la Cuenca Neuquina en el lapso de tiempo Pliensbachiano-Toarciano hasta el Calloviano Medio. Este ciclo se inicia, de acuerdo a estudios realizados por diferentes autores (Mosquera y Ramos 2006, entre otros), en una transición entre un episodio de rift inicial y una subsidencia generalizada. A través de sucesivas oscilaciones de la línea de costa este Grupo reúne un conjunto de rocas clásticas que representa ambientes marinos distales (Formación Los Molles), litorales (Formación Las Lajas), continentales (Formaciones Challacó y Punta Rosada) y evaporíticos (Formación Tábanos) representando un ciclo completo transgresivo-regresivo (Fig.2.5a-f).

A continuación se describen las Formaciones que integran al Grupo Cuyo.

\section{Formación Los Molles}

Weaver (1931) describió por primera vez a un conjunto de pelitas grises y gris oscuras con variable contenido orgánico como Formación Los Molles. La edad para esta unidad abarca desde el Pliensbachiano-Toarciano Temprano hasta el Aaleniano-Bajociano Temprano. Aflora en el suroeste de la provincia del Neuquén en los flancos del anticlinal de Chacaico, en el núcleo de los anticlinales de Picún Leufú y cerro Lotena. También se manifiesta en el norte de la provincia sobre el flanco oriental de la Cordillera del Viento sobre la margen sur de la ruta que une Chos Malal con Andacollo. Esta Formación alterna con arenas finas hasta gruesas. Dicho rasgo nos indica una configuración en la sedimentación de alta ciclicidad que le confiere a los depósitos un aspecto bandeado muy característico. Posee espesores variables, con máximos que superan los $2.000 \mathrm{~m}$. El ambiente de sedimentación ha sido interpretado como de carácter marino restringido de ba- 
ja energía y de naturaleza anóxica, donde intercalan cuerpos arenosos, interpretados como de origen turbidítico (Fig.2.5a-c).
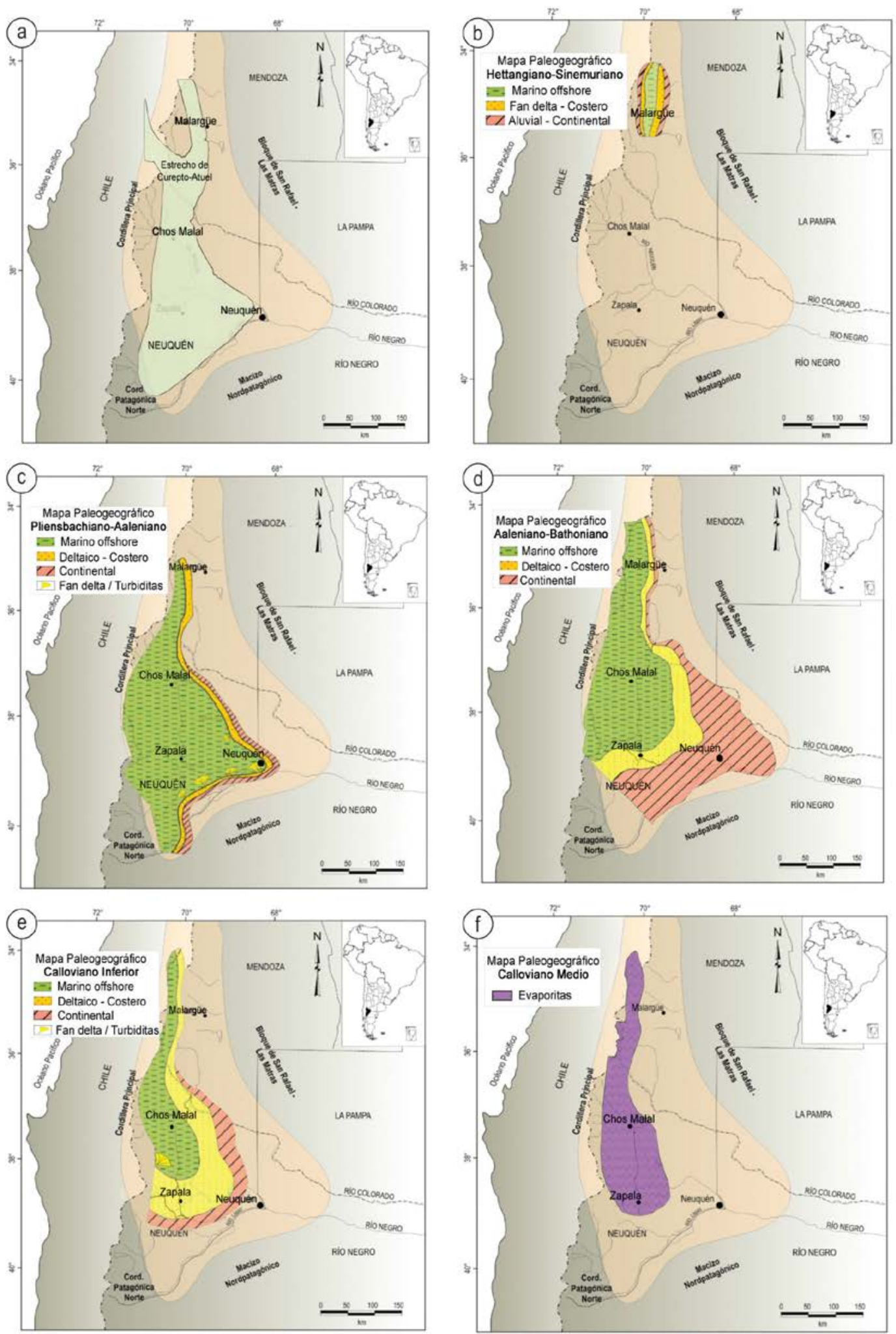

Figura 2.5: Mapas paleogeográficos de la depositación del Grupo Cuyo: a- mapa del ingreso del mar durante el Jurásico Temprano; b-f: Tomado de Gulisiano y Gutiérrez Pliemling (1994) y Gómez Omil et al. (2002) (c). 


\section{Formación Lajas}

Esta Formación fue denominada por Weaver (1931) al describir a las areniscas y, en menor medida, a pelitas oscuras y verdosas con abundantes restos carbonosos y conglomerados. Su localidad tipo está en el flanco occidental de la sierra de Vaca Muerta, donde desarrolla espesores promedio de $200 \mathrm{~m}$. Las rocas que constituyen este nivel estratigráfico fueron depositadas en ambientes marinos someros, deltaicos y estuáricos (Gulisano et al., 1984a; Gulisano y Hinterwimmer 1986) (Fig.2.5d) y ocupan el lapso Aaleniano-Calloviano Temprano. La depositación de esta Formación da comienzo a un gradual proceso de retracción del nivel del mar.

\section{Formación Tábanos}

Stipanicic (1966) describió este importante evento evaporítico del Jurásico Andino en el área de la sierra de Vaca Muerta y lo denominó Formación Tábanos. Ha sido asignada al Calloviano y está compuesta por paquetes calcáreo-yesosos blanco grisáceos de 25 a 30 m de espesor; cuando disminuye el contenido de yeso se desarrollan bancos de calizas macizas de color gris oscuro y niveles de brecha calcárea intraformacional. Estas evaporitas estarían confinadas al sector interno de la cuenca en condiciones hipersalinas (Legarreta y Uliana 1999). Las mismas representan un estadio final de acumulación donde se verifica la restricción del ambiente marino, asociado a un momento de déficit de suministro clástico (Gulisano et al., 1984a y b) (Fig.2.5f).

\section{GRUPO LOTENA}

Este Grupo fue propuesto por Leanza (1992) quedando representado temporalmente entre el Calloviano Medio y el Oxfordiano Tardío; constituye el segundo ciclo sedimentario del relleno de la Cuenca Neuquina, conocido también como ciclo LotenianoChacayano de Gulisano et al. (1984a y b). Ocupa una posición paleogeográfica más restringida que los ciclos infra-y suprayacentes y sus espesores resultan también menores. Se inicia luego de una reactivación tectónica (movimientos Intracallovianos) y culmina con otro reordenamiento de los campos de esfuerzos que antecede al diastrofismo Intramálmico. Los sectores donde aflora este Grupo son: sierra de Vaca Muerta, anticlinal de Picún Leufú, Loncopué y Chacay Melehue. El Grupo Lotena está constituido por sedimentos silicoclásticos (Formación Lotena), carbonáticos (Formación La Manga) y evaporíticos (Formación Auquilco) (Fig.2.6a-c). 


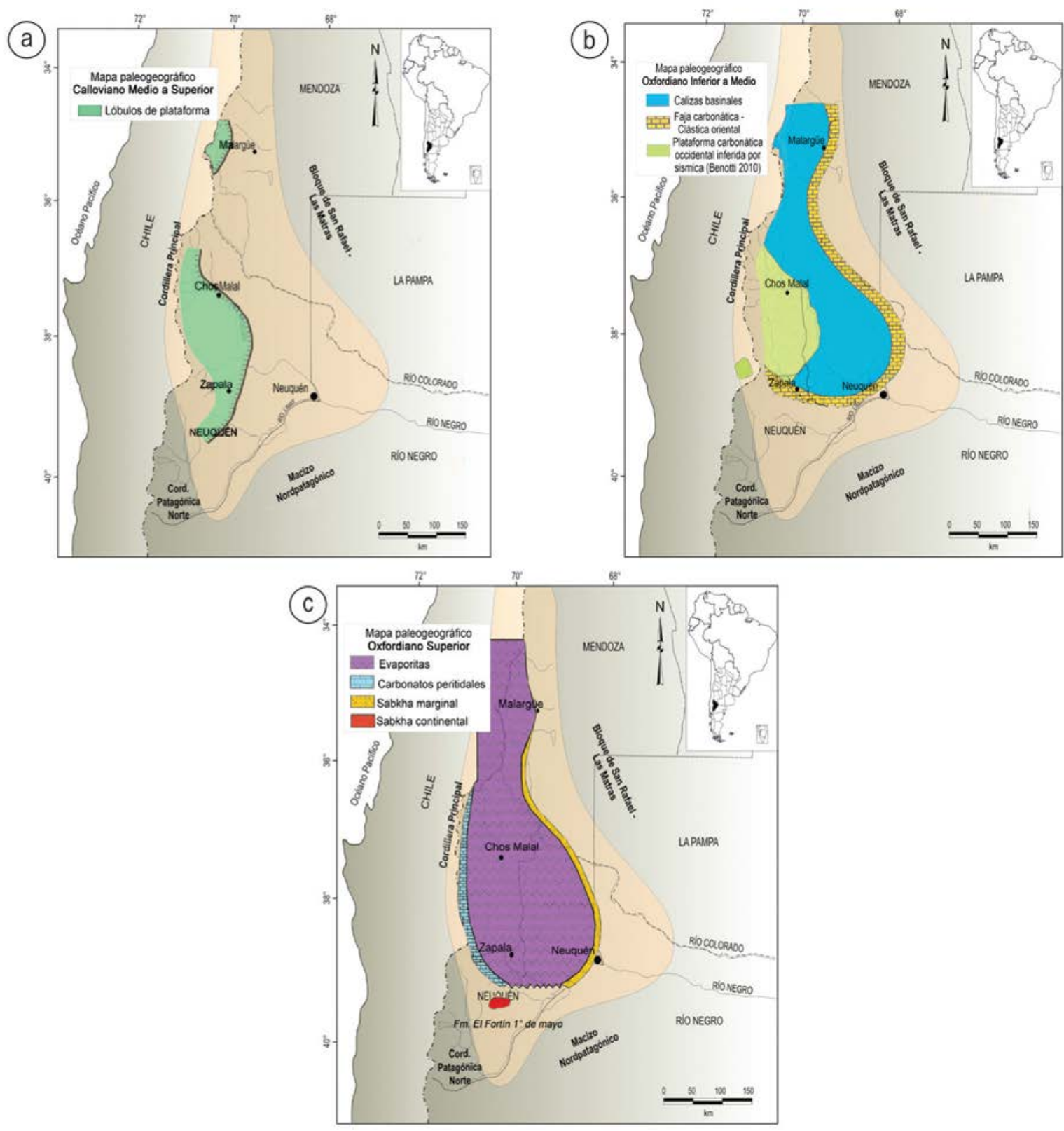

Figura 2.6: Mapas paleogeográficos de: a- Formación Lotena; b- Formación La Manga; cFormación Auquilco. Modificado de Arregui et al. (2011).

Seguidamente se describirá cada una de las Formaciones que integra dicho Grupo.

\section{Formación Lotena}

Originalmente fue establecida por Weaver (1931). Aflora desde el cerro Lotena hasta la sierra de Chacaico. Litológicamente se reconocen tres tramos en el área de la sierra de la Vaca Muerta: areniscas y conglomerados hacia la base que son cubiertos por pelitas gris verdosas rematando con cuerpos arenosos de ambiente marino por debajo del nivel de ola (Leanza y Hugo 1997) (Fig.2.6a), pudiendo alcanzar espesores de hasta $350 \mathrm{~m}$. De acuerdo con su fauna de ammonites y microfósiles, se la asigna al Calloviano Medio. 


\section{Formación La Manga}

Stipanicic y Mingramm (1952) describieron a esta unidad formacional en un informe inédito; años más tarde, Stipanicic (1966) definió formalmente con el término Manguense lo propuesto previamente en aquel informe. Los depósitos fueron acumulados durante el Calloviano Tardío-Oxfordiano Tardío y constituyen uno de los eventos carbonáticos más característicos del relleno de la cuenca (Fig.2.6b). Está compuesta por calizas muy duras, gris azuladas, con algunas intercalaciones arenosas, registrándose en el área de la sierra de la Vaca Muerta las mejores exposiciones que llegan a espesores que oscilan entre 10 y $120 \mathrm{~m}$. En algunos casos las calizas presentan notables abultamientos interpretados como verdaderos arrecifes de corales y esponjas. Estudios sedimentológicos de detalle fueron realizados por Matheos (1988) y Gulisano y Gutiérrez Pleimling (1994). Estos últimos autores dividieron a la unidad en tres tramos: inferior, donde se interpreta que los paquetes de calizas (wackestone) corresponden a la porción intermedia de una rampa carbonática; medio, inicialmente depositado en un ambiente litoral clástico, gradando progresivamente a la parte intermedia o distal de una rampa carbonática, mientras que los paquetes de calizas (grainstone) de la parte superior pertenecen a ambientes de plataforma externa.

\section{Formación Auquilco}

Schiller (1912) fue el primero en dar a conocer esta unidad en la literatura geológica denominándola Yeso Principal. Posteriormente, Weaver (1931) estableció a esta unidad como Formación Auquilco. Es una sucesión evaporítica blanquecina de hasta 400 $\mathrm{m}$ de espesor que constituye, junto con la Formación La Manga, uno de los principales eventos de restricción marina en el ámbito de la Cuenca Neuquina (Fig.2.6c). Aflora a lo largo del núcleo septentrional de la sierra de la Vaca Muerta, oeste de Chos Malal, Chacay Melehue y en la Yesera del Tromen en el norte de la provincia del Neuquén. Litológicamente está compuesta por calizas organógenas (boundstone criptoalgal), laminadas con estructuras tipo tepee, brechamiento y nódulos de anhidrita y yeso. La secuencia evaporítico-carbonática forma varves de sulfato-carbonato micrítico indicando condiciones someras, no más allá de los $100 \mathrm{~m}$ de profundidad (Nickelsen et al., 1985). La asociación de facies de esta unidad implica que se habría desarrollado en un ambiente de aguas someras e hipersalinas vinculadas de manera restringida con el océano Pacífico, lo que habría producido cambios relativos del nivel de base dentro del depocentro (Legarreta 2002). 


\section{GRUPO MENDOZA}

Este término, tal y como se conoce hoy en día, fue acuñado por Stipanicic et al. (1968) al sustituir al Mendociano de Groeber (1946) otorgándole el rango de Grupo. Groeber (1946), estableció el término Mendociano como parte del subciclo Ándico, donde agrupó en sentido de pisos estratigráficos al Vacamuertense, Quintucoense, Mulichincoense y Agrioense.

El conjunto de Formaciones que integra al Grupo Mendoza, tanto de carácter marino como continental, constituye una pila sedimentaria de hasta $2.500 \mathrm{~m}$ de espesor (Digregorio y Uliana 1980). Dicho Grupo se encuentra limitado en su base por la discordancia Intramálmica o Araucánica (154 Ma) y en su techo por la discordancia Intrabarremiana o Pampatrílica (127 Ma). El rango cronoestratigráfico abarca desde el Kimmeridgiano hasta el Barremiano (Leanza et al., 1977; Aguirre Urreta y Rawson 1997), momento en el que la cuenca comienza a perder su conexión marina.

El grupo Mendoza ha sido motivo de numerosos estudios (Gulisano et al., 1984a; Minniti et al., 1986; Legarreta y Gulisano, 1989; Legarreta et al., 1999), ya que las Formaciones que lo componen, presentan características tanto de roca madre, como de reservorio y sello para la generación y entrampamiento de hidrocarburos. Dentro de la zona de estudio, este Grupo se encuentra ampliamente representado.

A continuación se describen las Formaciones que conforman al Grupo Mendoza.

\section{Formación Tordillo}

Los depósitos sedimentarios continentales de esta unidad formacional fueron definidas por primera vez por Groeber (1946) como Tordillense. La Formación Tordillo (Stipanicic 1966) está constituida por potentes bancos de areniscas y conglomerados que fueron depositados durante el Kimmeridgiano representando condiciones de sedimentación continental (Fig.2.7). Desde el punto de vista de la evolución geodinámica e interés económico, esta unidad actúa como el principal reservorio de hidrocarburos de la Cuenca Neuquina (Spalletti et al., 2011a y b). 


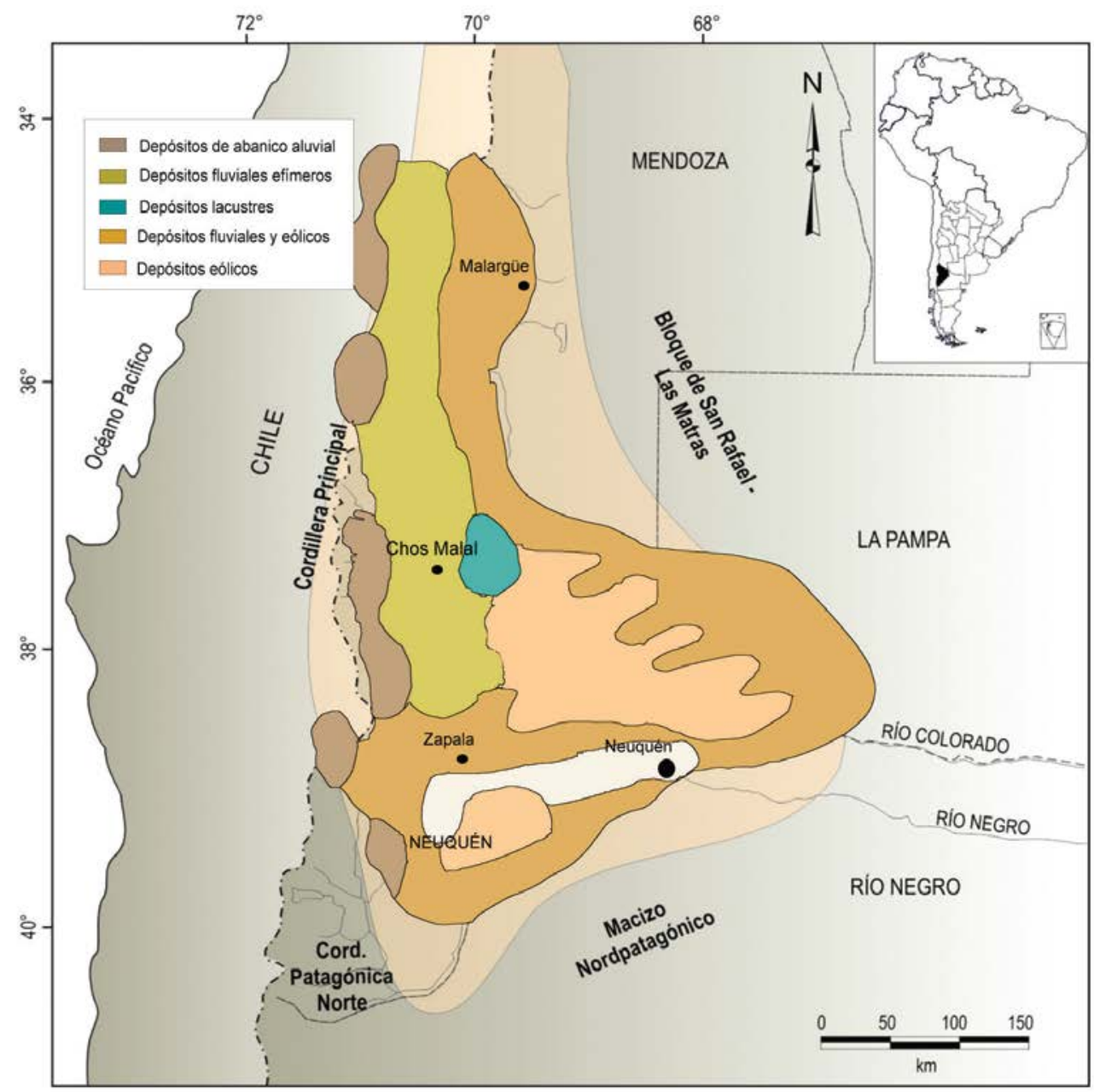

Figura 2.7: Distribución de los principales sistemas de depositación de la Formación Tordillo. Modificado de Giulisiano y Gutiérrez Pleimling (1994).

\section{Formación Vaca Muerta}

Weaver (1931) definió al conjunto de pelitas y calizas, con gran cantidad de materia orgánica, como Formación Vaca Muerta en la sierra homónima ubicada en el centro del Neuquén. Sus tonalidades, en general, son gris negruzcas, castaño oscuras, ocres y amarillentas. En el área de estudio afloran al pie del cerro Los Bueyes y en el núcleo del anticlinal de la sierra de Chorriaca.

La sedimentación de esta Formación representa un episodio de transgresión subsecuente sobre los depósitos de la Formación Tordillo, que indicaría un rápido ascenso del nivel mar y el restablecimiento de la conexión de la cuenca con el Pacífico (Legarreta y Uliana 1991) (Fig.2.8a y b). Este evento de inundación tuvo lugar en un ambiente marino de "off-shore", escasamente oxigenado (Uliana et al., 1999). El modelo deposicional propuesto para la asociación de facies, indica un ambiente de rampa carbonática caracterizado por procesos de decantación suspensiva de material silicoclástico y carbonático. Sobre la base de la bioestratigrafía se le ha asignado una edad tithoniana a 
valanginiana temprana. Esta Formación presenta dos Miembros: El Miembro Los Catutos definido por Leanza y Zeiss (1990) que corresponde a una unidad homogénea de calizas e intercalaciones margosas y el Miembro Huncal definido por Leanza et al. (2001) que corresponde a un paquete de areniscas dentro del tramo Berriasiano.
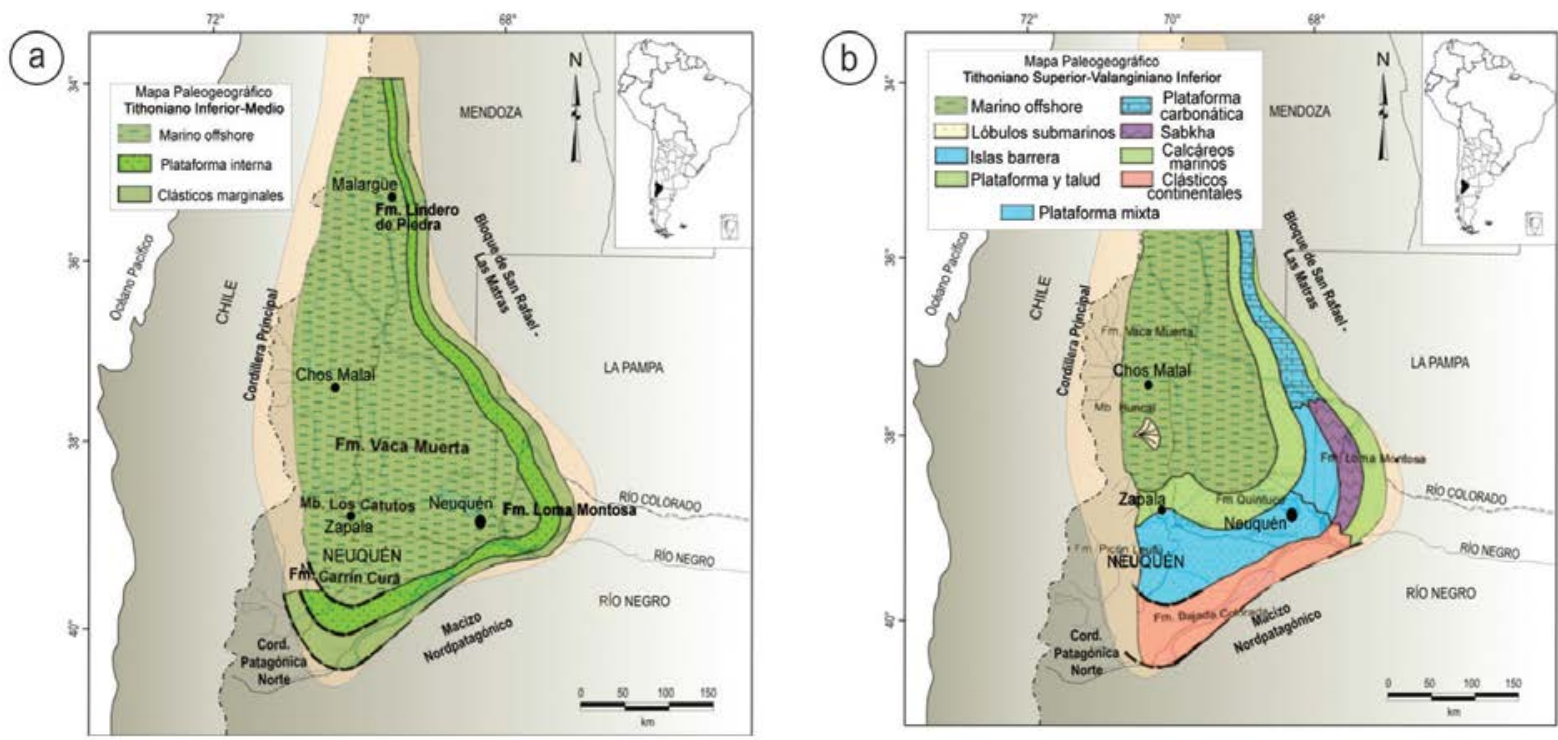

Figura 2.8: Mapas paleogeográficos del Grupo Mendoza durante: a- Tithoniano Inferior-Medio. Modificado de Legarreta y Uliana (1991); b- Tithoniano Superior-Valanginiano Superior. Modificado de Legarreta y Uliana (1991), Leanza y Hugo (1997).

La Formación Vaca Muerta representa la unidad estratigráfica más extensa del Grupo y ha sido muy estudiada por ser roca madre por excelencia de gran parte del petróleo producido en la Cuenca Neuquina. La sección basal de esta Formación es la que presenta mayores contenidos en materia orgánica, con un promedio de 4\% COT (Carbono Orgánico Total) y picos que pueden alcanzar el 12\% (Legarreta et al., 1999). Esta unidad grada hacia arriba y/o se interdigita con los depósitos de la Formación Quintuco (Leanza 1973, Gulisano et al., 1984a, Leanza et al., 2011). Esta última está compuesta por sedimentitas silicoclásticas marinas acumuladas en el segmento "nearshore" durante el Berriasiano Tardío al Valanginiano Temprano (Leanza et al., 2011).

\section{Formación Mulichinco}

Esta unidad fue reconocida y denominada por Weaver (1931) al describir al conjunto de sedimentos continentales, transicionales y marinos comprendido entre la Formaciones Quintuco y Agrio. Su localidad tipo se encuentra en la región de los cerros Mulichinco y Mocho en el centro oeste del Neuquén. En el área de estudio los 
afloramientos de dicha unidad se encuentran en el núcleo del anticlinal de la sierra de Chorriaca y de la loma del Naunauco.

La Formación Mulichinco está constituida por un paquete dominantemente arenoso con sedimentitas continentales y marinas que se desarrolló durante e inmediatamente después del descenso del nivel del mar en el Valanginiano Temprano (Gulisano et al., 1984a), probablemente influenciado por un alzamiento tectónico (Vergani et al., 1995; Schwarz et al., 2006). Desde el punto de vista petrolero, esta unidad es importante por sus características de roca reservorio de hidrocarburos.

\section{Formación Agrio}

Se emplea esta denominación para agrupar a las sedimentitas marinas comprendidas entre la Formación Mulichinco y la Formación Huitrín. Originalmente Weaver (1931) denominó como Formación Agrio a dichas rocas ubicadas en la sección media del río Agrio. Esta unidad formacional constituye el registro sedimentario de un amplio intervalo de tiempo del orden de los $7 \mathrm{Ma}$; se encuentra ampliamente distribuida en el área de estudio y representa una importante fase transgresiva que se registró a fines del Valanginiano Temprano-Hauteriviano Tardío (Fig.2.9a y b). La Formación Agrio se apoya en concordancia sobre la Formación Mulichinco y se caracteriza por la presencia dominante de pelitas y pelitas calcáreas, con intercalaciones bioclásticas. Primeramente ha sido subdividida en tres Miembros: Inferior, Avilé y Superior, posteriormente los Miembros Inferior y Superior fueron redenominados formalmente como Pilmatué y Agua de la Mula, respectivamente (Leanza y Hugo 2001). Tradicionalmente, el Miembro Avilé divide a la Formación Agrio en un tramo inferior y otro superior, constituyendo un evento de desecación instantánea de la cuenca, ya que pasa bruscamente de un ambiente marino offshore a uno fluvial y luego nuevamente a un ambiente offshore. La drástica somerización que representa el Miembro Avilé, coincide con una caída generalizada en el nivel del mar.

Estratigráficamente por encima se desarrolla un complejo sedimentario clásticocarbonático-evaporítico denominado Miembro Chorreado, el cual presenta controversia en cuanto a su posición estratigráfica. Originalmente, Groeber (1946) estableció a esta unidad como el término basal del Huitriniano. Legarreta y Gulisano (1989) si bien la han dejado dentro de la Formación Huitrín, la incluyen en la Mesosecuencia Mendoza Superior, quedando implícita su inclusión en el Mendociano y relacionándola más a una restricción 
del mar abierto que existía durante la depositación del Miembro Agua de la Mula, que a la rápida continentalización ocurrida en el Troncoso Inferior (Vergani et al., 2002). Si bien Leanza (2003), incluye al Miembro Chorreado (calizas y pelitas) en la parte superior de la Formación Agrio, en el presente trabajo de Tesis, seguiremos el esquema estratigráfico de aquellos investigadores que lo asimilan al sector basal de la Formación Huitrín (Groeber 1946; Legarreta y Gulisano 1989, entre otros).
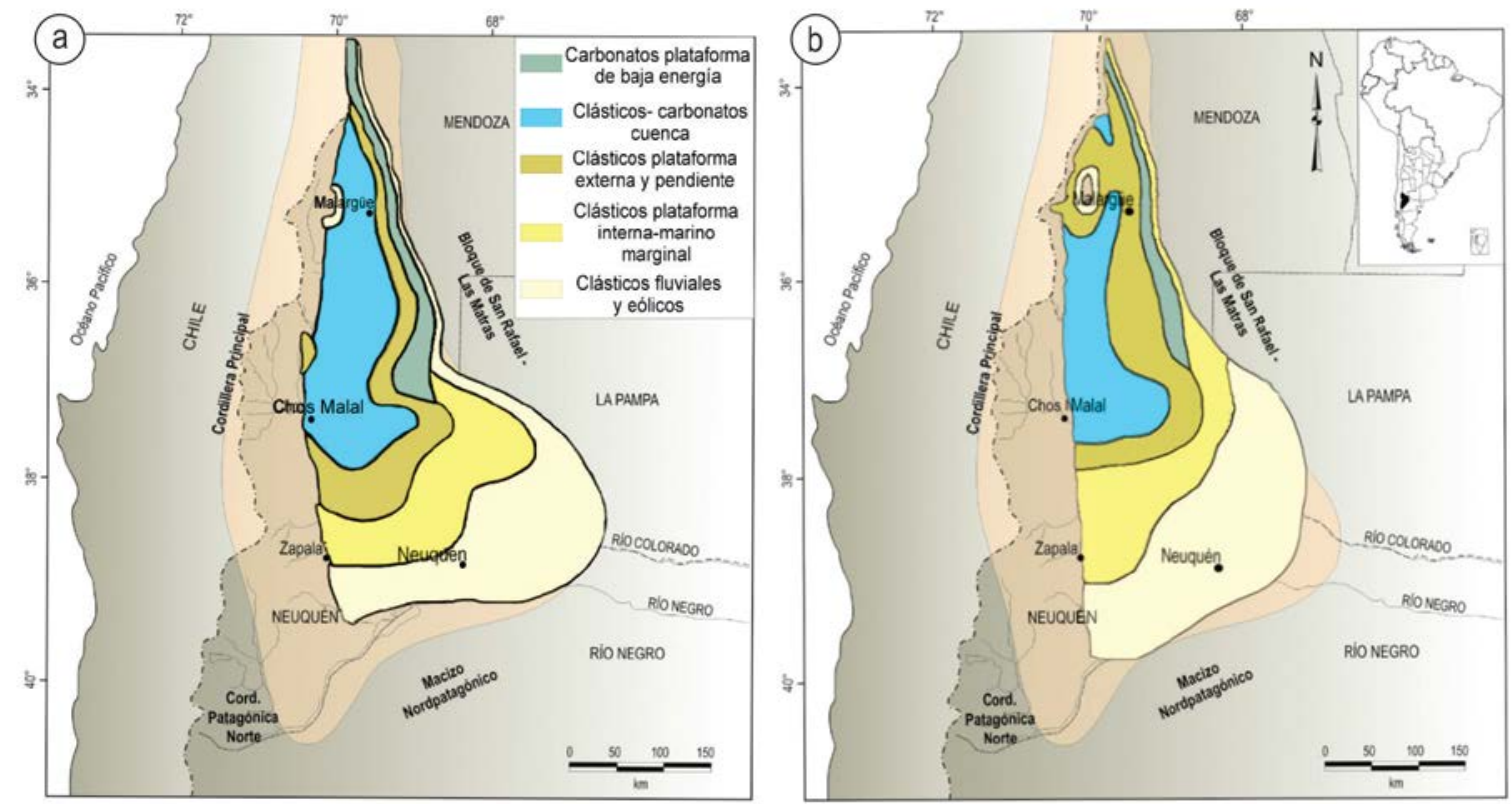

Figura 2.9: Reconstrucciones paleogeográficas correspondientes a los depósitos marinos de la Formación Agrio: a-Valanginiano Tardío-Hauteriviano; b-Hauteriviano Tardío. Modificado de Spalletti et al. (2011).

\section{GRUPO BAJADA DEL AGRIO}

La primera denominación la realizaron Uliana et al. (1975a y b) bajo el nombre de Grupo Rayoso; años más tarde, Méndez et al. (1995) propusieron reemplazar la denominación Grupo Rayoso por Grupo Bajada del Agrio. De acuerdo a Legarreta y Gulisano (1989), el Grupo Bajada del Agrio incluye a las Formaciones Huitrín (Barremiano-Aptiano) y Rayoso (Albiano-Cenomaniano Inferior) limitado en su piso y en su techo por los Grupos Mendoza y Neuquén respectivamente. Las sedimentitas huitrinianas y rayosianas han sido afectadas por discontinuidades importantes, la discordancia Miránica Inicial (Intrabarremiana, $127 \mathrm{Ma}$ ) en la base del Miembro Troncoso Inferior, la discordancia Miránica Intermedia (Intraptiana, $117 \mathrm{Ma}$ ) en la base del Miembro Rincón, y la discordancia Miránica Principal (límite Albiano/Cenomaniano, $99 \mathrm{Ma}$ ) en la base de la Formación Candeleros. 
Seguidamente se describirá cada una de las Formaciones que integra dicho Grupo.

\section{Formación Huitrín}

Las primeras descripciones de las características capas del Cretácico Temprano de la Cuenca Neuquina las realizó Groeber (1929). Posteriormente, Groeber (1946) denominó Huitriniano a estos estratos y los subdividió en Chorreadense, Troncosense, Tosquense, Salinense y Rincoenense. Luego, el término Huitriniano fue reemplazado por Formación Huitrín de acuerdo con las normas de nomenclatura estratigráficas. No obstante, según las distintas interpretaciones de los diferentes autores, los alcances y límites de esta clásica unidad han variado (Groeber 1929; Weaver 1931; Groeber 1946; Herrero Ducloux 1946; Uliana et al., 1975a y b; Legarreta 1985; Legarreta y Gulisano 1989; Gutiérrez Pleimling 1991; Vergani et al., 2002; Leanza 2003; entre otros). Aquí consideraremos el esquema estratigráfico propuesto por Groeber (1946), Legarreta y Gulisano (1989), entre otros, donde la Formación Huitrín queda constituida por los Miembros Chorreado, Troncoso Inferior y Superior, La Tosca y Salina. Los primeros tres miembros de dicha Formación en la zona de estudio se encuentran bien representados en los flancos de las grandes estructuras anticlinales.

\section{Miembro Chorreado}

Su asignación como parte de la Formación Huitrín se justifica en base a criterios de subsuelo donde se identificó un patrón sigmoidal con rumbo NNE-SSO progradando hacia el NO (Gutiérrez Pleimling et al., 2011). En el Cuadro 2.3 se muestran las equivalencias de nomenclaturas según diversos autores que trabajaron en este Miembro.

Las rocas que integran este Miembro corresponden a un ambiente marino restringido y fueron depositadas sobre una rampa carbonática de suave pendiente (Fig.2.10). Se han diferenciado dos secciones, denominadas informalmente Inferior y Superior (Gutiérrez Pleimling 1991). La primera se caracteriza por la alternancia clásticacarbonática, correspondiendo a un sector de mayor energía cercano a la línea de costa, y la sección Superior, con mayor predominio de evaporitas, representa un sector de menor energía en la parte más profunda. De un sector a otro se pasa en forma gradual, sin quiebres pronunciados (Gutiérrez Pleimling 1991, Barrionuevo 2002). 


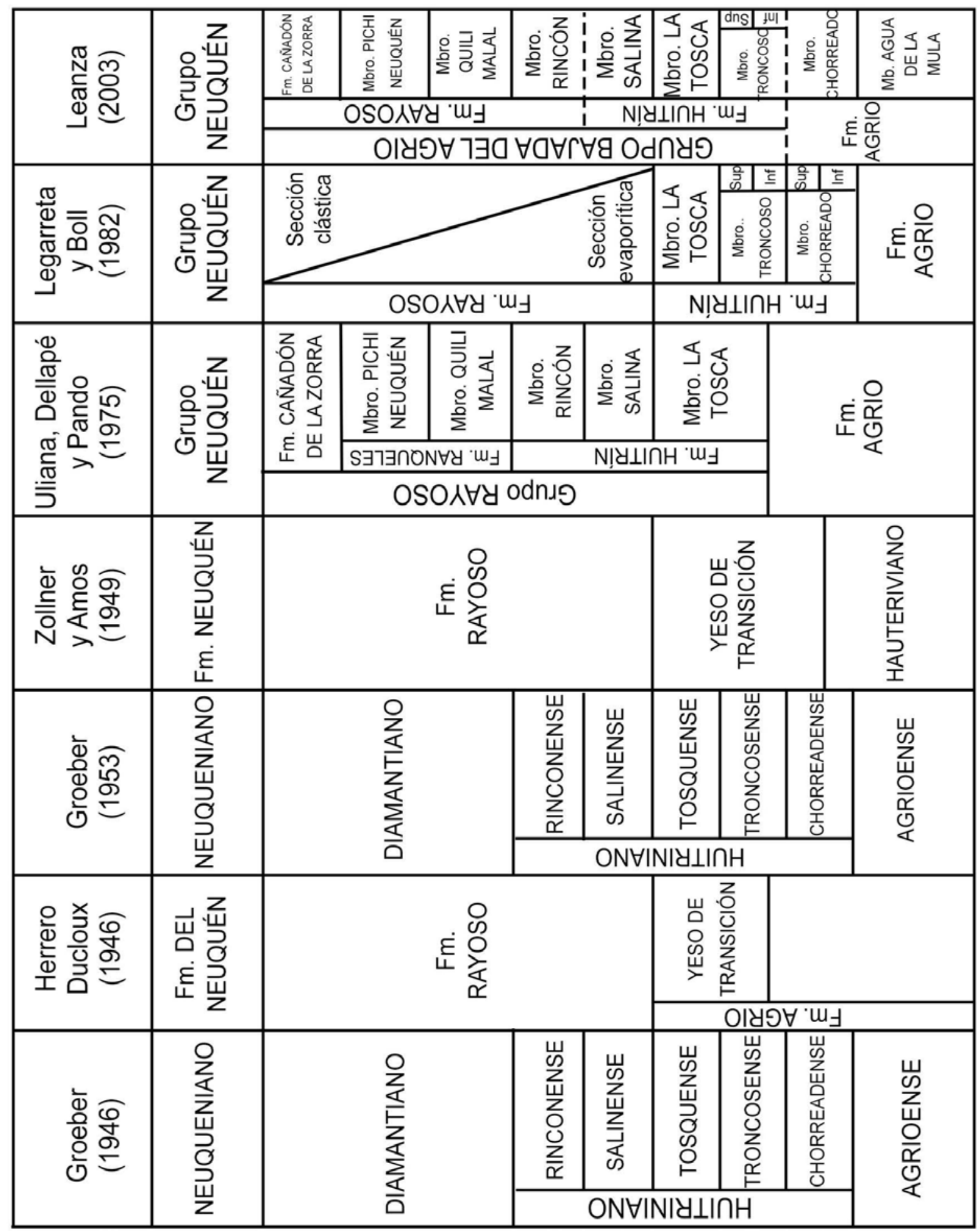

Cuadro 2.3: Equivalencias de nomenclaturas de las unidades sedimentarias eocretácicas según diversos autores. Modificado de Gutiérrez Pleimling et al. (2011). 


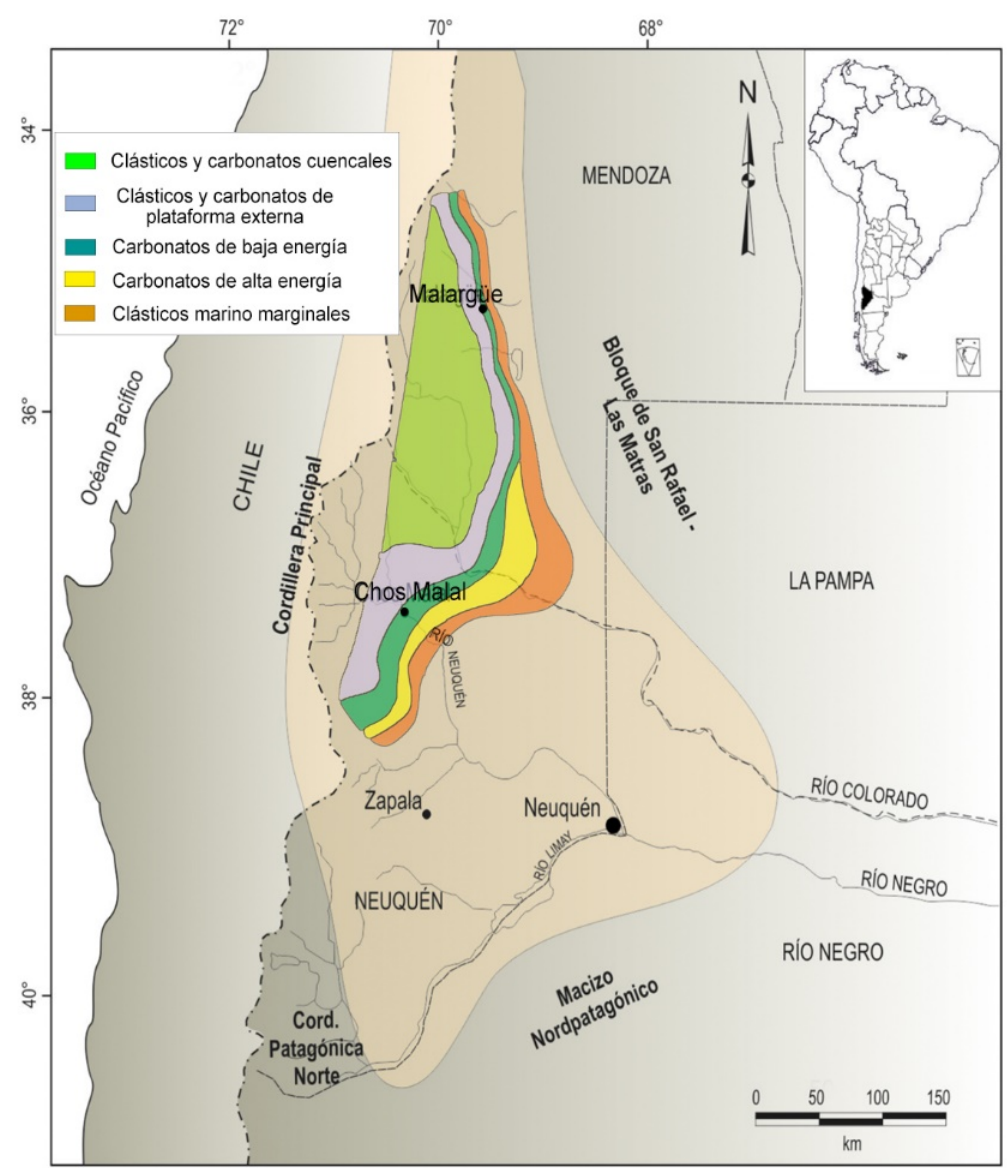

Figura 2.10: Distribución de las facies del Miembro Chorreado de la Formación Huitrín. Modificado de Gutiérrez Pleimling et al. (2011).

\section{Miembro Troncoso}

Su localidad tipo se encuentra en la Bajada del Troncoso en las cercanías de Buta Ranquil al norte de la provincia del Neuquén (Leanza 2003). Posteriormente, Legarreta y Boll (1982) dividieron a esta unidad en dos secciones: una Inferior dominada por depósitos clásticos y otra Superior de naturaleza evaporítica (Fig.2.11). La edad de dicha Formación aún es un tema controversial, Leanza et al. (2006) la asignan al Barremiano Superior.

La sección Inferior del Miembro Troncoso, denominada Troncoso Inferior, constituye la unidad clástica de origen continental compuesta por depósitos fluviales y eólicos, ampliamente representados en el centro y norte de la provincia de Neuquén (Veiga y Vergani 2011). Litológicamente está compuesta por areniscas de grano medio de coloración ocre, castaño amarillento o blanquecino. Esta sección representa condiciones de sedimentación típicas de ambientes continentales. Posteriormente y como resultado de una brusca inundación, se interrumpe súbitamente la depositación clástica, conformándose los 
depósitos evaporíticos de la sección Superior del Miembro Troncoso. Estos últimos presentan una estructura interna bandeada, definida por la alternancia rítmica de láminas claras y oscuras. Lateralmente, las evaporitas se interdigitan con carbonatos cristalinos de textura porosa, macizos o laminoideos, a veces brechados o bien son reemplazados por ellos (Leanza et al., 2006) por lo que dicho Miembro ha sido caracterizado como de naturaleza evaporítico-carbonática. En superficie, como consecuencia de la movilidad de la sal, los afloramientos correspondientes a este Miembro presentan un espesor reducido, restringido en la mayoría de los casos a unos pocos metros de anhidrita. Este Miembro ha constituido un nivel de importancia, desde el punto de vista petrolero, como sello regional y desde el punto de vista tectónico como nivel de despegue superior en las estructuras de la Faja Plegada y Corrida del Agrio. El evento de inundación culmina con la depositación del Miembro La Tosca, acumulado en un sistema de rampa con aguas de alta salinidad.

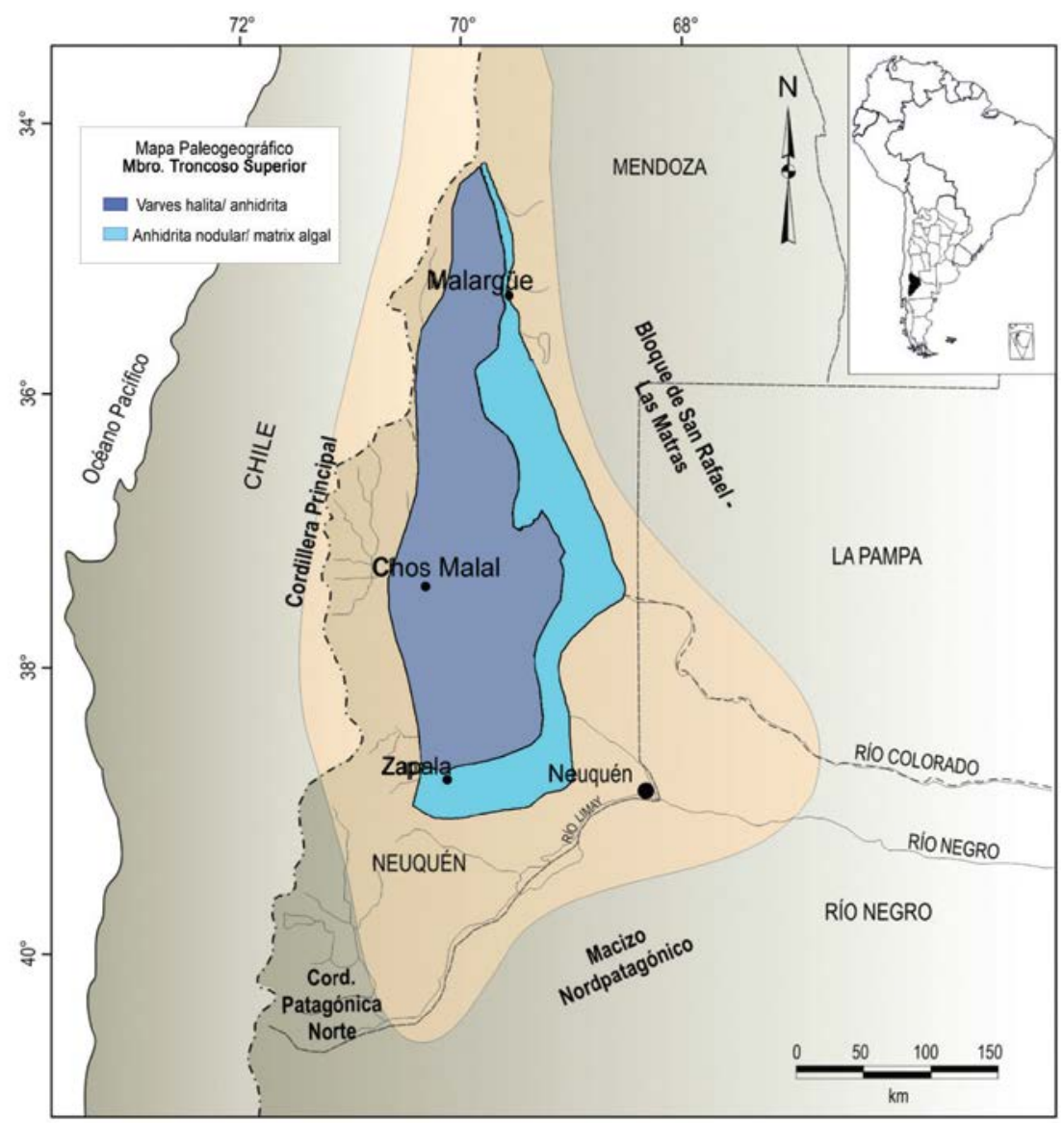

Figura 2.11: Mapa paleogeográfico del Miembro Troncoso Superior de la Formación Huitrín. Modificado de Legarreta y Uliana (1991). 


\section{Miembro La Tosca}

Está compuesto por depósitos carbonáticos (calizas y dolomías castañas claras de tipo wackestone-packstone esqueléticas y grainstone oolíticas) de edad barremiana (Olea et al., 2011). Las mismas presentan estratificación tabular bien definida con intercalaciones de pelitas laminares. En los planos de estratificación es común la presencia de conchillas de bivalvos bien preservadas. Este Miembro se apoya en concordancia sobre el Miembro Troncoso y su límite superior es contrastante debido a la presencia de arcilitas varicolores yesíferas del Miembro Salina, las que lo cubren concordantemente (Leanza 2003).

Estudios sedimentológicos de detalle (Legarreta 1985) indican que este Miembro fue depositado en un ambiente de rampa carbonática poco profunda con suave pendiente al noroeste, cuyas zonas costeras estaban parcialmente protegidas por barras oolíticas. Sobre la base de la fauna de bivalvos, Lazo y Damborenea (2011) infirieron que este Miembro corresponde a un ambiente marino restringido con variaciones en parámetros ambientales, lo cual condicionó el desarrollo de una fauna estrictamente euhalina.

\section{Miembro Salina}

Este Miembro está cubierto paraconcordantemente por el Miembro Rincón de la Formación Rayoso. Este límite representa la discordancia Intraptiana que es un importante límite de secuencia depositacional, el cual presenta una leve angularidad demostrada por Cobbold y Rosello (2003). El Miembro Salina está constituido por arcilitas y en menor medida por limolitas y areniscas. Se disponen en estratos tabulares gruesos y la coloración es abigarrada, siendo las tonalidades más sobresalientes las rojizas, verdosas, amarillentas, grises y castaño claras. Las acumulaciones de yeso conforman niveles de color blanco, con formas lenticulares, de poca extensión lateral y escasa potencia. La presencia de bancos de sal de roca (halita) en el subsuelo es típica en este Miembro.

Considerando el conjunto de evidencias litológicas presentes en el Miembro Salina, Uliana et al., (1975a) han estimado que las asociaciones de pelita-yeso-caliza están asociadas a un ambiente de lagunas someras de tipo sabkha marginal y barreal ("mudflats"). Una interpretación alternativa fue brindada por Ponce et al. (2002), quienes postularon para estas sedimentitas un paleoambiente lacustre. 


\section{Formación Rayoso}

La denominación Formación Rayoso (Herrero Ducloux 1946) fue asignada a una unidad clástica-evaporítica de hasta $1200 \mathrm{~m}$ de espesor y amplia distribución $\left(15.000 \mathrm{~km}^{2}\right)$ en la Cuenca Neuquina (Zavala y Ponce 2011). Dicha Formación está limitada por la discordancia Miránica Intermedia (Intraptiana, $117 \mathrm{Ma}$ ) en la base del Miembro Rincón (Leanza y Hugo 1995) y la discordancia Miránica Principal (límite Albiano/Cenomaniano, $99 \mathrm{Ma}$ ) en la base de la Formación Candeleros. Las principales investigaciones en esta unidad formacional se deben a Herrero Ducloux (1946), Groeber (1946, 1953), Uliana et al. (1975a y b), Ramos (1981), Legarreta y Boll (1982), Legarreta (1985) y Ponce et al. (2002), entre otros.

Corresponde a una unidad clástico-evaporítica (areniscas finas, pelitas rojas, carbonatos y evaporitas), acumulada en un medio predominantemente continental que marca la desconexión permanente de la Cuenca Neuquina con el océano Pacífico. El ambiente de depositación de esta Formación ha sido asociado a sistemas fluviales efímeros (Uliana et al., 1975a y b). De acuerdo con el análisis efectuado por Leanza (2003), se considera que la Formación Rayoso está integrada por los Miembros Rincón, Quili Malal, Pichi Neuquén y Cañadón de la Zorra. Posteriormente, Ramos (1981) dividió a la Formación Rayoso en tres Miembros: Inferior, correlacionable con el Miembro Rincón; Medio, correlacionable con el Miembro Quili Malal y Superior, equiparable con los Miembros Pichi Neuquén y Cañadón de la Zorra.

\section{Depósitos asociados al estadio de cuenca de antepaís}

La horizontalización del ángulo de subducción de la Placa de Farallón a fines del Cretácico Temprano generó un régimen tectónico compresivo (Ramos 1999) provocando la inversión de muchas estructuras extensionales previas (Vergani et al., 1995). Esta etapa se caracterizó por la gradual continentalización de los ambientes depositacionales, controlados mayoritariamente por una tectónica compresiva con la consiguiente generación de un frente de deformación y la migración hacia el este de los depocentros sedimentarios (Vergani et al., 1995; Franzese et al., 2003; Ramos y Folguera 2005; Howell et al., 2005).

\section{GRUPO NEUQUÉN}

Los depósitos que constituyen este Grupo forman parte del Ciclo Riográndico (Groeber 1946) o de la Supersecuencia Superior (Legarreta y Gulisano 1989). Estos 
depósitos han sido nombrados bajo diferentes denominaciones a lo largo del tiempo. Uno de los términos más relevantes fue "Estratos con Dinosaurios" (Keidel 1917) pero los primeros en utilizar el nombre de Grupo Neuquén, en base a las reglas de la nomenclatura estratigráfica, fueron Stipanicic et al. (1968). Este Grupo ha sido subdividido en tres Subgrupos: Río Limay (Ramos 1981), Río Neuquén y Río Colorado (Cazau y Uliana 1973). El Subgrupo Río Limay comprende las Formaciones Candeleros, Huincul y Cerro Lisandro, mientras que el Subgrupo Río Neuquén incluye las Formaciones Portezuelo y Plottier. Finalmente, el Subgrupo Río Colorado integra a las Formaciones Bajo de la Carpa y Anacleto.

El Grupo Neuquén está conformado por depósitos clásticos continentales de origen fluvial, eólico y lacustre somero de edad cretácica superior (Cenomaniano-Campaniano Medio), limitados en su base por la discordancia Patagonídica (Cenomaniano Tardío) (Leanza 2009; Tunik et al., 2010) y en su techo por la discordancia Huantráiquica (Campaniano Medio) (Dingus et al., 2009). Esta sucesión alcanza un espesor máximo de 1200 m; está compuesta, litológicamente, por un conjunto de capas rojas ("red beds") constituidas principalmente por areniscas, fangolitas y grauvacas, con una reducida participación de horizontes conglomerádicos. El ambiente tectosedimentario está vinculado al desarrollo de la fase de antepaís, como consecuencia del inicio de una tectónica compresional a fines del Cretácico Temprano (Tunik et al., 2010). Con posterioridad a la depositación de esta Supersecuencia, la cuenca tuvo un importante evento de deformación que condujo a la depositación de secuencias sinorogénicas de edad Mioceno Inferior (Conglomerados de Tralalhué). Dichos conglomerados fueron definidos por primera vez por Ramos (1998) para identificar unos depósitos que aparecen en el flanco occidental del cerro Naunauco.

\section{Estratigrafía de unidades magmáticas}

Hacia fines del Mesozoico, durante el comienzo del ciclo Ándico, se desarrolló en la Cuenca Neuquina un importante magmatismo de arco. Dicho magmatismo se extiende en una faja de unos $200 \mathrm{~km}$ de longitud, de rumbo aproximadamente norte-sur en el sector noroeste de la provincia del Neuquén (Fig.2.12). Su mayor desarrollo se exhibe en el sector interno de la Faja Plegada y Corrida del Agrio, sobreimpuesto a la secuencia sedimentaria mesozoica. Originalmente las rocas ígneas fueron denominadas por Groeber (1929) como Serie Andesítica Oligocena. Sin embargo, Groeber (1946) las redefinió como Mollelitense, 
donde incluyó bajo este término a todas las unidades volcánicas paleógenas. Yrigoyen (1972) adecuó el término a la nomenclatura estratigráfica vigente para la época, designándole el nombre de Grupo Molle. La amplia extensión de este magmatismo generó que, a partir de estudios locales, proliferaran diversas nomenclaturas, según el área involucrada. Llambías y Rapela $(1987,1989)$ le dieron la denominación de Provincia Volcánica Neuquino-Mendocina (PVNM) a todas las unidades descriptas por autores previos. Más recientemente, Llambías y Aragón (2011) las integraron al Cinturón Andesítico Naunauco (Cretácico Tardío-Paleógeno) (Fig.2.12). Rapela y Llambías (1985) definieron la Formación Cayanta para las facies volcánicas, mientras que Llambías y Rapela (1987) denominaron Formación Colipilli a las facies intrusivas. Posteriormente, para describir estas rocas Zamora Valcarce (2007) definió el Grupo Naunauco incluyendo a las Formaciones Colipilli y Cayanta.

En el sector interno de la Faja Plegada y Corrida del Agrio, Zamora Valcarce (2007) reconoció dos eventos magmáticos bien diferenciados: uno de edad Cretácico Temprano Alto constituido por una serie de diques de composición basáltica de rumbo este-oeste, denominados Basaltos de Cerro Mocho y otro de edad Cretácico TardíoPaleoceno Temprano compuesto por rocas con características de arco volcánico, que componen el Grupo Naunauco. Zamora Valcarce (2007) obtuvo edades radimétricas por

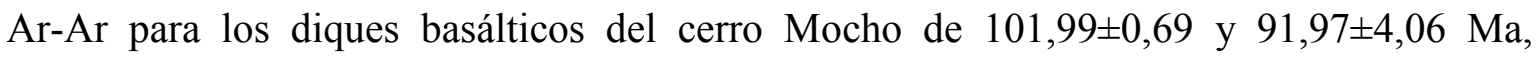
mientras que los fechados Ar-Ar para las rocas ígneas del Grupo Naunauco fueron de $65,5 \pm 0,46$ y $72,83 \pm 0,83$ Ma (Cuadro 2.4). Sobre la base de las edades radimétricas, características geoquímicas y petrológicas de las mismas Franchini et al. (2003), Mateo Fernández Caso et al. (2011), entre otros, subdividieron al magmatismo en tres grupos: el primero de edad Cretácico Tardío; el segundo de edad Cretácico Tardío-Paleocena y el tercero de edad Eocena Media. La presencia de estas rocas estaría indicando la posición del arco volcánico en la región para el Cretácico Tardío-Eoceno dando evidencia de la migración hacia el este y la extensión del mismo en las primeras fases del ciclo Ándico.

Durante el Mioceno, en el centro norte de la provincia, se desarrolló un nuevo evento magmático (Fig.2.12) caracterizada por basaltos y andesitas basálticas alcalinas; estas rocas afloran principalmente en la región de la sierra de Huantraico y sierra Negra. En base a su composición química fue referida como el producto de un volcanismo de intraplaca, desarrollado durante una etapa extensional de retroarco, con escasa conexión con el arco magmático (Ramos y Barbieri 1988; Kay y Copeland 2006). 


\begin{tabular}{|c|c|c|c|c|}
\hline Localidad & Método & Roca & Edad, Ma & Autor \\
\hline \multirow{2}{*}{ Campana Mahuida } & $\begin{array}{l}\text { SHRIMP U-Pb en } \\
\text { circones }\end{array}$ & $\begin{array}{l}\text { Intrusivo } \\
\text { andesítico }\end{array}$ & $61,0 \pm 1,4$ & Franchini et al. (2007) \\
\hline & K-Ar hornblenda & Diorita & $60,7 \pm 1,9$ & \multirow{4}{*}{ Franchini et al. (2003) } \\
\hline \multirow{3}{*}{ Cerro Nevazón } & K-Ar hornblenda & Gabro-Diorita & $59,1 \pm 2,9$ & \\
\hline & K-Ar hornblenda & Diorita & $56,0 \pm 1,7$ & \\
\hline & Ar-Ar plagioclasa & Gabro & $60,2 \pm 1,2$ & \\
\hline Varvarco & K-Ar roca total & Tonalita & $66,7 \pm 3,0$ & J.I.C.A./M.M.A.J. (2000) \\
\hline Los Maitenes & K-Ar roca total & Tonalita & $67,0 \pm 3,0$ & Domínguez et al. (1984) \\
\hline \multirow{2}{*}{ Campana Mahuida } & \multirow{2}{*}{ K-Ar biotita } & \multirow{2}{*}{$\begin{array}{l}\text { Alteración } \\
\text { hidrotermal } \\
\text { en andesita }\end{array}$} & $74,2 \pm 1,4$ & \multirow{2}{*}{ Sillitoe (1977) } \\
\hline & & & $60,7 \pm 1,9$ & \\
\hline Cayanta & \multirow{4}{*}{ K-Ar anfíbol } & Andesita & $39,9 \pm 9,1$ & \multirow{4}{*}{ Llambías y Rapela (1984 } \\
\hline Las Mellizas, Colipilli & & Microdiorita & $49,9 \pm 3,3$ & \\
\hline Cerro El Diablo & & Microdiorita & $48,4 \pm 2,4$ & \\
\hline Caicayén & & Microdiorita & $44,7 \pm 2,2$ & \\
\hline El Mayal & Ar-Ar roca total & Sill. Andesita & $39,7 \pm 0,2$ & Cobbold y Rosello (2003) \\
\hline \multirow{2}{*}{ Cerro Mocho } & \multirow{2}{*}{ Ar-Ar plagioclasa } & \multirow{2}{*}{ Dique. Basalto } & $101,9 \pm 0,7$ & \multirow{5}{*}{ Zamora Valcarce (2006) } \\
\hline & & & $91,9 \pm 4,0$ & \\
\hline Colipilli & Ar-Ar plagioclasa & Sill. Andesita & $56,6 \pm 0,4$ & \\
\hline \multirow{2}{*}{ Naunauco } & Ar-Ar anfibol & Sill. Andesita & $65,5 \pm 0,4$ & \\
\hline & Ar-Ar plagioclasa & Bomba volcánica & $72,8 \pm 0,8$ & \\
\hline \multirow{3}{*}{ Cayanta } & \multirow{3}{*}{ K-Ar roca total } & Intrusivo aplítico & $46,1 \pm 2,3$ & \multirow{3}{*}{ Rovere (1998) } \\
\hline & & \begin{tabular}{|l|} 
Dique. Andesita \\
\end{tabular} & $54,2 \pm 2,7$ & \\
\hline & & \begin{tabular}{|l|} 
Dacita \\
\end{tabular} & $42,0 \pm 2,1$ & \\
\hline Laguna del Hualpe & Ar-Ar roca total & Dique. Dacita & $61,1 \pm 0,3$ & \multirow{4}{*}{ Leanza et al. (2005) } \\
\hline Noroeste de Colipilli & Ar-Ar anfibol & Dique. Andesita & $63,9 \pm 0,5$ & \\
\hline Cerro Nonial & Ar-Ar roca total & Lacolito. Andesita & $54,3 \pm 1,9$ & \\
\hline Cerritos Colorados & Ar-Ar roca total & Lacolito. Andesita & $52,2 \pm 1,9$ & \\
\hline
\end{tabular}

Cuadro 2.4: Edades del Cinturón Paleógeno Naunauco, centro y noroeste del Neuquén. Tomado de Llambías y Aragón (2011). 


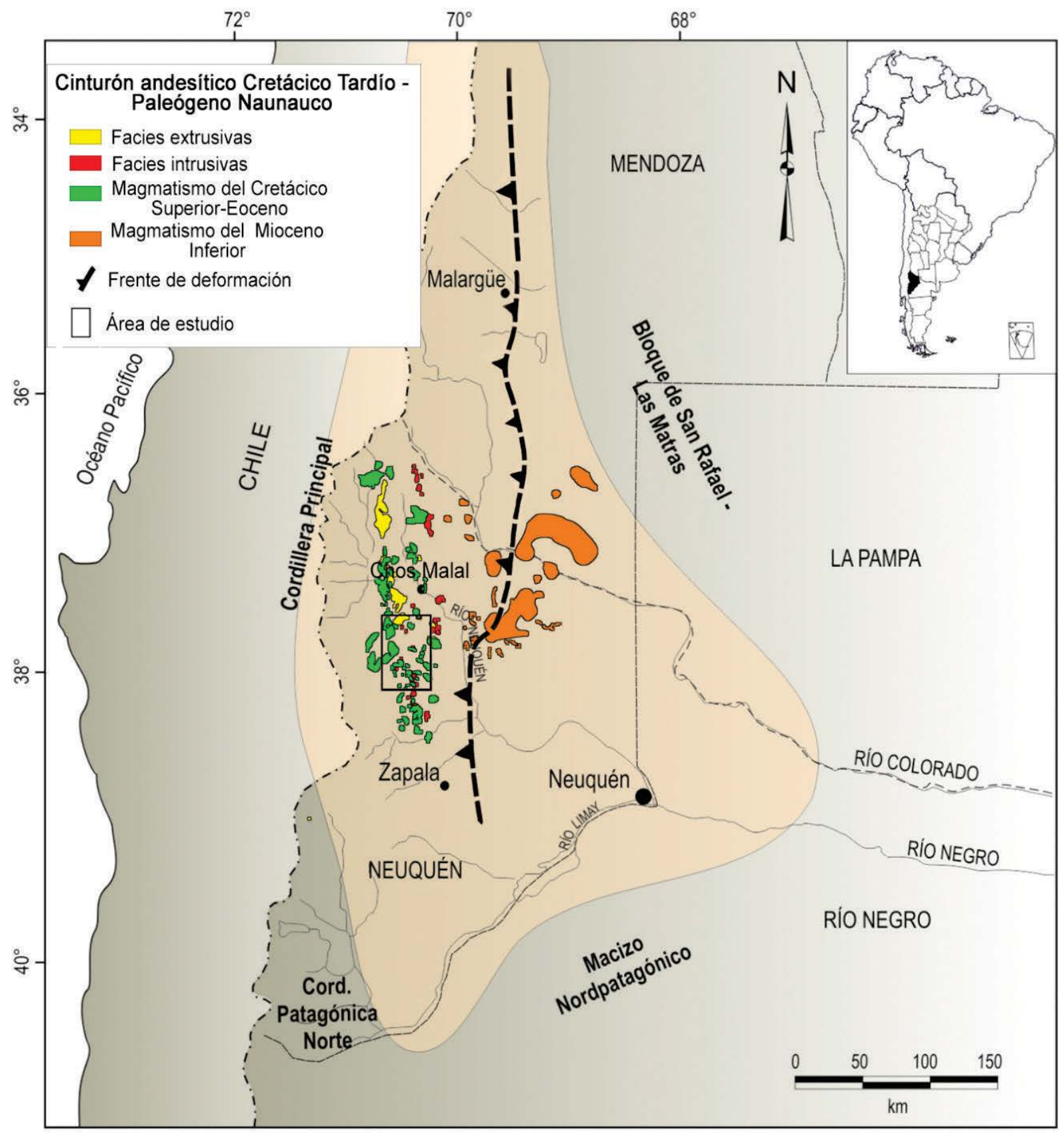

Figura 2.12: Distribución de rocas ígneas del magmatismo Cretácico Tardío- Eoceno y del Mioceno Inferior presentes en la provincia del Neuquén. Modificado de Llambías y Aragón (2011). 


\section{Antecedentes metalogenéticos}

Las mineralizaciones barito-polimetálicas (Ba-Fe-Pb-Cu-Zn-Mn) abordadas en la presente investigación se encuentran en un contexto geológico regional asociado principalmente a la secuencia carbonático-evaporítica del Cretácico Temprano y al volcanismo cenozoico-terciario. Sin embargo, la Cuenca Neuquina presenta además numerosos depósitos de $\mathrm{Ba}$ y $\mathrm{Sr}$ vinculados a secuencias carbonático-evaporíticas de edad jurásica.

Son varios los autores que han trabajado para dilucidar los aspectos genéticos de las mineralizaciones barito-celestínicas de la Cuenca Neuquina. Entre las primeras investigaciones se pueden citar las de Brodtkorb et al. (1975) y Hayase y Bengochea (1975). Brodtkorb et al. $(1985,1992)$, posteriormente, Brodtkorb et al. $(1997,1999)$ y más recientemente, Brodtkorb y Danieli (2011) propusieron para la gran mayoría de estos depósitos que su origen estuvo asociado a procesos evaporíticos (celestinas) u otros procesos de depositación química (baritinas) en ambientes evaporíticos jurásico-cretácicos. Además, observaron procesos de removilización que los atribuyeron al magmatismo del Grupo Naunauco. Por otra parte, Hayase y Bengochea (1975), Bengochea (1975) y años más tarde de Barrio y Vergani (2011) y de Barrio et al. (2014), señalaron que los depósitos de $\mathrm{Ba}-\mathrm{Sr}$ son epigenéticos, hidrotermales, asociados a procesos de reemplazo en rocas carbonáticas y yesíferas y removilización con relleno de fracturas y oquedades. Los primeros estudios geológico-metalogénicos en el área de Colipilli fueron realizados por Llambías y Malvicini (1978).

Las dimensiones de estas manifestaciones varían desde pequeños afloramientos hasta depósitos de regular extensión. Presentan una mineralogía sencilla con baritina y celestina (baritocelestinas y celestobaritinas) como minerales ampliamente dominantes, acompañados, en algunos casos, de proporciones minoritarias de magnetita, sulfuros (galena, esfalerita, pirita, calcopirita) junto a calcita y cuarzo. Los depósitos, en líneas generales, se presentan en tres yacencias distintas: vetiforme, mantiforme y cuerpos irregulares por relleno de oquedades formadas por disolución. En el área de estudio se identificaron dos tipos de mineralizaciones de acuerdo a su expresión morfológica: (a) mineralizaciones mantiformes, que se alojan principalmente en la Formación Huitrín y en el contacto roca sedimentaria-ígnea, y (b) cuerpos vetiformes que se encuentran emplazados en la Formación Agrio y en el contacto roca sedimentaria-ígnea. 


\section{Trabajos citados en el texto}

Aguirre Urreta, M.B. y Rawson, P.F. 1997. The ammonite sequence in the Agrio Formation (Lower Cretaceous), Neuquén basin, Argentina. Geological Magazine, 134: 449-458. London.

Arregui, C., Carbone, O. y Leanza, H. 2011. Contexto tectosedimentario. En: Leanza, H., Arregui, C., Carbone, O., Danieli, J.C., Vallés, J. (Eds.), Relatorio del XVIII Congreso Geológico Argentino, Geología y Recursos Naturales de la provincia del Neuquén: 29-36. Buenos Aires.

Barrionuevo, M. 2002. Yacimiento Puesto Hernández. Los reservorios del Miembro Troncoso Inferior de la Formación Huitrín. En: Schiuma, M., Hinterwimmer, G. y Vergani, G. (Eds.), Rocas reservorio de las cuencas productivas de la Argentina, $5^{\circ}$ Congreso de Exploración y Desarrollo de Hidrocarburos (IAPG), 443-454; 457-464 y 486-489. Mar del Plata.

Bengochea, L. 1975. Estudio geológico de los yacimientos de baritina-celestina de la provincia de Neuquén, República Argentina. Tesis doctoral. (Inédito). 107 p. Universidad Nacional del Sur, Bahía Blanca.

Bodenbender, G. 1889. Expedición al Neuquén. Instituto Geográfico Argentino, Boletín 10: 311329, Buenos Aires.

Bodenbender, G. 1891. Apuntes sobre rocas eruptivas de la pendiente oriental de los Andes entre el Río Diamante y Río Negro. Revista Argentina de Historia Natural. Tomo I. 27 p.

Bodenbender, G. 1892. Sobre el terreno jurásico y cretácico de los Andes argentinos, entre el río Diamante y el río Limay, en Boletín de la Academia Nacional de Ciencias, XIII: 5-44. Córdoba.

Brodtkorb, M.K. de, Ramos, V.A. y Ametrano, S. 1975. Los yacimientos estratoligados de celestina - baritina de la Formación Huitrín y su origen evaporítico. Provincia del Neuquén. Argentina. II Congreso Iberoamericano Geología Económica, 2: 143-168. Buenos Aires.

Brodtkorb, M.K. de, Schalamuk, I.B., Barbieri, M., Ametrano, S., Fernández, R.R., Etcheverry, R.O. y Aragón, E. 1985. Los yacimientos de baritina y celestina del Mesozoico de Mendoza y Neuquén. Argentina. IV Congreso Geológico Chileno, Actas II: 156-183.

Brodtkorb, M.K.de, Danieli, J.C., de Barrio, R.E., Etcheverry, R.O. y Giusiano, A. 1992. Los yacimientos de celestina-baritina, yeso, halita y sales de potasio relacionados a las sedimentitas cretácicas de la cuenca Neuquina, República Argentina. (M.K. de Brodtkorb y José Ferreira de Sousa, Eds.), En Recursos minerales y energéticos del Cretácico de América Latina: 1-24. IUGS, UNESCO, IGCP, 242. La Plata.

Brodtkorb, M.K.de, Barbieri, M., Žák, K., Hladíková, J., Tassinari, C., Ametrano, S., Etcheverry, R.O., de Barrio, R.E., Del Blanco, M. y Danieli, J.C. 1997. Isotope Data on barite and 
celestite deposits related to three Mesozoic evaporitic events of the Neuquén Basin, Argentina. W. Ernst y B. Skinner (Eds.), International Geology Review, 39: 307-316.

Brodtkorb, M.K. de, de Barrio, R.E., Del Blanco, M. y Etcheverry, R.O. 1999. Geología de los depósitos de baritina, celestina, yeso y halita de la Cuenca Neuquina. En Recursos minerales de la República Argentina, Zappettini, E (Ed.), Instituto de Geología y Recursos Minerales, SEGEMAR. Anales 35, II: 1041-1046. Buenos Aires.

Brodtkorb, M.K. de y Danieli, J.C. 2011. Yacimientos de baritina y celestina. En: Leanza, H., Arregui, C., Carbone, O., Danieli, J.C., Vallés, J. (Eds.), Relatorio del XVIII Congreso Geológico Argentino, Geología y Recursos Naturales de la provincia del Neuquén: 745754. Buenos Aires.

Cazau, L.B. y Uliana, M.A. 1973. El Cretácico superior continental de la Cuenca Neuquina. V Congreso Geológico Argentino, Actas 3: 131-163.

Cingolani, C.A., Zanettini, J.C.M. y Leanza, H.A. 2011. El Basamento ígneo y metamórfico. En: Leanza, H., Arregui, C., Carbone, O., Danieli, J.C., Vallés, J. (Eds.), Relatorio del XVIII Congreso Geológico Argentino, Geología y Recursos Naturales de la provincia del Neuquén: 37-47. Buenos Aires.

Cobbold, P.R. y Rossello, E.A. 2003. Aptian to Recent compressional deformation, foothills of the Neuquén Basin, Argentina. Marine and Petroleum Geology, 20: 429-443.

de Barrio, R.E. y Vergani, G. 2011. Las mineralizaciones de celestina-baritina y la Formación Huitrín (Cretácico inferior), provincia del Neuquén. XVIII Congreso Geológico Argentino, 1084-1085. Buenos Aires.

de Barrio, R.E., Etcheverry, R.O., Del Blanco, M.A., Domínguez, E.A., Recio Hernández, C., Escobar, R.I. y Salvioli, M.A. 2014. Nuevos datos y esquemas genéticos de los depósitos baríticocelestínicos vinculados a la secuencia jurásico-cretácica de la Cuenca Neuquina en la provincia del Neuquén. Revista de la Asociación Geológica Argentina. 71: 184-200. Buenos Aires.

Danieli, J.C., Casé, A.M., Leanza, H.A. y Bruna, M.A. 2011. Minerales y rocas industriales. En: Leanza, H., Arregui, C., Carbone, O., Danieli, J.C., Vallés, J. (Eds.), Relatorio del XVIII Congreso Geológico Argentino, Geología y Recursos Naturales de la provincia del Neuquén: 725-744. Buenos Aires.

Dellapé, D.A., Mombrú, C., Pando, G.A., Riccardi, A.C., Uliana, M.A. y Westermann, G.E. 1978. Edad y correlación de la Formación Tábanos en Chacay Melehue y otras localidades de Neuquén y Mendoza. Con consideraciones sobre la distribución y significado de las sedimentitas Lotenianas. Obra Centenario Museo de La Plata, Paleontología, 5: 81-105.

Digregorio, J.H. y Uliana, M.A. 1980. Cuenca Neuquina. En: Turner, J.C.M. (Ed.), II Simposio de Geología Regional Argentina. Academia Nacional de Ciencias, 2: 985-1032. Córdoba. 
Dingus, L., Garrido, A.C., Scott, G.R., Chiappe, L.M., Clarke, J. y Schmitt, J.G. 2009. The lito-, bio- and magnetostratigraphy of titanosaurian nesting sites in the Anacleto Formation at Auca Mahuevo (Campanian, Neuquen Province, Argentina). En: Barry Albright III, L. (Ed.), Papers on Geology, Vertebrate Paleontology, and Bioestratigraphy in Honor of Michel O. Woodburne. Museum of Northern Arizona Bulletin 65: 237-258.

Domínguez, E.A., Aliotta, G., Garrido, M., Danieli, J.C., Ronconi, N., Casé, A.M. y Palacios, M. 1984. Los Maitenes-El Salvaje, un sistema hidrotermal de tipo porfírico. $9^{\circ}$ Congreso Geológico Argentino, Actas 7: 443-458, San Carlos de Bariloche.

Escobar, R.I. 2016. Geología y génesis de las mineralizaciones barito-celestínicas asociadas a la secuencia cretácia entre las localidades Bajada del Agrio y Chos Malal, provincia del Neuquén. Tesis Doctoral, Universidad Nacional de La Plata. (Inédito). 207 p., La Plata.

Franchini, M., López Escobar, L., Schalamuk, I.B.A. y Meinert, L. 2003. Magmatic characteristics of the Paleocene Cerro Nevazón region and other Late Cretaceous to Early Tertiary calcalkaline subvolcanic to plutonic units in the Neuquén Andes, Argentina. Journal of South American Earth Sciences, 16: 399-421.

Franchini, M., Impiccini, A., Meinert, L., Grathoff, G. y Schalamuk, I.B.A. 2007. Clay Mineralogy and Zonation in the Campana Mahuida Porphyry $\mathrm{Cu}$ Deposit, Neuquén, Argentina: Implications for Porphyry Cu Exploration. Economic Geology 102: 27-54.

Franzese, J.R. y Spalletti, L.A. 2001. Late Triassic-Early Jurassic continental extension in southwestern Gondwana: tectonic segmentation and pre-break-up rifting. Journal of South American Earth Sciences, 14: 257-270.

Franzese, J.R., Spalletti, L.A., Gómez Pérez, I. y Macdonald, D. 2003. Tectonic and paleoenvironmental evolution of Mesozoic sedimentary basins along the Andean foothills of Argentina ( $\left.32^{\circ}-54^{\circ} \mathrm{S}\right)$. Journal of South American Earth Sciences, 16: 81-90.

Giusiano, A. y Bouhier, E. 2009. Mineralización de $\mathrm{Cu}$ en el Grupo Neuquén vinculada a la migración de hidrocarburos. Dorso de los Chihuidos, Neuquén, Argentina: Boletín de Informaciones Petroleras, Cuarta Época, 5: 6-18.

Gómez Omil, R., Schmithalter, J., Cangini, A., Albariño, L. y Corsi, A. 2002. El Grupo Cuyo en la Dorsal de Huincul, Consideraciones Estratigráficas, Tectónicas y Petroleras. Cuenca Neuquina. $5^{\circ}$ Congreso de Exploración y Desarrollo de Hidrocarburos (Mar del Plata), Actas en CD: $22 \mathrm{p}$.

Groeber, P. 1929. Líneas fundamentales de la geología del Neuquén, sur de Mendoza y regiones adyacentes. Dirección Nacional de Geología y Minería, Publicación 58: 1-109. Buenos Aires.

Groeber, P. 1946. Observaciones geológicas a lo largo del meridiano $70^{\circ}$. 1. Hoja Chos Malal. Revista de la Asociación Geológica Argentina, 1: 177-208. Buenos Aires. 
Groeber, P. 1953. Ándico. En: Groeber, P.: Mesozoico. Geografia de la República Argentina. Sociedad Argentina de Estudios Geográficos, GAEA, 2: 349-536. Buenos Aires.

Gulisano, C.A. 1981. El ciclo Cuyano en el norte de Neuquén y sur de Mendoza. VIII Congreso Geológico Argentino. Actas 3: 579-592. Buenos Aires.

Gulisano, C.A., Gutiérrez Pleimling, A. y Digregorio, R.E. 1984a. Análisis estratigráfico del intervalo Tithoniano - Valanginiano (Formaciones Vaca Muerta - Quintuco y Mulichinco) en el suroeste de la provincia del Neuquén. IX Congreso Geológico Argentino, Actas 1: 221-235. Buenos Aires.

Gulisano, C.A., Gutiérrez Pleimling, A.R. y Digregorio, R.E. 1984b. Esquema estratigráfico de la secuencia jurásica al oeste de la provincia del Neuquén. IX Congreso Geológico Argentino, Actas 1: 236-259. Buenos Aires.

Gulisano, C.A. y Gutiérrez Pleimling, A.R. 1994. The Jurassic of the Neuquén Basin, Neuquén Province. Field guide. Secretaría de Minería de la Nación. Asociación Geológica Argentina, 111 p. Buenos Aires.

Gulisano, C.A. y Hinterwimmer, G. 1986. Facies deltaicas del Jurásico medio en el oeste de Neuquén. Boletín de Informaciones Petroleras, Tercera Época. 8: 2-31.

Gutiérrez Pleimling, A.R. 1991. Estratigrafía de la Formación Huitrín: un estudio puntual sobre la ruta Nacional No 40, provincia del Neuquén. Boletín de Informaciones Petroleras: 85-100.

Gutiérrez Pleimling, A.R., Olea, G., Suárez, M. y Valenzuela, M. 2011. El Miembro Chorreado de la Formación Huitrín (Cretácico Temprano). En: Leanza, H., Arregui, C., Carbone, O., Danieli, J.C., Vallés, J. (Eds.), Relatorio del XVIII Congreso Geológico Argentino, Geología y Recursos Naturales de la provincia del Neuquén: 175-180. Buenos Aires.

Hayase, K. y Bengochea, A.L. 1975. Consideraciones sobre la génesis de algunos yacimientos de baritina-celestina; provincia de Neuquén; República Argentina. II Congreso Iberoamericano de Geología Económica, 2: 295-314. Buenos Aires.

Herrero Ducloux, A. 1946. Contribución al conocimiento geológico del Neuquén extraandino. Boletín de Informaciones Petroleras, 23: 245-281. Buenos Aires.

Howell, J.A., Schwarz, E., Spalletti, L.A. y Veiga, G. 2005. The Neuquén Basin: an overview. En Veiga, G.D., Spalletti, L.A., Howell, J.A. y Schwarz, E. (Eds.), The Neuquén Basin, Argentina: A case study in sequence stratigraphy and basin dynamics. Geological Society, London, Special Publications, 252: 1-14.

Kay, S.M., Ramos, V.A., Mpodozis, C. y Sruoga, P. 1989. Late Paleozoic to Jurassic silicic magmatism at the Gondwana margin: Analogy to Middle Proterozoic in North America. Geology 17: 324-328, Boulder.

Kay, S.M. y Copeland, P.C. 2006. Early to middle Miocene back-arc magmas of the Neuquén Basin: Geochemical consequences of slab shallowing and the westward drift of South 
America. En: Kay, S.M. y Ramos, V.A., (Eds.), Evolution of an Andean margin: A tectonic and magmatic view from the Andes to the Neuquén Basin $\left(35^{\circ}-39^{\circ} \mathrm{S}\right.$ lat): Geological Society of America Special Paper 407: 19-60.

Keidel, J. 1913. Informe geológico sobre el yacimiento petrolífero de Challacó (Territorio del Neuquén). Buenos Aires.

Keidel, J. 1917. Über das patagonische Tafelland und ihre ziehungen zu den geologischen erscheinnungen in den argentinischen Anden gebiet un Litoral. Zeitschrift der Deutsche Akademie Wissenschaft, 3: 219-245. Stuttgart.

Keidel, J. 1925. Sobre la estructura tectónica de las capas petrolíferas en el oriente del territorio del Neuquén. Dirección General de Minas, Geología e Hidrogeología, publicación 8: 1-67. Buenos Aires.

Lazo, D.G. y Damborenea, S.E. 2011. Barremian bivalves from the Huitrín Formation westcentral Argentina: Taxonomy and paleoecology of a restricted marine association. Journal of Paleontology, 85: 719-743.

Leanza, H.A. 1973. Estudio sobre los cambios faciales de los estratos limítrofes Jurásico Cretácicos entre Loncopué y Picún Leufú, provincia del Neuquén, República Argentina. Revista de la Asociación Geológica Argentina, 28: 97-132. Buenos Aires.

Leanza, H.A. 1992. Estratigrafía del Paleozoico y Mesozoico anterior a los Movimientos Intermálmicos en la comarca del Cerro Chachil, provincia del Neuquén, Argentina. Revista de la Asociación Geológica Argentina, 45: 272-299. Buenos Aires.

Leanza, H.A. 2003. Las sedimentitas huitrinianas y rayosianas (Cretácico Inferior) en el ámbito central y meridional de la Cuenca Neuquina, Argentina, SEGEMAR. Serie Contribuciones Técnicas, Geología, 2: 1-31. Buenos Aires.

Leanza, H.A. 2009. Las principales discordancias del Mesozoico de la cuenca Neuquina según observaciones de superficie. Revista del Museo Argentino de Ciencias Naturales, 11: 145184. Buenos Aires.

Leanza, H.A. y Zeiss, A. 1990. Upper Jurassic Limestones from Argentina (Neuquen Basin): Stratigraphy and Fossils. Facies 22: 169-186. Erlangen.

Leanza, H.A. y Hugo, C.A. 1995. Revisión estratigráfica del Cretácico Inferior continental en el ámbito sudoriental de la Cuenca Neuquina. Revista de la Asociación Geológica Argentina 50: 30-32. Buenos Aires.

Leanza H.A. y Hugo, C.A. 1997. Hoja Geológica 3969-III, Picún Leufú, provincias del Neuquén y Río Negro. Programa Nacional de Cartas Geológicas de la República Argentina a escala 1:250.000. Instituto de Geología y Recursos Minerales, SEGEMAR. Boletín 218: 1-135.

Leanza, H.A., Marchese, H.G. y Riggi, J.C. 1977. Estratigrafía del Grupo Mendoza con especial referencia a la Formación Vaca Muerta entre los paralelos $35^{\circ}$ y $40^{\circ}$ L.S., Cuenca 
Neuquina-Mendocina. Revista de la Asociación Geológica Argentina, 32: 190-208. Buenos Aires.

Leanza, H.A. y Hugo, C.A. 2001. Cretaceous red beds from southern Neuquén basin (Argentina): age, distribution and stratigraphic discontinuities. $7^{\text {th }}$ International Symposium on Mesozoic Terrestrial Ecosystems. Asociación Paleontológica Argentina, Publicación especial 7: 117-122. Buenos Aires.

Leanza, H.A., Hugo, C., Repol, D., González, R. y Danieli, J. 2001. Hoja Geológica 3969-I Zapala, Provincia del Neuquén. Instituto de Geología y Recursos Minerales, Servicio Geológico Minero Argentino, SEGEMAR. 128 p. Buenos Aires.

Leanza, H.A., Llambías, E.J. y Carbone, O. 2005. Unidades estratigráficas limitadas por discordancias en los depocentros de la Cordillera del Viento y la Sierra de Chacaico durante los inicios de la Cuenca Neuquina. $6^{\circ}$ Congreso de Exploración y Desarrollo. Versión CD ROM. Mar del Plata

Leanza, H.A., Repol, D., Hugo, C.H. y Sruoga, P. 2006. Hoja Geológica 3769-31, Chorriaca, Provincia del Neuquén. Instituto de Geología y Recursos Minerales. Servicio Geológico Minero Argentino, Boletín 354, 93 p. Buenos Aires.

Leanza, H.A., Sattler, F., Martinez, R.S. y Carbone, O. 2011. La Formación Vaca Muerta y equivalentes (Jurásico Tardío - Cretácico Temprano) en la Cuenca Neuquina. En: Leanza, H., Arregui, C., Carbone, O., Danieli, J.C., Vallés, J. (Eds.), Relatorio del XVIII Congreso Geológico Argentino, Geología y Recursos Naturales de la provincia del Neuquén: 113129. Buenos Aires.

Legarreta, L. 1985. Análisis estratigráfico de la Formación Huitrín (Cretácico inferior), provincia de Mendoza. Tesis Doctoral, Facultad de Ciencias Exactas y Naturales. Universidad de Buenos Aires. (Inédito). 197 p.

Legarreta, L. 2002. Eventos de desecación en la Cuenca Neuquina: depósitos continentales y distribución de hidrocarburos. $5^{\circ}$ Congreso de Exploración y Desarrollo de Hidrocarburos. Actas CD, 20 p. Mar del Plata.

Legarreta, L. y Boll, A. 1982. Formación Huitrín. Análisis estratigráfico y esquema prospectivo. Provincia de Mendoza. Yacimientos petrolíferos Fiscales. Buenos Aires. Inédito.

Legarreta, L. y Gulisano, C.A. 1989. Análisis estratigráfico secuencial de la Cuenca Neuquina (Triásico superior-Terciario inferior, Argentina). En: Chebli, G. y Spalletti, L. (Eds.), Cuencas Sedimentarias Argentinas. Serie Correlación Geológica, Universidad Nacional de Tucumán, 6: 221-243.

Legarreta, L. y Uliana, M.A. 1991. Jurassic-Cretaceous marine oscillations and geometry of back arc basin fill, Central Argentine Andes. In: MacDonald, D. I. M. (Ed.), Sedimentation, 
Tectonics and Eustasy - Sea-level Changes at Active Margins. International Association of Sedimentologists, Special Publications, 12: 429-450.

Legarreta, L. y Uliana, M.A. 1996. The Jurassic succession in west-central Argentina: stratal patterns, sequences and paleogeographic evolution. Paleogeography, Paleoclimatology, Paleoecology 120: 303-330.

Legarreta, L. y Uliana, M.A. 1999. Facies Sedimentarias. El Jurásico y Cretácico de la Cordillera Principal y la Cuenca Neuquina. En: Caminos, R. (Ed.), Geología Argentina. Instituto de Geología y Recursos Minerales Geología Argentina. Anales 29: 399-432. Buenos Aires.

Legarreta, L., Laffite, G.A. y Minniti, S.A. 1999. Cuenca Neuquina: Múltiples posibilidades en las series Jurásico-Cretácicas del depocentro periandino. IV Congreso de Exploración de Hidrocarburos. Actas 1: 145-175.

Llambías, E.J. y Malvicini, L. 1978. Geología, petrología y metalogénesis del área de Colipilli, provincia del Neuquén, República Argentina. Revista de la Asociación Geológica Argentina, 33: 257-276. Buenos Aires.

Llambías, E.J. y Rapela, C.W. 1987. Las vulcanitas de Colipilli y sus relaciones con las provincias volcánicas del Terciario inferior de Neuquén-Mendoza y Patagonia. X Congreso Geológico Argentino (San Miguel de Tucumán). Actas 4: 249-251.

Llambías, E.J. y Rapela, C.W. 1989. Las volcanitas de Colipilli, Neuquén $\left(37^{\circ} \mathrm{S}\right)$ y su relación con otras unidades paleógenas de la cordillera. Revista de la Asociación Geológica Argentina, 44: 224-236. Buenos Aires.

Llambías, E.J. y Aragón, E. 2011. Volcanismo Paleógeno. En: Leanza, H., Arregui, C., Carbone, O., Danieli, J.C., Vallés, J. (Eds.), Relatorio del XVIII Congreso Geológico Argentino, Geología y Recursos Naturales de la provincia del Neuquén: 265-274. Buenos Aires.

Llambías, E.J. y Sato, A.M. 2011. Ciclo Gondwánico: La provincia magmática Choiyoi en Neuquén. En: Leanza, H., Arregui, C., Carbone, O., Danieli, J.C., Vallés, J. (Eds.), Relatorio del XVIII Congreso Geológico Argentino, Geología y Recursos Naturales de la provincia del Neuquén: 53-62. Buenos Aires.

Mateo Fernández Caso, P.M., Montero, D.G., Leal, P.R y Ramos, V.A. 2011. Petrología y geoquímica del magmatismo Cretácico Superior- Eoceno en el área de Pichaihue, Provincia de Neuquén. Revista de la Asociación Geológica Argentina, 68: 173-184. Buenos Aires.

Matheos, S.D. 1988. Sedimentología y geoquímica de las sedimentitas carbonáticas jurásicas del sector sur de la Cuenca Neuquina. Universidad Nacional de La Plata. Tesis Doctoral. (Inédito). $223 \mathrm{p}$.

Méndez, V., Zanettini, J.C.M. y Zappettini, E.O. 1995. Geología y metalogénesis del Orógeno Andino Central, República Argentina. Dirección Nacional del Servicio Geológico, SEGEMAR. Anales 23: 1-190. 
Minniti, S.A., Gutiérrez Pleimling, A.R., Arteaga, M.E. y Pestalardo, F.S. 1986. Análisis estructural y estratigráfico de la faja plegada neuquina a la latitud de $37^{\circ} 30^{\prime}$. Departamentos de Ñorquín y Pehuenches, Provincia del Neuquén. Informe interno de YPF (Inédito).

Mitchum, R.M., Vail, P.R. y Thompson, S. 1977. Seismic Stratigraphy and global changes of sea level. Part. 2. The depositional sequence as a basic unit for stratigraphic analysis. American Association of Petroleum Geologists, 26: 53-62.

Mosquera, A. y Ramos, V.A. 2006. Intraplate deformation in the Neuquén Embayment, en Kay, S.M., and Ramos, V.A., (Eds.), Evolution of an Andean margin: A tectonic and magmatic view from the Andes to the Neuquén Basin ( $35^{\circ}-39^{\circ} \mathrm{S}$ lat): Geological Society of America Special Paper, 407: 97-123.

Nickelsen, B., Merrill, D. y Allen, R. 1985. Depositional environment and hydrocarbon potential of the Upper Jurassic La Manga and Auquilco Formations, Neuquén Province, Argentina. Earth Sciences and Resources Institute. University of South Carolina.

Olea, G., Suárez, M. y Valenzuela, M. 2011. El Miembro La Tosca de la Formación Huitrín (Cretácico temprano). En: Leanza, H., Arregui, C., Carbone, O., Danieli, J.C., Vallés, J. (Eds.), Relatorio del XVIII Congreso Geológico Argentino, Geología y Recursos Naturales de la provincia del Neuquén: 199-203. Buenos Aires.

Ponce, J.J., Zavala, C., Marteau, M. y Drittanti D. 2002. Análisis estratigráfico y modelo deposicional para la Formación Rayoso (Cretácico Inferior) en la Cuenca Neuquina, provincia del Neuquén. En: Cabaleri N., Cingolani, C.A., Linares, E., López De Luchi, M.G., Ostera, H.A. y Panarello, H.O. (Eds.), XV Congreso Geológico Argentino. Actas CD -ROM artículo 235. Calafate.

Ramos, V.A. 1978. Estructura. En Rolleri, E.O. (Ed.), Geología y recursos naturales de la provincia del Neuquén. Relatorio del VII Congreso Geológico Argentino, 233-237. Buenos Aires.

Ramos, V.A. 1981. Descripción geológica de la Hoja 33c, Los Chihuidos Norte. Boletín del Servicio Geológico Nacional 182 (escala 1:200.000), 103 p. Buenos Aires.

Ramos, V.A. 1998. Estructura del sector occidental de la Faja Plegada y Corrida del Agrio, Cuenca Neuquina, Argentina. $10^{\circ}$ Congreso Geológico Latinoamericano y $6^{\circ}$ Congreso Nacional de Geología Económica, Actas 2: 105-110. Buenos Aires.

Ramos, V.A. 1999. Plate tectonic setting of the Andean Cordillera. Episodes 22: 183-190.

Ramos, V.A. y Barbieri, M. 1988. El volcanismo Cenozoico de Huantraico: edad y relaciones isotópicas iniciales, provincia del Neuquén. Revista de la Asociación Geológica Argentina, 43: 210-223. Buenos Aires.

Ramos, V.A. y Folguera, A. 2005. Tectonic evolution of the Andes of Neuquén: Constraints derived from the magmatic arc and foreland deformation, in Spalletti, L., Veiga, G., 
Schwarz, E., and Howell, J., (Eds.), The Neuquén Basin: A case study in sequence stratigraphy and basin dynamics: Geological Society, London, Special Publications 252, $15-35$.

Rapela, C.W. y Llambías, E.J. 1985. La secuencia andesítica terciaria de Andacollo, Neuquén, Argentina. IV Congreso Geológico Chileno, 4: 458-488, Antofagasta.

Rovere, E. 1998. Volcanismo jurásico, paleógeno y neógeno en el noroeste del Neuquén, Argentina. $10^{\circ}$ Congreso Latinoamericano de Geología y $6^{\circ}$ Congreso Nacional de Geología Económica, Actas: 144-149, Buenos Aires.

Sillitoe, R.H. 1977. Permo-Carboniferous, Upper Cretaceous and Miocene porphyry copper-type mineralization in the Argentina Andes. Economic Geology 72: 99-103.

Schiller, W. 1912. La alta cordillera de San Juan y Mendoza y parte de la provincia de San Juan. Anales Ministerio de Agricultura, Sección Geología y Mineralogía 7: 1-68. Buenos Aires.

Schwarz, E., Spalletti, L.A. y Howell, J.A. 2006. Sedimentary response to a tectonically induced sea level fall in a shallow back-arc basin: the Mulichinco Formation (Lower Cretaceous), Neuquén Basin, Argentina. Sedimentology, 53: 55-81.

Spalletti, L.A., Franzese, J., Matheos, S.D. y Schwarz, E. 2000. Sequence stratigraphy of a tidally dominated carbonatesiliciclastic ramp; the Tithonian-Early Berriasian of the Southern Neuquén Basin, Argentina. Journal of the Geological Society, 157: 433-446. London.

Spalletti, L.A., Arregui, C.D. y Veiga, G. 2011a. La Formación Tordillo y equivalentes (Jurásico Tardío) en la Cuenca Neuquina. En: Leanza H, Arregui C, Carbone O, Danieli JC, Vallés J (Eds.), Relatorio del XVIII Congreso Geológico Argentino, Geología y Recursos Naturales de la provincia del Neuquén, 99-111. Neuquén.

Spalletti, L.A., Veiga, G.D. y Schwarz, E. 2011b. La Formación Agrio (Cretácico Temprano) en la Cuenca Neuquina. En: Leanza H, Arregui C, Carbone O, Danieli JC, Vallés J (Eds.), Relatorio del XVIII Congreso Geológico Argentino, Geología y Recursos Naturales de la provincia del Neuquén, 145-160. Neuquén.

Stipanicic, P.N. 1966. El Jurásico en Vega de la Veranada (Neuquén), el Oxfordense y el diastrofismo Divesiano (Agassiz-Yaila) en Argentina. Revista de la Asociación Geológica Argentina, 20: 403-478. Buenos Aires.

Stipanicic, P.N. y Mingramm M. 1952. Informe preliminar sobre la estratigrafía cronología y distribución facial de los sedimentos de Dogger-Malm en el sector neuquino-mendocino de la cubeta mesozoica argentino-chilena. Informe interno de YPF. (Inédito).

Stipanicic, P.N., Rodrigo, F., Baulies, O.L. y Martínez, C.G. 1968. Las formaciones presenonianas del denominado Macizo Nordpatagónico y regiones adyacentes. Revista de la Asociación Geológica Argentina, 23: 367-388. Buenos Aires. 
Tunik, M., Folguera A., Naipauer M., Pimentel M. y Ramos V.A. 2010. Early uplift and orogenic deformation in the Neuquén Basin: Constraints on the Andean uplift from $\mathrm{U}-\mathrm{Pb}$ and $\mathrm{Hf}$ isotopic data of detrital zircons. Tectonophysics, 489: 258-273.

Uliana, M.A., Dellapé, D.A. y Pando, G.A. 1975a. Distribución y génesis de las sedimentitas rayosianas. (Cretácico inferior de las provincias de Neuquén y Mendoza). II Congreso Iberoamericano de Geología Económica. Actas 1: 177-196. Buenos Aires.

Uliana, M.A., Dellapé, D.A. y Pando, G.A. 1975b. Estratigrafía de las sedimentitas rayosianas. (Cretácico inferior de las provincias de Neuquén y Mendoza). II Congreso Iberoamericano de Geología Económica. Actas 1: 151-176. Buenos Aires.

Uliana, M.A., Biddle K. y Cerdán J. 1989. Mesozoic extension and the formation of Argentina sedimentary basins. En: Tankard, A.J. y Balkwill H.R. (Eds.), Extensional Tectonics and Stratigraphy of the North Atlantic Margin. American Association of Petroleum Geologists. Memoir 46: 599-613. Tulsa.

Uliana, M.A., Legarreta, L., Laffitte, G.A. y Villar, H.J. 1999. Estratigrafía y geoquímica de las facies generadoras de hidrocarburos en las cuencas petrolíferas Argentinas. Petrotecnia, Revista del Instituto Argentino del Petróleo y Gas, XL 3: 12-25.

Veiga, G.D. y Vergani, G.D. 2011. El Miembro Troncoso Inferior de la Formación Huitrín (Cretácico Temprano). En: Leanza, H., Arregui, C., Carbone, O., Danieli, J.C., Vallés, J. (Eds.), Relatorio del XVIII Congreso Geológico Argentino, Geología y Recursos Naturales de la provincia del Neuquén. 181-188. Buenos Aires.

Vergani, G.D., Tankard, A.J., Belotti, H.J. y Welsink, H.J. 1995. Tectonic evolution and paleogeography of the Neuquén basin, Argentina. En: Tankard, A.J., Suárez, R., Welsink, H.J. (Eds.), Petroleum Basins of South America, American Association of Petroleum Geologists Memoire, 62: 383-402.

Vergani, G., Selva, G. y Boggetti, D. 2002. Estratigrafía y modelo de facies del Miembro Troncoso inferior, Formación Huitrín (Aptiano), en el noroeste de la Cuenca Neuquina, Argentina. XV Congreso Geológico Argentino. Actas (Versión en CD).

Weaver, C. 1927. The Roca Formation in Argentina. American Journal of Science, 5: 417-434.

Weaver, C. 1931. Paleontology of the Jurassic and Cretaceous of west central Argentina. Memoir University of Washington 1: 1-469. Seattle.

Yrigoyen, M.F. 1972. Cordillera Principal. En Leanza, A. F. (Ed.), Geología Regional Argentina. Academia Nacional de Ciencias: 345-364. Córdoba.

Zamora Valcarce, G., Zapata, T.R., del Pino, D. y Ansa, A. 2006. Structural evolution and magmatic characteristics of the Agrio fold-and-thrust belt. En: Kay, S.R. y Ramos V.A. (Eds.): Evolution of an Andean margin: a tectonic and magmatic view from the Andes to 


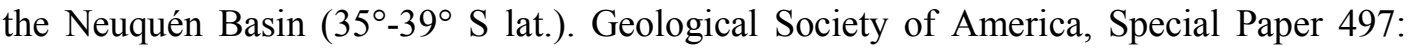
$125-145$

Zamora Valcarce, G. 2007. Estructura y cinemática de la faja plegada del Agrio. Tesis doctoral, Universidad de Buenos Aires. (Inédito). 304 p.

Zavala, C. y Ponce, J.J. 2011. La Formación Rayoso (Cretácico temprano) en la Cuenca Neuquina. En: Leanza, H., Arregui, C., Carbone, O., Danieli, J.C., Vallés, J. (Eds.) Relatorio del XVIII Congreso Geológico Argentino, Geología y Recursos Naturales de la provincia del Neuquén. 205-222. Buenos Aires.

Zappettini, E.O., Méndez, V. y Zanettini, J.C.M. 1987. Metasedimentitas mesopaleozoicas en el noroeste de la Provincia del Neuquén. Revista de la Asociación Geológica Argentina, 42: 206-207. Buenos Aires.

Zöllner W. y Amos, A.J. 1949. Informe preliminar de la Hoja 32b, Chos Malal, provincia del Neuquén. (Informe Inédito). Dirección Nacional de Minería. Buenos Aires. 


\section{Capítulo 3}

\section{MARCO TECTÓNICO}




\section{Introducción}

El área de Colipilli se localiza dentro de lo que Bracaccini (1970) denominó "Fosa del Agrio". Dicha estructuración consta de una serie de plegamientos asociados a fallas. Actualmente se la conoce como Faja Plegada y Corrida del Agrio (FPyCA) interpretada por Ramos (1978) como una deformación compresiva al este del arco volcánico activo y asociada a pliegues y fallas inversas despegados en los niveles evaporíticos de las estructuras profundas. Su estilo estructural ha tenido diversas interpretaciones, desde estructuras dominadas por basamento (Kozlowski et al., 1996), a faja de deformación epidérmica (Ploszkiewicz 1987, Ramos y Barbieri 1988) o de inversión tectónica (Chauveau et al., 1996; Booth y Coward 1996; Zapata et al., 1999; Zamora Valcarce 2007).

Este capítulo tiene como objetivo brindar una descripción general del contexto estructural en el cual se ubica el sector de estudio.

\section{Faja Plegada y Corrida del Agrio}

Esta unidad morfoestructural es una faja plegada bien desarrollada, actualmente inactiva, de $50 \mathrm{~km}$ de ancho, con afloramientos de muy buena calidad. Los límites considerados para la FPyCA son (Fig.3.1): el lineamiento de Cortaderas al norte, que corre en sentido NO-SE a la altura del río Neuquén; al oeste limita con la fosa de Loncopué (Ramos 1978), mientras que hacia el sur, la Sierra de la Vaca Muerta actuaría como un lineamiento similar al de Cortaderas (Repol 2006). Por último, el límite oriental de la faja está conformado por la gran estructura denominada Dorso de los Chihuidos (Vergani et al., 1995; Zapata et al., 1999; Mosquera y Ramos 2006). Las estructuras más comunes son grandes braquianticlinales formados por la participación del basamento en la deformación, estructuras epidérmicas elongadas en sentido norte-sur y separadas por amplias pampas que reflejan inversión de relieve (Zapata et al., 1999).

Se caracteriza por presentar una historia de deformación multiepisódica lo que ha permitido a diferentes autores (Ramos 1978, 1998; Zapata et al., 2002; Zamora Valcarce et al., 2006) separarlas en dos zonas: una zona externa donde las estructuras son principalmente de "piel fina" y una zona interna con predominio de estructuras de "piel gruesa" producto de la inversión del basamento. 


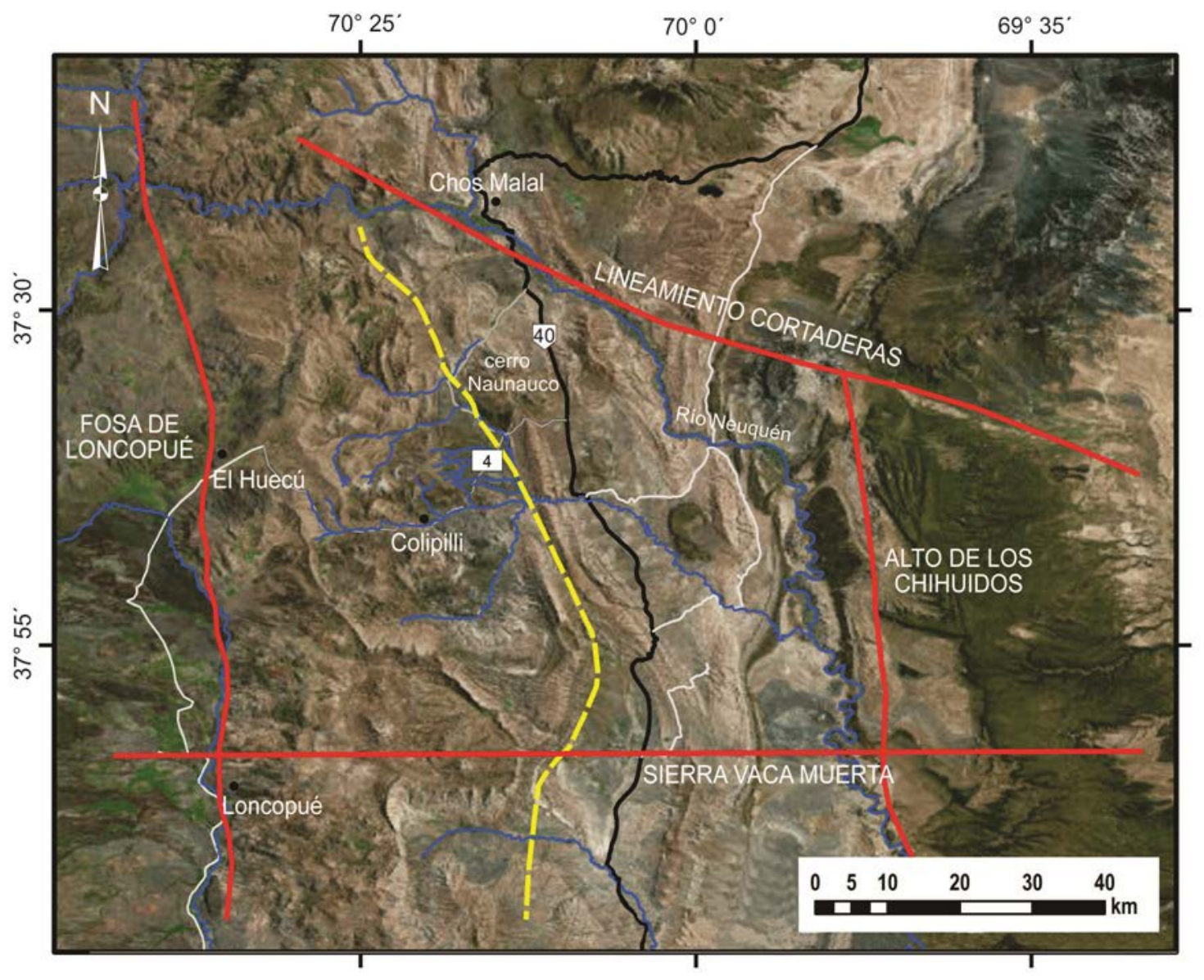

Figura 3.1: Ubicación y límites de la Faja Plegada y Corrida del Agrio. Modificado de Zamora Valcarce et al. (2006).

El dominio externo de naturaleza epidérmica, que se desarrolla en el pie de monte del Engolfamiento Neuquino, se caracteriza por presentar pliegues isoclinales de escala kilométrica, con ejes estructurales principales que varían su dirección a lo largo del rumbo desde NNO-SSE al norte a NNE-SSO al sur, dando una geometría convexa hacia el antepaís para la faja en general (Yagupsky 2009). Sus niveles de despegue se produjeron dentro de la cubierta mesozoica, particularmente en las Formaciones Auquilco, Vaca Muerta, Agrio y Huitrín (Zapata et al., 1999; Zamora Valcarce et al., 2009). Zapata et al. (2002) postularon que el basamento estaría también involucrado en la deformación en este dominio, reactivando en cierta medida las estructuras epidérmicas. Esta zona está constituida por los grandes trenes estructurales con características de tectónica de piel fina como son la sierra de Chorriaca, el Cordón del Salado, el anticlinal de Pichi Mula, entre otros. La vergencia predominante de las estructuras es hacia el este, pero algunas de ellas presentan una vergencia contraria, generando complejas zonas triangulares en el frente de corrimientos (Zamora Valcarce et al., 2006). 
La zona interna corresponde a la parte más montañosa (Precordillera Neuquina norte), y ha sido interpretada como parte del sistema extensional de Tres Chorros (Vergani et al., 1995). Zamora Valcarce et al. (2009) y Zapata y Folguera (2005) demostraron, a partir del análisis tanto de información sísmica como de superficie, que existe una serie de altos en el basamento que controlan el estilo estructural. Estos altos han dado lugar a la formación de grandes braquianticlinales producto de la inversión de estructuras previas. En los flancos de estas grandes estructuras se alojan los principales depósitos baríticos investigados. El control del basamento en la deformación se pone de manifiesto a través de un conjunto de bloques limitados en profundidad por fallas preliásicas sin expresión superficial. Éstas corresponden a antiguas fallas normales invertidas y a fallas transversales de acomodación, ambos tipos pertenecientes al antiguo sistema extensional jurásico reactivado durante la deformación compresiva Cretácico-Terciario (Fig.3.2). Como producto de dichas estructuras profundas, se identifican varios bloques en el sector interno: Los Bueyes, Colipilli, Huncal, Cerro Mocho, El Durazno y La Pampa del Salado (Ramos 1998). Los bloques Huncal y La Pampa del Salado han sido identificados por líneas sísmicas y mapas aeromagnéticos por Repol et al. (2002).

Las estructuras que se destacan en el sector interno de la FPyCA (Fig.3.3) son: el sinclinal Pichaihue, que es una estructura de orientación predominantemente NNO-SSE cuyo rasgo distintivo es una gran longitud de onda que le concede una amplitud muy grande (Leanza et al., 2006). El anticlinal de la sierra de Chorriaca, que es una estructura de unos $40 \mathrm{~km}$ de longitud; posee morfología cilíndrica de cresta subhorizontal y flancos con altas inclinaciones (Zamora Valcarce 2007). Se encuentra al sur del Arroyo Colipilli y su orientación general es NNO-SSE. En el núcleo del anticlinal aflora la Formación Vaca Muerta en tanto que en sus flancos se observa la Formación Mulichinco. El anticlinal del cerro Palao de Tralalhué, ubicado al norte del Arroyo Colipilli y al oeste del sinclinal de Colipilli, se caracteriza por una serie de estructuras plegadas menores que afectan a rocas de las Formaciones Vaca Muerta y Mulichinco. En general estas estructuras presentan una orientación NO-SE. El sinclinal de Colipilli es una depresión de gran tamaño a la que se le asocian anticlinales y sinclinales menores de segundo orden, conformando una estructura de sinclinorio (Llambías y Malvicini 1978). Dicha macro-estructura afecta a las sedimentitas eocretácicas y en ella afloran los depósitos volcánicos de la Formación Cayanta y los cuerpos intrusivos de la Formación Colipilli. Su flanco occidental posee una inclinación del orden de $40^{\circ}$, mientras que el flanco oriental, conformado por la sierra de Chorriaca, presenta inclinaciones mayores (Zamora Valcarce 2007). El sinclinal de 
Tralalhué, que se ubica al noreste del anterior, con una orientación general NNO-SSE, se encuentra en el hundimiento norte de la sierra de Chorriaca; ha sido interpretado como una cuenca de transpresión ("piggy-back") (Ramos 1998) rellena por los depósitos sinorogénicos del Conglomerado Tralalhué.

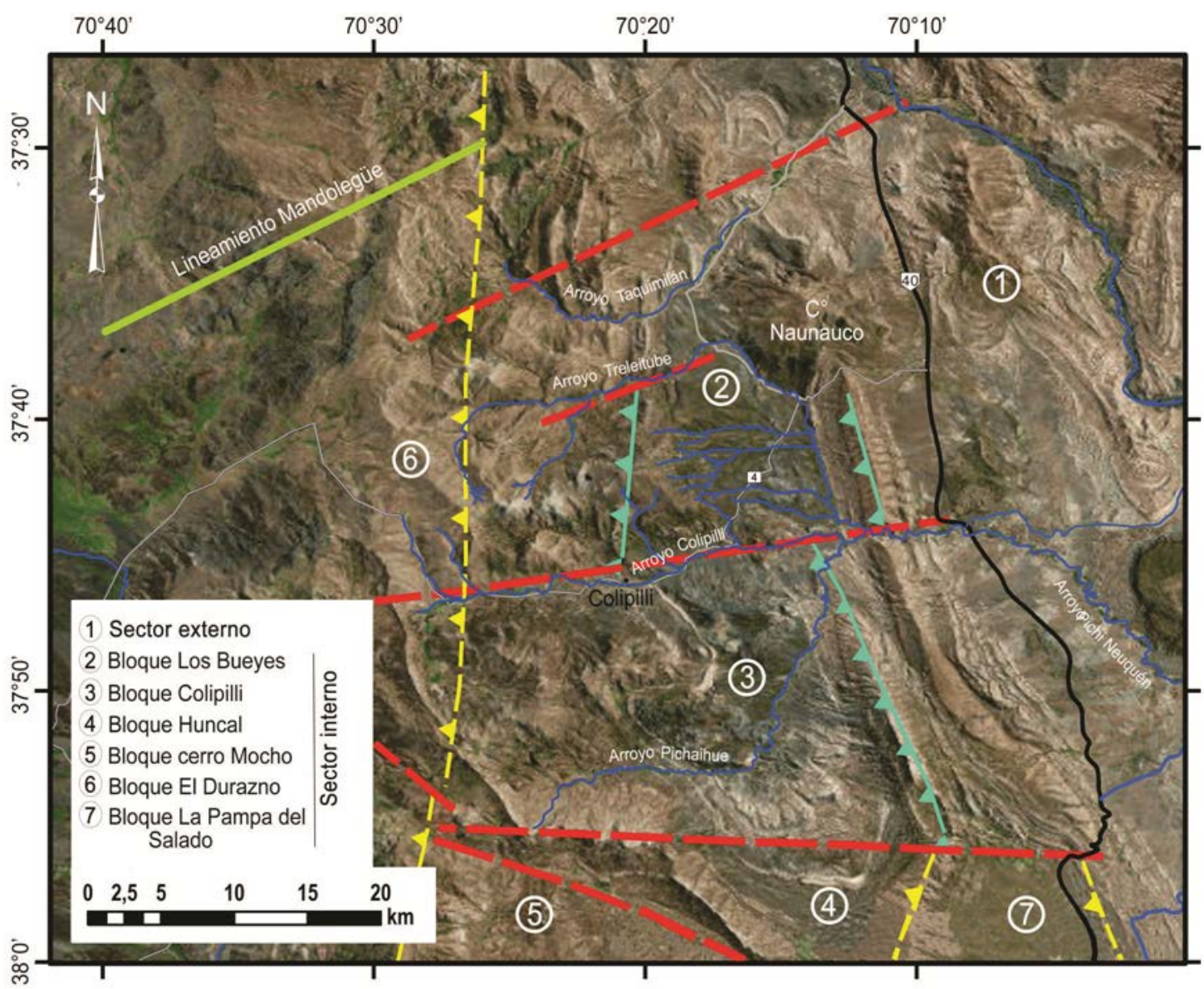

Figura 3.2: Esquema geotectónico del área de Colipilli. Modificado de Repol et al. (2002) y Rojas Vera (2011). Líneas entrecortadas rojas representan fallas preliásicas; líneas entrecortadas amarillas indican fallas preliásicas reactivas en sentido inverso; líneas turquesas muestran fallas inversas.

La configuración estructural previa al desarrollo del magmatismo andesítico habría ejercido un importante control en el espacio de acomodación del mismo. Durante su emplazamiento, el material magmático aprovechó los espacios de los bajos estructurales, es por ello que la mayoría de sus afloramientos se encuentran restringidos al área de los sinclinales de Colipilli y de Tralalhué. Posteriormente, procesos de erosión diferencial modelaron a estas rocas y actualmente se observa una importante inversión de relieve, donde la parte central del sinclinal posee mayor relieve respecto a algunas de las estructuras anticlinales vecinas. 


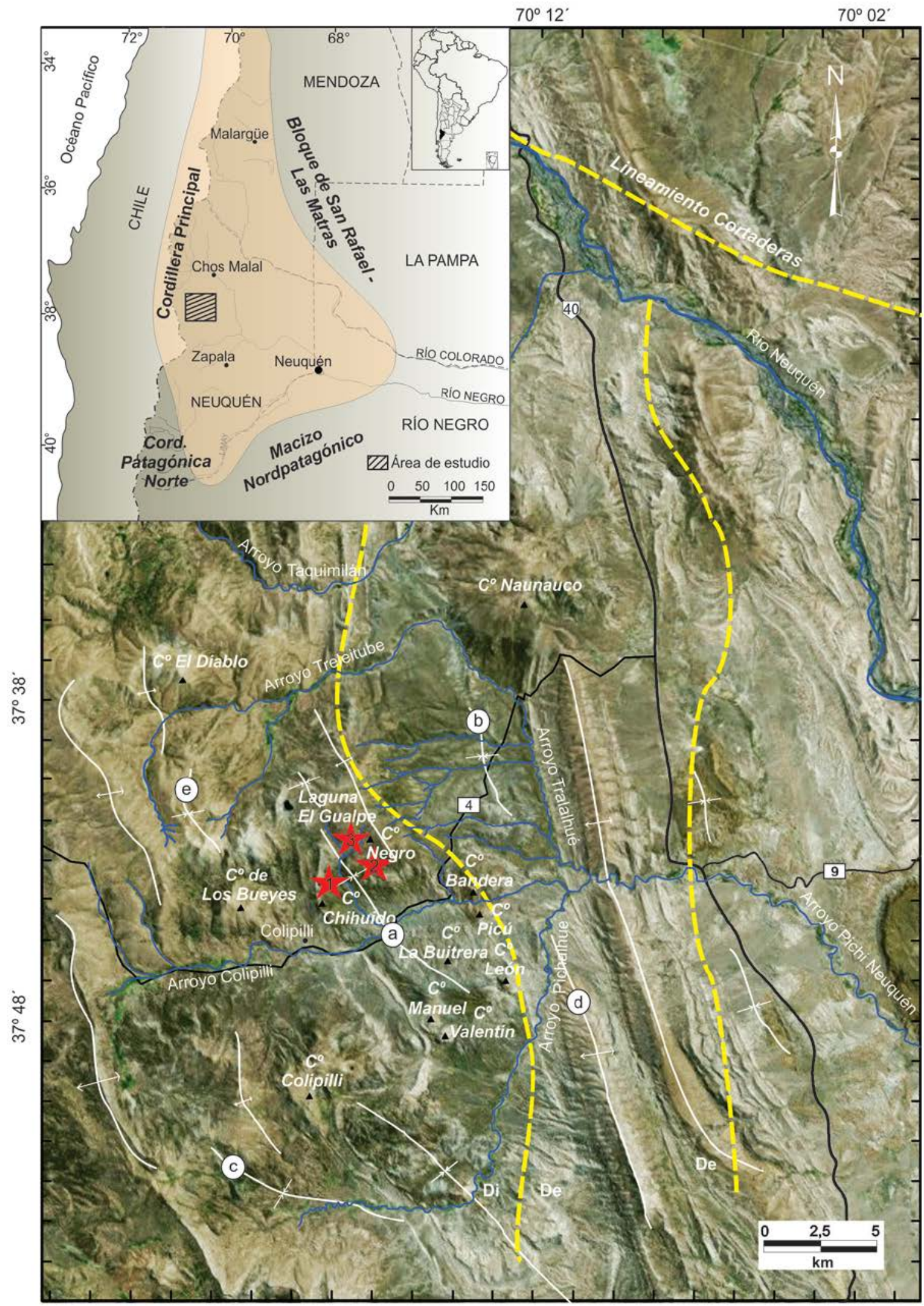

Figura 3.3: Ubicación de la zona de estudio. Se destacan las principales estructuras: a-sinclinal de Colipilli; b-sinclinal de Tralahué; c-sinclinal de Pichaihue; d-anticlinal de la sierra de Chorriaca; eanticlinal del cerro Palao del Tralalhué. Las principales minas: 1-San Eduardo-La Bienvenida; 2-La Bruja-Julio César; 3-Carlita-La Esperanza. Di: deformación interna, De: deformación externa. 


\section{Evolución tectónica}

En base a diversos trabajos de campo y dataciones radimétricas diversos autores reconocieron que la FPyCA fue afectada por dos pulsos de deformación (Ramos 1981; Zapata et al., 1999; Zapata et al., 2002; Zamora Valcarce et al., 2006; Zamora Valcarce et al., 2009). La estructuración habría comenzado en la parte interna durante el Cretácico Temprano, tal como lo documenta una serie de diques basálticos de rumbo este-oeste ubicados en el cerro Mocho (Zamora Valcarce 2007) y habría migrado hacia el dominio externo en una segunda fase durante el Mioceno (Zapata et al., 2002; Cobbold y Rossello 2003; Zapata y Folguera 2005; Zamora Valcarce et al., 2006; Zamora Valcarce et al., 2009).

Desde el punto de vista tectónico, la deformación de esta unidad morfoestructural se correlacionaría con una leve horizontalización de la placa oceánica subducida, que provocó la migración del arco volcánico hacia el antepaís, instaurándose en el área de Colipilli (Zamora Valcarce et al., 2011). Las rocas ígneas que afloran en dicha área (Grupo Naunauco) reportaron edades en promedio de $70 \mathrm{Ma}$. Dichas unidades se apoyan en la secuencia Mesozoica y a su vez la cortan, marcando el límite superior para el primer evento de deformación.

La segunda etapa de deformación se encuentra bien documentada por los depósitos sinorogénicos de la Formación Tralalhué o también nombrado Conglomerado Tralalhué. Este evento provocó la reactivación de toda la FPyCA mediante una deformación principalmente de piel gruesa (Zamora Valcarce et al., 2009) moldeándose el relieve actual. 


\section{Trabajos citados en el texto}

Booth, J.L.M. y Coward, M.P. 1996. Basament faulting and inversion of the NW Neuquén basin, Argentina: III International Symposium on Andean Geodynamics (Saint Maló). Abstracts: 295-298.

Bracaccini, I.O. 1970. Rasgos tectónicos de las acumulaciones mesozoicas en las provincias de Mendoza y Neuquén, República Argentina. Revista de la Asociación Geológica Argentina, 25: 275-282. Buenos Aires.

Chaveau, V., Niviere, B., Cobbold, P.R., Rosello, E.A., Ballard, J.F. y Eichenseer, H.T. 1996. Structure of the Andean foothills, Chos Malal region, Neuquén basin, Argentina: III $^{\circ}$ International Symposium on Andean Geodynamics (Saint Maló). Abstracts: 315-318.

Cobbold, P.R. y Rossello, E.A. 2003. Aptian to Recent compressional deformation, foothills of the Neuquén Basin, Argentina. Marine and Petroleum Geology, 20: 429-443.

Kozlowski, E.E., Cruz, C.E., y Sylwan C.A. 1996. Geología estructural de la zona de Chos Malal. Cuenca Neuquina, Argentina. XIII Congreso Geológico Argentino y III Congreso de Exploración de Hidrocarburos. Actas I: 15-26.

Leanza, H.A., Repol, D., Hugo, C.H. y Sruoga, P. 2006. Hoja Geológica 3769-31, Chorriaca, Provincia del Neuquén. Instituto de Geología y Recursos Minerales. Servicio Geológico Minero Argentino, Boletín 354, 93 p. Buenos Aires.

Llambías, E.J. y Malvicini, L. 1978. Geología, petrología y metalogénesis del área de Colipilli, provincia del Neuquén, República Argentina. Revista de la Asociación Geológica Argentina, 33: 257-276. Buenos Aires.

Mosquera, A. y Ramos, V.A., 2006. Intraplate deformation in the Neuquén Embayment. En Kay, S.M., and Ramos, V.A., (Eds.), Evolution of an Andean margin: A tectonic and magmatic view from the Andes to the Neuquén Basin ( $35^{\circ}-39^{\circ} \mathrm{S}$ lat). Geological Society of America Special Paper, 407: 97-123.

Ploszkiewicz, J. 1987. Las zonas triangulares de la faja fallada y plegada de la cuenca Neuquina, Argentina. X Congreso Geológico Argentino, Actas I: 177-180.

Ramos, V.A. 1978. Estructura. En Rolleri, E.O. (Ed.), Geología y recursos naturales de la provincia del Neuquén. Relatorio del VII Congreso Geológico Argentino, 233-237. Buenos Aires.

Ramos, V.A. 1981. Descripción geológica de la Hoja 33c, Los Chihuidos Norte. Servicio Geológico Nacional, Boletín 182 (escala 1:200.000), 103 p. Buenos Aires.

Ramos, V.A. 1998. Estructura del sector occidental de la faja plegada y corrida del Agrio, Cuenca Neuquina, Argentina. X Congreso Latinoamericano de Geología y VI Congreso Nacional de Geología Económica, 2: 105-110. Buenos Aires. 
Ramos, V.A. y Barbieri, M. 1988. El volcanismo Cenozoico de Huantraico: edad y relaciones isotópicas iniciales, provincia del Neuquén. Revista de la Asociación Geológica Argentina, 43: 210-223. Buenos Aires.

Repol, D. 2006. Structural geology and tectonics in the southern extent of the Agrio fold and thrust belt, Neuquén Basin, Argentina. Department of Geology and Geophysics, University of Calgary. MSc thesis, $180 \mathrm{p}$.

Repol, D., Leanza, H. A., Sruoga, P. y Hugo, C. A. 2002. Evolución tectónica del Cenozoico de la comarca de Chorriaca, Provincia del Neuquén, Argentina. XV Congreso Geológico Argentino. Actas 3: 200-205.

Rojas Vera, E.A. 2011. Evolución Tectónica de los Andes Centrales Australes (36-39º S): el caso de un orógeno reactivado extensionalmente, la Fosa de Loncopué. Tesis doctoral, Universidad de Buenos Aires. (Inédito), 190 p.

Vergani, G.D., Tankard, A.J., Belotti, H.J. y Welsink, H.J. 1995. Tectonic evolution and paleogeography of the Neuquén basin, Argentina. En: Tankard, A.J., Suárez, R., Welsink, H.J., (Eds.), Petroleum Basins of South America, American Association of Petroleum Geologists Memoire, 62: 383-402.

Yagupsky, D.L. 2009. Metodología para el estudio de sistemas compresivos y de sus controles estructurales. Tesis Doctoral. Universidad de Buenos Aires. (Inédito), 209 p.

Zamora Valcarce, G. 2007. Estructura y cinemática de la faja plegada del Agrio. Tesis doctoral, Universidad de Buenos Aires. (Inédito), 304 p.

Zamora Valcarce, G., Zapata, T., Del Pino, D. y Ansa, A. 2006. Structural evolution and magmatic characteristics of the Agrio fold-and thrust belt. En Kay, S.M. y Ramos, V.A., (Eds.), Evolution of an Andean margin: A tectonic and magmatic view from the Andes to the Neuquén Basin $\left(35^{\circ}-39^{\circ} \mathrm{S}\right.$ lat). Geological Society of America, Special Paper, 407: 125145.

Zamora Valcarce, G., Zapata, T., Ramos, V.A., Rodríguez, F. y Bernardo, L.M. 2009. Evolución tectónica del Frente Andino en Neuquén. Revista de la Asociación Geológica Argentina, 65: 192-203. Buenos Aires.

Zamora Valcarce, G., Zapata, T. y Ramos, V.A. 2011. La faja plegada y corrida del Agrio. En: Leanza, H.A., Arregui, C., Carbone, O., Danieli, J.C., Vallés, J.M., (Eds.), Relatorio Geología y Recursos Naturales de la provincia del Neuquén, 367-374. Buenos Aires.

Zapata, T., Brissón, I. y Dzelalija, F. 1999. La estructura de la faja plegada y corrida andina en relación con el control del basamento de la Cuenca Neuquina. Boletín de Informaciones Petroleras, 60: 113-121. 
Zapata, T.R., Córsico, S., Dzelalija, F. y Zamora Valcarce, G. 2002. La faja plegada y corrida del Agrio: Análisis estructural y su relación con los estratos terciarios de la cuenca neuquina, Argentina. V Congreso de exploración y desarrollo de Hidrocarburos. Actas electrónicas, Mar del Plata.

Zapata, T. y Folguera, A. 2005. Tectonic evolution of the Andean fold and thrust belt of the Southern Neuquén basin, Argentina. En: Veiga, G., Spalletti, L., Howell, J., Schwarz, E., (Eds.), The Neuquén Basin: A Case Study in Sequence Stratigraphy and Basin Dynamics. Special Publication. Geological Society of London, 37-56. 


\section{Capítulo 4}

\section{EL MAGMATISMO CRETÁCICO SUPERIOR-TERCIARIO}




\section{Introducción}

En la región de Colipilli se destaca la presencia de numerosos cuerpos intrusivos y coladas de composición esencialmente andesítico-dacítica pertenecientes al magmatismo cretácico superior-paleoceno (Fig.4.1), en notoria relación espacial con las mineralizaciones barítico-polimetálicas; por este motivo se lo trata especialmente en capítulo aparte. Este magmatismo fue denominado por Zamora Valcarce et al. (2006) como Grupo Naunauco; está integrado por las Formaciones Colipilli (rocas intrusivas, Llambías y Rapela 1987; 1989) y Cayanta (rocas extrusivas, Rapela y Llambías 1985).

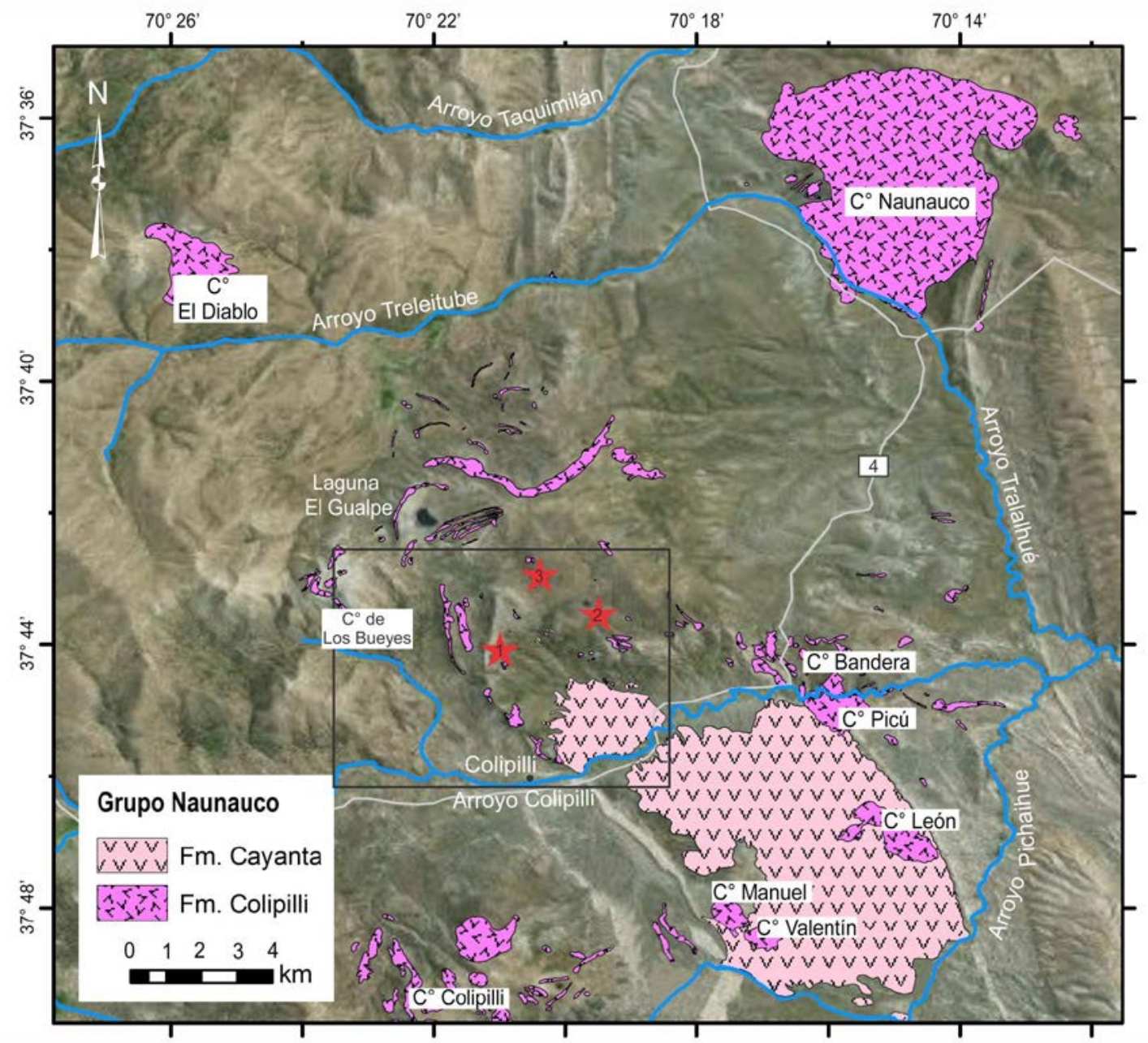

Figura 4.1: Distribución de los afloramientos del Grupo Naunauco en el área de estudio (rectángulo) donde se observa la ubicación de las principales minas estudiadas: 1-San Eduardo-La Bienvenida; 2-La Bruja-Julio César; 3-Carlita-La Esperanza. 
Los primeros estudios realizados en estas rocas ígneas fueron llevados a cabo por Llambías y Malvicini (1978) quienes identificaron cuerpos subvolcánicos de andesitas anfibólicas bajo la forma de stocks, lacolitos, filones capa y diques, cuya característica principal era la presencia de abundantes fenocristales de anfíbol. A su vez, reconocieron facies extrusivas conformadas por lavas con estructuras principalmente brechosas y aglomerados volcánicos. Además, estos mismos autores, consideraron que los depósitos metalíferos presentes en la región formaban parte de una amplia provincia metalogenética que se extendía desde el río Diamante, en la provincia de Mendoza, hasta el sur del Neuquén.

Este capítulo tiene como objetivo analizar las características geológicas, petrográficas, el nivel de emplazamiento y los rasgos geoquímicos de las unidades magmáticas que afloran en el área de estudio.

\section{Geología de las unidades magmáticas}

El Grupo Naunauco, integrado por las Formaciones Colipilli y Cayanta, presenta una amplia distribución en la región de estudio. La Formación Colipilli es de naturaleza hipabisal y en ella se diferencian cuerpos concordantes y discordantes de composición andesítica y dacítica, excepcionalmente diorítica mientras que en la Formación Cayanta se distinguen rocas extrusivas de composición andesítica.

Los cuerpos intrusivos más frecuentes que representan a la Formación Colipilli son filones capa y lacolitos de diferentes dimensiones, espesores y texturas. Los filones capa (Fig.4.2a) se presentan en el paisaje como bancos duros, lateralmente discontinuos, alojados en espacios interestratales, a veces en estructuras plegadas, siendo sus contactos netos y rectos con espesores comúnmente de 2 a $3 \mathrm{~m}$, y máximos de $10 \mathrm{~m}$. Sus texturas son porfíricas con mesostasis que gradan desde afanítica hasta microgranuda con fenocristales euhedrales de anfíbol, lo cual le otorga un cierto aspecto de lamprófiro. Con respecto a la granulometría de la mesostasis tan variable, desde fina a gruesa, se pueden asociar a los cuerpos ígneos de menor y mayor espesor, respectivamente. Una de las zonas más representativas es el sector de la laguna El Gualpe (Fig.4.1) donde se emplaza un enjambre de filones capa y facolitos. Por otro lado, los lacolitos son cuerpos más voluminosos con texturas desde porfíricas hasta granudas con tamaño medio de grano que varía entre $0,5 \mathrm{y}$ 1,5 cm. En la zona de estudio las mejores exposiciones se encuentran en los cerros 
Bandera, Picú, León, Manuel, Valentín y Colipilli localizados al sur del arroyo Colipilli (Fig.4.1).
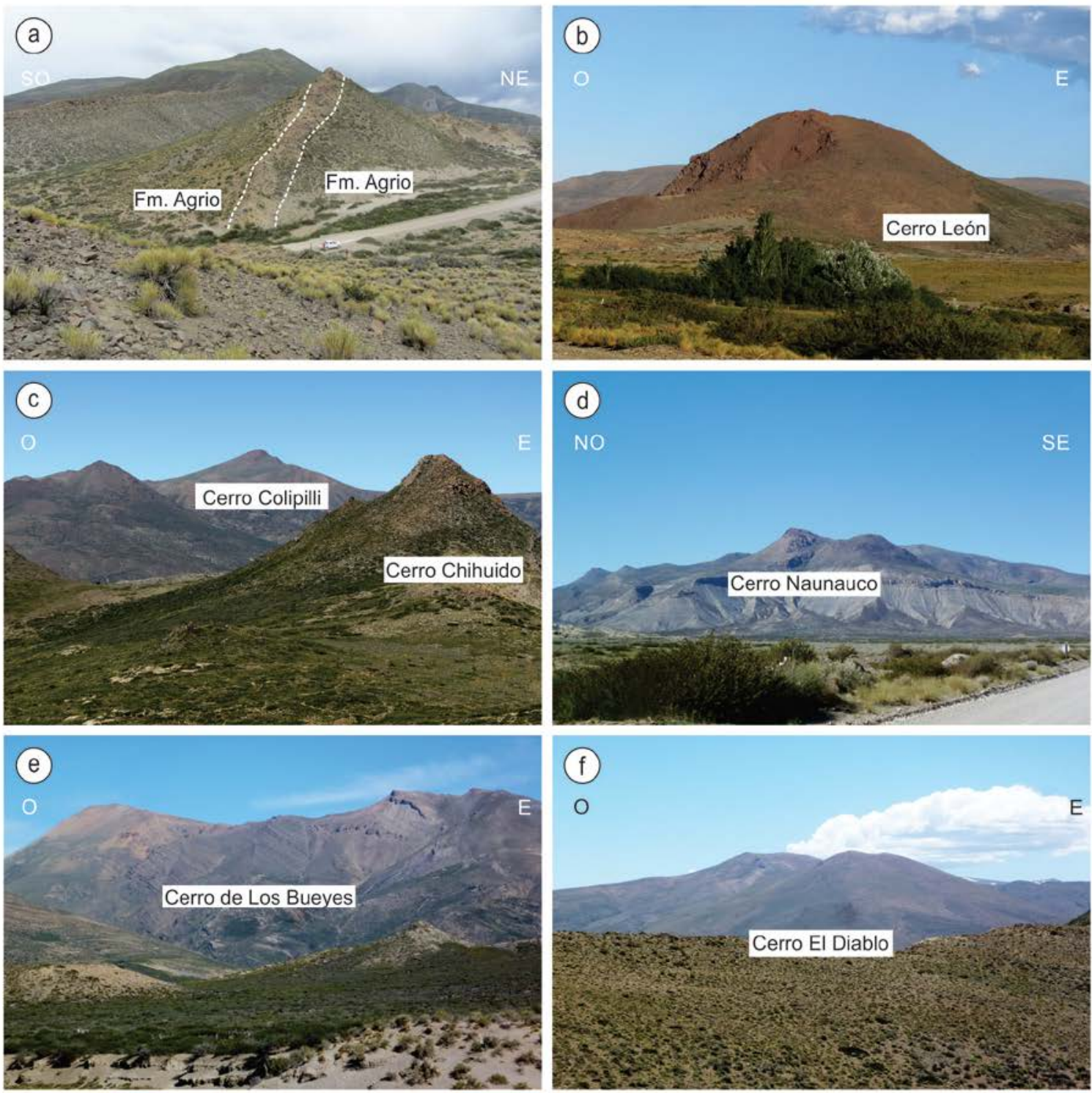

(g)

(h)
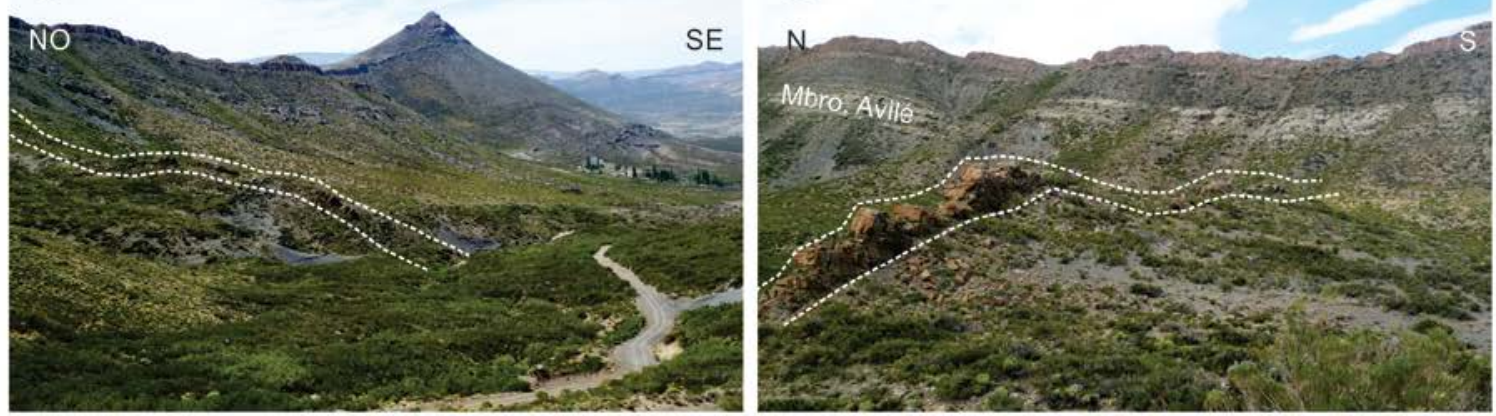

Figura 4.2: Fotos de unidades magmáticas aflorantes en el área de Colipilli: a-b filón capa y cerro León respectivamente, en ruta provincial 4; c- cerro Chihuido en mina San Eduardo; d- cerro Naunauco en ruta pcial. 29; e-f: cerros de Los Bueyes y El Diablo respectivamente, desde ruta pcial. 4; g-h: diques cortando a la secuencia eocretácica en el sector de cerro de Los Bueyes. 
Entre los cuerpos ígneos discordantes, los que más se destacan por su expresión topográfica positiva son los stocks que conforman los cerros Chihuido, Los Bueyes, El Diablo y Naunauco (Fig.4.2c-f). El primero, ubicado al norte del arroyo Colipilli, es el menor en tamaño y está constituido por rocas andesíticas. El cerro Los Bueyes, también ubicado al norte del mencionado arroyo, es la manifestación de un pórfido dacítico al que se le asocia un conjunto de diques con disposición radial (Llambías y Malvicini 1978). Por su parte, el cerro El Diablo es un pórfido diorítico cuarcífero, con una morfología elongada en dirección NNO, que se emplaza en el núcleo del anticlinal El Manzano (Llambías y Malvicini 1978; Zamora Valcarce 2007). Por último el Cerro Naunauco, situado en la zona nororiental del área de estudio, se caracteriza por la presencia de rocas dioríticoandesíticas. Es común observar fracturas en las rocas de caja adyacentes y bloques angulosos inmersos en el cuerpo ígneo. Dichos cuerpos se reconocen en el campo por sus tonalidades rojizas y grisáceas, de fácil identificación.

La mayor cantidad de diques (Fig.4.2g-h), también asignables a la Formación Colipilli, se concentra en las inmediaciones de los cerros Los Bueyes, Chihuido y Negro, como así también en cercanías de las minas La Esperanza, Carlita y La Bruja. Presentan entre 1,5 y $3 \mathrm{~m}$ de espesor y al igual que en las rocas previamente mencionadas las texturas dominantes son porfíricas con coloraciones grisáceas. Estos cuerpos de roca intruyen a toda la secuencia sedimentaria, pero los filones capa y diques afloran mayoritariamente intruidos en la Formación Agrio mientras que los lacolitos se encuentran frecuentemente emplazados en la Formación Huitrín. Por su parte, los stocks se observan generalmente en niveles estratigráficos más bajos (Formaciones Vaca Muerta y Mulichinco), excepto en el cerro Naunauco donde un uno de estos cuerpos corta la parte superior de la Formación Agrio y la Formación Huitrín.

Si bien los afloramientos lávicos de la Formación Cayanta (Fig.4.3c), constituidos por pequeños domos y extensas coladas brechosas y macizas, cubren en general grandes superficies, en la zona de estudio se circunscriben a los alrededores de la mina San Eduardo (Fig.4.3a y b). Aquí predominan las coladas brechosas que se encuentran intensamente diaclasadas y con variable silicificación. Se disponen en discordancia angular sobre las sedimentitas de la Formación Huitrín. Rasgos morfológicos del cerro La Buitrera, tales como disyunción columnar y fluidalidad vertical, en algunos sectores convoluta, permiten interpretarlo como un cuerpo ígneo dómico, asignable a la Formación Cayanta (Leanza et al., 2006). 

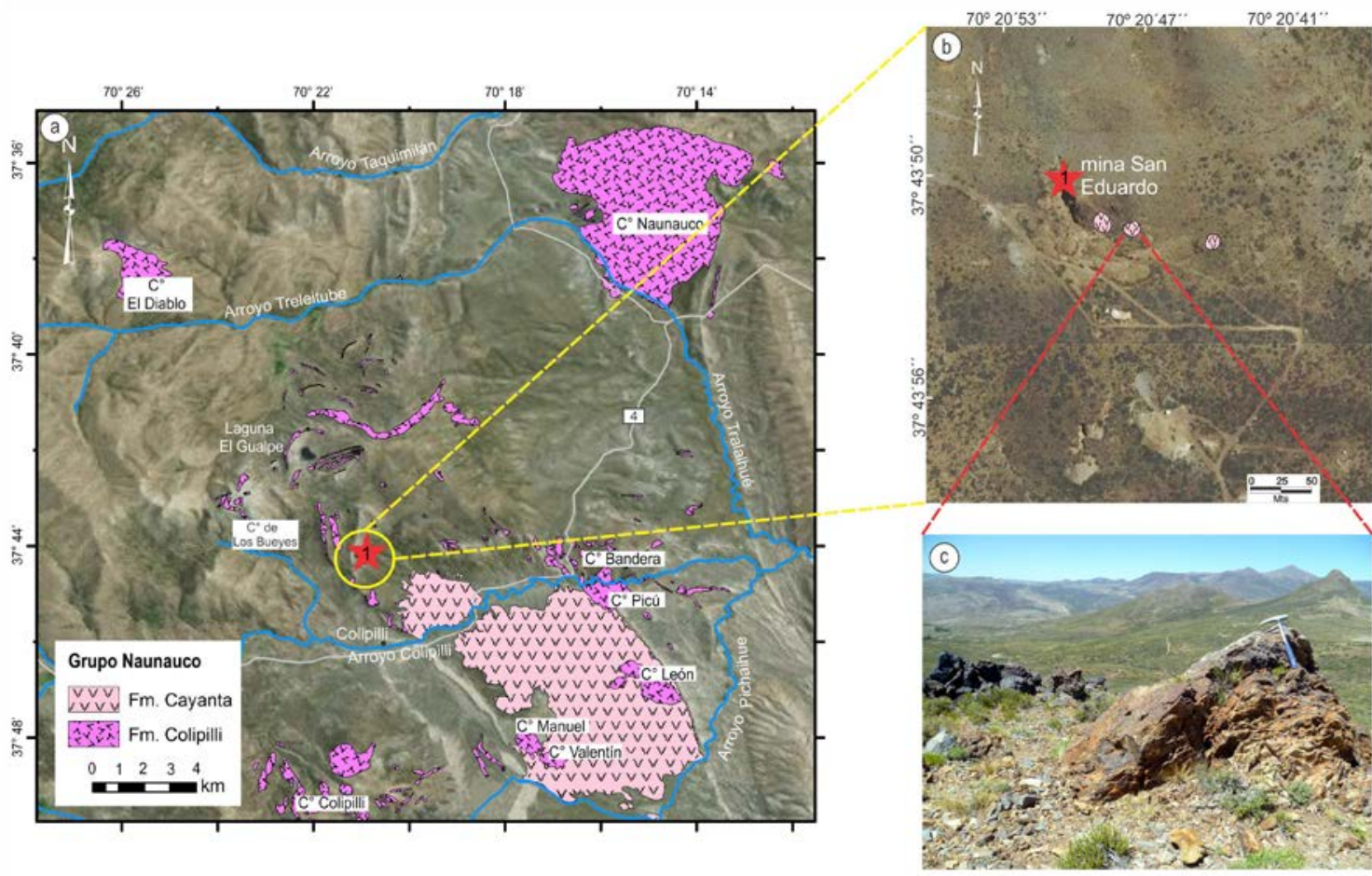

Figura 4.3: a- Imagen satelital en la que se indican afloramientos de la Formaciones Colipilli y Cayanta; b- Detalle de afloramientos de la Formación Cayanta en los alrededores de la mina San Eduardo; c- Afloramiento de la Formación Cayanta.

\section{Petrografia}

Para caracterizar a las rocas ígneas del área de estudio se seleccionaron en total 40 muestras de roca, 31 de la Formación Colipilli y 9 de la Formación Cayanta, y se realizaron cortes petrográficos de los cuales 18 son petro-calcográficos. En la Figura 4.4 se indica la ubicación de donde se tomaron las muestras de rocas ígneas más representativas y en el Anexo 1 se dan las coordenadas geográficas de la totalidad de las muestras estudiadas en esta Tesis.

Como ya se indicara en párrafos anteriores, la Formación Colipilli manifiesta diversas yacencias en el área de estudio y como consecuencia de ello, se registra una variación gradual desde texturas porfíricas a porfiroides, con pastas desde criptocristalinas a microgranosas. En el Cuadro 4.1 se muestran las características generales de los cuerpos ígneos aflorantes en la zona de Colipilli y áreas vecinas. 


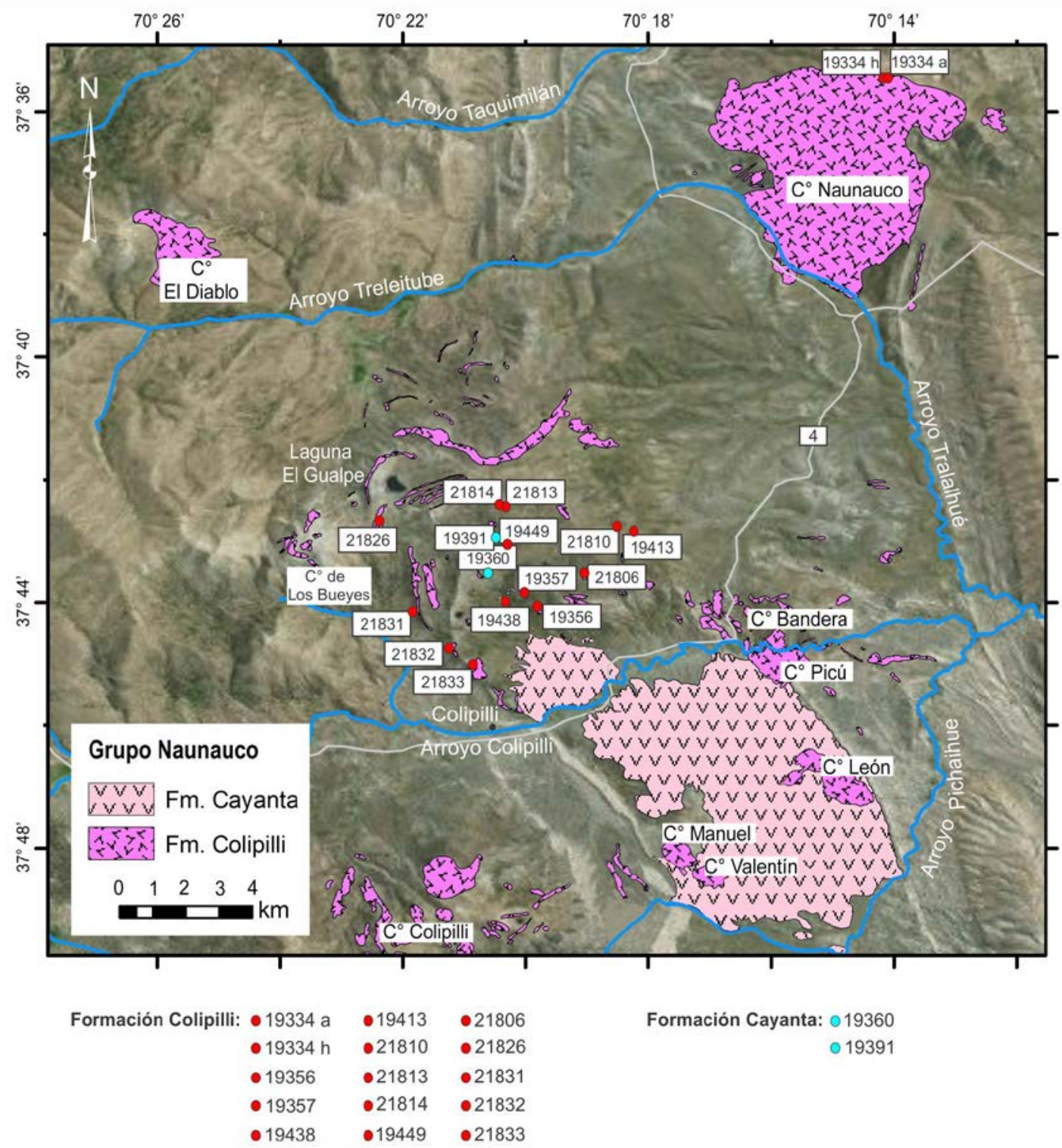

Figura 4.4: Ubicación espacial de las principales muestras de rocas ígneas estudiadas.

Las rocas andesíticas se encuentran representadas en los filones capa y lacolitos del Sector San Eduardo y en el cerro Chihuido; a escala mesoscópica son principalmente de coloración grisácea. Se distinguen fenocristales prismáticos de anfíboles de color negro de $1,5 \mathrm{~cm}$ de longitud en promedio, con máximos de hasta 3,5 cm (Fig.4.5a) y otros de plagioclasas de color blanco y hábito tabular, de $0,8 \mathrm{~cm}$ de tamaño medio. Al microscopio, la textura es porfírica con una mesostasis holocristalina, en algunos sectores con arreglos glomeroporfíricos compuestos por plagioclasas (Fig.4.5 d, e, f). Los individuos de plagioclasas (50-55\% de los fenocristales) presentan hábito tabular, maclado polisintético, marcada zonación (Fig.4.5b) y algunos se encuentran parcialmente fracturados y alterados a sericita y calcita. Su composición es entre andesina y labradorita ( $\left.\mathrm{An}_{46-66}\right)$. Los 
fenocristales de hornblenda (35-40\% de los fenocristales) se muestran con hábito prismático y pleocroísmo verde a castaño. Están parcialmente reemplazados por clorita, biotita, tremolita-actinolita y algunos presentan sus contornos difusos debido a la segregación de minerales opacos generados por desferrización (Fig.4.5c). La mesostasis (5-15\%) está constituida también por plagioclasas y además por minerales opacos. Estos últimos se encuentran distribuidos uniformemente, poseen formas euhedrales a subhedrales, hábito cúbico y secciones cuadradas y/o rómbicas. Su tamaño en general es de $0,1 \mathrm{~cm}$. Al microscopio calcográfico, se comprobó que se trata de magnetita, parcialmente martitizada y concentrada alrededor de las hornblendas y pirita. Esta última se encuentra en pequeñas cantidades y está parcialmente limonitizada.

\begin{tabular}{|c|c|c|c|c|c|c|c|c|c|}
\hline Área & Coordenadas & Formación & Yacencia & Composición & Textura & $\begin{array}{c}\text { Minerales } \\
\text { Mayoritarios }\end{array}$ & $\begin{array}{c}\text { Minerales } \\
\text { Minoritarios }\end{array}$ & Alteración & Observaciones \\
\hline $\begin{array}{l}\text { cerro } \\
\text { Chihuido }\end{array}$ & $\begin{array}{l}\text { N } 5823122 \\
\text { E } 2381026\end{array}$ & Colipilli & Stock & Andesitica & $\begin{array}{l}\text { Porfíica, } \\
\text { Porfiroide }\end{array}$ & $\begin{array}{c}55-60 \% \text { Plag. }\left(\mathrm{An}_{45-5 \mathrm{~s}}\right) \\
35-40 \% \mathrm{Hbl}\end{array}$ & $\begin{array}{c}0-10 \% \\
\text { Magnetita y } \\
\text { Pirita }\end{array}$ & $\begin{array}{l}\text { Silicificación } \\
\text { Sericitización } \\
\text { Propilitica }\end{array}$ & \\
\hline $\begin{array}{c}\text { cerro } \\
\text { Los Bueyes }\end{array}$ & $\begin{array}{l}\text { N } 5825515 \\
\text { E } 2378389\end{array}$ & Colipilli & Stock & Dacitica & Porfirica & $\begin{array}{c}40-45 \% \text { Plag. }\left(\mathrm{An}_{25-0}\right) \\
20-25 \% \mathrm{Qz} \\
10-15 \% \mathrm{Hbl}\end{array}$ & $\begin{array}{c}0-10 \% \\
\text { Magnetita }\end{array}$ & $\begin{array}{l}\text { Silicificación } \\
\text { Sericitización }\end{array}$ & \\
\hline $\begin{array}{c}\text { cerro } \\
\text { Naunauco }\end{array}$ & $\begin{array}{l}\text { N } 5841992 \\
\text { E } 2390778\end{array}$ & Colipilli & Stock & $\begin{array}{c}\text { Dioritico } \\
\text { Andésitica }\end{array}$ & Porfirica & $\begin{array}{c}50-55 \% \text { Plag. }\left(\mathrm{An}_{25+40}\right) \\
45-50 \% \mathrm{Hbl}\end{array}$ & $\begin{array}{c}0-5 \% \\
\text { Magnetita }\end{array}$ & $\begin{array}{l}\text { Cloritización } \\
\text { Sericitización }\end{array}$ & \\
\hline $\begin{array}{l}\text { cerro } \\
\text { Diablo }\end{array}$ & $\begin{array}{l}\text { N } 5834694 \\
\text { E } 2373409\end{array}$ & Colipilli & Stock & Dioritica & Porfirica & $\begin{array}{c}\text { 55-60\% Plag. }\left(\mathrm{An}_{25}\right) \\
40-45 \% \mathrm{Hbl}\end{array}$ & $\begin{array}{l}0-5 \% \\
\text { Cuarzo }\end{array}$ & $\begin{array}{l}\text { Cloritización } \\
\text { intensa } \\
\text { Sericitización } \\
\text { Silicificación }\end{array}$ & \\
\hline $\begin{array}{c}\text { Sector } \\
\text { San Eduardo }\end{array}$ & $\begin{array}{l}\text { N } 5823614 \\
\text { E } 2381226\end{array}$ & Cayanta & Extrusiva & Andesitica & $\begin{array}{l}\text { Porfirica } \\
\text { fina }\end{array}$ & $\begin{array}{c}\left.\text { 45-50\% Plag. (An }{ }_{65}\right) \\
25-30 \% \text { Hbl } \\
25-30 \% \text { Augita }\end{array}$ & $\begin{array}{l}0-5 \% \\
\text { Magnetita y } \\
\text { Pirita }\end{array}$ & $\begin{array}{l}\text { Cloritización } \\
\text { Sericitización } \\
\text { Silicificación }\end{array}$ & $\begin{array}{c}\text { Coladas con } \\
\text { estructuras de filetes } \\
\text { de flujo y de } \\
\text { auto-brechamiento }\end{array}$ \\
\hline $\begin{array}{c}\text { Sector } \\
\text { San Eduardo }\end{array}$ & $\begin{array}{l}\text { N } 5823583 \\
\text { E } 2381170\end{array}$ & Colipilli & Filón capa & Andesitica & $\begin{array}{l}\text { Porfirica a } \\
\text { Porfiroide }\end{array}$ & $\begin{array}{c}40-65 \% \mathrm{Hbl} \\
35-60 \% \text { Plag. }\left(\mathrm{An}_{46-64}\right)\end{array}$ & $\begin{array}{c}0-5 \% \\
\text { Magnetita y } \\
\text { Titanita }\end{array}$ & $\begin{array}{l}\text { Cloritización } \\
\text { Sericitización }\end{array}$ & $\begin{array}{l}\text { Cumulatos } \\
\text { de anfibol }\end{array}$ \\
\hline $\begin{array}{c}\text { Sector } \\
\text { San Eduardo }\end{array}$ & $\begin{array}{r}\text { N } 5823238 \\
\text { E } 2381112\end{array}$ & Colipilli & Lacolito & Andesitica & $\begin{array}{l}\text { Porfirica a } \\
\text { Porfiroide }\end{array}$ & $\begin{array}{c}40-65 \% \mathrm{Plag} .\left(\mathrm{An}_{40-64}\right) \\
35-60 \% \mathrm{Hbl}^{-}\end{array}$ & $\begin{array}{c}0-5 \% \\
\text { Magnetita y } \\
\text { Titanita }\end{array}$ & $\begin{array}{l}\text { Cloritización } \\
\text { Sericitización }\end{array}$ & \\
\hline
\end{tabular}

Cuadro 4.1: Características generales de los cuerpos ígneos aflorantes en la zona de Colipilli y áreas vecinas.

El grado de alteración que estas rocas poseen es moderado a alto, con tonalidades verdosas y blanquecinas. Se identificaron las siguientes alteraciones: (a) Silicificación, se manifiesta principalmente por la presencia de cuarzo rellenando oquedades y microfracturas, en cantidades minoritarias. (b) sericitización, en las plagioclasas. Durante este proceso, el $\mathrm{Ca}^{++}$de las plagioclasas quedó liberado y favoreció la formación de epidoto y titanita reflejando una alteración de tipo (c) propilítica. Este último tipo de alteración (Fig.4.5 g, h, i) está además representado por la paragénesis calcita + clorita.

Las rocas dacíticas del cerro Los Bueyes se distinguen por su coloración grisácea con algunas tonalidades castañas y textura porfírica. Los fenocristales están constituidos 
principalmente por plagioclasas, cuarzo y anfíbol. Las primeras son blanquecinas a castañas, poseen hábito tabular y tamaños que van desde 0,7 hasta $1 \mathrm{~cm}$. Los individuos de cuarzo son euhedrales, incoloros y de hasta $0,5 \mathrm{~cm}$ de tamaño. Los cristales de anfíbol tienen hábito prismático y color gris oscuro y desarrollan tamaños de hasta $0,4 \mathrm{~cm}$. La mesostasis es de color grisáceo y posee textura afanítica. Se identificaron pequeños cristales octaédricos de magnetita, de color negro y brillo submetálico de dispar distribución, concentrados por sectores. A veces, los cristales de magnetita poseen menor tamaño aún y se encuentran diseminados de manera uniforme.

Al microscopio, la textura porfírica exhibe fenocristales de plagioclasas (40-45\%). Los mismos se presentan euhedrales, de hábito tabular-prismático, algunos con marcada zonación y otros con maclas polisintéticas. Los fenocristales de cuarzo (20-25\%) se presentan en cristales subhedrales, algunos presentan bordes redondeados (Fig.4.5 j, k, 1). Son de tamaño variado (entre 0,15 y $0,30 \mathrm{~cm}$ ) y exhiben intensa fracturación. En menor cantidad, se identificaron fenocristales de anfíboles (10-15\%), variedad hornblenda, con secciones basales hexagonales y presencia de maclas simples. Presentan un tamaño máximo de $0,15 \mathrm{~cm}$, color verde oscuro, pleocroísmo marcado y colores de interferencia de segundo orden. La mesostasis (5-25\%) es de grano fino, está integrada por cristales anhedrales de cuarzo y feldespato (textura felsítica). Los cristales de magnetita (5-10\%) se encuentran dispersos. Éstos son euhedrales a subhedrales, con secciones de tamaño máximo de $0,03 \mathrm{~cm}$, y mínimo de $0,01 \mathrm{~cm}$.

Si bien las alteraciones identificadas en las rocas dacíticas son similares a las presentes en las andesíticas, en las primeras no se encuentra desarrollada la propilitización.

Las rocas de composición diorítica del cerro El Diablo exhiben coloraciones grisáceas y texturas porfíricas compuestas por fenocristales de $0,5 \mathrm{~cm}$ de tamaño en promedio de plagioclasas y $0,3 \mathrm{~cm}$ en general de anfíboles, rodeados de una mesostasis de grano grueso en la que se reconocen cristales menores $(0,1 \mathrm{~cm}$ en promedio) de plagioclasas y cuarzo. 

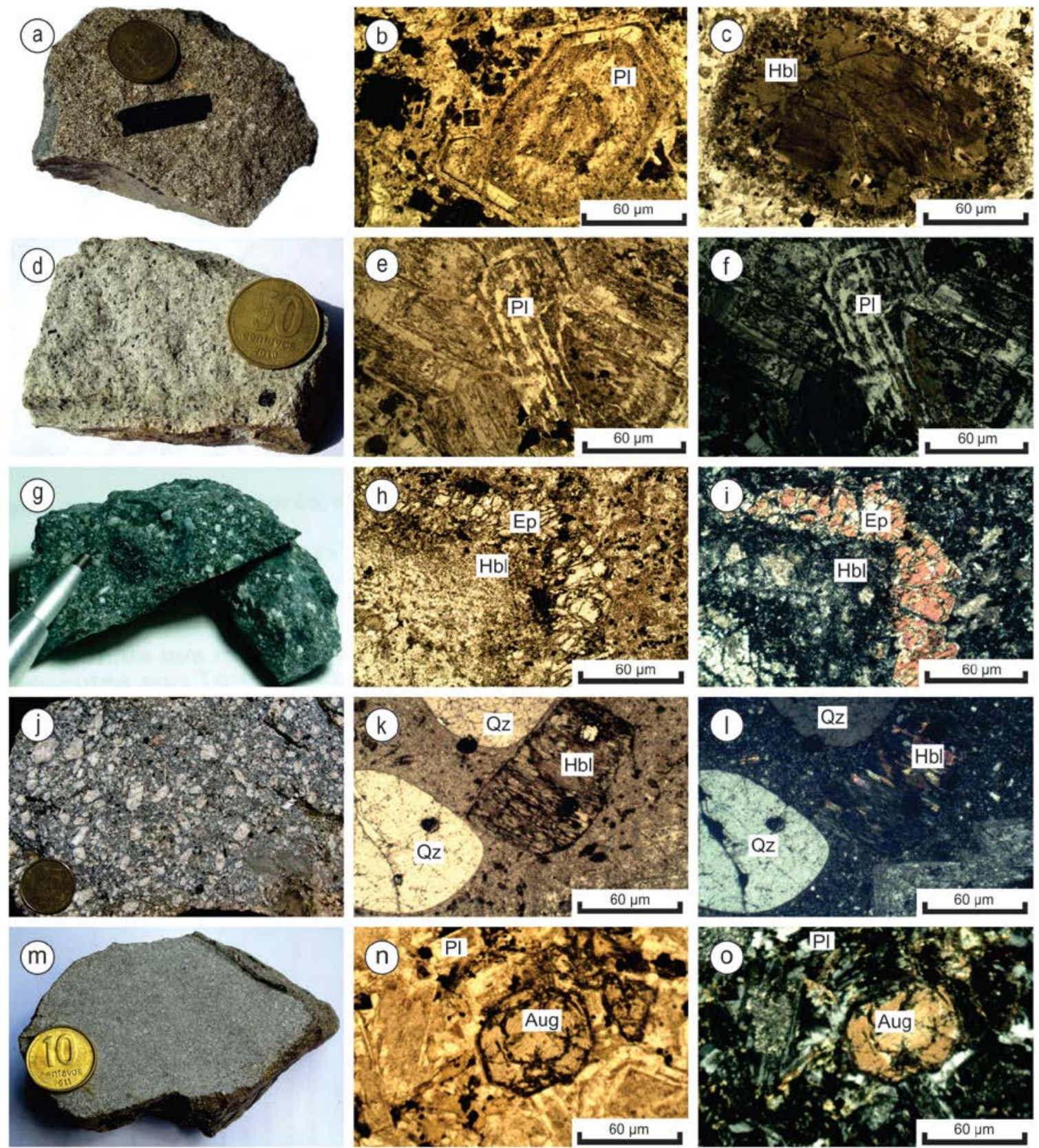

Figura 4.5: Fotografías de muestra de mano y de cortes delgados bajo microscopio de las unidades magmáticas: a- Vista mesoscópica de anfíbol de 3,5 cm de largo, cerro Negro; b- plagioclasa con marcada zonación, cerro Negro; c- anfíbol con contornos difusos debido a la segregación de óxidos, cerro Negro; d- aspecto mesoscópico de roca andesítica del cerro Chihuido; e-f: textura glomeroporfírica sin y con analizador respectivamente; g- aspecto mesoscópico de andesita con alteración propilítica, cerro Chihuido; $\mathrm{h}$-i: alteración propilítica sin $\mathrm{y}$ con analizador respectivamente; $\mathrm{j}$ - vista mesoscópica de la dacita, cerro Los Bueyes; $\mathrm{k}-\mathrm{l}$ : cristales de cuarzo corroídos sin y con analizador respectivamente; m- vista mesoscópica de andesita de la Formación Cayanta; n-o: augita sin y con analizador respectivamente. Las abreviaturas de minerales utilizadas según Whitney y Evans (2010). 
Al microscopio la textura es de tipo porfírica con una mesostasis microgranuda. Los individuos de plagioclasas (55-60\% de los fenocristales) son de naturaleza ácida (oligoclasa, $\mathrm{An}_{25}$ ) y se caracterizan por poseer maclas polisintéticas y de Carlsbad con ligera zonación. La alteración, de tipo sericítica, se concentra en los núcleos o en las fracturas de los cristales. Los anfíboles (30-35\% de los fenocristales) son hornblendas, tienen hábito prismático y algunos de ellos están completamente reemplazados a tremolitaactinolita, clorita, óxidos y biotita. La mesostasis (5-15\%) está compuesta por cristales de menor tamaño de la misma naturaleza que los fenocristales y además cuarzo. Los tipos de alteración que poseen estas rocas son cloritización y en menor medida, sericitización; manifiestan una intensidad moderada.

Por su parte, las rocas diorítico-andesíticas del cerro Naunauco muestran una clara textura porfírica con fenocristales de anfíboles (de $0,4 \mathrm{~cm}$ en general) y plagioclasas $(0,3$ $\mathrm{cm}$ en promedio) inmersos en una pasta de minerales de menor tamaño (del orden del $\mathrm{mm}$ ) de coloración grisácea a verdosa. Al microscopio la textura dominante es porfírica con una mesostasis holocristalina. Los individuos de plagioclasas (45-50\% de los fenocristales) presentan marcada zonación, maclas polisintéticas y de tipo Carlsbad y se encuentran parcialmente fracturados. Su composición es entre oligoclasa y andesina ( $\left.\mathrm{An}_{25-40}\right)$. Algunos cristales manifiestan alteración sericítica, principalmente aquellos que se encuentran con intensa fracturación. Los anfíboles (40-45\% de los fenocristales) son de naturaleza hornblendífera y asociados espacialmente a ellos, hay pequeños cristales octaédricos de magnetita. Otros individuos de hornblenda se encuentran intensamente alterados a clorita y biotita. La mesostasis (5-15\%) está compuesta principalmente por plagioclasas y hornblenda con tamaño en general de $0,2 \mathrm{~cm}$ y magnetitas (parcialmente martitizadas) y titanitas diseminadas, de tamaño promedio $0,1 \mathrm{~cm}$.

El grado de alteración que presentan estas rocas es medio a alto tratándose principalmente de cloritización, sericitización y en menor medida de silicificación.

Las rocas extrusivas de la Formación Cayanta son de composición andesítica, se caracterizan por sus colores grisáceos, con tonalidades castaño claras o verdosas y textura porfírica. En afloramiento exhiben filetes de flujo (Fig.4.6a-b) y estructuras de autobrechamiento (Fig.4.6c-d). Microscópicamente, son rocas preponderantemente porfíricas, aunque en algunos sectores exhiben una textura de tipo glomeroporfírica y en otros sectores textura pilotáxica. Los fenocristales que se observan son de plagioclasas (40$45 \%$ ), hornblenda (25-30\%) y augita (10-15\%) (Fig.4.5 m, n, o). Las plagioclasas son de hábito tabular, con maclado polisintético, se encuentran fuertemente zonadas y a veces 
están parcialmente reemplazadas por sericita y calcita. Sus tamaños varían entre 0,3 y 1 $\mathrm{cm}$. Su composición es de tipo labradorita $\left(\mathrm{An}_{65}\right)$. Los cristales de hornblenda alcanzan 0,8 $\mathrm{cm}$ de tamaño, tienen hábito prismático, pleocroísmo de coloración verdosa a castaña, relieve alto y birrefringencia de segundo orden. Algunos individuos muestran un reborde de minerales opacos producidos por segregación de óxidos y a su vez, se encuentran parcialmente reemplazados por un anfíbol de hábito fibroso posiblemente tremolitaactinolita, además de clorita y biotita. La augita se presenta con relieve alto, en secciones basales de ocho lados y con fracturas irregulares. Posee maclas diagonales y varía en tamaño desde 0,3 a $0,5 \mathrm{~cm}$. La mineralogía de la mesostasis (10-25\%) consta también de plagioclasas y hornblenda, en forma mayoritaria y de minerales opacos en cantidades accesorias. Entre estos últimos se identifican magnetita y pirita cuyo tamaño promedio es de $0,08 \mathrm{~cm}$. La primera es la más abundante y se presenta en formas euhedrales a subhedrales octaédricas mostrando secciones cuadradas y/o rómbicas.

Estas rocas evidencian un grado medio a alto de cloritización, sericitización y silicificación.
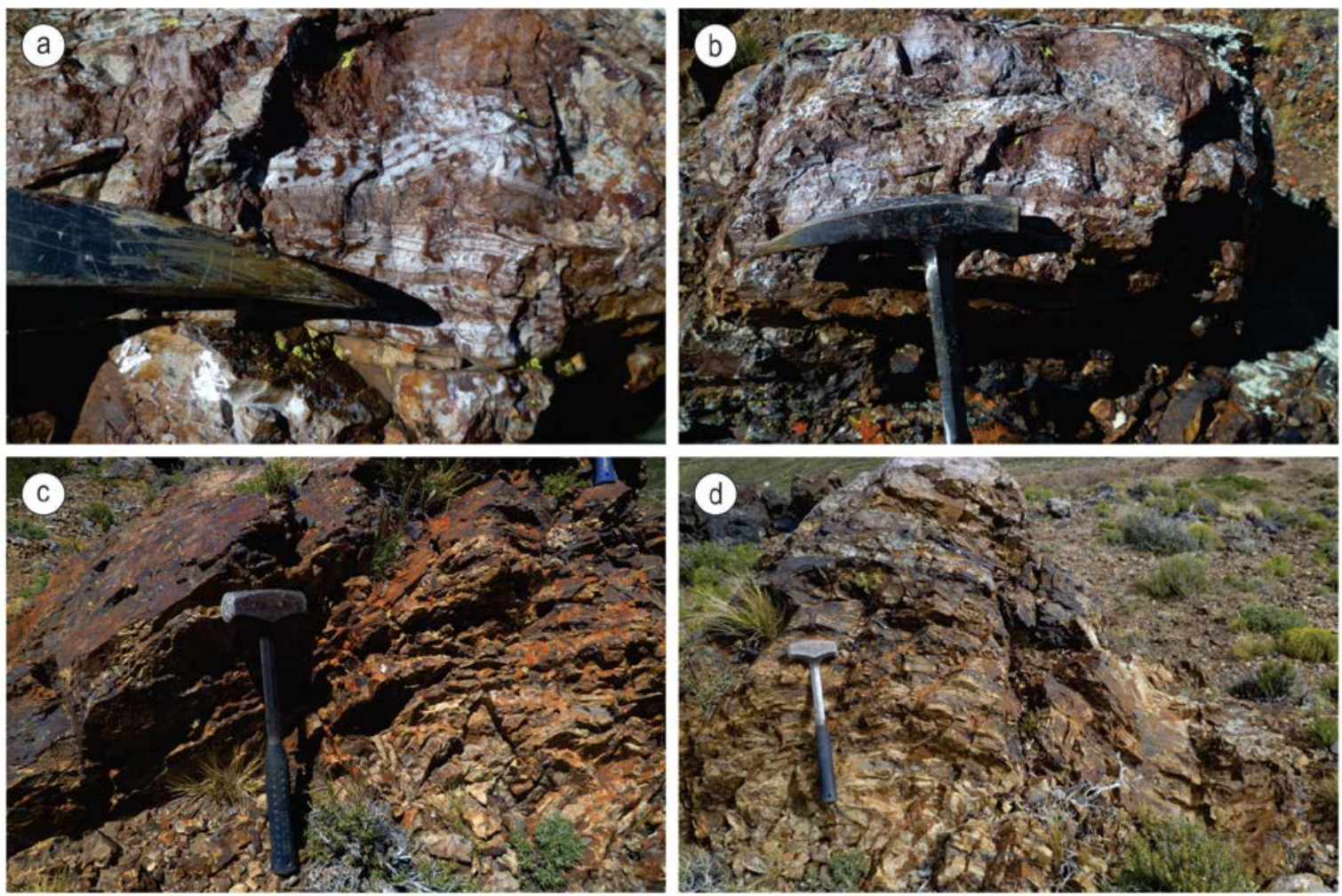

Figura 4.6: Filetes de flujo y alteración silícea (a-b) y estructuras de autobrechamiento (c-d) en los afloramientos de la Formación Cayanta. 


\section{Características geoquímicas}

Se caracterizó geoquímicamente el magmatismo del área de estudio a través del análisis de rocas provenientes esencialmente de las facies subvolcánicas de la Formación Colipilli. Las facies extrusivas representadas por la Formación Cayanta no fueron analizadas debido a que poseen un alto grado de alteración. Los análisis fueron realizados en los laboratorios Acme Labs (Canadá) y se presentan en el Cuadro 4.2. La concentración de cada elemento se determinó mediante espectrometría de masas con plasma acoplado inductivamente (ICP-MS). La pérdida por ignición (LOI) se determinó por calcinación de una fracción de la muestra y medición de la diferencia de masa. La norma CIPW se calculó con una planilla Excel creada por el Dr. Kurt T. Hollocher del Departamento de Geología de Unión College (Schenectady, Estados Unidos). Los resultados obtenidos se compararon con datos de Llambías y Malvicini (1978) en el sector de estudio y de áreas vecinas presentados por Zamora Valcarce (2007) y Mateo Fernández Caso et al. (2011).

Químicamente, las rocas analizadas presentan fuerte variación en el contenido de sílice (47,62 a 62,47\%). Para su clasificación se utilizaron los diagramas TAS (Le Maitre 1989) y el de Winchester y Floyd (1977) (Fig.4.7a y b). Donde en el primero de estos diagramas se tuvieron en cuenta aquellos análisis con LOI inferior al $2 \%$. Las muestras grafican mayoritariamente en los campos de las traqui-andesitas y andesitas, aunque levemente definen un conjunto composicional que incluye traqui-andesitas basálticas y dacitas. El diagrama de Winchester y Floyd (1977), $\mathrm{Zr} / \mathrm{TiO}_{2}$ vs Nb/Y, manifiesta un tren de evolución desde basaltos/andesitas a riodacitas/dacitas.

Los elementos trazas adquieren particular importancia para la caracterización del marco tectónico en el que las rocas se formaron, en especial aquellos considerados de baja movilidad geoquímica y por lo tanto estables durante los procesos de alteración. Los más utilizados en los diagramas de discriminación tectónica son $\mathrm{Zr}, \mathrm{Nb}, \mathrm{Y}, \mathrm{Ga}, \mathrm{Ta}, \mathrm{Ti}, \mathrm{Hf}$, Th. Se empleó como discriminador tectónico el diagrama de Wood (1980). Se plotearon los contenidos de Ta, Hf y Th. La distribución de los datos muestra que corresponden a rocas de arco volcánico continental (Fig.4.8a). Además, a partir del diagrama ternario AFM de Irvine y Baragar (1971) se distingue una clara tendencia calcoalcalina (Fig.4.8b). 


\begin{tabular}{|c|c|c|c|c|c|}
\hline Muestra $\rightarrow$ & $19334 a$ & $19334 \mathrm{H}$ & 19356 & 19438 & 19413 \\
\hline Sector $\rightarrow$ & $c^{\circ}$ Naunauco & $\mathrm{c}^{\circ}$ Naunauco & $\mathrm{c}^{\circ}$ Chihuido & $c^{\circ}$ Chihuido & $\mathrm{c}^{\circ}$ Espinal \\
\hline \multirow{2}{*}{ Ubicación $\rightarrow$} & $70^{\circ} 14^{\prime} 11^{\prime \prime}$ & $70^{\circ} 14^{\prime} 10^{\prime \prime}$ & $70^{\circ} 20^{\prime} 58^{\prime \prime}$ & $70^{\circ} 20^{\prime} 52^{\prime \prime}$ & $70^{\circ} 18^{\prime} 24^{\prime \prime}$ \\
\hline & $37^{\circ} 33^{\prime} 53^{\prime \prime}$ & $37^{\circ} 33^{\prime} 55^{\prime \prime}$ & $37^{\circ} 44^{\prime} 02^{\prime \prime}$ & $37^{\circ} 44^{\prime} 12^{\prime \prime}$ & $37^{\circ} 43^{\prime} 06^{\prime \prime}$ \\
\hline \multicolumn{6}{|l|}{$\%$ en peso } \\
\hline $\mathrm{SiO}_{2}$ & 52,02 & 57,81 & 55,30 & 53,54 & 57,93 \\
\hline $\mathrm{TiO}_{2}$ & 0,69 & 0,54 & 0,58 & 0,53 & 0,63 \\
\hline $\mathrm{Al}_{2} \mathrm{O}_{3}$ & 18,16 & 18,82 & 18,03 & 18,24 & 19,15 \\
\hline $\mathrm{Cr}_{2} \mathrm{O}_{3}$ & 0,008 & 0,006 & 0,008 & 0,006 & $<0,002$ \\
\hline $\mathrm{Fe}_{2} \mathrm{O}_{3}$ & 6,57 & 4,90 & 6,74 & 6,48 & 2,93 \\
\hline MnO & 0,09 & 0,07 & 0,11 & 0,16 & 0,08 \\
\hline MgO & 4,77 & 2,69 & 2,61 & 0,63 & 2,27 \\
\hline $\mathrm{CaO}$ & 6,05 & 5,56 & 6,53 & 8,49 & 9,10 \\
\hline $\mathrm{Na}_{2} \mathrm{O}$ & 6,22 & 6,70 & 3,85 & 4,30 & 4,41 \\
\hline $\mathrm{K}_{2} \mathrm{O}$ & 1,15 & 0,70 & 1,67 & 1,21 & 2,18 \\
\hline $\mathbf{P}_{2} \mathbf{O}_{5}$ & 0,19 & 0,25 & 0,19 & 0,21 & 0,31 \\
\hline LOI & 3,9 & 1,8 & 4,1 & 6,1 & 0,7 \\
\hline TOTAL & 99,82 & 99,85 & 99,72 & 99,90 & 99,69 \\
\hline $\mathrm{C}$ & 0,12 & 0,04 & 0,37 & 1,06 & $<0,02$ \\
\hline $\mathbf{S}$ & 0,03 & $<0,02$ & 0,02 & 0,03 & $<0,02$ \\
\hline \multicolumn{6}{|c|}{ Norma CIPW } \\
\hline Muestra $\rightarrow$ & $19334 a$ & $19334 \mathrm{H}$ & 19356 & 19438 & 19413 \\
\hline \multicolumn{6}{|l|}{$\%$ mineral } \\
\hline Q & 0,00 & 1,57 & 8,79 & 7,06 & 5,31 \\
\hline C & 0,00 & 0,00 & 0,00 & 0,00 & 0,00 \\
\hline Or & 7,11 & 4,23 & 10,37 & 7,66 & 13,04 \\
\hline $\mathbf{A b}$ & 45,77 & 57,99 & 34,22 & 38,96 & 37,76 \\
\hline An & 19,09 & 19,65 & 28,34 & 28,80 & 26,33 \\
\hline $\mathrm{Ne}$ & 5,05 & 0,00 & 0,00 & 0,00 & 0,00 \\
\hline Di & 8,79 & 5,50 & 3,56 & 11,38 & 13,66 \\
\hline Wo & 0,00 & 0,00 & 0,00 & 0,62 & 0,00 \\
\hline Нy & 0,00 & 6,15 & 9,02 & 0,00 & 0,11 \\
\hline Ol & 8,12 & 0,00 & 0,00 & 0,00 & 0,00 \\
\hline Mt & 4,23 & 3,26 & 4,08 & 3,93 & 1,86 \\
\hline II & 1,37 & 1,05 & 1,16 & 1,08 & 1,21 \\
\hline Ap & 0,46 & 0,59 & 0,46 & 0,52 & 0,73 \\
\hline TOTAL & 100,00 & 100,00 & 100,00 & 100,00 & 100,00 \\
\hline
\end{tabular}

C y S expresados en $\%$ en peso.

Cuadro 4.2: Análisis químicos de elementos mayoritarios y composición normativa de las rocas ígneas de los principales cuerpos magmáticos de la región de Colipilli. 


\begin{tabular}{|c|c|c|c|c|c|}
\hline Muestra $\rightarrow$ & 19449 & 21806 & 21810 & 21813 & 21814 \\
\hline Sector $\rightarrow$ & Norte de S.E. & Stock S.E. & $c^{\circ}$ Negro & $c^{\circ}$ Negro & $c^{\circ}$ Negro \\
\hline \multirow{2}{*}{ Ubicación $\rightarrow$} & $70^{\circ} 20^{\prime} 24^{\prime \prime}$ & $70^{\circ} 19^{\prime} 16^{\prime \prime}$ & $70^{\circ} 18^{\prime} 32^{\prime \prime}$ & $70^{\circ} 20^{\prime} 39^{\prime \prime}$ & $70^{\circ} 20^{\prime} 40^{\prime \prime}$ \\
\hline & $37^{\circ} 43^{\prime} 31^{\prime \prime}$ & $37^{\circ} 44^{\prime} 36^{\prime \prime}$ & $37^{\circ} 43^{\prime} 00^{\prime \prime}$ & $37^{\circ} 42^{\prime} 59^{\prime \prime}$ & $37^{\circ} 42^{\prime} 58^{\prime \prime}$ \\
\hline \multicolumn{6}{|l|}{$\%$ en peso } \\
\hline $\mathrm{SiO}_{2}$ & 51,96 & 59,81 & 58,62 & 58,60 & 47,62 \\
\hline $\mathrm{TiO}_{2}$ & 0,63 & 0,51 & 0,62 & 0,53 & 0,80 \\
\hline $\mathrm{Al}_{2} \mathrm{O}_{3}$ & 18,77 & 17,81 & 19,09 & 17,79 & 18,60 \\
\hline $\mathrm{Cr}_{2} \mathrm{O}_{3}$ & 0,004 & 0,015 & 0,008 & 0,007 & 0,003 \\
\hline $\mathrm{Fe}_{2} \mathrm{O}_{3}$ & 7,49 & 5,43 & 3,10 & 5,88 & 8,58 \\
\hline MnO & 0,23 & 0,16 & 0,06 & 0,23 & 0,22 \\
\hline MgO & 3,66 & 1,74 & 2,25 & 2,52 & 4,67 \\
\hline $\mathrm{CaO}$ & 6,02 & 6,02 & 8,44 & 4,46 & 6,29 \\
\hline $\mathrm{Na}_{2} \mathrm{O}$ & 4,03 & 4,22 & 5,50 & 4,80 & 4,72 \\
\hline $\mathbf{K}_{2} \mathbf{O}$ & 1,91 & 1,75 & 0,29 & 2,45 & 0,78 \\
\hline $\mathrm{P}_{2} \mathrm{O}_{5}$ & 0,27 & 0,17 & 0,34 & 0,17 & 0,27 \\
\hline LOI & 4,8 & 2,1 & 1,5 & 2,3 & 7,2 \\
\hline TOTAL & 99,77 & 99,74 & 99,82 & 99,74 & 99,75 \\
\hline C & 0,38 & 0,17 & 0,04 & 0,08 & 1,00 \\
\hline $\mathbf{S}$ & $<0,02$ & $<0,02$ & $<0,02$ & $<0,02$ & 0,10 \\
\hline \multicolumn{6}{|c|}{ Norma CIPW } \\
\hline Muestra $\rightarrow$ & 19449 & 21806 & 21810 & 21813 & 21814 \\
\hline \multicolumn{6}{|l|}{$\%$ mineral } \\
\hline $\mathbf{Q}$ & 1,82 & 13,62 & 7,56 & 7,73 & 0,00 \\
\hline C & 0,00 & 0,00 & 0,00 & 0,00 & 0,00 \\
\hline Or & 11,94 & 10,63 & 1,75 & 14,91 & 5,01 \\
\hline $\mathbf{A b}$ & 36,08 & 36,69 & 47,43 & 41,83 & 43,34 \\
\hline An & 29,08 & 25,16 & 27,05 & 20,35 & 29,63 \\
\hline $\mathrm{Ne}$ & 0,00 & 0,00 & 0,00 & 0,00 & 0,04 \\
\hline Di & 0,53 & 3,57 & 10,58 & 1,04 & 1,92 \\
\hline Wo & 0,00 & 0,00 & 0,00 & 0,00 & 0,00 \\
\hline Hy & 14,11 & 5,47 & 1,73 & 8,76 & 0,00 \\
\hline Ol & 0,00 & 0,00 & 0,00 & 0,00 & 12,78 \\
\hline Mt & 4,53 & 3,46 & 1,91 & 3,94 & 4,95 \\
\hline II & 1,27 & 1,00 & 1,20 & 1,04 & 1,65 \\
\hline Ap & 0,66 & 0,40 & 0,80 & 0,41 & 0,68 \\
\hline TOTAL & 100,00 & 100,00 & 100,00 & 100,00 & 100,00 \\
\hline
\end{tabular}

C y S expresados en $\%$ en peso.

Cuadro 4.2 (continuación): Análisis químicos de elementos mayoritarios y composición normativa de las rocas ígneas de los principales cuerpos magmáticos de la región de Colipilli. 


\begin{tabular}{|c|c|c|c|c|c|}
\hline \multirow{4}{*}{$\begin{array}{l}\text { Muestra } \rightarrow \\
\text { Sector } \rightarrow\end{array}$} & & & & & \\
\hline & $19334 a$ & $19334 \mathrm{H}$ & 19356 & 19438 & 19413 \\
\hline & $c^{\circ}$ Naunauco & $c^{\circ}$ Naunauco & $\mathrm{c}^{\circ}$ Chihuido & $\mathrm{c}^{\circ}$ Chihuido & $c^{\circ}$ Espinal \\
\hline & $70^{\circ} 14^{\prime} 11^{\prime \prime}$ & $70^{\circ} 14^{\prime} 10^{\prime \prime}$ & $70^{\circ} 20^{\prime} 58^{\prime \prime}$ & $70^{\circ} 20^{\prime} 52^{\prime \prime}$ & $70^{\circ} 18^{\prime} 24^{\prime \prime}$ \\
\hline Ubicación $\rightarrow$ & $37^{\circ} 33^{\prime} 53^{\prime \prime}$ & $37^{\circ} 33^{\prime} 55^{\prime \prime}$ & $37^{\circ} 44^{\prime} 02^{\prime \prime}$ & $37^{\circ} 44^{\prime} 12^{\prime \prime}$ & $37^{\circ} 43^{\prime} 06^{\prime \prime}$ \\
\hline \multicolumn{6}{|l|}{ ppm } \\
\hline $\mathrm{Be}$ & $<1$ & 1,00 & $<1$ & 2,00 & 3,00 \\
\hline Sc & 20,00 & 9,00 & 12,00 & 10,00 & 9,00 \\
\hline $\mathbf{V}$ & 189,00 & 106,00 & 140,00 & 111,00 & 131,00 \\
\hline Co & 10,80 & 12,00 & 11,60 & 10,60 & 12,90 \\
\hline $\mathbf{N i}$ & 7,60 & 1,70 & 4,00 & 3,00 & 4,10 \\
\hline $\mathrm{Cu}$ & 4,70 & 15,50 & 10,40 & 2,50 & 0,90 \\
\hline Zn & 6,00 & 12,00 & 34,00 & 14,00 & 16,00 \\
\hline $\mathbf{G a}$ & 15,30 & 17,10 & 15,10 & 15,50 & 18,40 \\
\hline As & $<0,5$ & $<0,5$ & 0,60 & 1,10 & 1,10 \\
\hline Se & $<0,5$ & $<0,5$ & $<0,5$ & $<0,5$ & $<0,5$ \\
\hline $\mathbf{R b}$ & 22,20 & 12,50 & 35,20 & 42,30 & 32,20 \\
\hline $\mathbf{S r}$ & 519,70 & 655,90 & 564,10 & 397,60 & 765,00 \\
\hline $\mathbf{Y}$ & 12,70 & 14,90 & 14,20 & 16,00 & 20,30 \\
\hline $\mathbf{Z r}$ & 78,30 & 105,80 & 92,70 & 87,50 & 149,80 \\
\hline Nb & 3,50 & 4,70 & 4,10 & 3,80 & 5,20 \\
\hline Mo & 0,20 & 0,20 & 0,50 & 0,50 & $<0,1$ \\
\hline Ag & $<0,1$ & $<0,1$ & $<0,1$ & $<0,1$ & $<0,1$ \\
\hline Cd & $<0,1$ & 0,10 & $<0,1$ & $<0,1$ & $<0,1$ \\
\hline Sn & $<1$ & $<1$ & $<1$ & $<1$ & 3,00 \\
\hline Sb & $<0,1$ & $<0,1$ & $<0,1$ & $<0,1$ & $<0,1$ \\
\hline $\mathrm{Cs}$ & 2,60 & 1,20 & 9,50 & 6,00 & 0,30 \\
\hline $\mathbf{B a}$ & 313,00 & 376,00 & 1096,00 & 421,00 & 733,00 \\
\hline $\mathbf{L a}$ & 9,70 & 17,20 & 17,40 & 18,50 & 18,30 \\
\hline $\mathrm{Ce}$ & 20,70 & 35,40 & 32,80 & 34,30 & 44,80 \\
\hline Pr & 2,70 & 4,22 & 3,79 & 4,09 & 5,90 \\
\hline Nd & 12,20 & 18,20 & 15,10 & 16,00 & 24,20 \\
\hline Sm & 2,62 & 3,27 & 2,90 & 2,98 & 4,84 \\
\hline Eu & 0,81 & 0,95 & 0,91 & 0,98 & 2,07 \\
\hline Gd & 2,44 & 3,07 & 2,79 & 2,92 & 4,53 \\
\hline Tb & 0,37 & 0,45 & 0,43 & 0,45 & 0,64 \\
\hline Dy & 2,17 & 2,45 & 2,56 & 2,59 & 3,77 \\
\hline Ho & 0,51 & 0,51 & 0,56 & 0,55 & 0,78 \\
\hline $\mathbf{E r}$ & 1,39 & 1,59 & 1,52 & 1,60 & 2,35 \\
\hline Tm & 0,22 & 0,25 & 0,23 & 0,25 & 0,36 \\
\hline $\mathbf{Y b}$ & 1,32 & 1,71 & 1,57 & 1,70 & 2,45 \\
\hline Lu & 0,22 & 0,27 & 0,27 & 0,27 & 0,39 \\
\hline Hf & 2,10 & 3,00 & 2,70 & 2,40 & 4,20 \\
\hline Ta & 0,20 & 0,30 & 0,20 & 0,30 & 0,90 \\
\hline $\mathbf{W}$ & 2,20 & 2,70 & 3,50 & 2,90 & 111,90 \\
\hline $\mathbf{A u}$ & 0,80 & 12,80 & 4,00 & 0,80 & 0,60 \\
\hline $\mathrm{Hg}$ & $<0,01$ & $<0,01$ & $<0,01$ & 0,02 & $<0,01$ \\
\hline TI & $<0,1$ & $<0,1$ & $<0,1$ & $<0,1$ & $<0,1$ \\
\hline $\mathbf{P b}$ & 2,40 & 2,60 & 56,80 & 1,20 & 2,50 \\
\hline $\mathbf{B i}$ & $<0,1$ & 0,10 & $<0,1$ & $<0,1$ & $<0,1$ \\
\hline Th & 3,60 & 4,90 & 5,30 & 4,20 & 7,60 \\
\hline $\mathbf{U}$ & 0,60 & 0,80 & 1,40 & 1,20 & 1,60 \\
\hline ¿ETR & 57,37 & 89,54 & 82,83 & 87,18 & 115,38 \\
\hline$(\mathrm{La} / \mathrm{Sm})_{N}$ & 2,31 & 3,28 & 3,75 & 3,88 & 2,36 \\
\hline$(\mathrm{La} / \mathrm{Yb})_{\mathrm{N}}$ & 4,99 & 6,83 & 7,53 & 7,39 & 5,07 \\
\hline$(\mathrm{Tb} / \mathrm{Yb})_{\mathrm{N}}$ & 1,25 & 1,17 & 1,22 & 1,18 & 1,17 \\
\hline$(\mathrm{La} / \mathrm{Lu})_{\mathrm{N}}$ & 4,58 & 6,61 & 6,69 & 7,11 & 4,87 \\
\hline $\mathbf{E u} / \mathbf{E u}$ * & 0,95 & 0,89 & 0,95 & 0,99 & 1,33 \\
\hline
\end{tabular}

Cuadro 4.2 (continuación): Elementos traza y tierras raras de las rocas ígneas de los principales cuerpos magmáticos de la región de Colipilli. 


\begin{tabular}{|c|c|c|c|c|c|}
\hline Muestra $\rightarrow$ & 19449 & 21806 & 21810 & 21813 & 21814 \\
\hline Sector $\rightarrow$ & Norte de S.E. & Stock S.E. & $\mathrm{c}^{\circ}$ Negro & $c^{\circ}$ Negro & $c^{\circ}$ Negro \\
\hline \multirow{2}{*}{ Ubicación $\rightarrow$} & $70^{\circ} 20^{\prime} 24^{\prime \prime}$ & $70^{\circ} 19^{\prime} 16^{\prime \prime}$ & $70^{\circ} 18^{\prime} 32^{\prime \prime}$ & $70^{\circ} 20^{\prime} 39^{\prime \prime}$ & $70^{\circ} 20^{\prime} 40^{\prime \prime}$ \\
\hline & $37^{\circ} 43^{\prime} 31^{\prime \prime}$ & $37^{\circ} 44^{\prime} 36^{\prime \prime}$ & $37^{\circ} 43^{\prime} 00^{\prime \prime}$ & $37^{\circ} 42^{\prime} 59^{\prime \prime}$ & $37^{\circ} 42^{\prime} 58^{\prime \prime}$ \\
\hline \multicolumn{6}{|l|}{ ppm } \\
\hline $\mathrm{Be}$ & $<1$ & $<1$ & $<1$ & $<1$ & $<1$ \\
\hline Sc & 13,00 & 8,00 & 8,00 & 11,00 & 21,00 \\
\hline $\mathbf{V}$ & 156,00 & 101,00 & 137,00 & 133,00 & 236,00 \\
\hline Co & 14,10 & 8,80 & 4,40 & 10,70 & 19,20 \\
\hline Ni & 2,80 & 4,20 & 2,80 & 3,30 & 8,30 \\
\hline $\mathrm{Cu}$ & 17,10 & 14,00 & 19,00 & 17,00 & 32,80 \\
\hline Zn & 90,00 & 80,00 & 10,00 & 105,00 & 57,00 \\
\hline $\mathbf{G a}$ & 16,80 & 16,60 & 16,90 & 15,20 & 16,60 \\
\hline As & 1,00 & 0,90 & 0,90 & $<0,5$ & 0,60 \\
\hline Se & $<0,5$ & $<0,5$ & $<0,5$ & $<0,5$ & $<0,5$ \\
\hline $\mathbf{R b}$ & 66,70 & 50,60 & 3,60 & 71,20 & 20,60 \\
\hline $\mathbf{S r}$ & 628,50 & 577,50 & 750,60 & 586,80 & 985,50 \\
\hline $\mathbf{Y}$ & 15,00 & 16,80 & 22,40 & 14,10 & 16,80 \\
\hline $\mathbf{Z r}$ & 83,20 & 149,50 & 151,10 & 105,60 & 80,60 \\
\hline Nb & 4,80 & 5,30 & 4,60 & 5,10 & 2,90 \\
\hline Mo & 0,80 & 1,10 & 1,00 & 0,50 & 0,50 \\
\hline Ag & $<0,1$ & $<0,1$ & $<0,1$ & $<0,1$ & $<0,1$ \\
\hline Cd & 0,20 & 0,30 & $<0,1$ & 0,20 & $<0,1$ \\
\hline Sn & $<1$ & $<1$ & 2,00 & $<1$ & $<1$ \\
\hline Sb & $<0,1$ & $<0,1$ & $<0,1$ & $<0,1$ & $<0,1$ \\
\hline Cs & 10,30 & 1,60 & 0,20 & 1,90 & 3,00 \\
\hline Ba & 708,00 & 960,00 & 220,00 & 912,00 & 376,00 \\
\hline $\mathbf{L a}$ & 19,60 & 24,90 & 33,40 & 22,90 & 17,10 \\
\hline $\mathrm{Ce}$ & 38,90 & 47,90 & 64,40 & 40,70 & 36,60 \\
\hline Pr & 4,44 & 5,31 & 7,47 & 4,65 & 4,53 \\
\hline Nd & 18,10 & 20,50 & 29,60 & 17,40 & 19,50 \\
\hline Sm & 3,46 & 4,07 & 5,46 & 3,14 & 3,96 \\
\hline Eu & 1,10 & 1,13 & 1,69 & 0,99 & 1,22 \\
\hline Gd & 3,08 & 3,25 & 4,70 & 2,87 & 3,58 \\
\hline Tb & 0,47 & 0,50 & 0,68 & 0,43 & 0,54 \\
\hline Dy & 2,69 & 2,78 & 4,06 & 2,39 & 2,98 \\
\hline Ho & 0,61 & 0,62 & 0,83 & 0,49 & 0,66 \\
\hline $\mathbf{E r}$ & 1,79 & 1,86 & 2,51 & 1,52 & 1,82 \\
\hline Tm & 0,26 & 0,26 & 0,38 & 0,23 & 0,27 \\
\hline Yb & 1,71 & 1,91 & 2,54 & 1,59 & 1,68 \\
\hline $\mathbf{L u}$ & 0,26 & 0,32 & 0,43 & 0,29 & 0,26 \\
\hline Hf & 2,50 & 3,80 & 3,90 & 3,00 & 2,30 \\
\hline Ta & 0,40 & 0,40 & 0,30 & 0,30 & 0,10 \\
\hline $\mathbf{W}$ & 2,30 & 6,90 & 3,90 & 3,30 & 0,70 \\
\hline $\mathbf{A u}$ & 0,90 & $<0,5$ & 3,60 & 1,10 & 1,20 \\
\hline Hg & $<0,01$ & $<0,01$ & $<0,01$ & $<0,01$ & $<0,01$ \\
\hline TI & $<0,1$ & $<0,1$ & $<0,1$ & $<0,1$ & $<0,1$ \\
\hline $\mathbf{P b}$ & 13,80 & 33,90 & 2,90 & 3,50 & 2,10 \\
\hline $\mathbf{B i}$ & $<0,1$ & $<0,1$ & $<0,1$ & $<0,1$ & $<0,1$ \\
\hline Th & 5,20 & 7,30 & 7,60 & 8,20 & 3,60 \\
\hline $\mathbf{U}$ & 1,20 & 1,40 & 2,80 & 1,40 & 0,80 \\
\hline इETR & 96,47 & 115,31 & 158,15 & 99,59 & 94,70 \\
\hline$(\mathrm{La} / \mathrm{Sm})_{\mathrm{N}}$ & 3,54 & 3,82 & 3,82 & 4,55 & 2,70 \\
\hline$(\mathrm{La} / \mathrm{Yb})_{\mathrm{N}}$ & 7,79 & 8,86 & 8,93 & 9,78 & 6,91 \\
\hline$(\mathrm{Tb} / \mathbf{Y b})_{\mathrm{N}}$ & 1,23 & 1,17 & 1,19 & 1,21 & 1,43 \\
\hline$(\mathrm{La} / \mathrm{Lu})_{\mathrm{N}}$ & 7,82 & 8,08 & 8,06 & 8,20 & 6,83 \\
\hline $\mathbf{E u} / \mathbf{E u}{ }^{*}$ & 0,98 & 0,87 & 0,97 & 0,97 & 0,95 \\
\hline
\end{tabular}

Cuadro 4.2 (continuación): Elementos traza y tierras raras de las rocas ígneas de los principales cuerpos magmáticos de la región de Colipilli. 
(a)

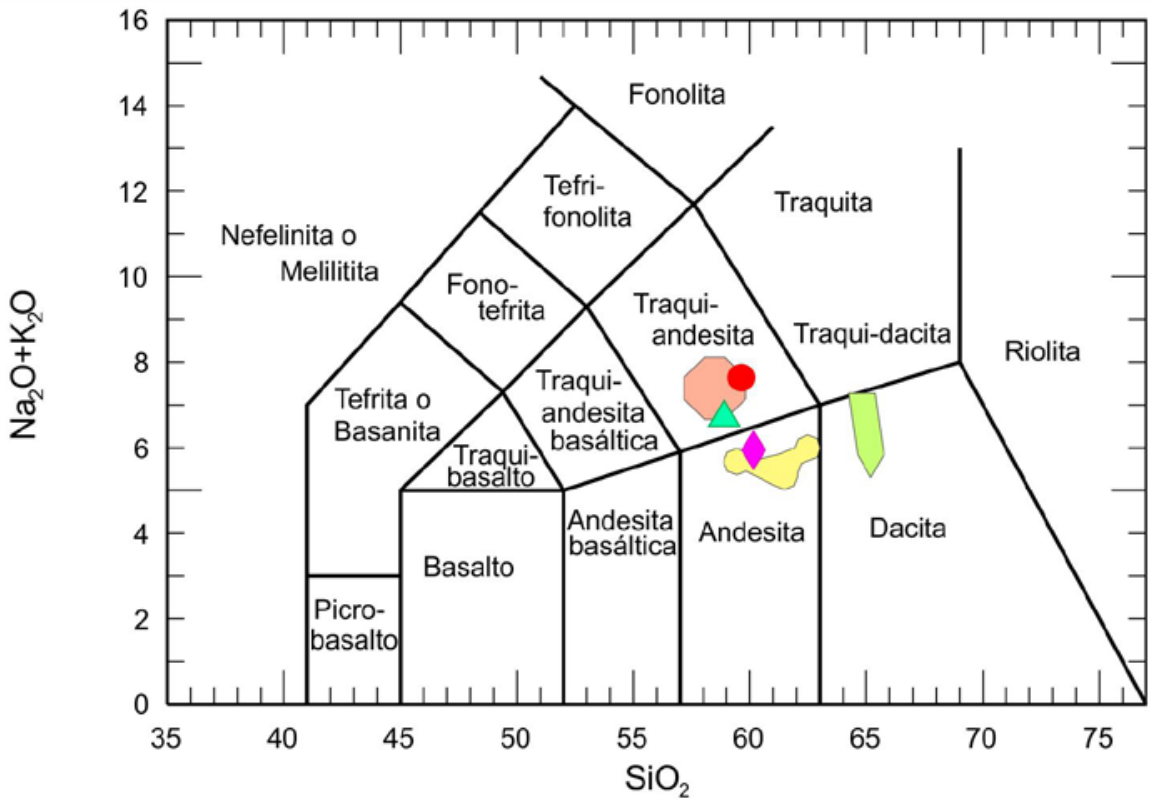

(b)

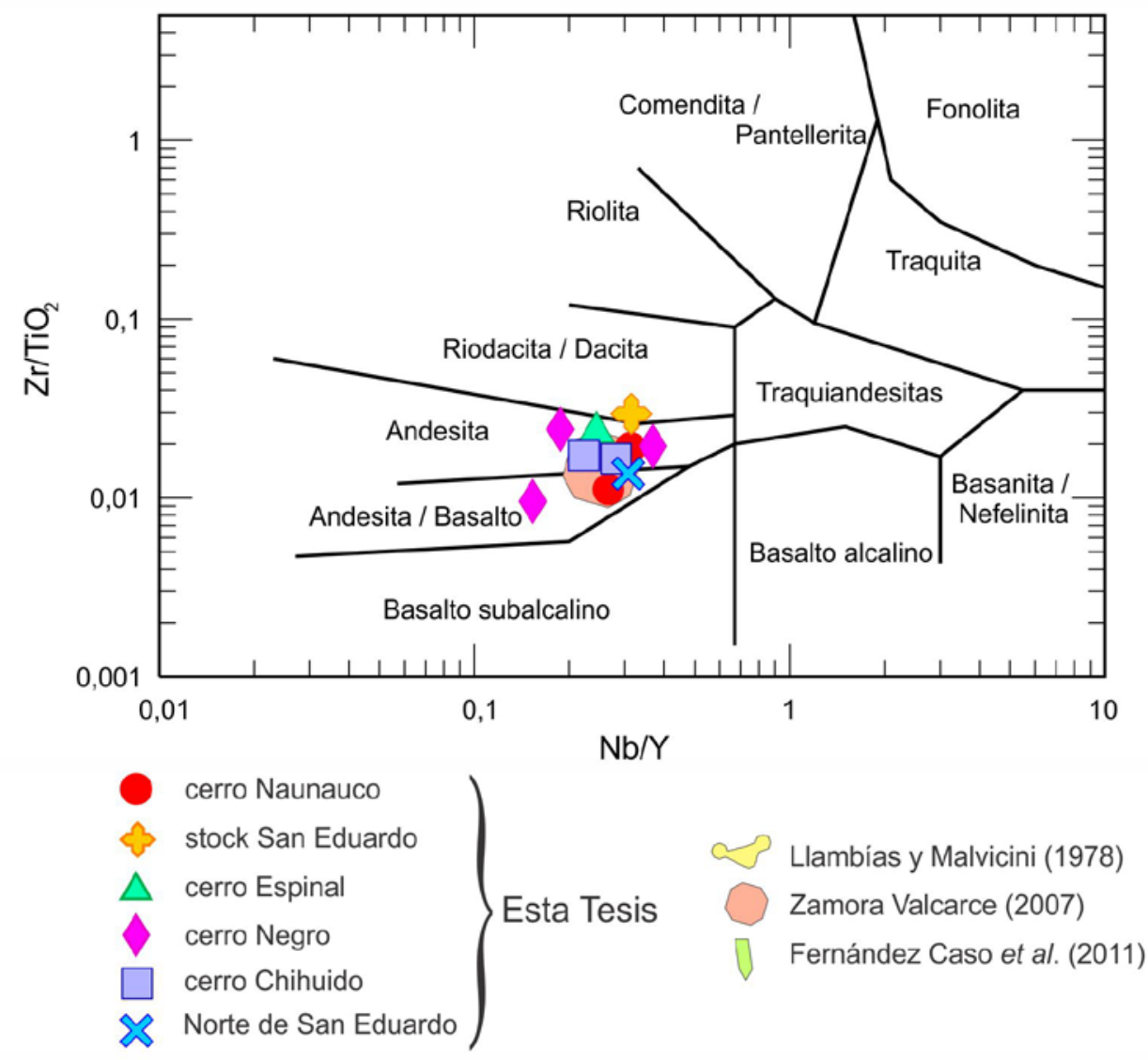

Figura 4.7: a- Diagrama TAS para clasificar a las rocas ígneas (Le Maitre 1989); b- Diagrama de Winchester y Floyd (1977). 
(a)

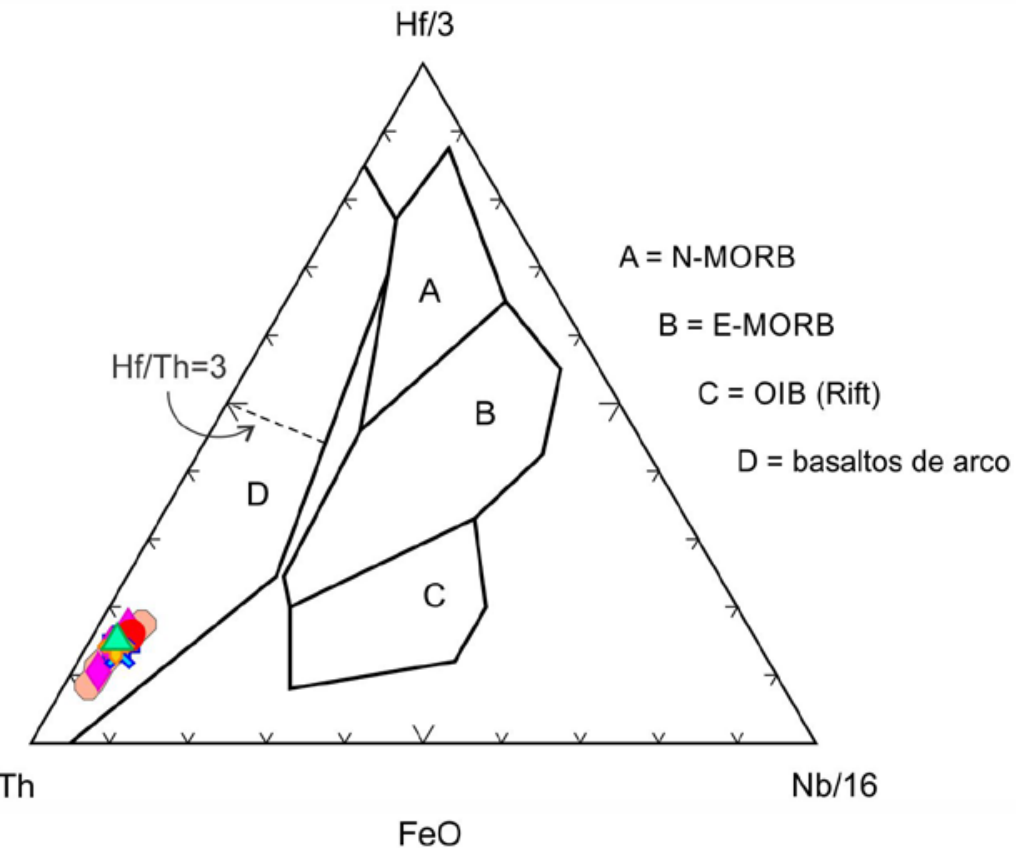

(b)
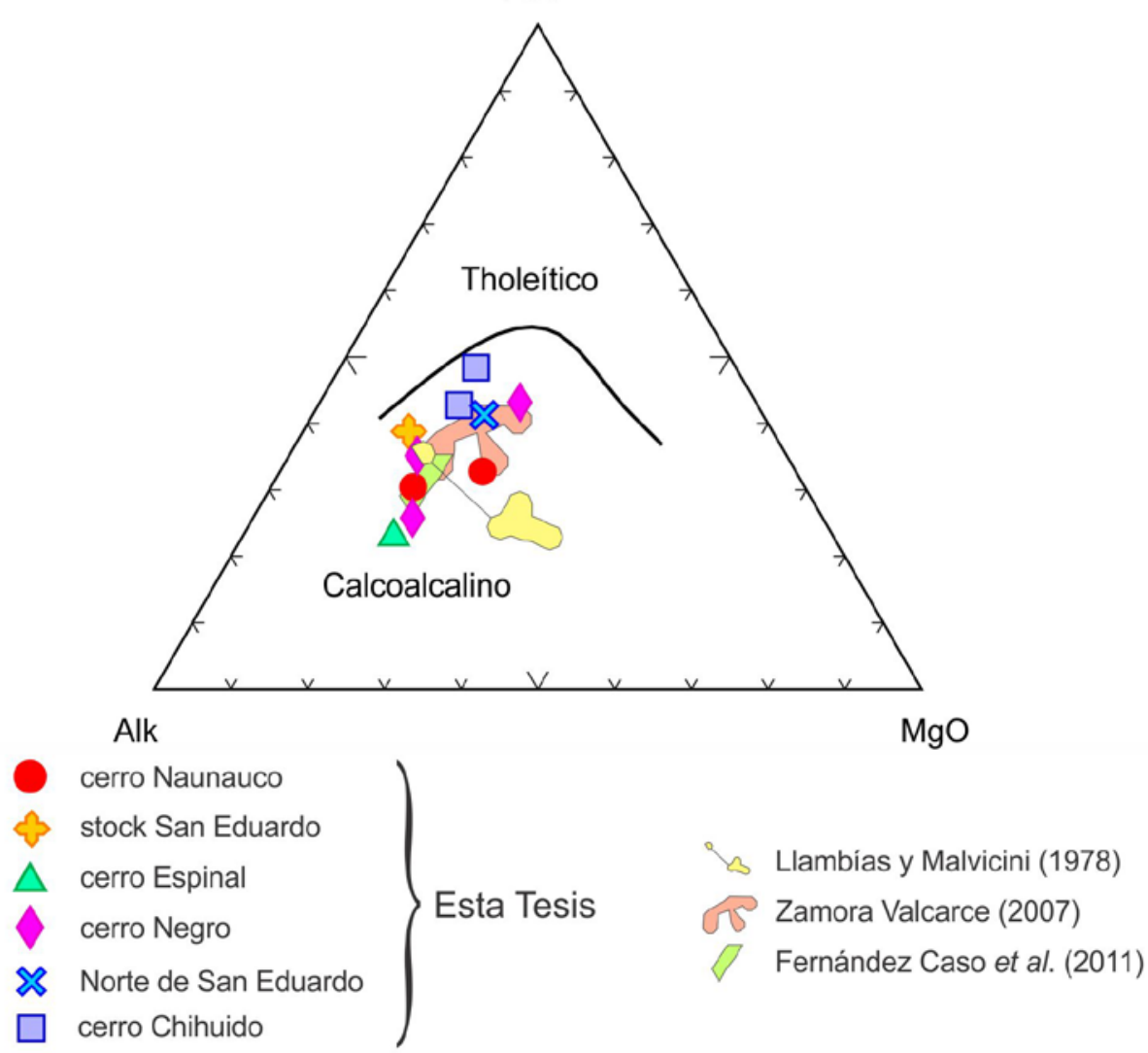

$\mathrm{gO}$

Figura 4.8: a- Diagrama de Wood (1980) como discriminador tectónico; b- Diagrama AFM de Irvine y Baragar (1971). 
Los diagramas Harker de variación de elementos mayoritarios (Fig.4.9), muestran en general diseño lineales poco marcados, algunos de ellos con moderada a alta dispersión, probablemente debida a diversas reacciones subsólidas favorecidas por la elevada presión de vapor de agua de estos magmas (Llambías y Rapela 1989). El contenido de Mg y Fe disminuye a medida que el magma evoluciona a estadios más diferenciados en los que se enriquece en sílice. En lo que respecta al contenido de elementos de las tierras raras, al analizar el diagrama multielemental normalizado a condrito (McDonough y Sun 1995) se observa un patrón similar en todas las muestras (Fig.4.10a). Presenta una moderada pendiente negativa en las tierras raras livianas y una sub-horizontalidad en las pesadas, coincidiendo con lo esperado para rocas calcoalcalinas de arco (Pearce 1982). Por otro lado, se distingue una anomalía positiva en Eu (Fig.4.10a). En los fundidos básicos e intermedios, el mineral formador de roca por excelencia en cuya estructura suele ingresar el Eu es la plagioclasa (en reemplazo del Ca, pero siempre en cantidades traza), es decir, se comporta como elemento compatible en dichos fundidos. El coeficiente de partición del Eu respecto de las plagioclasas en fundidos es 1,214 , lo cual concuerda con el hecho de que se comporte como compatible en este mineral.

En el diagrama multielemental normalizado a manto primitivo (Sun y McDonough 1989) (Fig.4.10b), se observa una manifiesta depresión en Ta, Nb y Ti. El hecho que estos elementos se encuentren deprimidos (anomalías negativas) estaría relacionado con que tienden a quedar en la fuente, es decir, no pasan al fundido (coeficientes de partición menores que 1).

La anomalía negativa de $\mathrm{Rb}$ estaría indicando depresión de este elemento incompatible en la fuente y/o su no incorporación posterior. Los coeficientes de partición del $\mathrm{Rb}$ en rocas andesíticas son muy bajos.

Por otra parte, también se observan anomalías positivas de Cs y Pb (Fig.4.10b). Las anomalías positivas suelen deberse a la presencia de algún mineral que está concentrando a ciertos elementos trazas, en el caso del Pb sería biotita y/o plagioclasas (Rollinson 1993). Con respecto al Cs, éste se comporta fuertemente compatible con la red cristalina de la hornblenda (Matsui et al., 1977). 

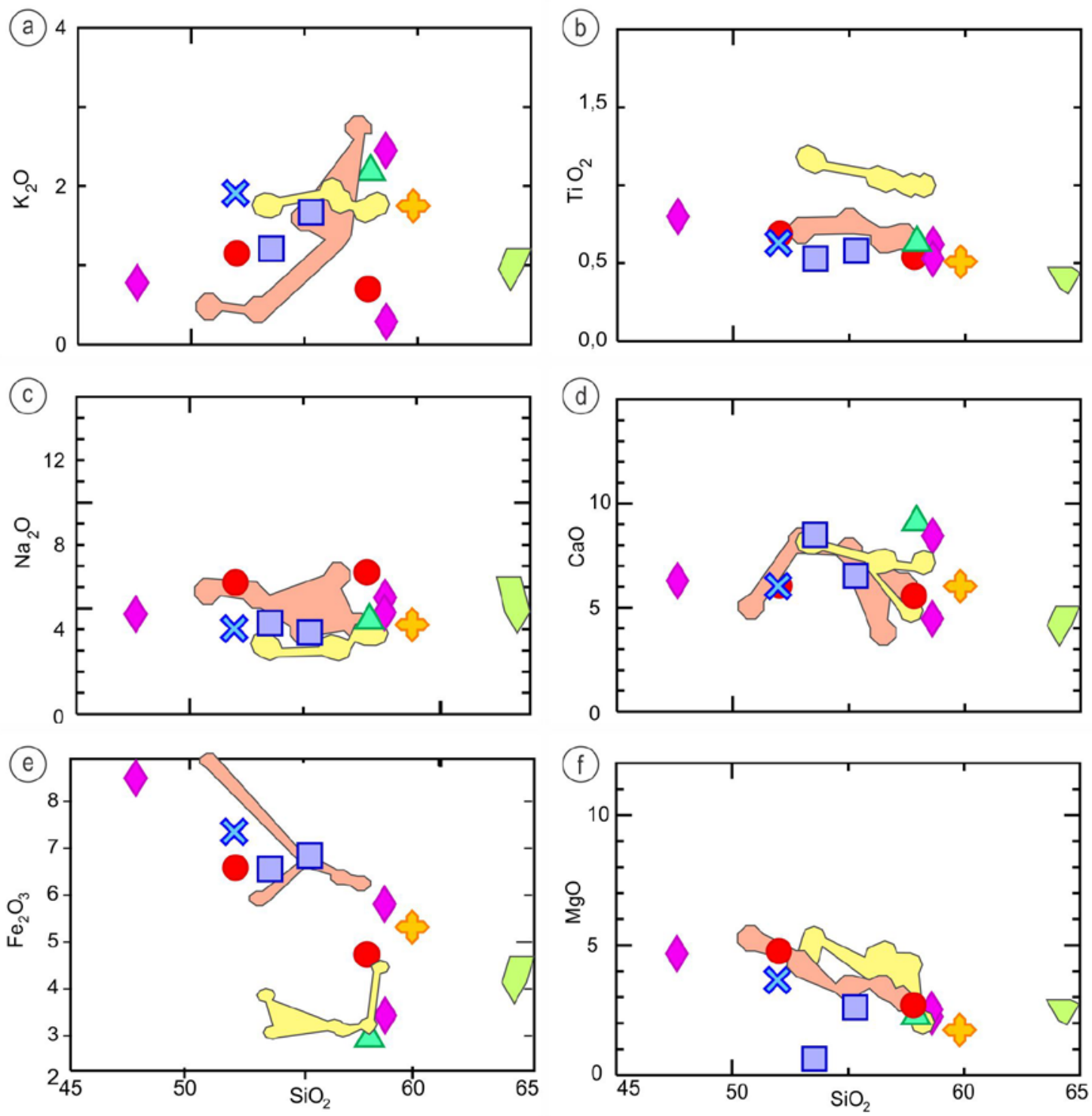

Figura 4.9: Diagramas Harker. Se graficaron las muestras seleccionadas de este trabajo junto con valores de Llambías y Malvicini (1978) y áreas vecinas según Zamora Valcarce (2007) y Fernández Caso et al. (2011). Los símbolos son los mismos de la Figura 4.7. 
(a)

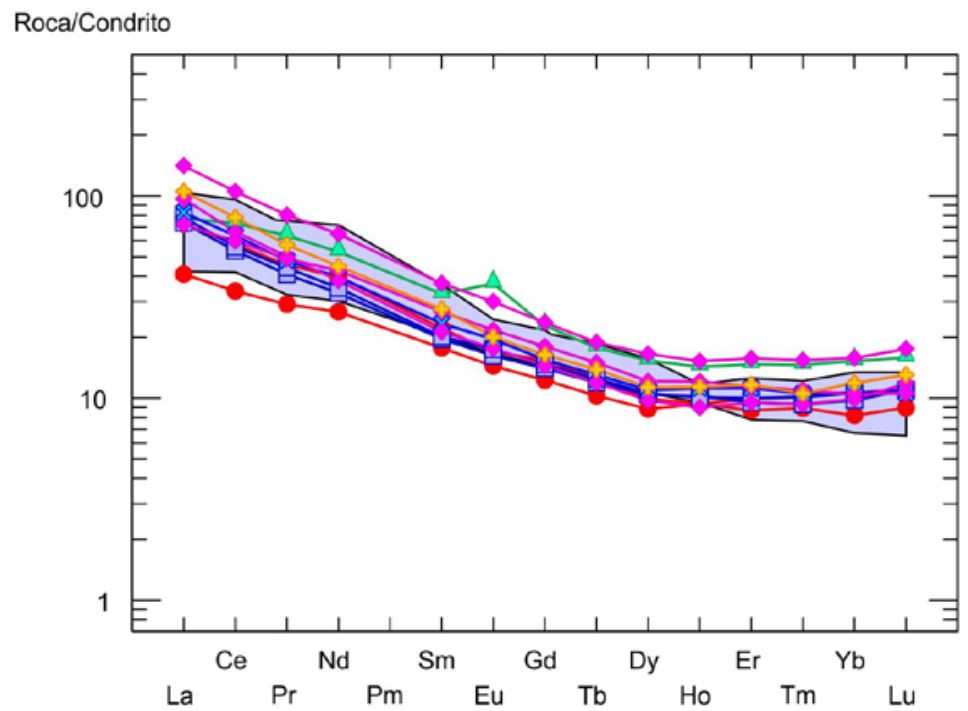

(b)

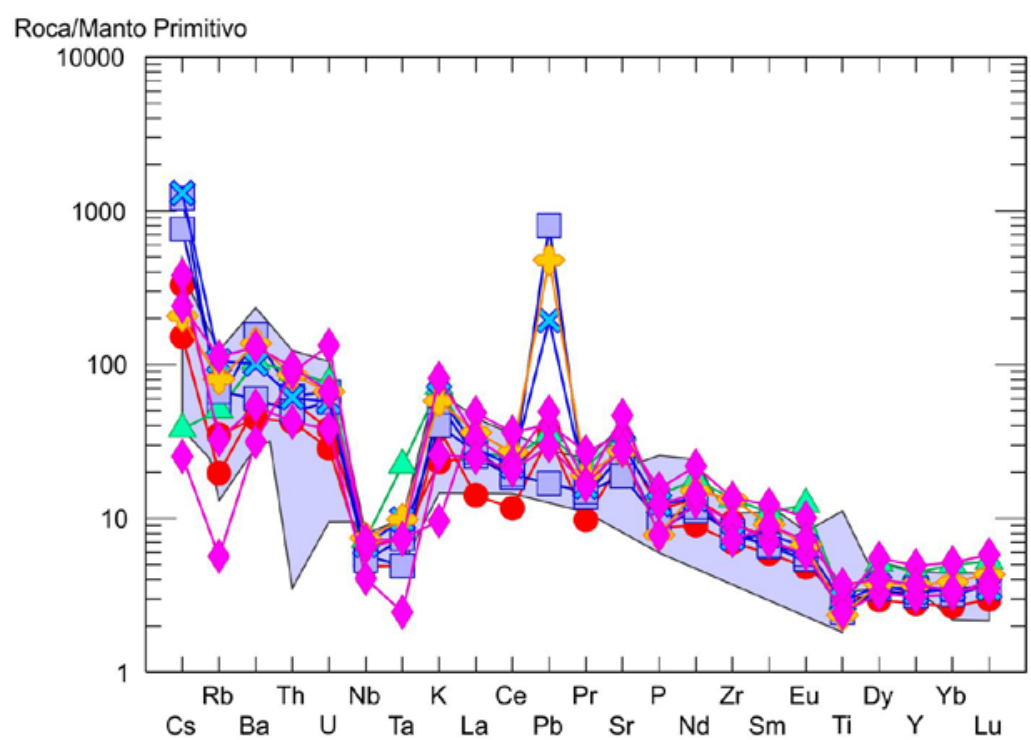

Figura 4.10: a- Diagrama multielementos de tierras raras normalizado a condrito (McDonought y Sun 1995). Los símbolos son los mismos de la Figura 4.6. El campo celeste representa las muestras analizadas por Zamora Valcarce (2007); b- Diagrama multielementos de tierras raras normalizado a manto primitivo (Sun y McDonought 1989). Los símbolos son los mismos de la Figura 4.7. El campo celeste corresponde a las muestras analizadas por Llambías y Malvicini (1978), Zamora Valcarce (2007) y Fernández Caso et al. (2011). 


\section{Discusión y Conclusiones parciales}

La profundidad de emplazamiento de los cuerpos ígneos pudo ser estimada mediante métodos indirectos basados en el análisis de las texturas, estructuras, morfologías de cuerpos ígneos, relaciones con la roca de caja y tipos de contactos. Si bien las texturas son variables entre porfírica, predominantemente, y granuda, se observa que estas últimas fueron formadas en los sectores centrales de los cuerpos ígneos, mientras que las porfíricas corresponden a zonas intermedias entre centro y borde. Las texturas porfíricas y la rigidez de la roca de caja, reflejan alto contraste térmico; las primeras indican dos tasas de enfriamiento diferentes y la segunda, se puede inferir por la relación y morfología de los contactos (netos y rectos). La formación de fracturas en el entorno del intrusivo junto a la presencia de bloques de roca de caja con contornos angulosos inmersos en el cuerpo ígneo, indican fracturación frágil. Todos estos atributos sugieren un nivel de emplazamiento somero con aureolas de contacto de muy escaso desarrollo, que no llegaron a la generación de facies tipo hornfels. Solamente se reconocieron cambios en la coloración de la roca de caja, en general de tonos rojizos, por oxidación de los minerales ferrosos.

En las rocas dacíticas, los fenocristales de cuarzo, además de los de plagioclasa y anfíbol, exhiben evidencias de desequilibrio en el magma a través de la presencia de corrosión de caras, vértices y aristas. Estas características indican que existieron procesos de reacción que tendieron a reestablecer el equilibrio de minerales bajo nuevas condiciones físico-químicas, que podrían responder a la circulación de una fase acuosa generada durante procesos tardío-magmáticos.

La interpretación de los resultados geoquímicos obtenidos de las rocas de la Formación Colipilli indica que son cogenéticas y corresponden a magmas calcoalcalinos que han evolucionado en un ambiente de arco volcánico continental. La posición del mencionado arco en la región queda delineada por estas rocas, formadas durante los eventos tectónicos asignados al lapso Cretácico Tardío-Paleoceno (Zamora Valcarce et al., 2006).

El patrón subhorizontal en las tierras raras pesadas del diagrama multielemental normalizado a condrito, al igual que el presentado por Mateo Fernández Caso et al. (2011) para las rocas andesíticas del anticlinal de Chorriaca, indicaría que provienen de una corteza continental poco engrosada. 
Las anomalías positivas de Eu suelen estar asociadas a texturas cumulares (López y Bellos 2006) tales como las identificadas en los cuerpos ígneos de composición andesítica. Las texturas glomeroporfíricas observadas al microscopio manifiestan que las plagioclasas no fueron fraccionadas, es decir que permanecieron en contacto con el fundido intentando equilibrarse con él.
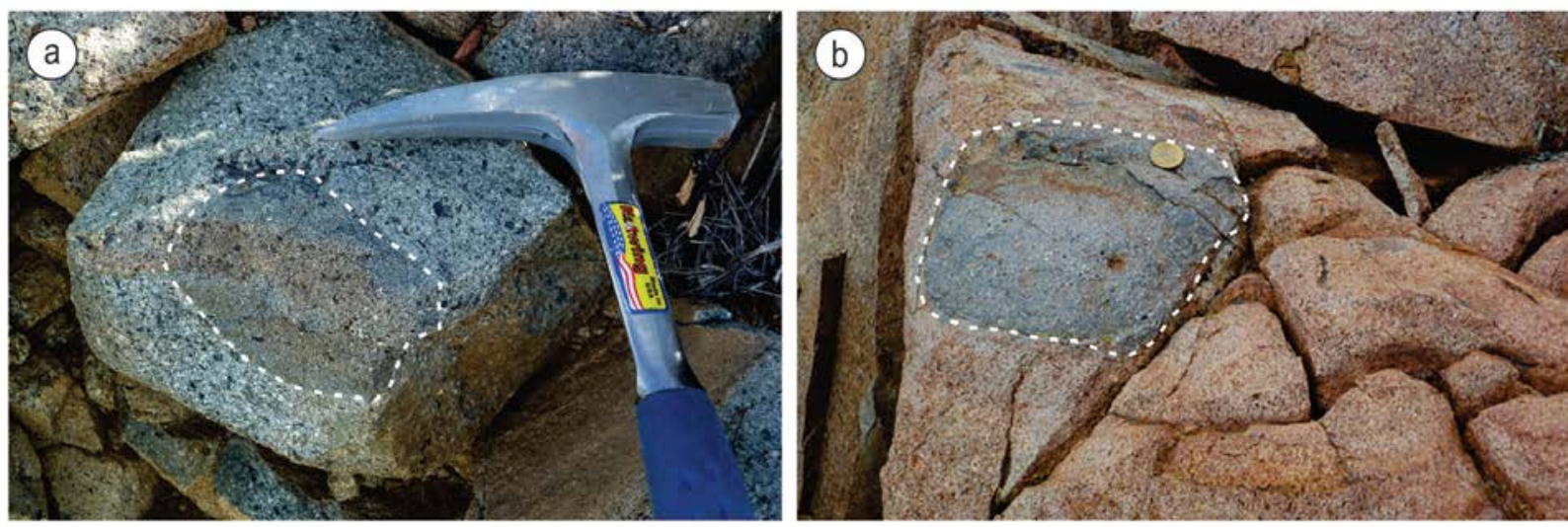

Figura 4.11: Cumulatos de anfíboles en: a- cerro Chihuido; b- cerro Espinal.

La variada concentración de fenocristales de hornblenda, incluso la formación de cumulatos de este mineral (Fig.4.11), es la evidencia más clara sobre el origen del magma en el área de estudio. Según Boettcher (1973) hay 5 teorías que explican la génesis de las andesitas en secuencias calcoalcalinas: 1) contaminación de magmas básicos con material de la corteza; 2) anatexis de la corteza; 3) cristalización fraccionada de magmas basálticos; 4) fusión y posterior diferenciación de peridotitas húmedas de la parte superior del manto; y 5) fusión de la litósfera en zona de subducción. En concordancia con las interpretaciones realizadas por Llambías y Malvicini (1978), las características texturales que manifiesta el anfíbol en el área de Colipilli apoya a la teoría que el proceso de cristalización fraccionada a partir de un magma básico fue el responsable de dar origen a los cuerpos ígneos de composición andesítica.

Los rasgos texturales y estructurales observados en la Formación Cayanta corresponden a facies volcánicas proximales, que según Leanza et al. (2006) posiblemente estén asociados a depósitos laháricos. Éstos últimos forman parte de la evolución de los estratovolcanes debido a sus empinadas pendientes (Llambías 2008), por lo tanto, podrían corresponder a uno o varios estratovolcanes profundamente erosionados. 


\section{Trabajos citados en el texto}

Boettcher, A.L. 1973. Volcanism and orogenic belts-The origin of andesite. Tectonophysics, 17: 223-240

Irvine, T. y Baragar, W. 1971. A guide to the chemical classification of the common volcanic rocks. Canadian Journal of Earth Sciences, 8: 523-548.

Le Maitre, R.W. 1989. A Classification of Igneous Rocks and Glossary of Terms. Blackwell, 193 p., Oxford.

Leanza, H.A., Repol, D., Hugo, C.H. y Sruoga, P. 2006. Hoja Geológica 3769-31, Chorriaca, Provincia del Neuquén. Instituto de Geología y Recursos Minerales. Servicio Geológico Minero Argentino, Boletín 354, 93 p. Buenos Aires.

Llambías, E.J. 2008. Geología de los cuerpos ígneos. Asociación Geológica Argentina - Serie B Didáctica y Complementaria $N^{\circ}$ 29. Instituto Superior de Correlación Geológica - Serie Correlación Geológica № 15. 221 p. Buenos Aires.

Llambías, E.J. y Malvicini, L. 1978. Geología, petrología y metalogénesis del área de Colipilli, provincia del Neuquén, República Argentina. Revista de la Asociación Geológica Argentina, 33: 257-276. Buenos Aires.

Llambías, E.J. y Rapela, C.W. 1987. Las vulcanitas de Colipilli y sus relaciones con las provincias volcánicas del Terciario inferior de Neuquén-Mendoza y Patagonia. $10^{\circ}$ Congreso Geológico Argentino, Actas 4: 249-251.

Llambías, E.J. y Rapela, C.W. 1989. Las volcanitas de Colipilli, Neuquén $\left(37^{\circ} \mathrm{S}\right)$ y su relación con otras unidades paleógenas de la cordillera. Revista de la Asociación Geológica Argentina, 44: 224-236. Buenos Aires.

López, J.P. y Bellos, L.I. 2006. Texturas y estructuras de las rocas ígneas: Significado petrológico e implicancias en las condiciones de formación de las rocas. Instituto Superior de Correlación Geológica -Serie Correlación Geológica $N^{\circ}$ 15. Consejo Nacional de Investigaciones Científicas y Técnicas de Ciencias Naturales e Instituto Miguel Lillo, Universidad Nacional de Tucumán. 60 p. San Miguel de Tucumán.

Mateo Fernández Caso, M.P., Montero, D.G., Leal, P. y Ramos, V.A. 2011. Petrografía y Geoquímica del magmatismo cretácico superior-eoceno en el área de Pichaihue, provincia de Neuquén. Revista de la Asociación Geológica Argentina, 68: 173-184, Buenos Aires.

Matsui, Y., Onuma, N., Nagasawa, H., Higuchi, H. y Banno, S. 1977. Crystal structure control in trace element partition between crystal and magma. Tectonics, 100: 315-324.

McDonough, W.F. y Sun, S.S. 1995. Composition of the Earth. Chemical Geology, 120: 223-253, Amsterdam.

Pearce, J.A. 1982. Trace element characteristics of lavas from destructive plate boundaries. En Thorpe R.S. (Ed.), Andesites: 525-548, Chichester. 
Rapela, C.W. y Llambías, E.J. 1985. La secuencia andesítica terciaria de Andacollo, Neuquén, Argentina. $4^{\circ}$ Congreso Geológico Chileno, Actas 4: 458-488. Antofagasta.

Rollinson, H.R. 1993. Using Geochemical Data: Evaluation, Presentation, Interpretation. 334 p. England.

Sun, S.S. y McDonough, W.F. 1989. Chemical and isotopic systematics of oceanic basalts: implications for mantle composition and processes. En Saunders A.D. y Norry M.J. (Eds.), Magmatism in ocean basins, Geological Society of London, Special Publication 42: 313345 , Boston.

Winchester, J.A. y Floyd, P.A. 1977. Geochemical discrimination of different magma series and their differentiation products using immobile elements. Chemical Geology, 20: 325-343, Amsterdam.

Wood, D.A. 1980. The application of a Th-Hf-Ta diagram to problems of tectono magmatic classification and to establishing the nature of crystal contamination of basaltic lavas of the British Tertiary volcanic province. Earth and Planetary Science Letters, 50: 11-30.

Zamora Valcarce, G. 2007. Estructura y cinemática de la faja plegada del Agrio. Tesis doctoral Universidad Nacional de Buenos Aires (Inédita), 304 p. Buenos Aires.

Zamora Valcarce, G., Zapata, T., Del Pino, D. y Ansa, A. 2006. Structural evolution of the Agrio fold and thrust belt. En Kay, S.M. y Ramos, V.A. (Eds.), Evolution of an Andean margin: A tectonic and magmatic view from the Andes to the Neuquén Basin (35 $-39^{\circ} \mathrm{S}$ Lat.). Geological Society of America, Special Paper, 407: 125-145, USA. 


\title{
Capítulo 5
}

\author{
GEOLOGÍA DE LAS \\ MINERALIZACIONES \\ BARÍTICO-POLIMETÁLICAS
}




\section{Introducción}

La exploración petrolífera en la Cuenca Neuquina durante la década del 50 promovió la explotación de baritina en la provincia del Neuquén iniciándose también la búsqueda de algunas arcillas especiales del tipo bentonitas, que en grandes volúmenes, serían utilizadas en los barros de perforación (Danieli y Casé 2004). Fueron los años del descubrimiento y la puesta en producción de la mina Arroyo Nuevo de la firma Sapag Hnos. (importante depósito de baritina ubicado unos $40 \mathrm{~km}$ al NO de Chos Malal) en el paraje Cura Mallín. Con su explotación, que durante varios años se mantuvo a un régimen de 1800-2000 t mensuales, sumada a la de los yacimientos de Mallín Quemado (Tomás González y Minera Tea) y de Gret Hnos. en Colipilli, se incrementó sensiblemente la producción de baritina en el Neuquén, la que ocupó durante mucho tiempo el primer puesto en el país, con una participación de 70 a $80 \%$ de la producción nacional (Angelelli et al., 1976).

Las mineralizaciones barítico-polimetálicas asociadas a la secuencia cretácica inferior del área de Colipilli involucran elementos metalotécticos que han sido determinantes para la formación de los depósitos. Por un lado presentan un fuerte control litoestratigráfico, vinculado a facies carbonáticas y, en menor medida, a silicoclásticas, y por otro, un control estructural producto de los distintos eventos de deformación que sufrió la secuencia sedimentaria mesozoica.

El área de estudio se dividió en distintos sectores para ser descripta con detalle (Fig.5.1). Estos depósitos baríticos presentan además concentraciones metalíferas bajo la forma de óxidos (magnetita, hematita), sulfuros (galena, esfalerita, calcopirita y pirita) y sulfosales (tetraedrita).

En este capítulo se describe la geología local, la mineralización, la petrografía y se hace un análisis geoquímico de cada sector investigado, poniendo énfasis en las unidades sedimentarias y magmáticas en las cuales se emplazan dichas mineralizaciones.

\section{Estratigrafia Local}

Las unidades estratigráficas más antiguas aflorantes en el sector de estudio (Fig.5.1 y Fig.5.3) corresponden al Grupo Mendoza (Formaciones Vaca Muerta, Mulichinco y Agrio). Los afloramientos de las pelitas oscuras de la Formación Vaca Muerta son escasos, concentrándose en los núcleos de los anticlinales que han sido erosionados, como por ejemplo en la sierra de Chorriaca y en los cerros de los Bueyes y El Diablo. 


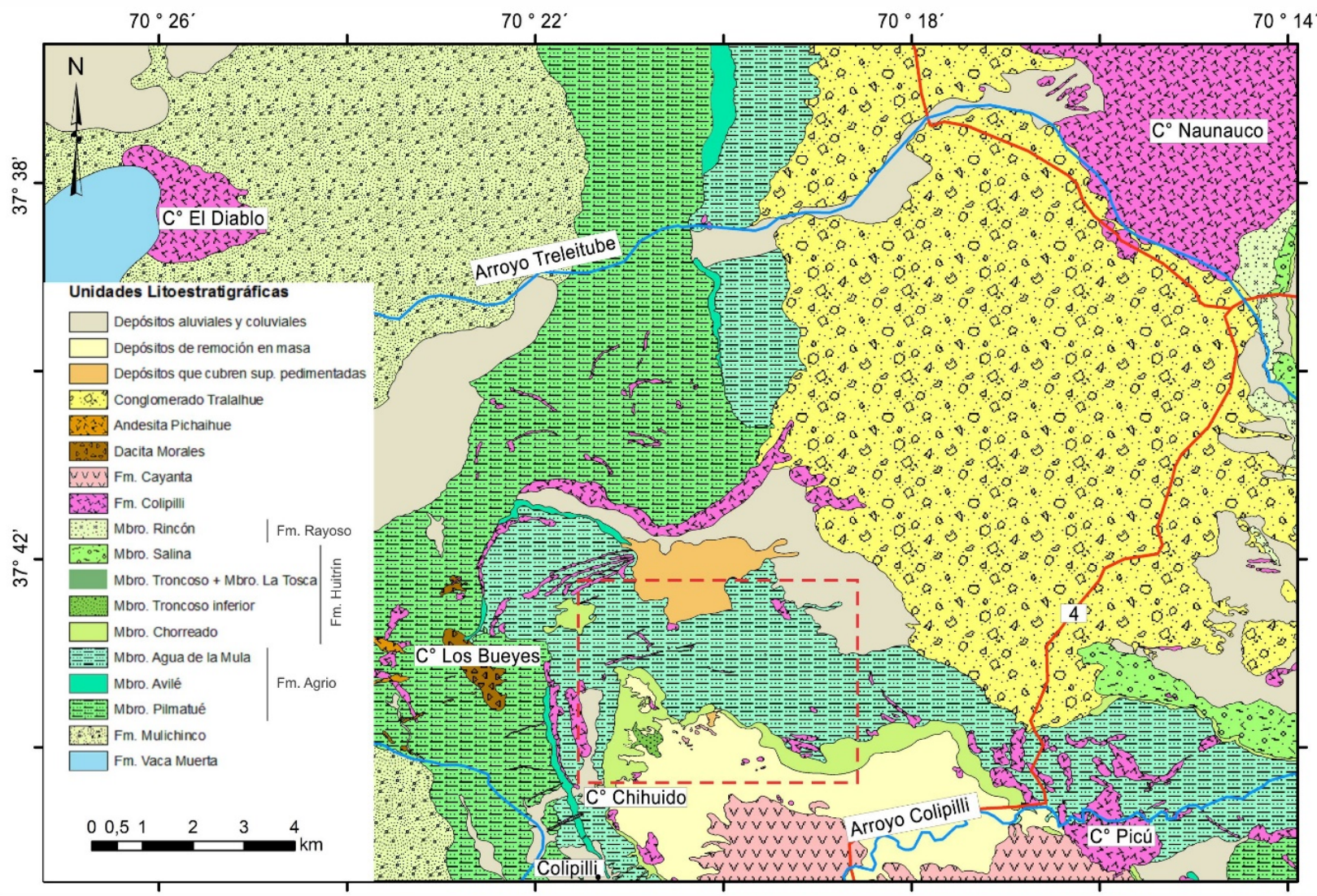

Figura 5.1: Mapa geológico del área de estudio y sectores adyacentes. Rectángulo rojo incluye sectores: mina San Eduardo, mina La Bienvenida, minas La Bruja-Julio César, minas La Esperanza-Carlita y mina Augusta.

Las areniscas de la Formación Mulichinco son de coloraciones castaño claras (Fig.5.2a) y poseen mayor potencial para preservarse y resistir a la erosión debido a la dureza de las rocas que la constituyen, también afloran en el núcleo del anticlinal de la sierra de Chorriaca, Loma del Naunauco y en el cerro Negro (Leanza et al., 2006). Por encima continúa la Formación Agrio (Fig.5.2b), que está integrada por los Miembros Pilmatué, Avilé y Agua de la Mula y se encuentra bien representada en la zona de tesis. El primero se caracteriza por la presencia dominante de pelitas, pelitas calcáreas y calizas de tonalidades gris verdosas a gris oscuras. El Miembro Avilé está constituido por areniscas bien seleccionadas de grano medio y color gris a castaño claro (Fig.5.2c). Se aprecian estructuras de estratificación cruzada planar y en artesa. Posee buenos afloramientos que rodean la estructura sinclinal de Pichaihue y la laguna El Gualpe y continúa hacia el norte en dirección al arroyo Taquimilán. Los niveles pelíticos, de coloración gris oscura intercalados con calizas micríticas castañas, son característicos del Miembro Agua de la Mula. Esta unidad se encuentra aflorando en las cercanías de la laguna El Gualpe y en el cerro Negro; es allí donde se emplazan mineralizaciones de yacencia discordante. Cabe mencionar que la Formación Agrio aflora ampliamente en los flancos de los anticlinales de Chorriaca y Loma de Naunauco. 

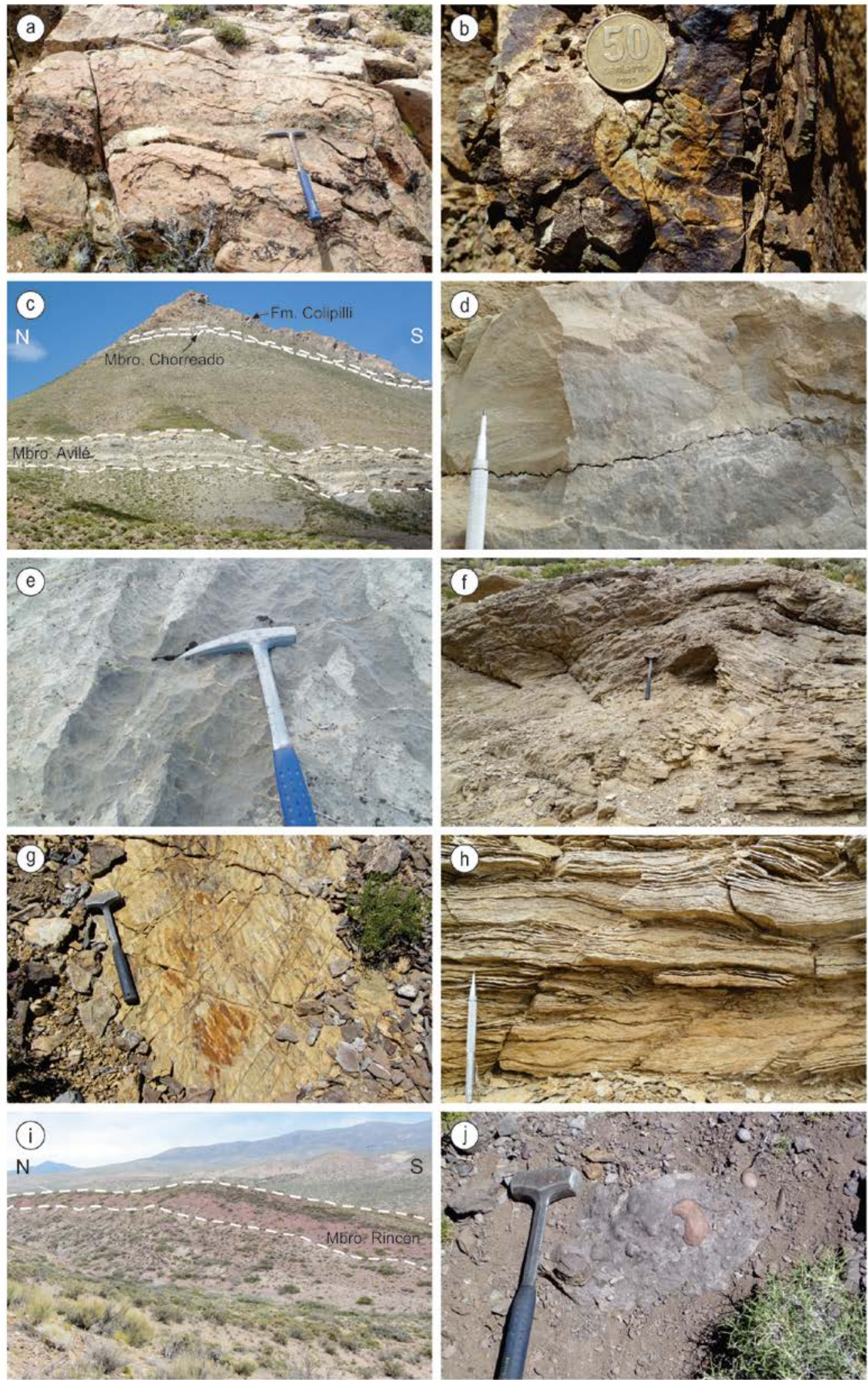

Figura 5.2: Fotos de unidades litoestratigráficas aflorantes en el área de estudio. a- areniscas de la Formación Mulichinco en Mallín Largo; b- Trigonia en pelitas de la Formación Agrio en cerro Negro; c- Perfil sedimentario en las cercanías de la localidad de Colipilli; d- e- y f- detalle de estilolita, canales de disolución y deformación en el Miembro Chorreado en el sector mina San Eduardo; g- areniscas finas con ondulitas en Miembro Troncoso Inferior en los alrededores de la mina San Eduardo; h- laminación microbial de las calizas del Miembro Troncoso Superior en labor sin denominación a $2 \mathrm{~km}$ al este de la mina San Eduardo; i- areniscas, fangolitas y limolitas rojizas del Miembro Rincón en ruta pcial. 4; j- conglomerado Tralalhué en las cercanías del cerro Chihuido. Diámetro de la moneda $25 \mathrm{~mm}$. 
Continúa la sucesión estratigráfica con las Formaciones que integran el Grupo Bajada del Agrio (Formaciones Huitrín y Rayoso). La Formación Huitrín reúne los Miembros Chorreado, Troncoso Inferior, Troncoso Superior, La Tosca y Salina. El primero está integrado principalmente por facies carbonáticas. La facies presente en el sector de estudio es de tipo grainstone oolítico y mudstone que según Gutiérrez Pleimling (1991) corresponde a un ambiente de rampa somera.
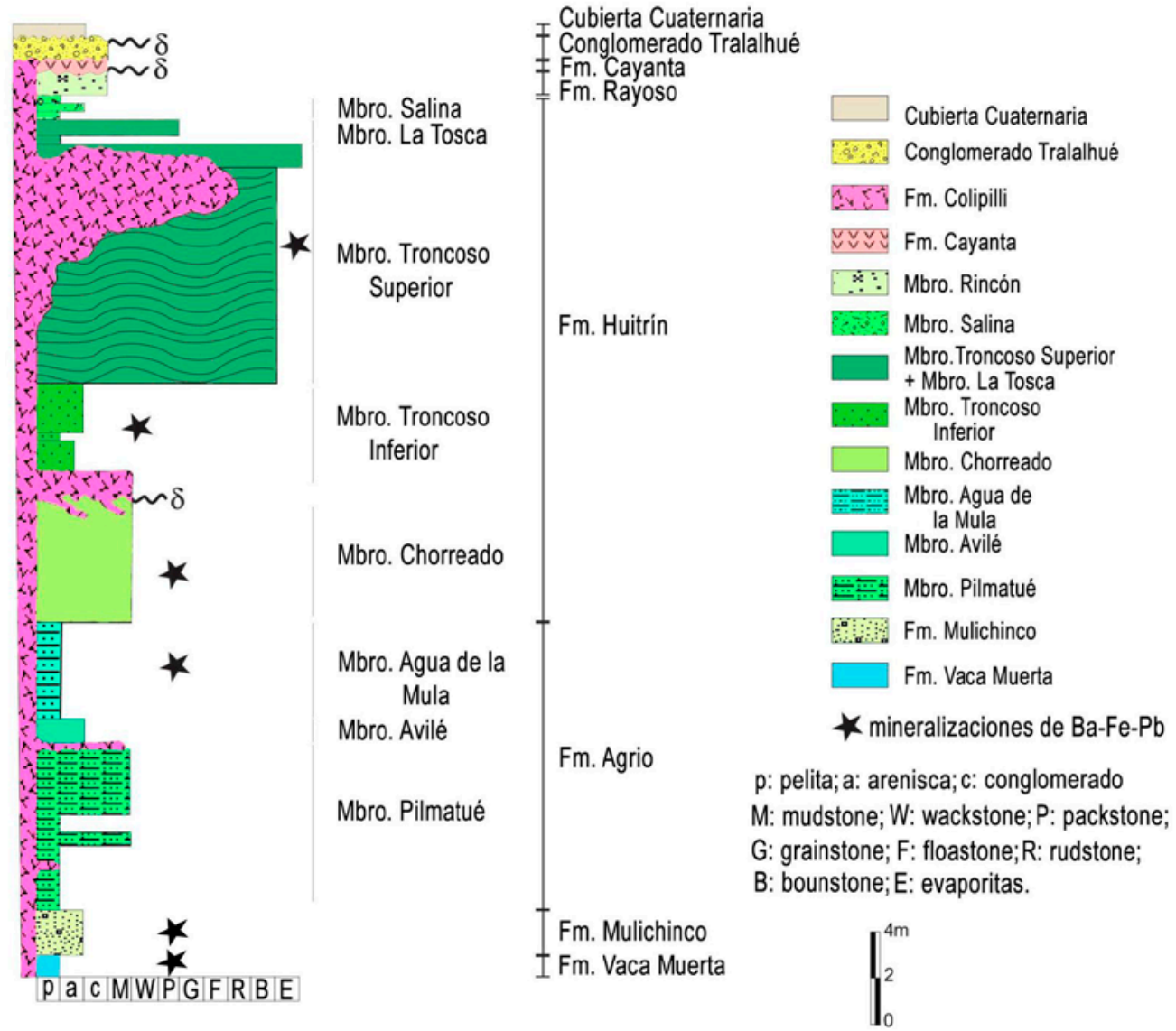

Figura 5.3: Columna estratigráfica del área de estudio.

Las estilolitas constituyen un rasgo diagenético frecuente en estas rocas (Fig.5.2d); por otra parte, en superficie de meteorización presenta numerosos canales de disolución (Fig.5.2e). Este Miembro aflora otorgándole al sector un relieve ondulante que refleja lo intensamente plegado que se encuentra (Fig.5.2f). La mineralización alojada en esta unidad se presenta principalmente de manera concordante. Mediando una superficie de discontinuidad y erosiva, está cubierto por las areniscas del Miembro Troncoso Inferior el cual está compuesto por areniscas de grano fino, porosas, de coloración ocre a blanquecina (Fig.5.2g), que muestran laminación fina y ondulitas. En esta unidad la mineralización se emplaza concordantemente a la estratificación. El Miembro Troncoso Superior, en el área de estudio, se presenta en facies carbonáticas de tipo boundstone con una conspicua 
laminación (Fig.5.2h). Tanto el Miembro La Tosca, compuesto por dolomías y calizas castaño claras de tipo wackestone y packstone con fuerte olor fétido, como el Miembro Salina, constituido por arcilitas varicolores, presentan escasos afloramientos en el área de estudio. La fuerte expresión morfológica de las areniscas rojizas con intercalaciones de fangolitas rojas es propia de la Formación Rayoso. Esta Formación está integrada por facies continentales tipo "red beds". El Miembro Rincón (que forma parte de esta Formación) se identifica cerca del puente del arroyo Treiletube (Fig.5.2i).

El magmatismo presente en el sector de estudio se expresa tanto en facies intrusivas como extrusivas; en estas rocas la mineralización es epigenética y se emplaza discordantemente. Por encima, se sucedieron depósitos sinorogénicos reunidos bajo la denominación de Conglomerado Tralalhué (Fig.5.2j), que junto con la cubierta cuaternaria, compuesta por depósitos aluviales y coluviales, completan la columna estratigráfica (Fig.5.3).

\section{Mineralizaciones barítico-polimetálicas}

Las mineralizaciones se muestran esencialmente de dos maneras: 1) mantos y vetas estratiformes (McKinstry 1955), encajados mayoritariamente en unidades correspondientes a la Formación Huitrín. La mineralogía predominante consiste en baritina, con textura cebrada y/o brechosa, y en menor proporción óxidos-hidróxidos de hierro con sulfuros de $\mathrm{Pb}, \mathrm{Cu}$ y $\mathrm{Zn}$ subordinados. Por otra parte, emplazados en horizontes calcáreos finos del Miembro Chorreado de la Formación Huitrín se presentan niveles mantiformes de magnetita. 2) Vetas discordantes que rellenan fracturas y zonas de brechamiento que se alojan en las sedimentitas de las Formaciones Vaca Muerta, Mulichinco, Agrio y Huitrín y en las diorito-andesitas de la Formación Colipilli. La paragénesis mineral está representada mayoritariamente por baritina espática, de grano grueso acompañada de óxidos-hidróxidos de hierro con proporciones minoritarias de galena. En el sector de mina San Eduardo la yacencia vetiforme se manifiesta en una estructura brechosa, de rumbo aproximado NESO, donde la paragénesis es marcadamente sulfurosa.

En la Figura 5.4 se muestra la secuencia paragenética integrada propuesta para las mineralizaciones del área de estudio.

Todos estos depósitos minerales han sido explotados por laboreos subterráneos a través de galerías y piques achiflonados y por rajos a cielo abierto, según la actitud del cuerpo mineralizado. En la actualidad están inactivos. 


\begin{tabular}{|c|c|c|c|}
\hline & \multirow{3}{*}{\begin{tabular}{|c|}
$1^{\circ}$ Evento \\
Mineralización Mantiforme
\end{tabular}} & \multirow{3}{*}{$\frac{2^{\circ} \text { Evento }}{\text { Mineralización Vetiforme }}$} & \multirow{3}{*}{$\begin{array}{c}3^{\circ} \text { Evento } \\
\text { Fluidos Finales }\end{array}$} \\
\hline & & & \\
\hline & & & \\
\hline \multicolumn{4}{|l|}{ Baritina microgranosa } \\
\hline \multicolumn{4}{|l|}{ Magnetita } \\
\hline Scheelita & - & & \\
\hline \multicolumn{4}{|l|}{ Baritina removilizada } \\
\hline \multicolumn{4}{|l|}{ Galena } \\
\hline \multicolumn{4}{|l|}{ Calcopirita } \\
\hline \multicolumn{4}{|l|}{ Pirita } \\
\hline Esfalerita & --- & - & \\
\hline Tetraedrita & & $\longrightarrow$ & \\
\hline \multicolumn{4}{|l|}{ Óxidos-Hidróxidos de Fe } \\
\hline Alteración supergénica & & & \\
\hline
\end{tabular}

Figura 5.4: Secuencia paragenética integrada propuesta para las mineralizaciones del área de estudio.

\section{A) Depósitos de baritina con sulfuros}

\section{Sector mina San Eduardo}

El acceso más importante y transitado (desde Chos Malal) es por la ruta nacional 40 hasta la ruta provincial 4 (ripio). El recorrido por esta última ruta es de aproximadamente $30 \mathrm{~km}$ hasta las cercanías de la localidad de Colipilli, desde donde se puede acceder directamente a la mina San Eduardo (37\% $45^{\prime}$ latitud sur, $70^{\circ} 17^{\prime}$ longitud oeste) a través de un camino vecinal (Fig.5.5). Desde allí, a pie y por medio de huellas mineras, se accede a la mina La Bienvenida $\left(37^{\circ} 42^{\prime}\right.$ latitud sur, $70^{\circ} 24^{\prime}$ longitud oeste) y a otras labores esencialmente de destape cercanas sin denominación (Fig.5.6).

En el área afloran rocas sedimentarias, principalmente de la Formación Huitrín y magmáticas tanto de naturaleza intrusiva como extrusiva, correspondientes a las Formaciones Colipilli y Cayanta, respectivamente. Las rocas ígneas de la Formación Colipilli se presentan caolinizadas, mientras que las rocas extrusivas se muestran bajo la forma de mantos o coladas intensamente brechadas y algo silicificadas. Estas últimas afloran en un área de aproximadamente unos $200 \mathrm{~m}^{2}$ al este de la labor principal. En cuanto a los cuerpos mineralizados, se alojan de manera concordante en las discontinuidades interestratales y en los contactos roca sedimentaria-roca ígnea; dichos contactos son netos y rectos. 


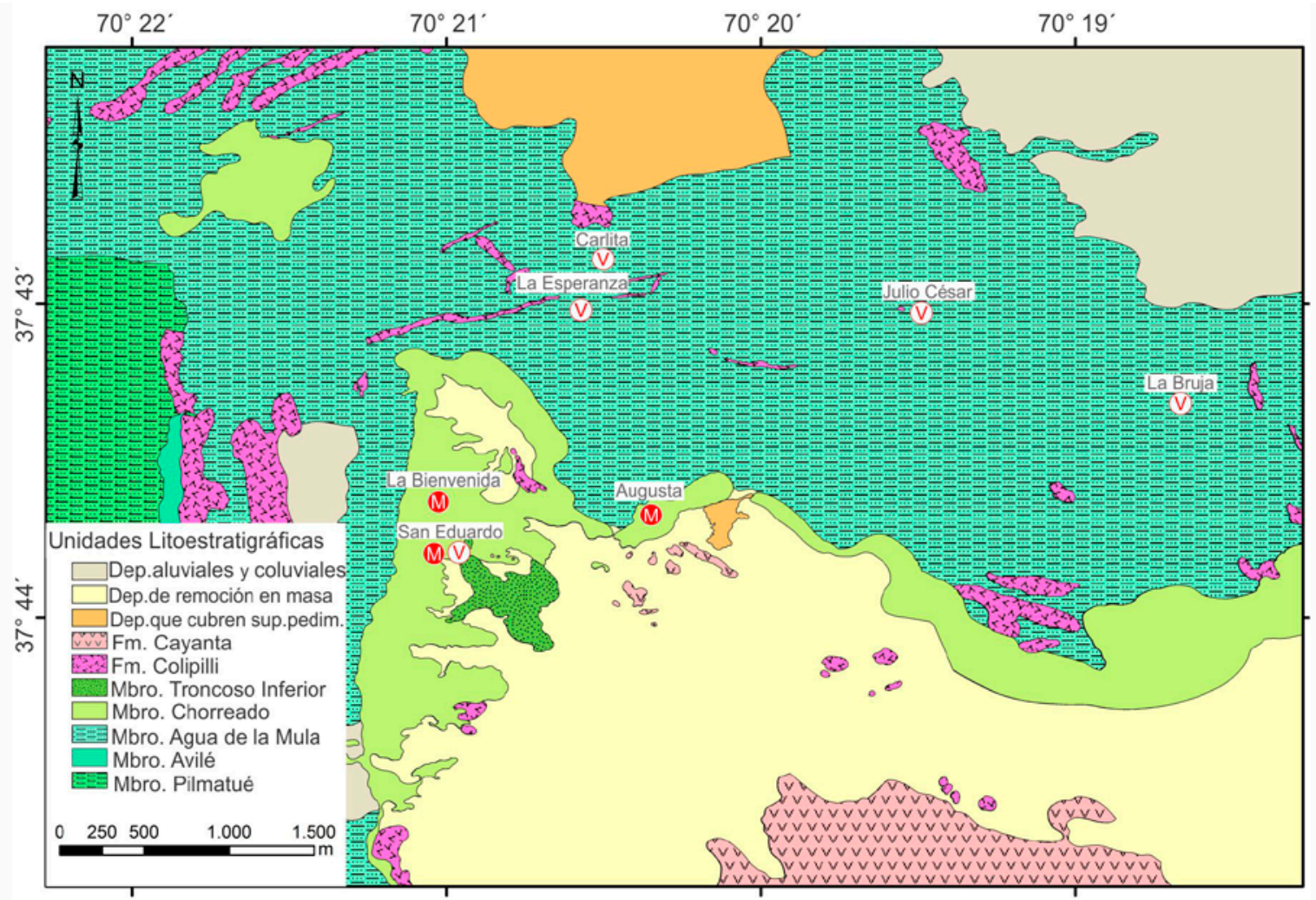

Figura 5.5: Mapa geológico de detalle del área de estudio, donde se ubican las principales minas, $\mathbb{M}$ yacencia mantiforme y Dyacencia vetiforme.

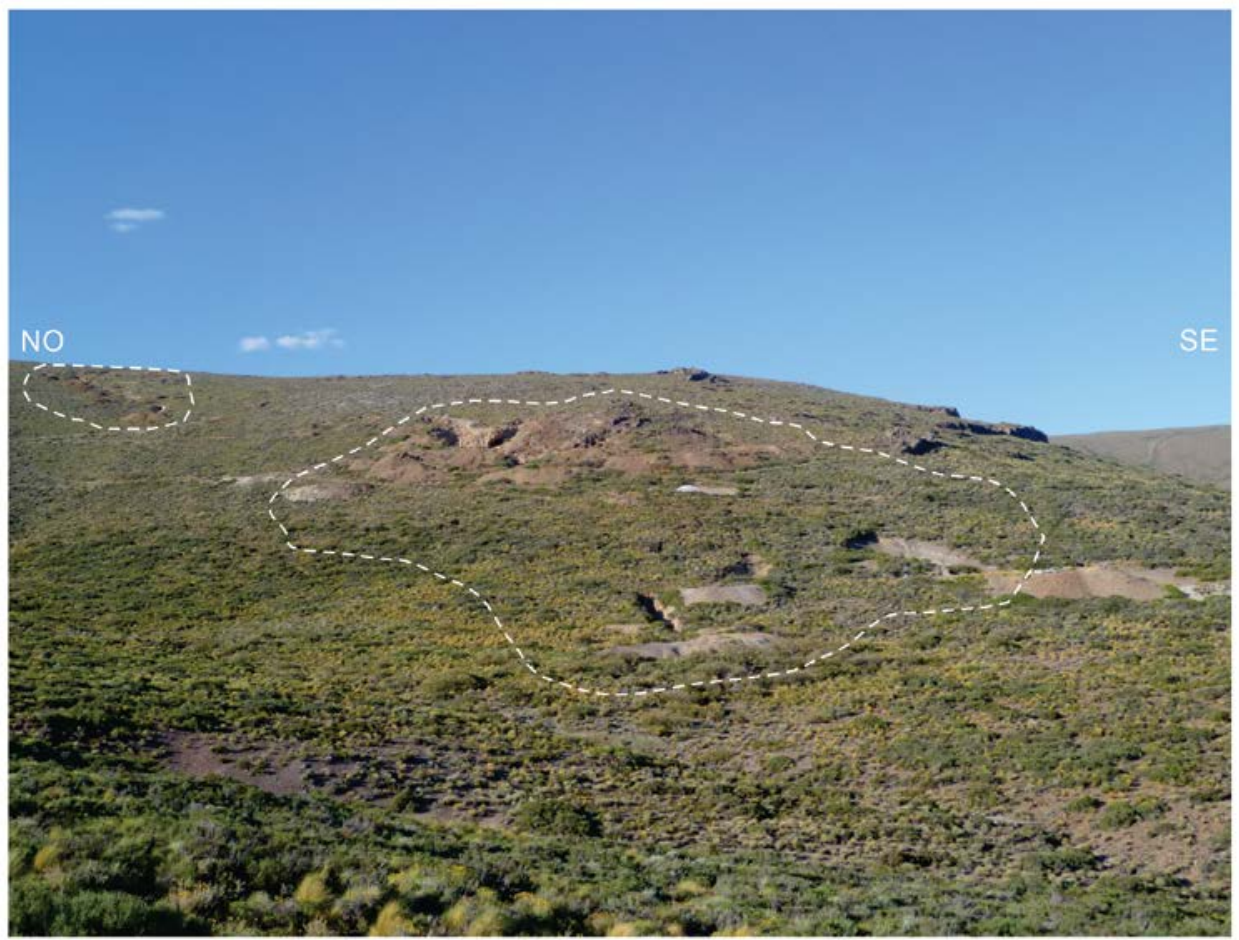

Figura 5.6: Vista panorámica de los sectores mina San Eduardo (circulo blanco en el centro) y mina La Bienvenida (circulo blanco a la izquierda). 
En la mina San Eduardo (Fig.5.7 a-b) los depósitos baríticos yacen bajo dos formas: mantiforme (estratiforme) y vetiforme. La primera posee un rumbo general NE-SO, inclinación variable entre $30^{\circ}$ y $55^{\circ} \mathrm{SE}$ y espesores de hasta $2 \mathrm{~m}$, aunque excepcionalmente puede alcanzar máximos de $6 \mathrm{~m}$ (Lyons et al. 1978). Dicha mineralización se emplaza en el contacto entre las calizas de los Miembro Chorreado y Troncoso Superior y las rocas magmáticas del Grupo Naunauco, esencialmente los niveles lávicos de la Formación Cayanta y algunos pequeños cuerpos subvolcánicos asignables a la Formación Colipilli. Éstas últimas, se tratan de filones capa de unos pocos metros de longitud, los cuales se muestran concordantes a la estratificación de las calizas e intensamente caolinizados aportándole a dichos afloramientos una coloración castaño clara. Su vinculación espacial a la yacencia vetiforme que se sobreimpone a la estratiforme en mina San Eduardo es muy evidente. Su rumbo es aproximadamente NE-SO, con una inclinación entre $75^{\circ}$ y $85^{\circ} \mathrm{SE}$, con espesores entre 2 y $3 \mathrm{~m}$ (Lyons et al. 1978). Esta mineralización se presenta en la actualidad inaccesible ya que las labores de acceso, socavón, cortaveta y piques, se encuentran aterrados. Sin embargo, en las escombreras de la labor principal a cielo abierto, se pudieron observar brechas con espejillo de falla, conformadas por fragmentos angulosos a sub-angulosos de hasta $3 \mathrm{~cm}$ de diámetro, constituidos por un $85 \%$ del total de baritina recristalizada de hábito tabular grueso, asociada a una paragénesis integrada por galena»〉 calcopirita> pirita> esfalerita> tetraedrita de fácil reconocimiento por su asociación con minerales de cobre color (malaquita y azurita).
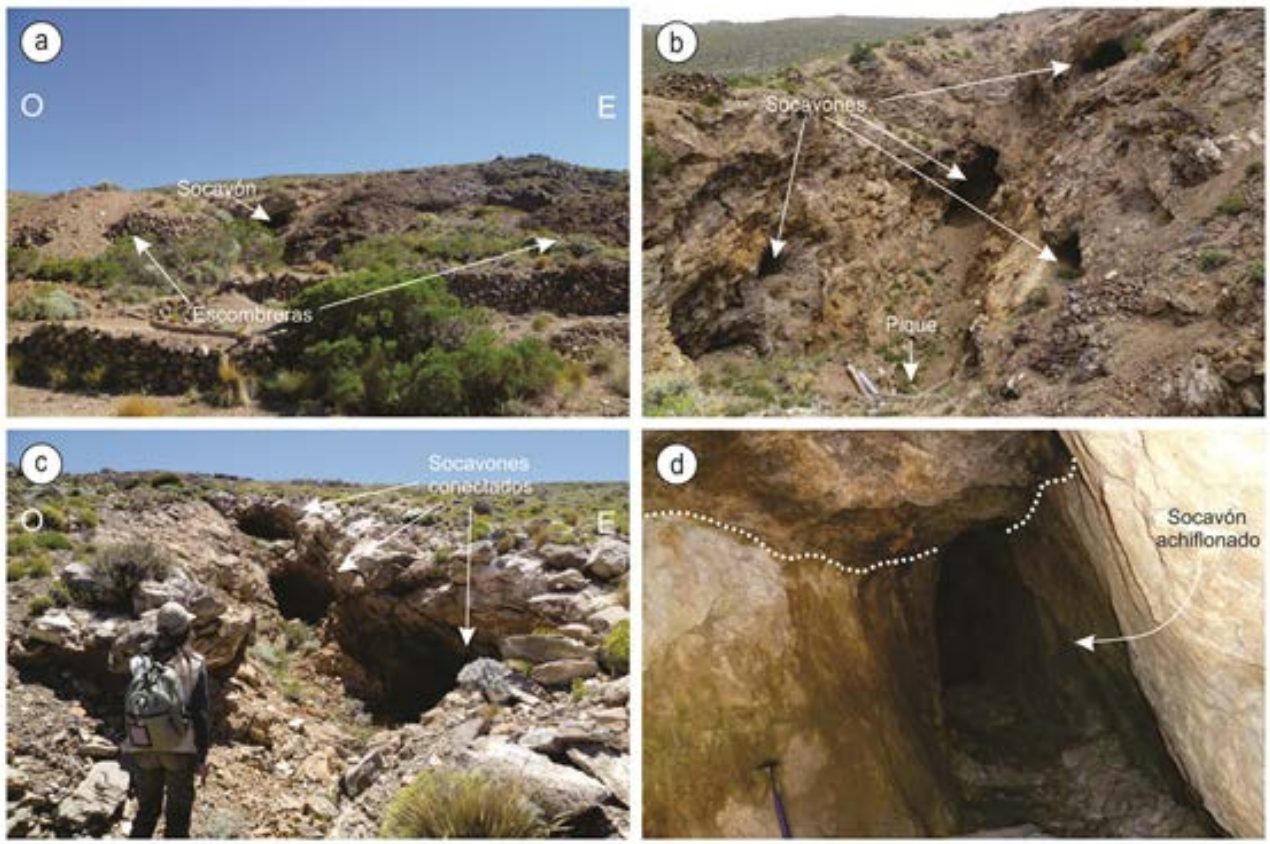

Figura 5.7: a- Mina San Eduardo. Vista panorámica de las labores principales; b- Rajo principal; c- Mina La Bienvenida; d- Socavones achiflonados. 
La mayor parte de baritina y galena fueron removidas y extraídas durante los procesos de explotación. La galena fresca identificada es escasa, ya que la gran mayoría se encuentra oxidada a cerusita; se presenta con hábito cúbico aunque algunos granos se muestran anhedrales, con un tamaño máximo de $1 \mathrm{~cm}$ (Fig.5.8 a-b). La calcopirita se reconoce como pátinas con oxidación incipiente, en agregados de $2-3 \mathrm{~cm}$ de tamaño y en ciertas ocasiones intensamente oxidada (Fig.5.8c). La pirita se encuentra en forma dispersa como un fino diseminado, excepcionalmente fresca y en la mayoría de los casos oxidada a limonitas. Frecuentemente, se observan oquedades de formas euhedrales cúbicas, de tamaño milimétrico, generadas por procesos de lixiviación. Sobre esta paragénesis primaria se han sobreimpuesto los ya indicados minerales supergénicos tales como malaquitaazurita, calcosina, cerusita, limonitas píceas y óxidos de manganeso, otorgándole una coloración rojiza, verdosa y gris oscura al conjunto (Fig.5.8d).
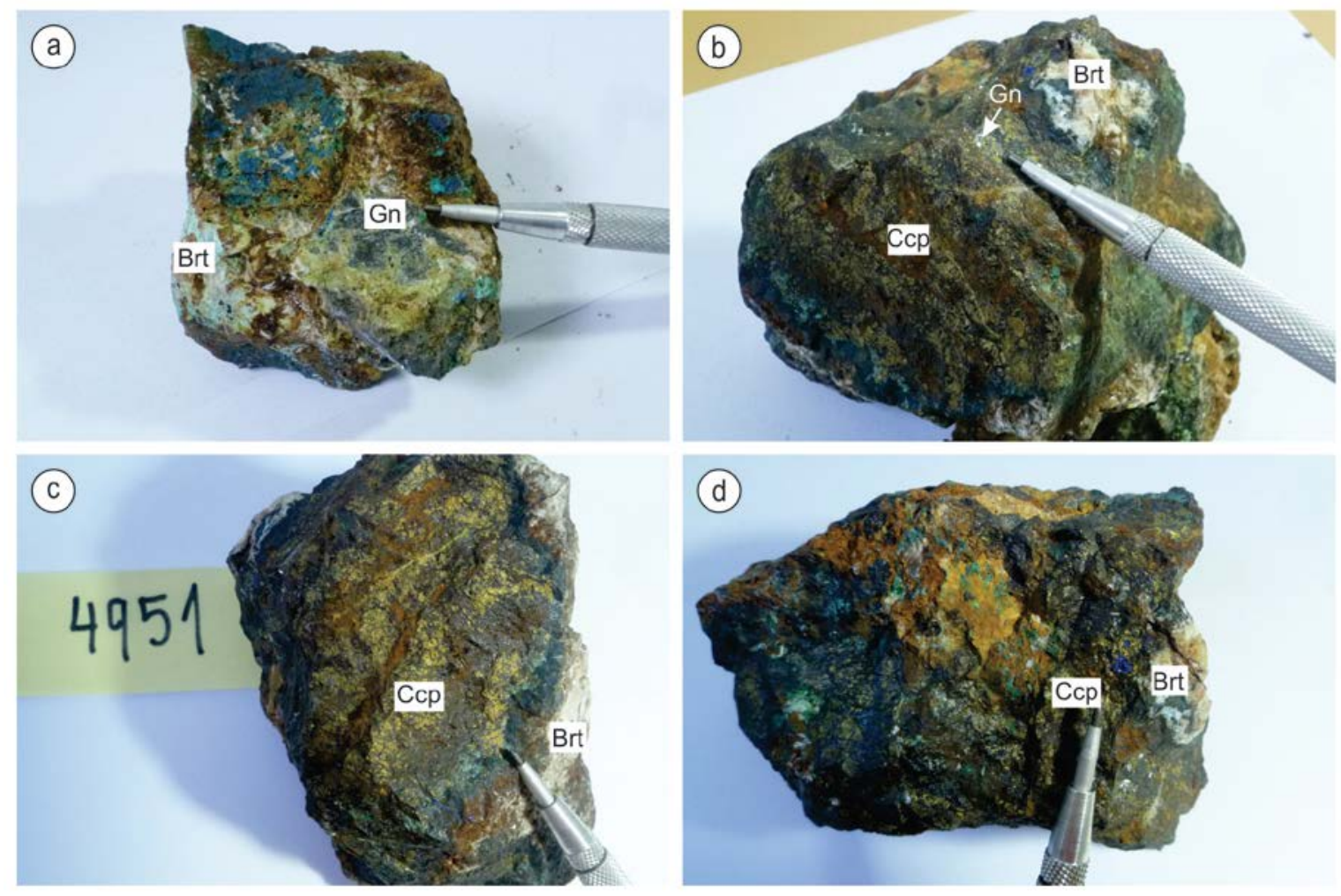

Figura 5.8: Fotografías de muestras de mano de la mineralización vetiforme presente en la mina San Eduardo: a-b: cristales de baritina (Brt) y galena $(\mathrm{Gn})$; c- calcopirita $(\mathrm{Ccp})$ en pátinas; dcompuestos oxidados de cobre (malaquita-azurita). Las abreviaturas de minerales utilizadas según Whitney y Evans (2010). 
En la roca carbonática se reconoce laminación microbial típica de ambientes marinos en que diversos grupos de microorganismos tales como cianobacterias (Riding 2000), bacterias sulfato reductoras (Tang et al., 2011) y algas microscópicas verdes y rojas (Tucker y Wright 1990; Riding 2000) están relacionados con la formación de estructuras sedimentarias a nivel macro, meso y microscópico. En facies calcáreas, un ejemplo de esto lo constituyen los carbonatos microbiales siendo los estromatolitos una de las estructuras más comunes (Riding 2006; Calner y Eriksson 2011; Noffke y Chafetz 2011). Se considera que las facies de las calizas laminares correspondientes al Miembro Troncoso Superior se desarrollaron en un ambiente intrasupramareal (Legarreta 1985) con la implantación de matas bentónicas dando forma a estructuras estromatolíticas (Gabriele 2016). Es en estas rocas carbonáticas con laminación microbial (Fig.5.9 a-d) donde se origina la textura cebrada (Escobar et al., 2013) mediante el reemplazo del mosaico calcítico y relleno de planos interlaminares por baritina. Por otro lado, las brechas emplazadas en planos y oquedades de fracturación en ocasiones exhiben espejos de falla. Están constituidas por clastos sub-angulosos de baritina y de caliza laminada, en partes con textura cebrada, cementados por baritina de grano grueso y de coloración blanquecina. En algunos lugares, la baritina, forma estructuras en escarapela, en peine y semisoles constituidos por cristales de hábito tabular fino que están impregnados por óxidos-hidróxidos de hierro (Fig.5.9 e-h). 

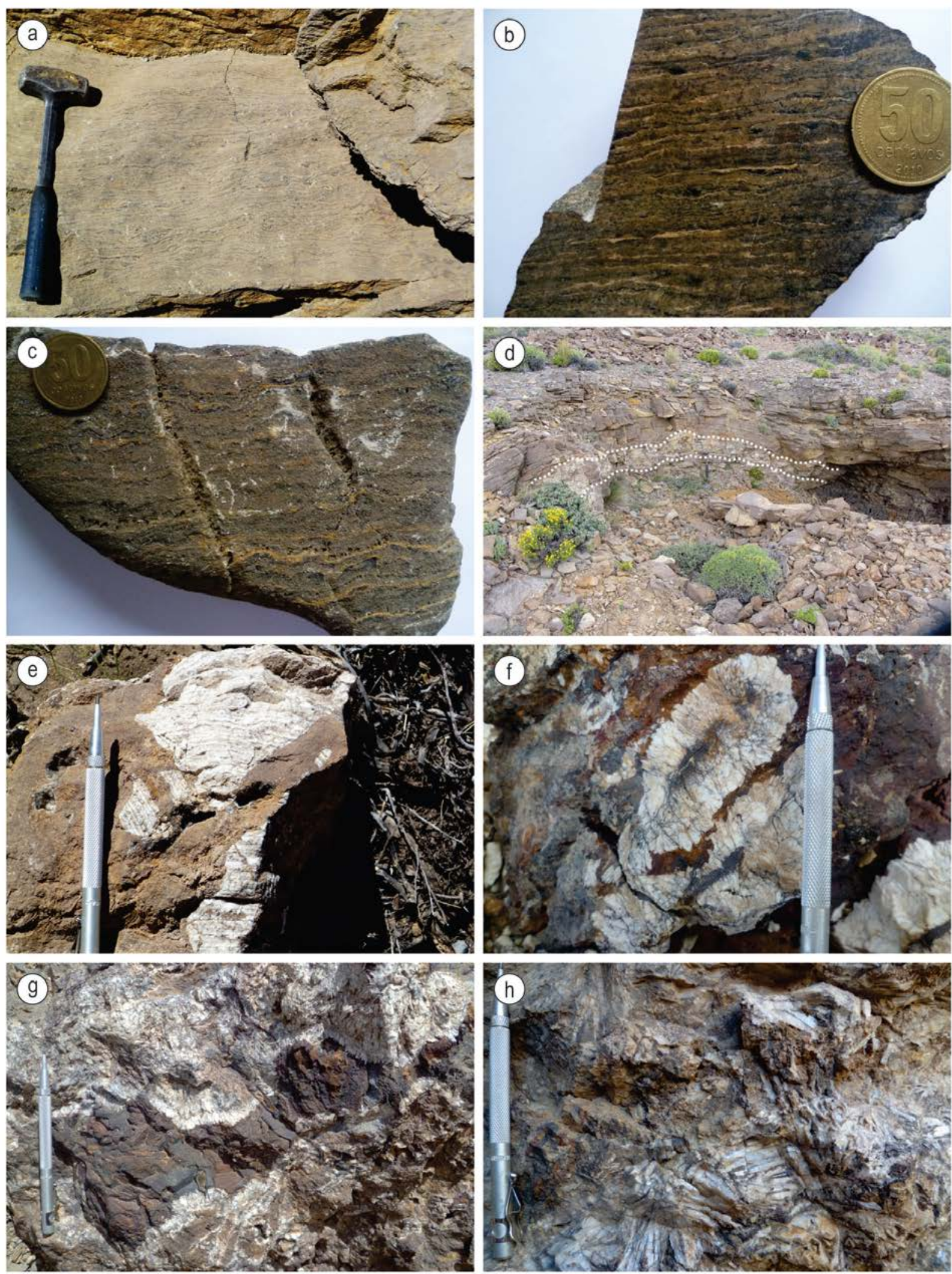

Figura 5.9: Fotografías de calizas con laminación microbial del Miembro Troncoso Superior del sector mina San Eduardo (a-c); d- calizas laminadas con textura cebrada en los alrededores de la mina San Eduardo, obsérvense las líneas punteadas y texturas brechosas en afloramientos: ecebrada en sector mina San Eduardo; f- en escarapela en cerro Negro; g- en peine en cerro Negro; h- cristales de baritina formando semisoles en sector minas La Bruja- Julio César. Diámetro de la moneda $25 \mathrm{~mm}$. 


\section{Sector mina La Bienvenida}

La mineralización de la mina La Bienvenida se manifiesta a través de rajos alineados de $45 \mathrm{~m}$ de extensión aproximadamente, los cuales mantienen igual rumbo (NS), pero presentan bruscas inflexiones que le dan un aspecto zigzagueante.

La mineralización (Fig.5.7 c-d) está alojada en areniscas finas y de coloraciones blanquecinas del Miembro Troncoso Inferior de la Formación Huitrín, con espesores de 0,5 hasta $1,5 \mathrm{~m}$ e inclinaciones que oscilan entre $35^{\circ}$ y $55^{\circ} \mathrm{SE}$. En algunos sectores, se interdigitan con los planos de laminación de las areniscas bandas finas de baritina que varían entre unos pocos milímetros y $1,5 \mathrm{~cm}$ de espesor; en las cuales se encuentra un diseminado de individuos de sulfuros, esencialmente granos de galena, de hasta $4 \mathrm{~mm}$ de diámetro, conformando en partes finos bandeados de $1,5 \mathrm{~cm}$ de espesor en general o distribuidos aleatoriamente sin mostrar un diseño definido (Fig.5.10). Los granos bien desarrollados muestran hábito subhedral a euhedral y sus tamaños en promedio son de 1 cm. También, asociados a galena se observan huecos de forma cúbica, de tamaño milimétrico, que probablemente correspondan a cristales de pirita, parcial o totalmente lixiviada y/o limonitizada.

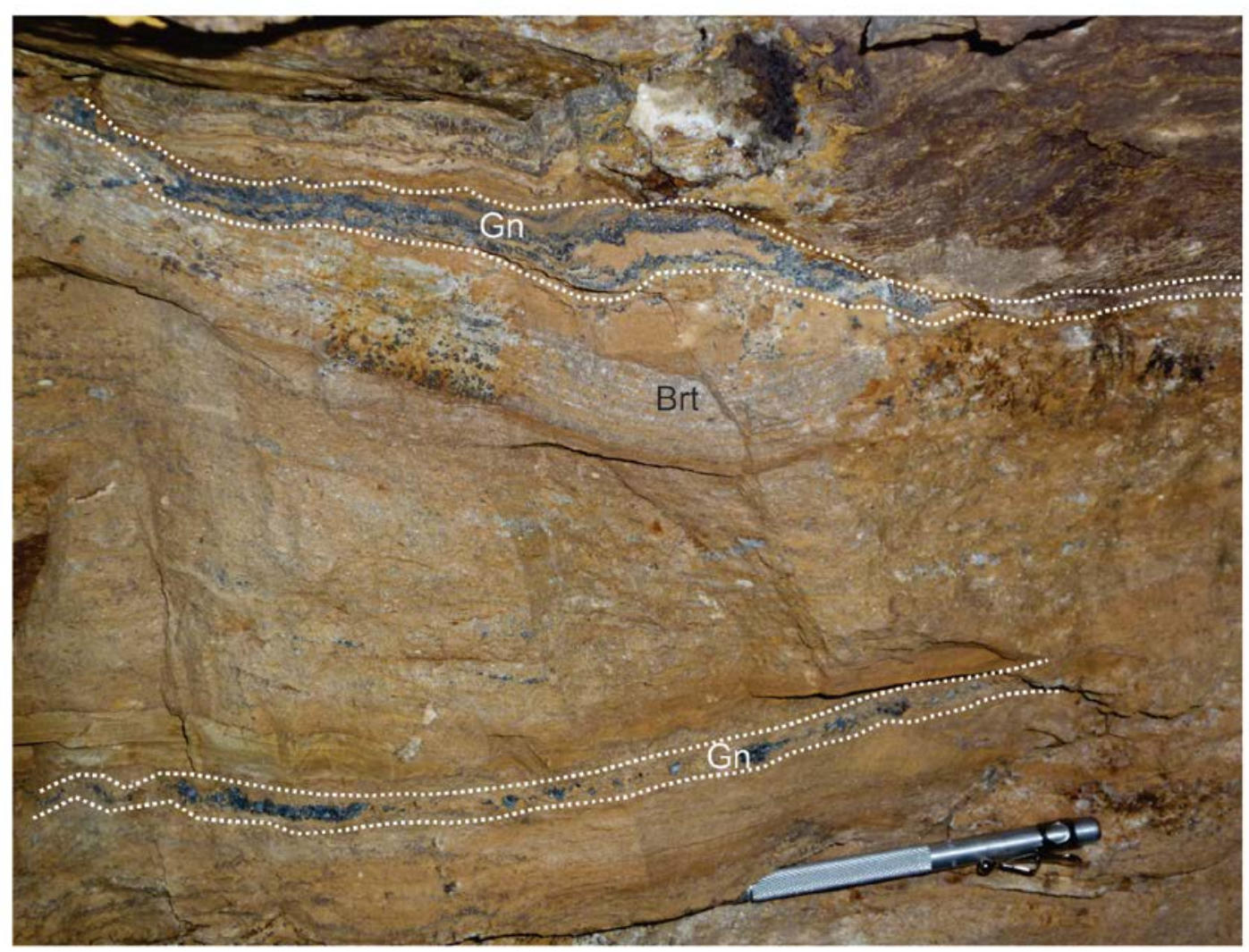

Figura 5.10: Fotografía de mineralización barítica (Brt) con granos de galena $(\mathrm{Gn})$ en las areniscas con laminación fina del Miembro Troncoso Inferior en sector mina La Bienvenida. 
Las reservas de baritina calculadas para ambos sectores (San Eduardo y La Bienvenida), según Lyons et al. (1978), fueron 32100 t de baritina cuya ley es de 69,12\% de $\mathrm{BaSO}_{4}$ y con un Pe promedio entre 4,32 y 4,20 gr/ $\mathrm{cm}^{3}$.

\section{Sector minas La Bruja - Julio César}

Se accede desde Chos Malal por la ruta nacional 40 hasta la ruta provincial 4 (ripio), desde allí se transitan unos $17 \mathrm{~km}$ hacia el oeste (Fig.5.5) hasta un camino minero, en mal estado de conservación, que llega a proximidades de la mina La Bruja (37\%43' latitud sur, $70^{\circ} 19^{\prime}$ longitud oeste). El acceso a la mina Julio César (37\%44' latitud sur, $70^{\circ} 21^{\prime}$ longitud oeste) y a otras manifestaciones sin nombre, actualmente es a pie, transitando huellas que se encuentran en muy mal estado de conservación.
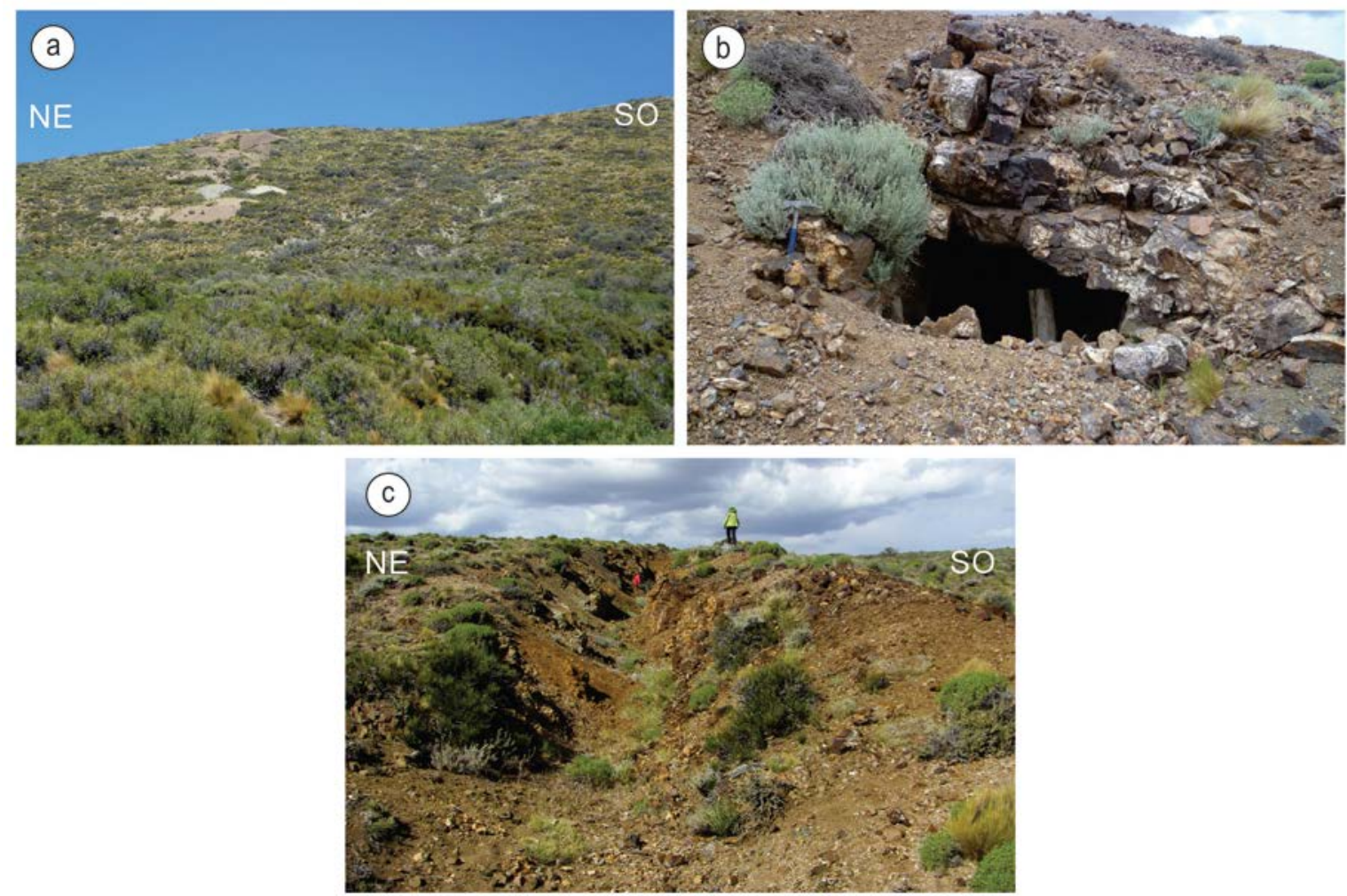

Figura 5.11: Sector minas La Bruja - Julio César: a-b: vista panorámica y de detalle de los labores de la mina La Bruja; c- rajo de la mina Julio César.

Este sector se ubica en el faldeo sur del cerro Negro (Fig.5.11). Las rocas que afloran principalmente corresponden a la Formación Colipilli y en menor medida a la Formación Agrio. Los afloramientos de rocas magmáticas se presentan poco expuestos debido a una profusa cubierta cuaternaria por lo que en diversos sectores solo es posible 
reconocer un regolito conformado por fragmentos de diorito-andesitas de hasta $70 \mathrm{~cm}$ de longitud, con marcada textura porfírica con fenocristales de anfíboles y plagioclasas. Por sectores se muestran muy brechados, fracturados y con un intenso grado de alteración que está representado por cloritización, sericitización y oxidación (Fig.5.12 a-b).
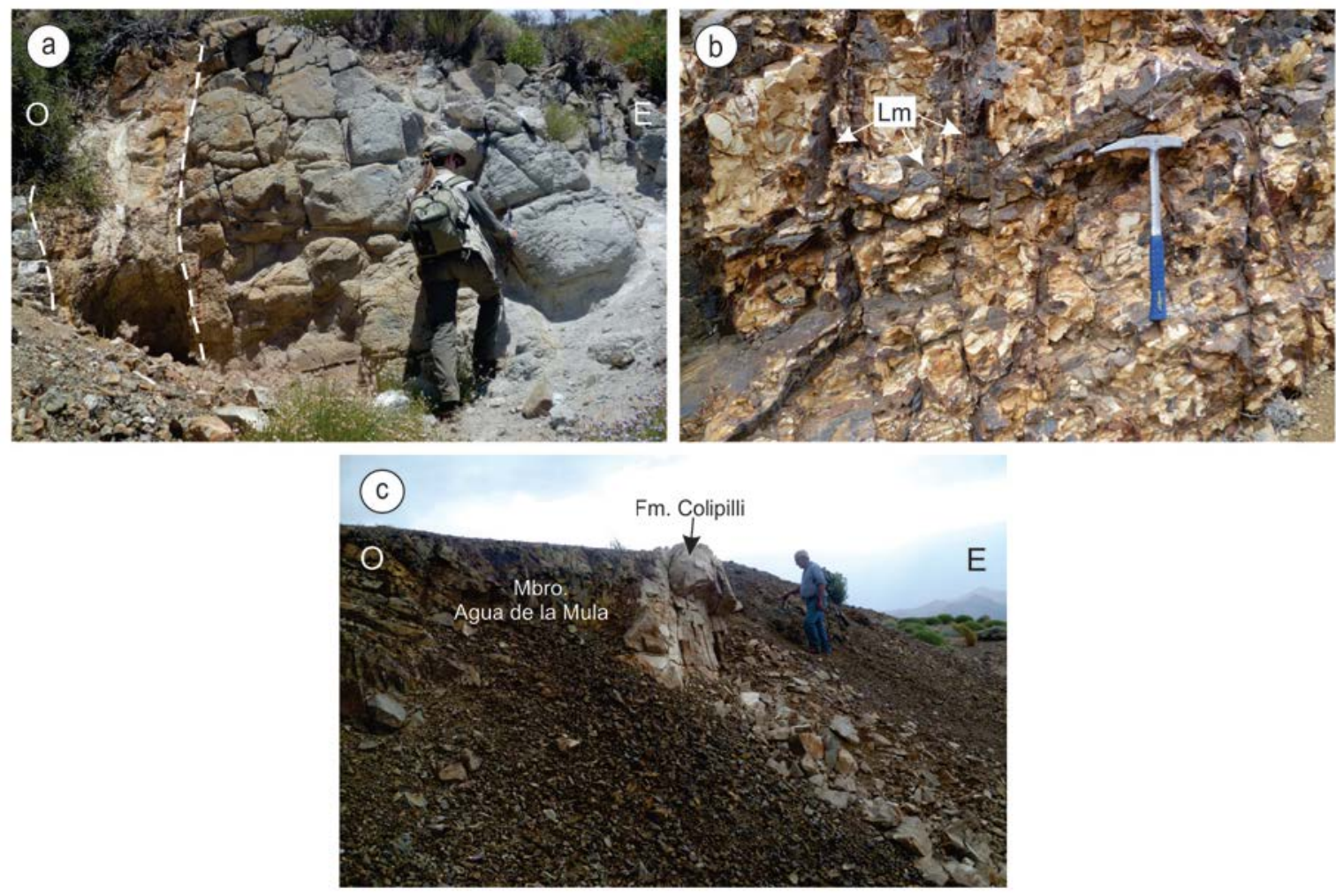

Figura 5.12: Mina La Bruja, Cerro Negro: a- veta de baritina en caja de rocas ígneas fracturadas e intensamente sericitizadas; b- stockwork limonítico en roca de caja (pelitas del Miembro Agua de la Mula); c- dique andesítico cortando a la Formación Agrio.

Las labores de explotación de ambas minas son rajos a cielo abierto de variable longitud (de hasta $200 \mathrm{~m}$ ). Las vetas se presentan en corridas discontinuas de pocas decenas de metros. Los rajos de la mina La Bruja permiten reconocer que la mineralización se emplaza en el contacto entre las pelitas del Miembro Agua de la Mula de la Formación Agrio y las andesitas de la Formación Colipilli. En las cercanías de dicha mina, aflora un cuerpo discordante de composición andesítica, coloración castaño clara, textura porfírica y de 1,5 a $3 \mathrm{~m}$ de espesor (Fig.5.12c). Por su parte, las labores en la mina Julio César permiten observar a la mineralización emplazada en rocas ígneas de la Formación Colipilli; dicho contacto es neto y recto.

Las mineralizaciones de este sector consisten en vetas compuestas principalmente por baritina y óxidos-hidróxidos de hierro con cantidades minoritarias de galena y ocasionalmente esfalerita y pirita. La baritina se muestra en cristales euhedrales de hábito 
tabular grueso, de hasta $10 \mathrm{~cm}$ de longitud; por otro lado, la galena y esfalerita forman agrupamientos irregulares de individuos con hábito anhedral y tamaños de hasta 1,5 cm.
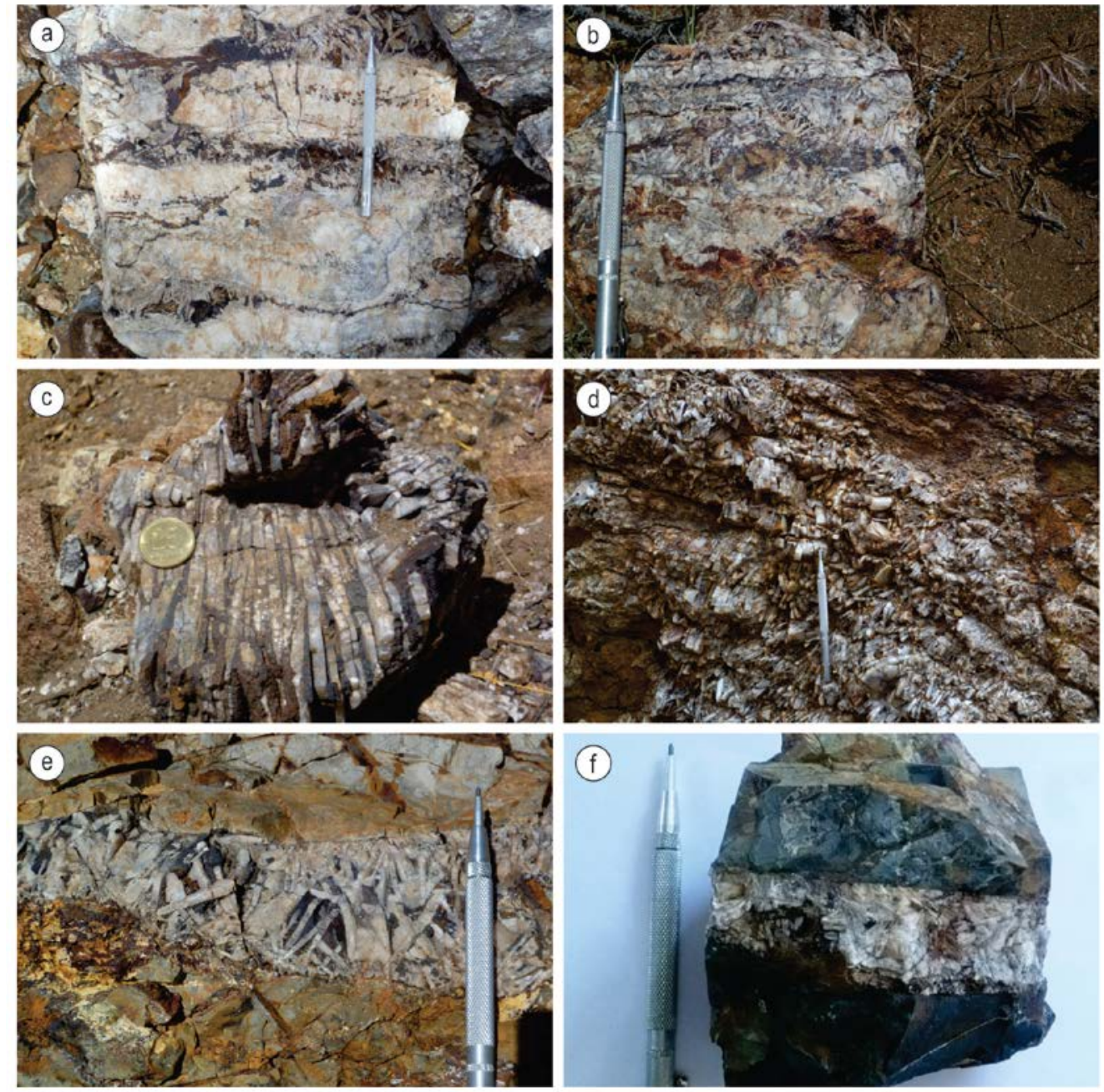

Figura 5.13: Texturas del Sector minas La Bruja- Julio César: a-b: bandeamiento; c-d: cristales de baritina recristalizados; e-f: relleno cortando a rocas ígneas de la Formación Colipilli y pelitas del Miembro Agua de la Mula (Formación Agrio), respectivamente. Diámetro de la moneda $24 \mathrm{~mm}$.

Las texturas más frecuentes son de tipo brechosa y bandeada (Fig.5.13). Las brechas están constituidas por fragmentos de baritina espática de hábito tabular grueso, de $8 \mathrm{~cm}$ de tamaño promedio y escasos fragmentos con granos de galena, de $2 \mathrm{~cm}$ de tamaño máximo, reemplazada parcialmente por cerusita; estos clastos están cementados por óxidos-hidróxidos de hierro y manganeso. La textura bandeada está integrada por la alternancia de bandas de baritina blanca con poca galena y óxidos-hidróxidos de hierro y bandas dominantemente de óxidos-hidróxidos de hierro y manganeso. Las vetas presentan un rumbo N-S e inclinación general $70-80^{\circ} \mathrm{E}$, poseen $1,5 \mathrm{~m}$ de espesor en promedio en el caso de la mina Julio César, mientras que en la mina La Bruja tienen un espesor máximo 
de $7 \mathrm{~m}$. A lo largo del rumbo de la mineralización se observa un apretado clivaje constituido por múltiples fracturas, aproximadamente paralelas y producidas por cizallamiento, que están rellenas por baritina recristalizada y óxidos-hidróxidos de Fe. En estos sectores fuertemente deformados, la roca de caja, andesítica, ostenta coloraciones verdoso-grisáceas producto de procesos de alteración propilítica. Asimismo, hacia los hastiales donde la roca de caja andesítica es más frágil se observa un craquelado o enrejado de pequeñas fracturas que está relleno por óxidos-hidróxidos de Fe y que se ha generado en una fase postmineralización ya que también cortan a fragmentos de baritina tabular.

Según Lyons et al. (1978) las reservas calculadas para ésta última fueron 8900 t con una ley de 59,75\% en $\mathrm{BaSO}_{4}$.

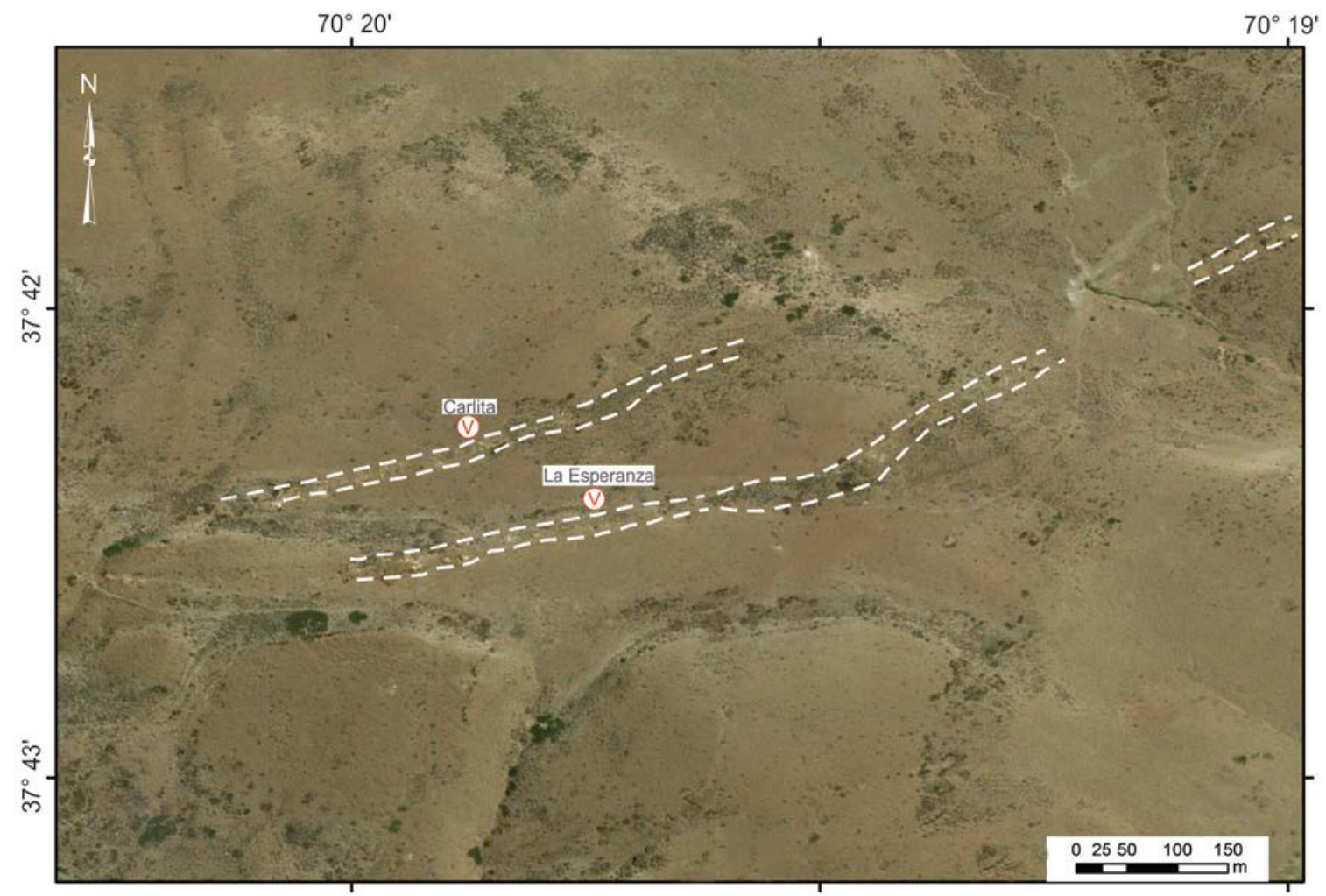

Figura 5.14: Imagen satelital Landsat de los laboreos de explotación de las minas Carlita y La Esperanza en la Formación Agrio.

\section{Sector minas La Esperanza - Carlita}

Se puede acceder a estas minas por el camino que lleva al Sector Julio César-La Bruja (Fig.5.5) y desde ahí a pie en dirección NNO unos $5 \mathrm{~km}$. Ambas pertenencias están muy cercanas entre sí (Fig.5.14), distan 50 m, (37 $57^{\prime}$ latitud sur, $70^{\circ} 03^{\prime}$ longitud oeste).

En este sector afloran principalmente rocas ígneas de la Formación Colipilli, intensamente alteradas a sericita, y rocas pelíticas correspondientes al Miembro Agua de la 
Mula, en forma subordinada. Estas últimas se muestran profusamente impregnadas por óxidos de hierro.

Las labores que destapan a cada una de las mineralizaciones se encuentran alineadas y tienen una extensión aproximada de $800 \mathrm{~m}$, presentándose las vetas en corridas discontinuas de pocas decenas de metros. Ambas manifestaciones se disponen paralelas siguiendo un sistema de fracturas de un rumbo aproximado $\mathrm{N} 70^{\circ} \mathrm{E}$ con una inclinación general de $70^{\circ} \mathrm{NO}$.

Las vetas se alojan cortando a las pelitas de la Formación Agrio (Fig.5.15 a-b) y, a veces, se emplazan en el contacto roca sedimentaria-roca ígnea; el tipo de contacto vetaroca de caja es neto y recto. Las vetas presentan un espesor máximo de 1,5 m y están compuestas por baritina, óxidos-hidróxidos de hierro y muy poca cantidad de galena. En afloramiento se observan cristales de baritina, de hasta $5 \mathrm{~cm}$ de longitud, fracturados y flexurados (Fig.5.15c). Las texturas más comunes que se observan son de tipo relleno y muy similares a las descriptas en el Sector La Bruja - Julio César (brechosa) (Fig.5.15d). La textura brechosa está constituida por fragmentos de cristales de baritina blanca, la mayoría fracturados, de $5 \mathrm{~cm}$ en promedio de longitud y escasos clastos con cristales de galena cementados por óxidos-hidróxidos de hierro que le otorgan una coloración castaña.
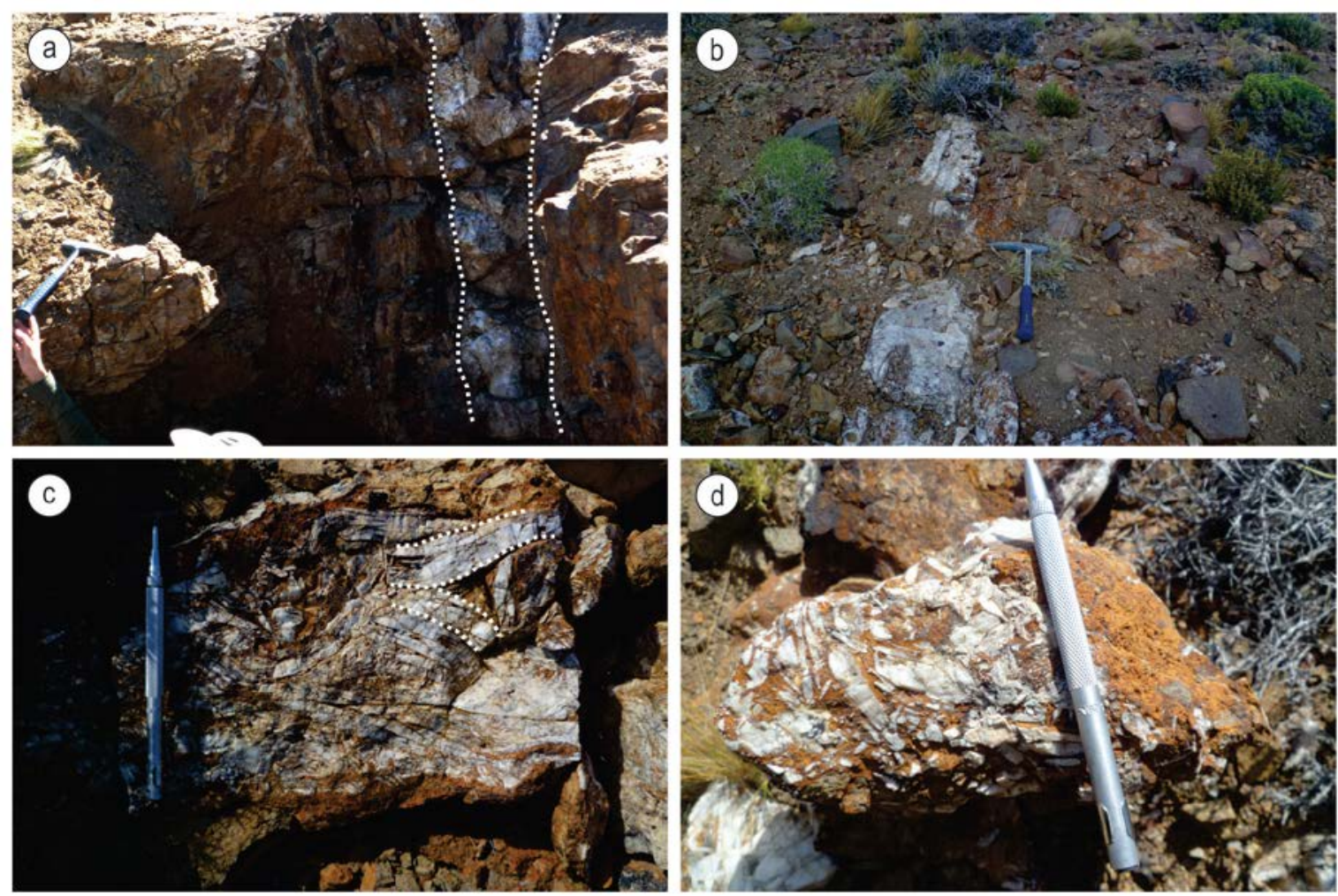

Figura 5.15: Fotografías del Sector minas La Esperanza - Carlita: a-b: laboreos de explotación de mineralización barítica; c- baritina con hábito tabular grueso fracturada y flexurada; dtextura brechosa con cristales de baritina y óxidos-hidróxidos de hierro como cemento. 


\section{Litogeoquímica de las mineralizaciones}

Con el fin de caracterizar geoquímicamente a las mineralizaciones se tomaron 9 muestras siguiendo el método de esquirleo discontinuo de la mineralización mantiforme de la labor principal y alrededores de la mina San Eduardo y La Bienvenida y de las mineralizaciones vetiformes de las minas La Bruja y Julio César, consideradas como más representativas volumétricamente de ambas yacencias. En los Cuadros 5.1 y 5.2 se presentan los análisis completos de las muestras investigadas.

\begin{tabular}{|c|c|c|c|c|c|}
\hline \multirow{2}{*}{$\begin{array}{c}\text { Muestra } \rightarrow \\
\text { Mina } \rightarrow\end{array}$} & 19351 & 19384 & 19400 & 19409 & \multirow{2}{*}{$\frac{19427}{\text { La Bienvenida }}$} \\
\hline & \multicolumn{4}{|c|}{ San Eduardo } & \\
\hline \multirow{2}{*}{ Ubicación $\rightarrow$} & $70^{\circ} 20^{\prime} 52^{\prime \prime}$ & $70^{\circ} 20^{\prime} 52^{\prime \prime}$ & $70^{\circ} 20^{\prime} 12^{\prime \prime}$ & $70^{\circ} 20^{\prime} 52^{\prime \prime}$ & $70^{\circ} 20^{\prime} 57^{\prime \prime}$ \\
\hline & $37^{\circ} 43^{\prime} 47^{\prime \prime}$ & $37^{\circ} 43^{\prime} 48^{\prime \prime}$ & $37^{\circ} 44^{\prime} 21^{\prime \prime}$ & $37^{\circ} 43^{\prime} 40^{\prime \prime}$ & $37^{\circ} 43^{\prime} 41^{\prime \prime}$ \\
\hline Yacencia $\rightarrow$ & \multicolumn{5}{|c|}{ Mantiforme } \\
\hline \multicolumn{6}{|l|}{ ppm } \\
\hline $\mathrm{Be}$ & $<0,5$ & $<0,5$ & $<0,5$ & $<0,5$ & $<0,5$ \\
\hline B & $<10$ & $<10$ & $<10$ & $<10$ & $<10$ \\
\hline $\mathbf{P}$ & 100,0 & 250,0 & 230,0 & 180,0 & 530,0 \\
\hline Sc & 1,0 & 1,0 & 1,0 & 2,0 & 15,0 \\
\hline V & 11,0 & 12,0 & 29,0 & 11,0 & 26,0 \\
\hline $\mathrm{Cr}$ & 6,0 & 8,0 & 4,0 & 18,0 & 3,0 \\
\hline Mn & 5770,0 & 4630,0 & 824,0 & 14200,0 & 21900,0 \\
\hline Co & 6,0 & 16,0 & 12,0 & 8,0 & 117,0 \\
\hline $\mathrm{Ni}$ & 6,0 & 18,0 & 7,0 & 6,0 & 51,0 \\
\hline $\mathrm{Cu}$ & 10,0 & 38,0 & 62,0 & 17,0 & 476,0 \\
\hline $\mathrm{Zn}$ & 353,0 & 1155,0 & 3600,0 & 3070,0 & $>10000$ \\
\hline Ga & $<10$ & $<10$ & $<10$ & $<10$ & 10,0 \\
\hline As & 32,0 & 85,0 & 57,0 & 37,0 & 124,0 \\
\hline $\mathrm{Sr}$ & 279,0 & 325,0 & 438,0 & 153,0 & 126,0 \\
\hline Mo & 13,0 & 36,0 & 18,0 & 18,0 & 47,0 \\
\hline Ag & 0,4 & 0,8 & 1,8 & 1,3 & 7,7 \\
\hline $\mathrm{Cd}$ & 1,3 & 2,1 & 11,6 & 15,6 & 89,7 \\
\hline Sb & $<2$ & $<2$ & 5,0 & 3,0 & $<2$ \\
\hline $\mathrm{Ba}$ & 2460,0 & 2560,0 & 190,0 & 2510,0 & 2310,0 \\
\hline La & $<10$ & 10,0 & $<10$ & 10,0 & 10,0 \\
\hline W & $<10$ & $<10$ & $<10$ & $<10$ & $<10$ \\
\hline $\mathrm{Au}$ & $<0.001$ & $<0.001$ & 0,0 & 0,0 & 0,0 \\
\hline $\mathrm{Hg}$ & $<1$ & $<1$ & 1,0 & $<1$ & 8,0 \\
\hline Tl & $<10$ & $<10$ & $<10$ & $<10$ & $<10$ \\
\hline $\mathrm{Pb}$ & 64,0 & 205,0 & $>10000$ & 323,0 & 3240,0 \\
\hline $\mathrm{Bi}$ & $<2$ & 5,0 & 2,0 & 3,0 & 6,0 \\
\hline Th & $<20$ & $<20$ & $<20$ & $<20$ & $<20$ \\
\hline $\mathbf{U}$ & $<10$ & $<10$ & $<10$ & $<10$ & $<10$ \\
\hline \multicolumn{6}{|l|}{ \% en peso } \\
\hline $\mathrm{Na}$ & $<0.01$ & 0,0 & 0,0 & 0,0 & 0,0 \\
\hline Mg & 0,0 & 0,0 & 0,0 & 0,0 & 0,0 \\
\hline Al & 0,1 & 0,3 & 0,3 & 0,2 & 0,9 \\
\hline $\mathbf{S}$ & 0,1 & 0,1 & 0,6 & 0,1 & 0,1 \\
\hline K & 0,0 & 0,0 & 0,0 & 0,1 & 0,0 \\
\hline $\mathrm{Ca}$ & 0,2 & 0,2 & 1,1 & 0,3 & 0,3 \\
\hline $\mathrm{Ti}$ & $<0.01$ & $<0.01$ & $<0.01$ & $<0.01$ & $<0.01$ \\
\hline $\mathrm{Fe}$ & 8,4 & 27,6 & 8,5 & 19,5 & 37,9 \\
\hline $\mathrm{Pb}$ & & & 1,9 & & \\
\hline $\mathrm{Zn}$ & & & & & 2,5 \\
\hline
\end{tabular}

Cuadro 5.1: Análisis geoquímicos de estructuras mineralizadas representativas de minas San Eduardo y La Bienvenida. 


\begin{tabular}{|c|c|c|c|c|}
\hline Muestra $\rightarrow$ & 19429 & 19372 & 19412 & 21812 \\
\hline Mina $\rightarrow$ & La Bienvenida & Julio César & \multicolumn{2}{|c|}{ La Bruja } \\
\hline \multirow{2}{*}{ Ubicación $\rightarrow$} & $70^{\circ} 20^{\prime} 58^{\prime \prime}$ & $70^{\circ} 20^{\prime} 57^{\prime \prime}$ & $70^{\circ} 18^{\prime} 24^{\prime \prime}$ & $70^{\circ} 18^{\prime} 25^{\prime \prime}$ \\
\hline & $37^{\circ} 43^{\prime} 39^{\prime \prime}$ & $37^{\circ} 43^{\prime} 40^{\prime \prime}$ & $37^{\circ} 43^{\prime} 01^{\prime \prime}$ & $37^{\circ} 43^{\prime} 02^{\prime \prime}$ \\
\hline Yacencia $\rightarrow$ & Mantiforme & \multicolumn{3}{|c|}{ Vetiforme } \\
\hline \multicolumn{5}{|l|}{ ppm } \\
\hline $\mathrm{Be}$ & $<0,5$ & $<0,5$ & $<0,5$ & $<0,5$ \\
\hline B & $<10$ & $<10$ & 10,0 & 10,0 \\
\hline $\mathbf{P}$ & 80,0 & 360,0 & 630,0 & 490,0 \\
\hline Sc & 1,0 & 5,0 & 5,0 & 4,0 \\
\hline V & 8,0 & 90,0 & 371,0 & 225,0 \\
\hline $\mathrm{Cr}$ & 2,0 & 3,0 & 30,0 & 11,0 \\
\hline Mn & 5270,0 & 1590,0 & 7190,0 & 6410,0 \\
\hline Co & 10,0 & 7,0 & 10,0 & 9,0 \\
\hline $\mathbf{N i}$ & 6,0 & 9,0 & 11,0 & 6,0 \\
\hline $\mathrm{Cu}$ & 56,0 & 90,0 & 93,0 & 10,0 \\
\hline $\mathrm{Zn}$ & 3470,0 & 6490,0 & $>10000$ & $>10000$ \\
\hline Ga & $<10$ & $<10$ & 10,0 & $<10$ \\
\hline As & 17,0 & 52,0 & 223,0 & 215,0 \\
\hline $\mathrm{Sr}$ & 489,0 & 217,0 & 114,0 & 214,0 \\
\hline Mo & 5,0 & 21,0 & 7,0 & 5,0 \\
\hline Ag & 2,1 & 1,6 & 19,0 & 8,3 \\
\hline Cd & 15,1 & 19,6 & 46,1 & 28,4 \\
\hline $\mathbf{S b}$ & 3,0 & 3,0 & 15,0 & 16,0 \\
\hline Ba & 1480,0 & 390,0 & 2820,0 & 2420,0 \\
\hline La & $<10$ & $<10$ & 10,0 & 10,0 \\
\hline W & $<10$ & $<10$ & $<10$ & $<10$ \\
\hline $\mathbf{A u}$ & $<0.001$ & 0,0 & 0,0 & 0,0 \\
\hline $\mathrm{Hg}$ & $<1$ & 1,0 & 15,0 & 17,0 \\
\hline $\mathrm{Tl}$ & $<10$ & $<10$ & $<10$ & $<10$ \\
\hline $\mathbf{P b}$ & $>10000$ & $>10000$ & 1790,0 & 1265,0 \\
\hline $\mathrm{Bi}$ & $<2$ & 3,0 & 3,0 & $<2$ \\
\hline Th & $<20$ & $<20$ & $<20$ & $<20$ \\
\hline $\mathbf{U}$ & $<10$ & $<10$ & $<10$ & $<10$ \\
\hline \multicolumn{5}{|l|}{$\%$ en peso } \\
\hline $\mathbf{N a}$ & $<0.01$ & 0,0 & 0,0 & 0,0 \\
\hline Mg & $<0.01$ & 0,0 & 0,1 & 0,1 \\
\hline Al & 0,2 & 0,2 & 0,9 & 0,7 \\
\hline $\mathbf{S}$ & 0,1 & 0,4 & 0,1 & 0,1 \\
\hline $\mathbf{K}$ & 0,0 & 0,1 & 0,0 & 0,0 \\
\hline $\mathrm{Ca}$ & 0,2 & 0,4 & 0,2 & 0,2 \\
\hline $\mathrm{Ti}$ & $<0.01$ & $<0.01$ & $<0.01$ & $<0.01$ \\
\hline $\mathrm{Fe}$ & 7,2 & 23,7 & 19,5 & 17,2 \\
\hline $\mathrm{Pb}$ & 2,7 & 1,2 & & \\
\hline $\mathrm{Zn}$ & & & 1,7 & 1,4 \\
\hline
\end{tabular}

Cuadro 5.2: Análisis geoquímicos de estructuras mineralizadas representativas de minas La Bienvenida, Julio César y La Bruja. 
Las muestras de ambos tipos de yacencias presentan contenidos similares en $\%$ en peso de $\mathrm{Al}$ y $\mathrm{K}$ y contenidos dispares en $\mathrm{Fe}(\leq 37,9 \%$ en peso), $\mathrm{Ca}(\leq 1,1 \%$ en peso) y $\mathrm{S}$ $(\leq 0,6 \%$ en peso), presentándose los mayores valores de estos últimos en las mineralizaciones mantiformes. Asimismo, se detectaron pequeñas cantidades de elementos de interés económico (metales preciosos y base, entre otros). Las concentraciones de Ag son $\leq 19,0$ ppm, siendo el contenido mayor en la yacencia vetiforme. Las concentraciones de $\mathrm{Ba}(\leq 2820,0 \mathrm{ppm}), \mathrm{Sr}(\leq 489,0 \mathrm{ppm}), \mathrm{Pb}(\leq 2,7 \%$ en peso), $\mathrm{Cu}(\leq 476,0 \mathrm{ppm}), \mathrm{Zn}(\leq 2,5 \%$ en peso) y Mn ( $\leq 21900,0 \mathrm{ppm})$ son en todos los casos, excepto el Ba, mayores en la yacencia mantiforme que en la vetiforme.

\section{B) Mineralizaciones de óxidos de hierro}

Desde hace varias décadas son mencionadas manifestaciones de óxido de hierro en los alrededores de la localidad de Colipilli y el cerro Negro. Según Jutorán y Malvicini (1961) y Llambías y Malvicini (1978) las mineralizaciones se emplazan principalmente en las calizas del Miembro Chorreado, son de pequeñas dimensiones y económicamente poco relevantes. En la presente Tesis se seleccionaron, caracterizaron y posteriormente compararon dos mineralizaciones ferríferas, la mina Augusta y un depósito ubicado en el cerro Naunauco, por presentar rasgos geológicos representativos de dichas mineralizaciones.

\section{Sector de mina Augusta}

A la mina Augusta, situada a los $37^{\circ} 43^{\prime}$ de latitud sur y $70^{\circ} 20^{\prime}$ de longitud oeste, se puede llegar a pie desde la mina San Eduardo, la cual se encuentra a unos $2 \mathrm{~km}$ al oeste de la anterior (Fig. 5.5).

En este sector sólo afloran calizas del Miembro Chorreado de la Formación Huitrín, representadas por mudstones o micritas de coloración gris oscura, en las cuales se observan sectores con magnetita diseminada en masas irregulares lobuladas aún más oscuras, donde los procesos de reemplazo son evidentes.

La mina Augusta (Fig.5.16) consiste en una labor superficial o destape a cielo abierto muy reducida en la que han quedado bloques de gran tamaño de colores castaño oscuro a negro y anaranjado a rojizo como remanentes de las tareas de exploración. Los bloques oscuros poseen fuerte magnetismo, mientras que los anaranjados deben su coloración a la alteración limonítica. 


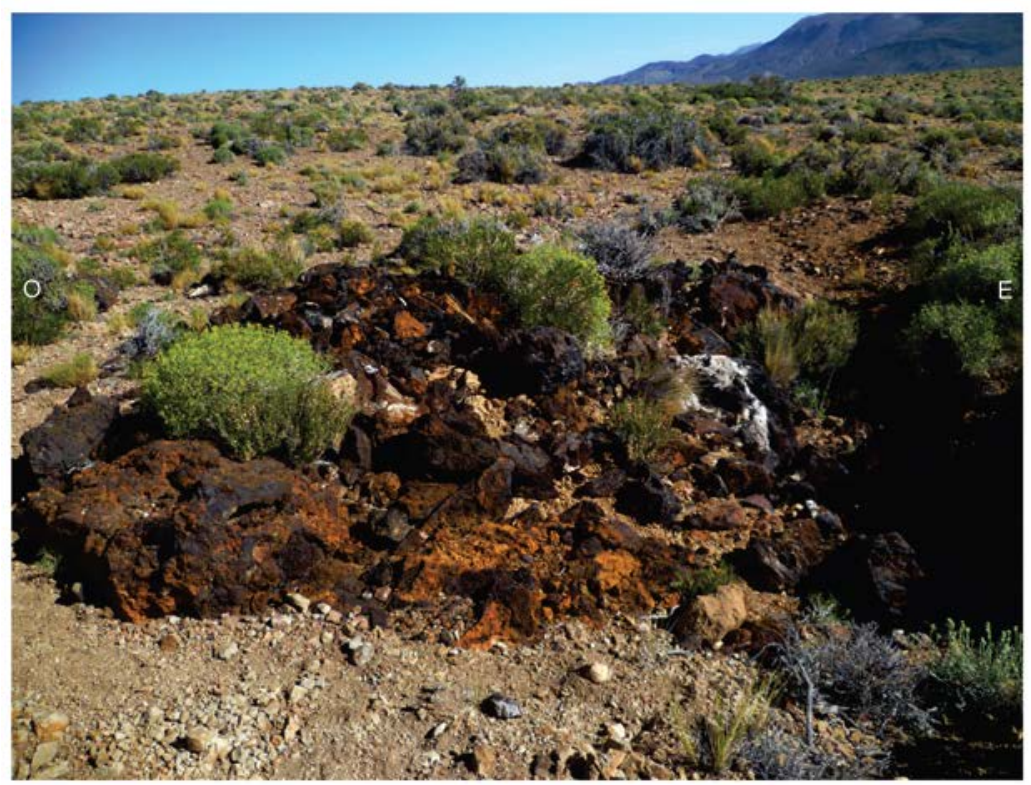

Figura 5.16: Labor de destape de mina Augusta. Altura promedio de arbusto: $50 \mathrm{~cm}$.

La magnetita se presenta en cristales sub- a euhedrales octaédricos de tamaño fino $(0,1 \mathrm{~cm}$ en promedio), con hábito granular, los cuales se disponen constituyendo una textura maciza (Fig.5.17a); ocasionalmente desarrollan cristales de mayor tamaño que alcanzan un máximo de $1,5 \mathrm{~cm}$ (Fig.5.17b). Se interpreta que estos últimos se formaron a partir de procesos de removilización y recristalización que permitieron la formación de cristales euhedrales en oquedades y espacios en la roca carbonática.
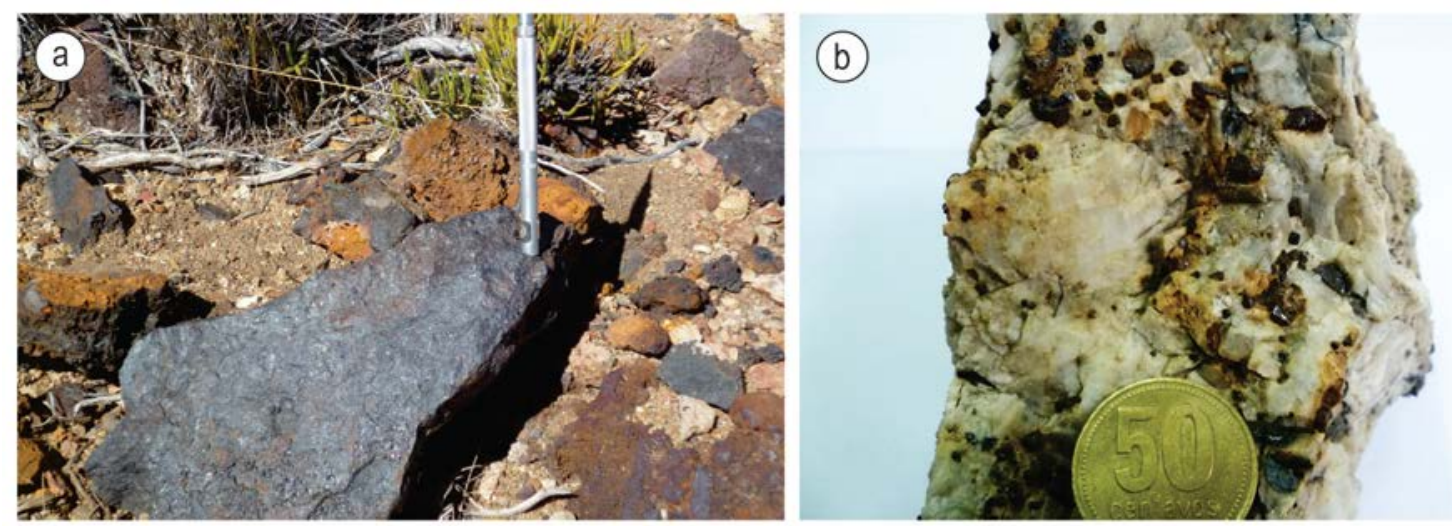

Figura 5.17: Texturas de las magnetitas de la mina Augusta: a- maciza; b- recristalizada. Diámetro de la moneda $25 \mathrm{~mm}$.

Según Zanettini (2011) las reservas de magnetita calculadas son de 350.000 t con leyes de $54 \%$ Fe y $2 \% \mathrm{Mn}$. 


\section{Sector del cerro Naunauco}

El área del cerro Naunauco se encuentra a unos $2 \mathrm{~km}$ al sur de la localidad de Taquimilán y aproximadamente a $15 \mathrm{~km}$ al sur de la ciudad de Chos Malal. Dentro de ésta, la mineralización de hierro se ubica a unos $3 \mathrm{~km}$ al oeste de la ruta nacional 40 . El acceso al área se puede hacer desde Taquimilán, a través de una antigua huella minera hasta la base del cerro y desde este punto a pie hasta una pequeña labor ubicada a los $37^{\circ} 34^{\prime}$ de latitud sur y $70^{\circ} 17^{\prime}$ de longitud oeste (Fig.5.18). Una alternativa para acceder a esta labor la constituye una huella vecinal que se acerca al cerro Naunauco por el este desde la ruta nacional 40 por espacio de unos $1,5 \mathrm{~km}$. A partir de allí, la senda se transforma en intransitable por lo que hay que continuar a pié, aunque a través del faldeo oriental de dicho cerro que es mucho menos empinado que el occidental.

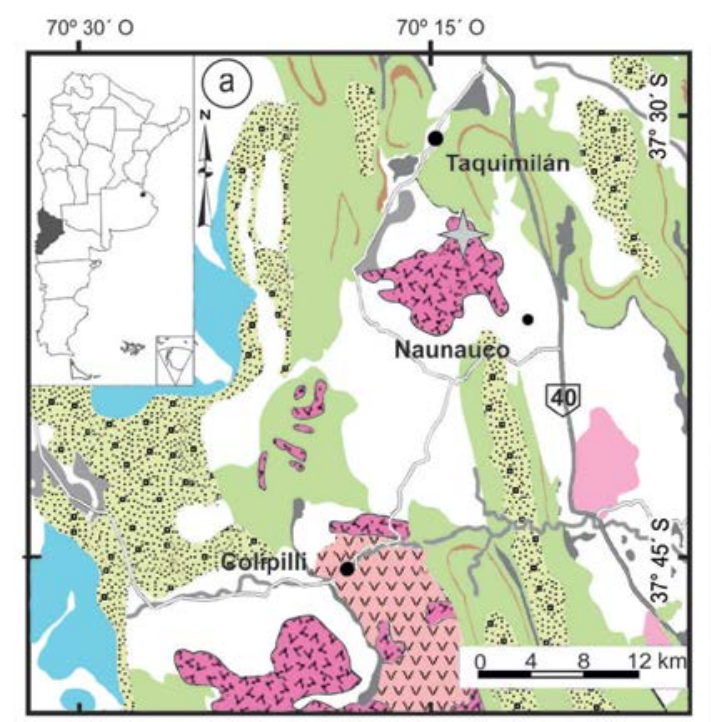

Referencias

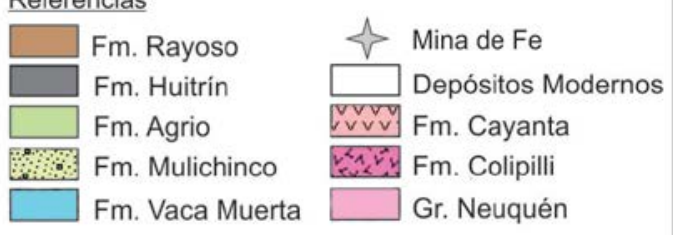

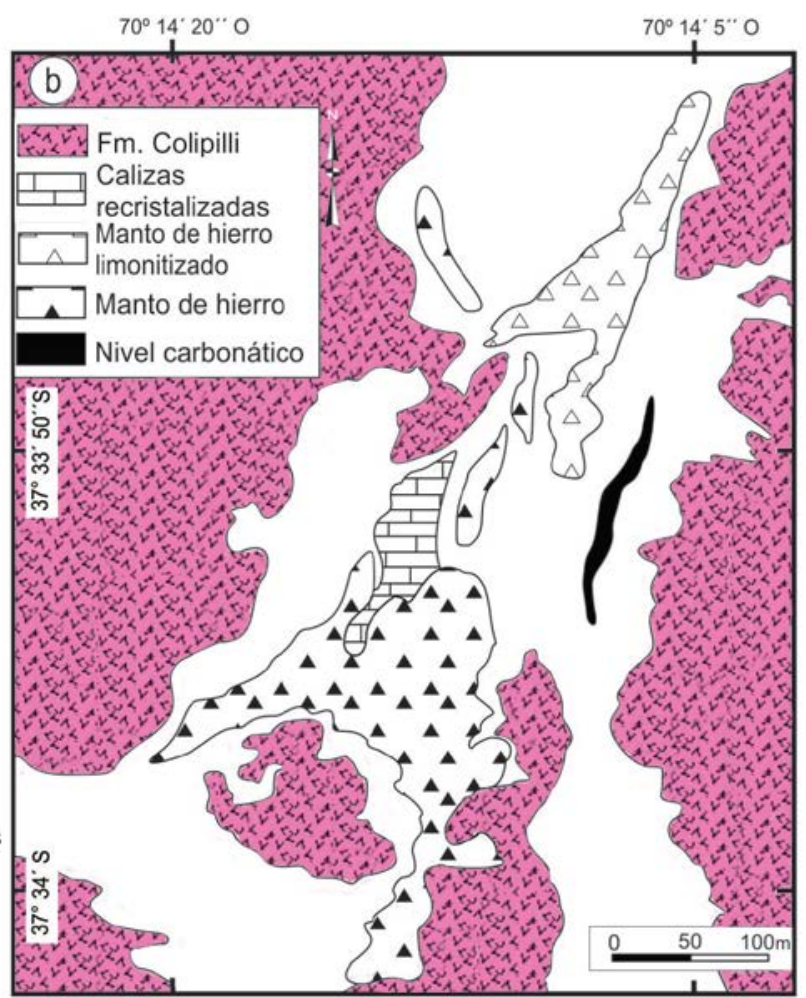

Figura 5.18: Mapa regional y de detalle del Sector cerro Naunauco. Modificado de Salvioli et al. (2013).

En la zona afloran rocas sedimentarias atribuibles a las Formaciones Agrio y Huitrín, las cuales se hallan intruidas por rocas diorítico-andesíticas de la Formación Colipilli. 


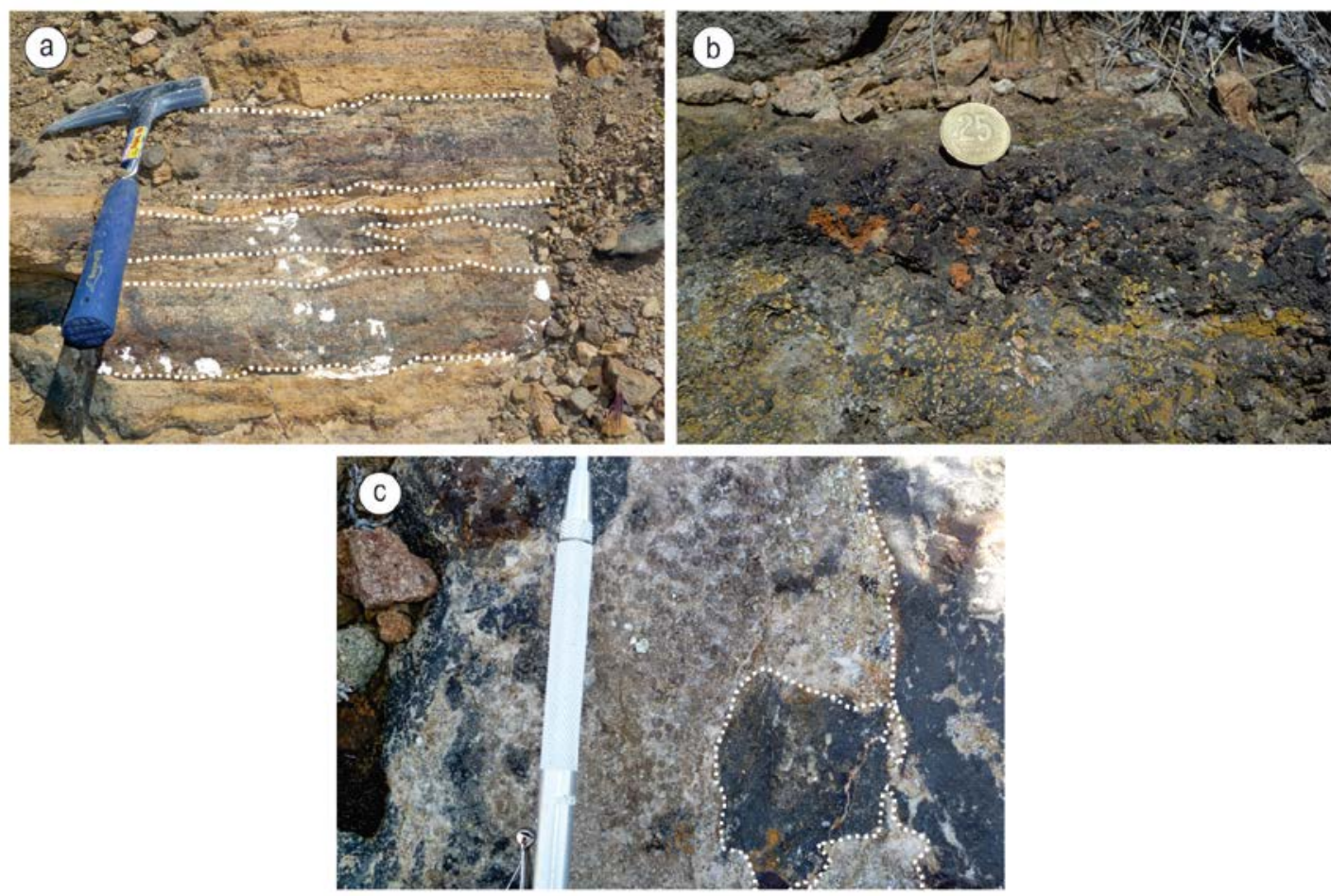

Figura 5.19: Afloramientos del Sector cerro Naunauco: a- manto de hierro laminado; b- cristales de magnetita recristalizada; c- caliza recristalizada, obsérvese como la magnetita invade a la caliza. Diámetro de la moneda $24 \mathrm{~mm}$.

La intrusión de cuerpos subvolcánicos de la Formación Colipilli en las sedimentitas del Miembro Chorreado dio lugar al desarrollo de una faja de alteración con la formación de las siguientes zonas: (1) calizas bandeadas, con fuerte recristalización. Estos bancos aparecen en asomos discontinuos pero se encuentran alineados, siguiendo el contacto con el intrusivo, (2) manto de hierro laminado (Fig.5.19a), cuyo espesor está en el orden de 1,5 m; está compuesto por magnetita parcialmente limonitizada por procesos meteóricos, (3) niveles carbonáticos finamente laminados, de coloración blanco grisácea, con cristales euhedrales a subhedrales de pirita de hasta $0,5 \mathrm{~cm}$ de tamaño, los cuales en general, se encuentran alterados a limonitas (Fig.5.19b). Análisis por difracción de rayos X de dichas piritas evidenciaron materiales de muy baja cristalinidad, casi amorfos, debido a que se encuentran intensamente alterados y reemplazados pseudomórficamente por limonitas. Estos niveles presentan alteración muscovítico-sericítica y reemplazo parcial por yeso, el cual desarrolla cristales prismáticos alargados y plumosos. Además, se identificó un diseminado de calcopirita y magnetita, en parte reemplazado por malaquita y limonitas; el espesor de esta zona es de $0,7 \mathrm{~m},(4)$ roca carbonática de coloración verdosa y grano fino; el espesor de esta zona es de unos pocos centímetros. Por último, la zona (5) es muy delgada y está compuesta por rocas blanquecinas de grano muy fino correspondientes a un nivel pelítico recristalizado. 


\section{Texturas asociadas a las mineralizaciones}

Las texturas que más se destacan en los depósitos investigados de baritina con sulfuros asociados son de tipo cebrada y brechosa. Con respecto a la primera, existe una gran diversidad de mineralizaciones a nivel mundial vinculadas a estas características texturales (por ej. yacimientos estratoligados de Pb-Zn-Ba-F tipo MVT) alojadas en rocas carbonáticas y depósitos de dolomita, magnesita y siderita (Tritlla et al., 2006). González Sánchez et al. (2009) asignan las texturas cebradas observadas en depósitos de baritinacelestina del estado de Coahuila, NE de México, a tipologías MVT.

La textura cebrada, o también denominada ritmita, está constituida por un bandeado composicional repetitivo compuesto por bandas oscuras y claras. Las bandas oscuras están integradas por niveles calcáreos en tanto que las claras por sulfatos. Entre los primeros estudios sobre el origen de estas texturas, se pueden mencionar a los de Fontboté y Amstutz (1983) quienes sobre la base de las observaciones realizadas en los depósitos estratoligados del Triásico alpino, sostienen que las texturas cebradas se generaron por procesos de recristalización diagenética (DCR). Por otra parte, Wallace et al. (1994) interpretan para los mismos depósitos que estas texturas se generaron por procesos de reemplazo y relleno. Nielsen et al. (1998) estudiaron las ritmitas dolomíticas, asociadas a los depósitos MVT en el macizo de Brabant-Gales (Bélgica) y proponen un origen epigenético, producto de procesos de reemplazo. Boni et al. (2000) consideran que las dolomitas cebradas, asociadas a los depósitos de $\mathrm{Ba}-\mathrm{Pb}-\mathrm{Ag}$ del suroeste de Cerdeña (Italia), fueron generadas a partir de un reemplazo epigenético. Lugli et al. (2000) proponen que las texturas cebradas de magnesita en los Pirineos occidentales (España) se formaron a partir de procesos de reemplazo metasomático a expensas de una roca carbonática, sosteniendo también un origen epigenético. Vanderginste et al. (2005) reconocen textura cebrada en las rocas carbonáticas de la faja plegada y corrida de las Montañas Rocallosas (Canadá) y las vinculan a procesos de reemplazo y recristalización, asociados a la circulación de salmueras cuencales, producto de esfuerzos tectónicos actuantes en la región. En la Cuenca Neuquina, ejemplos de textura cebrada han sido descriptos por Brodtkorb et al. (1975, 1982), Ramos y Brodtkorb (1990), entre otros; estos autores proponen un origen singenético mediante la precipitación rítmica y alternante de carbonatos y celestinas a partir del agua de mar. Hayase y Bengochea (1975) sugieren que el origen de la texturas cebradas en depósitos barito-celestínicos de la Formación Huitrín es producto de procesos de reemplazo epigenético de origen hidrotermal. 


\section{Texturas cebradas en las mineralizaciones del Sector San Eduardo}

La textura cebrada fue identificada en las calizas laminadas del Miembro Troncoso Superior. En muestra de mano, se caracterizan por una alternancia rítmica de bandas blanquecinas y otras castañas oscuras, cuyos espesores son milimétricos. Dicho bandeado composicional, en ocasiones, se ve interrumpido por pequeños desplazamientos de escasos milímetros de longitud o exhiben espejos de falla (Fig.5.20 a-b). En algunos casos la textura pierde lateralmente la ritmicidad y grada a arreglos brechosos (Fig.5.20c).

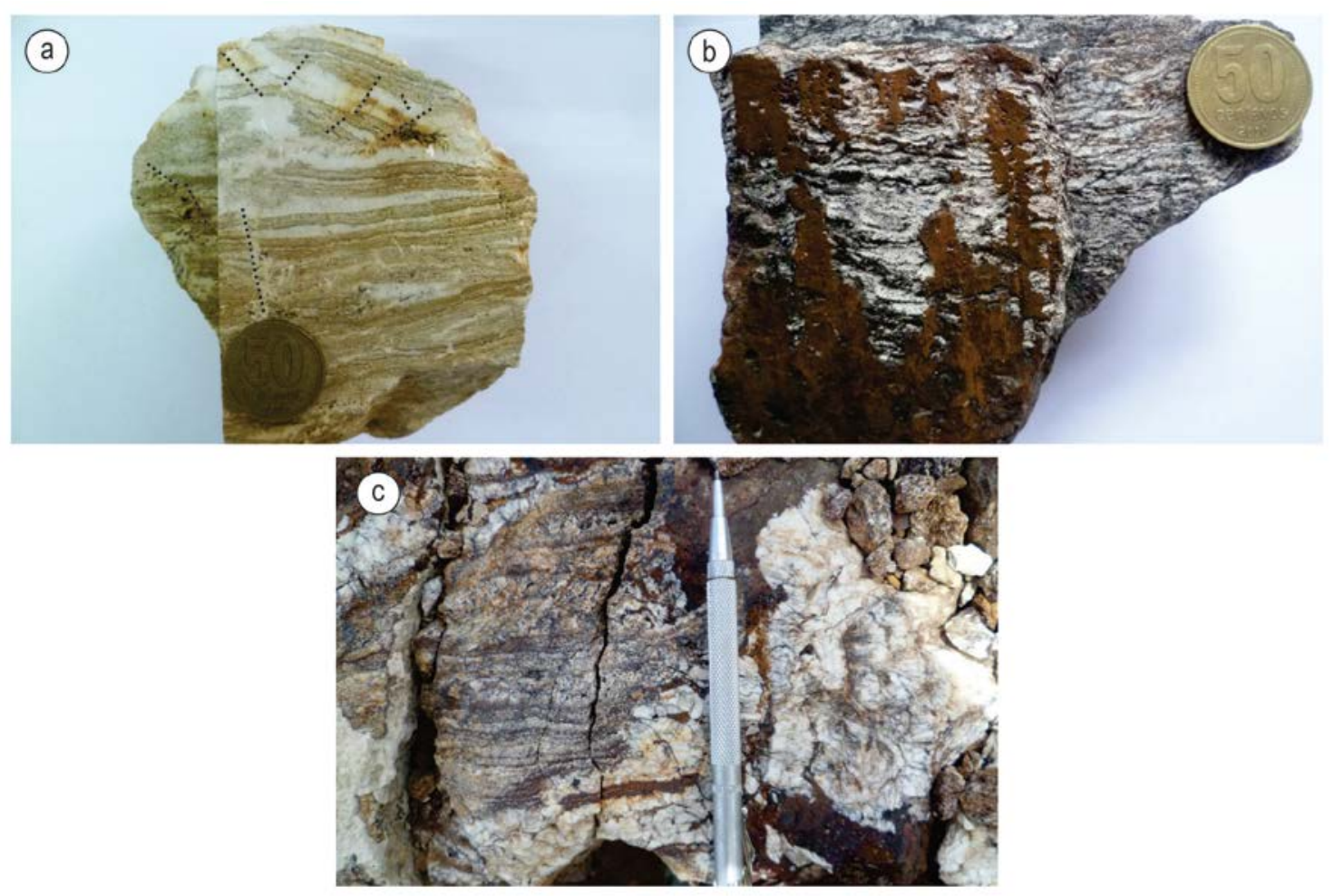

Figura 5.20: Textura cebrada en Sector mina San Eduardo: a- con pequeños desplazamientos, obsérvense las líneas punteadas; b- con espejo de falla; c- pierde lateralmente la ritmicidad y grada a arreglos brechosos. Diámetro de la moneda $25 \mathrm{~mm}$.

Las bandas claras están compuestas por baritina, con espesores de 0,3 cm en promedio. La baritina se presenta por sectores microgranosa y por otros, tabular de $1 \mathrm{~cm}$ en promedio de longitud. Algunos cristales se disponen de forma radial. Al microscopio, se presenta con hábito fibroso-prismático radial, con individuos de $2 \mathrm{~mm}$ de longitud; en algunas ocasiones presentan crecimiento bipolar. El crecimiento de estos cristales generó una sobrepresión interna fracturando y desplazando las bandas carbonáticas (Fig.5.21 a-b). Ciertos cristales muestran microfracturas y éstas están rellenas de material carbonático. En estas bandas, se reconocieron estructuras de disolución microestilolíticas con pirita dispersa de tamaño milimétrico (Fig.5.21 c-d). Estas superficies de disolución se encuentran rellenas de óxidos de hierro. 

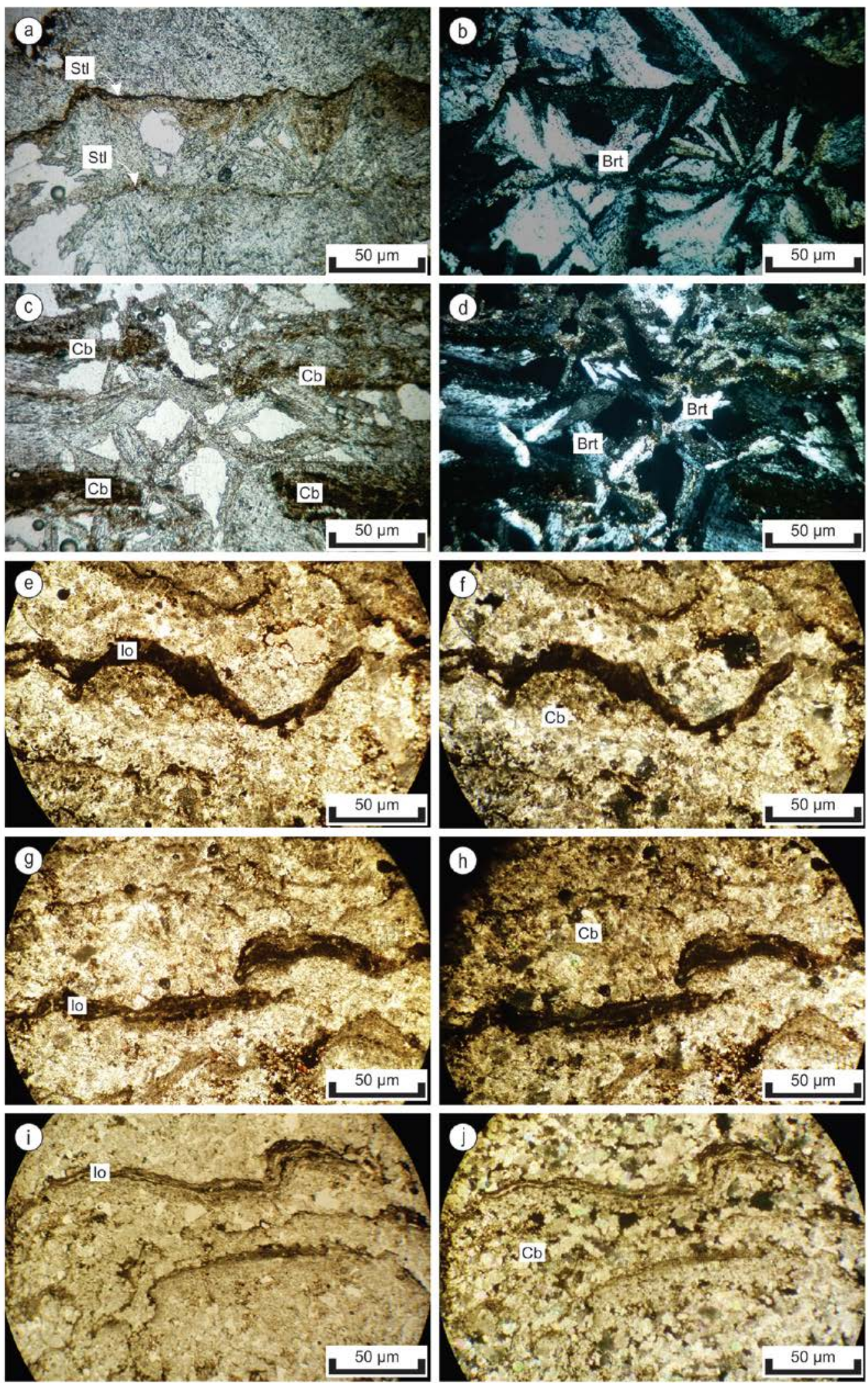

Figura 5.21: Fotomicrografías de textura cebrada en Sector mina San Eduardo: a-b: banda clara compuesta por cristales fribroso-radiales de baritina (Brt), nótese la superficie de disolución (microestilolita, $\mathrm{Stl}$ ), sin y con nicoles respectivamente; c-d: banda castaño oscura (carbonatos, $\mathrm{Cb}$ ) interrumpida por el crecimiento de cristales euhedrales de Brt, con y sin nicoles respectivamente; e$\mathrm{j}$ : láminas ondulantes (lo) de coloración rojiza en mosaico carbonático $(\mathrm{Cb})$. a-c-e-g-i: nicoles paralelos. b-d-f-j: nicoles cruzados. 
Los niveles castaño oscuros son de composición carbonática, de tamaño muy fino y presentan espesores de $0,5 \mathrm{~cm}$ en promedio. Dichas bandas heredan la laminación de la caliza microbial; en algunos sectores se encuentran delimitados por estilolitas en las cuales también se observan piritas lixiviadas y en otros se ven como dichas bandas son cortadas por vetillas de baritina. Al microscopio los cristales de carbonato de calcio son de tamaños del orden de micrómetros y se encuentran constituyendo un mosaico micrítico a microesparítico. En estos niveles se identificaron láminas ondulantes con coloración rojiza de hasta $10 \mu \mathrm{m}$ de espesor que se extienden de forma continua y discontinua a la laminación (Fig.5.21 e-j).
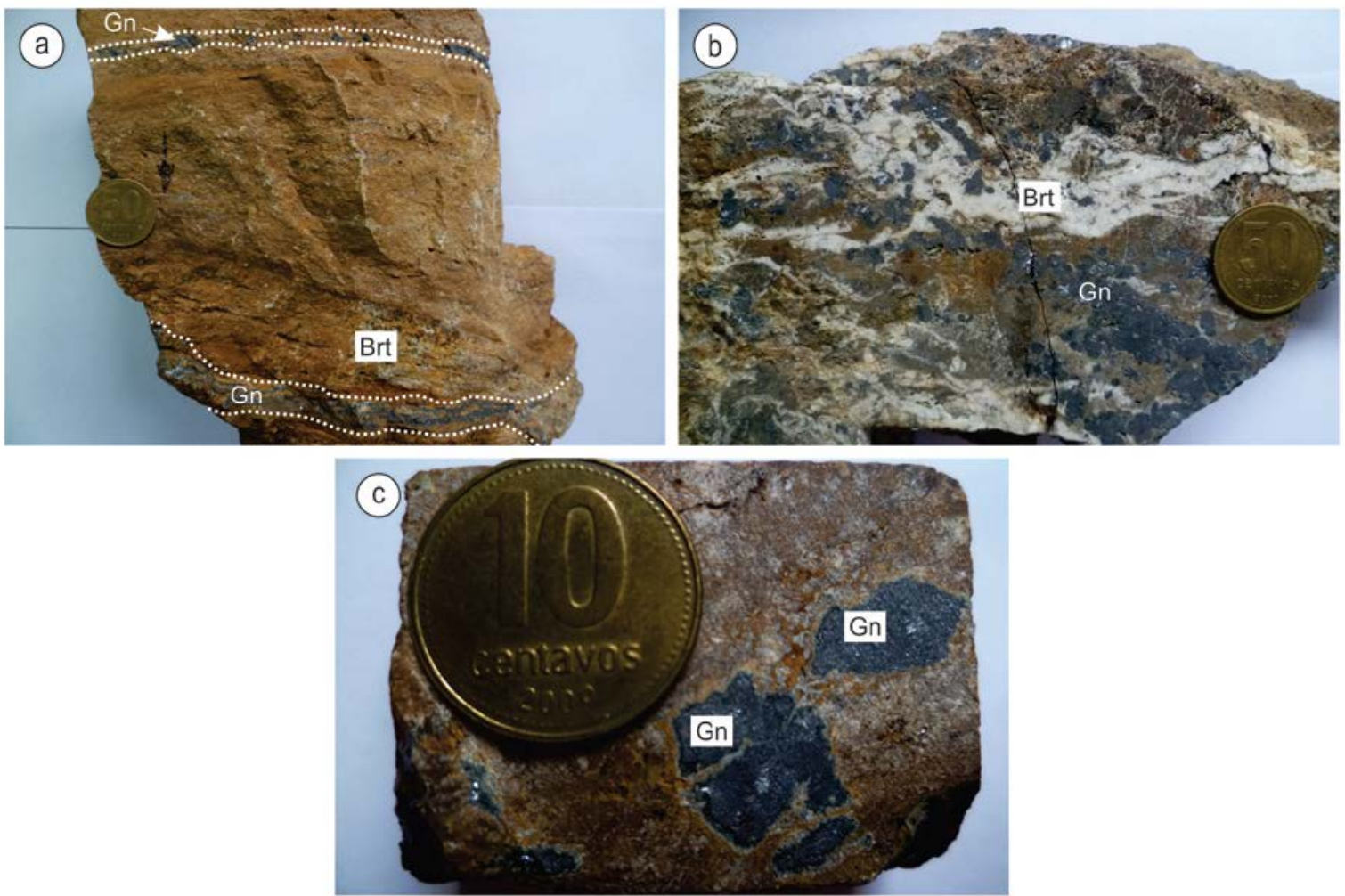

Figura 5.22: Mineralización en mina La Bienvenida: a- baritina (Brt) microgranosa y galena (Gn) heredando la laminación fina de la roca de caja, obsérvense las líneas punteadas; b- Brt recristalizada y Gn, nótese que aquí la laminación es grosera; c- detalle de cristales de Gn. Diámetro de monedas: $25 \mathrm{~mm}(\mathrm{a}-\mathrm{b})$ y $18 \mathrm{~mm}$ (c).

Posteriormente, se observa sobreimpuesta una calcitización penetrativa que afecta a ambas conjuntos de bandas y en consecuencia a todo el banco mineralizado.

Por otro lado, en la mina La Bienvenida la mineralización está alojada en areniscas finas del Miembro Troncoso Inferior (Fig.5.10). La baritina se presenta bajo la forma de cristales microgranosos (menores al centrímetro) heredando la laminación fina de las areniscas (Fig.5.22a) y recristalizada con tamaños de hasta $2 \mathrm{~cm}$, acompañada de granos de galena bien desarrollados (Fig.5.22 b-c). Al microscopio se reconoció baritina, galena y 
pirita (Fig.5.23); la primera se muestra sub- a euhedral, con hábito tabular-prismático de hasta $0,5 \mathrm{~cm}$ de longitud; en algunos cristales se identificó una incipiente alteración a carbonatos. La galena se presente en individuos subhedrales, de hasta $0,08 \mathrm{~cm}$ de tamaño y sus bordes se encuentran alterados a cerusita. En algunos granos de galena se observaron inclusiones de pirita de muy pequeño tamaño y se encuentran parcialmente limonitizados.
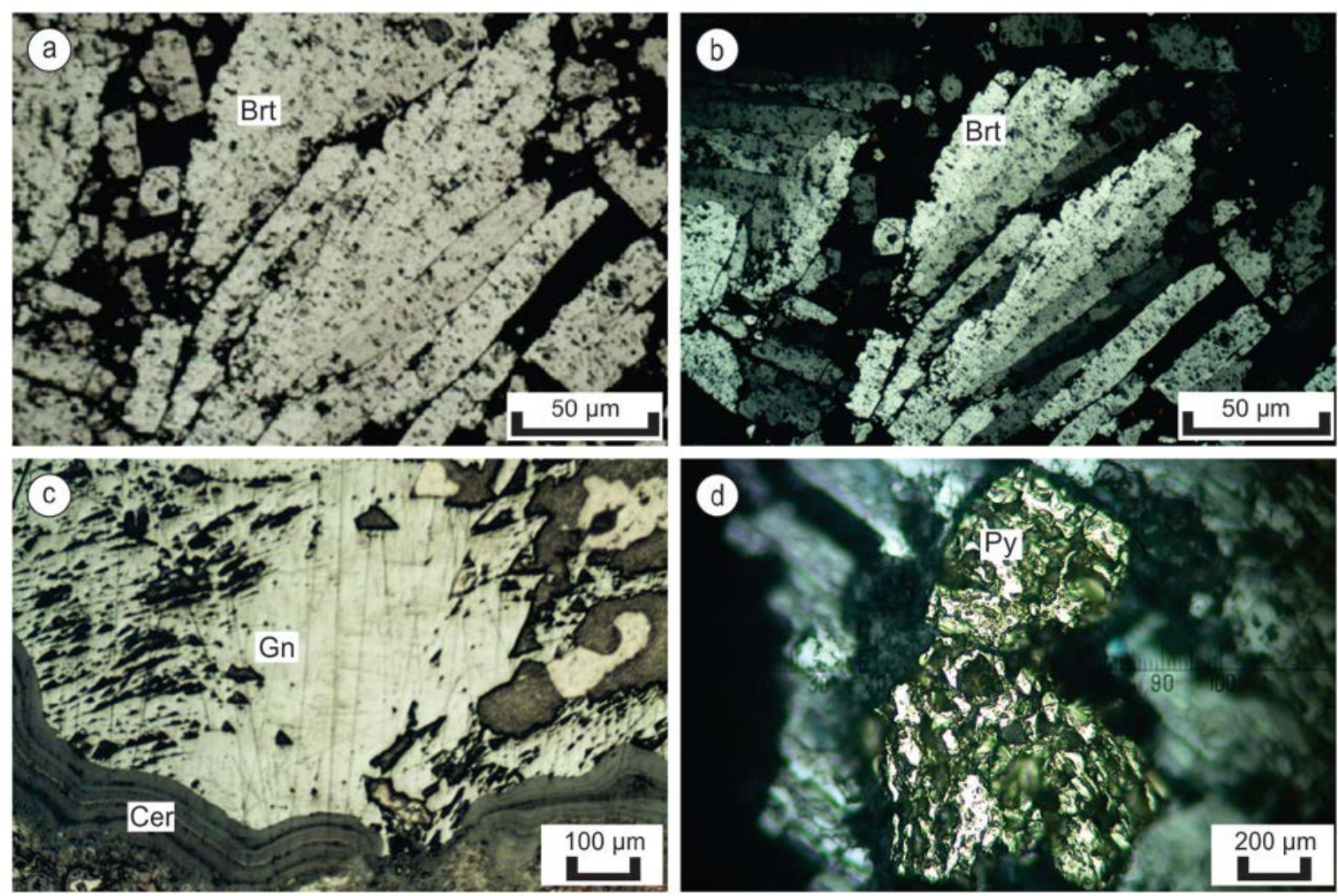

Figura 5.23: Mina La Bienvenida. Fotomicrografías de: a-b: cristales de baritina (Brt) recristalizada, sin y con nicoles cruzados respectivamente; c- individuo de galena (Gn), obsérvese en el contorno del cristal la alteración a cerusita (Cer); d- cristales de pirita (Py) hospedados en Gn.

\section{Texturas brechosas en las mineralizaciones de los sectores: San Eduardo, La Bruja -}

\section{Julio César y La Esperanza - Carlita}

En el primer sector (San Eduardo) la mineralización barítica vetiforme, caracterizada por cristales euhedrales de hábito tabular grueso, de hasta $5 \mathrm{~cm}$ de longitud, se vincula a zonas de brecha tectónica en las que se presenta como cemento (Llambías y Malvicini 1978). Los clastos son principalmente de caliza laminada de tamaño variable; algunos de ellos están rotados, fracturados y otros exhiben textura cebrada (Fig.5.9e y Fig.5.24 a-b). A su vez, estas brechas presentan clastos con la ya mencionada mineralización sulfurosa, otorgándole una coloración heterogénea, compuesta principalmente por granos de galena bien desarrollados y acompañados, en forma subordinada, por individuos de esfalerita, calcopirita, pirita y tetraedrita (Fig.5.8 a-b y 
Fig.5.24 c-d). Cabe destacar que se observan cristales de baritina cortando a los mencionados sulfuros y sulfosales, por lo que claramente existen al menos dos generaciones de baritina. El estudio al microscopio permitió reconocer baritina, galena, esfalerita, tetraedrita, calcopirita y pirita. Los cristales de baritina son sub- a euhedrales con hábito tabular a prismático y fibroso-radial (Fig.5.25 a-f); sus tamaños, en general, son de $0,3 \mathrm{~cm}$ de longitud. La gran mayoría se encuentra microfracturado y, en algunos cristales, se pudo distinguir que están rellenos de material carbonático. Los granos de galena (Fig.5.25g) muestran combinaciones de cubo con octaedro y sus tamaños en promedio son de $0,2 \mathrm{~cm}$, estando sus bordes alterados a cerusita. En la galena se observaron inclusiones de calcopirita con hábito subhedral y tamaño de $0,5 \mathrm{~mm}$. La esfalerita y tetraedrita, determinadas por microsonda electrónica (ver capítulo 6), se encuentran como inclusiones muy pequeñas en individuos de calcopirita y galena. También, asociados a galena, se observaron huecos de forma cúbica de tamaño milimétrico que corresponden a pirita totalmente lixiviada (Fig.5.25h).
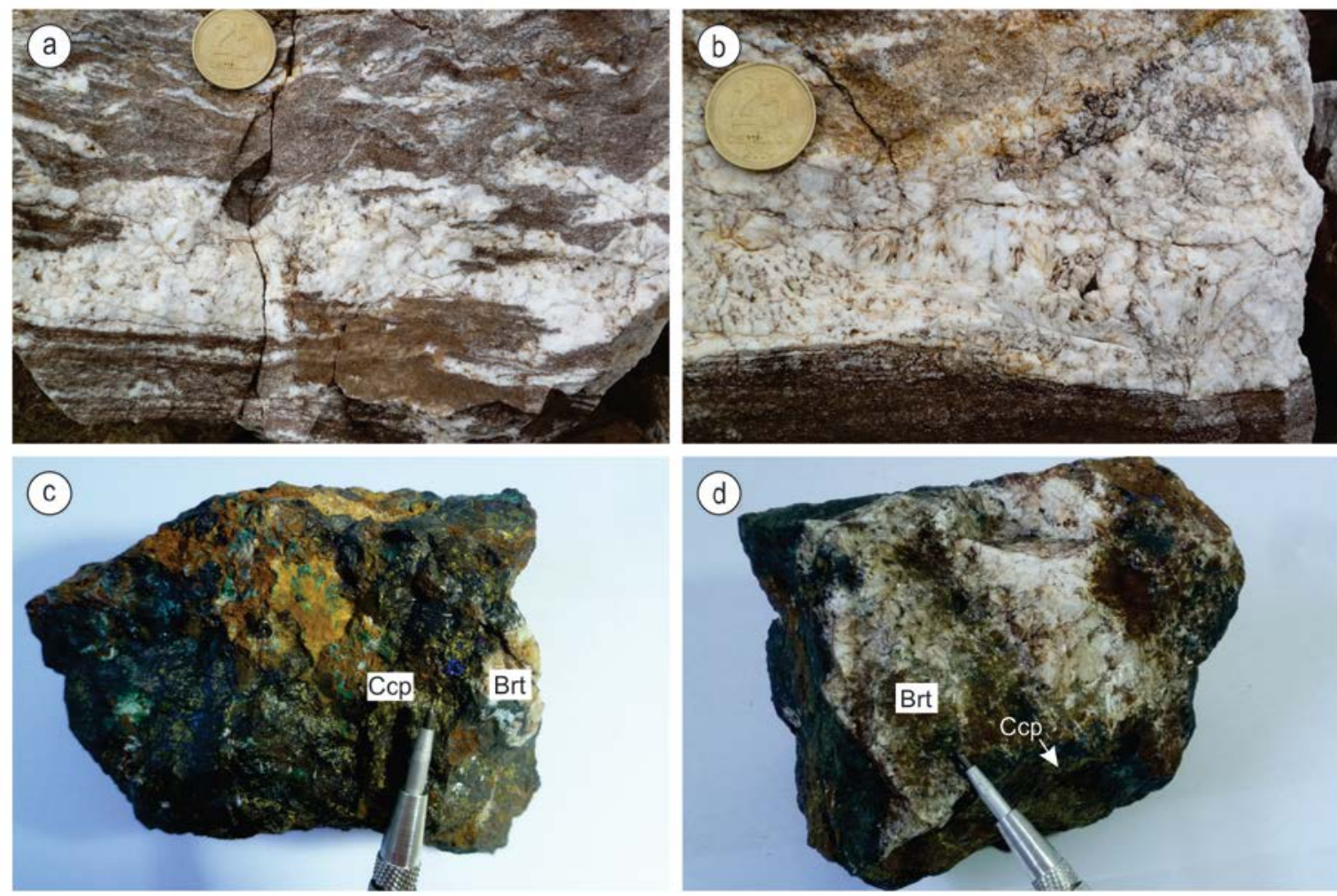

Figura 5.24: Textura brechosa en el Sector mina San Eduardo: a-b: con clastos de caliza con textura cebrada; c-d: con mineralización sulfurosa. Diámetro de la moneda $24 \mathrm{~mm}$. 

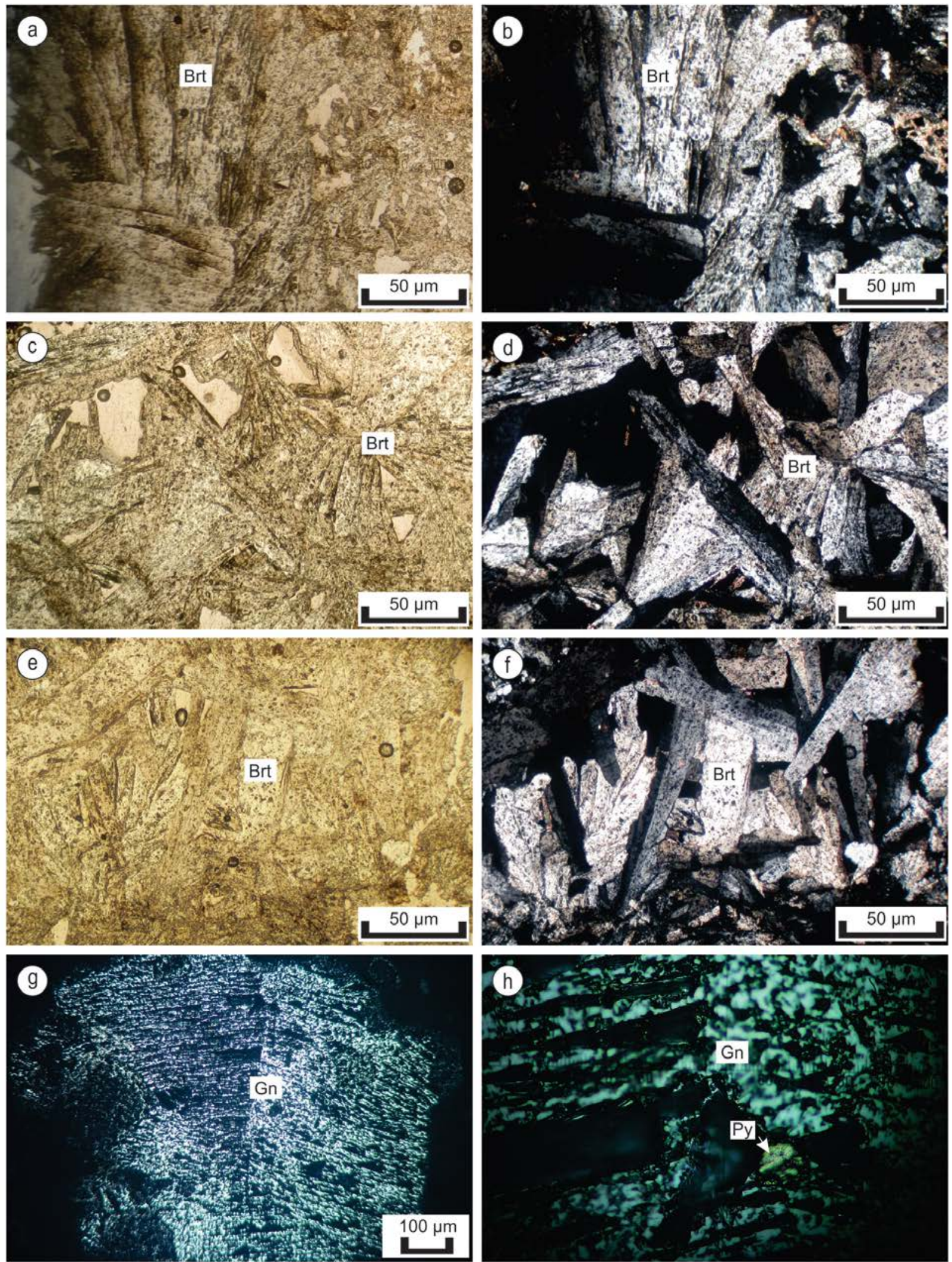

Figura 5.25: Fotomicrografías de cristales de: baritina (Brt) con hábito tabular a prismático (a-b y e-f) y con hábito fribroso-radial (c-d), sin y con nicoles cruzados respectivamente; g- galena (Gn); h- Gn con inclusión de pirita (Py), en el Sector mina San Eduardo. 
Los sectores La-Bruja - Julio César y La Esperanza - Carlita reúnen características geológicas similares. En líneas generales, en muestra de mano, la mineralización se presenta con fragmentos de cristales de baritina espática con hábito tabular grueso de hasta $10 \mathrm{~cm}$ de longitud y clastos con cristales de galena en cantidades escasas, dispuestos al azar sobre una matriz de color castaño a negro, compuesta por óxidos-hidróxidos de hierro y manganeso; en algunos sectores en los que estos últimos son predominantes el aspecto se torna pulverulento (Fig.5.13 y Fig.5.15). La baritina forma agrupamientos irregulares, de diferente tamaño, algunos granos son de pocos centímetros y otros de hasta $10 \mathrm{~cm}$ de longitud, con frecuencia se exhiben fracturados y flexurados. En cuanto a los granos de galena son de hasta $1,5 \mathrm{~cm}$ de tamaño y se presenten agrupados formando sectores ricos en estos sulfuros; algunos de ellos están parcialmente alterados. El estudio al microscopio petrocalcográfico permitió identificar cristales de baritina, galena y pirita. Los primeros se muestran límpidos, euhedrales, con hábito tabular-prismático y tamaño promedio de 0,7 cm (Fig.5.26 a-b). Todos estos cristales se distribuyen con un arreglo caótico, pero hay sectores que se muestran con hábito fibroso-radial, reflejando las texturas en peine y semisoles en escala mesoscópica. La galena se presenta con desarrollo subhedral a euhedral, 0,1 cm de tamaño en general y en algunos casos se observa, alrededor del contorno del cristal, cerusita como alteración (Fig.5.26 c-d). La pirita se reconoce en cristales cúbicos muy pequeños (de hasta $0,08 \mathrm{~cm}$ ) en forma diseminada; algunos individuos están parcialmente reemplazados por limonita.
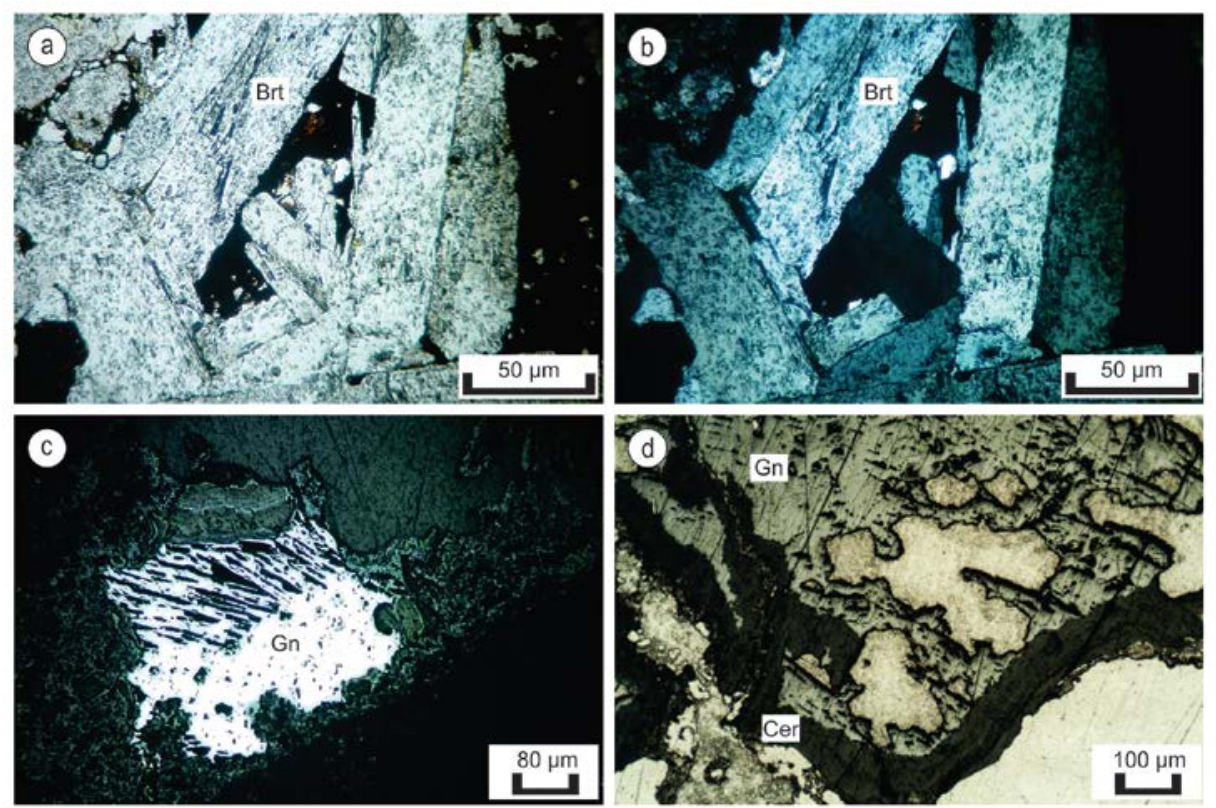

Figura 5.26: Fotomicrografías de cristales de: a-b: baritina (Brt) de hábito tabular-prismático, sin y con nicoles cruzados respectivamente; c-d: galena $(\mathrm{Gn})$, obsérvense en (d) los contornos del cristal alterado a cerusita (Cer), en Sector de minas La Bruja - Julio César y La Esperanza - Carlita. 


\section{Descripción textural de las mineralizaciones de óxidos de hierro}

La principal textura de las mineralizaciones ferríferas es maciza y en menor grado, diseminada.

En el Sector de mina Augusta los cristales de magnetita forman agregados macizos con individuos sub a euhedrales y de grano fino $(0,1 \mathrm{~cm}$ en general), aunque a veces, hay cristales bien desarrollados de hasta $1,5 \mathrm{~cm}$ maclados según la ley de espinelo. Bajo lupa binocular se observó que la forma más común de estos cristales es la octaédrica, pero también se identificaron combinaciones de octaedro con cubo. Al microscopio petrocalcográfico se presentan con un tamaño máximo de $0,1 \mathrm{~cm}$ y parcialmente martitizados; a su vez, se reconocieron cristales de hábito laminar-tabular de hasta $0,3 \mathrm{~cm}$ de longitud los cuales son magnéticos (Fig.5.27).
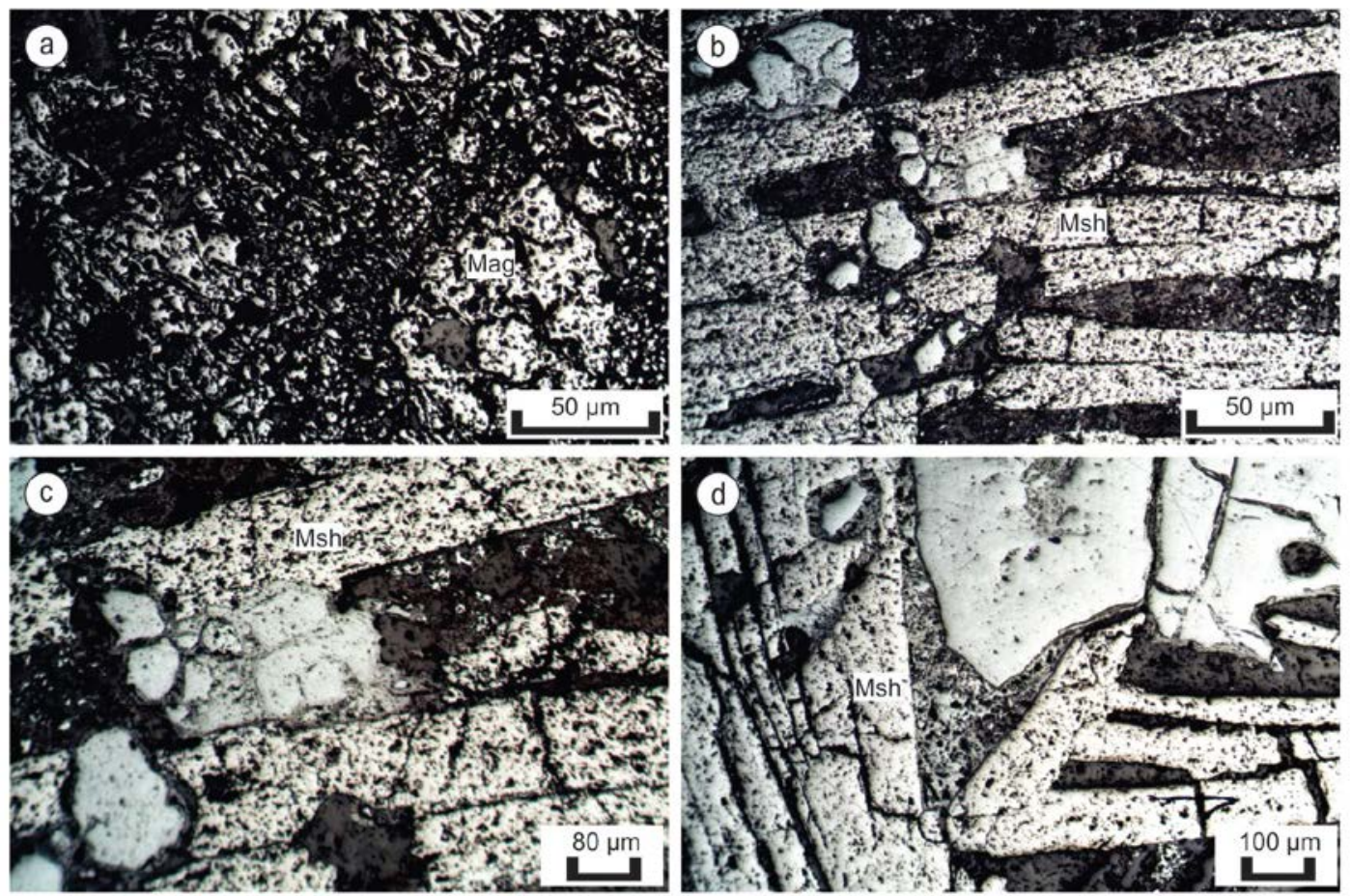

Figura 5.27: Fotomicrografías en microscopio calcográfico de: a- magnetitas (Mag) octaédricas; bc-y d: cristales de mushketovita (Msh) en el Sector mina Augusta. Nicoles cruzados.

La primera mención de magnetitas laminares en el área de Colipilli fue realizada por Malvicini (1977). Dicha magnetita laminar no es otra que la variedad mushketovita caracterizada por ser una magnetita pseudomórfica según especularita. La primera mención de hallazgo de mushketovita en Argentina, corresponde a Arrospide (1972) y Pons (2007). Estos autores, llevando a cabo investigaciones en el área de Vegas Peladas, sur de Mendoza, reconocieron cristales tabulares-lamelares de un mineral magnético de apariencia de hematita en depósitos de skarn generados en las sedimentitas cretácicas. La 
mushketovita es un mineral típico de ambiente de skarn, donde los fluidos metasomáticos la generaron a partir de procesos de reemplazo pseudomórfico. En los mencionados cristales de mushketovita, mediante análisis por energía dispersiva de rayos $\mathrm{X}$, se identificaron múltiples inclusiones de scheelita en granos xenomórficos que conforman un diseminado a lo largo de los cristales de magnetita laminar (ver capítulo 6). Una intensa alteración supergénica se manifiesta por oxidación de los cristales de magnetita bajo la forma de goethita y limonitas.
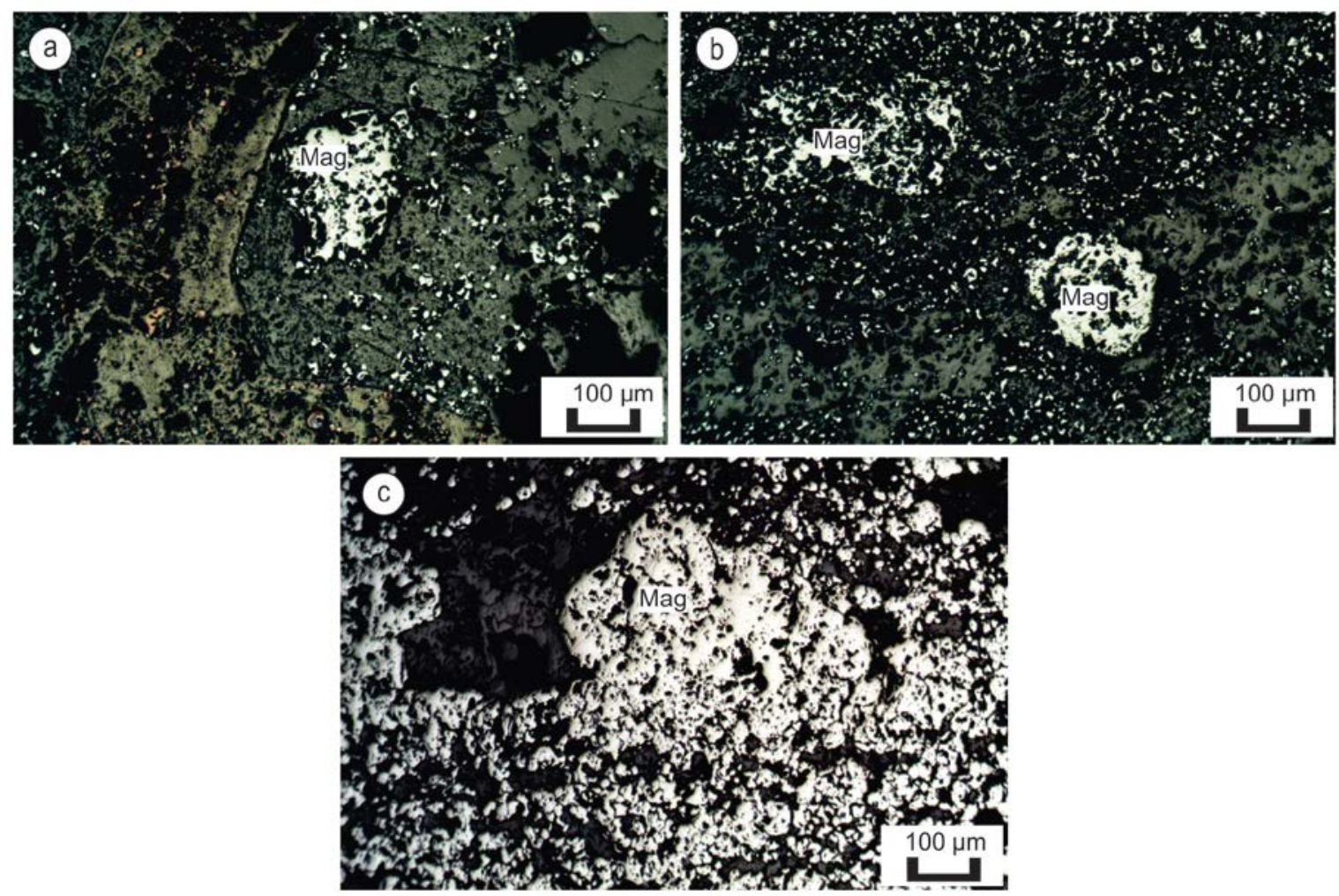

Figura 5.28: Fotomicrografías en microscopio calcográfico de magnetita (Mag) del Sector Naunauco. Nicoles cruzados.

En el Sector del cerro Naunauco la roca calcárea en la cual se aloja el manto de hierro presenta individuos de magnetita recristalizados de grano grueso de hasta $0,5 \mathrm{~cm}$ de tamaño, hábito cúbico y octaédrico, en ocasiones con maclas de contacto; otros cristales se encuentran formando una masa granular de tamaño muy fino; éstos últimos, al microscopio, se presentan con hábito cúbico y octaédrico, tamaño medio de $0,6 \mathrm{~cm}$ y con rasgos de martitización (Fig.5.28). También se reconocieron láminas flexuradas de biotita desferrizada de $0,01 \mathrm{~cm}$ de tamaño máximo y cloritas ferrosas con hábito fibroso que alcanzan un tamaño máximo de $0,004 \mathrm{~cm}$. En cuanto a los cristales de pirita, se presentan euhedrales a subhedrales de hasta $0,4 \mathrm{~cm}$ de tamaño que, en general, se encuentran reemplazados pseudomórficamente por limonitas. 


\section{Control litoestratigráfico y estructural}

La mineralización barítico-polimetálica se aloja mayoritariamente en las facies: carbonáticas de tipo grainstone oolítico y mudstone del Miembro Chorreado, arenosas finas silicoclásticas pertenecientes al Miembro Troncoso Inferior y carbonáticas de tipo boundstone desarrolladas en el Miembro Troncoso Superior de la Formación Huitrín. Dichas litologías son porosas y permeables, por lo que constituyen canales muy propicios para la circulación de los fluidos mineralizantes. Estas características fueron señaladas por de Barrio et al. (2009) en los niveles de calizas laminares correspondientes a la Formación Huitrín en diferentes depósitos barito-celestínicos emplazados en la secuencia fundamentalmente eocretácica del Neuquén donde el desarrollo de las mineralizaciones está espacialmente relacionado a los mencionados horizontes porosos y permeables. Por otro lado, las mineralizaciones se encuentran en los flancos de las grandes estructuras anticlinales, las cuales forman parte de la Faja Plegada y Corrida del Agrio (FPyCA), estructurada como resultado de la deformación andina.

La primera etapa de deformación de la FPyCA, en el Cretácico Tardío (Zamora Valcarce 2007), provocó el plegamiento y fallamiento de la secuencia sedimentaria. Durante este evento estructural, acompañado de la instauración del arco volcánico en el área de Colipilli, se generaron zonas de fractura que muy posiblemente funcionaron como conductos que favorecieron el transporte y la migración de fluidos. Uno de los aspectos más relevantes de la dinámica de intrusión de los cuerpos ígneos, vinculada al mencionado arco volcánico, radica en que este magmatismo pudo haber aportado calor suficiente como para generar celdas convectivas en las aguas formacionales que estarían directamente involucradas en la lixiviación de los elementos metálicos de la pila sedimentaria, constituida en gran parte por rocas carbonáticas y areniscas altamente reactivas. Es por este motivo que se considera que el primer evento de mineralización mantiforme hidrotermal (depósitos baríticos y de óxidos de hierro) está relacionado con dicha estructuración. La presencia de varios planos de megafractura de orientación preferencial E-O a ENE-OSO (identificables en las imágenes satelitales como grandes lineamientos) y otros planos menores de debilidad como discordancias y superficies interestratales, facilitaron la circulación de los fluidos mineralizantes como así también el ascenso del magma andesítico-dacítico del Grupo Naunauco. Por este hecho particular gran parte de los depósitos estratoligados se encuentran emplazados tanto en las superficies de discordancia 
entre los Miembros Chorreado y Troncoso Inferior como siguiendo los mencionados planos interestratales.

La segunda etapa de deformación de la FPyCA ocurrida durante el Mioceno (Zamora Valcarce 2007) está asociada a la reactivación de las estructuras y actividad ígnea (Grupo Huantraico); ésta última en el centro norte de la provincia. Se considera que dicho evento, fundamentalmente la reactivación estructural, puede haber promovido los procesos de removilización y relleno de la baritina y los óxidos-hidróxidos férricos, dando lugar a nuevas pulsaciones mineralizantes y removilizaciones en los depósitos vetiformes de San Eduardo y Cerro Negro.

\section{Discusión y Conclusiones Parciales}

El análisis detallado de las texturas cebradas reveló que la alternancia rítmica de bandas blanquecinas y otras castaño oscuras es indicadora del reemplazo preferencial del carbonato de calcio por baritina. Por otra parte, la identificación del alto grado de cristalinidad y crecimiento bipolar de cristales de baritina ponen en evidencia que actuaron procesos de relleno en los cuales los fluidos mineralizantes circularon, principalmente, por la marcada laminación microbial y superficies microestilolíticas de las calizas. Las rocas del Sector San Eduardo exhiben pequeñas fracturas con desplazamientos que interrumpen la alternancia rítmica de las bandas claras y oscuras (Fig.5.20a) al igual que sucede con las dolomías del sur del macizo de Brabant-Gales, Bélgica, reportadas por Nielsen et al. (1998). Según estos autores este tipo de microestructuras es típico de las texturas cebradas. Las texturas reconocidas por Vanderginste et al. (2005) en las rocas carbonáticas de las Montañas Rocallosas, Canadá, responden a similares procesos por esfuerzos tectónicos actuantes en la región. Asimismo, las superficies de disolución observadas pueden ser producto del soterramiento de la secuencia sedimentaria o el producto de la sobrecarga tectónica ocurrida en el área.

Se considera que la génesis de la textura cebrada en las mineralizaciones estudiadas estuvo influenciada por la circulación de fluidos hidrotermales (ya sean aguas de formación o connatas), la actividad magmática y la estructuración del área. Se puede sintetizar en las siguientes (Fig.5.29) tres etapas: (1) A partir de la caliza estromatolítica compactada, los planos de laminación junto con las superficies de disolución (estilolitas), se convierten en planos de debilidad actuando como zonas de mayor permeabilidad; (2) la circulación de los fluidos mineralizantes fue beneficiada por estos planos, generando 
procesos de relleno selectivo y reemplazo de las bandas carbonáticas; (3) posteriormente, la nucleación y crecimiento de los cristales de baritina generó una sobrepresión interna del fluido, provocando fracturación y desplazamiento de los niveles carbonáticos hasta generar la rotación de los mismos y evolucionar hasta conformar una brecha.
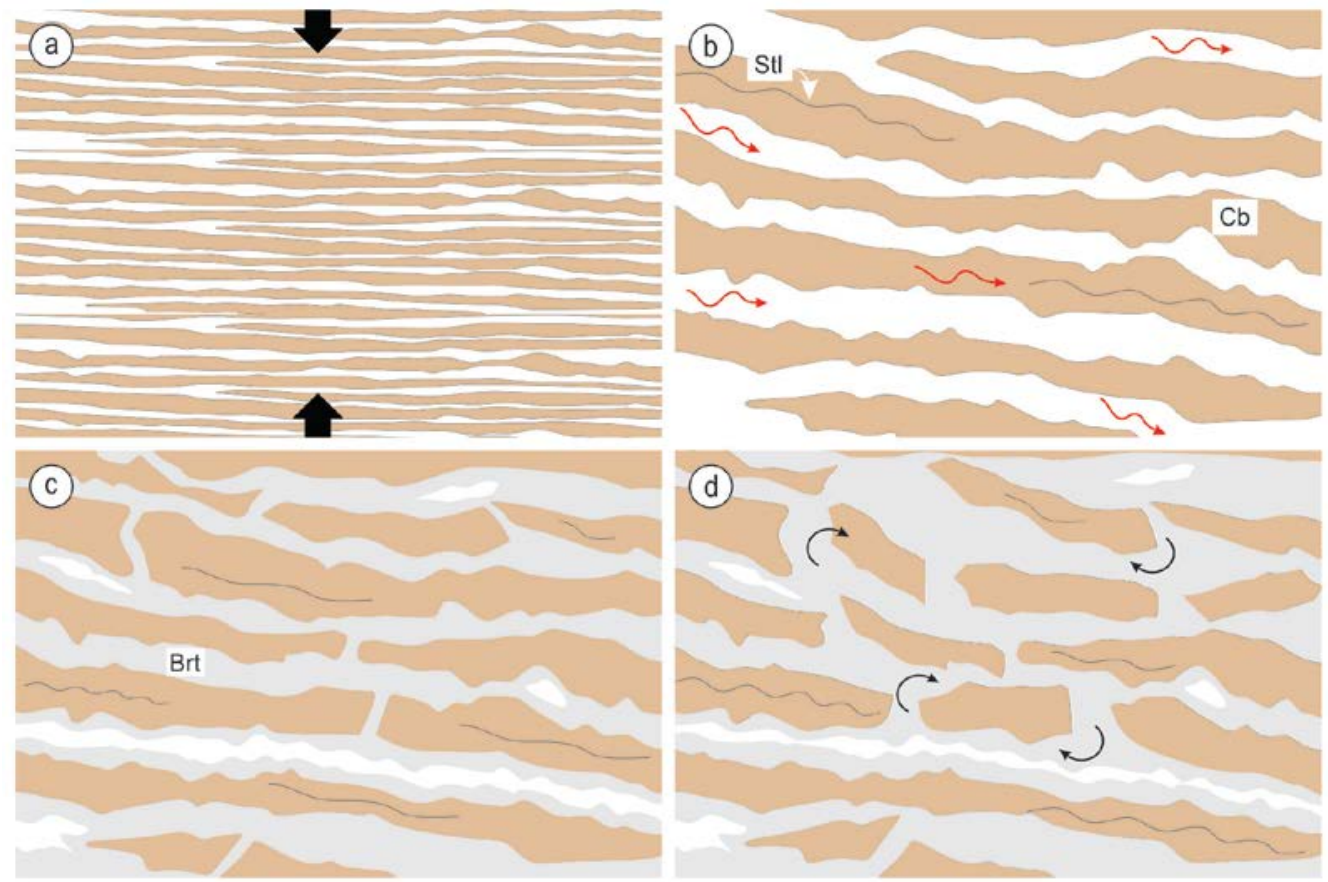

Figura 5.29: Etapas de formación de la textura cebrada: a- caliza estromatolítica compactada; bcirculación de fluidos a través de los planos de laminación y superficie de disolución (microestilolitas, Stl); c- textura cebrada a partir de procesos de reemplazo y relleno de las bandas carbonáticas $(\mathrm{Cb})$; d- rotación de las bandas carbonáticas, a partir del crecimiento de los cristales de baritina (Brt), conformándose brechas. Modificado de Escobar (2016).

Las láminas ondulantes identificadas en las bandas carbonáticas (Fig.5.21 e-j), podrían corresponder a materia orgánica, concentrada bajo dicha forma, como resultado de la actividad de algunos tipos de cianobacterias (Stal y Krumbein 1986).

Por otra parte, la identificación de cristales de baritina fracturados, flexurados, reemplazados y cementados por nuevos minerales de la misma naturaleza u otra (minerales sulfurosos) en rocas de los sectores San Eduardo, La Bruja - Julio César y Carlita - La Esperanza, evidencia que las texturas brechosas se intercalaron con sucesivos pulsos mineralizadores. La reactivación de las estructuras durante el Mioceno puede haber causado procesos de removilización y relleno, facilitados por los numerosos planos de debilidad, dando origen a las mineralizaciones vetiformes y beneficiando los procesos de enriquecimiento de la mineralización secundaria. 
Con respecto a las mineralizaciones de hierro, tanto en el Sector de mina Augusta como en el cerro Naunauco, se formaron a partir de procesos de reemplazo metasomático de la roca de caja carbonática; en el primero se observa, a escala microscópica, que la magnetita reemplazó al material carbonático aprovechando los planos de clivaje del mismo y en el segundo, se evidencia dicho proceso por heredar la estratificación fina de la roca carbonática. A su vez, la presencia de mushketovita e inclusiones de scheelita en el Sector de mina Augusta es indicadora de que ocurrieron procesos hidrotermales metasomáticos. Por otro lado, en el Sector Naunauco se produjo el desarrollo de asociaciones de alteración que siguiendo el esquema secuencial propuesto por McIntyre et al. (2005) para el prospecto Amargosa de la Baja California (México), pueden agruparse por lo tanto en los siguientes tipos: calco-sódica (magnetita+clorita), potásica (biotita+sericita), alteración calco-sódica (clorita+magnetita+calcopirita) y de cobre (calcopirita diseminada). Cabe mencionar que estas dos últimas están acompañadas por procesos de martitización. Por otra parte, la baja cristalinidad de las piritas evidenciada al microscopio y en los difractogramas, confirma la formación de materiales hidroxidados casi amorfos de composición ferrífera. La caracterización de los fluidos mineralizantes se desarrollará en los capítulos 6 y 7.

En conclusión, se observa que las mineralizaciones barítico-polimetálicas del área de Colipilli presentan un carácter epigenético, en yacencias estratiformes y vetiformes, con texturas laminadas cebradas y brechosas predominantes según la intensidad de los procesos actuantes, los cuales han sido de relleno y reemplazo, asociados a fluidos hidrotermales de diferente naturaleza química. Por un lado, con predominancia del Ba sobre los elementos metalíferos, en otros con removilización de esta paragénesis y con texturas de recristalización y en forma accesoria, paragénesis de minerales de $\mathrm{Fe} \mathrm{y} \mathrm{W}$ accesorio, esencialmente generadas en litologías carbonáticas. 


\section{Trabajos citados en el texto}

Angelelli, V., Schalamuk, I.B. y Arrospide, A. 1976. Los yacimientos no metalíferos y rocas de aplicación de la región Patagonia-Comahue. Secretaría de Estado de Minería, Anales 17: 1146. Buenos Aires.

Arrospide, A., 1972. Depósitos Minerales de Hierro de Vegas Peladas Mina Nenche. Dep. de Malargüe, Mendoza, Argentina. Revista de la Asociación Argentina de Mineralogía, Petrología y Sedimentología, 3: 117-131.

Brodtkorb, M.K., Ramos, V.A. y Ametrano, S. 1975. Los yacimientos estratoligados de celestina baritina de la Formación Huitrín y su origen evaporítico. Provincia del Neuquén. Argentina. II Congreso Iberoamericano Geología Económica, 2:143-168. Buenos Aires.

Brodtkorb, M.K.; Ramos, V.A.; Barbieri, M. y Ametrano, S., 1982. The Evaporitic Celestite-Barite Deposits of Neuquén, Argentina. Mineralium Deposita 17: 423-436.

Boni, M., Parente, G., Bechstädt, T., De Vivo, B. y Lannace, A. 2000. Hydrothermal dolomites in SW Sardinia (Italy): evidence for a widespread late-Variscan fluid flow event. Sedimentary Geology, 131: 181-200.

Calner, M., Erikson, M.A. 2011. The record of microbially induced sedimentary structures (MISS) in the Swedish Paleozoic, en Nofke, N., Chafetz, H. (Eds.), Microbial mats in siliciclastic depositional systems through time: Tulsa, Society for Sedimentary Geology, 29-35.

Danieli, J.C. y Casé, A.M. 2004. Neuquén. En: Historia de la minería Argentina. Tomo 2. Anales 40, 237-245. SEGEMAR. Buenos Aires.

de Barrio, R.E., Del Blanco, M., García, M. Martin-Izard, A. 2009. Estructuras estromatolíticas y su relación con las mineralizaciones de Ba-Sr emplazadas en la Formación Huitrín, Cuenca Neuquina. $9^{\circ}$ Congreso de Geología Económica: 45-51.

Escobar, R.I. 2016. Geología y génesis de las mineralizaciones barito-celestínicas asociadas a la secuencia cretácia entre las localidades Bajada del Agrio y Chos Malal, provincia del Neuquén. Tesis Doctoral, Universidad Nacional de La Plata. (Inédito). 207 p., La Plata.

Escobar, R.I., Salvioli, M.A, de Barrio, R.E., Lanfranchini, M.E. y Etcheverry, R.O. 2013. Texturas cebradas asociadas a las mineralizaciones de Ba-Sr alojadas en la Formación Huitrín, entre Chos Malal y Bajada del Agrio, Neuquén. Actas del XI Congreso de Mineralogía y Metalogenia: 211-216. San Juan.

Fontboté, L. y Amstutz, G.C. 1983. Facies and sequence analysis of diagenetic crystallization rhythmites in strata-bound $\mathrm{Pb} \pm \mathrm{Zn} \pm(\mathrm{Ba} \pm \mathrm{F})$ deposits in the Triassic of Central and Southern Europe. En: Mineral Deposits of the Alps and of the Alpine Epoch in Europe (Ed. H.G. Schneider), 347-358. Heidelberg.

Gabriele, N.A. 2016. Evapofacies del Miembro Troncoso superior de la Formación Huitrín (Cretácico Inferior, Cuenca Neuquina, Argentina) Paleoambientes, evolución y controles. Latin American Journal of Sedimentology and Basin Analysis: 35-69. 
González-Sánchez, F., Camprubí A., González-Partida E., Puente-Solís, R., Canet C., CentenoGarcía E. y Atudorei V. 2009. Regional stratigraphy and distribution of epigenetic stratabound celestine, fluorite, barite and $\mathrm{Pb}-\mathrm{Zn}$ deposits in the MVT province of northeastern Mexico. Mineralium Deposita: 44: 343-361.

Gutiérrez Pleimling, A.R. 1991. Estratigrafía de la Formación Huitrín: un estudio puntual sobre la ruta Nacional No 40, provincia del Neuquén. Boletín de Informaciones Petroleras: 85-100.

Hayase, K. y Bengochea, A.L. 1975. Consideraciones sobre la génesis de algunos yacimientos de baritina-celestina; provincia de Neuquén; República Argentina. II Congreso Iberoamericano de Geología Económica, 2: 295-314. Buenos Aires.

Jutorán, A. y Malvicini, L. 1961. Manifestaciones ferríferas del Dpto. de Norquín. Dir. Nac. Min. y Geol. (Informe Inédito), Buenos Aires.

Leanza, H.A., Repol, D., Hugo, C.H. y Sruoga, P. 2006. Hoja Geológica 3769-31, Chorriaca, Provincia del Neuquén. Instituto de Geología y Recursos Minerales. Servicio Geológico Minero Argentino, Boletín 354, 93 p. Buenos Aires.

Legarreta, L. 1985. Análisis estratigráfico de la Formación Huitrín (Cretácico inferior), provincia de Mendoza. Tesis Doctoral, Facultad de Ciencias Exactas y Naturales. Universidad de Buenos Aires. (Inédito), 197p.

Llambías, E.J. y Malvicini, L. 1978. Geología, petrología y metalogénesis del área de Colipilli, provincia del Neuquén, República Argentina. Revista de la Asociación Geológica Argentina, 33: 257-276. Buenos Aires.

Lugli, S., Torres-Ruiz, J., Garuti, G. y Olmedo, F. 2000. Petrography and geochemistry of the Eugui Magnesite Deposit (Western Pyrenees, Spain): evidence for the development of a peculiar zebra banding by dolomite replacement. Economic Geology, 95: 1775-1791.

Lyons, Muñiz y Asociados. 1978. Plantas regionales de tratamiento y beneficio de minerales de bario, Provincia del Neuquén. Consejo Federal de Inversiones. (Inédito), 732 p. Buenos Aires.

Malvicini, L. 1977. Las magnetitas laminares de cerro Negro Este, Colipilli, Provincia del Neuquén, República Argentina. AMPS, VII: 41-50, Buenos Aires.

Mcintyre, T., Eckberg, E., Morgan, C., Enns, S., Cruise, M., y Hitzman, M. 2005. IOCG Style Alteration of the Amargosa Prospect. Baja California Norte, México. www.cardero.com/i/pdf/armagosageorpt.pdf (versión online).

McKinstry, H.E. 1955. Structure of Hydrothermal ore deposits. Economic Geology 50th Ann Vol. $170-225$.

Nofke, N., Chafetz, H. 2011. Introduction, en Nofke, N., Chafetz, H. (Eds.), Microbial mats in siliciclastic depositional systems through time: Tulsa, Society of Sedimentary Geology, 1.

Nielsen, P., Swennen, R., Muchez, P.H. y Keppens, E. 1998. Origin of Dinantian zebra dolomites south of the Brabant-Wales Massif, Belgium. Sedimentology, 45: 727-743. 
Pons, M.J. 2007. Geología y metalogénesis de la mineralización de hierro asociada al skarn Vegas Peladas, SO de Mendoza, Cordillera Principal. Tesis Doctoral, Universidad Nacional de La Plata. (Inédito). 314 p. La Plata.

Ramos, V.A. y Brodtkorb, M.K. de. 1990. The barite and celestite metallotects. En: Fontboté L., Amstutz G., Cardozo M., Cedillo E. y Frutos J. (Eds.), Stratabound Ore Deposits in the Andes. VIII Special Publication of the Society for Geology Applied to Mineral Deposits, 2: 599-613. Praga.

Riding, R. 2000. Microbial carbonates: the geological record of calcified bacterial-algal mats and biofilms: Sedimentology, 47 (Supplement I), 179-214.

Ridding, R. 2006. Microbial carbonate abundance compared with fluctuation in metazoan diversity over geological time: Sedimentary Geology, 185, 229-238.

Stal, L.J., Krumbein, W.E. 1986. Metabolism of cyanobacteria in anaerobic marine sediments: Actes de Colloques, 3, 301-309.

Tang, D-J., Shi, X-Y., Jiang, G., Wang, X-Q. 2011. Morphological association of microbially induced sedimentary structures (MISS) as a paleoenvironmental indicator: an example from the proterozoic succession of the southern North China Platform, en Nofke, N., Chafetz, H. (Eds.). Microbial mats in siliciclastic depositional systems through time: Tulsa, Society of Sedimentary Geology, 3-14.

Tritlla, J., Levresse, G., Corona-Esquivel, R., Banks, D., Lamadrid, H. y Bourdet, J. 2006. Depósitos de $\mathrm{Pb}-\mathrm{Zn}-\mathrm{Cu}-\mathrm{Ba}-\mathrm{F}-\mathrm{Sr}$ epigenéticos estratoligados en series sedimentarias en relación con salmueras de cuenca: depósitos de tipo "Mississippi Valley" (MVT) y similares en México. Boletín de la Sociedad Geológica Mexicana, 58(1): 103-139.

Tucker, M.E., Wright, V.P. 1990. Carbonate sedimentology: Cambridge, Blackwell Science, 482 p. Vanderginste, V., Swennen, R., Gleeson, S.A., Ellam, R.M., Osadetz, K., Roure, F., 2005. Zebra dolomitization as a result of focused fluid flow in the Rocky Mountains Fold and Thrust Belt, Canada. Sedimentology, 52: 1067-1095.

Wallace, M.W., Both, R.A., Ruano, S.M., Hach-Ali, P.F. y Lees, T. 1994. Zebra textures from carbonate-hosted sulfide deposits: Sheetcavity networks produced by fracture and solution enlargement. Economic Geology, 89: 1183-1191.

Zanettini, J.C.M. 2011. Recursos de minerales metalíferos. Relatorio del XVIII Congreso Geológico Argentino, Neuquén. 709-724. Neuquén.

Zamora Valcarce, G. 2007. Estructura y cinemática de la faja plegada del Agrio. Universidad de Buenos Aires, Tesis doctoral (Inédita) 304 p., Buenos Aires. 


\section{Capítulo 6}

\section{GEOQUÍMICA MINERAL}




\section{Introducción}

Con el propósito de estudiar la composición química de los minerales que constituyen las mineralizaciones barítico-polimetálicas se analizaron mediante microsonda electrónica muestras representativas de sulfatos, sulfuros y óxidos de hierro de diversos sectores comprendidos en el área de estudio. Los resultados obtenidos han proporcionado información sobre la distribución de los elementos y las variaciones composicionales de las diferentes especies minerales, que contribuyeron a interpretar su génesis.

\section{Métodos Analíticos}

Los resultados obtenidos por microsonda electrónica, expresados en porcentaje en peso de óxidos, se trabajaron en hojas de cálculo Excel programadas por el Dr. Carlos A. Ballivián Justiniano (INREMI). Para obtener las fórmulas químicas exactas de los sulfatos y óxidos de hierro se calculó el número de cationes por unidad de fórmula (c.p.u.f.). Dicho cálculo se realizó para un determinado número total de oxígenos por unidad de fórmula según la siguiente expresión general (Ballivián Justiniano 2016):

$$
E_{\text {c.p.u.f. }}=\frac{\frac{m_{\text {óxido }}}{P M_{\text {óxido }}} \cdot O_{\text {óxido }} \cdot X}{\sum_{i=1}^{n}\left(\frac{m_{\text {oxido }}}{P M_{\text {óxido }}} \cdot O_{\text {óxido }}\right)_{i}} \cdot \frac{C_{\text {óxido }}}{O_{\text {óxido }}}
$$

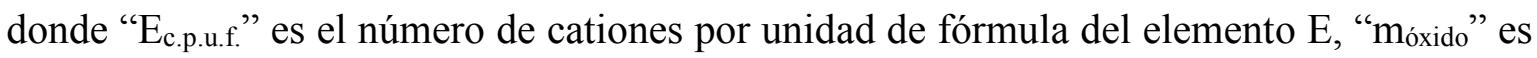
el porcentaje en peso del óxido del elemento E, "PMóxido" es el peso molecular del óxido del elemento E, "Oóxido" es igual al subíndice correspondiente al oxígeno en el óxido del elemento $\mathrm{E}$, "C $\mathrm{C}_{\text {óxido" }}$ es igual al subíndice correspondiente al elemento $\mathrm{E}$ en su óxido y " $\mathrm{X}$ " es el número total de oxígenos por unidad de fórmula. Esta última variable es función de la composición y estructura del mineral cuya fórmula se desea reconstruir. La expresión del denominador se refiere a la sumatoria del producto de la relación "móxido/PMóxido" por "Oóxido" de los "n" elementos analizados en un mineral dado.

En el caso de los óxidos de hierro, el $\mathrm{Fe}^{+3}$ y el $\mathrm{Fe}^{+2}$ fueron calculados según el criterio estequiométrico de Droop (1987). La proporciones moleculares de los componentes finales de los sulfatos y óxidos de hierro se calcularon a partir de las fórmulas reconstruidas según el método de Deer et al. (1992). Las abreviaturas de minerales utilizadas son las de Whitney y Evans (2010). 


\section{Determinaciones microanalíticas en sulfatos}

Los sulfatos son minerales que se caracterizan por presentar al $\mathrm{S}$ en posición tetraédrica con 4 oxígenos que lo rodean. Los enlaces covalentes $\mathrm{S}-\mathrm{O}$ son muy fuertes y permiten la formación del grupo $\mathrm{SO}_{4}$, unidad estructural fundamental de los sulfatos (Klein y Hurlbut 2006). A este grupo pertenecen numerosos minerales pero pocos son comunes. Se divide en sulfatos anhidros (ejemplos principales baritina, celestina, anhidrita, anglesita y crocoíta, entre otros) y sulfatos hidratados (yeso, antlerita y alunita, entre otros), con y sin aniones extraños.

Los sulfatos de $\mathrm{Ba}, \mathrm{Sr}$ y $\mathrm{Pb}$ conforman el grupo de la baritina y son isoestructurales. En la presente Tesis se compararon cristales de baritina de yacencia mantiforme y vetiforme con el fin de poder definir la existencia de variaciones composicionales, ya que a pesar de que la baritina es generalmente casi pura, el Ba puede ser sustituido por el Sr en una serie continua o solución sólida cuyos extremos son baritina y celestina. Los radios iónicos del $\mathrm{Ba}^{+2}$ y del $\mathrm{Sr}^{+2}$ son muy similares, siendo el primero de $1,35 \AA$ y el segundo de $1,13 \AA$ A. Las composiciones intermedias de la serie son conocidas en la naturaleza pero son poco comunes (Burkhard 1978, Tekin et al., 2002).

Los miembros de esta serie con preponderancia de átomos de $\mathrm{Ba}$ son llamados estronciobaritina o celestobaritina (baritina rica en $\mathrm{Sr}$ ) y aquellos miembros cercanos al extremo de $\mathrm{Sr}$, se los denomina baritocelestina (celestina rica en $\mathrm{Ba}$ ). A su vez, Burkhard (1978) subdividió a los sulfatos en relación al contenido en mol\% de $\mathrm{SrSO}_{4}$ en: baritina (0$10 \%)$, celestobaritina (10-50\%), baritocelestina (50-90\%) y celestina (90-100\%). La mayoría de las baritinas contiene menos del 7\% mol de $\mathrm{SrSO}_{4}$ y la mayoría de las celestinas contiene menos del 4\% mol $\mathrm{BaSO}_{4}$ (Hanor 1968). Por otra parte, reemplazos apreciables de $\mathrm{Ba}$ por $\mathrm{Pb}$ en baritinas, aumenta la densidad del mineral. La sustitución por $\mathrm{Ca}$ es mucho más rara. En las celestinas, el Ca puede sustituir al $\mathrm{Sr}$ en valores limitados de alrededor del 2-3\% (Deer et al., 1992).

La baritina es el sulfato anhidro más importante y el mineral de Ba más abundante en la corteza terrestre (Barbieri 1989). Este mineral se encuentra en sucesiones carbonáticas y generalmente se presenta como ganga en depósitos hidrotermales. También suele acumularse en forma de mantos residuales, formados por meteorización y primario, por depositación en sedimentos modernos de fondos marinos. Asimismo, muchos yacimientos de $\mathrm{Pb}-\mathrm{Zn}$ del mundo, como por ejemplo los del tipo Mississippi Valley 
(MVT), presentan baritina en general como ganga. Por otra parte, es un mineral común de los depósitos submarinos volcanogénicos de sulfuros masivos.

Por otra parte, el $\mathrm{Sr}$ es el metal alcalinotérreo menos abundante $(0,042 \%)$ en la corteza terrestre (Hanor 2000). La celestina tiene una distribución mucho más restringida que la baritina, encontrándose principalmente como producto de la reacción de fluidos hipersalinos portadores de $\mathrm{Sr}$ con yeso o anhidrita. Los depósitos que suele formar la celestina son epigenéticos y también se la encuentra en domos salinos y depósitos hidrotermales.

A partir de trabajos experimentales realizados por Gordon et al. (1954), Becker et al. (2000) entre otros, fue revelado que el Ba se concentra en la fase sólida, mientras que el $\mathrm{Sr}$ se concentra en la fase acuosa, durante la lenta precipitación de $(\mathrm{Sr}-\mathrm{Ba}) \mathrm{SO}_{4}$. Gordon et al. (1954) estudiaron soluciones acuosas durante la precipitación de baritina y celestina, y comprobaron que el Sr tiene una distribución heterogénea a lo largo de la solución sólida. Los cambios composicionales de la solución, después de la precipitación inicial del sulfato, dan origen a las composiciones intermedias (Burkhard 1978). Asimismo, Malinin y Urusov (1983), en base a la distribución de Ba-Sr en la solución sólida, propusieron que las composiciones intermedias son metaestables y tienden a exolverse por debajo de los $100^{\circ} \mathrm{C}$. Si bien existe una serie de solución sólida de baritina-celestina, según Prieto et al. (2000), la misma no es completa y hay un intervalo de inmiscibilidad a bajas temperaturas. De acuerdo a lo propuesto por Prieto et al. (2000), Becker et al. (2000) fue demostrado que para temperaturas inferiores a $200^{\circ} \mathrm{C}$ existe un hueco de inmiscibilidad. Por otro lado, Tekin et al. (2002) y Bolonin y Nikiforov (2014) demostraron la existencia de yacimientos de composiciones intermedias de sulfatos de Ba-Sr en Turquía y Rusia. Algunos de los depósitos reportados por estos autores son de importancia económica.

La solubilidad extremadamente baja del $\mathrm{BaSO}_{4}$, en comparación con la del $\mathrm{SrSO}_{4}$, sugiere que la cristalización inicial debe consistir en la nucleación de una fase rica en $\mathrm{BaSO}_{4}$ (Hanor 2000). En la naturaleza el volumen de los depósitos de baritina es mucho mayor que el de los de celestina. Por lo tanto, la presencia de celestina refleja la existencia de ambientes geológicos especiales donde existió una concentración preferencial de $\mathrm{Sr}$ sobre la de Ba.

Las muestras analizadas, correspondientes a yacencias mantiformes, se encuentran reemplazando a rocas carbonáticas, y provienen del rajo principal de la mina San Eduardo. Las muestras 11227a y 19407 presentan textura cebrada, mientras que la muestra 11227 b manifiesta rasgos de recristalización. Con respecto a los sulfatos que están asociados a 
yacencias vetiformes (muestras 4951, 21847 y 19373) la baritina se muestra formando medios soles, texturas que evidencian procesos de relleno. La muestra 4951 proviene del rajo principal de la mina San Eduardo y las dos restantes corresponden al cerro Negro.

\section{Resultados}

La rutina analítica contempló la medición de $\mathrm{FeO}, \mathrm{MnO}, \mathrm{CoO}, \mathrm{MgO}, \mathrm{CaO}, \mathrm{SrO}$, $\mathrm{BaO}, \mathrm{P}_{2} \mathrm{O}_{5}, \mathrm{PbO}, \mathrm{SO}_{3}$, y F. En el caso de $\mathrm{P}_{2} \mathrm{O}_{5}$ y $\mathrm{F}$ se obtuvieron valores prácticamente insignificantes. En la mayoría de los casos se efectuaron perfiles longitudinales y transversales al alargamiento de los cristales a los efectos de determinar posibles variaciones composicionales zonales desde el centro a los bordes de los individuos.

Los sulfatos analizados arrojaron contenidos de $\mathrm{BaO}$ entre 61,46 y $67,30 \%$ en peso, de $\mathrm{SrO}$ entre 0,11 y $3,59 \%$ en peso y de $\mathrm{CaO}$ entre 0 y $0,10 \%$ en peso. De acuerdo a la clasificación de Burkhard (1978) estos valores corresponden a baritina. En la Figura 6.1 se muestran imágenes por electrones retrodispersados de algunos de los cristales analizados.

En la Tabla 6.1 se presentan los contenidos promedios, desvíos estándar, mínimos y máximos de los análisis por microsonda electrónica de baritinas de yacencias mantiforme y vetiforme, junto al número de c.p.u.f. y las proporciones moleculares de los componentes finales. La totalidad de los análisis realizados $(\mathrm{N}=159)$ se presentan en el Anexo 2. El recálculo de la fórmula de la baritina se realizó en base a 4 oxígenos por unidad de fórmula. En la Tabla 6.2 se muestran las fórmulas químicas calculadas de los minerales analizados.

Con el fin de observar las variaciones composicionales de la serie baritina-celestina, se calcularon las proporciones moleculares de los componentes $\mathrm{BaSO}_{4}-\mathrm{SrSO}_{4}-\mathrm{CaSO}_{4}$ y se graficaron en un diagrama ternario seccionado al 10\% molar de $\mathrm{CaSO}_{4}$ (Fig.6.2). Los resultados obtenidos en esta Tesis fueron comparados con las composiciones de sulfatos de depósitos de carbonatitas y de skarn de magnetita de la región Angara, Rusia, según Bolonin y Nikiforov (2014) y con las composiciones de sulfatos de otros depósitos de la Cuenca Neuquina según de Barrio et al. (2016).

En el diagrama ternario se observa como las baritinas estudiadas se concentran en su totalidad en las cercanías del extremo del $\mathrm{Ba}$, reflejando una gran homogeneidad composicional y muy bajos contenidos de Sr. Igualmente, se puede observar en líneas generales, que en las yacencias vetiformes el contenido de $\mathrm{Sr}$ decrece respecto de los obtenidos en las morfologías estratiformes. 


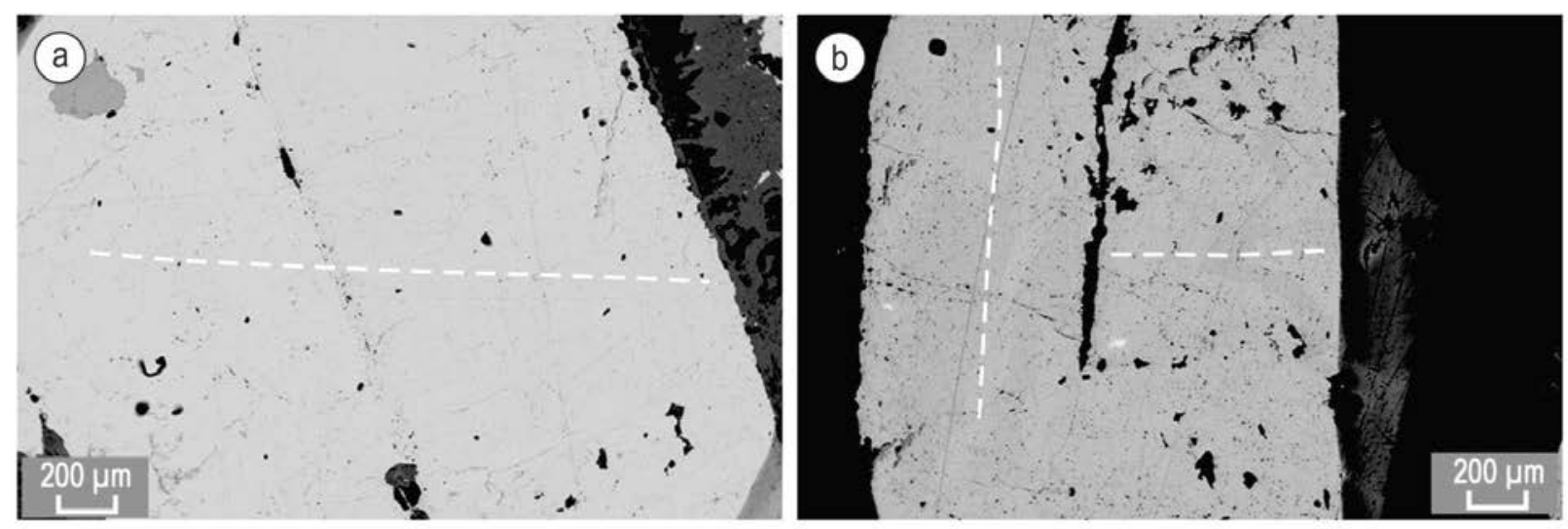

Figura 6.1: a-b: Imágenes por electrones retrodispersados de baritinas de veta Julio César. En líneas de trazos se indican los perfiles microanalíticos realizados.

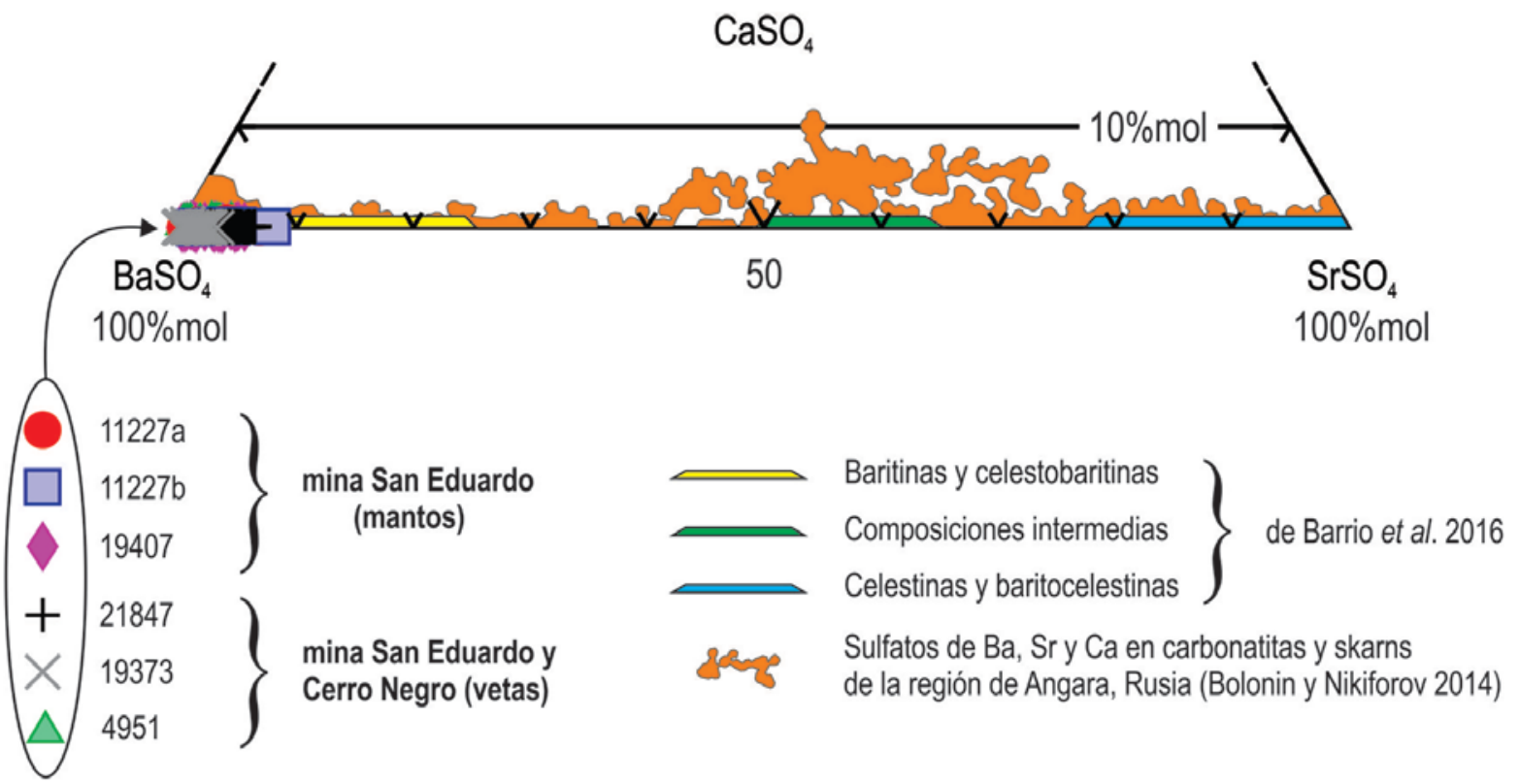

Figura 6.2: Diagrama ternario de $\mathrm{BaSO}_{4}-\mathrm{SrSO}_{4}-\mathrm{CaSO}_{4}$ (cortado a $10 \%$ CaSO4\% molar) de las baritinas investigadas en esta Tesis junto con las composiciones de sulfatos de otros depósitos minerales publicados por Bolonin y Nikiforov (2014) y de Barrio et al. (2016). 


\begin{tabular}{|c|c|c|}
\hline Muestra & Yacencia & Fórmula química \\
\hline $11227 a$ & mantiforme & $\left(\mathrm{Ba}_{0,964} \mathrm{Sr}_{0,033} \mathrm{Ca}_{0,001}\right)_{\Sigma=0,998} \mathrm{~S}_{0,993} \mathrm{O}_{4}$ \\
\hline $11227 b$ & mantiforme & $\left(\mathrm{Ba}_{0,960} \mathrm{Sr}_{0,035} \mathrm{Ca}_{0,010}\right)_{\Sigma=1,005} \mathrm{~S}_{0,996} \mathrm{O}_{4}$ \\
\hline 4951 & vetiforme & $\left(\mathrm{Ba}_{0,975} \mathrm{Sr}_{0,023}\right)_{\Sigma=0,998} \mathrm{~S}_{0,995} \mathrm{O}_{4}$ \\
\hline 19407 & mantiforme & $\left(\mathrm{Ba}_{0,972} \mathrm{Sr}_{0,025}\right)_{\Sigma=0,997} \mathrm{~S}_{0,994} \mathrm{O}_{4}$ \\
\hline 21847 & vetiforme & $\left(\mathrm{Ba}_{0,951} \mathrm{Sr}_{0,045}\right)_{\Sigma=0,996} \mathrm{~S}_{0,994} \mathrm{O}_{4}$ \\
\hline 19373 & vetiforme & $\left(\mathrm{Ba}_{0,987} \mathrm{Sr}_{0,012}\right)_{\sum=0,999} \mathrm{~S}_{0,990} \mathrm{O}_{4}$ \\
\hline
\end{tabular}

Tabla 6.2: Fórmulas químicas calculadas de baritinas de yacencias mantiformes y vetiformes.

\section{Determinaciones microanalíticas en sulfuros y sulfosales}

Los sulfuros y sulfosales constituyen una importante clase de minerales que incluye a la mayoría de las menas metalíferas. La fórmula estructural de los primeros viene dada por $\mathrm{A}_{\mathrm{m}} \mathrm{X}_{\mathrm{n}}$, en donde $\mathrm{A}$ representa los elementos metálicos y $\mathrm{X}$ el elemento no metálico, es decir, el $\mathrm{S}$; las sulfosales se expresan según la fórmula estructural $\mathrm{A}_{\mathrm{m}} \mathrm{B}_{\mathrm{n}} \mathrm{Xp}$, donde $\mathrm{A}$ representa a los metales $\mathrm{Cu}, \mathrm{Ag}$ y $\mathrm{Pb}, \mathrm{B}$ a los metaloides As, Sb, Bi y Sn y X al S (Palache et al., 1944). A continuación se detallan algunas de las características más destacadas de los sulfuros y sulfosales.

La galena $(\mathrm{PbS})$ es el mineral más importante de plomo. Se presenta en una gran variedad de ambientes tales como en depósitos de tipo MVT, depósitos metamórficos de contacto, raramente en pegmatitas y en depósitos hidrotermales con una amplia gama de temperaturas (Palache et al., 1944). Cuando se halla en filones hidrotermales, la galena se asocia a menudo con minerales de plata y frecuentemente contiene dicho elemento en cantidades traza. Otros elementos que sustituyen al $\mathrm{Pb}$ en pequeñas cantidades son $\mathrm{Fe}, \mathrm{Zn}$, $\mathrm{Cd}, \mathrm{Cu}, \mathrm{Mn}$ y $\mathrm{Bi}$. El azufre puede ser sustituido por el Sb, As y Se; a partir del reemplazo de este último (Se), se conoce una serie completa entre el PbS y el PbSe (Klein y Hurlbut 2006). Por lo general, la galena se encuentra asociada a esfalerita, calcopirita, pirita, tetraedrita, anglesita, baritina, fluorita, cuarzo, calcita, dolomita, cerusita, entre otros minerales. Es frecuente observar intercrecimientos de calcopirita y/o tetraedrita a lo largo de los planos de clivaje de la galena (Deer et al., 1966).

La esfalerita $(\mathrm{ZnS})$, el mineral más común de zinc, está íntimamente relacionado con la galena. También suele aparecer junto con calcopirita, pirita, pirrotina, marcasita, 
calcita, dolomita, entre otros minerales. La esfalerita casi siempre contiene $\mathrm{Fe}$ en su composición química, también es usual la presencia de Mn y Cd (Palache et al., 1944).

El mineral más corriente de cobre es la calcopirita $\left(\mathrm{CuFeS}_{2}\right)$ y es común en depósitos hidrotermales, pegmatíticos y de metamorfismo de contacto. También suele encontrarse como constituyente primario de rocas ígneas básicas (Klein y Hurlbut 2006). Este mineral suele contener cantidades minoritarias o trazas de elementos como Ag, $\mathrm{Au}$, $\mathrm{Pt}, \mathrm{Pb}, \mathrm{Co}, \mathrm{Ni}, \mathrm{Mn}, \mathrm{Sn}, \mathrm{Zn}$ en reemplazo del $\mathrm{Cu}$ o el Fe y As o Se sustituyendo al $\mathrm{S}$ (Deer et al., 1966). Es común identificar en la calcopirita pequeños intercrecimientos orientados de esfalerita, tetraedrita y/o galena (Palache et al., 1944).

La pirita $\left(\mathrm{FeS}_{2}\right)$ es el sulfuro más frecuente, se forma tanto a altas como a bajas temperaturas. Aparece como segregación magmática y como mineral accesorio en rocas ígneas. También suele estar presente en depósitos de metamorfismo de contacto y en filones hidrotermales. En rocas sedimentarias este mineral puede tener origen primario y/o secundario. Generalmente está asociado a calcopirita, galena y esfalerita (Klein y Hurlbut 2006). Se han encontrado intercrecimientos orientados de esfalerita, marcasita, arsenopirita, galena, pirrotina y/o tetraedrita en cristales de pirita (Palache et al., 1944). El Ni suele sustituir al Fe y formar una serie completa de soluciones sólidas cuyo extremo se extiende a la variedad bravoita $(\mathrm{Ni}, \mathrm{Fe}) \mathrm{S}_{2}$. El Co también puede reemplazar parcialmente al Fe (Palache et al., 1944).

La tetraedrita $\left[(\mathrm{Cu}, \mathrm{Fe})_{12} \mathrm{Sb}_{4} \mathrm{~S}_{13}\right]$ es el mineral más común de las sulfosales y se trata de un sulfoantimoniuro esencialmente de $\mathrm{Cu}$ pero el $\mathrm{Fe}, \mathrm{Zn}$ y $\mathrm{Ag}$ sustituyen parcialmente al $\mathrm{Cu}$; menos comúnmente suele reemplazar al $\mathrm{Cu}$ el $\mathrm{Hg}$ y el $\mathrm{Pb}$. El $\mathrm{Bi}$ usualmente reemplaza al As (Palache et al., 1944). Los elementos Sb-As forman una serie completa de soluciones sólidas cuyo extremo en As es la tennantita (Klein y Hurlbut 2006). La tetraedrita suele presentarse en depósitos de metamorfismo de contacto o hidrotermales de media a baja temperatura y se asocia a minerales tales como galena, calcopirita, esfalerita, pirita, bornita, siderita, baritina, calcita, fluorita, entre otros.

Las determinaciones microanalíticas se realizaron en individuos de galena, esfalerita, calcopirita, pirita y tetraedrita pertenecientes a afloramientos de yacencia vetiforme. Las muestras 4951 y 15024 provienen de la labor principal de la mina San Eduardo y las muestras 19369 y 19373 proceden de la mina Julio César. En estas últimas muestras solo se analizaron granos de galena.

Al microscopio calcográfico la galena se presenta en granos anhedrales; en el caso de la galena de la mina San Eduardo se observaron numerosas inclusiones de calcopirita. 
La esfalerita y tetraedrita se identificaron en forma de pequeñas inclusiones hospedadas en masas xenomorfas de calcopirita. La pirita se muestra en cristales euhedrales de tamaño muy pequeño (300 $\mu \mathrm{m}$ en promedio) y en algunos casos se encuentra parcialmente limonitizada.

\section{Resultados}

La rutina analítica contempló la medición de $\mathrm{Pb}, \mathrm{Sb}, \mathrm{Cd}, \mathrm{Ag}, \mathrm{As}, \mathrm{Zn}, \mathrm{Cu}, \mathrm{Co}, \mathrm{Mn}$, Fe y S para la galena de la mina Julio César. En los sulfuros de la mina San Eduardo, además de contemplar los elementos ya mencionados (excepto el Mn), se analizaron Bi, Tl, Hg, Au, W, Te, Sn, In, Se, Ge, Ga, Ni y Ti. En la Tabla 6.3 se presentan los contenidos promedios, desvíos estándar, mínimos y máximos de los análisis por microsonda electrónica de los sulfuros analizados de yacencia vetiforme. La totalidad de los análisis realizados $(\mathrm{N}=288)$ se presentan en el Anexo 3 y 4.

Los microanálisis correspondientes a la galena de la mina San Eduardo arrojaron cantidades minoritarias de $\mathrm{Bi}$ y $\mathrm{Sb}$, los cuales estarían reemplazando parcialmente al $\mathrm{Pb}$. Cabe aclarar que el contenido de Bi es muy inferior al 16\% requerido para ser considerada una galena bismutífera (www.mindat.org). Con respecto a la galena de la mina Julio César, los microanálisis indican la presencia de inclusiones de minerales de $\mathrm{Ag}$, como por ejemplo una variedad de tetraedrita rica en Ag llamada freibergita (Klein y Hurlbut 2006). En la Figura 6.3 se muestran imágenes de electrones retrodispersados de algunos de los minerales analizados.

Por otro lado, la esfalerita correspondiente a la mina San Eduardo, presenta contenidos minoritarios de $\mathrm{Pb}, \mathrm{Fe}, \mathrm{Au}$ y $\mathrm{Cd}$. Estos dos últimos suelen estar presentes en la composición de la esfalerita; sin embargo, la presencia de ciertos contenidos de $\mathrm{Pb}$ y Fe podría deberse a la fuerte asociación con minerales ricos en plomo y hierro (por ejemplo galena, calcopirita, pirita) y por lo tanto a la abundancia de plomo y hierro en el sistema mineralizante. Los contenidos de $\mathrm{Sb}$ y As en la calcopirita podrían estar reflejando un reemplazo parcial del $\mathrm{S}$ y las pequeñas cantidades de $\mathrm{Ag}$, $\mathrm{Au}$ y $\mathrm{Pb}$ estarían indicando una sustitución del $\mathrm{Cu}$ o Fe. Los microanálisis de los cristales de pirita expresan contenidos de $\mathrm{Co}$, As y $\mathrm{Pb}$ en cantidades minoritarias. La presencia de $\mathrm{As}$ y $\mathrm{Pb}$ se podría explicar por la asociación con minerales tales como galena y tetraedrita; por otro lado, es común la sustitución incompleta del Co en el Fe. La composición química obtenida de la tetraedrita arrojó valores intermedios dentro de la solución sólida tetraedrita-tennantita, tratándose de 
tetraedritas de composición mixta según Klein y Hurlbut (2006). La presencia de los elementos $\mathrm{Fe}, \mathrm{Zn}, \mathrm{Ag}$ y $\mathrm{Pb}$ estarían indicando la sustitución parcial del $\mathrm{Cu}$; el $\mathrm{Bi}$ suele reemplazar al As.
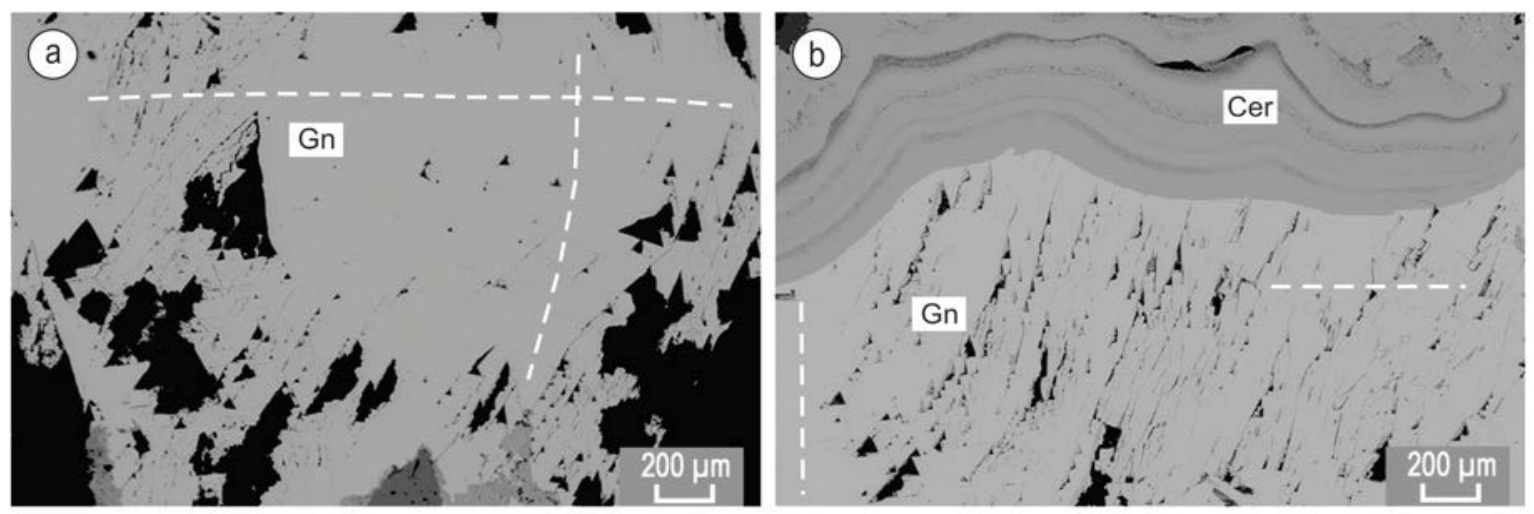

Figura 6.3: Fotomicrografías de galena $(\mathrm{Gn})$ de veta (a-b). En b- la Gn está alterada a cerusita (Cer). En líneas punteadas perfiles de microanálisis.

\section{Determinaciones microanalíticas en óxidos de hierro}

Los óxidos son un grupo de minerales que generalmente se presentan de manera accesoria en las rocas ígneas y metamórficas y como granos detríticos en los sedimentos y rocas sedimentarias (Palache et al., 1944). Este grupo tiene enlaces fuertemente iónicos y se subdivide en óxidos simples y óxidos múltiples. Los primeros, compuestos por un metal $(\mathrm{X})$ y oxígeno $(\mathrm{O})$, se expresan con diferentes relaciones $\mathrm{X}$ : $\mathrm{O}$ tales como $\mathrm{XO}, \mathrm{X}_{2} \mathrm{O}, \mathrm{X}_{2} \mathrm{O}_{3}$. Los óxidos múltiples se representan con la fórmula estructural $\mathrm{AB}_{2} \mathrm{O}_{4}$, donde tienen dos posiciones (A y B) con átomos metálicos no equivalentes (Klein y Hurlbut 2006).

La celda unitaria de los minerales del grupo de la espinela consta de 32 oxígenos y 24 cationes, de los cuales 8 se encuentran en capas con coordinación 8 (posiciones A) y 16 se encuentran en capas con coordinación 6 (posiciones B) (Deer et al. 1992). Según esto la fórmula estructural del grupo de la espinela puede representarse por $\mathrm{A}^{+2}{ }_{8} \mathrm{~B}^{+3}{ }_{16} \mathrm{O}_{32}$. El grupo es subdividido en tres series en función del tipo de catión trivalente dominante: serie de la espinela $(\mathrm{Al})$, serie de la magnetita $\left(\mathrm{Fe}^{+3}\right)$ y serie de la cromita $(\mathrm{Cr})$.

En la presente Tesis se estudiaron químicamente cristales de magnetita de un sector próximo a la mina General Belgrano (cerro Naunauco) y de la mina Augusta, además de analizar los cristales de mushketovita, presentes en esta última mina. Asimismo, se analizaron magnetitas constituyentes de rocas ígneas de los principales cuerpos intrusivos de la Formación Colipilli de indudable origen magmático. 

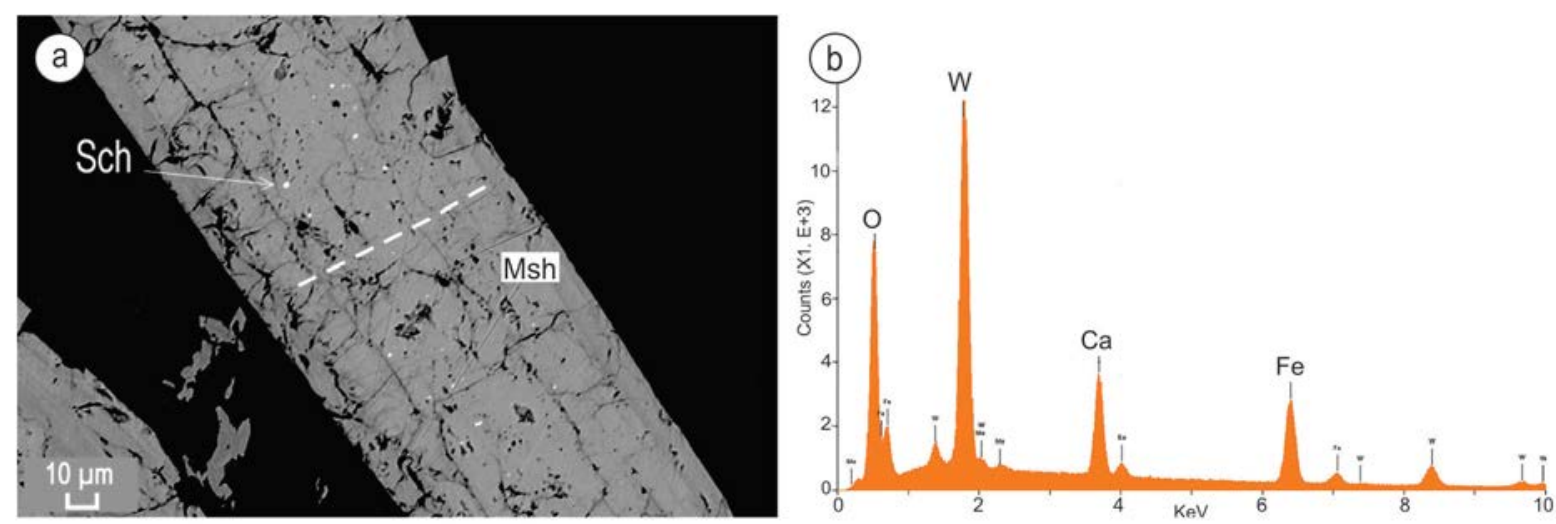

Figura 6.4: a- Fotomicrografía de mushketovita (Msh) con inclusiones de scheelita (Sch). En líneas punteadas perfil de microanálisis. b- Espectro de energía dispersiva de rayos X de Sch en mina Augusta.

Al microscopio calcográfico, las magnetitas de todos los sectores estudiados, se presentan en cristales subhedrales, con formas pseudo-octaédricas, entre 0,2 a 1,0 mm de longitud. En el caso de la mina Augusta, además de observarse la magnetita, se reconocieron cristales magnéticos de hábito laminar-tabular de hasta $0,3 \mathrm{~cm}$ de longitud, que corresponden a mushketovita; en éstas últimas se identificaron numerosas inclusiones de scheelita (Fig. 6.4).

La fórmula estructural de la magnetita es la siguiente: $\mathrm{R}^{+2}{ }_{9} \mathrm{M}^{+3}{ }_{14} \mathrm{~T}^{+4}{ }_{1} \mathrm{O}_{32}$ (Deer et al . 1992). $\mathrm{R}^{+2}$ corresponde a $\mathrm{Fe}^{+2}$ y a K$, \mathrm{Mn}^{+2}, \mathrm{Mg}^{+2}, \mathrm{Ca}^{+2}, \mathrm{Co}^{+2}, \mathrm{Ni}^{+2}, \mathrm{Zn}^{+2}$ que lo pueden reemplazar parcialmente. La posición $\mathrm{M}^{+3}$ es ocupada por el $\mathrm{Fe}^{+3}$ y cationes trivalentes como $\mathrm{Al}^{+3}, \mathrm{Cr}^{+3}, \mathrm{Sc}^{+3} \mathrm{y} \mathrm{V}^{+3}$. Finalmente, $\mathrm{T}^{+4}$ corresponde a cationes tetravalentes como $\mathrm{Si}^{+4} \mathrm{y} \mathrm{Ti}^{+4}$.

\section{Resultados}

La rutina analítica contempló la medición de $\mathrm{SiO}_{2}, \mathrm{TiO}_{2}, \mathrm{Sc}_{2} \mathrm{O}_{3}, \mathrm{Al}_{2} \mathrm{O}_{3}, \mathrm{Cr}_{2} \mathrm{O}_{3}$, $\mathrm{Fe}_{2} \mathrm{O}_{3}, \mathrm{MnO}, \mathrm{NiO}, \mathrm{MgO}, \mathrm{CaO}, \mathrm{CoO}, \mathrm{ZnO}, \mathrm{Na}_{2} \mathrm{O}, \mathrm{K}_{2} \mathrm{O}$ y $\mathrm{P}_{2} \mathrm{O}_{5}$. De los últimos ocho óxidos se obtuvieron valores prácticamente insignificantes. En la mayoría de los casos se efectuaron perfiles longitudinales y transversales en los cristales analizados a los efectos de determinar posibles variaciones composicionales de los individuos. En la Figura 6.5 se muestran imágenes de electrones retrodispersados de algunos de los cristales analizados. 

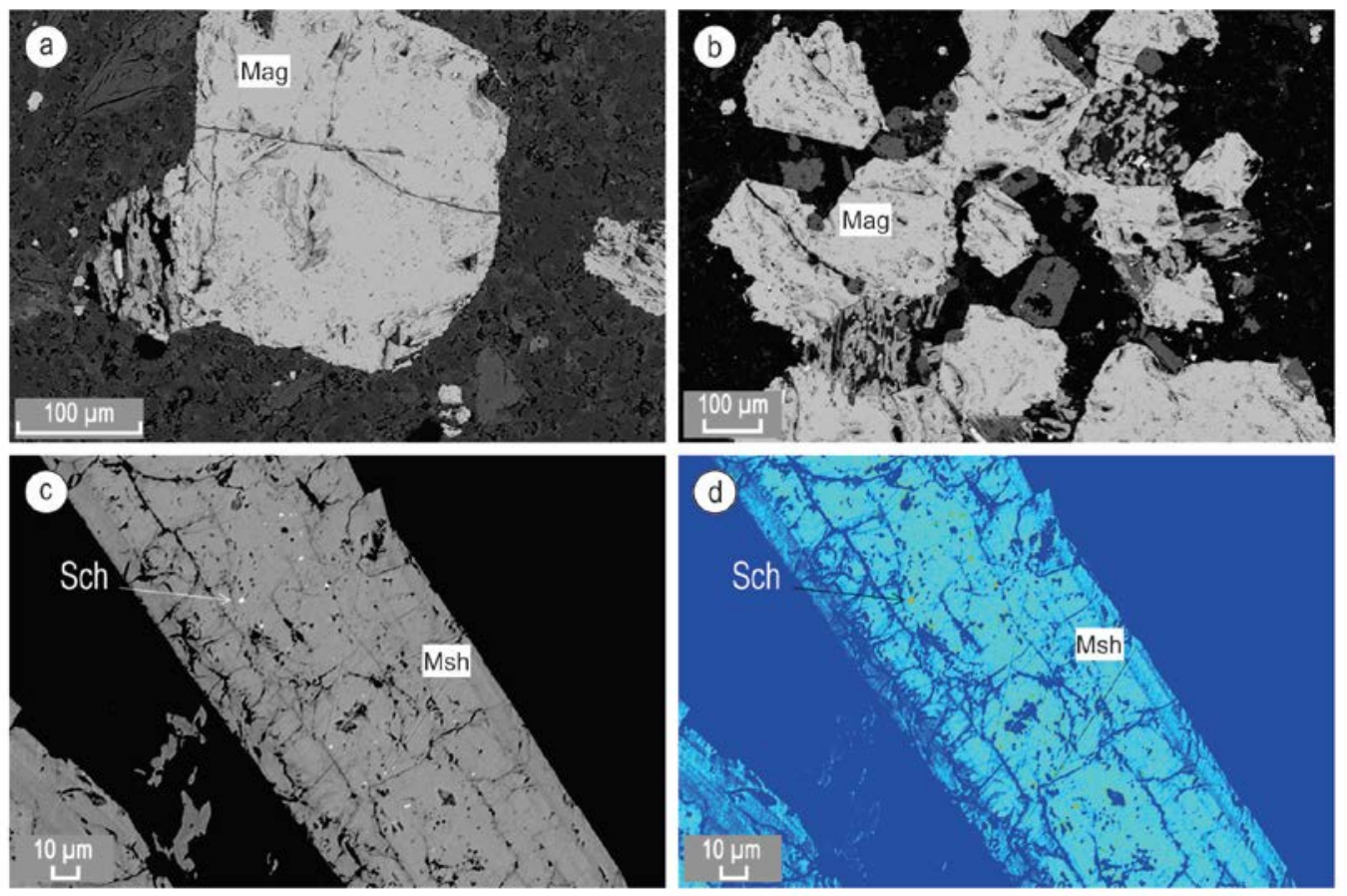

Figura 6.5: Fotomicrografias de: (a-b) magnetitas (Mag) en rocas andesíticas; (c-d) mushketovita (Msh) con inclusiones de scheelita (Sch) en mineralizaciones ferríferas de mina Augusta. d- imagen de falsos colores.

En la Tabla 6.4 se presentan los contenidos promedios, desvíos estándar, mínimos y máximos de los análisis por microsonda electrónica de magnetitas de rocas ígneas y mineralizaciones junto al número de c.p.u.f. y las proporciones moleculares de los componentes finales. La totalidad de los análisis realizados $(\mathrm{N}=103)$ se presentan en el Anexo 5. El recálculo de la fórmula de la magnetita se realizó en base a 32 oxígenos por unidad de fórmula. En la Tabla 6.5 se muestran las fórmulas químicas de los minerales

\section{Muestra}

\section{Fórmula química}

a- 21827

$$
\left(\mathrm{Fe}^{+2}{ }_{8,09} \mathrm{Mn}_{0,37}^{+2} \mathrm{Mg}_{0,31}^{+2} \mathrm{Zn}_{0.05}^{+2}\right)_{\Sigma=8,83}\left(\mathrm{Fe}^{+3}{ }_{13,62} \mathrm{Al}_{0,63}^{+3} \mathrm{Cr}_{0,01}^{+3} \mathrm{~V}_{0,08}^{+3}\right)_{\Sigma=14,34}\left(\mathrm{Si}_{0,06}^{+4} \mathrm{Ti}^{+4}{ }_{0,77}\right)_{\Sigma=0,83} \mathrm{O}_{32}
$$

b- 21824

$$
\left(\mathrm{Fe}^{+2}{ }_{8,09} \mathrm{Mn}^{+2}{ }_{0,42} \mathrm{Mg}^{+2}{ }_{0,29} \mathrm{Co}_{0,01}^{+2} \mathrm{Zn}_{0.04}^{+2}\right)_{\sum=8,86}\left(\mathrm{Fe}^{+3}{ }_{13,40} \mathrm{Al}^{+3}{ }_{0,80} \mathrm{Cr}_{0,01}^{+3} \mathrm{~V}_{0,08}^{+3}\right)_{\sum=14,28}\left(\mathrm{Si}_{0,09}^{+4} \mathrm{Ti}^{+4}{ }_{0,78}\right)_{\sum=0,86} \mathrm{O}_{32}
$$

c- 19334E $\quad\left(\mathrm{Fe}_{6,62}^{+2} \mathrm{Mn}_{0,03}^{+2} \mathrm{Mg}_{1,36}^{+2} \mathrm{Ca}_{0,02}^{+2} \mathrm{Co}_{0,04}^{+2} \mathrm{Zn}_{0,01}^{+2}\right)_{\Sigma=8,08}\left(\mathrm{Fe}^{+3}{ }_{15,55} \mathrm{Al}_{0,29}^{+3} \mathrm{~V}_{0,01}^{+3}\right)_{\sum=15,85}\left(\mathrm{Si}_{0,01}^{+4} \mathrm{Ti}_{0,06}^{+4}\right)_{\sum=0,07} \mathrm{O}_{32}$

d- Augusta $\quad\left(\mathrm{Fe}_{8,04}^{+2} \mathrm{Mn}_{0,02}^{+2} \mathrm{Mg}_{0,04}^{+2} \mathrm{Ca}_{0,06}^{+2} \mathrm{Co}_{0,04}^{+2} \mathrm{Zn}_{0,01}^{+2} \mathrm{~K}_{0,01}^{+}\right)_{\sum=8,22}\left(\mathrm{Fe}^{+3}{ }_{15,50} \mathrm{Al}^{+3}{ }_{0,05} \mathrm{~V}_{0,01}^{+3}\right)_{\sum=15,56}\left(\mathrm{Si}_{0,22}^{+4}\right)_{\Sigma=0.22} \mathrm{O}_{32}$ analizados.

Tabla 6.5: Fórmulas químicas recalculadas de magnetitas provenientes de rocas ígneas y mineralizaciones.

Las proporciones moleculares de las magnetitas de las rocas ígneas analizadas arrojaron contenidos de $94,33-95,54 \%$ de magnetita, $4,41-5,61 \%$ de espinela y $0,05-0,06 \%$ de cromita, mientras que las proporciones moleculares de las magnetitas correspondientes 
a los depósitos ferríferos presentaron contenidos de 98,13-99,68\% de magnetita, 0,31$1,86 \%$ de espinela y $0,01 \%$ de cromita. Asimismo se reconoció un mayor contenido de $\mathrm{TiO}_{2}$ en la magnetita de las rocas andesíticas (valor máximo: 3,44\% $\mathrm{TiO}_{2}$ ), con respecto a las magnetitas provenientes de los depósitos de hierro (valor máximo en cerro Naunauco: $0,28 \% \mathrm{TiO}_{2}$ y en mina Augusta: $0,02 \% \mathrm{TiO}_{2}$ ) confirmando que se trata de titanomagnetitas. Este hecho es coincidente con lo aseverado por Llambías y Malvicini (1978) para las magnetitas provenientes de rocas ígneas del área de Colipilli. En mina Augusta y cerro Naunauco los bajos contenidos en $\mathrm{TiO}_{2}$ son asimilables a una procedencia no magmática.

\section{Discusión y Conclusiones Parciales}

Los sulfatos de Ba-Sr se forman en un amplio rango de condiciones desde cuencas sedimentarias hasta sistemas magmáticos de alta temperatura. Para explicar las variaciones composicionales de los sulfatos de Ba-Sr, Hayase et al. (1977) experimentaron la síntesis de una solución hidrotermal pobre en estroncio, la cual se enriquece gradualmente en este elemento con respecto al $\mathrm{Ba}$ a medida que progresa la cristalización, denotando así, el bajo grado de solubilidad del sulfato de bario.

Hanor (2004) determinó que las aguas cuencales presentan altas relaciones $\mathrm{Sr} / \mathrm{Ba}$, por lo que éstas son más propensas a formar celestina en lugar de baritina. Además estableció que la concentración del estroncio en los fluidos está en directa relación con el incremento de la salinidad. La mayor solubilidad de la celestina respecto de la baritina (Hanor 2000) provoca que primeramente se precipite la baritina de las soluciones.

Con respecto a las baritinas estudiadas en la presente Tesis se observa que las correspondientes a vetas presentan menor contenido de $\mathrm{SrO}$ que las correspondientes a mantos. Dicha diferencia, concuerda con lo propuesto por Hanor 2000, debido a la mayor solubilidad y por ende, mayor movilidad del $\mathrm{Sr}$ en las soluciones acuosas con respecto al Ba.

El contenido de calcio en los sulfatos (Tabla 6.1) puede deberse a que los sulfatos $\mathrm{Ba}-\mathrm{Sr}$ se encuentran permanentemente asociados con minerales de $\mathrm{Ca}$ (calcita, anhidrita). Esta asociación indica la disponibilidad de un alto contenido de $\mathrm{Ca}$ en el medio de formación del sulfato (Bolonin y Nikiforov 2014).

En lo referente a las determinaciones mineraloquímicas en sulfuros no se observan anomalías marcadas en los elementos que pueden reemplazar al $\mathrm{S}$ o a los elementos 
metálicos, evidenciando así que se trata de especies casi puras, observándose solamente algunas ligeras anomalías en $\mathrm{Bi}$ y $\mathrm{Sb}$ en galenas y $\mathrm{Fe}$ y $\mathrm{Pb}$ en esfaleritas.

Por otro lado, las determinaciones microanáliticas de las magnetitas provenientes de las rocas andesíticas y de las mineralizaciones ferríferas, demostraron diferencias composicionales, las cuales sugieren un origen no magmático para las correspondientes a los depósitos de hierro. La naturaleza isotópica de las mismas se tratará en el capítulo 7. 


\begin{tabular}{|c|c|c|c|c|}
\hline \multirow{3}{*}{$\begin{array}{c}\text { Muestra } \rightarrow \\
\text { Ubicación } \rightarrow \\
\text { \% en peso }\end{array}$} & \multicolumn{4}{|c|}{ 11227a (San Eduardo, manto) $\mathrm{N}=16$} \\
\hline & \multicolumn{2}{|c|}{$70^{\circ} 20^{\prime} 53^{\prime \prime}$} & \multicolumn{2}{|c|}{$37^{\circ} 43^{\prime} 39^{\prime \prime}$} \\
\hline & Promedio & Desvío & Mínimo & Máximo \\
\hline $\mathrm{FeO}^{*}$ & 0,01 & 0,01 & 0,00 & 0,02 \\
\hline $\mathrm{MnO}$ & 0,00 & 0,00 & 0,00 & 0,00 \\
\hline $\mathrm{CoO}$ & 0,00 & 0,00 & 0,00 & 0,00 \\
\hline $\mathrm{MgO}$ & 0,01 & 0,01 & 0,00 & 0,02 \\
\hline $\mathrm{CaO}$ & 0,03 & 0,03 & 0,00 & 0,11 \\
\hline $\mathrm{SrO}$ & 1,49 & 0,68 & 0,24 & 3,13 \\
\hline $\mathrm{BaO}$ & 64,17 & 0,73 & 62,96 & 65,55 \\
\hline $\mathrm{P}_{2} \mathrm{O}_{5}$ & 0,00 & 0,00 & 0,00 & 0,01 \\
\hline $\mathrm{PbO}$ & 0,01 & 0,05 & 0,00 & 0,19 \\
\hline $\mathrm{SO}_{3}$ & 33,87 & 0,92 & 31,69 & 35,19 \\
\hline $\mathbf{F}$ & 0,00 & 0,00 & 0,00 & 0,02 \\
\hline TOTAL & 99,59 & & & \\
\hline
\end{tabular}

Número de cationes en base a 4 oxígenos por unidad de fórmula

\begin{tabular}{|c|c|c|c|c|}
\hline Muestra $\rightarrow$ & \multicolumn{4}{|c|}{ 11227a (San Eduardo, manto) } \\
\hline c.p.u.f. & Promedio & Desvío & Mínimo & Máximo \\
\hline $\mathrm{Fe}^{+2}$ & 0,0002 & 0,0003 & 0,0000 & 0,0008 \\
\hline Mn & 0,0000 & 0,0000 & 0,0000 & 0,0001 \\
\hline $\mathrm{Co}$ & 0,0000 & 0,0000 & 0,0000 & 0,0000 \\
\hline Mg & 0,0005 & 0,0005 & 0,0000 & 0,0012 \\
\hline $\mathrm{Ca}$ & 0,0014 & 0,0012 & 0,0000 & 0,0044 \\
\hline $\mathrm{Sr}$ & 0,0330 & 0,0150 & 0,0055 & 0,0684 \\
\hline $\mathrm{Ba}$ & 0,9647 & 0,0148 & 0,9300 & 0,9915 \\
\hline$P$ & 0,0000 & 0,0000 & 0,0000 & 0,0002 \\
\hline $\mathrm{Pb}$ & 0,0001 & 0,0005 & 0,0000 & 0,0020 \\
\hline Suma & 1,0000 & & & \\
\hline $\mathbf{S}$ & 0,9935 & 0,0086 & 0,9730 & 1,0059 \\
\hline
\end{tabular}

Proporciones moleculares de los componentes finales

\begin{tabular}{lrrrr}
\hline Anhidrita & 0,14 & 0,12 & 0,00 & 0,44 \\
Celestina & 3,30 & 1,50 & 0,55 & 6,85 \\
Baritina & 96,56 & 1,52 & 93,10 & 99,45 \\
\hline TOTAL & $\mathbf{1 0 0 , 0 0}$ & & & \\
\hline
\end{tabular}

Tabla 6.1: Análisis de BARITINA por microsonda electrónica 


\begin{tabular}{|c|c|c|c|c|}
\hline \multirow{3}{*}{$\begin{array}{c}\text { Muestra } \rightarrow \\
\text { Ubicación } \rightarrow \\
\% \text { en peso }\end{array}$} & \multicolumn{4}{|c|}{ 11227b (San Eduardo, manto) $N=11$} \\
\hline & \multicolumn{2}{|c|}{$70^{\circ} 20^{\prime} 53^{\prime \prime}$} & \multicolumn{2}{|c|}{$37^{\circ} 43^{\prime} 39^{\prime \prime}$} \\
\hline & Promedio & Desvío & Mínimo & Máximo \\
\hline $\mathrm{FeO}^{*}$ & 0,02 & 0,03 & 0,00 & 0,07 \\
\hline $\mathrm{MnO}$ & 0,00 & 0,00 & 0,00 & 0,00 \\
\hline $\mathrm{CoO}$ & 0,00 & 0,00 & 0,00 & 0,00 \\
\hline $\mathrm{MgO}$ & 0,01 & 0,01 & 0,00 & 0,02 \\
\hline $\mathrm{CaO}$ & 0,03 & 0,01 & 0,00 & 0,05 \\
\hline $\mathrm{SrO}$ & 1,61 & 0,83 & 0,58 & 3,60 \\
\hline $\mathrm{BaO}$ & 64,10 & 1,05 & 61,74 & 65,46 \\
\hline $\mathrm{P}_{2} \mathrm{O}_{5}$ & 0,02 & 0,03 & 0,00 & 0,10 \\
\hline $\mathrm{PbO}$ & 0,01 & 0,02 & 0,00 & 0,08 \\
\hline $\mathrm{SO}_{3}$ & 34,32 & 0,57 & 33,63 & 35,20 \\
\hline $\mathbf{F}$ & 0,00 & 0,00 & 0,00 & 0,01 \\
\hline
\end{tabular}

$*$ = asumido como $\mathrm{FeO}$ total.

Número de cationes en base a 4 oxígenos por unidad de fórmula Muestra $\rightarrow \quad 11227 \mathrm{~b}$ (San Eduardo, manto)

\begin{tabular}{crrrr}
\hline c.p.u.f. & Promedio & \multicolumn{1}{c}{ Desvío } & Mínimo & Máximo \\
\hline Fe $^{+2}$ & 0,0006 & 0,0008 & 0,0000 & 0,0022 \\
Mn & 0,0000 & 0,0000 & 0,0000 & 0,0000 \\
Co & 0,0000 & 0,0000 & 0,0000 & 0,0000 \\
Mg & 0,0004 & 0,0005 & 0,0000 & 0,0013 \\
Ca & 0,0010 & 0,0006 & 0,0000 & 0,0019 \\
Sr & 0,0356 & 0,0183 & 0,0129 & 0,0793 \\
Ba & 0,9608 & 0,0169 & 0,9192 & 0,9801 \\
P & 0,0006 & 0,0011 & 0,0000 & 0,0032 \\
Pb & 0,0001 & 0,0002 & 0,0000 & 0,0008 \\
\hline Suma & $\mathbf{0 , 9 9 9 1}$ & & & \\
\hline \multicolumn{7}{|c}{} \\
\hline S & $\mathbf{0 , 9 9 6 2}$ & 0,0046 & 0,9896 & 1,0029 \\
\hline \multicolumn{7}{c}{} \\
\hline TOTAL & $\mathbf{1 , 9 9 5 3}$ \\
\hline
\end{tabular}

Proporciones moleculares de los componentes finales

\begin{tabular}{lrrrr}
\hline Anhidrita & 0,10 & 0,06 & 0,00 & 0,19 \\
Celestina & 3,57 & 1,83 & 1,31 & 7,93 \\
Baritina & 96,33 & 1,86 & 91,98 & 98,69 \\
\hline TOTAL & $\mathbf{1 0 0 , 0 0}$ & & & \\
\hline
\end{tabular}

Tabla 6.1: Análisis de BARITINA por microsonda electrónica 


\begin{tabular}{|c|c|c|c|c|}
\hline \multirow{3}{*}{$\begin{array}{c}\text { Muestra } \rightarrow \\
\text { Ubicación } \rightarrow \\
\% \text { en peso }\end{array}$} & \multicolumn{4}{|c|}{4951 (San Eduardo, veta) $\mathrm{N}=12$} \\
\hline & \multicolumn{2}{|c|}{$70^{\circ} 20^{\prime} 45^{\prime \prime}$} & \multicolumn{2}{|c|}{$37^{\circ} 43^{\prime} 55^{\prime \prime}$} \\
\hline & Promedio & Desvío & Mínimo & Máximo \\
\hline $\mathrm{FeO}^{*}$ & 0,00 & 0,00 & 0,00 & 0,00 \\
\hline $\mathrm{MnO}$ & 0,00 & 0,00 & 0,00 & 0,00 \\
\hline $\mathrm{CoO}$ & 0,02 & 0,02 & 0,00 & 0,06 \\
\hline $\mathrm{MgO}$ & 0,00 & 0,00 & 0,00 & 0,01 \\
\hline $\mathrm{CaO}$ & 0,01 & 0,02 & 0,00 & 0,05 \\
\hline SrO & 1,03 & 0,61 & 0,17 & 2,00 \\
\hline $\mathrm{BaO}$ & 64,63 & 0,97 & 63,82 & 67,30 \\
\hline $\mathrm{P}_{2} \mathrm{O}_{5}$ & 0,00 & 0,00 & 0,00 & 0,00 \\
\hline $\mathrm{PbO}$ & 0,00 & 0,00 & 0,00 & 0,00 \\
\hline $\mathrm{SO}_{3}$ & 34,02 & 0,77 & 31,99 & 34,79 \\
\hline F & 0,00 & 0,00 & 0,00 & 0,00 \\
\hline
\end{tabular}

$*$ = asumido como $\mathrm{FeO}$ total.

Número de cationes en base a 4 oxígenos por unidad de fórmula Muestra $\rightarrow \quad 4951$ (San Eduardo, veta)

\begin{tabular}{crrrr}
\hline c.p.u.f. & Promedio & \multicolumn{1}{c}{ Desvío } & Mínimo & Máximo \\
\hline $\mathbf{F e}^{+2}$ & 0,0000 & 0,0000 & 0,0000 & 0,0000 \\
$\mathbf{M n}$ & 0,0000 & 0,0000 & 0,0000 & 0,0000 \\
$\mathbf{C o}$ & 0,0005 & 0,0006 & 0,0000 & 0,0019 \\
$\mathbf{M g}$ & 0,0001 & 0,0001 & 0,0000 & 0,0003 \\
$\mathbf{C a}$ & 0,0004 & 0,0006 & 0,0000 & 0,0020 \\
$\mathbf{S r}$ & 0,0231 & 0,0136 & 0,0039 & 0,0441 \\
$\mathbf{B a}$ & 0,9759 & 0,0136 & 0,9544 & 0,9958 \\
$\mathbf{P}$ & 0,0000 & 0,0000 & 0,0000 & 0,0000 \\
$\mathbf{P b}$ & 0,0000 & 0,0000 & 0,0000 & 0,0000 \\
\hline Suma & $\mathbf{1 , 0 0 0 0}$ & & & \\
\hline \multicolumn{7}{c}{} \\
\hline $\mathbf{S}$ & $\mathbf{0 , 9 9 5 7}$ & 0,0075 & 0,9738 & 1,0036 \\
\hline TOTAL & $\mathbf{1 , 9 9 5 7}$ \\
\hline \multicolumn{5}{c}{} \\
\hline
\end{tabular}

Proporciones moleculares de los componentes finales

\begin{tabular}{lrrrr}
\hline Anhidrita & 0,04 & 0,06 & 0,00 & 0,20 \\
Celestina & 2,31 & 1,36 & 0,39 & 4,42 \\
Baritina & 97,65 & 1,38 & 95,46 & 99,61 \\
\hline TOTAL & $\mathbf{1 0 0 , 0 0}$ & & & \\
\hline
\end{tabular}

Tabla 6.1: Análisis de BARITINA por microsonda electrónica 


\begin{tabular}{|c|c|c|c|c|}
\hline \multirow{2}{*}{$\begin{array}{c}\text { Muestra } \rightarrow \\
\text { Ubicación } \rightarrow\end{array}$} & \multicolumn{4}{|c|}{19407 (San Eduardo, manto) $\mathrm{N}=28$} \\
\hline & \multicolumn{2}{|c|}{$70^{\circ} 20^{\prime} 47^{\prime \prime}$} & \multicolumn{2}{|c|}{$37^{\circ} 43^{\prime} 47^{\prime \prime}$} \\
\hline$\%$ en peso & Promedio & Desvío & Mínimo & Máximo \\
\hline $\mathrm{FeO}^{*}$ & 0,00 & 0,00 & 0,00 & 0,00 \\
\hline $\mathrm{MnO}$ & 0,00 & 0,00 & 0,00 & 0,00 \\
\hline $\mathrm{CoO}$ & 0,02 & 0,02 & 0,00 & 0,06 \\
\hline MgO & 0,00 & 0,00 & 0,00 & 0,00 \\
\hline $\mathrm{CaO}$ & 0,01 & 0,02 & 0,00 & 0,06 \\
\hline $\mathrm{SrO}$ & 1,14 & 0,70 & 0,11 & 2,50 \\
\hline $\mathrm{BaO}$ & 64,50 & 0,96 & 62,57 & 65,99 \\
\hline $\mathrm{P}_{2} \mathrm{O}_{5}$ & 0,00 & 0,00 & 0,00 & 0,00 \\
\hline $\mathrm{PbO}$ & 0,04 & 0,07 & 0,00 & 0,23 \\
\hline $\mathrm{SO}_{3}$ & 33,88 & 0,80 & 32,39 & 35,41 \\
\hline $\mathbf{F}$ & 0,00 & 0,00 & 0,00 & 0,00 \\
\hline
\end{tabular}

$*$ = asumido como $\mathrm{FeO}$ total.

Número de cationes en base a 4 oxígenos por unidad de fórmula Muestra $\rightarrow \quad 19407$ (San Eduardo, manto)

\begin{tabular}{|c|c|c|c|c|}
\hline c.p.u.f. & Promedio & Desvío & Mínimo & Máximo \\
\hline $\mathrm{Fe}^{+2}$ & 0,0000 & 0,0000 & 0,0000 & 0,0000 \\
\hline Mn & 0,0000 & 0,0000 & 0,0000 & 0,0000 \\
\hline $\mathrm{Co}$ & 0,0007 & 0,0005 & 0,0000 & 0,0019 \\
\hline Mg & 0,0000 & 0,0000 & 0,0000 & 0,0000 \\
\hline $\mathrm{Ca}$ & 0,0006 & 0,0007 & 0,0000 & 0,0025 \\
\hline $\mathrm{Sr}$ & 0,0254 & 0,0156 & 0,0025 & 0,0556 \\
\hline $\mathrm{Ba}$ & 0,9729 & 0,0154 & 0,9431 & 0,9963 \\
\hline $\mathbf{P}$ & 0,0000 & 0,0000 & 0,0000 & 0,0000 \\
\hline $\mathrm{Pb}$ & 0,0004 & 0,0007 & 0,0000 & 0,0024 \\
\hline Suma & 1,0000 & & & \\
\hline $\mathbf{S}$ & 0,9945 & 0,0057 & 0,9839 & 1,0046 \\
\hline TOTAL & 1,9945 & & & \\
\hline
\end{tabular}

Proporciones moleculares de los componentes finales

\begin{tabular}{lrrrr}
\hline Anhidrita & 0,06 & 0,07 & 0,00 & 0,25 \\
Celestina & 2,54 & 1,56 & 0,25 & 5,56 \\
Baritina & 97,40 & 1,56 & 94,40 & 99,75 \\
\hline TOTAL & $\mathbf{1 0 0 , 0 0}$ & & & \\
\hline
\end{tabular}

Tabla 6.1: Análisis de BARITINA por microsonda electrónica 


\begin{tabular}{|c|c|c|c|c|}
\hline \multirow{3}{*}{$\begin{array}{l}\text { Muestra } \rightarrow \\
\text { Ubicación } \rightarrow\end{array}$} & \multicolumn{4}{|c|}{21847 (cerro Negro, veta) $\mathrm{N}=57$} \\
\hline & \multicolumn{2}{|c|}{$70^{\circ} 18^{\prime} 25^{\prime \prime}$} & \multicolumn{2}{|c|}{$37^{\circ} 43^{\prime} 02^{\prime \prime}$} \\
\hline & Promedio & Desvío & Mínimo & Máximo \\
\hline $\mathrm{FeO}^{*}$ & 0,01 & 0,02 & 0,00 & 0,09 \\
\hline $\mathrm{MnO}$ & 0,02 & 0,02 & 0,00 & 0,09 \\
\hline $\mathrm{CoO}$ & 0,01 & 0,01 & 0,00 & 0,07 \\
\hline $\mathrm{MgO}$ & 0,01 & 0,01 & 0,00 & 0,06 \\
\hline $\mathrm{CaO}$ & 0,02 & 0,01 & 0,00 & 0,05 \\
\hline $\mathrm{SrO}$ & 2,08 & 0,43 & 1,05 & 2,93 \\
\hline $\mathrm{BaO}$ & 63,73 & 1,06 & 61,46 & 66,11 \\
\hline $\mathrm{P}_{2} \mathrm{O}_{5}$ & 0,00 & 0,00 & 0,00 & 0,00 \\
\hline $\mathrm{PbO}$ & 0,00 & 0,00 & 0,00 & 0,00 \\
\hline $\mathrm{SO}_{3}$ & 34,22 & 0,60 & 30,77 & 34,97 \\
\hline F & 0,00 & 0,00 & 0,00 & 0,00 \\
\hline
\end{tabular}

$*$ = asumido como $\mathrm{FeO}$ total.

Número de cationes en base a 4 oxígenos por unidad de fórmula Muestra $\rightarrow \quad 21847$ (cerro Negro, veta)

\begin{tabular}{|c|c|c|c|c|}
\hline c.p.u.f. & Promedio & Desvío & Mínimo & Máximo \\
\hline $\mathrm{Fe}^{+2}$ & 0,0004 & 0,0006 & 0,0000 & 0,0029 \\
\hline Mn & 0,0008 & 0,0008 & 0,0000 & 0,0029 \\
\hline Co & 0,0002 & 0,0004 & 0,0000 & 0,0021 \\
\hline Mg & 0,0004 & 0,0006 & 0,0000 & 0,0033 \\
\hline $\mathrm{Ca}$ & 0,0006 & 0,0006 & 0,0000 & 0,0021 \\
\hline $\mathbf{S r}$ & 0,0459 & 0,0093 & 0,0234 & 0,0641 \\
\hline $\mathrm{Ba}$ & 0,9518 & 0,0095 & 0,9335 & 0,9754 \\
\hline $\mathbf{P}$ & 0,0000 & 0,0000 & 0,0000 & 0,0000 \\
\hline $\mathrm{Pb}$ & 0,0000 & 0,0000 & 0,0000 & 0,0000 \\
\hline Suma & 1,0000 & & & \\
\hline $\mathbf{S}$ & 0,9945 & 0,0071 & 0,9563 & 1,0058 \\
\hline TOTAL & 1,9945 & & & \\
\hline
\end{tabular}

Proporciones moleculares de los componentes finales

\begin{tabular}{lrrrr}
\hline Anhidrita & 0,06 & 0,06 & 0,00 & 0,21 \\
Celestina & 4,60 & 0,94 & 2,35 & 6,41 \\
Baritina & 95,34 & 0,93 & 93,50 & 97,61 \\
\hline TOTAL & $\mathbf{1 0 0 , 0 0}$ & & & \\
\hline
\end{tabular}

Tabla 6.1: Análisis de BARITINA por microsonda electrónica 


\begin{tabular}{|c|c|c|c|c|}
\hline \multirow{3}{*}{$\begin{array}{l}\text { Muestra } \rightarrow \\
\text { Ubicación } \rightarrow \\
\text { \% en peso }\end{array}$} & \multicolumn{4}{|c|}{19373 (Julio César, veta) $\mathrm{N}=35$} \\
\hline & \multicolumn{2}{|c|}{$70^{\circ} 20^{\prime} 57^{\prime \prime}$} & \multicolumn{2}{|c|}{$37^{\circ} 43^{\prime} 40^{\prime \prime}$} \\
\hline & Promedio & Desvío & Mínimo & Máximo \\
\hline $\mathrm{FeO}^{*}$ & 0,09 & 0,23 & 0,00 & 1,31 \\
\hline $\mathrm{MnO}$ & 0,03 & 0,03 & 0,00 & 0,10 \\
\hline $\mathrm{CoO}$ & 0,02 & 0,03 & 0,00 & 0,13 \\
\hline $\mathrm{MgO}$ & 0,01 & 0,01 & 0,00 & 0,03 \\
\hline $\mathrm{CaO}$ & 0,01 & 0,01 & 0,00 & 0,08 \\
\hline $\mathrm{SrO}$ & 0,57 & 0,45 & 0,00 & 1,43 \\
\hline $\mathrm{BaO}$ & 65,43 & 0,95 & 63,38 & 67,45 \\
\hline $\mathrm{P}_{2} \mathrm{O}_{5}$ & 0,00 & 0,00 & 0,00 & 0,00 \\
\hline $\mathrm{PbO}$ & 0,00 & 0,00 & 0,00 & 0,01 \\
\hline $\mathrm{SO}_{3}$ & 33,55 & 0,37 & 32,84 & 34,38 \\
\hline $\mathbf{F}$ & 0,00 & 0,00 & 0,00 & 0,00 \\
\hline TOTAL & 99,71 & & & \\
\hline
\end{tabular}

* = asumido como FeO total.

Número de cationes en base a 4 oxígenos por unidad de fórmula Muestra $\rightarrow \quad 19373$ (Julio César, veta)

\begin{tabular}{crrrr}
\hline c.p.u.f. & Promedio & \multicolumn{1}{c}{ Desvío } & Mínimo & Máximo \\
\hline Fe $^{+2}$ & 0,0029 & 0,0072 & 0,0000 & 0,0408 \\
$\mathbf{M n}$ & 0,0010 & 0,0009 & 0,0000 & 0,0034 \\
$\mathbf{C o}$ & 0,0006 & 0,0010 & 0,0000 & 0,0040 \\
$\mathbf{M g}$ & 0,0003 & 0,0005 & 0,0000 & 0,0015 \\
$\mathbf{C a}$ & 0,0002 & 0,0006 & 0,0000 & 0,0033 \\
$\mathbf{S r}$ & 0,0127 & 0,0099 & 0,0000 & 0,0323 \\
$\mathbf{B a}$ & 0,9821 & 0,0112 & 0,9559 & 0,9990 \\
$\mathbf{P}$ & 0,0000 & 0,0000 & 0,0000 & 0,0000 \\
$\mathbf{P b}$ & 0,0000 & 0,0000 & 0,0000 & 0,0001 \\
\hline Suma & $\mathbf{1 , 0 0 0 0}$ & & & \\
\hline \multicolumn{7}{c}{} \\
\hline $\mathbf{S}$ & $\mathbf{0 , 9 9 0 8}$ & 0,0046 & 0,9803 & 0,9982 \\
\hline \multicolumn{7}{c}{} \\
\hline TOTAL & $\mathbf{1 , 9 9 0 8}$ \\
\hline
\end{tabular}

Proporciones moleculares de los componentes finales

\begin{tabular}{lrrrr}
\hline Anhidrita & 0,02 & 0,06 & 0,00 & 0,33 \\
Celestina & 1,28 & 1,00 & 0,00 & 3,23 \\
Baritina & 98,70 & 0,99 & 96,77 & 100,00 \\
\hline TOTAL & $\mathbf{1 0 0 , 0 0}$ & & & \\
\hline
\end{tabular}

Tabla 6.1: Análisis de BARITINA por microsonda electrónica 


\begin{tabular}{|c|c|c|c|c|c|c|c|c|}
\hline \multirow{4}{*}{$\begin{array}{c}\text { Mina } \rightarrow \\
\text { Muestra } \rightarrow \\
\text { Ubicación } \rightarrow \\
\text { mineral } \rightarrow\end{array}$} & \multicolumn{8}{|c|}{ San Eduardo } \\
\hline & \multirow{2}{*}{\multicolumn{8}{|c|}{$\begin{array}{l}4951 \\
70^{\circ} 20^{\prime} 45^{\prime \prime}\end{array}$}} \\
\hline & & & & & & & & \\
\hline & \multicolumn{4}{|c|}{$\mathbf{7 0}^{\circ} \mathbf{2 0 ^ { \prime }} \mathbf{4 5}^{\prime \prime}$ Pirita $N=11$} & \multicolumn{4}{|c|}{ Galena $N=3$} \\
\hline$\%$ en peso & Promedio & Desvío & Mínimo & Máximo & Promedio & Desvío & Mínimo & Máximo \\
\hline $\mathrm{Bi}$ & 0,03 & 0,06 & 0,00 & 0,19 & 0,17 & 0,00 & 0,16 & 0,17 \\
\hline $\mathbf{P b}$ & 0,38 & 0,14 & 0,23 & 0,65 & 86,68 & 0,13 & 86,53 & 86,79 \\
\hline Tl & 0,01 & 0,02 & 0,00 & 0,08 & 0,00 & 0,00 & 0,00 & 0,00 \\
\hline $\mathrm{Hg}$ & 0,03 & 0,04 & 0,00 & 0,11 & 0,00 & 0,00 & 0,00 & 0,00 \\
\hline Au & 0,01 & 0,02 & 0,00 & 0,06 & 0,00 & 0,00 & 0,00 & 0,00 \\
\hline $\mathbf{W}$ & 0,02 & 0,03 & 0,00 & 0,07 & 0,00 & 0,00 & 0,00 & 0,00 \\
\hline Te & 0,01 & 0,02 & 0,00 & 0,06 & 0,00 & 0,00 & 0,00 & 0,00 \\
\hline Sb & 0,02 & 0,02 & 0,00 & 0,07 & 0,20 & 0,00 & 0,19 & 0,20 \\
\hline Sn & 0,02 & 0,03 & 0,00 & 0,09 & 0,02 & 0,00 & 0,02 & 0,03 \\
\hline In & 0,00 & 0,01 & 0,00 & 0,03 & 0,00 & 0,00 & 0,00 & 0,00 \\
\hline Cd & 0,01 & 0,03 & 0,00 & 0,08 & 0,00 & 0,00 & 0,00 & 0,00 \\
\hline Ag & 0,02 & 0,02 & 0,00 & 0,05 & 0,05 & 0,00 & 0,05 & 0,05 \\
\hline Se & 0,04 & 0,02 & 0,01 & 0,08 & 0,01 & 0,00 & 0,01 & 0,02 \\
\hline As & 0,13 & 0,11 & 0,00 & 0,38 & 0,00 & 0,00 & 0,00 & 0,00 \\
\hline Ge & 0,00 & 0,00 & 0,00 & 0,00 & 0,00 & 0,00 & 0,00 & 0,00 \\
\hline Ga & 0,00 & 0,00 & 0,00 & 0,00 & 0,00 & 0,00 & 0,00 & 0,01 \\
\hline $\mathrm{Zn}$ & 0,01 & 0,01 & 0,00 & 0,03 & 0,00 & 0,00 & 0,00 & 0,00 \\
\hline $\mathrm{Cu}$ & 0,03 & 0,06 & 0,00 & 0,22 & 0,05 & 0,00 & 0,05 & 0,05 \\
\hline $\mathrm{Ni}$ & 0,30 & 0,41 & 0,02 & 1,47 & 0,00 & 0,00 & 0,00 & 0,00 \\
\hline Co & 0,97 & 1,29 & 0,00 & 4,61 & 0,00 & 0,00 & 0,00 & 0,00 \\
\hline $\mathrm{Fe}$ & 45,69 & 1,25 & 42,47 & 46,99 & 0,02 & 0,00 & 0,02 & 0,02 \\
\hline $\mathbf{T i}$ & 0,00 & 0,00 & 0,00 & 0,01 & 0,00 & 0,00 & 0,00 & 0,00 \\
\hline $\mathrm{S}$ & 52,81 & 0,30 & 52,30 & 53,39 & 12,04 & 0,08 & 11,95 & 12,09 \\
\hline TOTAL & 100,56 & & & & 99,25 & & & \\
\hline
\end{tabular}

Tabla 6.3: Análisis de SULFUROS por microsonda electrónica

\begin{tabular}{|c|c|c|c|c|c|c|c|c|}
\hline \multirow{4}{*}{$\begin{array}{c}\text { Mina } \rightarrow \\
\text { Muestra } \rightarrow \\
\text { Ubicación } \rightarrow \\
\text { mineral } \rightarrow \\
\text { M }\end{array}$} & \multicolumn{8}{|c|}{ San Eduardo } \\
\hline & \multirow{2}{*}{\multicolumn{8}{|c|}{$\begin{array}{l}4951 \\
70^{\circ} 20^{\prime} 45^{\prime \prime}\end{array}$}} \\
\hline & & & & & & & & \\
\hline & \multicolumn{4}{|c|}{ Tetraedrita $\mathrm{N}=3$} & \multicolumn{4}{|c|}{ Calcopirita $\mathrm{N}=3$} \\
\hline$\%$ en peso & Promedio & Desvío & Mínimo & Máximo & Promedio & Desvío & Mínimo & Máximo \\
\hline $\mathbf{B i}$ & 0,22 & 0,197 & 0,00 & 0,37 & 0,08 & 0,04 & 0,04 & 0,12 \\
\hline $\mathbf{P b}$ & 1,66 & 0,811 & 1,10 & 2,59 & 0,21 & 0,06 & 0,15 & 0,26 \\
\hline TI & 0,04 & 0,034 & 0,00 & 0,07 & 0,02 & 0,03 & 0,00 & 0,05 \\
\hline Hg & 0,07 & 0,082 & 0,01 & 0,16 & 0,05 & 0,09 & 0,00 & 0,15 \\
\hline $\mathbf{A u}$ & 0,00 & 0,000 & 0,00 & 0,00 & 0,04 & 0,06 & 0,00 & 0,11 \\
\hline $\mathbf{W}$ & 0,00 & 0,000 & 0,00 & 0,00 & 0,00 & 0,00 & 0,00 & 0,00 \\
\hline $\mathrm{Te}$ & 0,00 & 0,000 & 0,00 & 0,00 & 0,02 & 0,01 & 0,01 & 0,03 \\
\hline Sb & 11,33 & 1,791 & 9,58 & 13,16 & 0,36 & 0,62 & 0,00 & 1,08 \\
\hline Sn & 0,06 & 0,026 & 0,03 & 0,08 & 0,02 & 0,03 & 0,00 & 0,05 \\
\hline In & 0,02 & 0,027 & 0,00 & 0,05 & 0,01 & 0,01 & 0,00 & 0,02 \\
\hline Cd & 0,03 & 0,025 & 0,00 & 0,04 & 0,00 & 0,01 & 0,00 & 0,01 \\
\hline Ag & 0,96 & 0,205 & 0,82 & 1,20 & 0,05 & 0,08 & 0,00 & 0,14 \\
\hline Se & 0,00 & 0,000 & 0,00 & 0,00 & 0,05 & 0,02 & 0,04 & 0,07 \\
\hline As & 10,14 & 1,491 & 8,60 & 11,58 & 0,18 & 0,31 & 0,00 & 0,54 \\
\hline Ge & 0,15 & 0,133 & 0,00 & 0,25 & 0,00 & 0,00 & 0,00 & 0,00 \\
\hline $\mathbf{G a}$ & 0,00 & 0,000 & 0,00 & 0,00 & 0,00 & 0,00 & 0,00 & 0,00 \\
\hline $\mathbf{Z n}$ & 2,30 & 0,046 & 2,24 & 2,33 & 0,00 & 0,01 & 0,00 & 0,01 \\
\hline $\mathrm{Cu}$ & 40,49 & 0,422 & 40,01 & 40,80 & 34,91 & 0,90 & 34,03 & 35,82 \\
\hline $\mathrm{Ni}$ & 0,01 & 0,010 & 0,00 & 0,02 & 0,01 & 0,01 & 0,00 & 0,02 \\
\hline Co & 0,11 & 0,031 & 0,07 & 0,14 & 0,00 & 0,00 & 0,00 & 0,00 \\
\hline $\mathrm{Fe}$ & 5,46 & 0,162 & 5,29 & 5,60 & 30,56 & 0,85 & 29,92 & 31,53 \\
\hline $\mathbf{T i}$ & 0,00 & 0,000 & 0,00 & 0,00 & 0,00 & 0,00 & 0,00 & 0,00 \\
\hline $\mathbf{S}$ & 26,58 & 0,271 & 26,28 & 26,81 & 34,61 & 0,21 & 34,36 & 34,75 \\
\hline TOTAL & 99,64 & & & & 101,18 & & & \\
\hline
\end{tabular}

Tabla 6.3: Análisis de SULFUROS por microsonda electrónica 


\begin{tabular}{|c|c|c|c|c|c|c|c|c|}
\hline \multirow{4}{*}{$\begin{array}{c}\text { Mina } \rightarrow \\
\text { Muestra } \rightarrow \\
\text { Ubicación } \rightarrow \\
\text { mineral } \rightarrow \\
\end{array}$} & \multicolumn{8}{|c|}{ San Eduardo } \\
\hline & \multirow{2}{*}{\multicolumn{8}{|c|}{$\begin{array}{l}15024 \\
70^{\circ} 20^{\prime} 48^{\prime \prime}\end{array}$}} \\
\hline & & & & & & & & \\
\hline & \multicolumn{4}{|c|}{ Pirita $N=34$} & \multicolumn{4}{|c|}{ Galena $N=7$} \\
\hline$\%$ en peso & Promedio & Desvio & Mínimo & Máximo & Promedio & Desvio & Mínimo & Máximo \\
\hline $\mathrm{Bi}$ & 0,14 & 0,11 & 0,00 & 0,46 & 0,59 & 0,22 & 0,25 & 0,82 \\
\hline $\mathbf{P b}$ & 0,40 & 0,22 & 0,15 & 1,06 & 86,90 & 0,27 & 86,46 & 87,21 \\
\hline Tl & 0,10 & 0,06 & 0,01 & 0,15 & 0,06 & 0,00 & 0,06 & 0,06 \\
\hline Hg & 0,06 & 0,04 & 0,01 & 0,15 & 0,05 & 0,03 & 0,01 & 0,08 \\
\hline $\mathrm{Au}$ & 0,05 & 0,02 & 0,01 & 0,11 & 0,02 & 0,03 & 0,00 & 0,06 \\
\hline $\mathbf{w}$ & 0,03 & 0,03 & 0,00 & 0,08 & 0,08 & 0,06 & 0,05 & 0,15 \\
\hline Te & 0,05 & 0,03 & 0,00 & 0,12 & 0,04 & 0,02 & 0,01 & 0,07 \\
\hline $\mathbf{S b}$ & 0,04 & 0,05 & 0,00 & 0,21 & 0,15 & 0,12 & 0,01 & 0,33 \\
\hline Sn & 0,04 & 0,02 & 0,01 & 0,09 & 0,00 & 0,01 & 0,00 & 0,01 \\
\hline In & 0,03 & 0,02 & 0,00 & 0,07 & 0,01 & 0,02 & 0,00 & 0,03 \\
\hline Cd & 0,03 & 0,02 & 0,00 & 0,09 & 0,00 & 0,00 & 0,00 & 0,00 \\
\hline Ag & 0,06 & 0,04 & 0,01 & 0,19 & 0,07 & 0,05 & 0,02 & 0,14 \\
\hline Se & 0,03 & 0,01 & 0,00 & 0,06 & 0,01 & 0,01 & 0,00 & 0,02 \\
\hline As & 0,85 & 1,27 & 0,01 & 4,56 & 0,00 & 0,00 & 0,00 & 0,00 \\
\hline Ge & 0,00 & 0,00 & 0,00 & 0,00 & 0,00 & 0,00 & 0,00 & 0,00 \\
\hline Ga & 0,02 & 0,01 & 0,00 & 0,03 & 0,01 & 0,00 & 0,00 & 0,01 \\
\hline $\mathrm{Zn}$ & 0,02 & 0,01 & 0,00 & 0,03 & 0,01 & 0,00 & 0,01 & 0,01 \\
\hline $\mathrm{Cu}$ & 0,02 & 0,02 & 0,00 & 0,08 & 0,03 & 0,01 & 0,01 & 0,05 \\
\hline $\mathrm{Ni}$ & 0,01 & 0,01 & 0,00 & 0,06 & 0,01 & 0,01 & 0,00 & 0,01 \\
\hline Co & 0,00 & 0,00 & 0,00 & 0,00 & 0,01 & 0,00 & 0,01 & 0,01 \\
\hline $\mathrm{Fe}$ & 47,46 & 0,81 & 44,81 & 48,91 & 0,01 & 0,00 & 0,00 & 0,01 \\
\hline $\mathbf{T i}$ & 0,01 & 0,01 & 0,00 & 0,04 & 0,01 & 0,00 & 0,01 & 0,01 \\
\hline $\mathbf{S}$ & 51,27 & 1,34 & 48,00 & 52,85 & 11,67 & 0,96 & 10,26 & 0,01 \\
\hline TOTAL & 100,70 & & & & 99,72 & & & \\
\hline
\end{tabular}

Tabla 6.3: Análisis de SULFUROS por microsonda electrónica

\begin{tabular}{|c|c|c|c|c|c|c|c|c|}
\hline \multirow{4}{*}{$\begin{array}{c}\text { Mina } \rightarrow \\
\text { Muestra } \rightarrow \\
\text { Ubicación } \rightarrow \\
\text { mineral } \rightarrow \\
\end{array}$} & \multicolumn{8}{|c|}{ San Eduardo } \\
\hline & \multirow{2}{*}{\multicolumn{8}{|c|}{$\begin{array}{l}15024 \\
70^{\circ} 20^{\prime} 48^{\prime \prime}\end{array}$}} \\
\hline & & & & & & & & \\
\hline & \multicolumn{4}{|c|}{ Calcopirita $\mathrm{N}=6$} & \multicolumn{4}{|c|}{ Esfalerita $\mathrm{N}=15$} \\
\hline$\%$ en peso & Promedio & Desvío & Mínimo & Máximo & Promedio & Desvío & Mínimo & Máximo \\
\hline $\mathbf{B i}$ & 0,18 & 0,14 & 0,02 & 0,30 & 0,11 & 0,07 & 0,01 & 0,20 \\
\hline $\mathbf{P b}$ & 1,08 & 0,19 & 0,88 & 1,42 & 0,20 & 0,08 & 0,09 & 0,32 \\
\hline TI & 0,24 & 0,00 & 0,24 & 0,24 & 0,07 & 0,05 & 0,01 & 0,12 \\
\hline Hg & 0,05 & 0,06 & 0,01 & 0,10 & 0,00 & 0,00 & 0,00 & 0,00 \\
\hline $\mathbf{A u}$ & 0,06 & 0,03 & 0,04 & 0,09 & 0,49 & 0,06 & 0,39 & 0,57 \\
\hline $\mathbf{W}$ & 0,03 & 0,02 & 0,00 & 0,05 & 0,00 & 0,00 & 0,00 & 0,00 \\
\hline $\mathrm{Te}$ & 0,02 & 0,01 & 0,01 & 0,04 & 0,04 & 0,03 & 0,01 & 0,11 \\
\hline Sb & 0,91 & 0,53 & 0,18 & 1,71 & 0,02 & 0,01 & 0,01 & 0,04 \\
\hline Sn & 0,04 & 0,04 & 0,00 & 0,07 & 0,02 & 0,02 & 0,00 & 0,07 \\
\hline In & 0,02 & 0,01 & 0,01 & 0,03 & 0,00 & 0,00 & 0,00 & 0,00 \\
\hline Cd & 0,04 & 0,03 & 0,00 & 0,07 & 0,49 & 0,20 & 0,23 & 0,82 \\
\hline Ag & 0,10 & 0,05 & 0,04 & 0,16 & 0,04 & 0,05 & 0,00 & 0,15 \\
\hline Se & 0,02 & 0,01 & 0,00 & 0,03 & 0,04 & 0,02 & 0,01 & 0,07 \\
\hline As & 1,10 & 0,14 & 0,89 & 1,25 & 0,02 & 0,01 & 0,01 & 0,04 \\
\hline Ge & 0,02 & 0,01 & 0,01 & 0,03 & 0,04 & 0,03 & 0,01 & 0,09 \\
\hline Ga & 0,00 & 0,00 & 0,00 & 0,00 & 0,03 & 0,02 & 0,01 & 0,07 \\
\hline$Z_{n}$ & 0,03 & 0,03 & 0,00 & 0,09 & 63,12 & 0,87 & 61,76 & 64,62 \\
\hline $\mathrm{Cu}$ & 34,99 & 0,69 & 34,03 & 35,91 & 0,06 & 0,05 & 0,01 & 0,19 \\
\hline $\mathrm{Ni}$ & 0,02 & 0,02 & 0,00 & 0,05 & 0,01 & 0,01 & 0,00 & 0,02 \\
\hline Co & 0,00 & 0,00 & 0,00 & 0,00 & 0,01 & 0,00 & 0,00 & 0,01 \\
\hline $\mathrm{Fe}$ & 27,78 & 0,78 & 26,96 & 28,83 & 1,51 & 1,08 & 0,13 & 3,55 \\
\hline $\mathbf{T i}$ & 0,00 & 0,00 & 0,00 & 0,00 & 0,01 & 0,01 & 0,00 & 0,02 \\
\hline $\mathbf{S}$ & 33,70 & 0,98 & 32,39 & 34,63 & 32,89 & 0,28 & 32,29 & 33,30 \\
\hline TOTAL & 100,43 & & & & 99,23 & & & \\
\hline
\end{tabular}

Tabla 6.3: Análisis de SULFUROS por microsonda electrónica 


\begin{tabular}{|c|c|c|c|c|c|c|c|c|}
\hline \multirow{4}{*}{$\begin{array}{c}\text { Mina } \rightarrow \\
\text { Muestra } \rightarrow \\
\text { Ubicación } \rightarrow \\
\text { mineral } \rightarrow \\
\end{array}$} & \multicolumn{4}{|c|}{ Julio César } & \multicolumn{4}{|c|}{ Julio César } \\
\hline & \multicolumn{4}{|l|}{19369} & \multicolumn{4}{|l|}{19373} \\
\hline & $70^{\circ} 20$ & 55" & \multicolumn{2}{|c|}{$37^{\circ} 43^{\prime} 43^{\prime \prime}$} & $70^{\circ} 20$ & 57" & \multicolumn{2}{|c|}{$37^{\circ} 43^{\prime} 40^{\prime \prime}$} \\
\hline & \multicolumn{4}{|c|}{ Galena $N=94$} & \multicolumn{4}{|c|}{ Galena $N=104$} \\
\hline$\%$ en peso & Promedio & Desvío & Mínimo & Máximo & Promedio & Desvío & Mínimo & Máximo \\
\hline $\mathbf{P b}$ & 87,01 & 0,60 & 85,48 & 88,52 & 86,80 & 0,72 & 84,52 & 88,54 \\
\hline Sb & 0,04 & 0,03 & 0,00 & 0,13 & 0,03 & 0,02 & 0,00 & 0,07 \\
\hline Cd & 0,03 & 0,03 & 0,00 & 0,09 & 0,03 & 0,02 & 0,00 & 0,10 \\
\hline Ag & 0,07 & 0,05 & 0,00 & 0,21 & 0,07 & 0,05 & 0,00 & 0,18 \\
\hline As & 0,02 & 0,02 & 0,00 & 0,06 & 0,03 & 0,02 & 0,00 & 0,07 \\
\hline Zn & 0,06 & 0,04 & 0,00 & 0,16 & 0,07 & 0,05 & 0,00 & 0,17 \\
\hline $\mathrm{Cu}$ & 0,04 & 0,02 & 0,00 & 0,09 & 0,03 & 0,03 & 0,00 & 0,10 \\
\hline Co & 0,02 & 0,01 & 0,00 & 0,05 & 0,02 & 0,02 & 0,00 & 0,06 \\
\hline Mn & 0,02 & 0,02 & 0,00 & 0,08 & 0,02 & 0,02 & 0,00 & 0,08 \\
\hline $\mathbf{F e}$ & 0,02 & 0,01 & 0,00 & 0,06 & 0,02 & 0,02 & 0,00 & 0,07 \\
\hline $\mathbf{S}$ & 12,99 & 0,19 & 12,54 & 13,48 & 12,97 & 0,13 & 12,70 & 13,34 \\
\hline TOTAL & 100,31 & & & & 100,09 & & & \\
\hline
\end{tabular}

Tabla 6.3: Análisis de SULFUROS por microsonda electrónica 


\begin{tabular}{|c|c|c|c|c|c|c|c|c|}
\hline \multirow{3}{*}{$\begin{array}{c}\text { Muestra } \rightarrow \\
\text { Ubicación } \rightarrow \\
\% \text { en peso }\end{array}$} & \multicolumn{4}{|c|}{21827 (cerro Los Bueyes) $\mathrm{N}=\mathbf{3 0}$} & \multicolumn{4}{|c|}{21824 (cerro Los Bueyes) $\mathrm{N}=\mathbf{2 4}$} \\
\hline & \multicolumn{2}{|c|}{$70^{\circ} 22^{\prime} 45^{\prime \prime}$} & \multicolumn{2}{|c|}{$37^{\circ} 42^{\prime} 43^{\prime \prime}$} & \multicolumn{2}{|c|}{$70^{\circ} 22^{\prime} 32^{\prime \prime}$} & \multicolumn{2}{|c|}{$37^{\circ} 43^{\prime} 35^{\prime \prime}$} \\
\hline & PROMEDIO & DESVIOO & MINIMO & MÁXIMO & PROMEDIO & DESVIOO & MINIMO & MÁXIMO \\
\hline $\mathrm{SiO}_{2}$ & 0,21 & 0,28 & 0,00 & 0,96 & 0,29 & 0,49 & 0,01 & 1,86 \\
\hline $\mathrm{TiO}_{2}$ & 3,41 & 0,24 & 2,95 & 3,84 & 3,44 & 0,24 & 2,98 & 3,82 \\
\hline $\mathrm{Sc}_{2} \mathrm{O}_{3}$ & 0,01 & 0,01 & 0,00 & 0,03 & 0,00 & 0,01 & 0,00 & 0,02 \\
\hline $\mathrm{Al}_{2} \mathrm{O}_{3}$ & 1,77 & 0,48 & 1,03 & 3,20 & 2,25 & 0,58 & 1,57 & 3,83 \\
\hline $\mathrm{Cr}_{2} \mathrm{O}_{3}$ & 0,03 & 0,02 & 0,00 & 0,09 & 0,03 & 0,02 & 0,00 & 0,08 \\
\hline $\mathrm{V}_{2} \mathrm{O}_{3}$ & 0,35 & 0,08 & 0,22 & 0,49 & 0,31 & 0,07 & 0,16 & 0,43 \\
\hline $\mathrm{Fe}_{2} \mathrm{O}_{3}{ }^{*}$ & 60,10 & 0,97 & 57,89 & 62,00 & 59,41 & 1,85 & 54,13 & 61,23 \\
\hline $\mathrm{FeO}^{*}$ & 32,14 & 0,66 & 31,08 & 33,93 & 32,26 & 0,84 & 31,32 & 34,42 \\
\hline MnO & 1,44 & 0,39 & 0,29 & 1,98 & 1,67 & 0,35 & 0,85 & 2,19 \\
\hline $\mathrm{NiO}$ & 0,00 & 0,01 & 0,00 & 0,03 & 0,00 & 0,01 & 0,00 & 0,03 \\
\hline $\mathrm{MgO}$ & 0,70 & 0,28 & 0,09 & 1,09 & 0,65 & 0,20 & 0,19 & 0,90 \\
\hline $\mathrm{CaO}$ & 0,00 & 0,00 & 0,00 & 0,00 & 0,00 & 0,00 & 0,00 & 0,00 \\
\hline $\mathrm{CoO}$ & 0,01 & 0,05 & 0,00 & 0,25 & 0,02 & 0,12 & 0,00 & 0,59 \\
\hline $\mathrm{ZnO}$ & 0,24 & 0,10 & 0,05 & 0,49 & 0,20 & 0,07 & 0,10 & 0,35 \\
\hline $\mathrm{Na}_{2} \mathrm{O}$ & 0,00 & 0,00 & 0,00 & 0,00 & 0,00 & 0,00 & 0,00 & 0,00 \\
\hline $\mathrm{K}_{2} \mathrm{O}$ & 0,01 & 0,01 & 0,00 & 0,05 & 0,01 & 0,02 & 0,00 & 0,05 \\
\hline $\mathrm{P}_{2} \mathrm{O}_{5}$ & 0,00 & 0,00 & 0,00 & 0,00 & 0,00 & 0,00 & 0,00 & 0,00 \\
\hline TOTAL & 100,41 & & & & 100,56 & & & \\
\hline
\end{tabular}

Tabla 6.4: Análisis de MAGNETITA por microsonda electrónica

Número de cationes en base a 32 oxígenos por unidad de fórmula

\begin{tabular}{|c|c|c|c|c|c|c|c|c|}
\hline \multicolumn{9}{|l|}{ Posiciones $\mathbf{R}^{+2}$} \\
\hline \multirow{3}{*}{$\begin{array}{c}\begin{array}{c}\text { Muestra } \rightarrow \\
\text { Ubicación } \rightarrow\end{array} \\
\text { c.p.u.f. }\end{array}$} & \multicolumn{4}{|c|}{21827 (cerro Los Bueyes) } & \multicolumn{4}{|c|}{21824 (cerro Los Bueyes) } \\
\hline & \multicolumn{2}{|c|}{$70^{\circ} 22^{\prime} 45^{\prime \prime}$} & \multicolumn{2}{|c|}{$37^{\circ} 42^{\prime} 43^{\prime \prime}$} & \multicolumn{2}{|c|}{$70^{\circ} 22^{\prime} 32^{\prime \prime}$} & \multicolumn{2}{|c|}{$37^{\circ} 43^{\prime} 35^{\prime \prime}$} \\
\hline & PROMEDIO & DESVÍO & MÍNIMO & MÁXIMO & PROMEDIO & DESVÍO & MÍNIMO & MÁXIMO \\
\hline $\mathrm{Fe}^{2+}$ & 8,09 & 0,18 & 7,86 & 8,60 & 8,09 & 0,20 & 7,84 & 8,53 \\
\hline Mn & 0,37 & 0,10 & 0,07 & 0,50 & 0,42 & 0,09 & 0,22 & 0,55 \\
\hline $\mathrm{Mg}$ & 0,31 & 0,12 & 0,04 & 0,48 & 0,29 & 0,09 & 0,09 & 0,40 \\
\hline $\mathrm{Ca}$ & 0,00 & 0,00 & 0,00 & 0,00 & 0,00 & 0,00 & 0,00 & 0,00 \\
\hline Co & 0,00 & 0,01 & 0,00 & 0,06 & 0,01 & 0,03 & 0,00 & 0,14 \\
\hline $\mathrm{Ni}$ & 0,00 & 0,00 & 0,00 & 0,01 & 0,00 & 0,00 & 0,00 & 0,01 \\
\hline $\mathrm{Zn}$ & 0,05 & 0,02 & 0,01 & 0,11 & 0,04 & 0,02 & 0,02 & 0,08 \\
\hline $\mathbf{K}$ & 0,00 & 0,00 & 0,00 & 0,02 & 0,00 & 0,01 & 0,00 & 0,02 \\
\hline Suma & 8,83 & & & & 8,86 & & & \\
\hline \multicolumn{9}{|l|}{ Posiciones $\mathbf{M}^{+3}$} \\
\hline $\mathrm{Fe}^{3+}$ & 13,62 & 0,30 & 12,96 & 14,15 & 13,40 & 0,45 & 12,08 & 13,83 \\
\hline Al & 0,63 & 0,17 & 0,37 & 1,12 & 0,80 & 0,20 & 0,56 & 1,35 \\
\hline $\mathrm{Cr}$ & 0,01 & 0,00 & 0,00 & 0,02 & 0,01 & 0,00 & 0,00 & 0,02 \\
\hline Sc & 0,00 & 0,00 & 0,00 & 0,00 & 0,00 & 0,00 & 0,00 & 0,00 \\
\hline $\mathbf{V}$ & 0,08 & 0,02 & 0,05 & 0,12 & 0,08 & 0,02 & 0,04 & 0,10 \\
\hline Suma & 14,34 & & & & 14,28 & & & \\
\hline \multicolumn{9}{|l|}{ Posiciones $\mathrm{T}^{+4}$} \\
\hline $\mathrm{Si}$ & 0,06 & 0,08 & 0,00 & 0,28 & 0,09 & 0,14 & 0,00 & $\overline{0,55}$ \\
\hline $\mathrm{Ti}$ & 0,77 & 0,05 & 0,67 & 0,87 & 0,78 & 0,05 & 0,67 & 0,86 \\
\hline Suma & 0,83 & & & & 0,86 & & & \\
\hline TOTAL & 24,00 & & & & 24,00 & & & \\
\hline \multicolumn{9}{|c|}{ Proporciones moleculares de los componentes finales* } \\
\hline Espinela & 4,41 & 1,18 & 2,53 & 7,75 & 5,61 & 1,51 & 3,88 & 9,41 \\
\hline Magnetita & 95,54 & 1,18 & 92,23 & 97,41 & 94,33 & 1,51 & 90,55 & 96,08 \\
\hline Cromita & 0,05 & 0,03 & 0,00 & 0,15 & 0,06 & 0,03 & 0,00 & 0,13 \\
\hline TOTAL & $\mathbf{1 0 0 , 0 0}$ & & & & 100,00 & & & \\
\hline
\end{tabular}

*=según Deer et al. 1992 


\begin{tabular}{|c|c|c|c|c|c|c|c|c|}
\hline \multicolumn{5}{|c|}{ Muestra $\rightarrow 19334 \mathrm{E}$ (cerro Naunauco) $\mathrm{N}=24$} & \multicolumn{4}{|c|}{ mina Augusta $N=25$} \\
\hline \multirow{2}{*}{$\begin{array}{l}\text { Ubicación } \rightarrow \\
\% \text { en peso } \\
\end{array}$} & \multicolumn{2}{|c|}{$70^{\circ} 14^{\prime} 10^{\prime \prime}$} & \multicolumn{2}{|c|}{$37^{\circ} 33^{\prime} 54^{\prime \prime}$} & \multicolumn{2}{|c|}{$70^{\circ} 20^{\prime} 07^{\prime \prime}$} & \multicolumn{2}{|c|}{$37^{\circ} 43^{\prime} 39^{\prime \prime}$} \\
\hline & PROMEDIO & DESVÍO & MÍNIMO & MÁXIMO & PROMEDIO & DESVÍO & MÍNIMO & MÁXIMO \\
\hline $\mathrm{SiO}_{2}$ & 0,03 & 0,08 & 0,00 & 0,36 & 0,70 & 0,88 & 0,00 & 3,01 \\
\hline $\mathrm{TiO}_{2}$ & 0,28 & 0,09 & 0,15 & 0,47 & 0,02 & 0,03 & 0,00 & 0,10 \\
\hline $\mathrm{Sc}_{2} \mathrm{O}_{3}$ & 0,01 & 0,01 & 0,00 & 0,04 & 0,01 & 0,01 & 0,00 & 0,04 \\
\hline $\mathrm{Al}_{2} \mathrm{O}_{3}$ & 0,84 & 0,38 & 0,26 & 1,39 & 0,13 & 0,12 & 0,02 & 0,55 \\
\hline $\mathrm{Cr}_{2} \mathrm{O}_{3}$ & 0,01 & 0,01 & 0,00 & 0,04 & 0,01 & 0,01 & 0,00 & 0,04 \\
\hline $\mathrm{V}_{2} \mathrm{O}_{3}$ & 0,02 & 0,04 & 0,00 & 0,17 & 0,03 & 0,04 & 0,00 & 0,12 \\
\hline $\mathrm{Fe}_{2} \mathrm{O}_{3}{ }^{*}$ & 69,07 & 0,37 & 68,22 & 69,79 & 66,78 & 2,30 & 60,91 & 69,05 \\
\hline $\mathrm{FeO}^{*}$ & 26,46 & 0,39 & 25,42 & 27,15 & 31,17 & 0,66 & 30,45 & 32,94 \\
\hline $\mathrm{MnO}$ & 0,11 & 0,04 & 0,05 & 0,19 & 0,07 & 0,03 & 0,02 & 0,16 \\
\hline $\mathrm{NiO}$ & 0,00 & 0,01 & 0,00 & 0,03 & 0,00 & 0,01 & 0,00 & 0,02 \\
\hline $\mathrm{MgO}$ & 3,06 & 0,37 & 2,57 & 3,91 & 0,09 & 0,11 & 0,00 & 0,43 \\
\hline $\mathrm{CaO}$ & 0,05 & 0,07 & 0,00 & 0,24 & 0,19 & 0,23 & 0,00 & 0,71 \\
\hline $\mathrm{CoO}$ & 0,16 & 0,03 & 0,12 & 0,21 & 0,17 & 0,03 & 0,12 & 0,23 \\
\hline $\mathrm{ZnO}$ & 0,03 & 0,05 & 0,00 & 0,17 & 0,03 & 0,04 & 0,00 & 0,14 \\
\hline $\mathrm{Na}_{2} \mathrm{O}$ & 0,00 & 0,00 & 0,00 & 0,00 & 0,00 & 0,00 & 0,00 & 0,00 \\
\hline $\mathrm{K}_{2} \mathrm{O}$ & 0,00 & 0,01 & 0,00 & 0,03 & 0,02 & 0,03 & 0,00 & 0,09 \\
\hline $\mathrm{P}_{2} \mathrm{O}_{5}$ & 0,00 & 0,00 & 0,00 & 0,00 & 0,00 & 0,00 & 0,00 & 0,00 \\
\hline TOTAL & 100,16 & & & & 99,46 & & & \\
\hline
\end{tabular}

* $=\mathrm{Fe}_{2} \mathrm{O}_{3}$ y FeO discriminado estequiométricamente según Droop 1987

Tabla 6.4: Análisis de MAGNETITA por microsonda electrónica

Número de cationes en base a 32 oxigenos por unidad de fórmula

Posiciones $\mathbf{R}^{+2}$

Muestra $\rightarrow 19334$ E (cerro Naunauco) mina Augusta

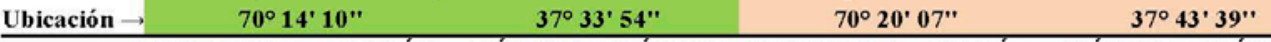

\begin{tabular}{|c|c|c|c|c|c|c|c|c|}
\hline c.p.u.f. & PROMEDIO & DESVÍO & MÍNIMO & MÁXIMO & PROMEDIO & DESVIOO & MÍNIMO & MÁXIMO \\
\hline $\mathrm{Fe}^{2+}$ & 6,62 & 0,15 & 6,27 & 6,83 & 8,04 & 0,15 & 7,88 & 8,40 \\
\hline Mn & 0,03 & 0,01 & 0,01 & 0,05 & 0,02 & 0,01 & 0,00 & 0,04 \\
\hline Mg & 1,36 & 0,15 & 1,15 & 1,72 & 0,04 & 0,05 & 0,00 & 0,20 \\
\hline $\mathrm{Ca}$ & 0,02 & 0,02 & 0,00 & 0,08 & 0,06 & 0,08 & 0,00 & 0,23 \\
\hline Co & 0,04 & 0,01 & 0,03 & 0,05 & 0,04 & 0,01 & 0,03 & 0,06 \\
\hline $\mathbf{N i}$ & 0,00 & 0,00 & 0,00 & 0,01 & 0,00 & 0,00 & 0,00 & 0,01 \\
\hline Zn & 0,01 & 0,01 & 0,00 & 0,04 & 0,01 & 0,01 & 0,00 & 0,03 \\
\hline $\mathbf{K}$ & 0,00 & 0,00 & 0,00 & 0,01 & 0,01 & 0,01 & 0,00 & 0,04 \\
\hline Suma & 8,08 & & & & 8,22 & & & \\
\hline \multicolumn{9}{|c|}{ Posiciones $\mathbf{M}^{+3}$} \\
\hline $\mathrm{Fe}^{3+}$ & 15,55 & 0,16 & 15,31 & 15,81 & 15,50 & 0,56 & 13,97 & 15,98 \\
\hline Al & 0,29 & 0,13 & 0,09 & 0,48 & 0,05 & 0,04 & 0,01 & 0,20 \\
\hline $\mathrm{Cr}$ & 0,00 & 0,00 & 0,00 & 0,01 & 0,00 & 0,00 & 0,00 & 0,01 \\
\hline Sc & 0,00 & 0,00 & 0,00 & 0,01 & 0,00 & 0,00 & 0,00 & 0,01 \\
\hline $\mathrm{V}$ & 0,01 & 0,01 & 0,00 & 0,04 & 0,01 & 0,01 & 0,00 & 0,03 \\
\hline Suma & $\mathbf{1 5 , 8 5}$ & & & & $\mathbf{1 5 , 5 6}$ & & & \\
\hline \multicolumn{9}{|c|}{ 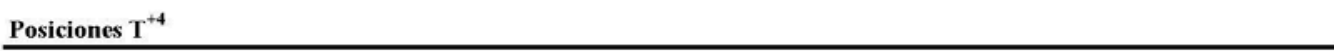 } \\
\hline $\mathbf{S i}$ & 0,01 & 0,02 & 0,00 & 0,11 & 0,22 & 0,27 & 0,00 & 0,92 \\
\hline Ti & 0,06 & 0,02 & 0,03 & 0,10 & 0,00 & 0,01 & 0,00 & 0,02 \\
\hline Suma & 0,07 & & & & 0,22 & & & \\
\hline TOTAL & 24,00 & & & & 24,00 & & & \\
\hline \multicolumn{9}{|c|}{ Proporciones moleculares de los componentes finales* } \\
\hline Espinela & 1,86 & 0,83 & 0,59 & 3,05 & 0,31 & 0,30 & 0,05 & 1,39 \\
\hline Magnetita & 98,13 & 0,82 & 96,89 & 99,41 & 99,68 & 0,30 & 98,61 & 99,92 \\
\hline Cromita & 0,01 & 0,02 & 0,00 & 0,07 & 0,01 & 0,02 & 0,00 & 0,06 \\
\hline TOTAL & 100,00 & & & & 100,00 & & & \\
\hline
\end{tabular}

Tabla 6.4: Análisis de MAGNETITA por microsonda electrónica 


\section{Trabajos citados en el texto}

Ballivián Justiniano, C.A. 2016. Geología y aspectos estructurales del área Cerro Pan de AzúcarCerro del Corral. Procesos petrogenéticos/geoquímica del skarn Loma Marcelo, Sierras Australes de Buenos Aires. Tesis Doctoral, Universidad Nacional de La Plata. (Inédito), 452 p., La Plata.

Barbieri, M. 1989. Geochemistry of Barium. En M.K. de Brodtkorb (Ed.), Nonmetalliferous Stratabound Ore Fields 2: 9-16. Van Nostrand Reinhold, New York.

Becker, U., Fernández-González, A., Prieto, M., Harrison, R. y Putnis, A. 2000. Direct calculation of the thermodynamic properties of the barite/celestite solid solution from molecular principles. Physical Chemical Mineralogy, 27: 291-300.

Bolonin, A.V. y Nikiforov, A.V. 2014. Intermediate sulfates in barite-celestite isomorphic series: Composition and mode of occurrence. Geology of Ore Deposits, 56: 302-314.

Burkhard, A. 1978. Baryt-Celestin and ihre Mischkristalle aus Schweizer Alpen and Jura. Schweizerische Mineralogische and Petrographische Mitteilungen, 58: 1-96.

Deer, W.A., Howie, R.A. y Zussman, J. 1992. An Introduction to the Rock-Forming Minerals, Ortho- and Ring Silicates. Eighth Impression, Longman Group, 1: 1-332. London.

Deer, W.A., Howie, R.A. y Zussman, J. 1966. An Introduction to the Rock-Forming Minerals, Eighth impression, Longman Group, 1-519. London.

de Barrio, R.E., Del Blanco, M.A., Colombo, F., Martín-Izard, A., Ramis, A.M. y Curci, M.V. 2016. Variaciones composicionales en baritinas y celestinas de depósitos de $\mathrm{Ba}-\mathrm{Sr}$ emplazados en la secuencia jurásico-cretácica de la provincia del Neuquén. Acta geológica lilloana 28: 117-123. San Miguel de Túcuman.

Droop, G.T.R. 1987. A general equation for estimating $\mathrm{Fe}^{+3}$ concentrations in ferromagnesian silicates and oxides from microprobe analysis, using stoichiometric criteria. Mineralogical Magazine 51: 431-435.

Gordon, L., Reimer, C.C. y Burit, P.B. 1954. Distribution of strontium within barium sulfate precipitated from homogeneous solution. Analytical Chemistry, 26: 842-846.

Hanor, J.S. 1968. Frequency distribution of compositions in the barite-celestite series. The American Mineralogist, 53: 1215-1222.

Hanor, J.S. 2000. Barite-celestine geochemistry and environment of formation. Sulfate mineralsCrystallography, geochemistry and environmental significance. Reviews in Mineralogy \& Geochemistry, 40: 193-275.

Hanor, J.S. 2004. A model for the origin of large carbonate- and evaporite-hosted celestine $\left(\mathrm{SrSO}_{4}\right)$ deposits. Journal of Sedimentary Research, 74: 168-175.

Hayase, K., Mas, G.R. y Bengochea, L. 1977. Synthesis of barium-strontium sulphate solid solution and some considerations ond the genesis of barite-celestite deposits in Neuquén 
province, Argentina. The Journal of the Japanese Association of Mineralogists, Petrologists and Economic Geologists, 72: 93-102.

Klein, C. y Hurlbut, C. 2006. Manual de Mineralogía (cuarta edición). Editorial Reverté, 760 p. Barcelona.

Llambías, E.J. y Malvicini, L. 1978. Geología, petrología y metalogénesis del área de Colipilli, provincia del Neuquén, República Argentina. Revista de la Asociación Geológica Argentina, 33: 257-276. Buenos Aires.

Malinin, S.D. y Urusov, V.S. 1983. The experimental and theoretical data on isomorphism in the $(\mathrm{Ba}, \mathrm{Sr}) \mathrm{SO}_{4}$ system in relation to barite formation. Geokhimiya, 9: 1324-1334. Rusia.

Palache, C.H., Berman, H. y Frondel, C. 1944. Dana's system of mineralogy, (Seventh edition). London.

Prieto, M., Fernandez-Gonzalez, A., Becker, U. y Putnis, A. 2000. Computing Lippman diagrams from direct calculation of mixing properties of solid solutions. Aquatic Geochemistry, 6: 133-146.

Tekin, E., Varol, B. y Sayili, I.S. 2002. Indications of intermediate compositions in the $\mathrm{BaSO}_{4^{-}}$ $\mathrm{SrSO}_{4}$ solid-solutions series from the Bahçeciktepe celestine deposit, Sivas, East-Central Anatolia, Turkey. Canadian Mineralogist, 40: 895-908.

Whitney, D.L. y Evans, B.W. 2010. Abbreviations for names of rock-forming minerals. American Mineralogist 95: 185-187. 


\section{Capítulo 7}

\section{FLUIDOS MINERALIZANTES}




\section{INCLUSIONES FLUIDAS}

\section{Introducción}

La mayoría de los minerales se forma en un medio acuoso, por lo que partes mínimas de estos líquidos pueden quedar atrapadas en su interior durante las etapas de crecimiento cristalino constituyendo lo que se denomina inclusiones fluidas (IF) (Roedder y Bodnar 1980, Velasco 2004). Los estudios de IF se han llevado a cabo en diferentes tipos de depósitos minerales pero comúnmente priorizando especímenes de buena transparencia como por ejemplo el cuarzo, la baritina.

En la presente Tesis Doctoral el estudio de las IF se efectuó en cristales de baritina presentes tanto en mineralizaciones mantiformes como vetiformes, las cuales además de proveer datos indispensables para la caracterización de los fluidos mineralizantes permitieron su ulterior comparación con otros depósitos minerales de la región. El mencionado estudio incluyó el análisis petrográfico, de fluorescencia y microtermométrico de los fluidos entrampados y tuvo como objetivo determinar las condiciones de formación de los minerales tales como temperatura, presión, densidad y composición. Ante la posible presencia de hidrocarburos $(\mathrm{HC})$ resultó imprescindible emplear la técnica de fluorescencia con luz UV para su identificación, especialmente debido a que las mediciones microtermométricas efectuadas en fluidos de estas características suelen arrojar resultados erróneos y no representativos.

\section{Petrografía de inclusiones fluidas con luz trasmitida}

La caracterización de las inclusiones fluidas permitió reconocer IF primarias y secundarias (Roedder 1984) y evidencias de cambios post-entrampamiento como estrangulamientos ("necking down"). Las inclusiones primarias son aquellas entrampadas durante el crecimiento del mineral hospedante. Por este motivo son las que mejor representan las condiciones de formación de los cristales. Por otro lado, las inclusiones de origen secundario contienen entrampados a los fluidos que circularon con posterioridad a la formación de los cristales. El reconocimiento de estos dos tipos de inclusiones es fundamental para obtener una correcta temperatura y salinidad del fluido mineralizante. Se analizaron sólo las IF bifásicas de origen primario, donde se considera que el sistema se mantuvo cerrado. 


\begin{tabular}{|c|c|c|c|c|c|}
\hline $\begin{array}{l}\text { Número de } \\
\text { fases presentes }\end{array}$ & $\begin{array}{l}\text { Forma } \\
\text { Inclusión }\end{array}$ & $\begin{array}{c}\text { Tipos de } \\
\text { fases presentes }\end{array}$ & $\begin{array}{l}\text { Tipos de } \\
\text { morfologías }\end{array}$ & Fluorescencia & Interpretación \\
\hline I & Is & L & $\sigma$ & $x$ & Acuosa \\
\hline \multirow{10}{*}{ II } & II a & $L+B$ & $\because$ & $X$ & Acuosa \\
\hline & II e & $L+B$ & on & X & Acuosa \\
\hline & II a & $L+B$ & 9 & $X$ & Acuosa \\
\hline & II a & $B+L$ & $\infty$ & 7 & $\mathrm{HC}+\mathrm{Gas}$ \\
\hline & II t & $B+L$ & & & $\mathrm{HC}+\mathrm{Gas}(\mathrm{x} 2)$ \\
\hline & II 0 & $B+L$ & & 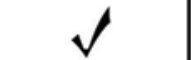 & $\mathrm{HC}+\mathrm{Gas}(\mathrm{x} 2)$ \\
\hline & II $e^{*}$ & $L+B$ & & $\sqrt{ }$ & $\mathrm{HC}+\mathrm{Gas}$ \\
\hline & $\mathrm{II}_{0}$ & $L+B$ & & $\sqrt{ }$ & $\mathrm{HC}+\mathrm{Gas}$ \\
\hline & II t & $L+B$ & & J & $\mathrm{HC}+\mathrm{Gas}$ \\
\hline & II a & $L+S$ & & $\sqrt{ }$ & $\mathrm{HC}+$ Cera \\
\hline \multirow{3}{*}{ III } & III e & $B+L+S 1+S 2$ & & $\sqrt{ }$ & $\begin{array}{c}\mathrm{H} 2 \mathrm{O}+\mathrm{HC}+ \\
\mathrm{GaS}\end{array}$ \\
\hline & III e & $L+B+S$ & $\infty$ & $X$ & Acuosa \\
\hline & III a & $S$ & & $x$ & Acuosa \\
\hline
\end{tabular}

Cuadro 7.1: Tipos de inclusiones fluidas en las mineralizaciones mantiformes y vetiformes estudiadas. I: monofásica; II: bifásico; III: multifásico; s: subhedral; a: anhedral; e: euhedral; t: tabular; o: ovoidal; e*: estrellado; L: líquido; B: burbuja; S: sólido; S1: sólido 1; S2: sólido 2.

Considerando entonces la posibilidad de que entre los fluidos entrampados se encontrara $\mathrm{HC}$, se realizaron observaciones petrográficas teniendo en cuenta los siguientes criterios (Burrus 1981):

- Color: las IF con HC pueden ser de color amarillo, castaño y/o negro, característica que no ocurre con las inclusiones acuosas y que facilita su diferenciación. Sin embargo, hay HC que son incoloros. 
-Índice de refracción: los HC tienen índices de refracción que se aproximan a los de los minerales hospedantes. Se pueden distinguir de las IF acuosas por su relieve mucho más bajo.

- Comportamiento de las fases a baja temperatura: durante el congelamiento pueden observarse varios fenómenos como separación de una fase de bitumen sólida (Roedder 1963), cese del movimiento browniano, expansión de la burbuja de vapor o deformación de la fase vapor.

- Microscopía de fluorescencia: las IF que contienen HC aromáticos emiten fluorescencia bajo luz ultravioleta (Burrus 1981, Riecker 1962).

Las inclusiones que predominan en las baritinas estudiadas de ambas yacencias son: monofásicas de tipo L (líquido), bifásicas de tipo L+B (burbuja) y L+S (sólido), y minoritariamente, multifásicas $\mathrm{L}+\mathrm{B}+\mathrm{S}, \mathrm{L}+\mathrm{B}+\mathrm{S} 1+\mathrm{S} 2, \mathrm{~S} 1+\mathrm{S} 2+\mathrm{S} 3$. Se reconocieron varios tipos de familias de IF (Cuadro 7.1). La única familia de IF que se identificó del tipo monofásica está caracterizada por un hábito subhedral y relieve normal. Las inclusiones bifásicas se conforman por cuatro familias; la primera de hábito anhedral presenta un L cuyo índice de refracción es muy similar al de la baritina $(1,63-1,64)$, por lo que el relieve es muy bajo; la segunda familia se caracteriza por tener hábito también anhedral pero con un L cuyo relieve, a diferencia de la anterior, es moderado. La tercera familia reúne IF de hábito euhedral, la burbuja es incolora, el factor de relleno es entre 0,9 y 0,95 y no fluorescen bajo luz ultravioleta, al igual que las familias anteriores. La cuarta familia se caracteriza por presentar IF de hábito anhedral y relieve moderado a alto. Asimismo, se reconocieron inclusiones cuyos hábitos son tabulares y ovoides encontrándose dos variedades de las mismas, una de alto relieve y otra de bajo relieve. También se identificaron formas estrelladas. En todos los casos las burbujas son de mayor tamaño que las de las familias de IF no fluorescentes y muestran una coloración rosada y un factor de relleno de 0,5 . Por otro lado, se encontraron formas ovoides y tabulares cuya relación B-L es baja. Las inclusiones bifásicas del tipo $\mathrm{L}+\mathrm{S}$ son de hábito anhedral y relieve normal. Todas estas familias de IF descriptas son las más abundantes y presentan fluorescencia. Con respecto a las inclusiones multifásicas todas presentan relieves normales y se reconocieron dos tipos: aquellas con hábitos euhedrales, fluorescentes o no fluorescentes y aquellas con hábitos anhedrales no fluorescentes.

Los tamaños de las IF en general varían entre 20 y $30 \mu \mathrm{m}$ hasta tamaños máximos excepcionales de $50 \mu \mathrm{m}$. 
El color de la inclusión depende de la composición de la fase dominante. El color de la fase líquida es mayoritariamente incoloro mientras que la burbuja es incolora a rosada. Con respecto a las fases sólidas observadas son incoloras y presentan hábito tabular prismático.

\section{Fluorescencia de luz ultravioleta en inclusiones fluidas}

Algunos HC poseen la propiedad de fluorescer cuando son expuestos a luz ultravioleta, sin embargo, hay que tener presente que su aparente ausencia no descarta su presencia, ya que algunos HC no fluorescen (Cesaretti y Domínguez 1997). Solo los HC más pesados, como el petróleo crudo y los condensados, contienen suficiente cantidad de moléculas aromáticas para emitir fluorescencia bajo luz UV (Burrus 1981). De este modo, si el HC presente es de bajo peso molecular y no posee estructura aromática, como por ejemplo metano o etano, no es posible identificarlo con el método de fluorescencia.

El color de fluorescencia emitido varía con la gravedad API (American Petroleum Institute) del $\mathrm{HC}$, que es una medida de cuán ligero o pesado es un $\mathrm{HC}$ con respecto al agua (Feely et al., 2013).

La composición de los $\mathrm{HC}$ y por lo tanto su fluorescencia, dependen de su origen y madurez térmica (Barrés et al., 1987). Los compuestos más livianos (alta gravedad API) emiten fluorescencia en longitudes de onda corta y los componentes más pesados (baja a media gravedad API), emiten fluorescencia en longitudes de onda mayores. En consecuencia, las inclusiones de HC emiten coloraciones dependiendo de su composición predominante. Los $\mathrm{HC}$ de base parafínica emiten fluorescencia en color azul a blanco (HC ligeros), los de base asfáltica en amarillo a amarillo-verdoso y los crudos asfálticos en rojo (HC pesados), según Riecker (1962).

Para condiciones similares de entrampamiento, un fluido orgánico desarrollará una burbuja mayor que su equivalente acuoso, debido a que el petróleo tiene una compresibilidad cuatro veces mayor que la del agua (Roedder 1963). Por lo tanto, la diferencia en la compresibilidad entre los fluidos orgánicos y los acuosos se manifiesta en los diferentes volúmenes de burbuja. Esto implica que las inclusiones con un volumen de burbuja del $20 \%$ podrían haberse entrampado en condiciones similares a la de una hidrocarburada (fluorescente) con una burbuja que ocupa más del 60\% de la cavidad. 


\section{Resultados de luz incidente ultravioleta}

La mayoría de las IF irradiadas con luz ultravioleta, correspondiente a yacencias mantiformes y vetiformes, emitieron fluorescencia de tonalidades azuladas. En ciertos casos se observó que fluoresce el líquido (L), en otros la burbuja (B) y en otros sólo el contorno de la inclusión (Fig.7.1 a y b).

\section{Microtermometría en inclusiones fluidas}

Las determinaciones microtermométricas se llevaron a cabo en cristales de baritina de buena transparencia, representativos de los depósitos mantiformes de la mina San Eduardo y La Bienvenida y vetiformes de la mina La Esperanza. Se seleccionaron las IF bifásicas acuosas y que no presentaron evidencias de escape de fluidos, estrangulamiento o decrepitación a fin de obtener datos fidedignos del fluido, evitando aquellos valores que pudieron haber sido modificados por procesos post-entrampamiento (Goldstein y Reynolds 1994) o por la presencia de HC, resultando así poca cantidad de dichas IF. Los cambios de fases a bajas temperaturas se midieron principalmente para minimizar la posibilidad de decrepitación de IF. Todas las muestras fueron inicialmente enfriadas a $-120^{\circ} \mathrm{C}$, con el fin de poder detectar $\mathrm{CO}_{2}$. Luego durante el calentamiento gradual hasta estabilizarse el sistema, se determinaron las temperaturas de la primera fusión (Tfi), que corresponde a una temperatura eutéctica (Te) y de fusión final del hielo (Tff) (Fig. 7.2). Con estos datos se pudo determinar el sistema salino al cual pertenece el fluido, utilizando las tablas de Goldstein y Reynolds (1994) y su salinidad mediante la ecuación de Bodnar (1993). A su vez, se manifestaron puntos de fusión por encima de $0^{\circ} \mathrm{C}$, los que son atribuibles a la presencia de clatratos, que son indicativos de la existencia de carbono en dicha inclusión.

Se continuó con el calentamiento para determinar las temperaturas de homogeneización líquido-vapor o mínima de entrampamiento (Th) de las IF acuosas (Roedder 1984). A partir de estos datos, se calcularon las densidades $\left(\mathrm{g} / \mathrm{cm}^{3}\right)$ y la presión mínima de entrampamiento (bares) del fluido. 

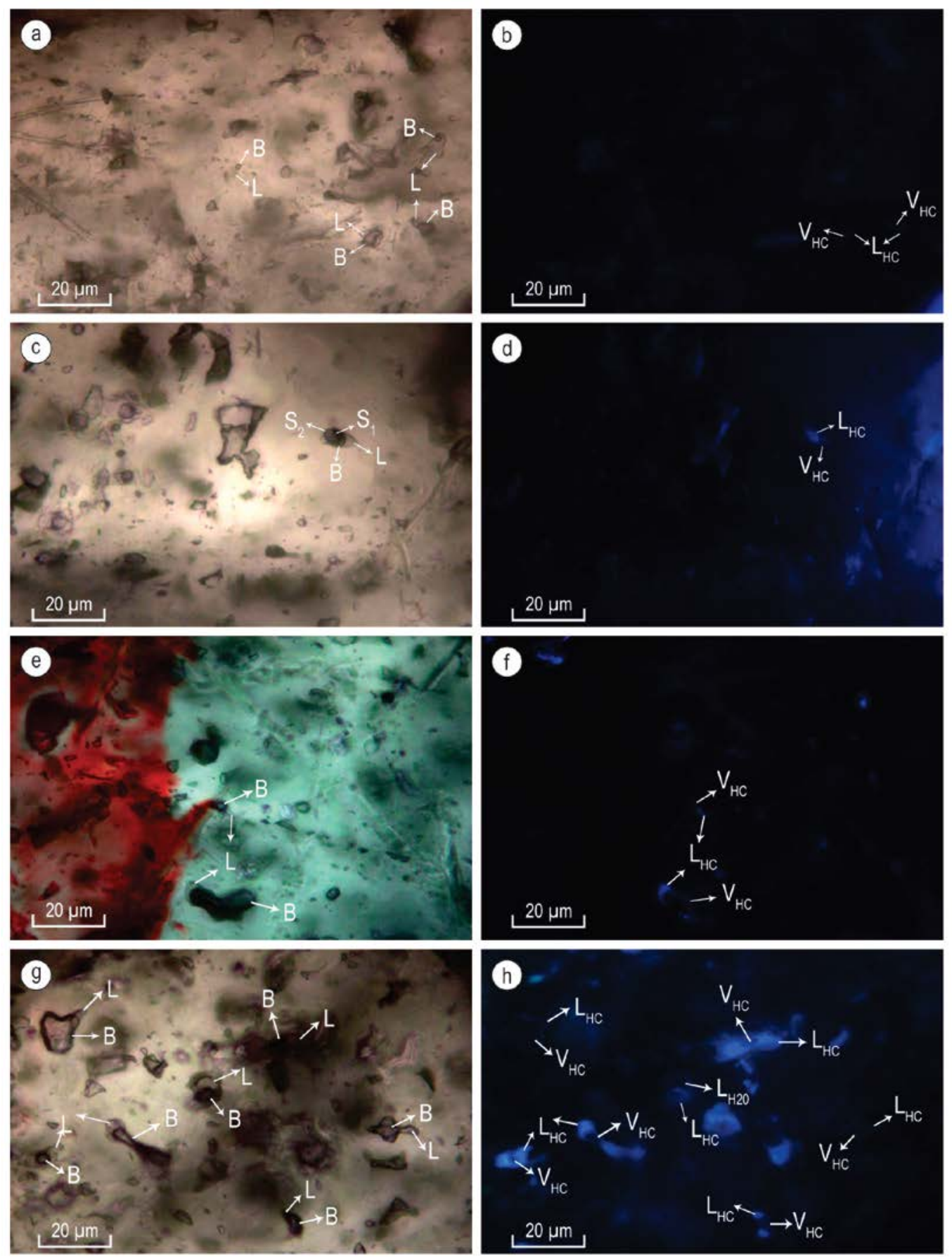

Figura 7.1a: a- IF observadas con luz trasmitida del tipo $L+B$ en baritina. b- IF observadas con luz UV. Las coloraciones de fluorescencia de las fases L son celestes. El par de IF que no fluoresce son acuosas. c- IF observadas con luz trasmitida del tipo L + B + S1 +S2. d- IF observadas con luz UV. La coloración de la fase L es celeste. e- IF vistas con luz trasmitida del tipo L + B. f- IF vistas con luz UV. Las fases L fluorescen de color celeste. En la pared inferior de la IF de mayor tamaño se observa el fenómeno de adherencia. g- IF vistas con luz trasmitida del tipo L + B. h- IF vistas con luz UV. Las coloraciones de las fases L son celestes.

L: líquido B: burbuja LHC: líquido hidrocarburado VHC: vapor hidrocarburado (gas). 

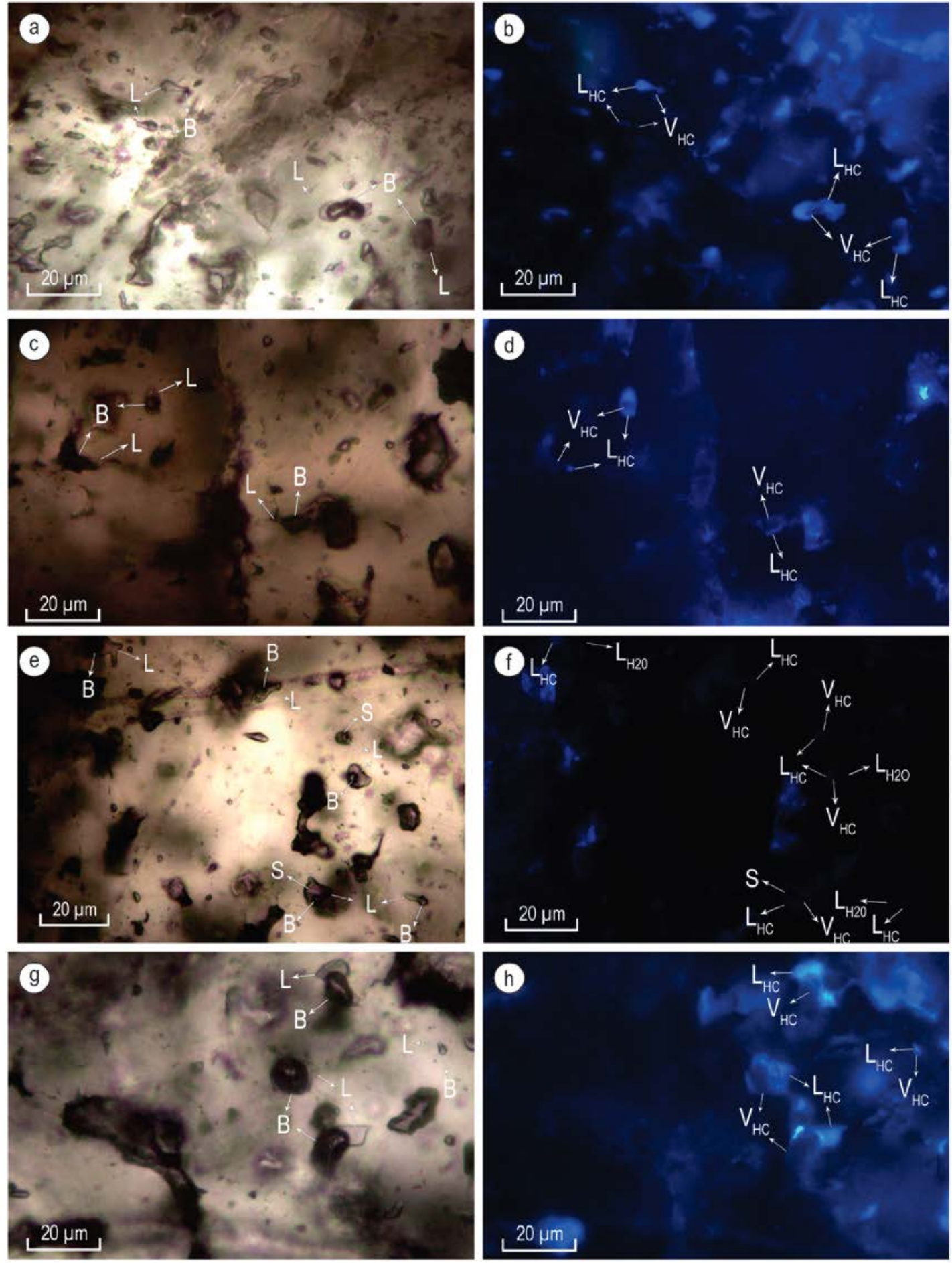

Figura 7.1b: a- IF vistas con luz trasmitida de tipo L + B en baritina. b- IF vistas con luz UV. La coloración de las fases L es celeste. c- IF vistas con luz trasmitida de tipo L + B. d- IF con luz UV. Las fases L fluorescen de color celeste. e- IF vistas con luz trasmitida de tipo L + B + S. f- IF vistas con luz UV. Se observa que, en algunas inclusiones, hay dos fluidos inmiscibles $\left(\mathrm{LH}_{2} \mathrm{O}\right.$, no fluorece y LHC, fluoresce con color celeste). g- IF vistas con luz trasmitida. h- IF vistas con luz UV. Las fases $\mathrm{L}$ fluorescen con coloraciones celestes.

L: líquido; B: burbuja; $\mathrm{LH}_{2} 0$ : agua; LHC: líquido hidrocarburado; VHC: vapor hidrocarburado (gas). 

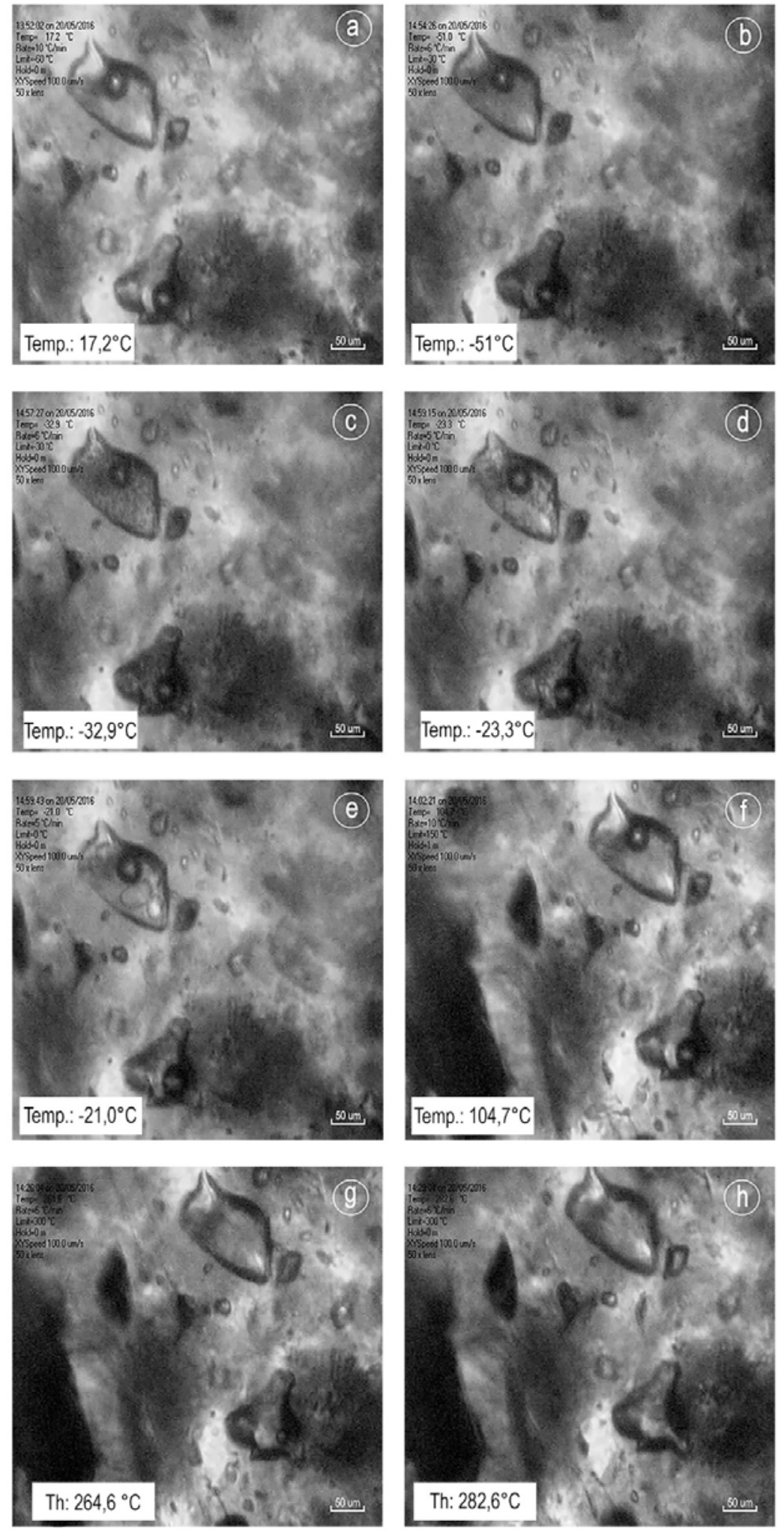

Figura 7.2: Fotomicrografías de ensayos de enfriamiento y calentamiento en IF representativas de mineralizaciones vetiformes: a- en condiciones ambientales; b- etapa de criogenia; c-, d- y e- en recuperación del sistema a temperatura ambiente; f-, g- y h- etapa de calentamiento y obtención de las Th de ambas IF. 


\section{Resultados de las mediciones microtermométricas}

\section{Mineralizaciones Mantiformes:}

Durante las etapas de enfriamiento, las burbujas de las IF bifásicas desaparecieron normalmente. Posteriormente, durante la recuperación de la temperatura del sistema se pudo reconocer una Tfi de amplia distribución entre $-44,0^{\circ}$ y $-21,1^{\circ} \mathrm{C}$ (Tabla 7.1 ), por lo que se interpreta que la composición del fluido no se ha podido registrar en forma precisa debido a que está compuesto por más de un componente: agua con una o más sales disueltas. Las temperaturas del eutéctico registradas en este estudio pueden corresponder a los sistemas $\mathrm{NaCl}-\mathrm{H}_{2} \mathrm{O}, \mathrm{NaCl}-\mathrm{CaCl}_{2}, \mathrm{NaCl}-\mathrm{MgCl}_{2}-\mathrm{H}_{2} \mathrm{O}$ metaestable y NaCl-KCl- $\mathrm{H}_{2} \mathrm{O}$ metaestable (Goldstein y Reynolds 1994), siendo el más frecuente el de tipo $\mathrm{NaCl}-\mathrm{H}_{2} \mathrm{O}$. Las Tff se observaron entre $-4,5^{\circ}$ y $-0,1^{\circ} \mathrm{C}$. En relación a estas últimas se determinaron las salinidades que oscilaron entre 0,18 y $7,17 \%$ en peso equiv. de $\mathrm{NaCl}$ (Tabla 7.1). Cabe aclarar que se identificaron IF con cristales hijos, de hábito tabular, los cuales indican salinidades mayores a $23 \%$ en peso equiv. de $\mathrm{NaCl}$. Durante el calentamiento de las inclusiones bifásicas, la gran mayoría de las burbujas mostraron un movimiento browniano y homogeneizaron a líquido entre $156,2^{\circ}$ y $176,0^{\circ} \mathrm{C}$ (Tabla 7.1). Las densidades calculadas, a partir de dichas temperaturas, varían entre 0,915 y 0,929 g/cm ${ }^{3}$ (Fig.7.3, Barnes 1979). Las presiones mínimas de entrampamiento estimadas para estos valores de Th corresponden a un rango de 4 a 12 bares (Fig.7.4, Crawford 1981).

\section{Mineralizaciones Vetiformes:}

En los ensayos de congelamiento la deformación de la burbuja y su aspecto rugoso indican la formación de clatratos en la interfase líquido/burbuja de ciertas inclusiones. Los clatratos consisten en hidratos de metano que perduran a temperaturas superiores a $0^{\circ} \mathrm{C}$. Durante la recuperación de la temperatura del sistema se identificó una Tfi cuyos valores rondan entre $-52,0^{\circ}$ y $-23,3^{\circ} \mathrm{C}$ (Tabla 7.2). Este rango, al igual que en el caso anterior, sugiere la presencia de una o más sales disueltas en agua. Las Te registradas pueden ser coherentes con los sistemas NaCl- $\mathrm{MgCl}_{2}-\mathrm{H}_{2} \mathrm{O}$ metaestable, $\mathrm{NaCl}-\mathrm{CaCl}_{2}-\mathrm{H}_{2} \mathrm{O}$, NaCl-KCl$\mathrm{H}_{2} \mathrm{O}$ y NaCl- $\mathrm{H}_{2} \mathrm{O}$ (Goldstein y Reynolds 1994), siendo los más comunes los dos últimos. Las Tff rondan entre $-5,3^{\circ}$ y $-0,3^{\circ} \mathrm{C}$ (Tabla 7.2). A partir de estos valores se determinaron salinidades del orden de $0,53-8,28 \%$ en peso equiv. de $\mathrm{NaCl}$. También se estimaron valores mayores a $23 \%$ en peso equiv. de $\mathrm{NaCl}$ debido a la presencia de cristales hijos de sulfato en algunas IF. 


\begin{tabular}{|c|c|c|c|c|}
\hline Tfi $\left({ }^{\circ} \mathrm{C}\right)$ & Componentes Asignados & Tff $\left({ }^{\circ} \mathrm{C}\right)$ & Concentración & Th $\left({ }^{\circ} \mathrm{C}\right)$ \\
\hline$-24,6$ & $\mathrm{NaCl}$ equiv. & $-3,9$ & $6,3 \% \mathrm{NaCl}$ equiv. & 156,2 \\
$-37,0$ & $\mathrm{NaCl}+\mathrm{MgCl}_{2}+\mathrm{H}_{2} \mathrm{O}$ & $-1,0$ & $1,7 \% \mathrm{NaCl}$ equiv. & 156,2 \\
$-39,0$ & $\mathrm{NaCl}+\mathrm{MgCl}_{2}+\mathrm{H}_{2} \mathrm{O}$ & $-3,9$ & $6,3 \% \mathrm{NaCl}$ & 157,0 \\
$-27,0$ & $\mathrm{NaCl}$ metaestable & $-3,4$ & $5,6 \% \mathrm{NaCl}$ equiv. & 157,0 \\
$-44,0$ & $\mathrm{NaCl}+\mathrm{CaCl}_{2}$ & $-4,5$ & $7,2 \% \mathrm{NaCl}$ equiv. & 156,2 \\
$-29,8$ & $\mathrm{NaCl}+\mathrm{KCl}+\mathrm{H}_{2} \mathrm{O}_{\text {metaestable }}$ & $-0,1$ & $0,2 \% \mathrm{NaCl}$ equiv. & 176,0 \\
$-37,9$ & $\mathrm{NaCl}+\mathrm{MgCl}_{2}+\mathrm{H}_{2} \mathrm{O}$ & $-0,1$ & $0,2 \% \mathrm{NaCl}$ equiv. & 173,0 \\
$-21,1$ & $\mathrm{NaCl}+\mathrm{H}_{2} \mathrm{O}$ & $-3,0$ & $5,0 \% \mathrm{NaCl}$ equiv. & 166,4 \\
\hline
\end{tabular}

Tabla 7.1: Ensayos microtermométricos de IF de baritinas representativas de mineralizaciones mantiformes. Tfi: Temperatura de fusión inicial. Tff: Temperatura de fusión final. Th: Temperatura de homogeneización.

\begin{tabular}{|c|c|c|c|c|}
\hline Tfi $\left({ }^{\circ} \mathrm{C}\right)$ & Componentes Asignados & Tff $\left({ }^{\circ} \mathrm{C}\right)$ & Concentración & Th $\left({ }^{\circ} \mathrm{C}\right)$ \\
\hline- & $\mathrm{NaCl}$ equiv. & $-1,0$ & $1,7 \% \mathrm{NaCl}$ & 253,3 \\
$-37,0$ & $\mathrm{NaCl}+\mathrm{MgCl}_{2}+\mathrm{H}_{2} \mathrm{O}$ metaestable & $\mathrm{e} /-5,3 \mathrm{y}-4,8$ & $7,6 \% \mathrm{NaCl}$ equiv. & 235,0 \\
$-36,8$ & $\mathrm{NaCl}+\mathrm{MgCl}_{2}+\mathrm{H}_{2} \mathrm{O}$ metaestable & $-3,7$ & $6,0 \% \mathrm{NaCl}$ equiv. & 229,5 \\
$-52,0$ & $\mathrm{NaCl}+\mathrm{CaCl}_{2}+\mathrm{H}_{2} \mathrm{O}$ & $-0,3$ & $0,5 \% \mathrm{NaCl}$ equiv. & 163,0 \\
$-23,3$ & $\mathrm{NaCl}+\mathrm{KCl}^{2} \mathrm{H}_{2} \mathrm{O}$ & $-2,5$ & $4,2 \% \mathrm{NaCl}$ equiv. & 269,0 \\
$-24,0$ & $\mathrm{NaCl}+\mathrm{KCl}+\mathrm{H}_{2} \mathrm{O}$ & $-2,5$ & $4,2 \% \mathrm{NaCl}$ equiv. & 223,6 \\
$-28,8$ & $\mathrm{NaCl}+\mathrm{H}_{2} \mathrm{O}$ & $-4,0$ & $6,4 \% \mathrm{NaCl}$ equiv. & 264,6 \\
- & $\mathrm{NaCl}$ equiv. & $-5,3$ & $8,3 \% \mathrm{NaCl}$ equiv. & 280,6 \\
$-36,0$ & $\mathrm{NaCl}+\mathrm{MgCl}+\mathrm{H}_{2} \mathrm{O}$ metaestable & $-5,0$ & $7,9 \% \mathrm{NaCl}$ equiv. & 227,0 \\
$-25,0$ & $\mathrm{NaCl}+\mathrm{KCl}_{2}+\mathrm{H}_{2} \mathrm{O}$ & $-1,2$ & $2,1 \% \mathrm{NaCl}$ equiv. & 265,1 \\
\hline
\end{tabular}

Tabla 7.2: Ensayos microtermométricos de IF de baritina representativas de mineralizaciones vetiformes. Tfi: Temperatura de fusión inicial. Tff: Temperatura de fusión final. Th: Temperatura de homogeneización. 


\begin{tabular}{l|l|l|c|c}
\hline Hidrocarburo & $\mathrm{Tf}^{\circ} \mathrm{C}$ & $\mathrm{Teb}^{\circ} \mathrm{C}$ & $\mathrm{\rho}^{20} \mathrm{Kg} / \mathrm{m}^{3}$ & $n^{20} \mathrm{D}$ \\
\hline Ciclopropano & $-126,9$ & $-33,3$ & - & - \\
Ciclobutano & $-90,7$ & 12,9 & 703,0 & - \\
Ciclopentano & $-94,4$ & 49,3 & 745,4 & 1,4064 \\
Metilciclopentano & $-142,7$ & 71,9 & 748,8 & 1,4099 \\
Etilciclopentano & $-137,9$ & 103,4 & 765,7 & 1,4197 \\
1,1-Dimetilciclopentano & $-76,4$ & 87,5 & 752,3 & 1,4126 \\
cis-1,2-Dimetilciclopentano & $-52,5$ & 99,2 & 772,3 & 1,4276 \\
trans-1,2-Dimetilciclopentano & $-120,0$ & 91,9 & 751,9 & 1,4120 \\
1,3-Dimetilciclopentano & $-136,7$ & 90,7 & 745,6 & 1,4076 \\
Propilciclopentano & $-120,3$ & 130,8 & 775,6 & 1,4265 \\
Isopropilciclopentano & $-112,7$ & 126,8 & 776,6 & 1,4265 \\
cis-1,2-Metiletilciclopentano & - & 128,2 & 785,0 & - \\
trans-1,2-Metiletilciclopentano & - & 121,4 & 769,1 & - \\
1,3-Metiletilciclopentano & - & 120,7 & 766,9 & 1,4210 \\
Butilciclopentano & $-108,2$ & 156,8 & 784,3 & 1,4315 \\
Isoamilciclopentano & - & 169,0 & 784,0 & 1,4320 \\
\hline Ciclohexano & $-6,5$ & 80,8 & 778,1 & 1,4264 \\
\hline Metilciclohexano & $-126,3$ & 100,8 & 769,2 & 1,4230 \\
Etilciclohexano & $-114,4$ & 132,0 & 777,2 & 1,4324 \\
1,1-Dimetilciclohexano & $-34,1$ & 120,5 & 784,0 & 1,4293 \\
cis-2,2-Dimetilciclohexano & $-50,1$ & 128,0 & 796,5 & 1,4333 \\
trans-1,2-Dimetilciclohexano & $-89,4$ & 125,0 & 776,0 & 1,4303 \\
cis-1,3-Dimetilciclohexano & $-86,0$ & 121,0 & 783,5 & 1,4260 \\
trans-1,3-Dimetilciclohexano & $-79,4$ & 119,0 & 762,0 & 1,4254 \\
cis-1,4-Dimetilciclohexano & -85 & 121,7 & 767,1 & 1,4230 \\
trans-1,4-Dimetilciclohexano & $-33,5$ & 119,6 & 765,5 & 1,4205 \\
Propilciclohexano & $-94,5$ & 154,7 & 793,2 & 1,4371 \\
Isopropilciclohexano & $-89,8$ & 154,5 & 799,2 & 1,4410 \\
1,2-Metiletilciclohexano & - & 153,6 & 805,0 & 1,4400 \\
1,3-Metiletilciclohexano & - & 155,5 & 791,0 & 1,4344 \\
1,4-Metiletilciclohexano & $-78,6$ & 151 & 789,0 & 1,4343 \\
Butilciclohexano & - & 179 & 799,0 & 1,4412 \\
Amilciclohexano & - & 204 & 804,0 & 1,4428 \\
Cicloheptano & -12 & 117 & 810,0 & - \\
Ciclooctano & 14,2 & 146 & 839,0 & - \\
Ciclononano & - & 170 & - & - \\
Ciclodecano & -31 & 201 & - & - \\
Ciclododecano & -6 & - & & \\
Ciclotetradecano & - & & - & - \\
Ciclopentadecano & - & & - \\
\hline
\end{tabular}

Tabla 7.3: Propiedades físicas de algunos HC de tipo cicloalcanos (Tomado de Proskuriakuv y Drabkin 1984). Tf: temperatura de fusión; Teb: temperatura de ebullición; $\rho 20 \mathrm{Kg} / \mathrm{m} 3$ : densidad a $20^{\circ} \mathrm{C}$; n20D: índice de refracción a $20^{\circ} \mathrm{C}$. 
Durante los ensayos de calentamiento todas las IF bifásicas homogeneizaron a líquido; en algunas inclusiones monofásicas se produjo la formación de una nueva burbuja. En ciertos casos se observaron cambios de fases instantáneos (fenómeno crítico) de la burbuja, hasta su homogeneización. Algunas inclusiones a elevadas temperaturas no homogeneizaron sino que experimentaron una disminución de tamaño de la burbuja; e inmediatamente, a los $144^{\circ} \mathrm{C}$, se agrandó y apareció otra burbuja coalescente (Fig.7.5). Seguidamente, a $\operatorname{los} 158^{\circ} \mathrm{C}$, la nueva burbuja desapareció y la burbuja original volvió a achicarse y luego homogeneizó a los $163^{\circ} \mathrm{C}$; este comportamiento sugiere la presencia de metano en la IF (Worden et al., 1995).

En síntesis, todas las IF ensayadas mostraron un movimiento browniano y homogeneizaron a líquido entre $163,0^{\circ}$ y $280,6^{\circ} \mathrm{C}$ (Tabla 7.2). A partir de dichas temperaturas, se calculó la densidad que ronda entre 0,796 y $0,935 \mathrm{~g} / \mathrm{cm}^{3}$ (Fig.7.3, Barnes 1979) y las presiones mínimas de entrampamiento. Estas últimas oscilan entre 5 y 55,5 bares (Fig.7.4, Crawford 1981).

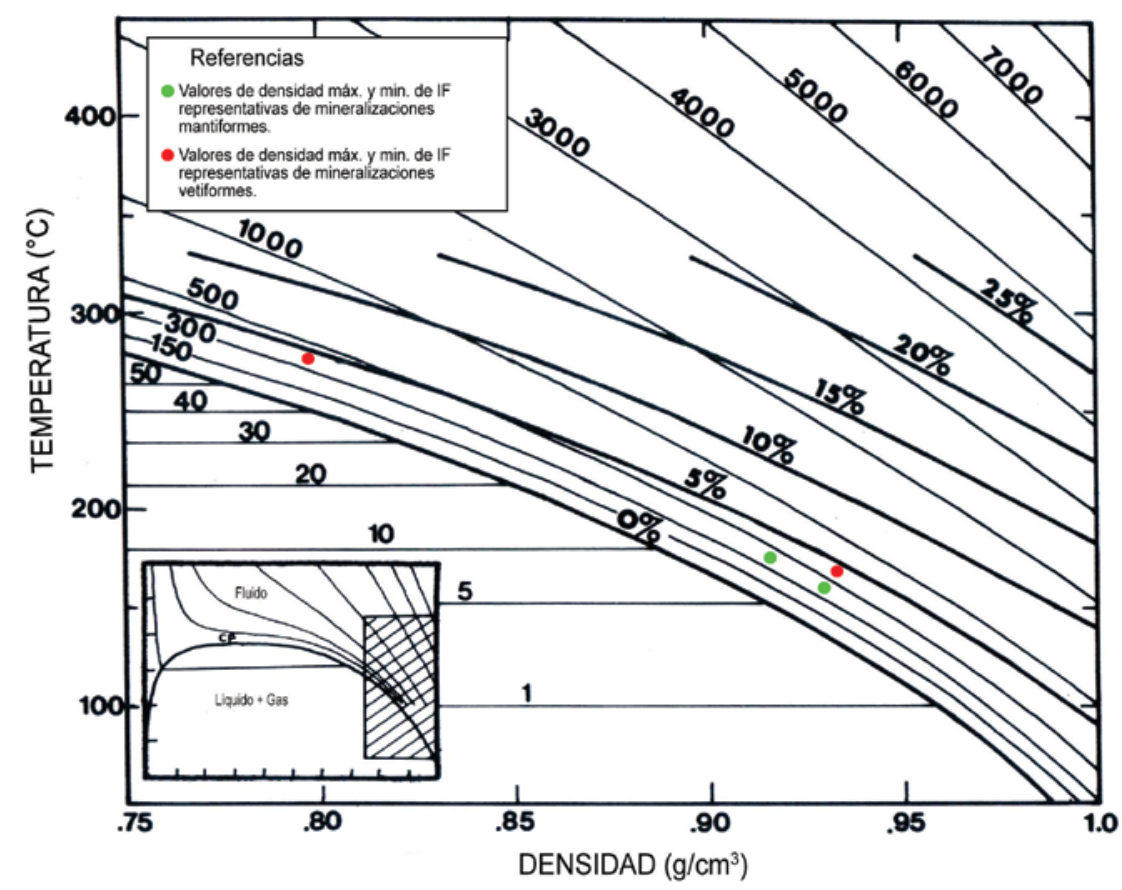

Figura 7.3: Diagrama de estimación de la densidad promedio calculada de las IF de baritinas de las mineralizaciones en estudio, a partir de la temperatura de homogeneización y la salinidad promedio calculada. Las curvas en el interior del gráfico se refieren a la salinidad en peso equiv. de $\mathrm{NaCl}$ (Extraído de Barnes 1979). 


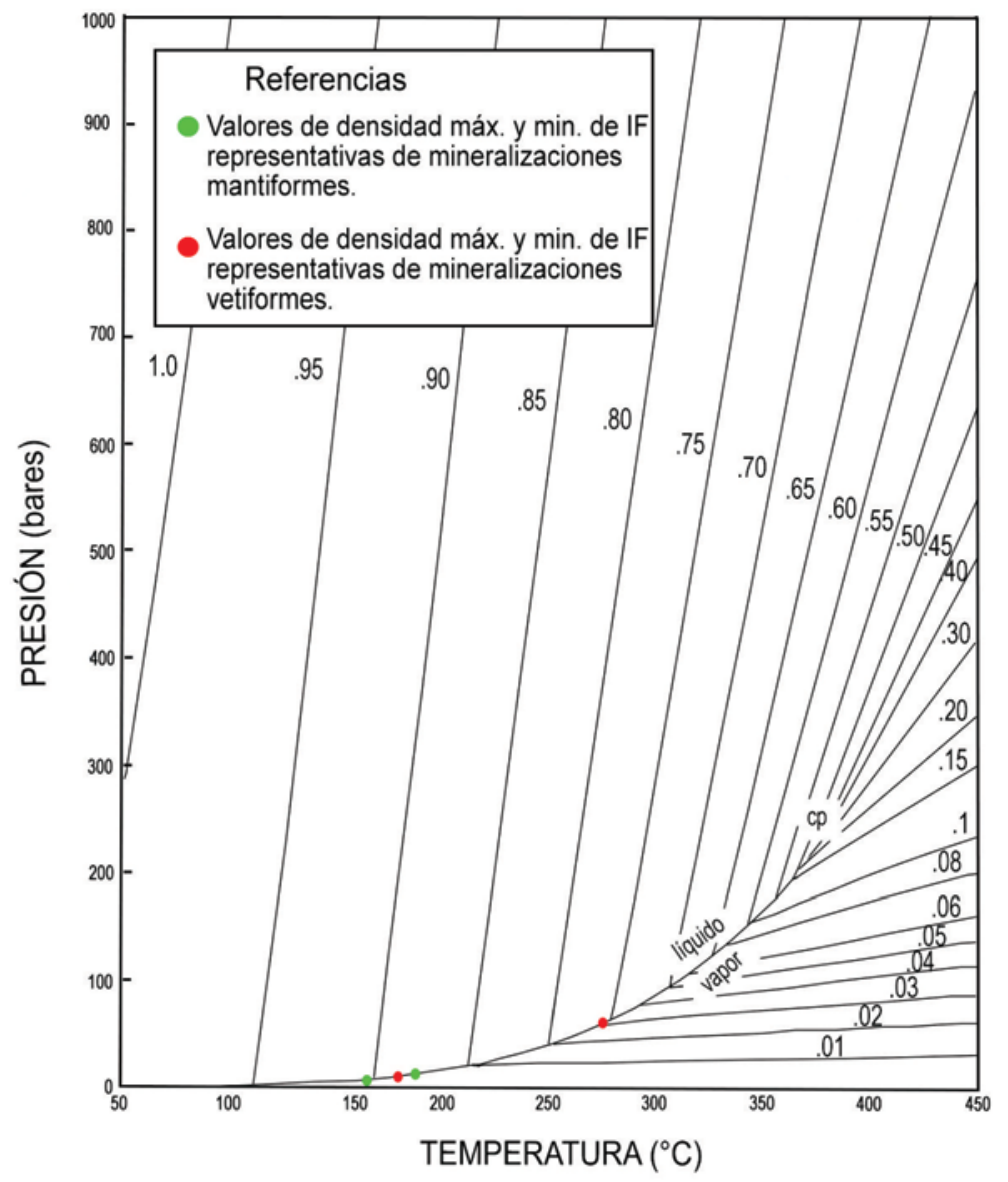

Figura 7.4: Diagrama de estimación de la presión de entrampamiento alcanzada por las IF de baritina de las mineralizaciones en estudio, a partir de la temperatura de homogeneización. (Extraído de Crawford 1981).

Cabe aclarar que durante los ensayos de calentamiento el hidrocarburo líquido contenido en algunas IF se crackeó generando fases vapor que se adicionaron a la fase gaseosa. Por lo tanto, la temperatura de homogeneización de estas inclusiones no indica la temperatura de entrampamiento original (Cesaretti 1993, Cesaretti et al. 2000) sino que es característica del tipo de HC que la misma contiene (Goldstein y Reynolds 1994). La temperatura de vaporización del fluido orgánico de las IF con $\mathrm{HC}$ ensayadas fue de $81^{\circ} \mathrm{C}$.

\section{Discusión y Conclusiones parciales}

Las investigaciones que abarcan el estudio de IF en los depósitos estudiados o en áreas vecinas son escasas, pudiéndose citar a Hayase y Bengochea (1975), Collao et al. (1998) y recientemente Leal y Mateo (2015) y Escobar (2016).

Hayase y Bengochea (1975) comunicaron datos de temperatura de homogeneización del orden de $160,9^{\circ} \mathrm{C}$ proponiendo que la formación de las mineralizaciones baríticas fue producto de soluciones hidrotermales relacionadas a la 
actividad ígnea. Por su parte, Collao et al. (1998) ensayaron inclusiones fluidas en celestinas asociadas a la Formación Huitrín y obtuvieron temperaturas de homogeneización medias variables del orden de $323^{\circ} \mathrm{C}, 276^{\circ} \mathrm{C}, 268^{\circ} \mathrm{C}$ y $205^{\circ} \mathrm{C}$ y salinidades mayoritariamente fluctuantes entre $7,6 \%, 5,9 \%, 2,7 \%$ y $3,6 \%$ en peso equiv. de $\mathrm{NaCl}$, respectivamente. Estos autores consideran que los datos obtenidos reflejan la acción de soluciones hidrotermales derivadas de cuerpos intrusivos de edad eocena. Por otra parte, Leal y Mateo (2015) obtuvieron temperaturas de homogeneización en baritinas alojadas en la Formación Agrio en el sector del anticlinal de Chorriaca, situado inmediatamente al sur del arroyo Colipilli. Los resultados microtermométricos dieron valores superiores a los $300^{\circ} \mathrm{C}$ y soluciones con bajas salinidades. De acuerdo a la investigación realizada por Escobar (2016), las temperaturas de homogeneización en las mineralizaciones baríticocelestínicas asociadas a la Formación Huitrín localizadas en Bajada del Agrio, arrojaron valores entre $147^{\circ} \mathrm{C}$ y $243^{\circ} \mathrm{C}$ con salinidades variables entre 0,18 y $16,67 \%$ en peso equiv. de $\mathrm{NaCl}$. Las mineralizaciones del área estudiada las consideró de origen hidrotermal no magmático.

\begin{tabular}{lcc}
\hline Mineralizaciones & mantiformes & vetiformes \\
Mineral & Baritina & Baritina \\
Tipo de inclusión & $\mathrm{L}+\mathrm{B}$ & $\mathrm{L}+\mathrm{B}$ \\
Número de mediciones & 8 & 10 \\
$\mathrm{Te}\left({ }^{\circ} \mathrm{C}\right)$ & $-44,0$ a $-21,1$ & $-52,0$ a $-23,3$ \\
$\mathrm{Tff}\left({ }^{\circ} \mathrm{C}\right)$ & $-4,5$ a $-0,1$ & $-5,3$ a $-0,3$ \\
$\mathrm{Tf}$ clatratos $\left({ }^{\circ} \mathrm{C}\right)$ & & 40 \\
$\mathrm{Th}\left({ }^{\circ} \mathrm{C}\right)$ & 156,2 a 176,0 & 163,0 a 280,6 \\
Salinidad $(\%$ en peso equiv. de $\mathrm{NaCl})$ & 0,2 a 7,2 & 0,5 a 8,3 \\
Densidad $\left(\mathrm{g} / \mathrm{cm}^{3}\right)$ & 0,9 & 0,8 \\
Presión mín.de entrampamiento(bares $)$ & 15,4 & 38,5 \\
\hline
\end{tabular}

Tabla 7.4: Resumen de datos obtenidos a partir de los ensayos microtermométricos realizados en IF bifásicas acuosas de baritinas representativas de las mineralizaciones. 

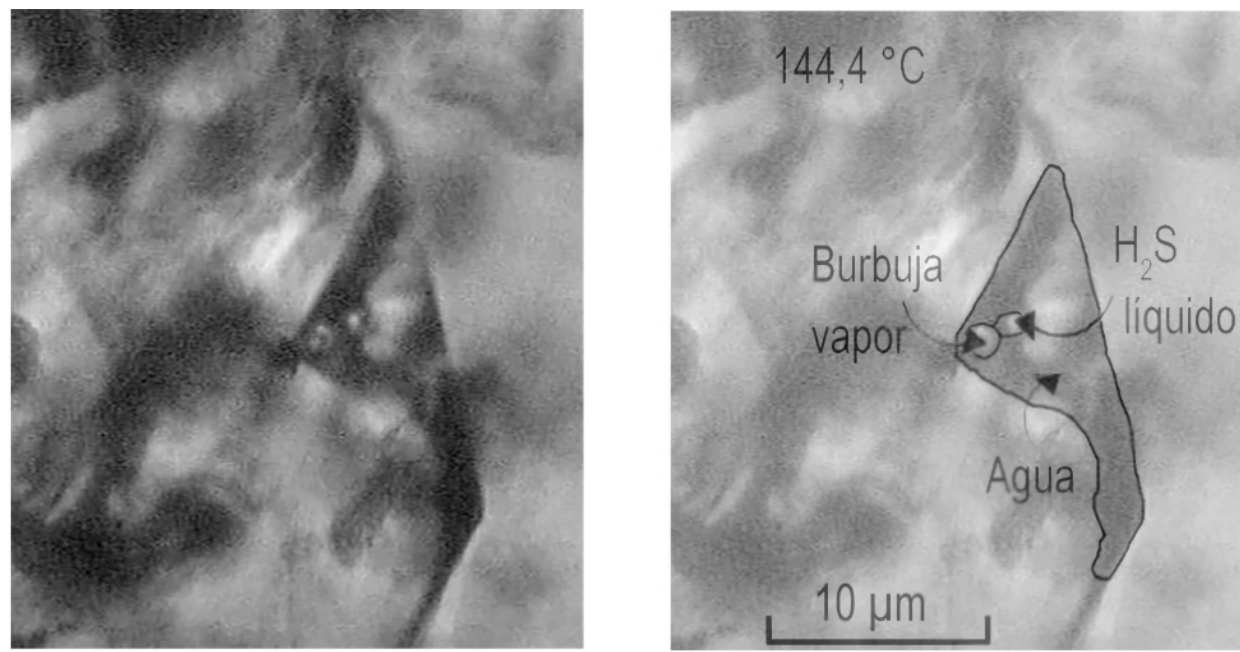

Figura 7.5: Fotomicrografía e ilustración de IF de baritina de veta con tres fases generadas como consecuencia de la reducción termoquímica del sulfato (TSR). La fase dominante (agua) contiene dos burbujas inmiscibles, una de vapor de agua y otra de $\mathrm{H}_{2} \mathrm{~S}$ líquido.

Los datos obtenidos de las IF (Tabla 7.4) sugieren que la baritina de ambas yacencias, precipitó a partir de un sistema heterogéneo compuesto por un fluido acuoso y un fluido orgánico y que a partir del entrampamiento de dichos fluidos inmiscibles, se nuclearon IF con distintas relaciones de fases, incorporando los dos extremos (inclusiones completamente acuosas e inclusiones completamente orgánicas) y todos los términos intermedios. Los procesos físicos observados tales como la deformación de burbujas, la formación de clatratos y los procesos de adherencia en las paredes de las inclusiones, observados a través de los ensayos de fluorescencia, son los que sustentan que parte de los fluidos entrampados son de origen orgánico. Además del reconocimiento de los fluidos orgánicos, fue posible estimar la composición del HC en base a su color de fluorescencia (tonalidades azuladas) y su punto de ebullición. Los resultados de la fluorescencia revelan que los fluidos orgánicos presentan una avanzada madurez y tienden a ser livianos, con una gravedad API mediana a alta, correlacionable con la ventana de generación de hidrocarburos líquidos/gaseosos (Cuadro 7.2). Según el punto de vaporización se trata de un HC de tipo ciclohexano (Tabla 7.3, Proskuriakuv y Drabkin 1984), que se caracteriza por ser de cadenas simples y derivar de materia orgánica terrestre vegetal. 


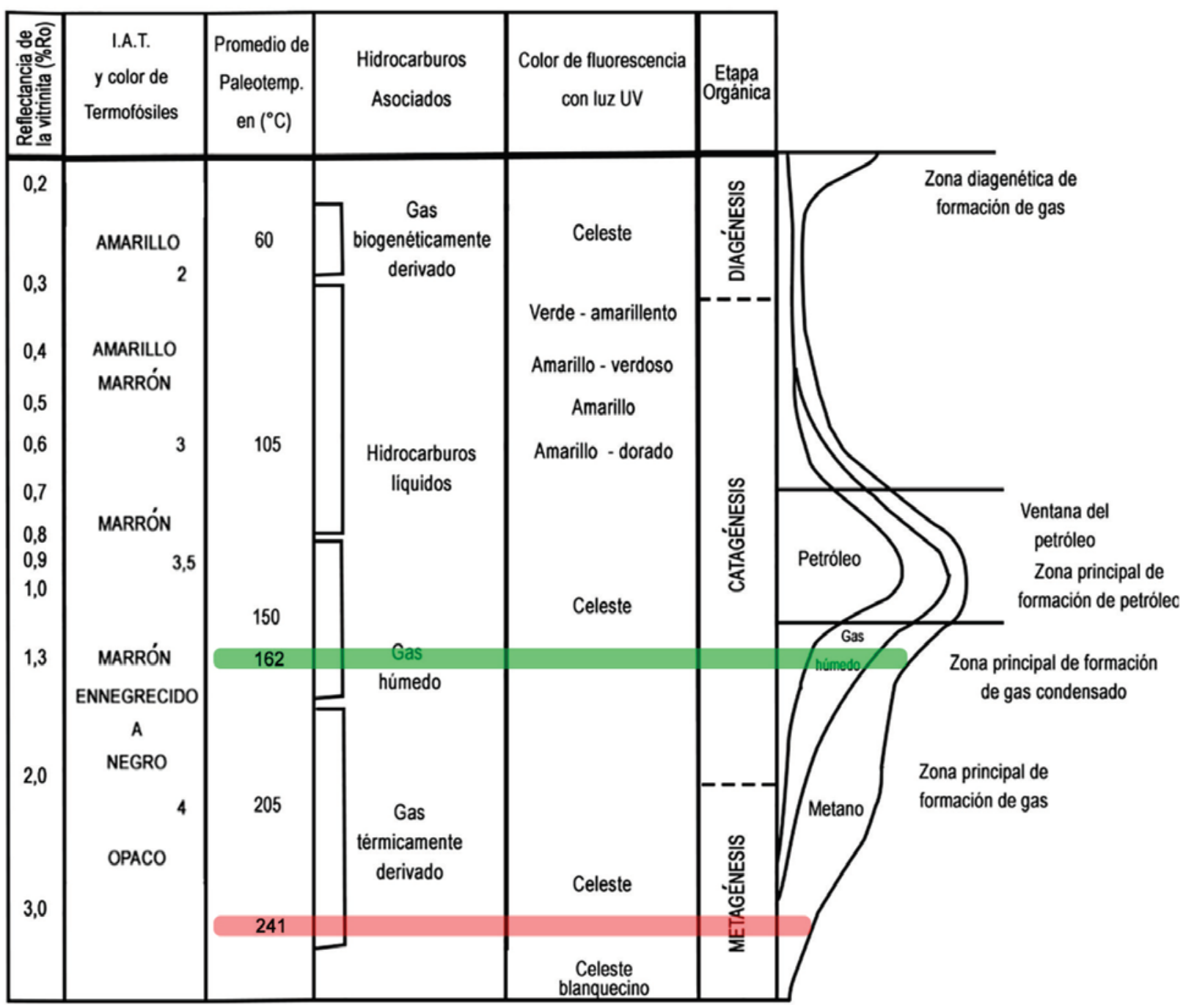

Cuadro 7.2: Diagrama de datos de la reflectancia de vitrinita, termofósiles, hidrocarburos, fluorescencia y etapa orgánica según Salas y Seiler (1980), Merril (1991) y Riecker (1962). En color verde Th promedio de IF de los mantos y en color rojo Th promedio de IF de las vetas.

La aparición de una doble burbuja durante el ensayo de calentamiento de una IF acuosa puede estar indicando, de acuerdo a los estudios efectuados por Worden et al. (1995) en carbonatos y sulfatos, la presencia de $\mathrm{H}_{2} \mathrm{~S}$ (Fig.7.5). Dichos autores trabajaron con carbonatos de Abu Dhabi y proponen que a temperaturas superiores a los $140^{\circ} \mathrm{C}$ el único proceso que contribuye con el aumento en la concentración de $\mathrm{H}_{2} \mathrm{~S}(>10 \%)$ en la fase gaseosa es la reducción termoquímica del sulfato (TSR). Otra evidencia de la presencia de $\mathrm{H}_{2} \mathrm{~S}$, es que tanto la roca de caja (calizas) como la propia baritina, tienen olor fétido al ser golpeadas. Otros procesos observados durante los ensayos microtermométricos tales como la desaparición de una burbuja y su falta de nucleación 
durante la recuperación y como también el nucleamiento de IF monofásicas, pueden deberse a procesos de metaestabilidad según Roedder (1984).

Dados los valores tan bajos de presión mínima de entrampamiento del fluido, no se consideró a la presión como un factor importante en la modificación de la temperatura. Con respecto a los bajos valores de salinidad de las mineralizaciones baríticas (mantiformes y vetiformes) éstos pueden ser consecuencia del desarrollo de procesos de TSR, de acuerdo a estudios realizados por Worden et al. (1996) en rocas evaporíticas. Dichos autores estudiaron carbonatos y sulfatos de Abu Dhabi y postularon que la TSR puede diluir hasta cinco veces la salinidad original de los fluidos. 


\section{ISÓTOPOS ESTABLES}

\section{Introducción}

Los isótopos estables, principalmente los de carbono, hidrógeno, oxígeno y azufre, son buenos trazadores de la fuente de fluidos como así también de los procesos de interacción fluido-roca en una gran variedad de ambientes hidrotermales (Bowman 1998). Con el objeto de caracterizar los fluidos vinculados a la formación de los depósitos barítico-polimetálicos presentes en la región de Colipilli y aportar datos sobre su procedencia, se realizaron análisis de isótopos estables de $\mathrm{O}$ y $\mathrm{S}$.

Estos análisis se practicaron en baritinas y galenas presentes en las mineralizaciones barítico-sulfurosas de los sectores mina San Eduardo, mina La Bienvenida, minas La Esperanza-Carlita y minas La Bruja-Julio César y en magnetitas de la mina Augusta y de un sector próximo a la mina General Belgrano (cerro Naunauco). Asimismo, se analizaron magnetitas constituyentes de rocas ígneas de los principales cuerpos intrusivos de la Formación Colipilli, con la finalidad de comparar estos datos, de indudable procedencia magmática, con los correspondientes a las magnetitas de las mineralizaciones mencionadas.

\section{Resultados}

\section{En sulfatos y sulfuros:}

Con respecto a las mineralizaciones barítico-polimetálicas, los valores isotópicos de $\delta^{18} \mathrm{O}_{\text {SMOw }}$ y $\delta^{34} \mathrm{~S}_{\mathrm{CDT}}$ en baritina se encuentran entre $10,4 \%$ y $17,0 \%$ y entre $15,3 \%$ y $23,4 \%$, respectivamente, mientras que las determinaciones isotópicas realizadas en galena arrojaron valores marcadamente negativos de $\delta^{34} \mathrm{~S}_{\mathrm{CDT}}$ (entre -10,6\% y -18,6\%o) (Tabla 7.5). Estos últimos resultados son similares a los obtenidos por Kesler y Jones (1981) en los depósitos celesto-baríticos del estado de Coahuila, México, los cuales fueron interpretados como hidrotermales no magmáticos por estos autores. 


\begin{tabular}{|c|c|c|c|c|c|c|}
\hline Yacencia & Sector investigado & Mineral & $\delta^{34} \mathrm{~S}_{\mathrm{SCDT}}$ & $\delta^{18} \mathrm{O}_{\text {SMOW }}$ & $\delta^{34} \mathrm{~S}_{\text {Fluido }}$ & $\delta^{18} \mathrm{O}_{\text {Fluido }}$ \\
\hline \multirow{15}{*}{ mantiforme } & \multirow{8}{*}{ La Bienvenida } & \multirow{8}{*}{ Baritina } & 22,2 & 16,8 & $-11,5$ & 8,2 \\
\hline & & & 18,3 & 13,7 & $-15,4$ & 5,1 \\
\hline & & & 18,4 & 14,2 & $-15,3$ & 5,6 \\
\hline & & & 24,1 & 15 & $-9,6$ & 6,5 \\
\hline & & & 17,4 & 13,9 & $-16,3$ & 5,3 \\
\hline & & & 17,2 & 12 & $-16,5$ & 3,4 \\
\hline & & & 16,8 & 14,1 & $-16,9$ & 5,5 \\
\hline & & & 22,2 & 16,8 & $-11,5$ & 8,2 \\
\hline & \multirow{3}{*}{ San Eduardo } & \multirow{3}{*}{ Baritina } & 17,2 & 12,8 & $-16,5$ & 4,2 \\
\hline & & & 23,4 & 15,5 & $-10,3$ & 6,9 \\
\hline & & & 16 & 12,7 & $-17,7$ & 4,1 \\
\hline & \multirow{4}{*}{ La Bienvenida } & \multirow{4}{*}{ Galena } & $-18,6$ & & $-15,2$ & \\
\hline & & & $-15,6$ & & $-12,2$ & \\
\hline & & & $-22,7$ & & $-19,3$ & \\
\hline & & & $-18,1$ & & $-15,6$ & \\
\hline \multirow{18}{*}{ vetiforme } & San Eduardo & Baritina & 15,3 & 10,4 & $-18,4$ & 1,8 \\
\hline & \multirow{6}{*}{ La Bruja } & \multirow{6}{*}{ Baritina } & 17,4 & 14,3 & $-8,4$ & 10,2 \\
\hline & & & 16,7 & 15,7 & $-9,1$ & 11,6 \\
\hline & & & 18,3 & 15,9 & $-7,5$ & 11,8 \\
\hline & & & 18,4 & 14,6 & $-7,4$ & 10,5 \\
\hline & & & 15,9 & 15,1 & $-9,9$ & 11 \\
\hline & & & 16,9 & 14,8 & $-8,9$ & 10,7 \\
\hline & \multirow{3}{*}{ Julio César } & \multirow{3}{*}{ Baritina } & 14,6 & 9,9 & $-11,2$ & 5,8 \\
\hline & & & 14,6 & 13,5 & $-11,2$ & 9,4 \\
\hline & & & 15,3 & 17 & $-10,5$ & 12,9 \\
\hline & Chihuido & Baritina & 16,5 & 11,3 & $-9,3$ & 7,2 \\
\hline & Saúl Chico & Baritina & 16,1 & 14,1 & $-9,7$ & 10 \\
\hline & La Esperanza & Baritina & 18,3 & 14,6 & $-7,5$ & 10,5 \\
\hline & Carlita & Baritina & 16 & 14,1 & $-9,8$ & 10 \\
\hline & La Bruja & Galena & $-10,6$ & & $-8,1$ & \\
\hline & \multirow{2}{*}{ Julio César } & \multirow{2}{*}{ Galena } & $-12,4$ & & $-9,9$ & \\
\hline & & & $-13,2$ & & $-10,7$ & \\
\hline & La Esperanza & Galena & $-11,9$ & & $-9,4$ & \\
\hline
\end{tabular}

Tabla 7.5: Resultados de los análisis de isótopos estables de los depósitos barítico-polimetálicos investigados.

En el diagrama de la Figura 7.6 se observan los valores de $\delta^{34} \mathrm{~S}_{\mathrm{CDT}}$ de las baritinas analizadas conjuntamente con aquellos valores publicados por otros investigadores (Kesler y Jones 1981; González Sánchez 2009 y de Barrio et al., 2014) con fines comparativos. En la Figura 7.7ayb se graficaron los valores isotópicos de $\delta^{34} \mathrm{~S}_{\mathrm{CDT}}$ y $\delta^{18} \mathrm{O}_{\mathrm{SMOW}}$ correspondientes a las baritinas estudiadas. Asimismo, los resultados isotópicos obtenidos a partir de las galenas, fueron graficados en la Figura 7.8 y además comparados con datos de $\delta^{34} \mathrm{~S}_{\mathrm{CDT}}$ de otros depósitos de la Cuenca Neuquina (de Barrio et al., 2014). Estos últimos muestran tendencias similares a las observadas en los depósitos investigados (un marcado empobrecimiento en isótopos livianos). Los valores isotópicos de $\delta^{34} \mathrm{~S}_{\mathrm{CDT}}$ de las baritinas y las galenas se muestran en la Figura 7.9 conjuntamente con valores de $\delta^{34} \mathrm{~S}_{\mathrm{CDT}}$ de minerales típicos de depósitos hidrotermales, también con fines comparativos. 


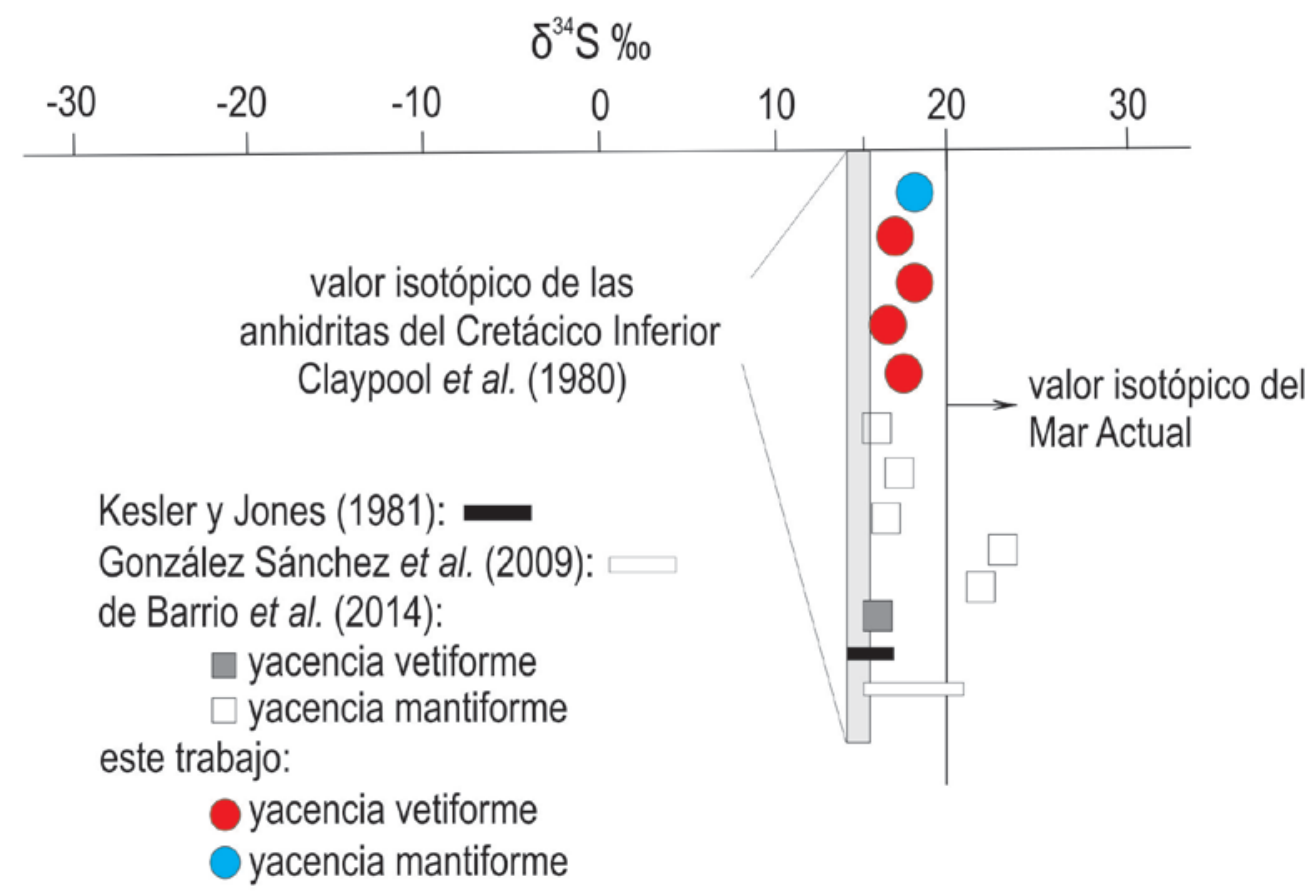

Figura 7.6: Gráfico de valores isotópicos de la baritina estudiada cotejadas con los valores isotópicos del mar actual, anhidritas del Cretácico Inferior según Claypool (1980) y depósitos barítico-celestínicos estudiados por Kesler y Jones (1981), González Sánchez et al. (2009) y de Barrio et al. (2014).

En base a los valores isotópicos de las baritinas y galenas se calculó la composición isotópica del $\delta^{34} \mathrm{~S}$ y $\delta^{18} \mathrm{O}$ del fluido que estuvo en equilibrio con dichos minerales. Cabe mencionar que los valores isotópicos están condicionados por el $\mathrm{pH}$ y la fugacidad del oxígeno $\left(\mathrm{fO}_{2}\right)$, los cuales determinan la/s fase/es en equilibrio en un momento dado. Se consideró a la baritina como la fase portadora del S; la temperatura utilizada para calcular el $\delta^{34}$ SFLUido fue la temperatura media obtenida de las determinaciones microtermométricas (Th: para los mantos $162,2^{\circ} \mathrm{C}$ y para las vetas $241,1^{\circ} \mathrm{C}$ ). Los cálculos fueron realizados en la calculadora de fraccionamiento de isótopos estables "AlphaDelta" (Beaudoin y Therrien 2004, 2009) disponible en http:/www2.ggl.ulaval.ca/cgibin/alphadelta/alphadelta.cgi. Los valores de $\delta^{34} \mathrm{~S}$ del fluido en equilibrio con las baritinas fueron calculados a partir de la ecuación de Ohmoto y Rye (1979) y los valores de $\delta^{34} \mathrm{~S}$ del fluido en equilibrio con las galenas fueron calculados a partir la ecuación de Li y Liu (2006). Por otro lado, los valores de $\delta^{18} \mathrm{O}$ del fluido en equilibrio con las baritinas fueron calculados a partir de la ecuación Kusakabe y Robinson (1977) (Tabla 7.5). 

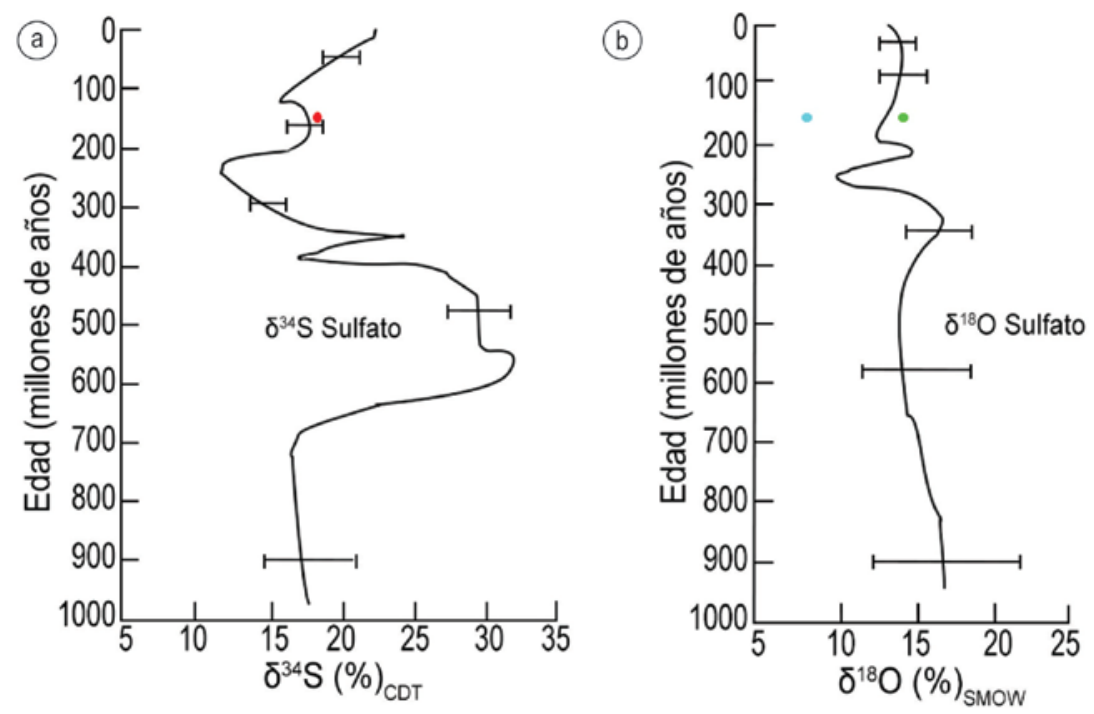

Figura 7.7: a-b Diagramas de edad para $\delta^{34} \mathrm{~S}_{\mathrm{CDT}}$ y $\delta^{18} \mathrm{O}_{\mathrm{SMO}}$ en sulfato en equilibrio en el agua de mar. Modificado de Claypool et al. (1980). Círculo en rojo valor promedio de $\delta^{34} \mathrm{~S}_{\mathrm{CDT}}$ en baritina, círculo en verde valor promedio de $\delta^{18} \mathrm{O}_{\text {SMOw }}$ en baritina y círculo en celeste valor promedio de $\delta^{18} \mathrm{O}_{\text {Fluido }}$ en equilibrio con la baritina.

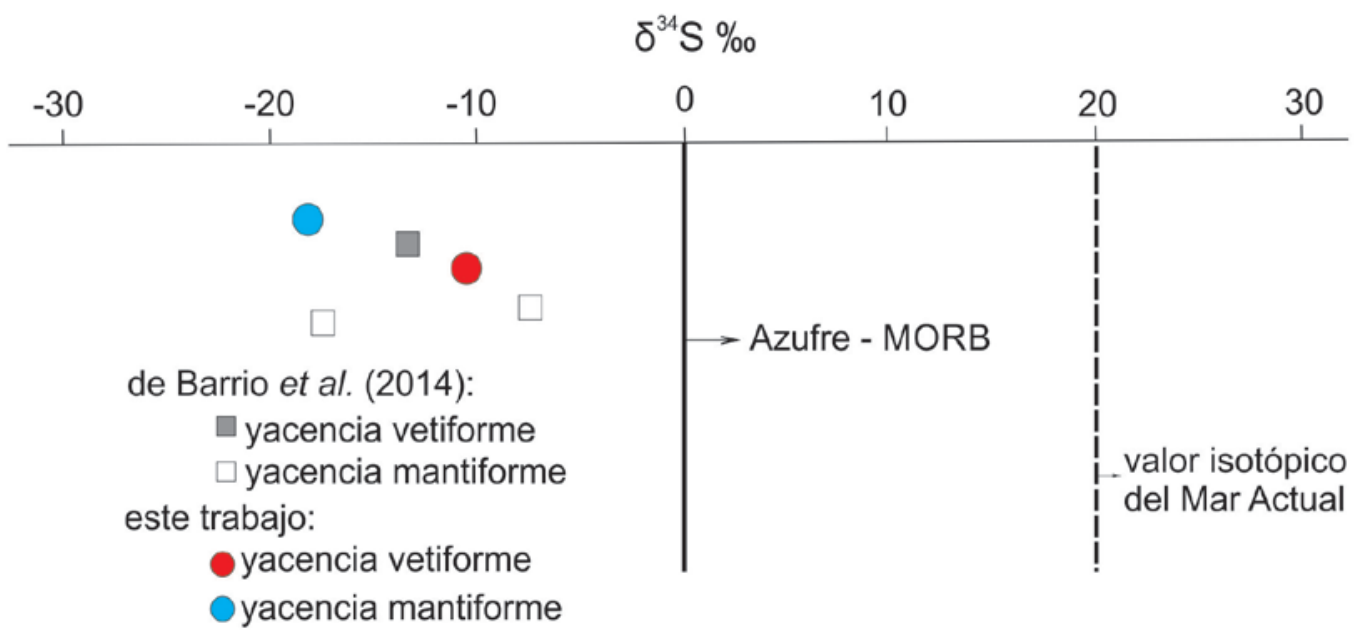

Figura 7.8: Rango de valores isotópicos de las galenas analizadas junto con los publicados por de Barrio et al. (2014). 


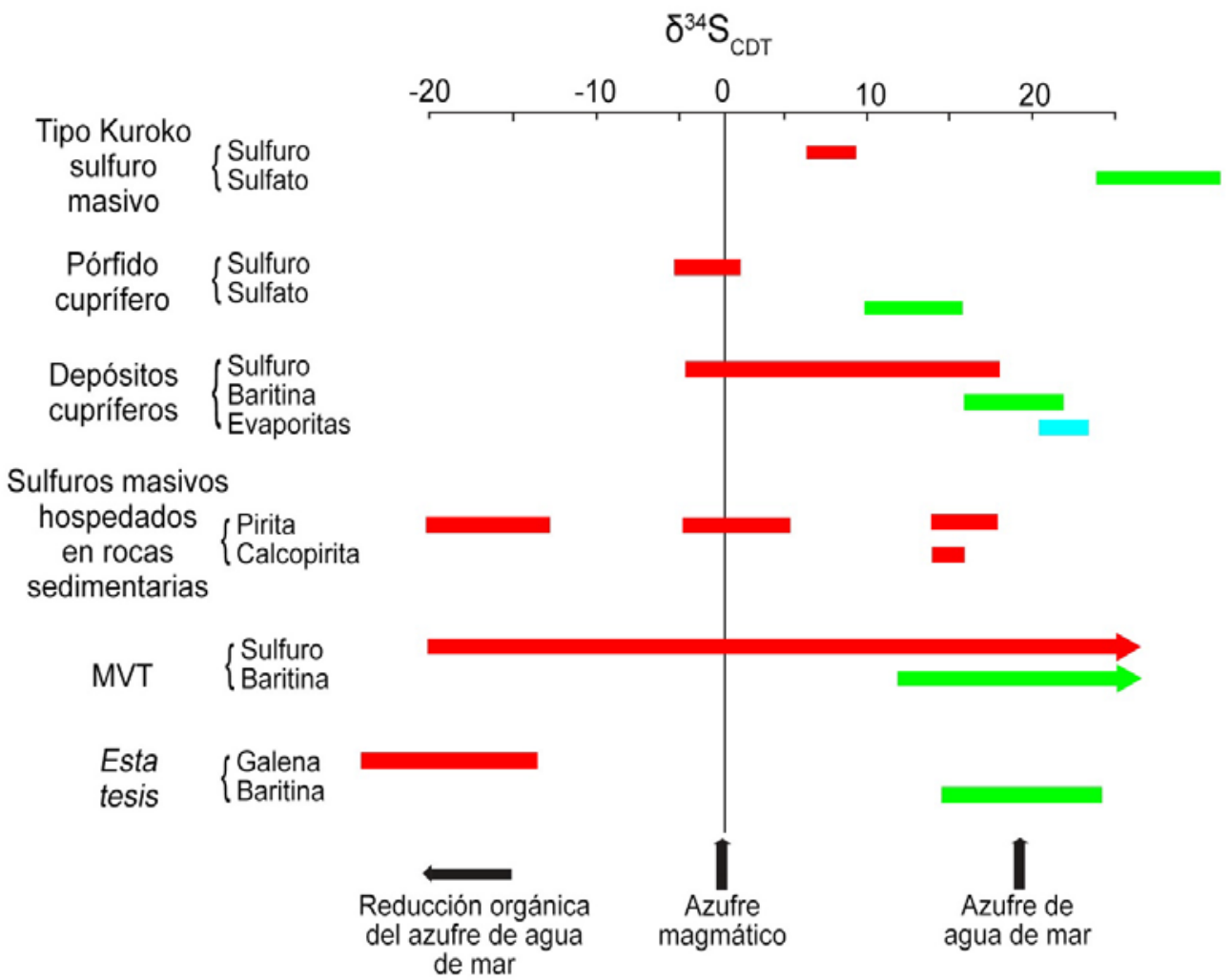

Figura 7.9: Gráfico en el que se comparan los valores isotópicos de la baritina y galena analizada con distintos depósitos hidrotermales. Modificado de Rollinson (1993). En rojo se indican los valores isotópicos correspondientes a sulfuros, en verde se señalan los valores isotópicos correspondientes a sulfatos y en celeste los correspondientes a evaporitas.

\section{En magnetitas:}

Los resultados obtenidos de las magnetitas de las manifestaciones ferríferas y de las rocas ígneas arrojaron valores positivos de $\delta^{18} \mathrm{O}$ (Tabla 7.6). Las primeras presentaron valores contrastantes, variando entre 2,9\%o (mina Augusta) y 9,1\%o (mina General Belgrano) de $\delta^{18} \mathrm{O}$. Por su parte, las magnetitas provenientes de diferentes cuerpos ígneos presentaron valores que se agruparon en una población que tiene un mínimo de $\delta^{18} \mathrm{O}$ de $3,3 \%$ y un máximo de $6,4 \%$. Todos los valores de $\delta^{18} \mathrm{O}$ de las magnetitas analizadas, fueron graficados en el diagrama de la Figura 7.10, donde son comparados con distintos reservorios naturales de oxígeno. 


\begin{tabular}{|c|c|c|c|}
\hline & Sector/Mina & Mineral & $\overline{\delta^{18} O_{\text {SMOW }}}$ \\
\hline \multirow{5}{*}{ rocas ígneas } & Cerro Los Bueyes & Magnetita & $\begin{array}{l}3,3 \\
3,6\end{array}$ \\
\hline & Stock & Magnetita & 4,1 \\
\hline & Cerro Naunauco & Magnetita & 4,1 \\
\hline & Dique & Magnetita & 6,4 \\
\hline & Chihuido & Magnetita & $\begin{array}{l}5,3 \\
4,1\end{array}$ \\
\hline \multirow{2}{*}{ mineralizaciones } & Augusta & Magnetita & 2,9 \\
\hline & Cerro Naunauco & Magnetita & 9,1 \\
\hline
\end{tabular}

Tabla 7.6: Resultados de los análisis de isótopos estables de las magnetitas de las rocas ígneas y mineralizaciones ferríferas.

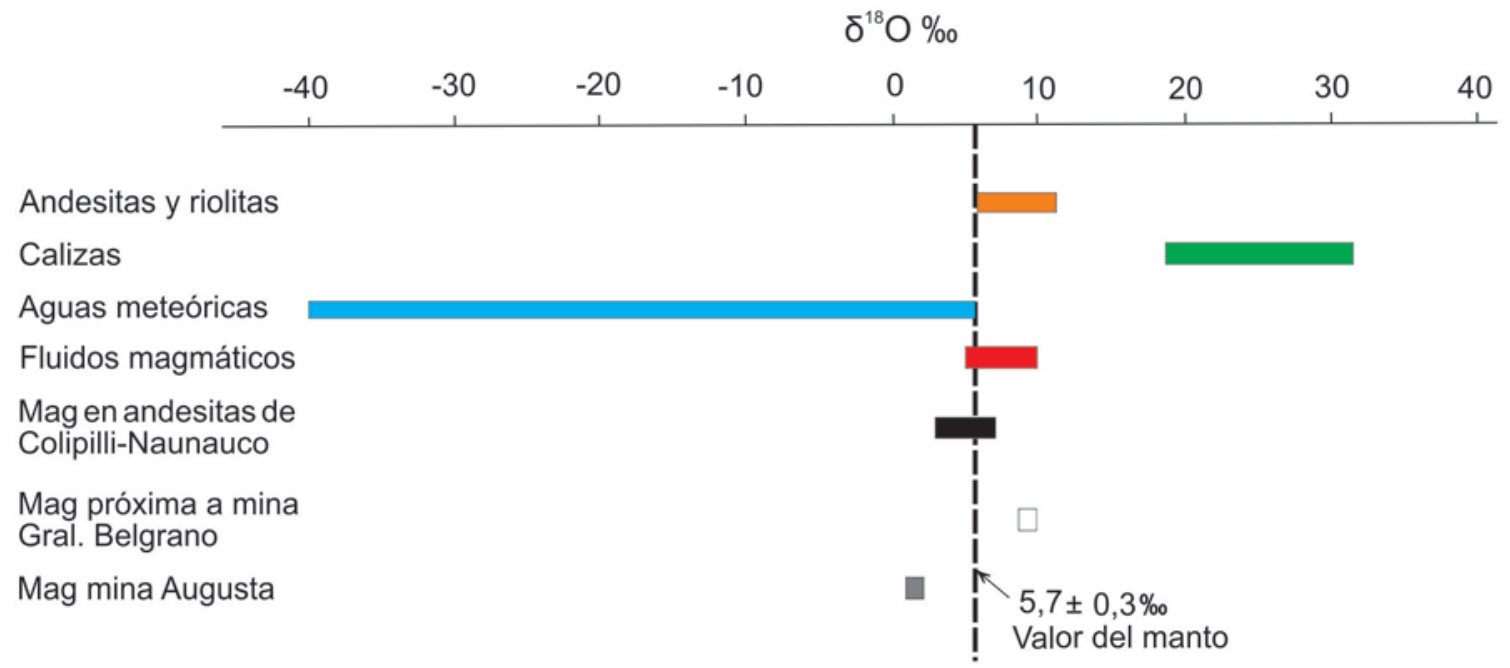

Tabla 7.10: Diagrama en el que se comparan los valores isotópicos de la magnetita analizada con distintos reservorios naturales de oxígeno, modificado de Rollinson (1993).

\section{Discusión y Conclusiones parciales}

Si bien las mineralizaciones del área de Colipilli han sido motivo de algunos estudios metalogénicos previos de carácter general, hasta la actualidad no se contaba con un análisis isotópico pormenorizado que permitiese esclarecer la procedencia de los elementos que las constituyen. En este sentido, los valores de $\delta^{34} \mathrm{~S}_{\mathrm{CDT}}$ obtenidos en baritinas del área de estudio muestran un claro enriquecimiento isotópico según el rango 
establecido por Claypool et al. (1980) para las evaporitas del Cretácico Inferior, solo algunos valores coinciden parcialmente (Fig.7.6 y Fig.7.7ayb). Kesler y Jones (1981) reportaron tenores de $\delta^{34} \mathrm{~S}$ muy amplios e inusualmente altos para depósitos de celestina y baritina emplazados en la secuencia cretácica del noreste de México (16,8 a 38,3\%), superiores a las evaporitas mesozoicas, lo que sugiere que existió un fraccionamiento isotópico que enriqueció los isótopos de azufre. Richardson et al. (1988) y Decrée et al. (2008) determinaron que los valores de $\delta^{34} S$ elevados pueden corresponder a fraccionamientos isotópicos de azufre en un sistema cerrado controlado por fraccionamiento Rayleigh, de esta manera, la composición isotópica del azufre se enriquece en isótopos pesados.

Dicho fraccionamiento en las baritinas estudiadas podría estar vinculado a procesos de reducción. La asociación sulfato-HC disuelto es termodinámicamente inestable en todos los ambientes diagenéticos. A causa de dicha inestabilidad, se desatan reacciones de tipo redox en las que el sulfato se reduce ya sea por actividad bacteriana (BSR) o inorgánicamente (reducción termoquímica del sulfato, TSR) (Machel 1998). La composición isotópica final del $\mathrm{H}_{2} \mathrm{~S}$ (producto de las reacciones redox) dependerá de si la reducción se produjo en un sistema abierto o cerrado. Según Machel (2001) en un sistema abierto el resultado de la reducción bacteriana del sulfato dará fraccionamientos $\Delta^{34} \mathrm{~S}-10 \mathrm{a}$ $-20 \%$. En un sistema cerrado, donde el suministro de sulfato es restringido, se alcanzan valores $\delta^{34} \mathrm{~S}$ menos fraccionados y los enriquecimientos pueden llegar hasta los $40 \%$ (Ohmoto 1986).

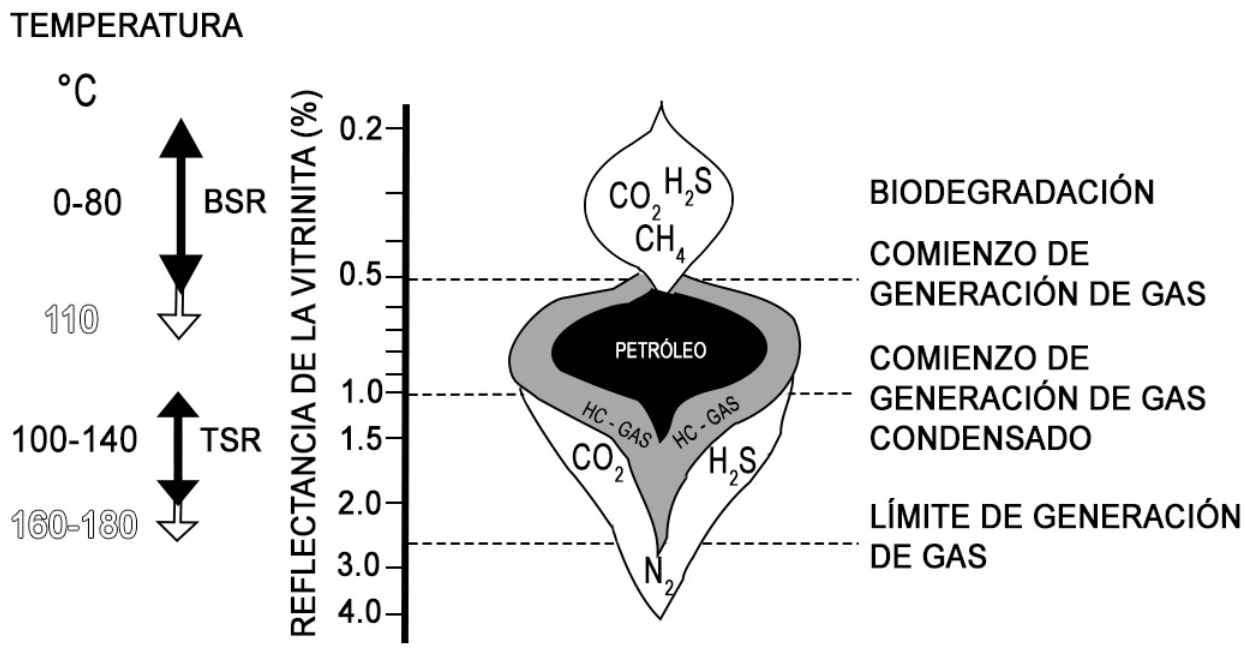

Figura 7.11: Diagrama integrador con datos de la generación de petróleo y gas, la temperatura, la madurez térmica y los procesos BSR y TSR. Modificado de Machel (1998). 
BSR es el proceso considerado más importante en la formación de sulfuros (Machel 1998). Es común entre $0^{\circ}$ y $60-80^{\circ} \mathrm{C}$ (Fig.7.11), por encima de este rango de temperatura, casi todas las bacterias reductoras del sulfato dejan de metabolizar (Machel 1998). El fraccionamiento isotópico entre el sulfato y el sulfuro es un proceso cinéticamente controlado, en el cual el sulfato es enriquecido en ${ }^{34} \mathrm{~S}$ en relación con el sulfuro. Las bacterias utilizan el oxígeno de los sulfatos en la respiración anaeróbica de su ciclo vital, dando lugar a la generación de $\mathrm{H}_{2} \mathrm{~S}$, a su vez, metabolizan más rápidamente el ${ }^{32} \mathrm{~S}$ que el ${ }^{34} \mathrm{~S}$. De este modo, el sulfato acuoso residual es enriquecido en ${ }^{34} \mathrm{~S}$ durante el progreso de la reacción (Seal II 2006). Para tener BSR, además de disponer de una fuente de sulfato, se requiere de la presencia de un medio reductor que posibilite el desarrollo del metabolismo bacteriano (Seal II 2006). En la zona de estudio, la presencia de HC en inclusiones fluidas podría ser el responsable de dicho ambiente reductor. Los procesos reductores mencionados se pueden explicar con la siguiente ecuación:

$$
2 \mathrm{CH}_{2}+\mathrm{SO}_{4}{ }^{2-}=\mathrm{H}_{2} \mathrm{~S}+2 \mathrm{HCO}^{3-} \quad \text { (Seal II 2006) }
$$

Los sulfuros que se forman a partir del proceso BRS inicialmente son fases metaestables que luego recristalizan en pirita, marcasita, y/o pirrotina (Rickard et al., 1995).

Además de la BSR, la TSR en presencia de materia orgánica es otro proceso que produce grandes cantidades de $\mathrm{H}_{2} \mathrm{~S}$. El rango de temperatura en el que actúa dicho proceso es entre $\operatorname{los} 100^{\circ}$ y $140^{\circ} \mathrm{C}$ (Fig.7.11), aunque hay registro de temperaturas mayores a 160 $180^{\circ} \mathrm{C}$ (Machel 1998). Por otro lado, Richardson et al. (1988) determinaron que los altos valores de $\delta^{34} \mathrm{~S}$ responden a sistemas abiertos donde hay escape o pérdida de $\mathrm{H}_{2} \mathrm{~S}$ y de esta manera la composición isotópica del sulfato remanente cambia, enriqueciéndose en ${ }^{34} \mathrm{~S}$. Sin embargo, Machel et al. (1995) estiman que los fraccionamientos generados a partir de procesos de TSR en ambientes abiológicos pueden ser $\Delta^{34} \mathrm{~S} \geq-20 \%$. Además, el proceso TSR es más eficiente a temperaturas mayores a $100^{\circ} \mathrm{C}$. Worden et al. (1995) analizaron IF de carbonatos de Abu Dhabi y propusieron que a temperaturas superiores a los $140^{\circ} \mathrm{C}$ el único proceso que contribuye al aumento en la concentración de $\mathrm{H}_{2} \mathrm{~S}(>10 \%)$ en la fase gaseosa es la reducción termoquímica del sulfato (TSR). Los sulfuros más comunes que se forman como subproductos del proceso TSR son galena, esfalerita, pirita de manera subordinada. La signatura isotópica definida tanto para la galena como para la baritina (Fig.7.9) es típica de los depósitos tipo MVT, hecho concordante con la mineralogía (galena + esfalerita + pirita). 
Con respecto a los valores $\delta^{18} \mathrm{O}$ de las magnetitas de las rocas ígneas, al compararlas con los valores isotópicos normales de este tipo de rocas, muestran una tendencia a empobrecerse en el isótopo pesado de oxígeno (Fig.7.10). Dicha disminución en los valores $\delta^{18} \mathrm{O}$ puede ser producto de un descenso en la temperatura probablemente debido a una mezcla con aguas meteóricas (Bowman 1998). Con respecto a las mineralizaciones ferríferas, los valores de $\delta^{18} \mathrm{O}$ de las magnetitas son bien contrastantes; el valor de $\delta^{18} \mathrm{O}$ de la magnetita de mina Augusta podría estar apuntando a una mezcla de aguas formacionales y meteóricas, mientras que el $\delta^{18} \mathrm{O}$ de la magnetita del sector próximo a la mina General Belgrano estaría indicando más bien a valores de las aguas de formación. 


\section{Trabajos citados en el texto}

Barrés, O., Burneau, A., Dubessy, J. y Pagel, M. 1987. Application of micro-FT-IR spectroscopy to individual hydrocarbon fluid inclusion analysis. Applied Spectroscopy, 41: 1000-1008.

Barnes, H.L. 1979. Geochemistry of hydrothermal ore deposits. The Pennsylvania State University. Second Edition. New York.

Beaudoin, G. y Therrien, P. 2004. The web stable isotope fractionation calculator. En: De Groot, P.A. (Ed.), Handbook of stable isotope analytical techniques (V. I), Elsevier: 1045-1047.

Beaudoin, G. y Therrien, P. 2009. The updated web stable isotope fractionation calculator. En: De Groot, P.A. (Ed.), Handbook of stable isotope analytical techniques (V. II), Elsevier: 11201122.

Bodnar, R.J. 1993. Revised equation and table for determining the freezing point depression of $\mathrm{H}_{2} \mathrm{O}-\mathrm{NaCl}$ solutions. Geochimica Et Cosmochimica Acta, 57: 683-684.

Bowman, J.R. 1998. Stable-Isotope Systematics of Skarns. En: Lentz, D.R. (Ed.), Mineralized Intrusion-Related Skarn Systems, Mineralogical Association of Canada, Short Course V. 26: 99-145, Quebec.

Burrus, R.C. 1981. Hydrocarbon fluid inclusions in studies on sedimentary diagenesis. En Hollister, L.S. y Crawford, M.L. (Eds.), Short Course handbook, V. 6, Fluid inclusions: applications to petrology. Mineralogical Association of Canadá: 138-154.

Cesaretti, N.N. 1993. Inclusiones fluidas de hidrocarburos: Su utilidad en la interpretación del proceso de migración y maduración del petróleo. Tesis doctoral, Universidad Nacional del Sur, 170 p., Bahía Blanca.

Cesaretti, N.N. y Domínguez, E.A. 1997. Inclusiones fluidas y porosidad: indicadores diagenéticos y sus implicancias oleogenéticas en la Formación Yacoraite (Cretácico - Terciario). Subcuenca de Lomas de Olmedo. Cuenca Cretácica del Noroeste Argentino. Asociación Geológica Argentina. Revista, 52: 1-25. Buenos Aires.

Cesaretti, N.N., Parnell, J. y Domínguez, E.A. 2000. Pore fluid evolution within a hydrocarbon reservoir: Yacoraite Formation (Upper Cretaceous), North west Basin, Argentina. Journal of Petroleum Geology 23: 375-398.

Claypool, G.E., Holser, W.T., Kaplan, I.R., Sakai, H. y Zak, I. 1980. The age curves of sulfur and oxygen isotopes in marine sulfate and their mutual interpretation. Chemical Geology, 28 : 199-260, Amsterdam.

Collao, S., Brodtkorb, M.K. de, Etcheverry R. 1998. Inclusiones fluidas en celestinas de los yacimientos de la Formación Huitrín, provincia de Neuquén, Argentina. 40 Congresso Brasileiro de Geología, Belo Horizonte, Brasil. Abstract: 174. 
Crawford, M.L. 1981. Aqueous Fluid. En Hollister, L.S. y Crawford, M.L. (Eds.), Short Course handbook, V. 6, Fluid inclusions: applications to petrology: 304 p. Calgary Mineralogical Association of Canadá.

de Barrio, R.E., Etcheverry, R.O., del Blanco, M.A., Domínguez, E.A., Recio Hernández, C., Escobar, R.I. y Salvioli, M.A. 2014. Nuevos datos y esquemas genéticos de los depósitos barítico-celestínicos vinculados a la secuencia Jurásico-Cretácica de la Cuenca Neuquina en la provincia del Neuquén. Revista de la Asociación Geológica Argentina, 71: 184-200, Buenos Aires.

Decrée, S., Marignac, C., De Putter, T., Deloule E., Liégeois, J.P. y Demaiffe, D. 2008. Pb-Zn mineralization in a Miocene regional extensional context: The case of the Sidi Driss and the Douahria ore deposits (Nefza mining district, northern Tunisia). Ore Geology Reviews, 34: 285-303.

Escobar, R.I. 2016. Geología y génesis de las mineralizaciones barítico-celestínicas asociadas a la secuencia cretácia entre las localidades Bajada del Agrio y Chos Malal, provincia del Neuquén. Tesis Doctoral, Universidad Nacional de La Plata. (Inédito). 207 p., La Plata.

Feely, M., Costanzo, A. y O'Rourke, B. 2013. The Application of Fluid Inclusion Studies to Investigations of Hydrocarbon Systems. Atlantic Ireland Conference. Poster. Dublin.

González-Sánchez, F., Camprubí, A., González-Partida, E., Puente-Solís, R., Canet, C., CentenoGarcía, E. y Atudorei, V. 2009. Regional stratigraphy and distribution of epigenetic stratabound celestine, fluorite, barite and $\mathrm{Pb}-\mathrm{Zn}$ deposits in the MVT province of northeastern Mexico. Mineralium Deposita, 44: 343-361.

Goldstein, R.H. y Reynolds, T.J. 1994. Systematics of Fluid Inclusions in Diagenetic Minerals. SEPM Short Course 31, 199 p.

Hayase, K. y Bengochea, A.L. 1975. Consideraciones sobre la génesis de algunos yacimientos de baritina-celestina, provincia de Neuquén, República Argentina. $2^{\circ}$ Congreso Iberoamericano de Geología Económica, Actas 2: 295-314, Buenos Aires.

Kesler, S.E. y Jones, C.M. 1981. Sulfur- and strontium-isotopic geochemistry of celestite, barite, and gypsum from the Mesozoic basins of north-eastern Mexico. Chemical Geology 31: 211-224.

Kusakabe, M. y Robinson, B.W. 1977. Oxygen and sulfur isotopic equilibria in the $\mathrm{BaSO}_{4}-\mathrm{HSO}_{4}{ }^{-}-$ $\mathrm{H} 2 \mathrm{O}$ system from $110^{\circ}$ to $350^{\circ} \mathrm{C}$ and applications. Geochimica Et Cosmochimica Acta, 41: 1033-1040.

Leal, P. y Mateo, P. 2015. Paragénesis y microtermometría de las manifestaciones de baritina del anticlinal de Chorriaca, provincia del Neuquén. Revista de la Asociación Geológica Argentina 72: 195-209, Buenos Aires. 
Li, Y.B. y Liu, J.M. 2006. Calculation of sulfur isotope fractionation in sulfides. Geochimica Et Cosmochimica Acta, 70: 1789-1795.

Machel, H.G. 1998. Gas Souring by Thermochemical Sulfate Reduction at $140^{\circ} \mathrm{C}$ : Discussion. AAPG Bulletin, V. 82: 1870-1873, USA.

Machel, H.G. 2001. Bacterial and thermochemical sulfate reduction in diagenetic settings: old and new insights. Sedimentary Geology, 140: 143-175.

Machel, H.G., Krouse, H.R. y Sassen, R. 1995. Products and distinguishing criteria of bacterial and thermochemical sulfate reduction. Applied Geochemistry, 10: 373-389.

Ohmoto, H. 1986. Stable isotope geochemistry of ore deposits. En: J.W. Valley, H.P. Taylor Jr. y J.R. O'Neil (Eds.), Stable Isotopes in High Temperature Geological Processes. Reviews in Mineralogy and Geochemistry, 16: 491-560.

Ohmoto, H. y Rye, R.O. 1979. Isotopes of sulfur and carbon. En: H.L. Barnes (Ed.), Geochemistry of Hydrothermal Ore Deposits, 2nd Ed. Wiley, New York, 509-561.

Proskuriakuv y Drabkin. 1984. Química del petróleo y del gas. Editorial: MIR MOSCU.

Richardson, C.K., Rye, R.O. y Wasserman M.D. 1988. The chemical and thermal evolution of the fluids in the Cave-in-Rock fluorspar district, Illinois: stable isotope systematics at the Deardorff mine. Economic Geology 83: 765-783.

Riecker, R.E. 1962. Hydrocarbon fluorescence and migration of petroleum. American Association of Petroleum Geologists, Bulletin 46: 60-75.

Rickard, D., Martin A.A. y Luther G.W. III. 1995. Chemistry of iron sulfides in sedimentary environments, Geochemical Transformations of Sedimentary Sulfur. ACS Symposium Series 612, ACS Press, Washington, DC, 168-193.

Roedder, E. 1963. Studies of fluid inclusions II: Freezing data and their interpretation. Economic Geology 58: 167-211.

Roedder, E. 1984. Fluid inclusions: Reviews in Mineralogy 12. Mineralogical Society of America: $644 \mathrm{p}$.

Roedder, E. y Bodnar, R. 1980. Geologic pressure determinations from fluid inclusion studies. Annual review of earth and planetary sciences, 8: 263.

Seal II, R.R. 2006. Sulfur Isotope Geochemistry of Sulfide Minerals. Reviews in Mineralogy and Geochemistry 61: 633-677.

Velasco, F. 2004. Introducción al estudio de las inclusiones fluidas. XXIII Curso Latinoamericano de Metalogenia. 98 p, Mendoza.

Worden, R.H., Smalley, P.C y Oxtoby, N.H. 1995. Gas Souring by Thermochemical Sulfate Reduction at $140^{\circ} \mathrm{C}$. The American Association of Petroleum Geologists. V. 79: 854-863, USA. 
Worden, R.H., Smalley, P.C y Oxtoby, N.H. 1996. The effects of thermochemical sulfate reduction upon formation water salinity and oxygen isotopes in carbonate gas reservoirs. Geochimica et Cosmochimica Acta, V. 60: 3925-3931, USA. 


\section{Capítulo 8}

\section{MODELO GENÉTICO Y CONCLUSIONES FINALES}




\section{Introducción}

Depósitos de Ba y $\mathrm{Sr}$ con similares rasgos geológicos a los observados en la Cuenca Neuquina han sido investigados por diversos autores en distintos lugares del mundo. Entre otros, Kesler y Jones (1981) y Tritlla et al. (2006) indican procesos de reemplazo y relleno sobre carbonatos estromatolíticos que generaron mineralizaciones de baritina y celestina en el noreste de México las cuales son asignadas a la tipología MVT. Hanor $(2000,2004)$ postula, para la génesis de depósitos mantiformes de baritina y celestina, procesos de reemplazo epigenéticos y relleno de cavidades en calizas y/o yeso-anhidrita. Más recientemente, Torres Ruiz (2008) cita para los yacimientos celestínicos de Montevive y Escúzar, localizados en la depresión de Granada (España), fundamentalmente el proceso de reemplazo en la facies carbonático-estromatolítica y relleno de espacios abiertos.

Son varios los autores que han trabajado para dilucidar los aspectos genéticos de las mineralizaciones barítico-celestínicas alojadas en la Formación Huitrín de la Cuenca Neuquina, pero hasta el presente no son numerosas las investigaciones en las que se han empleado técnicas analíticas modernas en su estudio (fluorescencia y microtermometría en inclusiones fluidas, análisis de isótopos estables, litogeoquímica y geoquímica mineral, entre otras) que permitan clarificar los procesos mineralogenéticos sucedidos en estos depósitos minerales. También son escasas las contribuciones que han tratado de explicar el rol que desempeñó el magmatismo presente en el área de estudio en la génesis de los depósitos barítico-polimetálicos (Ba-Fe-Pb-Cu-Zn-Mn) el cual fue inicialmente indicado por Llambías y Malvicini (1978).

En el presente capítulo se realiza la integración de los resultados de los estudios geológicos, petrológicos, mineralógicos y geoquímicos de las mineralizaciones baríticopolimetálicas y de las unidades magmáticas presentes en el área de Colipilli con el fin de arribar a un modelo geológico-genético (Fig.8.1) de características regionales que pretende explicar la mecánica evolutiva de los fluidos mineralizantes movilizados por el magmatismo cretácico-terciario en un ámbito dominado por la presencia de secuencias sedimentarias litológica, estructural y geoquímicamente receptivas que han sido propicias para albergar las mineralizaciones barítico-polimetálicas. 


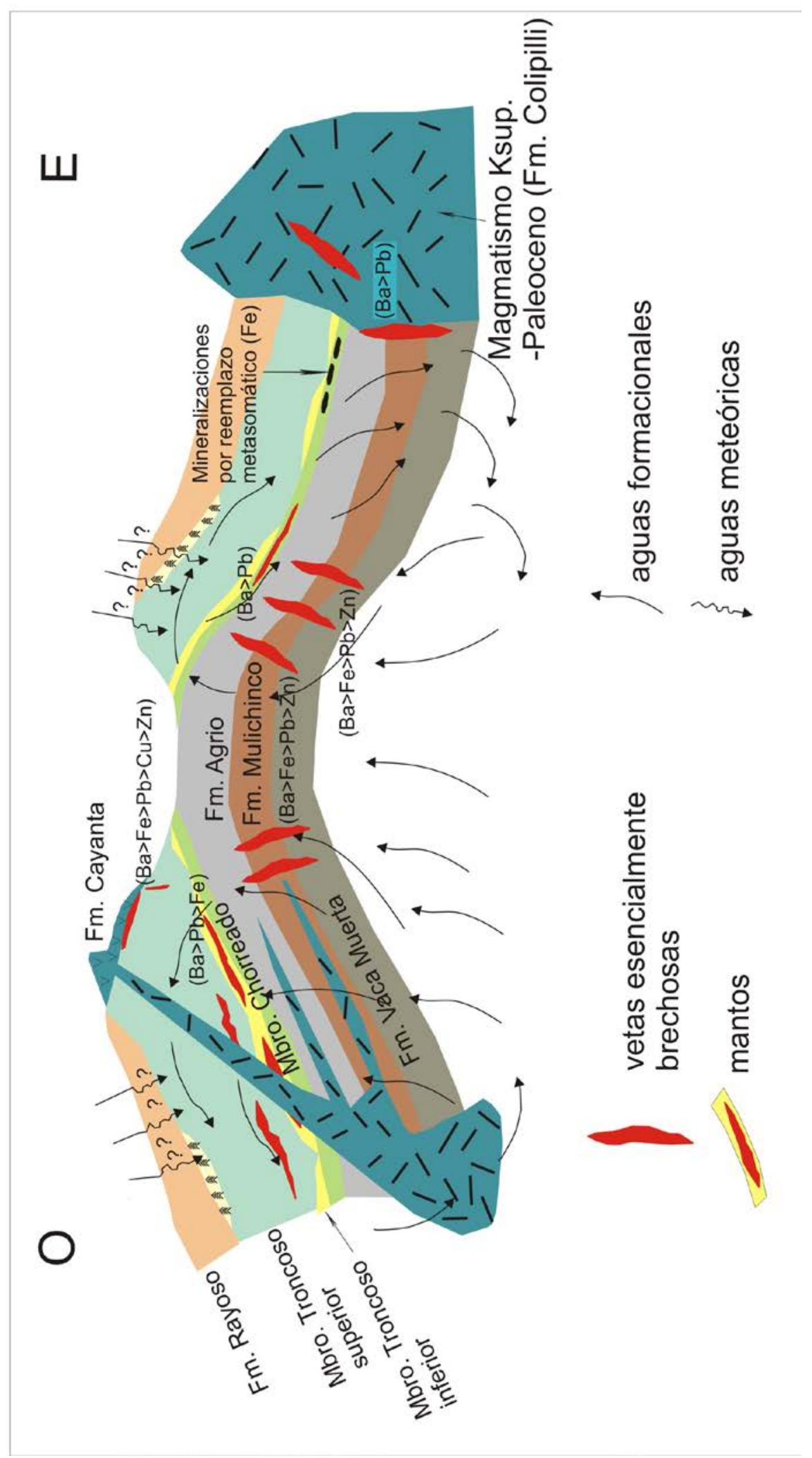

Figura 8.1: Esquema de modelo geológico-genético de las mineralizaciones barítico-polimetálicas de la región de Colipilli. Sin escala. 


\section{Modelo Genético}

En la región de Colipilli se ha implantado un significativo conjunto de sistemas hidrotermales polimetálicos vinculados espacialmente a la extendida secuencia eocretácica y a destacados cuerpos intrusivos. Presentan un carácter estratoligado en el cual los horizontes carbonáticos, y en menor medida silicoclásticos, han desempeñado un rol determinante en la generación de las mineralizaciones. El estudio detallado de los depósitos minerales permite considerar que su formación estuvo acompañada por la circulación de fluidos hidrotermales, la migración-expulsión de hidrocarburos, la actividad magmática y la deformación cretácico-terciarias del área. Ahora bien, cabe hacerse una pregunta de importancia crucial: ¿Cuál es la fuente de los fluidos ricos en Ba y Sr?

Fluidos enriquecidos en bario y estroncio pueden provenir fundamentalmente de: (1) la liberación de fluidos durante la deshidratación del yeso (Orti et al., 2002); (2) salmueras de cuenca que lixiviaron el estroncio y bario de los feldespatos de los estratos arcósicos (Scholle et al., 1990) como también de micas y de rocas volcánicas y volcaniclásticas; (3) salmueras generadas por disolución de evaporitas (Hitzman et al., 1996, 2002), (4) la sucesión de estratos rojos "red beds" suprayacentes al sistema carbonático-evaporítico, en la que la circulación de aguas meteóricas pudieron lixiviar estroncio y bario (Taberner et al., 2002).

Por otro lado, durante los eventos de máxima inundación, la depositación de pelitas negras ("black shales") pudo enriquecerse en elementos metálicos y convertirse en fuente para la generación de fluidos con contenidos anómalos de metales Ruffell (1998).

Llambías y Malvicini (1978), sin más datos que los provenientes de observaciones de campo y estudios petrocalcográficos, fueron los primeros en postular un significativo esquema genético para las mineralizaciones barítico-polimetálicas del área de Colipilli considerando que el magmatismo terciario actuó solo como agente removilizador de elementos de la secuencia sedimentaria, originando yacimientos hidrotermales, es decir, depositados por soluciones acuosas calientes constituidas por aguas meteóricas o connatas, calentadas.

Las inclusiones fluidas (IF) entrampadas en las mineralizaciones estudiadas (mantiformes y vetiformes) indican que los fluidos están constituidos por los siguientes sistemas salinos: $\mathrm{NaCl}-\mathrm{H}_{2} \mathrm{O}, \quad \mathrm{NaCl}-\mathrm{CaCl}_{2}, \quad \mathrm{NaCl}-\mathrm{CaCl}_{2}-\mathrm{H}_{2} \mathrm{O}, \quad \mathrm{NaCl}-\mathrm{MgCl}_{2}-\mathrm{H}_{2} \mathrm{O}$ metaestable, $\mathrm{NaCl}-\mathrm{KCl}-\mathrm{H}_{2} \mathrm{O}$ metaestable, los cuales sugieren una composición de fluidos 
con más de un componente, siendo el sistema más frecuente el $\mathrm{NaCl}-\mathrm{H}_{2} \mathrm{O}$. Por otro lado los datos de $\delta^{34} \mathrm{~S}$ obtenidos en baritina, de ambas yacencias, muestran una clara tendencia a tener valores más altos que los correspondientes a las anhidritas del Cretácico Temprano, según el rango establecido por Claypool et al. (1980). Si se considera que los fluidos mineralizantes podrían haber derivado de aguas formacionales, esta diferencia entre los valores isotópicos hallados podría deberse a un cierto fraccionamiento isotópico del $\mathrm{S}$ en las baritinas estudiadas probablemente debido a reducción por actividad bacteriana (BSR) (Seal II 2006), ya que el desarrollo del metabolismo bacteriano es beneficiado por la presencia de hidrocarburos. Además, otro proceso que produce grandes cantidades de $\mathrm{H}_{2} \mathrm{~S}$, en presencia de materia orgánica, es la reducción termoquímica del sulfato (TSR). A diferencia de la BSR, este proceso es más eficiente a temperaturas superior de las $110^{\circ} \mathrm{C}$, ambiente en el cuál las bacterias de tipo cianobacterias ya no actúan. A partir de dichas consideraciones las evaporitas de la Formación Huitrín podrían haber sido la fuente de salmueras sulfuradas capaces de transportar los elementos metálicos (hierro, plomo, cinc, cobre) y proveer el azufre. En este sentido, las aguas de las Formaciones Vaca Muerta, Los Molles y Agrio (secuencias pelíticas oscuras ubicadas en posición subyacente a las mineralizaciones estudiadas) podrían haber contribuido con dichas salmueras. En cuanto a la procedencia del bario y estroncio podrían derivar de Formaciones carbonáticoevaporíticas representadas tanto por la Formación Huitrín como así también por las Formaciones Auquilco y/o Tábanos (Lo Forte et al., 2005), que están por debajo del nivel mineralizado y/o silicoclásticas representadas por la Formación Rayoso y/o Grupo Neuquén, que se encuentran en posición suprayacente a la Formación Huitrín.

Ahora bien, surge una nueva pregunta: ¿Cómo circularon los fluidos? La circulación de los fluidos está condicionada por las diferencias de presión y densidad del fluido, por las características geológico-estructurales en las cuales se encuentran (Hanor 1987) y/o por la presencia de una fuente de calor (Staude et al., 2009), que en nuestro caso podría estar dado por los cuerpos ígneos del magmatismo del Grupo Naunauco (Fig.8.1). El primer mecanismo de movilización de los fluidos depende del estadio de evolución en el que se encuentra la cuenca y del momento de la movilización y expulsión de los fluidos. Considerando la combinación de estos factores, puede generarse un flujo de agua connata al que se puede sumar la compactación de sedimentos (Jackson y Beales 1967) y esfuerzos tectónicos (Sharp 1978). 
Se considera que como consecuencia, quizás, de un fuerte gradiente hidrostático en una espesa pila sedimentaria carbonático-evaporítica-silicoclástica, los fluidos cuencales comenzaron inicialmente a circular (Fig.8.1), a enriquecerse en elementos metalíferos $(\mathrm{Ba}>>\mathrm{Fe}>\mathrm{Pb}>\mathrm{Zn}>\mathrm{Cu}>\mathrm{Sr}$ ) y a reaccionar con rocas geoquímicamente receptivas (de Barrio et al., 2014). En forma muy puntual, en las rocas carbonáticas (mudstones) del Miembro Chorreado se desarrollaron procesos de reemplazo metasomático formándose los depósitos de hierro de mina Augusta y Naunauco. En estas mineralizaciones, los datos químicos provenientes de estudios por microsonda electrónica (muy bajos tenores de $\mathrm{TiO}_{2}$ ) sumados a los isótopos de oxígeno, apuntan a un origen no magmático para los fluidos responsables de ese metasomatismo. Por su parte, en las areniscas del Miembro Troncoso Inferior se produjeron procesos de relleno y reemplazo, mientras que en el Miembro Troncoso Superior, los procesos de relleno/reemplazo generaron la textura cebrada. Los resultados obtenidos por microtermometría y fluorescencia en la baritina mantiforme revelan temperaturas entre $156,2^{\circ}$ y $176^{\circ} \mathrm{C}$ e indican que los fluidos de este primer evento mineralizante, al momento de la precipitación, estaban constituidos por un sistema acuoso inorgánico y otro orgánico, entrampados en distintas proporciones, constituyendo un sistema polifásico (heterogéneo).

Ahora bien, en la actualidad los depósitos tipo Mississippi Valley (MVT) se consideran como parte de la evolución de una cuenca sedimentaria. Los fluidos presentes en dicha cuenca pueden desplazarse como respuesta al: gradiente hidrostático causado por compactación, al gradiente geotérmico, al relieve, a la deformación, entre otros factores (Anderson y Macqueen 1982). Tales procesos provocan el cambio constante en la composición química de los mencionados fluidos, condicionando la precipitación mineral y/o el reemplazo de minerales preexistentes. Tritlla et al. (2006) consignan que los depósitos MVT se dividen en distintos subtipos: Sensu-Stricto, Alpino-Apalachiano, Irlandés, Laisvall, Fluorítico y otros depósitos de posible afinidad como tipo Terlingua y filones con ganga carbonática. De todos ellos, el subtipo Laisvall, se caracteriza por presentar mineralizaciones de $\mathrm{Pb}>\mathrm{Zn}(\mathrm{Cu})$ alojadas en areniscas, conglomerados o arcosas, tanto de origen continental como litoral, que pasan a carbonatos marinos y/o evaporitas y que se disponen mediando una discordancia sobre un zócalo granítico o gnéisico, generalmente rico en plomo (Bjorlykke y Sangster 1981). Frecuentemente, las areniscas tienen tonalidades grisáceas por el ambiente reductor que viene favorecido por la presencia de materia orgánica. Los contenidos medios de $\mathrm{Pb}$ y $\mathrm{Zn}$ son 2 al 5\% y 0,2 al 0,8\%, 
respectivamente. Algunos de los minerales presentes son: galena, pirita, esfalerita, calcopirita, bravoíta, cerusita, baritina, cuarzo, freibergita, calcosina, entre otros, (Tritlla y Canals 1997). Con respecto a las temperaturas de homogeneización de las inclusiones fluidas del subtipo Laisvall varían desde los $35^{\circ} \mathrm{C}$ (Ngoyanadji 1988) a los $188^{\circ} \mathrm{C}$ (Wilbur et al., 1990 en Schrijver 1992), con una media que supera los $100^{\circ} \mathrm{C}$ en la mayoría de depósitos. Las salinidades son muy variables (entre 0,2 y $24,5 \%$ en peso equiv.de $\mathrm{NaCl}$ ), con un promedio que supera el $15 \%$ en peso equiv.de $\mathrm{NaCl}$.

Las mineralizaciones mantiformes del sector mina La Bienvenida comparten muchas características con los depósitos mencionados anteriormente, ya que se alojan en areniscas finas de coloraciones castaño claro, presentan contenidos de hasta $2,7 \%$ en $\mathrm{Pb}$ y cantidades máximas de 2,5\% en $\mathrm{Zn}$. Como minerales principales presentan baritina y galena y las temperaturas de homogeneización promedio son de $162,2^{\circ} \mathrm{C}$ con salinidades de 0,2 hasta $7,2 \%$ en peso equiv.de $\mathrm{NaCl}$. Cabe aclarar que se identificaron IF con cristales hijos, los cuales indican salinidades mayores a $23 \%$ en peso equiv. de $\mathrm{NaCl}$. Todos estos rasgos proponen una gran similitud con los depósitos MVT subtipo Laisvall.

Asimismo, en las mineralizaciones estratiformes baríticas alojadas en las calizas microbiales laminadas del Miembro Troncoso Superior (por ej. mina San Eduardo) se observa un fuerte carácter estratoligado, con procesos de relleno como de reemplazo. Sus formas son aproximadamente tabulares a lenticulares, con el desarrollo de ritmitas o texturas cebradas con olor fétido al ser golpeadas debido a la presencia de materia orgánica (hidrocarburos). Todos estos rasgos apuntan a una tipología MVT similar a la establecida por Tritlla et al. (2006) y González-Sánchez et al. (2009), entre otros, para los depósitos de $\mathrm{Pb}-\mathrm{Zn}$-Ba-Sr-F del estado de Coahuila, México.

La primera etapa de deformación representada por la generación de la Faja Plegada y Corrida del Agrio (FPyCA) fue en el Cretácico Tardío (Zamora Valcarce 2007) y la concomitante instauración del arco volcánico en el área de Colipilli (representada por filones capa, lacolitos, stocks, diques) deben haber creado las condiciones para incrementar la temperatura en las celdas convectivas donde las aguas formacionales pueden haber comenzado a recircular y a lixiviar elementos metálicos de toda la pila sedimentaria altamente reactiva (Fig.8.1). En fases posteriores, las reactivaciones tectonomagmáticas generaron replegamiento y reactivación de fallamiento de la secuencia eocretácica evidenciado en el campo a través de las estructuras flexuradas de los mantos baríticos y de las laminaciones de galena deformadas en el Miembro Troncoso Inferior. La intrusión de 
los cuerpos ígneos de la Formación Colipilli y los esfuerzos compresivos, desarrollaron un ambiente propicio para la removilización de las mineralizaciones y la formación de depósitos vetiformes que se alojaron en discontinuidades estratigráficas y en fajas de cizalla con la generación de estructuras brechosas y en mucha menor medida bandeadas (vetas La Bruja, Julio César y otras). Como resultado de esto, los espesores mineralizados no son importantes, rondando por lo general los $2 \mathrm{~m}$ de potencia. Las texturas predominantes que manifiestan dichos procesos están representadas por brechas constituidas por clastos de caliza laminada, en partes con textura cebrada, cementados por baritina de grano grueso (de hasta $5 \mathrm{~cm}$ de longitud) y con minerales metalíferos (galena, calcopirita, esfalerita). Todo el conjunto se encuentra impregnado por óxidos-hidróxidos de hierro y manganeso, que en algunos casos afectaron a la roca de caja produciendo stockworks hematítico-limoníticos.

La segunda etapa de deformación de la FPyCA ocurrida durante el Mioceno (Zamora Valcarce 2007), asociada fundamentalmente a la reactivación de las estructuras y actividad ígnea del Grupo Huantraico, puede haber promovido nuevos episodios de removilización y relleno. A su vez, dicha deformación posiblemente favoreció la migración de $\mathrm{H}_{2} \mathrm{~S}$ desde la Formación Vaca Muerta y/o Formación Agrio. Por este motivo, la morfología de los cuerpos de roca de caja y la estructuración de la región en ese momento, influenciaron de manera directa en la geometría y distribución del pulso mineralizante de yacencia vetiforme, afectando a diversas unidades estratigráficas tales como las Formaciones Vaca Muerta, Mulichinco, Agrio e inclusive a rocas magmáticas del Grupo Naunauco (por ejemplo en el área de Cerro El Diablo). Por otra parte, la composición química de dicho sulfato definida por análisis por microsonda electrónica evidencia un menor contenido de estroncio en relación a la baritina presente en los mantos. Esto se explica por los procesos de removilización que ocurrieron, ya que el estroncio es más móvil en comparación con el bario. En cuanto a las salinidades de los depósitos estudiados (mantiformes y vetiformes) en promedio son de $6,0 \%$ y $7,3 \%$ en peso equiv. de $\mathrm{NaCl}$, respectivamente. Estos bajos a moderados valores son menores a los esperados para salmueras cuencales típicas. Sin embargo, pueden ser consecuencia del desarrollo de los mencionados procesos de reducción termoquímica del sulfato (TSR) de acuerdo a los estudios realizados por Worden et al. (1996), quienes postulan que la TSR puede diluir hasta cinco veces la salinidad original de los fluidos. 
En la Figura 8.2 se muestra la secuencia paragenética integrada propuesta para las mineralizaciones estudiadas en la presente Tesis, junto con el contexto estructural del área de estudio.

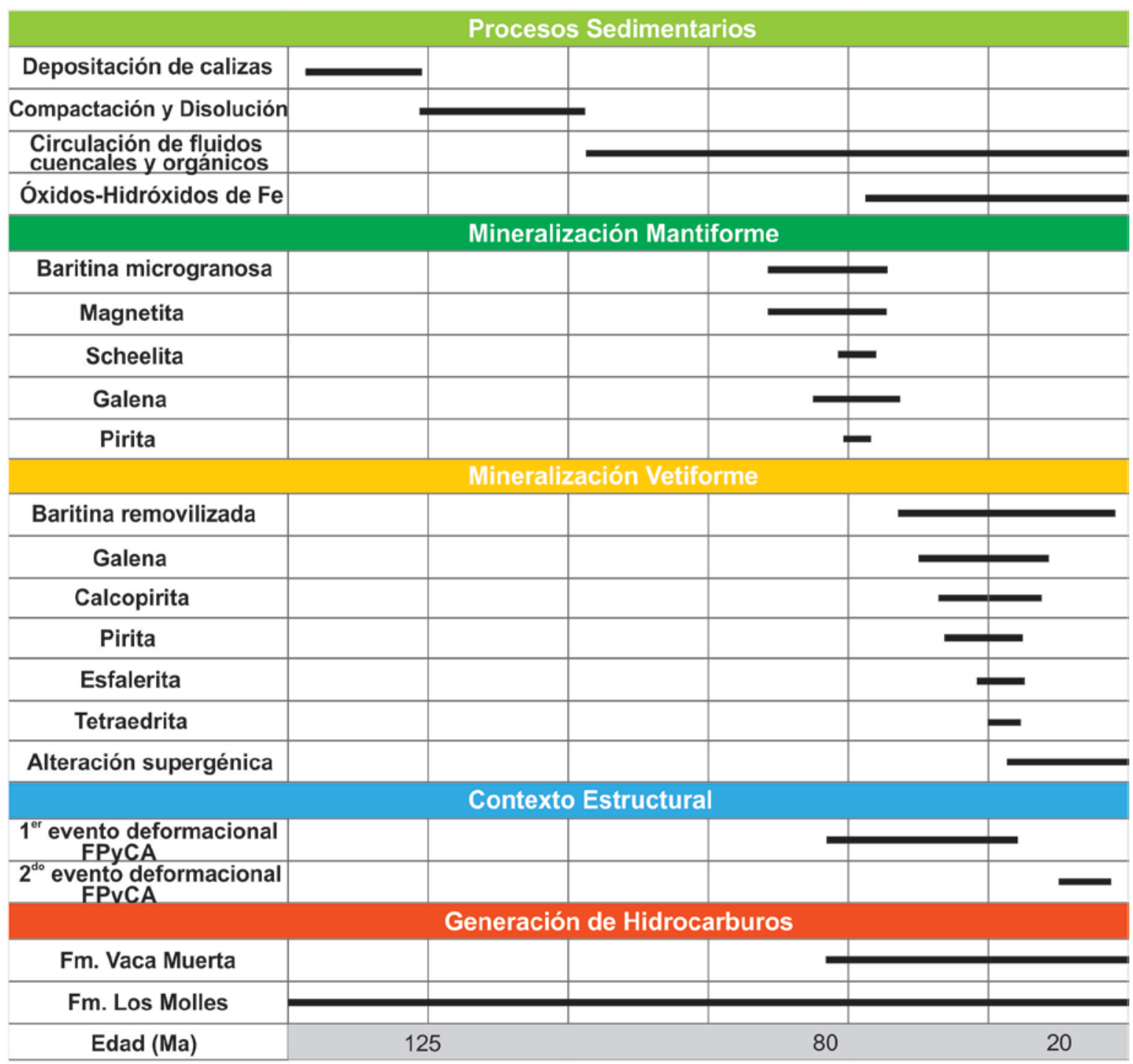

Figura 8.2: Secuencia paragenética del área de Colipilli. 


\section{Conclusiones finales}

De acuerdo a los resultados expuestos en los capítulos anteriores y al modelo genético precedente, se concluye lo siguiente:

- La mineralización barítico-polimetálica se aloja siguiendo un definido intervalo litoestratigráfico del Cretácico Temprano, revelando un carácter estratoligado. Los depósitos estratiformes con mineralización esencialmente de $\mathrm{Ba}-\mathrm{Fe}-\mathrm{Pb}$ son epigenéticos y se alojan mayoritariamente en las facies carbonáticas de tipo grainstone oolítico y mudstone del Miembro Chorreado, arenosas finas silicoclásticas pertenecientes al Miembro Troncoso Inferior y carbonáticas de tipo boundstone del Miembro Troncoso Superior de la Formación Huitrín. Dichas litologías son porosas y permeables, por lo que constituyen canales muy propicios para la circulación de los fluidos mineralizantes. Por otra parte, las yacencias vetiformes se hospedan en niveles estratigráficos subyacentes a las mineralizaciones anteriores (Formaciones Vaca Muerta, Mulichinco y Agrio), aunque en sectores localizados, afectan a la Formación Huitrín, a través de estructuras brechosas donde aumenta la complejidad composicional en elementos metalíferos. También se hospedan en las rocas ígneas del Grupo Naunauco y en los contactos roca sedimentariaígnea.

- Las mineralizaciones se encuentran en los flancos de las grandes estructuras anticlinales, las cuales forman parte de la FPyCA, estructurada como resultado de la deformación andina en el Cretácico Tardío, marcando un definido control estructural.

- En las calizas con laminación microbial del Miembro Troncoso Superior se desarrolló textura cebrada constituida esencialmente por la alternancia de bandas de baritina con carbonatos. Su génesis ha involucrado procesos de relleno y reemplazo observados tanto macro como microscópicamente.

- Las características estratigráficas, mineralógicas y texturales de los depósitos en el sector de mina La Bienvenida, son similares a los depósitos MVT subtipo Laisvall, mientras que los rasgos geológicos observados en las mineralizaciones estratiformes de mina San Eduardo, parecen asimilarse a una tipología MVT al estilo de los depósitos del Noreste de México.

- La baritina que integra la yacencia mantiforme, generada a temperaturas de homogeneización entre $156,2^{\circ}$ y $176^{\circ} \mathrm{C}$, representaría el primer pulso mineralizante. 
- El segundo estadio de mineralización es barítico-polimetálico y se asocia al primer evento tectonomagmático de la cuenca, mientras que los sucesivos pulsos de mineralización se vincularon a la reactivación de la deformación de la FPyCA. Son de yacencia vetiforme y se formaron a temperaturas mayores que los depósitos mantiformes (entre $163^{\circ}$ y $280,6^{\circ} \mathrm{C}$ ).

- La intrusión de los cuerpos ígneos del Cretácico Tardío-Paleoceno pudo haber aportado el calor suficiente para reactivar las celdas convectivas desarrolladas en las aguas formacionales. Éstas, estarían directamente involucradas en la lixiviación de los elementos metálicos de la pila sedimentaria, constituida en gran parte por rocas carbonáticas, yesíferas y silicoclásticas altamente reactivas.

- En los depósitos de mina Augusta se detectó el reemplazo metasomático de hematita generándose mushketovita, una variedad laminar pseudomórfica de magnetita, que representa la segunda cita de su hallazgo en Argentina.

- Los valores isotópicos de $\delta^{18} \mathrm{O}_{\mathrm{SMOW}} \mathrm{y} \delta^{34} \mathrm{~S}_{\mathrm{CDT}}$ en baritina se encuentran entre $+10,4 \%$ y $+17,0 \%$ y entre $+15,3 \%$ y $+23,4 \%$, respectivamente, mientras que las determinaciones isotópicas realizadas en galena arrojaron valores marcadamente negativos de $\delta^{34} \mathrm{~S}_{\mathrm{CDT}}$ entre $-10,6 \%$ y $-18,6 \%$, sin encontrarse grandes diferencias entre las yacencias mantiformes y las vetiformes.

- El azufre de los sulfuros estuvo muy posiblemente relacionado tanto a procesos de reducción bacteriana del sulfato catalizados por la presencia de materia orgánica en el sistema, como a reducción termoquímica por acción de la presencia de HC. Sus valores altamente negativos apuntan a un origen no magmático.

- Las aguas formacionales serían las responsables de la lixiviación de los elementos metálicos de la pila sedimentaria (esencialmente $\mathrm{Ba}$ de rocas silicoclásticas y carbonáticas) y el azufre (proveniente de unidades evaporíticas). Por otro lado, la procedencia del $\mathrm{Pb}$ podría estar relacionada a las secuencias pelíticas de interior de cuenca (Formaciones Vaca Muerta, Los Molles y Agrio). Todos estos fluidos deben haber circulado a través de las estructuras falladas y plegadas activas. 
En definitiva, las mineralizaciones barítico-polimetálicas del área de Colipilli presentan un carácter estratoligado, epigenético, en yacencias estratiformes y vetiformes, con texturas laminadas cebradas y brechosas predominantes según la intensidad de los procesos actuantes, los cuales han sido de relleno y reemplazo y con sucesivas reactivaciones tectónicas. Están asociadas a fluidos hidrotermales de temperaturas oscilantes entre $156,2^{\circ}$ y $280,6^{\circ} \mathrm{C}$, con salinidades bajas a moderadas. Se considera que el magmatismo cretácico-terciario ha tenido un papel preponderante en la movilización de los fluidos cuencales, pero sin aportar elementos de procedencia ígnea. No se descarta la posibilidad de la mezcla de las aguas formacionales hidrotermales con aguas meteóricas.

En los sistemas hidrotermales de la región de Colipilli el Ba ha sido el elemento metálico de mucha mayor abundancia, con una disponibilidad moderada de Fe y reducida de $\mathrm{Pb}>\mathrm{Zn}>\mathrm{Cu}$. 


\section{Trabajos citados en el texto}

Anderson, J.M. y Macqueen, R.W. 1988. Mississippi Valley-Type Lead Zinc Deposits., en Roberts, R.G., Sheahan, P.A. (Ed.), Ore Deposit Models: Geoscience Canada Reprint Series 3, 7990.

Bjorlykke, A. y Sangster, D.F. 1981. An overview of sanstone lead desposits and their relation to red-bed copper and carbonate-hosted lead-zinc deposits: Economic Geology 75th Anniversary Volume, 179-213.

Claypool, G.E., Holser, W.T., Kaplan, I.R., Sakai, H. y Zak, I. 1980. The age curves of sulfur and oxygen isotopes in marine sulfate and their mutual interpretation. Chemical Geology, 28: 199-260, Amsterdam.

de Barrio, R.E., Etcheverry, R.O., del Blanco, M.A., Domínguez, E.A., Recio Hernández, C., Escobar, R.I. y Salvioli, M.A. 2014. Nuevos datos y esquemas genéticos de los depósitos barítico-celestínicos vinculados a la secuencia Jurásico-Cretácica de la Cuenca Neuquina en la provincia del Neuquén. Revista de la Asociación Geológica Argentina, 71: 184-200, Buenos Aires.

González-Sánchez, F., Camprubí, A., González-Partida, E., Puente-Solís, R., Canet, C., Centeno-García, E. y Atudorei, V. 2009. Regional stratigraphy and distribution of epigenetic stratabound celestine, fluorite, barite and $\mathrm{Pb}-\mathrm{Zn}$ deposits in the MVT province of northeastern Mexico. Mineralium Deposita 44:343-361.

Hanor, J.S. 1987. Origin and migration of subsurface sedimentary brines. Lecture notes for short course $\mathrm{N}^{\circ} 21$. Sponsored by Society of Economic Paleontologists and Mineralogists, $247 \mathrm{p}$.

Hanor, J.S. 2000. Barite-celestine geochemistry and environment of formation. Sulfate mineralsCrystallography, geochemistry and environmental significance. Reviews in Mineralogy and Geochemistry, 40: 193-275.

Hanor, J.S. 2004. A model for the origin of large carbonate- and evaporite-hosted celestine $\left(\mathrm{SrSO}_{4}\right)$ deposits. Journal of Sedimentary Research, 74: 168-175.

Hitzman, M.W. y Beaty, D.W. 1996. The Irish Zn-Pb-(Ba) ore field. En: Carbonate-hosted leadzinc deposits (Ed. D.F. Sangster), Society of Economic Geologists Special Volume, 4: $112-143$

Hitzman, M.W., Redmond, P.B. y Beaty, D.W. 2002. The carbonate-hosted Lisheen Zn-Pb-Ag deposit, County Tipperary, Ireland: Economic Geology, 97: 1627-1655.

Jackson, S.A. y Beales, F.W. 1967. An aspect of sedimentary basin evolution: the concentration of Mississippi Valley-type ores during the late stages of diagenesis. Bulletin of the Canadian Society of Petroleum Geologists, 15: 393-433. 
Kesler, S.E. y Jones, L.M. 1981. Sulfur- and strontium-isotopic geochemistry of celestite, barite and gypsum from the Mesozoic basins of North-Eastern Mexico. Chemical Geology, 31: $211-224$

Llambías, E.J. y Malvicini, L. 1978. Geología, petrología y metalogénesis del área de Colipilli, provincia del Neuquén, República Argentina. Revista de la Asociación Geológica Argentina, 33: 257-276.

Lo Forte, G.L., Orti, F. y Rosell, L. 2005. Isotopic characterization of Jurassic evaporites. Aconcagua-Neuquén Basin, Argentina. Geológica Acta 3- 2: 155-161.

Ngoyanadji, N. 1988. Le gisement de Pb-Zn de Largentière (Ardèche- France): apport de l'étude des inclusions fl uides et des isotopes du soufre au problème de sa genèse, Nancy, France, National Polytechnique de Lorraine, Tesis Doctoral (Inédito).

Orti, F., Helvaci, C., Rosell, L. y Gundogan, I. 2002. Sodium sulphate deposits of Neogene age: the Kirmir Formation, Beypazari Basin, Turkey: Sedimentary Geology, 146: 305-355.

Ruffell, A. 1998. Tectonic accentuation of sequence boundaries: evidence from the Lower Cretaceous of southern England. En: Development, Evolution and Petroleum Geology of the Wessex Basin. (Ed. J.R. Underhill), Geological Society Special Publication, 133: 331348.

Schrijver, K. 1992. Basinal brines and groundwaters as possible metal carriers in the formation of sandstone-hosted lead-zinc deposits: Mineralium Deposita, 27: 109-114.

Scholle, P.A., Stemmerik, L. y Harpoth, O. 1990. Origin of major karst-associated celestite mineralization in Karstrynggen, Central East Greenland. Journal of Sedimentary Petrology, 60: 397-410.

Seal II, R.R. 2006. Sulfur Isotope Geochemistry of Sulfide Minerals. Reviews in Mineralogy and Geochemistry 61: 633-677.

Sharp, J.M. 1978. Energy and momentum transport model of the Ouachita basin and its posible impact on formation of economic mineral deposits. Economic Geology, 73: 1057-1068.

Staude, S., Bons. P.D. y Markl, G. 2009. Hydrothermal vein formation by extension-driven dewatering of the middle crust: an example from SW Germany. Earth and Planetary Science Letters, 286: 387-395.

Taberner, C., Marshall, J.D., Hendry, J.P., Pierre, C. y Thirwall, M.F. 2002. Celestite formation, bacterial sulphate reduction and carbonate cementation of Eocene reefs and basinal sediments (Igualada, NE Spain). Sedimentology, 49: 171-190.

Torres Ruiz, J. 2008. Depósitos de celestina de la depresión de Granada (Yacimientos Montevive y Escúzar). Master en Geología y Gestión Ambiental de Recursos Minerales. Universidad Internacional de Andalucía. (Inédito). 12 p. 
Tritlla, J. y Canals, A. 1997. Mineralizaciones estratoligadas de metales de base en carbonatos, rocas siliciclásticas, en J.C. Melgarejo (Ed.), Atlas de Asociaciones Minerales en Lámina Delgada: Barcelona, Edicions de la Universitat de Barcelona, 273-286.

Tritlla, J., Levresse, G., Corona-Esquivel, R., Banks, D., Lamadrid, H. y Bourdet, J. 2006. Depósitos de $\mathrm{Pb}-\mathrm{Zn}$-Cu-Ba-F-Sr epigenéticos estratoligados en series sedimentarias en relación a salmueras de Cuenca: depósitos de tipo "Mississippi Valley" (MVT) y similares en México. Boletín de la Sociedad Geológica Mexicana, 58: 103-139.

Worden, R.H., Smalley, P.C y Oxtoby, N.H. 1996. The effects of thermochemical sulfate reduction upon formation water salinity and oxygen isotopes in carbonate gas reservoirs. Geochimica et Cosmochimica Acta, Vol. 60: 3925-3931, USA.

Zamora Valcarce, G. 2007. Estructura y cinemática de la faja plegada del Agrio. Tesis doctoral, Universidad de Buenos Aires. (Inédito). 304 p. 
ANEXOS 


\section{ANEXO 1:}

Coordenadas geográficas de las rocas ígneas analizadas petrográficamente 
Ubicación de las rocas ígneas analizadas petrográficamente.

\begin{tabular}{|c|c|c|c|}
\hline & Sector & \multicolumn{2}{|c|}{ Ubicación } \\
\hline \multirow{31}{*}{ Formación Colipilli } & \multirow{8}{*}{ San Eduardo } & $70^{\circ} 20^{\prime} 52^{\prime \prime}$ & $37^{\circ} 43^{\prime} 47^{\prime \prime}$ \\
\hline & & $70^{\circ} 20^{\prime} 49^{\prime \prime}$ & $37^{\circ} 43^{\prime} 48^{\prime \prime}$ \\
\hline & & $70^{\circ} 20^{\prime} 44^{\prime \prime}$ & $37^{\circ} 43^{\prime} 52^{\prime \prime}$ \\
\hline & & $70^{\circ} 20^{\prime} 44^{\prime \prime}$ & $37^{\circ} 43^{\prime} 52^{\prime \prime}$ \\
\hline & & $70^{\circ} 20^{\prime} 50^{\prime \prime}$ & $37^{\circ} 43^{\prime} 48^{\prime \prime}$ \\
\hline & & $70^{\circ} 20^{\prime} 52^{\prime \prime}$ & $37^{\circ} 43^{\prime} 47^{\prime \prime}$ \\
\hline & & $70^{\circ} 20^{\prime} 24^{\prime \prime}$ & $37^{\circ} 43^{\prime} 31^{\prime \prime}$ \\
\hline & & $70^{\circ} 19^{\prime} 16^{\prime \prime}$ & $37^{\circ} 44^{\prime} 36^{\prime \prime}$ \\
\hline & \multirow{5}{*}{$\mathrm{c}^{\circ}$ Chihuido } & $70^{\circ} 20^{\prime} 53^{\prime \prime}$ & $37^{\circ} 43^{\prime} 56^{\prime \prime}$ \\
\hline & & $70^{\circ} 20^{\prime} 52^{\prime \prime}$ & $37^{\circ} 44^{\prime} 12^{\prime \prime}$ \\
\hline & & $70^{\circ} 20^{\prime} 55^{\prime \prime}$ & $37^{\circ} 44^{\prime} 11^{\prime \prime}$ \\
\hline & & $70^{\circ} 20^{\prime} 58^{\prime \prime}$ & $37^{\circ} 44^{\prime} 02^{\prime \prime}$ \\
\hline & & $70^{\circ} 20^{\prime} 52^{\prime \prime}$ & $37^{\circ} 44^{\prime} 12^{\prime \prime}$ \\
\hline & \multirow{10}{*}{$\mathrm{c}^{\circ}$ Negro } & $70^{\circ} 18^{\prime} 13^{\prime \prime}$ & $37^{\circ} 42^{\prime} 51^{\prime \prime}$ \\
\hline & & $70^{\circ} 18^{\prime} 24^{\prime \prime}$ & $37^{\circ} 43^{\prime} 01^{\prime \prime}$ \\
\hline & & $70^{\circ} 19^{\prime} 22^{\prime \prime}$ & $37^{\circ} 43^{\prime} 02^{\prime \prime}$ \\
\hline & & $70^{\circ} 18^{\prime} 32^{\prime \prime}$ & $37^{\circ} 43^{\prime} 10^{\prime \prime}$ \\
\hline & & $70^{\circ} 18^{\prime} 49^{\prime \prime}$ & $37^{\circ} 42^{\prime} 17^{\prime \prime}$ \\
\hline & & $70^{\circ} 20^{\prime} 14^{\prime \prime}$ & $37^{\circ} 42^{\prime} 53^{\prime \prime}$ \\
\hline & & $70^{\circ} 18^{\prime} 32^{\prime \prime}$ & $37^{\circ} 43^{\prime} 00^{\prime \prime}$ \\
\hline & & $70^{\circ} 20^{\prime} 39^{\prime \prime}$ & $37^{\circ} 42^{\prime} 59^{\prime \prime}$ \\
\hline & & $70^{\circ} 20^{\prime} 40^{\prime \prime}$ & $37^{\circ} 42^{\prime} 58^{\prime \prime}$ \\
\hline & & $70^{\circ} 18^{\prime} 24^{\prime \prime}$ & $37^{\circ} 43^{\prime} 06^{\prime \prime}$ \\
\hline & \multirow{4}{*}{$c^{\circ}$ Los Bueyes } & $70^{\circ} 22^{\prime} 45^{\prime \prime}$ & $37^{\circ} 42^{\prime} 43^{\prime \prime}$ \\
\hline & & $70^{\circ} 21^{\prime} 52^{\prime \prime}$ & $37^{\circ} 44^{\prime} 54^{\prime \prime}$ \\
\hline & & $70^{\circ} 22^{\prime} 15^{\prime \prime}$ & $37^{\circ} 44^{\prime} 14^{\prime \prime}$ \\
\hline & & $70^{\circ} 21^{\prime} 56^{\prime \prime}$ & $37^{\circ} 45^{\prime} 20^{\prime \prime}$ \\
\hline & \multirow{2}{*}{ ruta pcial. 4} & $70^{\circ} 16^{\prime} 39^{\prime \prime}$ & $37^{\circ} 44^{\prime} 15^{\prime \prime}$ \\
\hline & & $70^{\circ} 13^{\prime} 42^{\prime \prime}$ & $37^{\circ} 39^{\prime} 05^{\prime \prime}$ \\
\hline & \multirow{2}{*}{$c^{\circ}$ Naunauco } & $70^{\circ} 14^{\prime} 11^{\prime \prime}$ & $37^{\circ} 33^{\prime} 53^{\prime \prime}$ \\
\hline & & $70^{\circ} 14^{\prime} 10^{\prime \prime}$ & $37^{\circ} 33^{\prime} 55^{\prime \prime}$ \\
\hline \multirow{9}{*}{ Formación Cayanta } & \multirow{8}{*}{ San Eduardo } & $70^{\circ} 20^{\prime} 47^{\prime \prime}$ & $37^{\circ} 43^{\prime} 48^{\prime \prime}$ \\
\hline & & $70^{\circ} 19^{\prime} 39^{\prime \prime}$ & $37^{\circ} 44^{\prime} 51^{\prime \prime}$ \\
\hline & & $70^{\circ} 11^{\prime} 35^{\prime \prime}$ & $37^{\circ} 29^{\prime} 51^{\prime \prime}$ \\
\hline & & $70^{\circ} 20^{\prime} 50^{\prime \prime}$ & $37^{\circ} 43^{\prime} 46^{\prime \prime}$ \\
\hline & & $70^{\circ} 20^{\prime} 47^{\prime \prime}$ & $37^{\circ} 43^{\prime} 49^{\prime \prime}$ \\
\hline & & $70^{\circ} 11^{\prime} 35^{\prime \prime}$ & $37^{\circ} 29^{\prime} 50^{\prime \prime}$ \\
\hline & & $70^{\circ} 20^{\prime} 50^{\prime \prime}$ & $37^{\circ} 43^{\prime} 47^{\prime \prime}$ \\
\hline & & $70^{\circ} 11^{\prime} 34^{\prime \prime}$ & $37^{\circ} 29^{\prime} 52^{\prime \prime}$ \\
\hline & ruta pcial. 4 & $70^{\circ} 17^{\prime} 07^{\prime \prime}$ & $37^{\circ} 44^{\prime} 42^{\prime \prime}$ \\
\hline
\end{tabular}




\section{ANEXO 2:}

Mapa geológico del área de estudio 


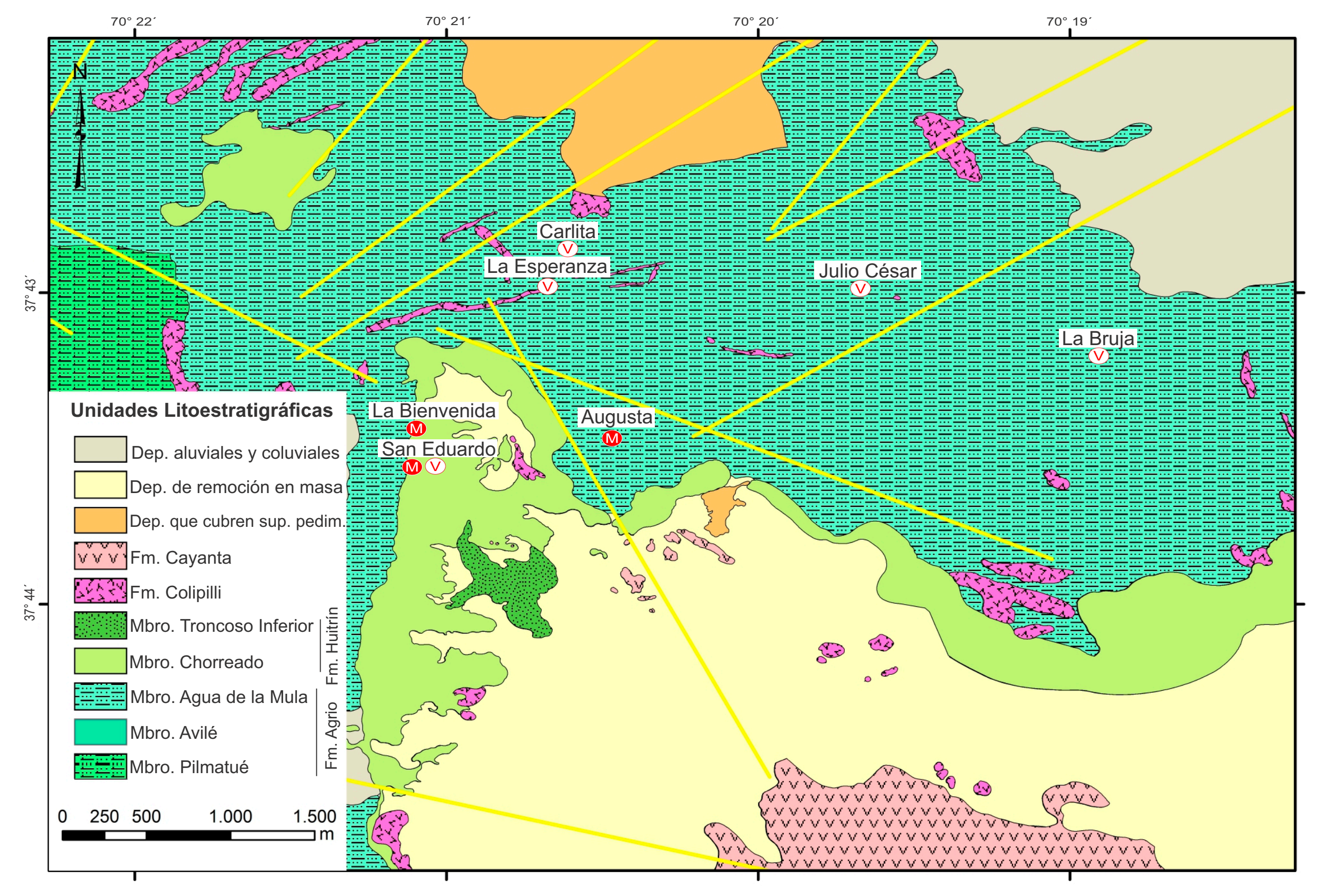




\section{ANEXO 3:}

\section{Análisis de baritina por microsonda electrónica}


Análisis de BARITINA por microsonda electrónica

\begin{tabular}{|c|c|c|c|c|c|c|}
\hline \multicolumn{7}{|c|}{ Muestra $\rightarrow 11227$ a (mina San Eduardo) } \\
\hline Yacencia $\rightarrow$ & Manto & Manto & Manto & Manto & Manto & Manto \\
\hline$\%$ en peso & 1 & 2 & 3 & 4 & 5 & 6 \\
\hline $\mathrm{FeO} *$ & 0,02 & b.1.d. & b.1.d. & 0,01 & 0,02 & b.l.d. \\
\hline MnO & b.1.d. & b.l.d. & b.l.d. & b.1.d. & b.1.d. & b.l.d. \\
\hline $\mathrm{CoO}$ & b.l.d. & b.l.d. & b.1.d. & b.l.d. & b.l.d. & b.l.d. \\
\hline MgO & 0,01 & b.l.d. & 0,01 & 0,01 & 0,00 & 0,02 \\
\hline $\mathrm{CaO}$ & 0,01 & 0,08 & 0,02 & 0,00 & 0,02 & 0,02 \\
\hline SrO & 0,55 & 1,75 & 1,95 & 0,24 & 1,65 & 0,86 \\
\hline $\mathrm{BaO}$ & 65,55 & 64,63 & 63,51 & 64,97 & 64,04 & 64,84 \\
\hline $\mathbf{P}_{2} \mathbf{O}_{5}$ & 0,01 & b.1.d. & b.1.d. & b.l.d. & b.l.d. & b.l.d. \\
\hline PbO & b.1.d. & b.l.d. & b.l.d. & 0,19 & b.l.d. & b.l.d. \\
\hline $\mathrm{SO}_{3}$ & 33,70 & 31,69 & 34,04 & 34,37 & 33,64 & 33,62 \\
\hline $\mathbf{F}$ & b.1.d. & b.1.d. & b.1.d. & 0,02 & b.1.d. & b.1.d. \\
\hline TOTAL & $\mathbf{9 9 , 8 5}$ & 98,15 & 99,53 & 99,81 & 99,38 & 99,35 \\
\hline
\end{tabular}

$*=$ asumido como $\mathrm{FeO}$ total. b.l.d. = bajo el límite de detección

Número de cationes en base a 4 oxígenos por unidad de fórmula

\begin{tabular}{|c|c|c|c|c|c|c|}
\hline \multicolumn{7}{|c|}{ Muestra $\rightarrow$ 11227a (mina San Eduardo) } \\
\hline \multicolumn{7}{|c|}{ Yacencia $\rightarrow$ Manto $\quad$ Manto $\quad$ Manto } \\
\hline c.p.u.f. & 1 & 2 & 3 & 4 & 5 & 6 \\
\hline $\mathrm{Fe}^{+2}$ & 0,0008 & 0,0000 & 0,0000 & 0,0004 & 0,0007 & 0,0000 \\
\hline Mn & 0,0000 & 0,0000 & 0,0000 & 0,0000 & 0,0000 & 0,0000 \\
\hline Co & 0,0000 & 0,0000 & 0,0000 & 0,0000 & 0,0000 & 0,0000 \\
\hline Mg & 0,0005 & 0,0000 & 0,0007 & 0,0006 & 0,0002 & 0,0012 \\
\hline $\mathbf{C a}$ & 0,0005 & 0,0031 & 0,0008 & 0,0000 & 0,0010 & 0,0007 \\
\hline Sr & 0,0122 & 0,0384 & 0,0435 & 0,0055 & 0,0367 & 0,0192 \\
\hline Ba & 0,9856 & 0,9586 & 0,9550 & 0,9915 & 0,9614 & 0,9790 \\
\hline $\mathbf{P}$ & 0,0002 & 0,0000 & 0,0000 & 0,0000 & 0,0000 & 0,0000 \\
\hline $\mathbf{P b}$ & 0,0000 & 0,0000 & 0,0000 & 0,0020 & 0,0000 & 0,0000 \\
\hline Suma & $\mathbf{0 , 9 9 9 7}$ & 1,0000 & 1,0000 & 1,0000 & 1,0000 & 1,0000 \\
\hline $\mathbf{S}$ & 0,9924 & 0,9730 & 0,9950 & 1,0011 & 0,9916 & 0,9929 \\
\hline TOTAL & 1,9921 & 1,9730 & 1,9950 & 2,0011 & 1,9916 & 1,9929 \\
\hline
\end{tabular}

Proporciones moleculares de los componentes finales

\begin{tabular}{lrrrrrr}
\hline Anhidrita & 0,05 & 0,31 & 0,08 & 0,00 & 0,10 & 0,07 \\
Celestina & 1,22 & 3,84 & 4,35 & 0,55 & 3,67 & 1,92 \\
Baritina & 98,72 & 95,86 & 95,57 & 99,45 & 96,23 & 98,01 \\
\hline TOTAL & $\mathbf{1 0 0 , 0 0}$ & $\mathbf{1 0 0 , 0 0}$ & $\mathbf{1 0 0 , 0 0}$ & $\mathbf{1 0 0 , 0 0}$ & $\mathbf{1 0 0 , 0 0}$ & $\mathbf{1 0 0 , 0 0}$ \\
\hline
\end{tabular}


Análisis de BARITINA por microsonda electrónica

\begin{tabular}{|c|c|c|c|c|c|c|}
\hline \multicolumn{7}{|c|}{ Muestra $\rightarrow 11227$ a (mina San Eduardo) } \\
\hline Yacencia $\rightarrow$ & Manto & Manto & Manto & Manto & Manto & Manto \\
\hline$\%$ en peso & 7 & 8 & 9 & 10 & 11 & 12 \\
\hline FeO* & 0,01 & b.l.d. & 0,01 & b.l.d. & b.1.d. & b.l.d. \\
\hline MnO & b.1.d. & b.l.d. & b.1.d. & b.l.d. & b.l.d. & b.l.d. \\
\hline $\mathrm{CoO}$ & b.l.d. & b.l.d. & b.l.d. & b.l.d. & b.l.d. & b.l.d. \\
\hline MgO & 0,01 & b.l.d. & b.l.d. & 0,01 & 0,02 & b.l.d. \\
\hline $\mathrm{CaO}$ & 0,03 & 0,03 & 0,02 & 0,11 & 0,01 & 0,01 \\
\hline SrO & 1,81 & 1,72 & 1,06 & 1,76 & 3,13 & 1,63 \\
\hline $\mathbf{B a O}$ & 63,98 & 63,65 & 64,33 & 63,22 & 62,96 & 63,93 \\
\hline $\mathbf{P}_{2} \mathbf{O}_{5}$ & b.l.d. & b.1.d. & 0,00 & b.1.d. & b.1.d. & b.1.d. \\
\hline PbO & b.l.d. & b.1.d. & b.l.d. & b.1.d. & b.1.d. & b.1.d. \\
\hline $\mathrm{SO}_{3}$ & 34,17 & 34,95 & 33,64 & 34,31 & 32,15 & 34,31 \\
\hline $\mathbf{F}$ & b.1.d. & 0,00 & b.1.d. & b.1.d. & 0,00 & 0,01 \\
\hline TOTAL & 100,02 & 100,35 & 99,06 & 99,40 & 98,27 & 99,89 \\
\hline
\end{tabular}

$*=$ asumido como $\mathrm{FeO}$ total. b.l.d. = bajo el límite de detección

Número de cationes en base a 4 oxígenos por unidad de fórmula

\begin{tabular}{|c|c|c|c|c|c|c|}
\hline \multicolumn{7}{|c|}{ Muestra $\rightarrow$ 11227a (mina San Eduardo) } \\
\hline \multicolumn{7}{|c|}{ Yacencia $\rightarrow$ Manto $\quad$ Manto $\quad$ Manto } \\
\hline c.p.u.f. & 7 & 8 & 9 & 10 & 11 & 12 \\
\hline $\mathrm{Fe}^{+2}$ & 0,0004 & 0,0000 & 0,0003 & 0,0000 & 0,0000 & 0,0000 \\
\hline Mn & 0,0000 & 0,0000 & 0,0000 & 0,0000 & 0,0000 & 0,0000 \\
\hline Co & 0,0000 & 0,0000 & 0,0000 & 0,0000 & 0,0000 & 0,0000 \\
\hline Mg & 0,0008 & 0,0000 & 0,0000 & 0,0006 & 0,0010 & 0,0000 \\
\hline $\mathbf{C a}$ & 0,0013 & 0,0011 & 0,0008 & 0,0044 & 0,0006 & 0,0004 \\
\hline Sr & 0,0402 & 0,0384 & 0,0237 & 0,0393 & 0,0684 & 0,0363 \\
\hline Ba & 0,9574 & 0,9605 & 0,9750 & 0,9557 & 0,9300 & 0,9632 \\
\hline $\mathbf{P}$ & 0,0000 & 0,0000 & 0,0001 & 0,0000 & 0,0000 & 0,0000 \\
\hline $\mathbf{P b}$ & 0,0000 & 0,0000 & 0,0000 & 0,0000 & 0,0000 & 0,0000 \\
\hline Suma & 1,0000 & 1,0000 & 0,9999 & 1,0000 & 1,0000 & 1,0000 \\
\hline $\mathbf{S}$ & 0,9948 & 1,0025 & 0,9940 & 0,9983 & 0,9757 & 0,9974 \\
\hline TOTAL & 1,9948 & 2,0025 & 1,9938 & 1,9983 & 1,9757 & 1,9974 \\
\hline
\end{tabular}

Proporciones moleculares de los componentes finales

\begin{tabular}{lrrrrrr}
\hline Anhidrita & 0,13 & 0,11 & 0,08 & 0,44 & 0,06 & 0,04 \\
Celestina & 4,02 & 3,84 & 2,37 & 3,93 & 6,85 & 3,63 \\
Baritina & 95,85 & 96,05 & 97,55 & 95,63 & 93,10 & 96,32 \\
\hline TOTAL & $\mathbf{1 0 0 , 0 0}$ & $\mathbf{1 0 0 , 0 0}$ & $\mathbf{1 0 0 , 0 0}$ & $\mathbf{1 0 0 , 0 0}$ & $\mathbf{1 0 0 , 0 0}$ & $\mathbf{1 0 0 , 0 0}$ \\
\hline
\end{tabular}


Análisis de BARITINA por microsonda electrónica

\begin{tabular}{|c|c|c|c|c|c|c|}
\hline \multicolumn{4}{|c|}{ Muestra $\rightarrow 11227$ a (mina San Eduardo) } & \multicolumn{3}{|c|}{ 11227b (mina S.E.) } \\
\hline Yacencia $\rightarrow$ & Manto & Manto & Manto & Manto & Manto & Manto \\
\hline$\%$ en peso & 13 & 14 & 15 & 16 & 1 & 2 \\
\hline FeO* & 0,02 & b.l.d. & 0,01 & b.l.d. & b.l.d. & 0,02 \\
\hline MnO & b.1.d. & b.l.d. & 0,00 & b.l.d. & b.l.d. & b.1.d. \\
\hline $\mathrm{CoO}$ & b.l.d. & b.1.d. & b.1.d. & b.l.d. & b.1.d. & b.l.d. \\
\hline MgO & b.1.d. & 0,02 & b.l.d. & 0,02 & 0,00 & 0,00 \\
\hline $\mathrm{CaO}$ & 0,03 & 0,06 & 0,03 & 0,07 & 0,05 & 0,04 \\
\hline SrO & 1,71 & 0,70 & 1,64 & 1,63 & 2,23 & 1,79 \\
\hline $\mathbf{B a O}$ & 64,34 & 65,01 & 63,26 & 64,48 & 63,27 & 63,81 \\
\hline $\mathbf{P}_{2} \mathbf{O}_{5}$ & b.l.d. & b.1.d. & b.1.d. & b.1.d. & b.1.d. & b.l.d. \\
\hline PbO & b.l.d. & b.l.d. & b.l.d. & b.l.d. & b.l.d. & b.l.d. \\
\hline $\mathrm{SO}_{3}$ & 34,15 & 33,30 & 35,19 & 34,71 & 35,09 & 35,20 \\
\hline $\mathbf{F}$ & 0,01 & b.1.d. & b.1.d. & b.1.d. & b.1.d. & 0,00 \\
\hline TOTAL & 100,26 & 99,08 & 100,14 & 100,91 & 100,64 & 100,87 \\
\hline
\end{tabular}

$*=$ asumido como FeO total. b.l.d. = bajo el límite de detección

Número de cationes en base a 4 oxígenos por unidad de fórmula

\begin{tabular}{|c|c|c|c|c|c|c|}
\hline \multicolumn{4}{|c|}{ Muestra $\rightarrow$ 11227a (mina San Eduardo) } & \multicolumn{3}{|c|}{ 11227b (mina S.E.) } \\
\hline Yacencia $\rightarrow$ & Manto & Manto & Manto & Manto & Manto & Manto \\
\hline c.p.u.f. & 13 & 14 & 15 & 16 & 1 & 2 \\
\hline $\mathrm{Fe}^{+2}$ & 0,0007 & 0,0000 & 0,0005 & 0,0000 & 0,0000 & 0,0007 \\
\hline Mn & 0,0000 & 0,0000 & 0,0001 & 0,0000 & 0,0000 & 0,0000 \\
\hline Co & 0,0000 & 0,0000 & 0,0000 & 0,0000 & 0,0000 & 0,0000 \\
\hline Mg & 0,0000 & 0,0009 & 0,0000 & 0,0011 & 0,0001 & 0,0001 \\
\hline $\mathbf{C a}$ & 0,0012 & 0,0024 & 0,0013 & 0,0029 & 0,0019 & 0,0016 \\
\hline $\mathrm{Sr}$ & 0,0378 & 0,0156 & 0,0368 & 0,0359 & 0,0494 & 0,0398 \\
\hline $\mathbf{B a}$ & 0,9603 & 0,9811 & 0,9613 & 0,9601 & 0,9485 & 0,9579 \\
\hline $\mathbf{P}$ & 0,0000 & 0,0000 & 0,0000 & 0,0000 & 0,0000 & 0,0000 \\
\hline $\mathbf{P b}$ & 0,0000 & 0,0000 & 0,0000 & 0,0000 & 0,0000 & 0,0000 \\
\hline Suma & 1,0000 & 1,0000 & 1,0000 & 1,0000 & 1,0000 & 1,0000 \\
\hline $\mathbf{S}$ & 0,9940 & 0,9904 & 1,0059 & 0,9974 & 1,0019 & 1,0029 \\
\hline TOTAL & 1,9940 & 1,9904 & 2,0059 & 1,9974 & 2,0019 & 2,0029 \\
\hline
\end{tabular}

Proporciones moleculares de los componentes finales

\begin{tabular}{lrrrrrr}
\hline Anhidrita & 0,12 & 0,24 & 0,13 & 0,29 & 0,19 & 0,16 \\
Celestina & 3,79 & 1,56 & 3,69 & 3,59 & 4,94 & 3,98 \\
Baritina & 96,10 & 98,20 & 96,18 & 96,12 & 94,86 & 95,86 \\
\hline TOTAL & $\mathbf{1 0 0 , 0 0}$ & $\mathbf{1 0 0 , 0 0}$ & $\mathbf{1 0 0 , 0 0}$ & $\mathbf{1 0 0 , 0 0}$ & $\mathbf{1 0 0 , 0 0}$ & $\mathbf{1 0 0 , 0 0}$ \\
\hline
\end{tabular}


Análisis de BARITINA por microsonda electrónica

\begin{tabular}{|c|c|c|c|c|c|c|}
\hline \multicolumn{7}{|c|}{ Muestra $\rightarrow 11227 b$ (mina San Eduardo) } \\
\hline \multicolumn{7}{|c|}{ Yacencia $\rightarrow \quad$ Manto $\quad$ Manto $\quad$ Manto } \\
\hline$\%$ en peso & 3 & 4 & 5 & 6 & 7 & 8 \\
\hline $\mathrm{FeO} *$ & 0,01 & 0,00 & 0,01 & b.l.d. & b.l.d. & 0,07 \\
\hline MnO & b.1.d. & b.1.d. & b.1.d. & b.l.d. & b.l.d. & b.1.d. \\
\hline $\mathrm{CoO}$ & b.l.d. & b.l.d. & b.l.d. & b.l.d. & b.l.d. & b.l.d. \\
\hline MgO & 0,01 & b.l.d. & 0,00 & b.l.d. & b.l.d. & 0,02 \\
\hline $\mathrm{CaO}$ & 0,03 & 0,02 & 0,04 & 0,01 & b.l.d. & 0,04 \\
\hline SrO & 1,44 & 2,03 & 1,30 & 1,00 & 0,58 & 1,51 \\
\hline $\mathrm{BaO}$ & 64,81 & 63,64 & 64,29 & 65,18 & 64,87 & 63,63 \\
\hline $\mathbf{P}_{2} \mathbf{O}_{5}$ & 0,05 & b.l.d. & b.1.d. & 0,05 & 0,10 & b.l.d. \\
\hline PbO & b.l.d. & b.l.d. & 0,08 & b.l.d. & b.l.d. & b.l.d. \\
\hline $\mathrm{SO}_{3}$ & 33,75 & 34,80 & 33,63 & 34,42 & 34,64 & 33,87 \\
\hline $\mathbf{F}$ & b.1.d. & 0,00 & 0,00 & 0,01 & 0,00 & b.l.d. \\
\hline TOTAL & 100,10 & 100,50 & 99,36 & 100,67 & 100,19 & 99,13 \\
\hline
\end{tabular}

$*=$ asumido como $\mathrm{FeO}$ total. b.l.d. = bajo el límite de detección

Número de cationes en base a 4 oxígenos por unidad de fórmula

\begin{tabular}{|c|c|c|c|c|c|c|}
\hline \multicolumn{7}{|c|}{ Muestra $\rightarrow 11227 b$ (mina San Eduardo) } \\
\hline Yacencia $\rightarrow$ & Manto & Manto & Manto & Manto & Manto & Manto \\
\hline c.p.u.f. & 3 & 4 & 5 & 6 & 7 & 8 \\
\hline $\mathrm{Fe}^{+2}$ & 0,0005 & 0,0001 & 0,0004 & 0,0000 & 0,0000 & 0,0022 \\
\hline Mn & 0,0000 & 0,0000 & 0,0000 & 0,0000 & 0,0000 & 0,0000 \\
\hline Co & 0,0000 & 0,0000 & 0,0000 & 0,0000 & 0,0000 & 0,0000 \\
\hline Mg & 0,0006 & 0,0000 & 0,0002 & 0,0000 & 0,0000 & 0,0010 \\
\hline $\mathbf{C a}$ & 0,0013 & 0,0009 & 0,0017 & 0,0005 & 0,0000 & 0,0015 \\
\hline $\mathbf{S r}$ & 0,0315 & 0,0451 & 0,0289 & 0,0220 & 0,0129 & 0,0337 \\
\hline $\mathbf{B a}$ & 0,9621 & 0,9540 & 0,9680 & 0,9731 & 0,9791 & 0,9616 \\
\hline $\mathbf{P}$ & 0,0016 & 0,0000 & 0,0000 & 0,0017 & 0,0032 & 0,0000 \\
\hline $\mathbf{P b}$ & 0,0000 & 0,0000 & 0,0008 & 0,0000 & 0,0000 & 0,0000 \\
\hline Suma & 0,9976 & 1,0000 & 1,0000 & 0,9974 & $\mathbf{0 , 9 9 5 3}$ & 1,0000 \\
\hline $\mathbf{S}$ & 0,9896 & 0,9997 & 0,9923 & 0,9960 & 1,0003 & 0,9950 \\
\hline TOTAL & 1,9871 & 1,9997 & 1,9923 & 1,9934 & 1,9955 & 1,9950 \\
\hline
\end{tabular}

Proporciones moleculares de los componentes finales

\begin{tabular}{lrrrrrr}
\hline Anhidrita & 0,13 & 0,09 & 0,17 & 0,05 & 0,00 & 0,15 \\
Celestina & 3,17 & 4,51 & 2,89 & 2,21 & 1,31 & 3,38 \\
Baritina & 96,71 & 95,40 & 96,93 & 97,74 & 98,69 & 96,47 \\
\hline TOTAL & $\mathbf{1 0 0 , 0 0}$ & $\mathbf{1 0 0 , 0 0}$ & $\mathbf{1 0 0 , 0 0}$ & $\mathbf{1 0 0 , 0 0}$ & $\mathbf{1 0 0 , 0 0}$ & $\mathbf{1 0 0 , 0 0}$ \\
\hline
\end{tabular}


Análisis de BARITINA por microsonda electrónica

\begin{tabular}{|c|c|c|c|c|c|c|}
\hline \multicolumn{4}{|c|}{ Muestra $\rightarrow 11227 b$ (mina San Eduardo) } & \multicolumn{3}{|c|}{1951 (mina San Eduardo) } \\
\hline Yacencia $\rightarrow$ & Manto & Manto & Manto & Veta & Veta & Veta \\
\hline \% en peso & 9 & 10 & 11 & 1 & 2 & 3 \\
\hline $\mathrm{FeO}^{*}$ & b.l.d. & 0,02 & 0,07 & b.l.d. & b.l.d. & b.l.d. \\
\hline MnO & b.l.d. & b.1.d. & b.1.d. & b.l.d. & b.l.d. & b.l.d. \\
\hline $\mathrm{CoO}$ & b.l.d. & b.l.d. & b.l.d. & 0,00 & b.l.d. & 0,05 \\
\hline MgO & 0,02 & b.l.d. & 0,02 & b.l.d. & b.l.d. & b.l.d. \\
\hline $\mathrm{CaO}$ & 0,02 & 0,02 & 0,01 & 0,00 & 0,02 & 0,05 \\
\hline SrO & 1,49 & 3,60 & 0,72 & 1,52 & 1,43 & 1,20 \\
\hline $\mathrm{BaO}$ & 64,36 & 61,74 & 65,46 & 63,87 & 64,13 & 64,37 \\
\hline $\mathbf{P}_{2} \mathbf{O}_{5}$ & b.1.d. & b.1.d. & b.1.d. & b.1.d. & b.1.d. & b.l.d. \\
\hline PbO & b.l.d. & b.l.d. & b.l.d. & b.l.d. & b.l.d. & b.l.d. \\
\hline $\mathrm{SO}_{3}$ & 34,48 & 33,76 & 33,91 & 34,32 & 33,94 & 34,71 \\
\hline $\mathbf{F}$ & b.1.d. & 0,01 & 0,01 & b.l.d. & b.1.d. & b.1.d. \\
\hline TOTAL & 100,37 & 99,15 & 100,20 & 99,72 & 99,52 & 100,37 \\
\hline
\end{tabular}

$*=$ asumido como $\mathrm{FeO}$ total. b.l.d. = bajo el límite de detección

Número de cationes en base a 4 oxígenos por unidad de fórmula

\begin{tabular}{|c|c|c|c|c|c|c|}
\hline \multicolumn{4}{|c|}{ Muestra $\rightarrow 11227 b$ (mina San Eduardo) } & \multicolumn{3}{|c|}{4951 (mina San Eduardo) } \\
\hline Yacencia $\rightarrow$ & Manto & Manto & Manto & Veta & Veta & Veta \\
\hline c.p.u.f. & 9 & 10 & 11 & 1 & 2 & 3 \\
\hline $\mathrm{Fe}^{+2}$ & 0,0000 & 0,0007 & 0,0022 & 0,0000 & 0,0000 & 0,0000 \\
\hline Mn & 0,0000 & 0,0000 & 0,0000 & 0,0000 & 0,0000 & 0,0000 \\
\hline Co & 0,0000 & 0,0000 & 0,0000 & 0,0001 & 0,0000 & 0,0016 \\
\hline Mg & 0,0012 & 0,0000 & 0,0013 & 0,0000 & 0,0000 & 0,0000 \\
\hline $\mathbf{C a}$ & 0,0008 & 0,0009 & 0,0005 & 0,0002 & 0,0009 & 0,0020 \\
\hline $\mathrm{Sr}$ & 0,0331 & 0,0793 & 0,0159 & 0,0340 & 0,0319 & 0,0267 \\
\hline Ba & 0,9650 & 0,9192 & 0,9801 & 0,9657 & 0,9671 & 0,9697 \\
\hline $\mathbf{P}$ & 0,0000 & 0,0000 & 0,0000 & 0,0000 & 0,0000 & 0,0000 \\
\hline $\mathbf{P b}$ & 0,0000 & 0,0000 & 0,0000 & 0,0000 & 0,0000 & 0,0000 \\
\hline Suma & 1,0000 & 1,0000 & 1,0000 & 1,0000 & 1,0000 & 1,0000 \\
\hline $\mathbf{S}$ & 0,9975 & 0,9904 & 0,9930 & 0,9984 & 0,9950 & 1,0003 \\
\hline TOTAL & 1,9975 & 1,9904 & 1,9930 & 1,9984 & 1,9950 & 2,0003 \\
\hline
\end{tabular}

Proporciones moleculares de los componentes finales

\begin{tabular}{lrrrrrr}
\hline Anhidrita & 0,08 & 0,09 & 0,05 & 0,02 & 0,09 & 0,20 \\
Celestina & 3,31 & 7,93 & 1,60 & 3,40 & 3,19 & 2,68 \\
Baritina & 96,61 & 91,98 & 98,35 & 96,58 & 96,71 & 97,12 \\
\hline TOTAL & $\mathbf{1 0 0 , 0 0}$ & $\mathbf{1 0 0 , 0 0}$ & $\mathbf{1 0 0 , 0 0}$ & $\mathbf{1 0 0 , 0 0}$ & $\mathbf{1 0 0 , 0 0}$ & $\mathbf{1 0 0 , 0 0}$ \\
\hline
\end{tabular}


Análisis de BARITINA por microsonda electrónica

\begin{tabular}{|c|c|c|c|c|c|c|}
\hline \multicolumn{7}{|c|}{ Muestra $\rightarrow 4951$ (mina San Eduardo) } \\
\hline Yacencia $\rightarrow$ & Veta & Veta & Veta & Veta & Veta & Veta \\
\hline \% en peso & 4 & 5 & 6 & 7 & 8 & 9 \\
\hline FeO* & b.l.d. & b.l.d. & b.l.d. & b.l.d. & b.l.d. & b.1.d. \\
\hline MnO & b.l.d. & b.l.d. & b.l.d. & b.l.d. & b.l.d. & b.l.d. \\
\hline $\mathrm{CoO}$ & 0,03 & 0,02 & b.l.d. & 0,01 & b.l.d. & 0,02 \\
\hline MgO & 0,00 & b.1.d. & 0,00 & b.1.d. & b.l.d. & 0,01 \\
\hline $\mathrm{CaO}$ & 0,01 & b.l.d. & 0,01 & 0,03 & 0,00 & 0,00 \\
\hline SrO & 0,43 & 1,59 & 1,36 & 2,00 & 0,79 & 1,34 \\
\hline $\mathrm{BaO}$ & 65,06 & 63,82 & 64,04 & 63,84 & 64,50 & 64,94 \\
\hline $\mathbf{P}_{2} \mathbf{O}_{5}$ & b.l.d. & b.l.d. & b.1.d. & b.l.d. & b.l.d. & b.l.d. \\
\hline PbO & b.l.d. & b.l.d. & b.l.d. & b.l.d. & b.l.d. & b.l.d. \\
\hline $\mathrm{SO}_{3}$ & 34,30 & 34,45 & 33,96 & 34,72 & 34,79 & 33,81 \\
\hline $\mathbf{F}$ & b.1.d. & b.1.d. & b.1.d. & b.1.d. & b.1.d. & b.1.d. \\
\hline TOTAL & $\mathbf{9 9 , 8 3}$ & $\mathbf{9 9 , 8 8}$ & 99,38 & 100,59 & 100,08 & 100,12 \\
\hline
\end{tabular}

* = asumido como FeO total. b.l.d. = bajo el límite de detección

Número de cationes en base a 4 oxígenos por unidad de fórmula

\begin{tabular}{|c|c|c|c|c|c|c|}
\hline \multicolumn{7}{|c|}{ Muestra $\rightarrow 4951$ (mina San Eduardo) } \\
\hline Yacencia $\rightarrow$ & Veta & Veta & Veta & Veta & Veta & Veta \\
\hline c.p.u.f. & 4 & 5 & 6 & 7 & 8 & 9 \\
\hline $\mathrm{Fe}^{+2}$ & 0,0000 & 0,0000 & 0,0000 & 0,0000 & 0,0000 & 0,0000 \\
\hline Mn & 0,0000 & 0,0000 & 0,0000 & 0,0000 & 0,0000 & 0,0000 \\
\hline Co & 0,0009 & 0,0006 & 0,0000 & 0,0002 & 0,0000 & 0,0006 \\
\hline Mg & 0,0002 & 0,0000 & 0,0003 & 0,0000 & 0,0000 & 0,0003 \\
\hline $\mathbf{C a}$ & 0,0005 & 0,0000 & 0,0003 & 0,0013 & 0,0001 & 0,0001 \\
\hline $\mathbf{S r}$ & 0,0096 & 0,0355 & 0,0305 & 0,0441 & 0,0177 & 0,0295 \\
\hline $\mathbf{B a}$ & 0,9889 & 0,9639 & 0,9690 & 0,9544 & 0,9822 & 0,9695 \\
\hline $\mathbf{P}$ & 0,0000 & 0,0000 & 0,0000 & 0,0000 & 0,0000 & 0,0000 \\
\hline $\mathbf{P b}$ & 0,0000 & 0,0000 & 0,0000 & 0,0000 & 0,0000 & 0,0000 \\
\hline Suma & 1,0000 & 1,0000 & 1,0000 & 1,0000 & 1,0000 & 1,0000 \\
\hline $\mathbf{S}$ & 0,9996 & 0,9991 & 0,9960 & 0,9985 & 1,0036 & 0,9915 \\
\hline TOTAL & 1,9996 & 1,9991 & 1,9960 & 1,9985 & 2,0036 & 1,9915 \\
\hline
\end{tabular}

Proporciones moleculares de los componentes finales

\begin{tabular}{lrrrrrr}
\hline Anhidrita & 0,05 & 0,00 & 0,03 & 0,13 & 0,01 & 0,01 \\
Celestina & 0,96 & 3,56 & 3,05 & 4,42 & 1,77 & 2,95 \\
Baritina & 98,99 & 96,44 & 96,92 & 95,46 & 98,22 & 97,04 \\
\hline TOTAL & $\mathbf{1 0 0 , 0 0}$ & $\mathbf{1 0 0 , 0 0}$ & $\mathbf{1 0 0 , 0 0}$ & $\mathbf{1 0 0 , 0 0}$ & $\mathbf{1 0 0 , 0 0}$ & $\mathbf{1 0 0 , 0 0}$ \\
\hline
\end{tabular}


Análisis de BARITINA por microsonda electrónica

\begin{tabular}{|c|c|c|c|c|c|c|}
\hline \multicolumn{3}{|c|}{ Muestra $\rightarrow 4951$ (mina San Eduardo) } & \multicolumn{4}{|c|}{19407 (mina San Eduardo) } \\
\hline Yacencia $\rightarrow$ & Veta & Veta & Veta & Manto & Manto & Manto \\
\hline$\%$ en peso & 10 & 11 & 12 & c1-1 & $\mathrm{c} 1-2$ & $\mathrm{c} 1-3$ \\
\hline $\mathrm{FeO}^{*}$ & b.l.d. & b.l.d. & b.l.d. & b.l.d. & b.l.d. & b.l.d. \\
\hline MnO & b.l.d. & b.l.d. & b.l.d. & b.l.d. & b.1.d. & b.l.d. \\
\hline $\mathrm{CoO}$ & 0,06 & 0,02 & 0,00 & 0,02 & 0,02 & 0,03 \\
\hline MgO & b.1.d. & b.1.d. & 0,00 & b.1.d. & b.l.d. & b.1.d. \\
\hline $\mathrm{CaO}$ & b.l.d. & b.l.d. & b.1.d. & 0,05 & 0,04 & b.l.d. \\
\hline SrO & 0,26 & 0,34 & 0,17 & 0,39 & 1,30 & 2,13 \\
\hline $\mathrm{BaO}$ & 64,42 & 67,30 & 65,27 & 65,21 & 63,69 & 63,16 \\
\hline $\mathbf{P}_{2} \mathbf{O}_{5}$ & b.l.d. & b.l.d. & b.l.d. & b.l.d. & b.l.d. & b.l.d. \\
\hline PbO & b.l.d. & b.l.d. & b.l.d. & b.l.d. & b.l.d. & b.l.d. \\
\hline $\mathrm{SO}_{3}$ & 33,45 & 31,99 & 33,75 & 33,02 & 34,04 & 35,28 \\
\hline $\mathbf{F}$ & b.1.d. & b.1.d. & b.1.d. & b.l.d. & b.1.d. & b.1.d. \\
\hline TOTAL & $\mathbf{9 8 , 2 0}$ & 99,65 & 99,20 & 98,69 & 99,09 & 100,60 \\
\hline
\end{tabular}

$*=$ asumido como FeO total. b.l.d. = bajo el límite de detección

Número de cationes en base a 4 oxígenos por unidad de fórmula

\begin{tabular}{|c|c|c|c|c|c|c|}
\hline \multicolumn{3}{|c|}{ Muestra $\rightarrow 4951$ (mina San Eduardo) } & \multicolumn{4}{|c|}{19407 (mina San Eduardo) } \\
\hline Yacencia $\rightarrow$ & Veta & Veta & Veta & Manto & Manto & Manto \\
\hline c.p.u.f. & 10 & 11 & 12 & $\mathrm{c} 1-1$ & $\mathrm{c} 1-2$ & $\mathrm{c} 1-3$ \\
\hline $\mathrm{Fe}^{+2}$ & 0,0000 & 0,0000 & 0,0000 & 0,0000 & 0,0000 & 0,0000 \\
\hline Mn & 0,0000 & 0,0000 & 0,0000 & 0,0000 & 0,0000 & 0,0000 \\
\hline Co & 0,0019 & 0,0006 & 0,0001 & 0,0006 & 0,0006 & 0,0009 \\
\hline Mg & 0,0000 & 0,0000 & 0,0002 & 0,0000 & 0,0000 & 0,0000 \\
\hline $\mathbf{C a}$ & 0,0000 & 0,0000 & 0,0000 & 0,0021 & 0,0017 & 0,0000 \\
\hline Sr & 0,0060 & 0,0073 & 0,0039 & 0,0087 & 0,0293 & 0,0475 \\
\hline Ba & 0,9921 & 0,9920 & 0,9958 & 0,9886 & 0,9685 & 0,9516 \\
\hline $\mathbf{P}$ & 0,0000 & 0,0000 & 0,0000 & 0,0000 & 0,0000 & 0,0000 \\
\hline $\mathbf{P b}$ & 0,0000 & 0,0000 & 0,0000 & 0,0000 & 0,0000 & 0,0000 \\
\hline Suma & 1,0000 & 1,0000 & 1,0000 & 1,0000 & 1,0000 & 1,0000 \\
\hline $\mathbf{S}$ & 0,9966 & 0,9738 & 0,9965 & 0,9893 & 0,9978 & 1,0044 \\
\hline TOTAL & 1,9966 & 1,9738 & 1,9965 & 1,9893 & 1,9978 & 2,0044 \\
\hline
\end{tabular}

Proporciones moleculares de los componentes finales

\begin{tabular}{lrrrrrr}
\hline Anhidrita & 0,00 & 0,00 & 0,00 & 0,21 & 0,17 & 0,00 \\
Celestina & 0,60 & 0,73 & 0,39 & 0,88 & 2,93 & 4,75 \\
Baritina & 99,40 & 99,27 & 99,61 & 98,92 & 96,91 & 95,25 \\
\hline TOTAL & $\mathbf{1 0 0 , 0 0}$ & $\mathbf{1 0 0 , 0 0}$ & $\mathbf{1 0 0 , 0 0}$ & $\mathbf{1 0 0 , 0 0}$ & $\mathbf{1 0 0 , 0 0}$ & $\mathbf{1 0 0 , 0 0}$ \\
\hline
\end{tabular}


Análisis de BARITINA por microsonda electrónica

\begin{tabular}{|c|c|c|c|c|c|c|}
\hline \multicolumn{7}{|c|}{ Muestra $\rightarrow 19407$ (mina San Eduardo) } \\
\hline Yacencia $\rightarrow$ & Manto & Manto & Manto & Manto & Manto & Manto \\
\hline$\%$ en peso & $\mathrm{c} 1-4$ & $\mathrm{c} 1-5$ & $\mathrm{c} 1-6$ & $\mathrm{c} 1-7$ & $\mathrm{c} 1-8$ & $\mathrm{c} 1-9$ \\
\hline FeO* & b.l.d. & b.l.d. & b.1.d. & b.l.d. & b.1.d. & b.l.d. \\
\hline MnO & b.l.d. & b.l.d. & b.l.d. & b.l.d. & b.l.d. & b.l.d. \\
\hline $\mathrm{CoO}$ & 0,01 & 0,02 & 0,03 & 0,01 & b.l.d. & b.l.d. \\
\hline MgO & b.1.d. & b.l.d. & b.l.d. & b.1.d. & b.l.d. & b.l.d. \\
\hline $\mathrm{CaO}$ & 0,01 & 0,01 & 0,03 & b.1.d. & 0,01 & b.l.d. \\
\hline SrO & 2,50 & 2,20 & 2,23 & 1,52 & 1,33 & 1,63 \\
\hline $\mathrm{BaO}$ & 62,78 & 63,30 & 62,57 & 64,29 & 64,11 & 63,74 \\
\hline $\mathbf{P}_{2} \mathbf{O}_{5}$ & b.l.d. & b.1.d. & b.1.d. & b.1.d. & b.1.d. & b.l.d. \\
\hline PbO & 0,06 & 0,19 & 0,05 & b.l.d. & b.l.d. & b.l.d. \\
\hline $\mathrm{SO}_{3}$ & 34,00 & 34,10 & 33,26 & 33,21 & 33,14 & 33,11 \\
\hline $\mathbf{F}$ & b.1.d. & b.1.d. & b.1.d. & b.1.d. & b.1.d. & b.1.d. \\
\hline TOTAL & 99,36 & 99,82 & 98,17 & 99,03 & $\mathbf{9 8 , 5 9}$ & 98,48 \\
\hline
\end{tabular}

$*=$ asumido como $\mathrm{FeO}$ total. b.l.d. = bajo el límite de detección

Número de cationes en base a 4 oxígenos por unidad de fórmula

\begin{tabular}{|c|c|c|c|c|c|c|}
\hline \multicolumn{7}{|c|}{ Muestra $\rightarrow 19407$ (mina San Eduardo) } \\
\hline Yacencia $\rightarrow$ & Manto & Manto & Manto & Manto & Manto & Manto \\
\hline c.p.u.f. & $\mathrm{c} 1-4$ & $\mathrm{c} 1-5$ & $\mathrm{c} 1-6$ & $\mathrm{c} 1-7$ & $\mathrm{c} 1-8$ & $\mathrm{c} 1-9$ \\
\hline $\mathrm{Fe}^{+2}$ & 0,0000 & 0,0000 & 0,0000 & 0,0000 & 0,0000 & 0,0000 \\
\hline Mn & 0,0000 & 0,0000 & 0,0000 & 0,0000 & 0,0000 & 0,0000 \\
\hline Co & 0,0003 & 0,0006 & 0,0009 & 0,0003 & 0,0000 & 0,0000 \\
\hline Mg & 0,0000 & 0,0000 & 0,0000 & 0,0000 & 0,0000 & 0,0000 \\
\hline $\mathbf{C a}$ & 0,0004 & 0,0004 & 0,0012 & 0,0000 & 0,0004 & 0,0000 \\
\hline $\mathbf{S r}$ & 0,0556 & 0,0488 & 0,0500 & 0,0338 & 0,0298 & 0,0365 \\
\hline $\mathbf{B a}$ & 0,9431 & 0,9483 & 0,9473 & 0,9659 & 0,9698 & 0,9635 \\
\hline $\mathbf{P}$ & 0,0000 & 0,0000 & 0,0000 & 0,0000 & 0,0000 & 0,0000 \\
\hline $\mathbf{P b}$ & 0,0006 & 0,0020 & 0,0005 & 0,0000 & 0,0000 & 0,0000 \\
\hline Suma & 1,0000 & 1,0000 & 1,0000 & 1,0000 & 1,0000 & 1,0000 \\
\hline $\mathbf{S}$ & 0,9944 & 0,9945 & 0,9909 & 0,9885 & 0,9897 & 0,9893 \\
\hline TOTAL & 1,9944 & 1,9945 & 1,9909 & 1,9885 & 1,9897 & 1,9893 \\
\hline
\end{tabular}

Proporciones moleculares de los componentes finales

\begin{tabular}{lrrrrrr}
\hline Anhidrita & 0,04 & 0,04 & 0,12 & 0,00 & 0,04 & 0,00 \\
Celestina & 5,56 & 4,89 & 5,00 & 3,38 & 2,98 & 3,65 \\
Baritina & 94,40 & 95,07 & 94,87 & 96,62 & 96,98 & 96,35 \\
\hline TOTAL & $\mathbf{1 0 0 , 0 0}$ & $\mathbf{1 0 0 , 0 0}$ & $\mathbf{1 0 0 , 0 0}$ & $\mathbf{1 0 0 , 0 0}$ & $\mathbf{1 0 0 , 0 0}$ & $\mathbf{1 0 0 , 0 0}$ \\
\hline
\end{tabular}


Análisis de BARITINA por microsonda electrónica

\begin{tabular}{|c|c|c|c|c|c|c|}
\hline \multicolumn{7}{|c|}{ Muestra $\rightarrow 19407$ (mina San Eduardo) } \\
\hline Yacencia $\rightarrow$ & Manto & Manto & Manto & Manto & Manto & Manto \\
\hline$\%$ en peso & $\mathrm{c} 1-10$ & $\mathrm{c} 2-1$ & $\mathrm{c} 2-2$ & $\mathrm{c} 2-3$ & $\mathrm{c} 2-4$ & $\mathrm{c} 2-5$ \\
\hline $\mathrm{FeO} *$ & b.1.d. & b.l.d. & b.1.d. & b.l.d. & b.1.d. & b.1.d. \\
\hline MnO & b.l.d. & b.1.d. & b.1.d. & b.1.d. & b.1.d. & b.1.d. \\
\hline $\mathrm{CoO}$ & b.l.d. & 0,05 & 0,03 & 0,04 & 0,02 & 0,01 \\
\hline MgO & b.l.d. & b.l.d. & b.l.d. & b.l.d. & b.1.d. & b.1.d. \\
\hline $\mathrm{CaO}$ & 0,05 & 0,02 & 0,03 & 0,02 & b.1.d. & 0,01 \\
\hline SrO & 1,94 & 1,26 & 1,37 & 0,96 & 0,11 & 0,62 \\
\hline $\mathrm{BaO}$ & 63,71 & 64,02 & 64,16 & 64,67 & 65,89 & 64,97 \\
\hline $\mathbf{P}_{2} \mathbf{O}_{5}$ & b.1.d. & b.1.d. & b.1.d. & b.1.d. & b.1.d. & b.l.d. \\
\hline PbO & 0,06 & b.l.d. & b.l.d. & b.1.d. & 0,06 & b.l.d. \\
\hline $\mathrm{SO}_{3}$ & 32,72 & 33,82 & 34,72 & 32,46 & 33,55 & 34,20 \\
\hline $\mathbf{F}$ & b.1.d. & b.1.d. & b.1.d. & b.1.d. & b.1.d. & b.l.d. \\
\hline TOTAL & 98,48 & 99,17 & 100,31 & 98,15 & 99,63 & 99,81 \\
\hline
\end{tabular}

* = asumido como FeO total. b.l.d. = bajo el límite de detección

Número de cationes en base a 4 oxígenos por unidad de fórmula

\begin{tabular}{|c|c|c|c|c|c|c|}
\hline \multicolumn{7}{|c|}{ Muestra $\rightarrow 19407$ (mina San Eduardo) } \\
\hline Yacencia $\rightarrow$ & Manto & Manto & Manto & Manto & Manto & Manto \\
\hline c.p.u.f. & $\mathrm{c} 1-10$ & $\mathrm{c} 2-1$ & $\mathrm{c} 2-2$ & $\mathrm{c} 2-3$ & $\mathrm{c} 2-4$ & $\mathrm{c} 2-5$ \\
\hline $\mathrm{Fe}^{+2}$ & 0,0000 & 0,0000 & 0,0000 & 0,0000 & 0,0000 & 0,0000 \\
\hline Mn & 0,0000 & 0,0000 & 0,0000 & 0,0000 & 0,0000 & 0,0000 \\
\hline Co & 0,0000 & 0,0015 & 0,0009 & 0,0012 & 0,0006 & 0,0003 \\
\hline Mg & 0,0000 & 0,0000 & 0,0000 & 0,0000 & 0,0000 & 0,0000 \\
\hline $\mathbf{C a}$ & 0,0020 & 0,0008 & 0,0012 & 0,0008 & 0,0000 & 0,0004 \\
\hline $\mathrm{Sr}$ & 0,0430 & 0,0282 & 0,0306 & 0,0214 & 0,0025 & 0,0139 \\
\hline $\mathbf{B a}$ & 0,9543 & 0,9694 & 0,9673 & 0,9765 & 0,9963 & 0,9854 \\
\hline $\mathbf{P}$ & 0,0000 & 0,0000 & 0,0000 & 0,0000 & 0,0000 & 0,0000 \\
\hline $\mathbf{P b}$ & 0,0006 & 0,0000 & 0,0000 & 0,0000 & 0,0006 & 0,0000 \\
\hline Suma & 1,0000 & 1,0000 & 1,0000 & 1,0000 & 1,0000 & 1,0000 \\
\hline $\mathbf{S}$ & 0,9839 & 0,9951 & 1,0006 & 0,9839 & 0,9927 & 0,9983 \\
\hline TOTAL & 1,9839 & 1,9951 & 2,0006 & 1,9839 & 1,9927 & 1,9983 \\
\hline
\end{tabular}

Proporciones moleculares de los componentes finales

\begin{tabular}{lrrrrrr}
\hline Anhidrita & 0,20 & 0,08 & 0,12 & 0,08 & 0,00 & 0,04 \\
Celestina & 4,30 & 2,83 & 3,06 & 2,15 & 0,25 & 1,39 \\
Baritina & 95,49 & 97,09 & 96,82 & 97,77 & 99,75 & 98,57 \\
\hline TOTAL & $\mathbf{1 0 0 , 0 0}$ & $\mathbf{1 0 0 , 0 0}$ & $\mathbf{1 0 0 , 0 0}$ & $\mathbf{1 0 0 , 0 0}$ & $\mathbf{1 0 0 , 0 0}$ & $\mathbf{1 0 0 , 0 0}$ \\
\hline
\end{tabular}


Análisis de BARITINA por microsonda electrónica

\begin{tabular}{|c|c|c|c|c|c|c|}
\hline \multicolumn{7}{|c|}{ Muestra $\rightarrow 19407$ (mina San Eduardo) } \\
\hline Yacencia $\rightarrow$ & Manto & Manto & Manto & Manto & Manto & Manto \\
\hline$\%$ en peso & $\mathrm{c} 2-6$ & $\mathrm{c} 2-7$ & $\mathrm{c} 2-8$ & c2-9 & $\mathrm{c} 2-10$ & $\mathrm{c} 3-1$ \\
\hline $\mathrm{FeO} *$ & b.l.d. & b.l.d. & b.1.d. & b.l.d. & b.l.d. & b.1.d. \\
\hline MnO & b.1.d. & b.1.d. & b.1.d. & b.l.d. & b.1.d. & b.l.d. \\
\hline $\mathrm{CoO}$ & 0,06 & 0,03 & 0,03 & 0,03 & 0,01 & 0,04 \\
\hline MgO & b.l.d. & b.l.d. & b.l.d. & b.1.d. & b.l.d. & b.1.d. \\
\hline $\mathrm{CaO}$ & 0,03 & b.l.d. & 0,06 & 0,01 & b.l.d. & b.l.d. \\
\hline SrO & 0,27 & 0,22 & 0,46 & 0,59 & 0,65 & 1,69 \\
\hline $\mathrm{BaO}$ & 65,53 & 65,82 & 65,12 & 64,98 & 64,48 & 63,99 \\
\hline $\mathbf{P}_{2} \mathbf{O}_{5}$ & b.1.d. & b.l.d. & b.1.d. & b.l.d. & b.l.d. & b.l.d. \\
\hline PbO & 0,07 & b.l.d. & 0,14 & 0,01 & 0,05 & b.l.d. \\
\hline $\mathrm{SO}_{3}$ & 34,05 & 33,91 & 33,87 & 32,39 & 33,92 & 33,79 \\
\hline $\mathbf{F}$ & b.1.d. & b.1.d. & b.1.d. & b.1.d. & b.1.d. & b.1.d. \\
\hline TOTAL & 100,01 & 99,98 & 99,68 & 98,01 & 99,11 & 99,51 \\
\hline
\end{tabular}

* = asumido como FeO total. b.l.d. = bajo el límite de detección

Número de cationes en base a 4 oxígenos por unidad de fórmula

\begin{tabular}{|c|c|c|c|c|c|c|}
\hline \multicolumn{7}{|c|}{ Muestra $\rightarrow 19407$ (mina San Eduardo) } \\
\hline Yacencia $\rightarrow$ & Manto & Manto & Manto & Manto & Manto & Manto \\
\hline c.p.u.f. & $\mathrm{c} 2-6$ & $\mathrm{c} 2-7$ & $\mathrm{c} 2-8$ & $\mathrm{c} 2-9$ & $\mathrm{c} 2-10$ & $\mathrm{c} 3-1$ \\
\hline $\mathrm{Fe}^{+2}$ & 0,0000 & 0,0000 & 0,0000 & 0,0000 & 0,0000 & 0,0000 \\
\hline Mn & 0,0000 & 0,0000 & 0,0000 & 0,0000 & 0,0000 & 0,0000 \\
\hline Co & 0,0019 & 0,0009 & 0,0009 & 0,0009 & 0,0003 & 0,0012 \\
\hline Mg & 0,0000 & 0,0000 & 0,0000 & 0,0000 & 0,0000 & 0,0000 \\
\hline $\mathbf{C a}$ & 0,0012 & 0,0000 & 0,0025 & 0,0004 & 0,0000 & 0,0000 \\
\hline $\mathrm{Sr}$ & 0,0060 & 0,0049 & 0,0103 & 0,0132 & 0,0147 & 0,0376 \\
\hline $\mathbf{B a}$ & 0,9901 & 0,9942 & 0,9848 & 0,9853 & 0,9845 & 0,9612 \\
\hline $\mathbf{P}$ & 0,0000 & 0,0000 & 0,0000 & 0,0000 & 0,0000 & 0,0000 \\
\hline $\mathbf{P b}$ & 0,0007 & 0,0000 & 0,0015 & 0,0001 & 0,0005 & 0,0000 \\
\hline Suma & 1,0000 & 1,0000 & 1,0000 & 1,0000 & 1,0000 & 1,0000 \\
\hline $\mathbf{S}$ & 0,9963 & 0,9951 & 0,9952 & 0,9844 & 0,9979 & 0,9929 \\
\hline TOTAL & 1,9963 & 1,9951 & 1,9952 & 1,9844 & 1,9979 & 1,9929 \\
\hline
\end{tabular}

Proporciones moleculares de los componentes finales

\begin{tabular}{lrrrrrr}
\hline Anhidrita & 0,12 & 0,00 & 0,25 & 0,04 & 0,00 & 0,00 \\
Celestina & 0,61 & 0,49 & 1,03 & 1,33 & 1,47 & 3,76 \\
Baritina & 99,27 & 99,51 & 98,72 & 98,63 & 98,53 & 96,24 \\
\hline TOTAL & $\mathbf{1 0 0 , 0 0}$ & $\mathbf{1 0 0 , 0 0}$ & $\mathbf{1 0 0 , 0 0}$ & $\mathbf{1 0 0 , 0 0}$ & $\mathbf{1 0 0 , 0 0}$ & $\mathbf{1 0 0 , 0 0}$ \\
\hline
\end{tabular}


Análisis de BARITINA por microsonda electrónica

\begin{tabular}{|c|c|c|c|c|c|c|}
\hline \multicolumn{7}{|c|}{ Muestra $\rightarrow 19407$ (mina San Eduardo) } \\
\hline \multicolumn{7}{|c|}{$\begin{array}{l}\text { Vuestra } \rightarrow 1940 /(\text { mina San Eauardo) } \\
\text { Yacencia } \rightarrow \quad \text { Manto } \quad \text { Manto }\end{array}$} \\
\hline \% en peso & $\mathrm{c} 3-2$ & $\mathrm{c} 3-3$ & $\mathrm{c} 3-4$ & $\mathrm{c} 3-5$ & $\mathrm{c} 3-6$ & $\mathrm{c} 3-7$ \\
\hline FeO* & b.l.d. & b.l.d. & b.l.d. & b.l.d. & b.l.d. & b.1.d. \\
\hline MnO & b.1.d. & b.l.d. & b.l.d. & b.1.d. & b.1.d. & b.1.d. \\
\hline $\mathrm{CoO}$ & 0,01 & b.l.d. & b.l.d. & 0,04 & 0,03 & 0,04 \\
\hline MgO & b.1.d. & b.l.d. & b.l.d. & b.l.d. & b.1.d. & b.1.d. \\
\hline $\mathrm{CaO}$ & 0,01 & b.1.d. & 0,01 & b.1.d. & b.1.d. & 0,01 \\
\hline $\mathrm{SrO}$ & 1,47 & 0,66 & 0,56 & 0,66 & 1,61 & 0,19 \\
\hline $\mathrm{BaO}$ & 64,37 & 65,13 & 65,79 & 65,65 & 64,06 & 65,99 \\
\hline $\mathbf{P}_{2} \mathbf{O}_{5}$ & b.1.d. & b.l.d. & b.1.d. & b.1.d. & b.1.d. & b.l.d. \\
\hline PbO & 0,01 & b.l.d. & 0,18 & 0,23 & 0,08 & b.l.d. \\
\hline $\mathrm{SO}_{3}$ & 33,56 & 34,61 & 35,21 & 34,58 & 35,41 & 34,24 \\
\hline $\mathbf{F}$ & b.1.d. & b.1.d. & b.1.d. & b.1.d. & b.1.d. & b.1.d. \\
\hline TOTAL & 99,43 & 100,40 & 101,75 & 101,16 & 101,19 & 100,47 \\
\hline
\end{tabular}

* = asumido como FeO total. b.l.d. = bajo el límite de detección

Número de cationes en base a 4 oxígenos por unidad de fórmula

\begin{tabular}{|c|c|c|c|c|c|c|}
\hline \multicolumn{7}{|c|}{ Muestra $\rightarrow 19407$ (mina San Eduardo) } \\
\hline Yacencia $\rightarrow$ & Manto & Manto & Manto & Manto & Manto & Manto \\
\hline c.p.u.f. & $\mathrm{c} 3-2$ & $\mathrm{c} 3-3$ & $\mathrm{c} 3-4$ & $\mathrm{c} 3-5$ & $\mathrm{c} 3-6$ & $\mathrm{c} 3-7$ \\
\hline $\mathrm{Fe}^{+2}$ & 0,0000 & 0,0000 & 0,0000 & 0,0000 & 0,0000 & 0,0000 \\
\hline Mn & 0,0000 & 0,0000 & 0,0000 & 0,0000 & 0,0000 & 0,0000 \\
\hline Co & 0,0003 & 0,0000 & 0,0000 & 0,0012 & 0,0009 & 0,0012 \\
\hline Mg & 0,0000 & 0,0000 & 0,0000 & 0,0000 & 0,0000 & 0,0000 \\
\hline $\mathbf{C a}$ & 0,0004 & 0,0000 & 0,0004 & 0,0000 & 0,0000 & 0,0004 \\
\hline $\mathbf{S r}$ & 0,0327 & 0,0148 & 0,0124 & 0,0146 & 0,0358 & 0,0042 \\
\hline $\mathbf{B a}$ & 0,9665 & 0,9852 & 0,9853 & 0,9818 & 0,9625 & 0,9941 \\
\hline $\mathbf{P}$ & 0,0000 & 0,0000 & 0,0000 & 0,0000 & 0,0000 & 0,0000 \\
\hline $\mathbf{P b}$ & 0,0001 & 0,0000 & 0,0019 & 0,0024 & 0,0008 & 0,0000 \\
\hline Suma & 1,0000 & 1,0000 & 1,0000 & 1,0000 & 1,0000 & 1,0000 \\
\hline $\mathbf{S}$ & 0,9910 & 1,0007 & 1,0025 & 0,9976 & 1,0046 & 0,9969 \\
\hline TOTAL & 1,9910 & 2,0007 & 2,0025 & 1,9976 & 2,0046 & 1,9969 \\
\hline
\end{tabular}

Proporciones moleculares de los componentes finales

\begin{tabular}{lrrrrrr}
\hline Anhidrita & 0,04 & 0,00 & 0,04 & 0,00 & 0,00 & 0,04 \\
Celestina & 3,27 & 1,48 & 1,24 & 1,47 & 3,59 & 0,42 \\
Baritina & 96,69 & 98,52 & 98,72 & 98,53 & 96,41 & 99,53 \\
\hline TOTAL & $\mathbf{1 0 0 , 0 0}$ & $\mathbf{1 0 0 , 0 0}$ & $\mathbf{1 0 0 , 0 0}$ & $\mathbf{1 0 0 , 0 0}$ & $\mathbf{1 0 0 , 0 0}$ & $\mathbf{1 0 0 , 0 0}$ \\
\hline
\end{tabular}


Análisis de BARITINA por microsonda electrónica

\begin{tabular}{|c|c|c|c|c|c|c|}
\hline \multicolumn{7}{|c|}{ Muestra $\rightarrow 19407$ (S.E.) 21847 (Cerro Negro) } \\
\hline Yacencia $\rightarrow$ & Manto & Veta & Veta & Veta & Veta & Veta \\
\hline$\%$ en peso & $\mathrm{c} 3-8$ & $\mathrm{c} 1-1$ & $\mathrm{c} 1-2$ & $\mathrm{c} 1-3$ & $\mathrm{c} 1-4$ & $\mathrm{c} 1-5$ \\
\hline FeO* & b.1.d. & b.1.d. & b.1.d. & b.1.d. & b.1.d. & 0,03 \\
\hline MnO & b.l.d. & 0,05 & 0,05 & 0,04 & 0,04 & 0,00 \\
\hline $\mathrm{CoO}$ & 0,03 & 0,06 & b.1.d. & b.l.d. & b.l.d. & b.l.d. \\
\hline MgO & b.l.d. & b.1.d. & 0,02 & 0,06 & 0,00 & b.1.d. \\
\hline $\mathrm{CaO}$ & b.l.d. & b.1.d. & b.1.d. & b.l.d. & 0,03 & b.1.d. \\
\hline SrO & 1,37 & 2,33 & 2,00 & 2,02 & 2,15 & 1,94 \\
\hline $\mathrm{BaO}$ & 64,86 & 63,86 & 62,97 & 62,36 & 61,52 & 62,79 \\
\hline $\mathbf{P}_{2} \mathbf{O}_{5}$ & b.l.d. & b.l.d. & b.l.d. & b.l.d. & b.l.d. & b.1.d. \\
\hline PbO & b.l.d. & b.l.d. & b.1.d. & b.l.d. & b.1.d. & b.l.d. \\
\hline $\mathrm{SO}_{3}$ & 34,58 & 34,16 & 34,75 & 34,24 & 34,57 & 34,70 \\
\hline $\mathbf{F}$ & b.1.d. & b.1.d. & b.1.d. & b.1.d. & b.l.d. & b.1.d. \\
\hline TOTAL & 100,84 & 100,46 & 99,78 & 98,71 & 98,31 & 99,47 \\
\hline
\end{tabular}

* = asumido como $\mathrm{FeO}$ total. b.l.d. = bajo el límite de detección

Número de cationes en base a 4 oxígenos por unidad de fórmula

\begin{tabular}{|c|c|c|c|c|c|c|}
\hline \multicolumn{7}{|c|}{ Muestra $\rightarrow 19407$ (S.E.) 21847 (Cerro Negro) } \\
\hline Yacencia $\rightarrow$ & Manto & Veta & Veta & Veta & Veta & Veta \\
\hline c.p.u.f. & $\mathrm{c} 3-8$ & c1-1 & $\mathrm{c} 1-2$ & $\mathrm{c} 1-3$ & $\mathrm{c} 1-4$ & $\mathrm{c} 1-5$ \\
\hline $\mathrm{Fe}^{+2}$ & 0,0000 & 0,0000 & 0,0000 & 0,0000 & 0,0000 & 0,0011 \\
\hline Mn & 0,0000 & 0,0015 & 0,0015 & 0,0012 & 0,0012 & 0,0000 \\
\hline Co & 0,0009 & 0,0019 & 0,0000 & 0,0000 & 0,0000 & 0,0000 \\
\hline Mg & 0,0000 & 0,0000 & 0,0010 & 0,0033 & 0,0002 & 0,0000 \\
\hline $\mathbf{C a}$ & 0,0000 & 0,0000 & 0,0000 & 0,0000 & 0,0012 & 0,0000 \\
\hline $\mathbf{S r}$ & 0,0303 & 0,0511 & 0,0448 & 0,0455 & 0,0490 & 0,0437 \\
\hline $\mathbf{B a}$ & 0,9688 & 0,9456 & 0,9527 & 0,9500 & 0,9484 & 0,9552 \\
\hline $\mathbf{P}$ & 0,0000 & 0,0000 & 0,0000 & 0,0000 & 0,0000 & 0,0000 \\
\hline $\mathbf{P b}$ & 0,0000 & 0,0000 & 0,0000 & 0,0000 & 0,0000 & 0,0000 \\
\hline Suma & 1,0000 & 1,0000 & 1,0000 & 1,0000 & 1,0000 & 1,0000 \\
\hline $\mathbf{S}$ & 0,9973 & 0,9920 & 1,0017 & 0,9997 & 1,0051 & 1,0027 \\
\hline TOTAL & 1,9973 & 1,9920 & 2,0017 & 1,9997 & 2,0051 & 2,0027 \\
\hline
\end{tabular}

Proporciones moleculares de los componentes finales

\begin{tabular}{lrrrrrr}
\hline Anhidrita & 0,00 & 0,00 & 0,00 & 0,00 & 0,12 & 0,00 \\
Celestina & 3,03 & 5,12 & 4,49 & 4,57 & 4,91 & 4,37 \\
Baritina & 96,97 & 94,88 & 95,51 & 95,43 & 94,97 & 95,63 \\
\hline TOTAL & $\mathbf{1 0 0 , 0 0}$ & $\mathbf{1 0 0 , 0 0}$ & $\mathbf{1 0 0 , 0 0}$ & $\mathbf{1 0 0 , 0 0}$ & $\mathbf{1 0 0 , 0 0}$ & $\mathbf{1 0 0 , 0 0}$ \\
\hline
\end{tabular}


Análisis de BARITINA por microsonda electrónica

\begin{tabular}{|c|c|c|c|c|c|c|}
\hline \multicolumn{7}{|c|}{ Muestra $\rightarrow 21847$ (Cerro Negro) } \\
\hline Yacencia $\rightarrow$ & Veta & Veta & Veta & Veta & Veta & Veta \\
\hline$\%$ en peso & $\mathrm{c} 1-6$ & $\mathrm{c} 1-7$ & $\mathrm{c} 1-8$ & c1-9 & $\mathrm{c} 1-10$ & $\mathrm{c} 1-11$ \\
\hline FeO* & 0,04 & 0,00 & b.1.d. & 0,06 & 0,01 & 0,04 \\
\hline MnO & 0,05 & b.1.d. & 0,09 & b.1.d. & 0,04 & 0,06 \\
\hline $\mathrm{CoO}$ & 0,01 & b.l.d. & 0,07 & b.l.d. & b.l.d. & b.l.d. \\
\hline MgO & b.l.d. & b.l.d. & b.1.d. & 0,03 & b.l.d. & 0,02 \\
\hline $\mathrm{CaO}$ & 0,00 & 0,01 & b.l.d. & b.1.d. & 0,01 & 0,02 \\
\hline SrO & 2,05 & 2,18 & 2,18 & 2,52 & 2,21 & 2,06 \\
\hline $\mathrm{BaO}$ & 62,23 & 62,12 & 66,11 & 62,24 & 62,10 & 61,85 \\
\hline $\mathbf{P}_{2} \mathbf{O}_{5}$ & b.1.d. & b.1.d. & b.1.d. & b.1.d. & b.1.d. & b.1.d. \\
\hline PbO & b.l.d. & b.l.d. & b.l.d. & b.l.d. & b.l.d. & b.l.d. \\
\hline $\mathrm{SO}_{3}$ & 34,56 & 34,95 & 30,77 & 34,73 & 34,56 & 34,66 \\
\hline $\mathbf{F}$ & b.1.d. & b.1.d. & b.1.d. & b.l.d. & b.1.d. & b.l.d. \\
\hline TOTAL & 98,94 & 99,27 & 99,23 & 99,58 & 98,94 & 98,71 \\
\hline
\end{tabular}

$*=$ asumido como $\mathrm{FeO}$ total. b.l.d. = bajo el límite de detección

Número de cationes en base a 4 oxígenos por unidad de fórmula

\begin{tabular}{|c|c|c|c|c|c|c|}
\hline \multicolumn{7}{|c|}{ Muestra $\rightarrow 21847$ (Cerro Negro) } \\
\hline Yacencia $\rightarrow$ & Veta & Veta & Veta & Veta & Veta & Veta \\
\hline c.p.u.f. & $\mathrm{c} 1-6$ & $\mathrm{c} 1-7$ & $\mathrm{c} 1-8$ & $\mathrm{c} 1-9$ & $\mathrm{c} 1-10$ & $\mathrm{c} 1-11$ \\
\hline $\mathrm{Fe}^{+2}$ & 0,0013 & 0,0001 & 0,0000 & 0,0021 & 0,0004 & 0,0014 \\
\hline Mn & 0,0017 & 0,0000 & 0,0029 & 0,0000 & 0,0014 & 0,0019 \\
\hline Co & 0,0002 & 0,0000 & 0,0021 & 0,0000 & 0,0000 & 0,0000 \\
\hline Mg & 0,0000 & 0,0000 & 0,0000 & 0,0015 & 0,0000 & 0,0012 \\
\hline $\mathbf{C a}$ & 0,0000 & 0,0006 & 0,0000 & 0,0000 & 0,0005 & 0,0006 \\
\hline $\mathbf{S r}$ & 0,0463 & 0,0493 & 0,0463 & 0,0563 & 0,0499 & 0,0467 \\
\hline Ba & 0,9504 & 0,9500 & 0,9487 & 0,9401 & 0,9478 & 0,9482 \\
\hline $\mathbf{P}$ & 0,0000 & 0,0000 & 0,0000 & 0,0000 & 0,0000 & 0,0000 \\
\hline $\mathbf{P b}$ & 0,0000 & 0,0000 & 0,0000 & 0,0000 & 0,0000 & 0,0000 \\
\hline Suma & 1,0000 & 1,0000 & 1,0000 & 1,0000 & 1,0000 & 1,0000 \\
\hline $\mathbf{S}$ & 1,0027 & 1,0058 & 0,9563 & 1,0012 & 1,0025 & 1,0043 \\
\hline TOTAL & 2,0027 & 2,0058 & 1,9563 & 2,0012 & 2,0025 & 2,0043 \\
\hline
\end{tabular}

Proporciones moleculares de los componentes finales

\begin{tabular}{lrrrrrr}
\hline Anhidrita & 0,00 & 0,06 & 0,00 & 0,00 & 0,05 & 0,06 \\
Celestina & 4,65 & 4,93 & 4,65 & 5,65 & 5,00 & 4,69 \\
Baritina & 95,35 & 95,01 & 95,35 & 94,35 & 94,95 & 95,24 \\
\hline TOTAL & $\mathbf{1 0 0 , 0 0}$ & $\mathbf{1 0 0 , 0 0}$ & $\mathbf{1 0 0 , 0 0}$ & $\mathbf{1 0 0 , 0 0}$ & $\mathbf{1 0 0 , 0 0}$ & $\mathbf{1 0 0 , 0 0}$ \\
\hline
\end{tabular}


Análisis de BARITINA por microsonda electrónica

\begin{tabular}{|c|c|c|c|c|c|c|}
\hline \multicolumn{7}{|c|}{ Muestra $\rightarrow 21847$ (Cerro Negro) } \\
\hline Yacencia $\rightarrow$ & Veta & Veta & Veta & Veta & Veta & Veta \\
\hline$\%$ en peso & $\mathrm{c} 1-12$ & $\mathrm{c} 2-1$ & $\mathrm{c} 2-2$ & $\mathrm{c} 2-3$ & $\mathrm{c} 2-4$ & $\mathrm{c} 2-5$ \\
\hline $\mathrm{FeO}^{*}$ & 0,00 & 0,01 & b.1.d. & 0,03 & b.l.d. & 0,01 \\
\hline MnO & 0,01 & 0,03 & b.l.d. & b.l.d. & 0,02 & b.1.d. \\
\hline $\mathrm{CoO}$ & b.l.d. & b.l.d. & b.l.d. & b.l.d. & b.l.d. & 0,02 \\
\hline MgO & 0,01 & b.1.d. & 0,01 & b.l.d. & 0,00 & 0,02 \\
\hline $\mathrm{CaO}$ & 0,00 & b.l.d. & 0,02 & 0,01 & 0,03 & 0,04 \\
\hline SrO & 1,83 & 2,19 & 1,92 & 2,52 & 2,70 & 2,00 \\
\hline $\mathrm{BaO}$ & 62,89 & 64,01 & 63,05 & 61,46 & 63,90 & 64,00 \\
\hline $\mathbf{P}_{2} \mathbf{O}_{5}$ & b.l.d. & b.l.d. & b.1.d. & b.l.d. & b.1.d. & b.l.d. \\
\hline PbO & b.l.d. & b.1.d. & b.l.d. & b.1.d. & b.l.d. & b.l.d. \\
\hline $\mathrm{SO}_{3}$ & 34,45 & 33,94 & 34,32 & 34,63 & 34,08 & 34,01 \\
\hline $\mathbf{F}$ & b.1.d. & b.l.d. & b.l.d. & b.l.d. & b.1.d. & b.1.d. \\
\hline TOTAL & 99,19 & 100,18 & 99,31 & 98,65 & 100,74 & 100,09 \\
\hline
\end{tabular}

$*=$ asumido como $\mathrm{FeO}$ total. b.l.d. = bajo el límite de detección

Número de cationes en base a 4 oxígenos por unidad de fórmula

\begin{tabular}{|c|c|c|c|c|c|c|}
\hline \multicolumn{7}{|c|}{ Muestra $\rightarrow 21847$ (Cerro Negro) } \\
\hline Yacencia $\rightarrow$ & Veta & Veta & Veta & Veta & Veta & Veta \\
\hline c.p.u.f. & $\mathrm{c} 1-12$ & $\mathrm{c} 2-1$ & $\mathrm{c} 2-2$ & $\mathrm{c} 2-3$ & $\mathrm{c} 2-4$ & $\mathrm{c} 2-5$ \\
\hline $\mathrm{Fe}^{+2}$ & 0,0001 & 0,0005 & 0,0000 & 0,0009 & 0,0000 & 0,0005 \\
\hline Mn & 0,0003 & 0,0009 & 0,0000 & 0,0000 & 0,0007 & 0,0000 \\
\hline Co & 0,0000 & 0,0000 & 0,0000 & 0,0000 & 0,0000 & 0,0005 \\
\hline Mg & 0,0006 & 0,0000 & 0,0004 & 0,0000 & 0,0001 & 0,0010 \\
\hline $\mathbf{C a}$ & 0,0000 & 0,0000 & 0,0007 & 0,0004 & 0,0013 & 0,0014 \\
\hline $\mathbf{S r}$ & 0,0412 & 0,0481 & 0,0431 & 0,0571 & 0,0587 & 0,0440 \\
\hline $\mathbf{B a}$ & 0,9578 & 0,9506 & 0,9559 & 0,9416 & 0,9392 & 0,9526 \\
\hline $\mathbf{P}$ & 0,0000 & 0,0000 & 0,0000 & 0,0000 & 0,0000 & 0,0000 \\
\hline $\mathbf{P b}$ & 0,0000 & 0,0000 & 0,0000 & 0,0000 & 0,0000 & 0,0000 \\
\hline Suma & 1,0000 & 1,0000 & 1,0000 & 1,0000 & 1,0000 & 1,0000 \\
\hline $\mathbf{S}$ & 1,0012 & 0,9911 & 0,9991 & 1,0040 & 0,9895 & 0,9922 \\
\hline TOTAL & 2,0012 & 1,9911 & 1,9991 & 2,0040 & 1,9895 & 1,9922 \\
\hline
\end{tabular}

Proporciones moleculares de los componentes finales

\begin{tabular}{lrrrrrr}
\hline Anhidrita & 0,00 & 0,00 & 0,07 & 0,04 & 0,13 & 0,14 \\
Celestina & 4,13 & 4,82 & 4,31 & 5,72 & 5,88 & 4,41 \\
Baritina & 95,87 & 95,18 & 95,63 & 94,24 & 93,99 & 95,44 \\
\hline TOTAL & $\mathbf{1 0 0 , 0 0}$ & $\mathbf{1 0 0 , 0 0}$ & $\mathbf{1 0 0 , 0 0}$ & $\mathbf{1 0 0 , 0 0}$ & $\mathbf{1 0 0 , 0 0}$ & $\mathbf{1 0 0 , 0 0}$ \\
\hline
\end{tabular}


Análisis de BARITINA por microsonda electrónica

\begin{tabular}{|c|c|c|c|c|c|c|}
\hline \multicolumn{7}{|c|}{ Muestra $\rightarrow 21847$ (Cerro Negro) } \\
\hline Yacencia $\rightarrow$ & Veta & Veta & Veta & Veta & Veta & Veta \\
\hline$\%$ en peso & $\mathrm{c} 2-6$ & $\mathrm{c} 2-7$ & $\mathrm{c} 2-8$ & $\mathrm{c} 2-9$ & $\mathrm{c} 2-10$ & $\mathrm{c} 2-11$ \\
\hline $\mathrm{FeO} *$ & b.l.d. & b.1.d. & b.1.d. & b.l.d. & b.l.d. & b.l.d. \\
\hline MnO & 0,01 & 0,01 & 0,02 & 0,03 & 0,03 & 0,03 \\
\hline $\mathrm{CoO}$ & b.l.d. & 0,04 & 0,03 & b.l.d. & b.l.d. & b.l.d. \\
\hline MgO & 0,00 & 0,01 & b.l.d. & b.1.d. & b.1.d. & 0,03 \\
\hline $\mathrm{CaO}$ & 0,02 & 0,02 & 0,02 & 0,00 & 0,03 & 0,00 \\
\hline $\mathrm{SrO}$ & 1,86 & 1,79 & 1,85 & 2,09 & 2,20 & 2,02 \\
\hline $\mathrm{BaO}$ & 64,34 & 64,64 & 64,97 & 63,97 & 64,57 & 64,78 \\
\hline $\mathbf{P}_{2} \mathbf{O}_{5}$ & b.l.d. & b.l.d. & b.l.d. & b.1.d. & b.l.d. & b.1.d. \\
\hline PbO & b.l.d. & b.l.d. & b.l.d. & b.l.d. & b.l.d. & b.1.d. \\
\hline $\mathrm{SO}_{3}$ & 33,72 & 34,57 & 33,98 & 33,62 & 34,67 & 34,06 \\
\hline $\mathbf{F}$ & b.1.d. & b.1.d. & b.1.d. & b.1.d. & b.1.d. & b.1.d. \\
\hline TOTAL & 99,95 & 101,08 & 100,88 & 99,71 & 101,50 & 100,92 \\
\hline
\end{tabular}

$*=$ asumido como $\mathrm{FeO}$ total. b.l.d. = bajo el límite de detección

Número de cationes en base a 4 oxígenos por unidad de fórmula

\begin{tabular}{|c|c|c|c|c|c|c|}
\hline \multicolumn{7}{|c|}{ Muestra $\rightarrow 21847$ (Cerro Negro) } \\
\hline Yacencia $\rightarrow$ & Veta & Veta & Veta & Veta & Veta & Veta \\
\hline c.p.u.f. & $\mathrm{c} 2-6$ & $\mathrm{c} 2-7$ & $\mathrm{c} 2-8$ & c2-9 & $\mathrm{c} 2-10$ & $\mathrm{c} 2-11$ \\
\hline $\mathrm{Fe}^{+2}$ & 0,0000 & 0,0000 & 0,0000 & 0,0000 & 0,0000 & 0,0000 \\
\hline Mn & 0,0003 & 0,0002 & 0,0006 & 0,0009 & 0,0011 & 0,0011 \\
\hline Co & 0,0000 & 0,0013 & 0,0010 & 0,0000 & 0,0000 & 0,0000 \\
\hline Mg & 0,0001 & 0,0008 & 0,0000 & 0,0000 & 0,0000 & 0,0016 \\
\hline $\mathbf{C a}$ & 0,0009 & 0,0008 & 0,0009 & 0,0001 & 0,0011 & 0,0001 \\
\hline $\mathrm{Sr}$ & 0,0410 & 0,0392 & 0,0403 & 0,0461 & 0,0479 & 0,0440 \\
\hline $\mathbf{B a}$ & 0,9578 & 0,9577 & 0,9571 & 0,9530 & 0,9500 & 0,9532 \\
\hline $\mathbf{P}$ & 0,0000 & 0,0000 & 0,0000 & 0,0000 & 0,0000 & 0,0000 \\
\hline $\mathbf{P b}$ & 0,0000 & 0,0000 & 0,0000 & 0,0000 & 0,0000 & 0,0000 \\
\hline Suma & 1,0000 & 1,0000 & 1,0000 & 1,0000 & 1,0000 & 1,0000 \\
\hline $\mathbf{S}$ & 0,9900 & 0,9952 & 0,9893 & 0,9895 & 0,9941 & 0,9896 \\
\hline TOTAL & 1,9900 & 1,9952 & 1,9893 & 1,9895 & 1,9941 & 1,9896 \\
\hline
\end{tabular}

Proporciones moleculares de los componentes finales

\begin{tabular}{lrrrrrr}
\hline Anhidrita & 0,09 & 0,08 & 0,09 & 0,01 & 0,11 & 0,01 \\
Celestina & 4,10 & 3,93 & 4,04 & 4,61 & 4,79 & 4,41 \\
Baritina & 95,81 & 95,99 & 95,87 & 95,38 & 95,10 & 95,58 \\
\hline TOTAL & $\mathbf{1 0 0 , 0 0}$ & $\mathbf{1 0 0 , 0 0}$ & $\mathbf{1 0 0 , 0 0}$ & $\mathbf{1 0 0 , 0 0}$ & $\mathbf{1 0 0 , 0 0}$ & $\mathbf{1 0 0 , 0 0}$ \\
\hline
\end{tabular}


Análisis de BARITINA por microsonda electrónica

\begin{tabular}{|c|c|c|c|c|c|c|}
\hline \multicolumn{7}{|c|}{ Muestra $\rightarrow 21847$ (Cerro Negro) } \\
\hline Yacencia $\rightarrow$ & Veta & Veta & Veta & Veta & Veta & Veta \\
\hline$\%$ en peso & $\mathrm{c} 2-12$ & $\mathrm{c} 2-13$ & c2-14 & $\mathrm{c} 2-15$ & $\mathrm{c} 2-16$ & $\mathrm{c} 2-17$ \\
\hline $\mathrm{FeO}^{*}$ & b.1.d. & b.l.d. & b.l.d. & b.l.d. & 0,03 & b.l.d. \\
\hline MnO & 0,02 & b.1.d. & b.1.d. & 0,05 & 0,03 & 0,01 \\
\hline $\mathrm{CoO}$ & b.l.d. & 0,02 & 0,00 & 0,01 & b.l.d. & b.l.d. \\
\hline MgO & b.1.d. & 0,01 & b.1.d. & b.1.d. & 0,02 & 0,01 \\
\hline $\mathrm{CaO}$ & 0,01 & 0,01 & 0,04 & 0,03 & 0,04 & 0,04 \\
\hline SrO & 2,10 & 1,74 & 2,18 & 2,18 & 1,65 & 1,89 \\
\hline $\mathrm{BaO}$ & 64,48 & 65,07 & 64,01 & 64,00 & 64,39 & 64,80 \\
\hline $\mathbf{P}_{2} \mathbf{O}_{5}$ & b.1.d. & b.l.d. & b.1.d. & b.l.d. & b.l.d. & b.l.d. \\
\hline PbO & b.l.d. & b.l.d. & b.l.d. & b.l.d. & b.l.d. & b.l.d. \\
\hline $\mathrm{SO}_{3}$ & 33,98 & 34,07 & 34,35 & 34,18 & 33,94 & 34,36 \\
\hline $\mathbf{F}$ & b.1.d. & b.1.d. & b.1.d. & b.1.d. & b.1.d. & b.l.d. \\
\hline TOTAL & 100,59 & 100,92 & 100,58 & 100,45 & 100,10 & 101,11 \\
\hline
\end{tabular}

$*$ = asumido como $\mathrm{FeO}$ total. b.l.d. = bajo el límite de detección

Número de cationes en base a 4 oxígenos por unidad de fórmula

\begin{tabular}{|c|c|c|c|c|c|c|}
\hline \multicolumn{7}{|c|}{ Muestra $\rightarrow 21847$ (Cerro Negro) } \\
\hline Yacencia $\rightarrow$ & Veta & Veta & Veta & Veta & Veta & Veta \\
\hline c.p.u.f. & $\mathrm{c} 2-12$ & $\mathrm{c} 2-13$ & c2-14 & $\mathrm{c} 2-15$ & $\mathrm{c} 2-16$ & $\mathrm{c} 2-17$ \\
\hline $\mathrm{Fe}^{+2}$ & 0,0000 & 0,0000 & 0,0000 & 0,0000 & 0,0008 & 0,0000 \\
\hline Mn & 0,0008 & 0,0000 & 0,0000 & 0,0015 & 0,0009 & 0,0002 \\
\hline Co & 0,0000 & 0,0006 & 0,0000 & 0,0004 & 0,0000 & 0,0000 \\
\hline Mg & 0,0000 & 0,0004 & 0,0000 & 0,0000 & 0,0010 & 0,0007 \\
\hline $\mathbf{C a}$ & 0,0004 & 0,0004 & 0,0015 & 0,0011 & 0,0018 & 0,0017 \\
\hline $\mathbf{S r}$ & 0,0459 & 0,0380 & 0,0479 & 0,0478 & 0,0364 & 0,0413 \\
\hline $\mathbf{B a}$ & 0,9529 & 0,9606 & 0,9506 & 0,9492 & 0,9591 & 0,9561 \\
\hline $\mathbf{P}$ & 0,0000 & 0,0000 & 0,0000 & 0,0000 & 0,0000 & 0,0000 \\
\hline $\mathbf{P b}$ & 0,0000 & 0,0000 & 0,0000 & 0,0000 & 0,0000 & 0,0000 \\
\hline Suma & 1,0000 & 1,0000 & 1,0000 & 1,0000 & 1,0000 & 1,0000 \\
\hline $\mathbf{S}$ & 0,9901 & 0,9905 & 0,9941 & 0,9925 & 0,9918 & 0,9925 \\
\hline TOTAL & 1,9901 & 1,9905 & 1,9941 & 1,9925 & 1,9918 & 1,9925 \\
\hline
\end{tabular}

Proporciones moleculares de los componentes finales

\begin{tabular}{lrrrrrr}
\hline Anhidrita & 0,04 & 0,04 & 0,15 & 0,11 & 0,18 & 0,17 \\
Celestina & 4,60 & 3,80 & 4,79 & 4,79 & 3,65 & 4,13 \\
Baritina & 95,36 & 96,15 & 95,06 & 95,10 & 96,18 & 95,70 \\
\hline TOTAL & $\mathbf{1 0 0 , 0 0}$ & $\mathbf{1 0 0 , 0 0}$ & $\mathbf{1 0 0 , 0 0}$ & $\mathbf{1 0 0 , 0 0}$ & $\mathbf{1 0 0 , 0 0}$ & $\mathbf{1 0 0 , 0 0}$ \\
\hline
\end{tabular}


Análisis de BARITINA por microsonda electrónica

\begin{tabular}{|c|c|c|c|c|c|c|}
\hline \multicolumn{7}{|c|}{ Muestra $\rightarrow 21847$ (Cerro Negro) } \\
\hline Yacencia $\rightarrow$ & Veta & Veta & Veta & Veta & Veta & Veta \\
\hline$\%$ en peso & $\mathrm{c} 2-18$ & $\mathrm{c} 2-19$ & $\mathrm{c} 2-20$ & $\mathrm{c} 2-21$ & $\mathrm{c} 2-22$ & $\mathrm{c} 2-23$ \\
\hline FeO* & b.l.d. & b.1.d. & b.1.d. & 0,01 & b.l.d. & 0,03 \\
\hline MnO & b.l.d. & 0,02 & b.l.d. & 0,03 & 0,02 & 0,01 \\
\hline $\mathrm{CoO}$ & 0,02 & b.l.d. & b.l.d. & 0,02 & b.l.d. & 0,01 \\
\hline MgO & 0,01 & b.l.d. & b.l.d. & b.l.d. & b.l.d. & b.l.d. \\
\hline $\mathrm{CaO}$ & 0,03 & 0,03 & 0,01 & 0,01 & 0,02 & 0,03 \\
\hline SrO & 2,00 & 2,04 & 2,12 & 2,08 & 2,75 & 2,86 \\
\hline $\mathrm{BaO}$ & 64,03 & 63,84 & 64,08 & 64,50 & 63,50 & 62,10 \\
\hline $\mathbf{P}_{2} \mathbf{O}_{5}$ & b.l.d. & b.l.d. & b.l.d. & b.l.d. & b.l.d. & b.l.d. \\
\hline PbO & b.l.d. & b.l.d. & b.1.d. & b.l.d. & b.l.d. & b.l.d. \\
\hline $\mathrm{SO}_{3}$ & 33,93 & 34,54 & 33,79 & 34,21 & 34,62 & 34,68 \\
\hline $\mathbf{F}$ & b.1.d. & b.1.d. & b.l.d. & b.1.d. & b.1.d. & b.1.d. \\
\hline TOTAL & 100,01 & 100,47 & 100,00 & 100,86 & 100,91 & 99,72 \\
\hline
\end{tabular}

* = asumido como FeO total. b.l.d. = bajo el límite de detección

Número de cationes en base a 4 oxígenos por unidad de fórmula

\begin{tabular}{|c|c|c|c|c|c|c|}
\hline \multicolumn{7}{|c|}{ Muestra $\rightarrow 21847$ (Cerro Negro) } \\
\hline Yacencia $\rightarrow$ & Veta & Veta & Veta & Veta & Veta & Veta \\
\hline c.p.u.f. & $\mathrm{c} 2-18$ & $\mathrm{c} 2-19$ & $\mathrm{c} 2-20$ & $\mathrm{c} 2-21$ & $\mathrm{c} 2-22$ & $\mathrm{c} 2-23$ \\
\hline $\mathrm{Fe}^{+2}$ & 0,0000 & 0,0000 & 0,0000 & 0,0003 & 0,0000 & 0,0010 \\
\hline Mn & 0,0000 & 0,0006 & 0,0000 & 0,0008 & 0,0007 & 0,0003 \\
\hline Co & 0,0006 & 0,0000 & 0,0000 & 0,0005 & 0,0000 & 0,0004 \\
\hline Mg & 0,0006 & 0,0000 & 0,0000 & 0,0000 & 0,0000 & 0,0000 \\
\hline $\mathbf{C a}$ & 0,0011 & 0,0011 & 0,0004 & 0,0005 & 0,0006 & 0,0013 \\
\hline $\mathbf{S r}$ & 0,0441 & 0,0451 & 0,0467 & 0,0454 & 0,0601 & 0,0636 \\
\hline $\mathbf{B a}$ & 0,9537 & 0,9532 & 0,9530 & 0,9523 & 0,9385 & 0,9335 \\
\hline $\mathbf{P}$ & 0,0000 & 0,0000 & 0,0000 & 0,0000 & 0,0000 & 0,0000 \\
\hline $\mathbf{P b}$ & 0,0000 & 0,0000 & 0,0000 & 0,0000 & 0,0000 & 0,0000 \\
\hline Suma & 1,0000 & 1,0000 & 1,0000 & 1,0000 & 1,0000 & 1,0000 \\
\hline $\mathbf{S}$ & 0,9918 & 0,9969 & 0,9903 & 0,9916 & 0,9949 & 0,9996 \\
\hline TOTAL & 1,9918 & 1,9969 & 1,9903 & 1,9916 & 1,9949 & 1,9996 \\
\hline
\end{tabular}

Proporciones moleculares de los componentes finales

\begin{tabular}{lrrrrrr}
\hline Anhidrita & 0,11 & 0,11 & 0,04 & 0,05 & 0,06 & 0,13 \\
Celestina & 4,41 & 4,51 & 4,67 & 4,55 & 6,02 & 6,37 \\
Baritina & 95,48 & 95,38 & 95,30 & 95,39 & 93,92 & 93,50 \\
\hline TOTAL & $\mathbf{1 0 0 , 0 0}$ & $\mathbf{1 0 0 , 0 0}$ & $\mathbf{1 0 0 , 0 0}$ & $\mathbf{1 0 0 , 0 0}$ & $\mathbf{1 0 0 , 0 0}$ & $\mathbf{1 0 0 , 0 0}$ \\
\hline
\end{tabular}


Análisis de BARITINA por microsonda electrónica

\begin{tabular}{|c|c|c|c|c|c|c|}
\hline \multicolumn{7}{|c|}{ Muestra $\rightarrow 21847$ (Cerro Negro) } \\
\hline Yacencia $\rightarrow$ & Veta & Veta & Veta & Veta & Veta & Veta \\
\hline$\%$ en peso & c3-1 & c3-2 & c3-3 & c3-4 & c3-5 & c3-6 \\
\hline FeO* & 0,01 & 0,00 & b.1.d. & 0,05 & 0,02 & b.1.d. \\
\hline MnO & 0,07 & 0,02 & 0,03 & b.1.d. & 0,04 & 0,08 \\
\hline $\mathrm{CoO}$ & b.l.d. & b.l.d. & b.1.d. & b.l.d. & b.l.d. & b.l.d. \\
\hline MgO & b.l.d. & b.1.d. & b.1.d. & 0,01 & b.1.d. & 0,01 \\
\hline $\mathrm{CaO}$ & 0,00 & 0,05 & 0,02 & b.l.d. & 0,01 & 0,01 \\
\hline SrO & 1,83 & 1,16 & 1,34 & 1,52 & 2,36 & 2,68 \\
\hline $\mathrm{BaO}$ & 62,45 & 64,63 & 64,25 & 64,59 & 63,49 & 63,22 \\
\hline $\mathbf{P}_{2} \mathbf{O}_{5}$ & b.1.d. & b.l.d. & b.1.d. & b.1.d. & b.1.d. & b.l.d. \\
\hline PbO & b.l.d. & b.l.d. & b.1.d. & b.1.d. & b.1.d. & b.l.d. \\
\hline $\mathrm{SO}_{3}$ & 34,17 & 33,85 & 34,55 & 33,42 & 34,55 & 34,31 \\
\hline $\mathbf{F}$ & b.1.d. & b.1.d. & b.1.d. & b.1.d. & b.1.d. & b.1.d. \\
\hline TOTAL & 98,53 & 99,71 & 100,19 & 99,59 & 100,46 & 100,32 \\
\hline
\end{tabular}

$*=$ asumido como $\mathrm{FeO}$ total. b.l.d. = bajo el límite de detección

Número de cationes en base a 4 oxígenos por unidad de fórmula

\begin{tabular}{|c|c|c|c|c|c|c|}
\hline \multicolumn{7}{|c|}{ Muestra $\rightarrow 21847$ (Cerro Negro) } \\
\hline Yacencia $\rightarrow$ & Veta & Veta & Veta & Veta & Veta & Veta \\
\hline c.p.u.f. & $\mathrm{c} 3-1$ & $\mathrm{c} 3-2$ & $\mathrm{c} 3-3$ & $\mathrm{c} 3-4$ & $\mathrm{c} 3-5$ & $\mathrm{c} 3-6$ \\
\hline $\mathrm{Fe}^{+2}$ & 0,0004 & 0,0001 & 0,0000 & 0,0015 & 0,0006 & 0,0000 \\
\hline Mn & 0,0023 & 0,0006 & 0,0010 & 0,0000 & 0,0011 & 0,0026 \\
\hline Co & 0,0000 & 0,0000 & 0,0000 & 0,0000 & 0,0000 & 0,0000 \\
\hline Mg & 0,0000 & 0,0000 & 0,0000 & 0,0007 & 0,0000 & 0,0007 \\
\hline $\mathbf{C a}$ & 0,0000 & 0,0021 & 0,0009 & 0,0000 & 0,0005 & 0,0006 \\
\hline $\mathrm{Sr}$ & 0,0414 & 0,0258 & 0,0299 & 0,0336 & 0,0520 & 0,0588 \\
\hline $\mathbf{B a}$ & 0,9559 & 0,9715 & 0,9682 & 0,9642 & 0,9458 & 0,9373 \\
\hline $\mathbf{P}$ & 0,0000 & 0,0000 & 0,0000 & 0,0000 & 0,0000 & 0,0000 \\
\hline $\mathbf{P b}$ & 0,0000 & 0,0000 & 0,0000 & 0,0000 & 0,0000 & 0,0000 \\
\hline Suma & 1,0000 & 1,0000 & 1,0000 & 1,0000 & 1,0000 & 1,0000 \\
\hline $\mathbf{S}$ & 1,0004 & 0,9935 & 0,9993 & 0,9885 & 0,9964 & 0,9934 \\
\hline TOTAL & 2,0004 & 1,9935 & 1,9993 & 1,9885 & 1,9964 & 1,9934 \\
\hline
\end{tabular}

Proporciones moleculares de los componentes finales

\begin{tabular}{lrrrrrr}
\hline Anhidrita & 0,00 & 0,21 & 0,09 & 0,00 & 0,05 & 0,06 \\
Celestina & 4,16 & 2,58 & 2,99 & 3,37 & 5,21 & 5,90 \\
Baritina & 95,84 & 97,21 & 96,92 & 96,63 & 94,74 & 94,04 \\
\hline TOTAL & $\mathbf{1 0 0 , 0 0}$ & $\mathbf{1 0 0 , 0 0}$ & $\mathbf{1 0 0 , 0 0}$ & $\mathbf{1 0 0 , 0 0}$ & $\mathbf{1 0 0 , 0 0}$ & $\mathbf{1 0 0 , 0 0}$ \\
\hline
\end{tabular}


Análisis de BARITINA por microsonda electrónica

\begin{tabular}{|c|c|c|c|c|c|c|}
\hline \multicolumn{7}{|c|}{ Muestra $\rightarrow 21847$ (Cerro Negro) } \\
\hline Yacencia $\rightarrow$ & Veta & Veta & Veta & Veta & Veta & Veta \\
\hline$\%$ en peso & $\mathrm{c} 3-7$ & $\mathrm{c} 3-8$ & c3-9 & c3-10 & $\mathrm{c} 3-11$ & c3-12 \\
\hline $\mathrm{FeO}^{*}$ & b.1.d. & b.1.d. & b.1.d. & 0,04 & 0,03 & 0,01 \\
\hline MnO & 0,03 & 0,04 & b.1.d. & 0,00 & 0,01 & 0,00 \\
\hline $\mathrm{CoO}$ & 0,02 & b.l.d. & 0,01 & b.l.d. & 0,01 & b.l.d. \\
\hline MgO & 0,00 & b.1.d. & b.1.d. & 0,03 & b.1.d. & 0,01 \\
\hline $\mathrm{CaO}$ & b.1.d. & 0,03 & 0,02 & 0,00 & 0,02 & 0,02 \\
\hline SrO & 2,51 & 2,37 & 2,31 & 1,27 & 2,38 & 2,25 \\
\hline $\mathrm{BaO}$ & 63,50 & 64,29 & 64,05 & 65,68 & 63,89 & 62,48 \\
\hline $\mathbf{P}_{2} \mathbf{O}_{5}$ & b.1.d. & b.1.d. & b.1.d. & b.1.d. & b.1.d. & b.l.d. \\
\hline PbO & b.l.d. & b.l.d. & b.l.d. & b.l.d. & b.l.d. & b.l.d. \\
\hline $\mathrm{SO}_{3}$ & 33,48 & 33,77 & 34,97 & 34,34 & 34,24 & 34,24 \\
\hline $\mathbf{F}$ & b.1.d. & b.1.d. & b.1.d. & b.1.d. & b.1.d. & b.l.d. \\
\hline TOTAL & 99,54 & 100,50 & 101,36 & 101,37 & 100,58 & 99,01 \\
\hline
\end{tabular}

* = asumido como FeO total. b.l.d. = bajo el límite de detección

Número de cationes en base a 4 oxígenos por unidad de fórmula

\begin{tabular}{|c|c|c|c|c|c|c|}
\hline \multicolumn{7}{|c|}{ Muestra $\rightarrow 21847$ (Cerro Negro) } \\
\hline Yacencia $\rightarrow$ & Veta & Veta & Veta & Veta & Veta & Veta \\
\hline c.p.u.f. & $\mathrm{c} 3-7$ & $\mathrm{c} 3-8$ & c3-9 & $\mathrm{c} 3-10$ & c3-11 & $\mathrm{c} 3-12$ \\
\hline $\mathrm{Fe}^{+2}$ & 0,0000 & 0,0000 & 0,0000 & 0,0014 & 0,0008 & 0,0002 \\
\hline Mn & 0,0008 & 0,0011 & 0,0000 & 0,0001 & 0,0005 & 0,0001 \\
\hline Co & 0,0007 & 0,0000 & 0,0002 & 0,0000 & 0,0003 & 0,0000 \\
\hline Mg & 0,0002 & 0,0000 & 0,0000 & 0,0017 & 0,0000 & 0,0007 \\
\hline $\mathbf{C a}$ & 0,0000 & 0,0014 & 0,0008 & 0,0000 & 0,0008 & 0,0009 \\
\hline $\mathrm{Sr}$ & 0,0552 & 0,0516 & 0,0506 & 0,0277 & 0,0521 & 0,0505 \\
\hline $\mathbf{B a}$ & 0,9432 & 0,9459 & 0,9484 & 0,9690 & 0,9455 & 0,9476 \\
\hline $\mathbf{P}$ & 0,0000 & 0,0000 & 0,0000 & 0,0000 & 0,0000 & 0,0000 \\
\hline $\mathbf{P b}$ & 0,0000 & 0,0000 & 0,0000 & 0,0000 & 0,0000 & 0,0000 \\
\hline Suma & 1,0000 & 1,0000 & 1,0000 & 1,0000 & 1,0000 & 1,0000 \\
\hline $\mathbf{S}$ & 0,9876 & 0,9874 & 0,9979 & 0,9924 & 0,9924 & 0,9986 \\
\hline TOTAL & 1,9876 & 1,9874 & 1,9979 & 1,9924 & 1,9924 & 1,9986 \\
\hline
\end{tabular}

Proporciones moleculares de los componentes finales

\begin{tabular}{lrrrrrr}
\hline Anhidrita & 0,00 & 0,14 & 0,08 & 0,00 & 0,08 & 0,09 \\
Celestina & 5,53 & 5,17 & 5,06 & 2,78 & 5,22 & 5,05 \\
Baritina & 94,47 & 94,70 & 94,85 & 97,22 & 94,70 & 94,85 \\
\hline TOTAL & $\mathbf{1 0 0 , 0 0}$ & $\mathbf{1 0 0 , 0 0}$ & $\mathbf{1 0 0 , 0 0}$ & $\mathbf{1 0 0 , 0 0}$ & $\mathbf{1 0 0 , 0 0}$ & $\mathbf{1 0 0 , 0 0}$ \\
\hline
\end{tabular}


Análisis de BARITINA por microsonda electrónica

\begin{tabular}{|c|c|c|c|c|c|c|}
\hline \multicolumn{7}{|c|}{ Muestra $\rightarrow 21847$ (Cerro Negro) } \\
\hline Yacencia $\rightarrow$ & Veta & Veta & Veta & Veta & Veta & Veta \\
\hline$\%$ en peso & c3-13 & $\mathrm{c} 3-14$ & $\mathrm{c} 3-15$ & $\mathrm{c} 3-16$ & $\mathrm{c} 3-17$ & $\mathrm{c} 3-18$ \\
\hline FeO* & 0,09 & b.1.d. & b.1.d. & b.l.d. & b.l.d. & b.1.d. \\
\hline MnO & 0,03 & 0,01 & 0,00 & b.l.d. & 0,00 & 0,07 \\
\hline $\mathrm{CoO}$ & b.l.d. & b.l.d. & b.1.d. & 0,00 & 0,02 & b.l.d. \\
\hline MgO & 0,02 & 0,00 & b.l.d. & b.l.d. & b.l.d. & b.1.d. \\
\hline $\mathrm{CaO}$ & 0,02 & b.l.d. & 0,01 & 0,03 & 0,00 & b.l.d. \\
\hline SrO & 2,00 & 1,27 & 1,67 & 1,72 & 2,93 & 2,66 \\
\hline $\mathrm{BaO}$ & 64,10 & 64,60 & 65,01 & 65,04 & 63,27 & 63,03 \\
\hline $\mathbf{P}_{2} \mathbf{O}_{5}$ & b.l.d. & b.l.d. & b.l.d. & b.l.d. & b.l.d. & b.l.d. \\
\hline PbO & b.l.d. & b.l.d. & b.l.d. & b.l.d. & b.l.d. & b.l.d. \\
\hline $\mathrm{SO}_{3}$ & 33,94 & 34,43 & 34,15 & 34,88 & 34,66 & 33,85 \\
\hline $\mathbf{F}$ & b.1.d. & b.1.d. & b.1.d. & b.1.d. & b.1.d. & b.1.d. \\
\hline TOTAL & 100,20 & 100,31 & 100,84 & 101,68 & 100,89 & 99,61 \\
\hline
\end{tabular}

* = asumido como FeO total. b.l.d. = bajo el límite de detección

Número de cationes en base a 4 oxígenos por unidad de fórmula

\begin{tabular}{|c|c|c|c|c|c|c|}
\hline \multicolumn{7}{|c|}{ Muestra $\rightarrow 21847$ (Cerro Negro) } \\
\hline Yacencia $\rightarrow$ & Veta & Veta & Veta & Veta & Veta & Veta \\
\hline c.p.u.f. & $\mathrm{c} 3-13$ & $\mathrm{c} 3-14$ & $\mathrm{c} 3-15$ & $\mathrm{c} 3-16$ & $\mathrm{c} 3-17$ & $\mathrm{c} 3-18$ \\
\hline $\mathrm{Fe}^{+2}$ & 0,0029 & 0,0000 & 0,0000 & 0,0000 & 0,0000 & 0,0000 \\
\hline Mn & 0,0008 & 0,0003 & 0,0001 & 0,0000 & 0,0001 & 0,0023 \\
\hline Co & 0,0000 & 0,0000 & 0,0000 & 0,0000 & 0,0006 & 0,0000 \\
\hline Mg & 0,0009 & 0,0001 & 0,0000 & 0,0000 & 0,0000 & 0,0000 \\
\hline $\mathbf{C a}$ & 0,0008 & 0,0000 & 0,0004 & 0,0014 & 0,0000 & 0,0000 \\
\hline $\mathbf{S r}$ & 0,0439 & 0,0283 & 0,0366 & 0,0376 & 0,0641 & 0,0586 \\
\hline $\mathbf{B a}$ & 0,9506 & 0,9714 & 0,9629 & 0,9610 & 0,9352 & 0,9391 \\
\hline $\mathbf{P}$ & 0,0000 & 0,0000 & 0,0000 & 0,0000 & 0,0000 & 0,0000 \\
\hline $\mathbf{P b}$ & 0,0000 & 0,0000 & 0,0000 & 0,0000 & 0,0000 & 0,0000 \\
\hline Suma & 1,0000 & 1,0000 & 1,0000 & 1,0000 & 1,0000 & 1,0000 \\
\hline $\mathbf{S}$ & 0,9907 & 0,9978 & 0,9920 & 0,9967 & 0,9952 & 0,9912 \\
\hline TOTAL & 1,9907 & 1,9978 & 1,9920 & 1,9967 & 1,9952 & 1,9912 \\
\hline
\end{tabular}

Proporciones moleculares de los componentes finales

\begin{tabular}{lrrrrrr}
\hline Anhidrita & 0,08 & 0,00 & 0,04 & 0,14 & 0,00 & 0,00 \\
Celestina & 4,41 & 2,83 & 3,66 & 3,76 & 6,41 & 5,88 \\
Baritina & 95,51 & 97,17 & 96,30 & 96,10 & 93,59 & 94,12 \\
\hline TOTAL & $\mathbf{1 0 0 , 0 0}$ & $\mathbf{1 0 0 , 0 0}$ & $\mathbf{1 0 0 , 0 0}$ & $\mathbf{1 0 0 , 0 0}$ & $\mathbf{1 0 0 , 0 0}$ & $\mathbf{1 0 0 , 0 0}$ \\
\hline
\end{tabular}


Análisis de BARITINA por microsonda electrónica

\begin{tabular}{|c|c|c|c|c|c|c|}
\hline \multicolumn{4}{|c|}{ Muestra $\rightarrow 21847$ (Cerro Negro) } & \multicolumn{3}{|c|}{19373 (mina J.C.) } \\
\hline Yacencia $\rightarrow$ & Veta & Veta & Veta & Veta & Veta & Veta \\
\hline$\%$ en peso & c3-19 & $\mathrm{c} 3-20$ & $\mathrm{c} 3-21$ & c3-22 & 1 & 2 \\
\hline $\mathrm{FeO}^{*}$ & 0,06 & b.1.d. & b.l.d. & 0,03 & 0,0281 & 0,2754 \\
\hline MnO & 0,01 & 0,08 & b.l.d. & 0,05 & b.1.d. & 0,0409 \\
\hline $\mathrm{CoO}$ & 0,01 & b.l.d. & b.l.d. & b.l.d. & 0,0119 & 0,0049 \\
\hline MgO & 0,00 & 0,01 & 0,01 & b.l.d. & b.l.d. & 0,0171 \\
\hline $\mathrm{CaO}$ & 0,03 & 0,01 & 0,01 & 0,01 & 0,0308 & b.l.d. \\
\hline SrO & 1,56 & 2,66 & 1,05 & 2,79 & 0,0303 & 0,876 \\
\hline $\mathrm{BaO}$ & 64,67 & 63,14 & 64,83 & 63,10 & 66,46 & 64,28 \\
\hline $\mathbf{P}_{2} \mathbf{O}_{5}$ & b.l.d. & b.l.d. & b.1.d. & b.l.d. & n.a. & n.a. \\
\hline PbO & b.l.d. & b.l.d. & b.l.d. & b.l.d. & b.l.d. & b.l.d. \\
\hline $\mathrm{SO}_{3}$ & 34,59 & 34,27 & 33,67 & 34,78 & 34,18 & 34,38 \\
\hline $\mathbf{F}$ & b.1.d. & b.1.d. & b.1.d. & b.1.d. & n.a. & n.a. \\
\hline TOTAL & 100,93 & 100,17 & $\mathbf{9 9 , 5 8}$ & 100,76 & 100,74 & 99,87 \\
\hline
\end{tabular}

* = asumido como $\mathrm{FeO}$ total. b.l.d. = bajo el límite de detección

Número de cationes en base a 4 oxígenos por unidad de fórmula

\begin{tabular}{|c|c|c|c|c|c|c|}
\hline \multicolumn{5}{|c|}{ Muestra $\rightarrow 21847$ (Cerro Negro) } & \multicolumn{2}{|c|}{19373 (mina J.C.) } \\
\hline Yacencia $\rightarrow$ & Veta & Veta & Veta & Veta & Veta & Veta \\
\hline c.p.u.f. & c3-19 & $\mathrm{c} 3-20$ & $\mathrm{c} 3-21$ & $\mathrm{c} 3-22$ & 1 & 2 \\
\hline $\mathrm{Fe}^{+2}$ & 0,0018 & 0,0000 & 0,0000 & 0,0010 & 0,0009 & 0,0089 \\
\hline Mn & 0,0004 & 0,0025 & 0,0000 & 0,0015 & 0,0000 & 0,0013 \\
\hline Co & 0,0004 & 0,0000 & 0,0000 & 0,0000 & 0,0004 & 0,0002 \\
\hline Mg & 0,0001 & 0,0005 & 0,0007 & 0,0000 & 0,0000 & 0,0010 \\
\hline $\mathbf{C a}$ & 0,0011 & 0,0005 & 0,0005 & 0,0004 & 0,0013 & 0,0000 \\
\hline $\mathbf{S r}$ & 0,0343 & 0,0585 & 0,0234 & 0,0612 & 0,0007 & 0,0195 \\
\hline $\mathbf{B a}$ & 0,9620 & 0,9381 & 0,9754 & 0,9359 & 0,9968 & 0,9691 \\
\hline $\mathbf{P}$ & 0,0000 & 0,0000 & 0,0000 & 0,0000 & 0,0000 & 0,0000 \\
\hline $\mathbf{P b}$ & 0,0000 & 0,0000 & 0,0000 & 0,0000 & 0,0000 & 0,0000 \\
\hline Suma & 1,0000 & 1,0000 & 1,0000 & 1,0000 & 1,0000 & 1,0000 \\
\hline $\mathbf{S}$ & 0,9963 & 0,9937 & 0,9924 & 0,9970 & 0,9954 & 0,9982 \\
\hline TOTAL & 1,9963 & 1,9937 & 1,9924 & 1,9970 & 1,9954 & 1,9982 \\
\hline
\end{tabular}

Proporciones moleculares de los componentes finales

\begin{tabular}{lrrrrrr}
\hline Anhidrita & 0,11 & 0,05 & 0,05 & 0,04 & 0,13 & 0,00 \\
Celestina & 3,44 & 5,87 & 2,35 & 6,14 & 0,07 & 1,98 \\
Baritina & 96,45 & 94,09 & 97,61 & 93,82 & 99,81 & 98,02 \\
\hline TOTAL & $\mathbf{1 0 0 , 0 0}$ & $\mathbf{1 0 0 , 0 0}$ & $\mathbf{1 0 0 , 0 0}$ & $\mathbf{1 0 0 , 0 0}$ & $\mathbf{1 0 0 , 0 0}$ & $\mathbf{1 0 0 , 0 0}$ \\
\hline
\end{tabular}


Análisis de BARITINA por microsonda electrónica

\begin{tabular}{|c|c|c|c|c|c|c|}
\hline \multicolumn{7}{|c|}{ Muestra $\rightarrow 19373$ (mina Julio César) } \\
\hline Yacencia $\rightarrow$ & Veta & Veta & Veta & Veta & Veta & Veta \\
\hline$\%$ en peso & 3 & 4 & 5 & 6 & 7 & 8 \\
\hline $\mathrm{FeO} *$ & 0,0585 & b.l.d. & b.1.d. & b.1.d. & b.l.d. & 0,0531 \\
\hline MnO & 0,0167 & 0,0336 & 0,0638 & b.l.d. & 0,067 & 0,1041 \\
\hline $\mathrm{CoO}$ & 0,0143 & b.l.d. & b.1.d. & b.l.d. & 0,0428 & b.l.d. \\
\hline MgO & b.l.d. & 0,0162 & b.1.d. & 0,0163 & b.l.d. & b.1.d. \\
\hline $\mathbf{C a O}$ & b.l.d. & b.l.d. & 0,0047 & b.l.d. & 0,081 & 0,0055 \\
\hline SrO & 0,9235 & 0,0759 & 0,6716 & 0,0403 & 0,2533 & 0,8518 \\
\hline $\mathrm{BaO}$ & 66,94 & 66,03 & 64,88 & 65,94 & 65,66 & 65,02 \\
\hline $\mathbf{P}_{2} \mathbf{O}_{5}$ & n.a. & n.a. & n.a. & n.a. & n.a. & n.a. \\
\hline PbO & b.l.d. & b.l.d. & b.l.d. & b.l.d. & b.l.d. & b.1.d. \\
\hline $\mathrm{SO}_{3}$ & 33,2 & 33,85 & 33,03 & 33,87 & 33,38 & 34,13 \\
\hline $\mathbf{F}$ & n.a. & n.a. & n.a. & n.a. & n.a. & n.a. \\
\hline
\end{tabular}

* = asumido como $\mathrm{FeO}$ total. b.l.d. = bajo el límite de detección. n.a. = no analizado

Número de cationes en base a 4 oxígenos por unidad de fórmula

\begin{tabular}{|c|c|c|c|c|c|c|}
\hline \multicolumn{7}{|c|}{ Muestra $\rightarrow 19373$ (mina Julio César) } \\
\hline Yacencia $\rightarrow$ & Veta & Veta & Veta & Veta & Veta & Veta \\
\hline c.p.u.f. & 3 & 4 & 5 & 6 & 7 & 8 \\
\hline $\mathrm{Fe}^{+2}$ & 0,0018 & 0,0000 & 0,0000 & 0,0000 & 0,0000 & 0,0017 \\
\hline Mn & 0,0005 & 0,0011 & 0,0021 & 0,0000 & 0,0022 & 0,0034 \\
\hline Co & 0,0004 & 0,0000 & 0,0000 & 0,0000 & 0,0013 & 0,0000 \\
\hline Mg & 0,0000 & 0,0009 & 0,0000 & 0,0009 & 0,0000 & 0,0000 \\
\hline $\mathbf{C a}$ & 0,0000 & 0,0000 & 0,0002 & 0,0000 & 0,0033 & 0,0002 \\
\hline $\mathbf{S r}$ & 0,0200 & 0,0017 & 0,0151 & 0,0009 & 0,0056 & 0,0189 \\
\hline Ba & 0,9773 & 0,9963 & 0,9827 & 0,9982 & 0,9875 & 0,9758 \\
\hline $\mathbf{P}$ & 0,0000 & 0,0000 & 0,0000 & 0,0000 & 0,0000 & 0,0000 \\
\hline $\mathbf{P b}$ & 0,0000 & 0,0000 & 0,0000 & 0,0000 & 0,0000 & 0,0000 \\
\hline Suma & 1,0000 & 1,0000 & 1,0000 & 1,0000 & 1,0000 & 1,0000 \\
\hline $\mathbf{S}$ & 0,9810 & 0,9944 & 0,9892 & 0,9954 & 0,9901 & 0,9952 \\
\hline TOTAL & 1,9810 & 1,9944 & 1,9892 & 1,9954 & 1,9901 & 1,9952 \\
\hline
\end{tabular}

Proporciones moleculares de los componentes finales

\begin{tabular}{lrrrrrr}
\hline Anhidrita & 0,00 & 0,00 & 0,02 & 0,00 & 0,33 & 0,02 \\
Celestina & 2,00 & 0,17 & 1,51 & 0,09 & 0,57 & 1,90 \\
Baritina & 98,00 & 99,83 & 98,47 & 99,91 & 99,10 & 98,08 \\
\hline TOTAL & $\mathbf{1 0 0 , 0 0}$ & $\mathbf{1 0 0 , 0 0}$ & $\mathbf{1 0 0 , 0 0}$ & $\mathbf{1 0 0 , 0 0}$ & $\mathbf{1 0 0 , 0 0}$ & $\mathbf{1 0 0 , 0 0}$ \\
\hline
\end{tabular}


Análisis de BARITINA por microsonda electrónica

\begin{tabular}{|c|c|c|c|c|c|c|}
\hline \multicolumn{7}{|c|}{ Muestra $\rightarrow 19373$ (mina Julio César) } \\
\hline Yacencia $\rightarrow$ & Veta & Veta & Veta & Veta & Veta & Veta \\
\hline$\%$ en peso & 9 & 10 & 11 & 12 & 13 & 14 \\
\hline $\mathrm{FeO}^{*}$ & 0,0111 & 0,0309 & b.1.d. & 0,0391 & b.l.d. & 1,31 \\
\hline MnO & 0,0603 & 0,0338 & 0,01 & 0,0503 & b.l.d. & 0,0201 \\
\hline $\mathrm{CoO}$ & b.l.d. & 0,0742 & 0,0476 & b.l.d. & 0,0451 & b.l.d. \\
\hline MgO & 0,0108 & b.l.d. & b.l.d. & b.l.d. & b.l.d. & 0,0063 \\
\hline $\mathbf{C a O}$ & b.l.d. & b.l.d. & 0,0176 & 0,0118 & b.1.d. & 0,0011 \\
\hline SrO & 0,3443 & 0,8674 & 0,066 & 0,0638 & 0,9073 & 0,103 \\
\hline $\mathrm{BaO}$ & 65,71 & 65,65 & 67,31 & 65,97 & 65,83 & 65,54 \\
\hline $\mathbf{P}_{2} \mathbf{O}_{5}$ & n.a. & n.a. & n.a. & n.a. & n.a. & n.a. \\
\hline PbO & b.1.d. & b.1.d. & b.1.d. & b.1.d. & b.1.d. & 0,0114 \\
\hline $\mathrm{SO}_{3}$ & 33,5 & 33,2 & 33,84 & 33,27 & 33,24 & 33,14 \\
\hline $\mathbf{F}$ & n.a. & n.a. & n.a. & n.a. & n.a. & n.a. \\
\hline
\end{tabular}

\begin{tabular}{lllllll} 
TOTAL & 99,64 & 99,86 & 101,29 & 99,41 & 100,02 & 100,13 \\
\hline
\end{tabular}

$*=$ asumido como $\mathrm{FeO}$ total. b.l.d. = bajo el límite de detección. n.a. = no analizado

Número de cationes en base a 4 oxígenos por unidad de fórmula

\begin{tabular}{|c|c|c|c|c|c|c|}
\hline \multicolumn{7}{|c|}{ Muestra $\rightarrow 19373$ (mina Julio César) } \\
\hline Yacencia $\rightarrow$ & Veta & Veta & Veta & Veta & Veta & Veta \\
\hline c.p.u.f. & 9 & 10 & 11 & 12 & 13 & 14 \\
\hline $\mathrm{Fe}^{+2}$ & 0,0004 & 0,0010 & 0,0000 & 0,0013 & 0,0000 & 0,0408 \\
\hline Mn & 0,0020 & 0,0011 & 0,0003 & 0,0016 & 0,0000 & 0,0006 \\
\hline Co & 0,0000 & 0,0023 & 0,0014 & 0,0000 & 0,0014 & 0,0000 \\
\hline Mg & 0,0006 & 0,0000 & 0,0000 & 0,0000 & 0,0000 & 0,0003 \\
\hline $\mathbf{C a}$ & 0,0000 & 0,0000 & 0,0007 & 0,0005 & 0,0000 & 0,0000 \\
\hline $\mathrm{Sr}$ & 0,0077 & 0,0191 & 0,0014 & 0,0014 & 0,0200 & 0,0022 \\
\hline $\mathbf{B a}$ & 0,9894 & 0,9766 & 0,9961 & 0,9952 & 0,9787 & 0,9559 \\
\hline $\mathbf{P}$ & 0,0000 & 0,0000 & 0,0000 & 0,0000 & 0,0000 & 0,0000 \\
\hline $\mathbf{P b}$ & 0,0000 & 0,0000 & 0,0000 & 0,0000 & 0,0000 & 0,0001 \\
\hline Suma & 1,0000 & 1,0000 & 1,0000 & 1,0000 & 1,0000 & 1,0000 \\
\hline $\mathbf{S}$ & 0,9913 & 0,9859 & 0,9894 & 0,9900 & 0,9860 & 0,9803 \\
\hline TOTAL & 1,9913 & 1,9859 & 1,9894 & 1,9900 & 1,9860 & 1,9803 \\
\hline
\end{tabular}

Proporciones moleculares de los componentes finales

\begin{tabular}{lrrrrrr}
\hline Anhidrita & 0,00 & 0,00 & 0,07 & 0,05 & 0,00 & 0,00 \\
Celestina & 0,77 & 1,92 & 0,14 & 0,14 & 2,00 & 0,23 \\
Baritina & 99,23 & 98,08 & 99,78 & 99,81 & 98,00 & 99,76 \\
\hline TOTAL & $\mathbf{1 0 0 , 0 0}$ & $\mathbf{1 0 0 , 0 0}$ & $\mathbf{1 0 0 , 0 0}$ & $\mathbf{1 0 0 , 0 0}$ & $\mathbf{1 0 0 , 0 0}$ & $\mathbf{1 0 0 , 0 0}$ \\
\hline
\end{tabular}


Análisis de BARITINA por microsonda electrónica

\begin{tabular}{|c|c|c|c|c|c|c|}
\hline \multicolumn{7}{|c|}{ Muestra $\rightarrow 19373$ (mina Julio César) } \\
\hline \multicolumn{7}{|c|}{$\begin{array}{l}\text { Muestra } \rightarrow \\
\text { Yacencia } \rightarrow \quad \text { Veta } \quad \text { Veta }\end{array}$} \\
\hline$\%$ en peso & 15 & 16 & 17 & 18 & 19 & 20 \\
\hline $\mathrm{FeO} *$ & 0,078 & 0,0028 & 0,0473 & 0,0866 & 0,4857 & 0,1788 \\
\hline MnO & 0,0301 & 0,0268 & 0,0469 & 0,0202 & 0,094 & 0,0705 \\
\hline $\mathrm{CoO}$ & 0,0356 & b.1.d. & 0,0618 & b.l.d. & 0,0952 & 0,0143 \\
\hline MgO & b.l.d. & b.l.d. & b.1.d. & 0,0119 & 0,0022 & 0,0211 \\
\hline $\mathbf{C a O}$ & b.1.d. & b.l.d. & 0,0069 & b.l.d. & 0,0077 & 0,0095 \\
\hline SrO & 0,0058 & b.l.d. & 1,1802 & 0,5458 & 0,0247 & 0,9441 \\
\hline $\mathrm{BaO}$ & 67,45 & 65,7 & 64,15 & 64,66 & 66,21 & 64,46 \\
\hline $\mathbf{P}_{2} \mathbf{O}_{5}$ & n.a. & n.a. & n.a. & n.a. & n.a. & n.a. \\
\hline PbO & 0,0076 & b.l.d. & b.l.d. & b.l.d. & b.l.d. & b.l.d. \\
\hline $\mathrm{SO}_{3}$ & 33,58 & 33,51 & 33,17 & 33,7 & 33,68 & 33,7 \\
\hline $\mathbf{F}$ & n.a. & n.a. & n.a. & n.a. & n.a. & n.a. \\
\hline TOTAL & 101,19 & 99,24 & 98,66 & 99,02 & 100,60 & $\mathbf{9 9 , 4 0}$ \\
\hline
\end{tabular}

* = asumido como $\mathrm{FeO}$ total. b.l.d. = bajo el límite de detección. n.a. = no analizado

Número de cationes en base a 4 oxígenos por unidad de fórmula

\begin{tabular}{|c|c|c|c|c|c|c|}
\hline \multicolumn{7}{|c|}{ Muestra $\rightarrow 19373$ (mina Julio César) } \\
\hline Yacencia $\rightarrow$ & Veta & Veta & Veta & Veta & Veta & Veta \\
\hline c.p.u.f. & 15 & 16 & 17 & 18 & 19 & 20 \\
\hline $\mathrm{Fe}^{+2}$ & 0,0025 & 0,0001 & 0,0015 & 0,0028 & 0,0153 & 0,0057 \\
\hline Mn & 0,0010 & 0,0009 & 0,0015 & 0,0007 & 0,0030 & 0,0023 \\
\hline Co & 0,0011 & 0,0000 & 0,0019 & 0,0000 & 0,0029 & 0,0004 \\
\hline Mg & 0,0000 & 0,0000 & 0,0000 & 0,0007 & 0,0001 & 0,0012 \\
\hline $\mathbf{C a}$ & 0,0000 & 0,0000 & 0,0003 & 0,0000 & 0,0003 & 0,0004 \\
\hline $\mathbf{S r}$ & 0,0001 & 0,0000 & 0,0264 & 0,0123 & 0,0005 & 0,0210 \\
\hline $\mathbf{B a}$ & 0,9953 & 0,9990 & 0,9684 & 0,9836 & 0,9778 & 0,9689 \\
\hline $\mathbf{P}$ & 0,0000 & 0,0000 & 0,0000 & 0,0000 & 0,0000 & 0,0000 \\
\hline $\mathbf{P b}$ & 0,0001 & 0,0000 & 0,0000 & 0,0000 & 0,0000 & 0,0000 \\
\hline Suma & 1,0000 & 1,0000 & 1,0000 & 1,0000 & 1,0000 & 1,0000 \\
\hline $\mathbf{S}$ & 0,9867 & 0,9938 & 0,9894 & 0,9954 & 0,9877 & 0,9924 \\
\hline TOTAL & 1,9867 & 1,9938 & 1,9894 & 1,9954 & 1,9877 & 1,9924 \\
\hline
\end{tabular}

Proporciones moleculares de los componentes finales

\begin{tabular}{lrrrrrr}
\hline Anhidrita & 0,00 & 0,00 & 0,03 & 0,00 & 0,03 & 0,04 \\
Celestina & 0,01 & 0,00 & 2,65 & 1,23 & 0,06 & 2,12 \\
Baritina & 99,99 & 100,00 & 97,32 & 98,77 & 99,91 & 97,84 \\
\hline TOTAL & $\mathbf{1 0 0 , 0 0}$ & $\mathbf{1 0 0 , 0 0}$ & $\mathbf{1 0 0 , 0 0}$ & $\mathbf{1 0 0 , 0 0}$ & $\mathbf{1 0 0 , 0 0}$ & $\mathbf{1 0 0 , 0 0}$ \\
\hline
\end{tabular}


Análisis de BARITINA por microsonda electrónica

\begin{tabular}{|c|c|c|c|c|c|c|}
\hline \multicolumn{7}{|c|}{ Muestra $\rightarrow 19373$ (mina Julio César) } \\
\hline Yacencia $\rightarrow$ & Veta & Veta & Veta & Veta & Veta & Veta \\
\hline$\%$ en peso & 21 & 22 & 23 & 24 & 25 & 26 \\
\hline FeO* & 0,0531 & 0,0977 & 0,0419 & 0,0447 & b.1.d. & 0,0308 \\
\hline MnO & b.l.d. & b.1.d. & 0,0167 & b.l.d. & 0,0235 & b.1.d. \\
\hline $\mathrm{CoO}$ & b.l.d. & 0,0238 & b.1.d. & b.l.d. & b.l.d. & b.l.d. \\
\hline MgO & b.l.d. & 0,0218 & 0,0028 & b.l.d. & b.l.d. & b.1.d. \\
\hline $\mathbf{C a O}$ & b.l.d. & b.l.d. & 0,0039 & 0,0049 & b.1.d. & b.l.d. \\
\hline SrO & 0,3362 & 0,1105 & 0,1238 & 1,0011 & 1,43 & 1,0095 \\
\hline $\mathrm{BaO}$ & 64,35 & 65,29 & 66,38 & 65,83 & 63,38 & 65,38 \\
\hline $\mathbf{P}_{2} \mathbf{O}_{5}$ & n.a. & n.a. & n.a. & n.a. & n.a. & n.a. \\
\hline PbO & b.l.d. & b.l.d. & b.l.d. & b.l.d. & b.l.d. & b.l.d. \\
\hline $\mathrm{SO}_{3}$ & 33,46 & 33,66 & 33,98 & 33,98 & 33,97 & 33,69 \\
\hline $\mathbf{F}$ & n.a. & n.a. & n.a. & n.a. & n.a. & n.a. \\
\hline
\end{tabular}

* = asumido como $\mathrm{FeO}$ total. b.l.d. = bajo el límite de detección. n.a. = no analizado

Número de cationes en base a 4 oxígenos por unidad de fórmula

\begin{tabular}{|c|c|c|c|c|c|c|}
\hline \multicolumn{7}{|c|}{ Muestra $\rightarrow 19373$ (mina Julio César) } \\
\hline Yacencia $\rightarrow$ & Veta & Veta & Veta & Veta & Veta & Veta \\
\hline c.p.u.f. & 21 & 22 & 23 & 24 & 25 & 26 \\
\hline $\mathrm{Fe}^{+2}$ & 0,0017 & 0,0032 & 0,0013 & 0,0014 & 0,0000 & 0,0010 \\
\hline Mn & 0,0000 & 0,0000 & 0,0005 & 0,0000 & 0,0008 & 0,0000 \\
\hline Co & 0,0000 & 0,0007 & 0,0000 & 0,0000 & 0,0000 & 0,0000 \\
\hline Mg & 0,0000 & 0,0013 & 0,0002 & 0,0000 & 0,0000 & 0,0000 \\
\hline $\mathbf{C a}$ & 0,0000 & 0,0000 & 0,0002 & 0,0002 & 0,0000 & 0,0000 \\
\hline Sr & 0,0077 & 0,0025 & 0,0027 & 0,0220 & 0,0323 & 0,0223 \\
\hline Ba & 0,9906 & 0,9923 & 0,9951 & 0,9764 & 0,9669 & 0,9767 \\
\hline $\mathbf{P}$ & 0,0000 & 0,0000 & 0,0000 & 0,0000 & 0,0000 & 0,0000 \\
\hline $\mathbf{P b}$ & 0,0000 & 0,0000 & 0,0000 & 0,0000 & 0,0000 & 0,0000 \\
\hline Suma & 1,0000 & 1,0000 & 1,0000 & 1,0000 & 1,0000 & 1,0000 \\
\hline $\mathbf{S}$ & 0,9966 & 0,9949 & 0,9938 & 0,9911 & 0,9981 & 0,9907 \\
\hline TOTAL & 1,9966 & 1,9949 & 1,9938 & 1,9911 & 1,9981 & 1,9907 \\
\hline
\end{tabular}

Proporciones moleculares de los componentes finales

\begin{tabular}{lrrrrrr}
\hline Anhidrita & 0,00 & 0,00 & 0,02 & 0,02 & 0,00 & 0,00 \\
Celestina & 0,77 & 0,25 & 0,28 & 2,20 & 3,23 & 2,23 \\
Baritina & 99,23 & 99,75 & 99,71 & 97,78 & 96,77 & 97,77 \\
\hline TOTAL & $\mathbf{1 0 0 , 0 0}$ & $\mathbf{1 0 0 , 0 0}$ & $\mathbf{1 0 0 , 0 0}$ & $\mathbf{1 0 0 , 0 0}$ & $\mathbf{1 0 0 , 0 0}$ & $\mathbf{1 0 0 , 0 0}$ \\
\hline
\end{tabular}


Análisis de BARITINA por microsonda electrónica

\begin{tabular}{|c|c|c|c|c|c|c|}
\hline \multicolumn{7}{|c|}{ Muestra $\rightarrow 19373$ (mina Julio César) } \\
\hline Yacencia $\rightarrow$ & Veta & Veta & Veta & Veta & Veta & Veta \\
\hline$\%$ en peso & 27 & 28 & 29 & 30 & 31 & 32 \\
\hline $\mathrm{FeO} *$ & 0,0502 & b.l.d. & b.l.d. & 0,0362 & b.l.d. & 0,0476 \\
\hline MnO & 0,0235 & b.1.d. & 0,0602 & b.1.d. & 0,037 & 0,0504 \\
\hline $\mathrm{CoO}$ & 0,0476 & 0,0665 & b.1.d. & 0,1306 & b.l.d. & b.l.d. \\
\hline MgO & b.1.d. & b.1.d. & 0,0267 & 0,0144 & 0,0103 & b.1.d. \\
\hline $\mathrm{CaO}$ & b.1.d. & b.1.d. & 0,0093 & b.1.d. & b.1.d. & 0,0021 \\
\hline SrO & 0,9239 & 0,0115 & 1,0651 & 0,8523 & 0,7998 & 1,1538 \\
\hline $\mathrm{BaO}$ & 65,04 & 66,59 & 65,72 & 65,39 & 64 & 64,38 \\
\hline $\mathbf{P}_{2} \mathbf{O}_{5}$ & n.a. & n.a. & n.a. & n.a. & n.a. & n.a. \\
\hline PbO & b.l.d. & b.l.d. & b.l.d. & b.l.d. & b.l.d. & b.l.d. \\
\hline $\mathrm{SO}_{3}$ & 33,05 & 33,02 & 32,84 & 33,48 & 33,69 & 33,71 \\
\hline $\mathbf{F}$ & n.a. & n.a. & n.a. & n.a. & n.a. & n.a. \\
\hline TOTAL & 99,14 & 99,69 & 99,72 & 99,90 & 98,54 & 99,34 \\
\hline
\end{tabular}

* = asumido como $\mathrm{FeO}$ total. b.l.d. = bajo el límite de detección. n.a. = no analizado

Número de cationes en base a 4 oxígenos por unidad de fórmula

\begin{tabular}{|c|c|c|c|c|c|c|}
\hline \multicolumn{7}{|c|}{ Muestra $\rightarrow 19373$ (mina Julio César) } \\
\hline Yacencia $\rightarrow$ & Veta & Veta & Veta & Veta & Veta & Veta \\
\hline c.p.u.f. & 27 & 28 & 29 & 30 & 31 & 32 \\
\hline $\mathrm{Fe}^{+2}$ & 0,0016 & 0,0000 & 0,0000 & 0,0012 & 0,0000 & 0,0015 \\
\hline Mn & 0,0008 & 0,0000 & 0,0019 & 0,0000 & 0,0012 & 0,0016 \\
\hline Co & 0,0015 & 0,0020 & 0,0000 & 0,0040 & 0,0000 & 0,0000 \\
\hline Mg & 0,0000 & 0,0000 & 0,0015 & 0,0008 & 0,0006 & 0,0000 \\
\hline $\mathbf{C a}$ & 0,0000 & 0,0000 & 0,0004 & 0,0000 & 0,0000 & 0,0001 \\
\hline $\mathbf{S r}$ & 0,0205 & 0,0003 & 0,0233 & 0,0188 & 0,0181 & 0,0258 \\
\hline $\mathbf{B a}$ & 0,9757 & 0,9977 & 0,9729 & 0,9752 & 0,9801 & 0,9710 \\
\hline $\mathbf{P}$ & 0,0000 & 0,0000 & 0,0000 & 0,0000 & 0,0000 & 0,0000 \\
\hline $\mathbf{P b}$ & 0,0000 & 0,0000 & 0,0000 & 0,0000 & 0,0000 & 0,0000 \\
\hline Suma & 1,0000 & 1,0000 & 1,0000 & 1,0000 & 1,0000 & 1,0000 \\
\hline $\mathbf{S}$ & 0,9869 & 0,9863 & 0,9818 & 0,9887 & 0,9970 & 0,9933 \\
\hline TOTAL & 1,9869 & 1,9863 & 1,9818 & 1,9887 & 1,9970 & 1,9933 \\
\hline
\end{tabular}

Proporciones moleculares de los componentes finales

\begin{tabular}{lrrrrrr}
\hline Anhidrita & 0,00 & 0,00 & 0,04 & 0,00 & 0,00 & 0,01 \\
Celestina & 2,06 & 0,03 & 2,34 & 1,89 & 1,82 & 2,58 \\
Baritina & 97,94 & 99,97 & 97,62 & 98,11 & 98,18 & 97,41 \\
\hline TOTAL & $\mathbf{1 0 0 , 0 0}$ & $\mathbf{1 0 0 , 0 0}$ & $\mathbf{1 0 0 , 0 0}$ & $\mathbf{1 0 0 , 0 0}$ & $\mathbf{1 0 0 , 0 0}$ & $\mathbf{1 0 0 , 0 0}$ \\
\hline
\end{tabular}


Análisis de BARITINA por microsonda electrónica

\begin{tabular}{|c|c|c|c|}
\hline \multicolumn{4}{|c|}{ Muestra $\rightarrow 19373$ (mina Julio César) } \\
\hline Yacencia $\rightarrow$ & Veta & Veta & Veta \\
\hline \% en peso & 33 & 34 & 35 \\
\hline FeO* & b.1.d. & 0,0531 & 0,0865 \\
\hline MnO & 0,0671 & 0,0403 & 0,0167 \\
\hline $\mathrm{CoO}$ & b.l.d. & 0,0024 & 0,0166 \\
\hline MgO & b.l.d. & b.1.d. & 0,0058 \\
\hline $\mathrm{CaO}$ & 0,0088 & b.l.d. & b.l.d. \\
\hline SrO & 1,0483 & 0,4553 & 0,9528 \\
\hline $\mathrm{BaO}$ & 65,12 & 65 & 64,32 \\
\hline $\mathbf{P}_{2} \mathbf{O}_{5}$ & n.a. & n.a. & n.a. \\
\hline PbO & b.l.d. & b.l.d. & b.l.d. \\
\hline $\mathrm{SO}_{3}$ & 33,56 & 33,23 & 33,36 \\
\hline $\mathbf{F}$ & n.a. & n.a. & n.a. \\
\hline
\end{tabular}

$\begin{array}{llll}\text { TOTAL } & 99,80 & 98,78 & 98,76\end{array}$

* = asumido como $\mathrm{FeO}$ total. b.l.d. = bajo el límite de detección. n.a. = no analizado

Número de cationes en base a 4 oxígenos por unidad de fórmula

\begin{tabular}{|c|c|c|c|}
\hline \multicolumn{4}{|c|}{ Muestra $\rightarrow 19373$ (mina Julio César) } \\
\hline Yacencia $\rightarrow$ & Veta & Veta & Veta \\
\hline c.p.u.f. & 33 & 34 & 35 \\
\hline $\mathrm{Fe}^{+2}$ & 0,0000 & 0,0017 & 0,0028 \\
\hline Mn & 0,0022 & 0,0013 & 0,0005 \\
\hline Co & 0,0000 & 0,0001 & 0,0005 \\
\hline Mg & 0,0000 & 0,0000 & 0,0003 \\
\hline $\mathbf{C a}$ & 0,0004 & 0,0000 & 0,0000 \\
\hline $\mathrm{Sr}$ & 0,0232 & 0,0102 & 0,0214 \\
\hline $\mathbf{B a}$ & 0,9743 & 0,9867 & 0,9744 \\
\hline $\mathbf{P}$ & 0,0000 & 0,0000 & 0,0000 \\
\hline $\mathbf{P b}$ & 0,0000 & 0,0000 & 0,0000 \\
\hline Suma & 1,0000 & 1,0000 & 1,0000 \\
\hline $\mathbf{S}$ & 0,9901 & 0,9913 & 0,9918 \\
\hline TOTAL & 1,9901 & 1,9913 & 1,9918 \\
\hline
\end{tabular}

Proporciones moleculares de los componentes finales

\begin{tabular}{lrrr}
\hline Anhidrita & 0,04 & 0,00 & 0,00 \\
Celestina & 2,33 & 1,03 & 2,14 \\
Baritina & 97,64 & 98,97 & 97,86 \\
\hline TOTAL & $\mathbf{1 0 0 , 0 0}$ & $\mathbf{1 0 0 , 0 0}$ & $\mathbf{1 0 0 , 0 0}$ \\
\hline
\end{tabular}




\section{ANEXO 4:}

\section{Análisis de sulfuros por microsonda electrónica}


Análisis de SULFUROS por microsonda electrónica en MINERALIZACIONES VETIFORMES

\begin{tabular}{|c|c|c|c|c|c|c|c|c|c|c|c|}
\hline \multirow{3}{*}{$\begin{array}{c}\text { Mina } \rightarrow \\
\text { Muestra } \rightarrow \\
\text { Mineral } \rightarrow\end{array}$} & \multicolumn{11}{|c|}{ San Eduardo } \\
\hline & \multicolumn{11}{|l|}{4951} \\
\hline & Pirita & Pirita & Pirita & Pirita & Pirita & Pirita & Pirita & Pirita & Pirita & Pirita & Pirita \\
\hline \% en peso & 1 & 2 & 3 & 4 & 5 & 6 & 7 & 8 & 9 & 10 & 11 \\
\hline $\mathbf{B i}$ & b.1.d. & b.1.d. & b.1.d. & 0,0127 & 0,1263 & b.1.d. & b.1.d. & 0,1894 & b.1.d. & 0,0127 & 0,0229 \\
\hline $\mathbf{P b}$ & 0,3493 & 0,3787 & 0,3292 & 0,5727 & 0,3489 & 0,6491 & 0,2386 & 0,3783 & 0,2506 & 0,5018 & 0,2306 \\
\hline $\mathbf{T I}$ & b.1.d. & b.1.d. & b.1.d. & b.l.d. & b.1.d. & 0,0792 & b.1.d. & b.l.d. & 0,0080 & b.l.d. & b.1.d. \\
\hline Hg & b.1.d. & b.1.d. & 0,0383 & 0,0785 & b.1.d. & b.1.d. & 0,0974 & 0,1147 & b.1.d. & b.1.d. & 0,0440 \\
\hline Au & 0,0034 & b.1.d. & 0,0569 & 0,0057 & 0,0172 & b.1.d. & 0,0527 & b.1.d. & 0,0108 & 0,0016 & b.1.d. \\
\hline $\mathbf{W}$ & 0,0196 & 0,0727 & b.l.d. & b.1.d. & 0,0533 & b.l.d. & b.l.d. & b.l.d. & b.l.d. & 0,0197 & 0,0301 \\
\hline Te & b.1.d. & 0,0102 & 0,0630 & b.1.d. & 0,0191 & b.l.d. & b.1.d. & 0,0307 & 0,0076 & b.l.d. & b.1.d. \\
\hline Sb & b.1.d. & b.1.d. & 0,0518 & 0,0694 & b.1.d. & b.1.d. & 0,0250 & b.1.d. & 0,0307 & 0,0176 & 0,0094 \\
\hline Sn & 0,0320 & 0,0044 & b.l.d. & 0,0023 & 0,0228 & 0,0943 & 0,0109 & 0,0409 & 0,0081 & b.l.d. & 0,0199 \\
\hline In & b.l.d. & b.1.d. & b.1.d. & b.1.d. & b.1.d. & b.l.d. & b.1.d. & 0,0278 & b.1.d. & b.l.d. & 0,0017 \\
\hline Cd & b.l.d. & 0,0659 & 0,0777 & b.l.d. & b.l.d. & b.l.d. & b.l.d. & b.1.d. & b.1.d. & b.l.d. & b.1.d. \\
\hline Ag & b.l.d. & b.l.d. & b.l.d. & 0,0296 & 0,0544 & 0,0188 & b.1.d. & b.1.d. & 0,0421 & b.l.d. & 0,0538 \\
\hline Se & 0,0557 & 0,0273 & 0,0691 & 0,0422 & 0,0058 & 0,0450 & 0,0195 & 0,0442 & 0,0489 & 0,0338 & 0,0758 \\
\hline As & 0,1973 & 0,3802 & 0,1041 & 0,1708 & 0,1532 & 0,1896 & 0,0631 & 0,1443 & b.1.d. & 0,0124 & 0,0105 \\
\hline Ge & b.l.d. & b.1.d. & b.l.d. & b.1.d. & b.1.d. & b.1.d. & b.1.d. & b.1.d. & b.1.d. & b.l.d. & b.1.d. \\
\hline Ga & 0,0033 & b.1.d. & b.1.d. & b.l.d. & b.1.d. & b.l.d. & b.1.d. & b.1.d. & b.1.d. & b.1.d. & b.1.d. \\
\hline $\mathbf{Z n}$ & b.1.d. & b.1.d. & b.1.d. & 0,0269 & b.1.d. & 0,0254 & b.1.d. & 0,0168 & 0,0036 & 0,0107 & 0,0088 \\
\hline $\mathrm{Cu}$ & 0,0072 & 0,0024 & 0,0016 & 0,0080 & 0,0183 & 0,0036 & b.1.d. & 0,0144 & 0,0376 & 0,2186 & 0,0153 \\
\hline $\mathrm{Ni}$ & 0,0845 & 0,1745 & 0,2211 & 0,2406 & 0,3206 & 0,0589 & 0,3140 & 0,4265 & 1,4685 & 0,0155 & 0,0185 \\
\hline Co & 0,4268 & 1,5495 & 0,1795 & 0,7011 & 0,2448 & 0,4266 & 0,5789 & 1,1417 & b.1.d. & 4,6050 & 0,7998 \\
\hline $\mathrm{Fe}$ & 46,4744 & 46,1676 & 46,9888 & 46,4427 & 46,2408 & 45,6837 & 45,2830 & 44,5805 & 45,8562 & 42,4664 & 46,3605 \\
\hline $\mathbf{T i}$ & b.1.d. & b.1.d. & b.l.d. & 0,0031 & b.l.d. & 0,0128 & b.1.d. & b.l.d. & 0,0021 & 0,0014 & b.1.d. \\
\hline $\mathbf{S}$ & 52,7978 & 53,0949 & 52,5863 & 52,8191 & 52,7089 & 53,0881 & 53,3857 & 52,7564 & 52,5786 & 52,2953 & 52,8316 \\
\hline TOTAL & 100,4513 & 101,9283 & 100,7674 & 101,2254 & 100,3344 & 100,3751 & 100,0688 & 99,9066 & 100,3534 & 100,2125 & 100,5332 \\
\hline
\end{tabular}

b.1.d. = bajo el límite de detección 


\section{Análisis de SULFUROS por microsonda electrónica en MINERALIZACIONES VETIFORMES}

\begin{tabular}{|c|c|c|c|c|c|c|c|c|c|c|c|}
\hline \multirow{3}{*}{$\begin{array}{c}\text { Mina } \rightarrow \\
\text { Muestra } \rightarrow \\
\text { Mineral } \rightarrow\end{array}$} & \multicolumn{11}{|c|}{ San Eduardo } \\
\hline & 4951 & & & & & & & & & 15024 & \\
\hline & Galena & Galena & Galena & Tetraedrita & Tetraedrita & Tetraedrita & Calcopirita & Calcopirita & Calcopirita & Pirita & Pirita \\
\hline \% en peso & 1 & 2 & 3 & 1 & 2 & 3 & 1 & 2 & 3 & 1 & 2 \\
\hline $\mathbf{B i}$ & 0,1644 & 0,1691 & 0,1654 & 0,3056 & 0,3690 & b.1.d. & 0,1197 & 0,0367 & 0,0879 & 0,0954 & b.l.d \\
\hline $\mathbf{P b}$ & 86,5342 & 86,7866 & 86,7090 & 2,5913 & 1,2964 & 1,0992 & 0,2599 & 0,1528 & 0,2287 & 0,3795 & 0,5122 \\
\hline $\mathbf{T l}$ & b.1.d. & b.1.d. & b.1.d. & 0,0457 & 0,0670 & b.1.d. & b.l.d. & 0,0495 & b.1.d. & b.1.d & b.1.d \\
\hline Hg & b.l.d. & b.1.d. & b.1.d. & 0,0050 & 0,0502 & 0,1644 & b.l.d. & b.1.d. & 0,1513 & 0,0239 & 0,0829 \\
\hline $\mathbf{A u}$ & b.1.d. & b.1.d. & b.1.d. & b.1.d. & b.1.d. & b.1.d. & b.1.d. & 0,1111 & b.1.d. & b.1.d & 0,0564 \\
\hline $\mathbf{W}$ & b.l.d. & b.l.d. & b.l.d. & b.l.d. & b.l.d. & b.l.d. & b.l.d. & b.l.d. & b.l.d. & 0,0019 & 0,0140 \\
\hline Te & b.l.d. & b.l.d. & b.1.d. & b.1.d. & b.l.d. & b.l.d. & 0,0250 & 0,0245 & 0,0076 & 0,0623 & b.1.d \\
\hline $\mathbf{S b}$ & 0,1945 & 0,1980 & 0,1950 & 9,5794 & 11,2591 & 13,1595 & b.1.d. & b.1.d. & 1,0800 & b.1.d & 0,0214 \\
\hline Sn & 0,0206 & 0,0227 & 0,0257 & 0,0732 & 0,0816 & 0,0332 & 0,0200 & b.1.d. & 0,0510 & 0,0167 & b.1.d \\
\hline In & b.1.d. & b.1.d. & b.1.d. & b.1.d. & 0,0474 & b.1.d. & b.1.d. & b.l.d. & 0,0175 & b.1.d & b.1.d \\
\hline Cd & b.l.d. & b.l.d. & b.l.d. & 0,0440 & 0,0413 & b.l.d. & 0,0118 & b.l.d. & b.l.d. & b.1.d & 0,0321 \\
\hline Ag & 0,0508 & 0,0535 & 0,0548 & 0,8160 & 0,8751 & 1,1974 & 0,0075 & b.l.d. & 0,1417 & b.l.d & b.1.d \\
\hline Se & 0,0159 & 0,0128 & 0,0129 & b.l.d. & b.1.d. & b.l.d. & 0,0470 & 0,0684 & 0,0356 & 0,0450 & 0,0209 \\
\hline As & b.l.d. & b.1.d. & b.l.d. & 11,5812 & 10,2486 & 8,6048 & b.l.d. & b.1.d. & 0,5372 & b.1.d & 0,7350 \\
\hline Ge & b.l.d. & b.l.d. & b.l.d. & b.l.d. & 0,2086 & 0,2474 & b.1.d. & b.1.d. & b.l.d. & b.1.d & b.l.d \\
\hline $\mathbf{G a}$ & 0,0090 & 0,0039 & 0,0011 & b.l.d. & b.1.d. & b.l.d. & b.1.d. & b.l.d. & b.l.d. & b.1.d & b.l.d \\
\hline $\mathbf{Z n}$ & b.l.d. & b.l.d. & b.l.d. & 2,3201 & 2,3287 & 2,2446 & b.l.d. & b.l.d. & 0,0114 & 0,0344 & 0,0158 \\
\hline $\mathrm{Cu}$ & 0,0533 & 0,0499 & 0,0543 & 40,6556 & 40,7970 & 40,0060 & 34,0294 & 35,8207 & 34,8672 & b.l.d & 0,0195 \\
\hline $\mathbf{N i}$ & b.l.d. & b.1.d. & b.1.d. & 0,0173 & b.1.d. & b.l.d. & 0,0205 & 0,0077 & b.l.d. & b.1.d & 0,0225 \\
\hline Co & b.l.d. & b.1.d. & b.l.d. & 0,0746 & 0,1111 & 0,1363 & b.1.d. & b.l.d. & b.l.d. & b.1.d & b.1.d \\
\hline $\mathbf{F e}$ & 0,0227 & 0,0200 & 0,0249 & 5,5051 & 5,6029 & 5,2868 & 31,5287 & 30,2310 & 29,9227 & 48,7734 & 47,6975 \\
\hline $\mathbf{T i}$ & b.l.d. & b.l.d. & b.l.d. & b.l.d. & b.1.d. & b.l.d. & b.l.d. & 0,0013 & b.l.d. & 0,0021 & b.1.d \\
\hline $\mathbf{S}$ & 12,0929 & 11,9506 & 12,0766 & 26,8113 & 26,6510 & 26,2827 & 34,7484 & 34,3615 & 34,7059 & 49,9761 & 48,8872 \\
\hline TOTAL & 99,1583 & 99,2671 & 99,3197 & 100,4254 & 100,0350 & 98,4623 & 100,8179 & 100,8652 & 101,8457 & 99,4107 & 98,1174 \\
\hline
\end{tabular}

b.1.d. = bajo el límite de detección 
Análisis de SULFUROS por microsonda electrónica en MINERALIZACIONES VETIFORMES

\begin{tabular}{|c|c|c|c|c|c|c|c|c|c|c|c|}
\hline \multirow{3}{*}{$\begin{array}{c}\text { Mina } \rightarrow \\
\text { Muestra } \rightarrow \\
\text { Mineral } \rightarrow\end{array}$} & \multicolumn{11}{|c|}{ San Eduardo } \\
\hline & 15024 & & & & & & & & & & \\
\hline & Pirita & Pirita & Pirita & Pirita & Pirita & Pirita & Pirita & Pirita & Pirita & Pirita & Pirita \\
\hline$\%$ en peso & 3 & 4 & 5 & 6 & 7 & 8 & 9 & 10 & 11 & 12 & 13 \\
\hline $\mathbf{B i}$ & b.1.d & b.1.d & b.1.d & b.1.d & 0,1400 & 0,0398 & 0,1128 & b.1.d & 0,1974 & b.1.d & 0,1562 \\
\hline $\mathbf{P b}$ & 0,4107 & 0,3884 & 0,4894 & 0,6087 & 0,5418 & 0,6747 & 0,1789 & 0,8078 & 0,9384 & 0,2487 & 0,2388 \\
\hline $\mathbf{T l}$ & b.1.d & b.1.d & b.1.d & 0,1453 & b.1.d & b.1.d & b.1.d & b.1.d & 0,0989 & b.1.d & b.1.d \\
\hline Hg & 0,0333 & b.1.d & b.1.d & b.1.d & 0,1026 & 0,0386 & 0,0304 & b.1.d & 0,0364 & 0,0207 & 0,0141 \\
\hline Au & 0,0222 & b.l.d & b.1.d & 0,0625 & b.1.d & b.1.d & b.1.d & b.1.d & 0,0488 & b.1.d & 0,0557 \\
\hline $\mathbf{W}$ & 0,0615 & 0,0408 & b.1.d & b.1.d & 0,0019 & 0,0157 & 0,0826 & b.1.d & b.1.d & 0,0075 & b.1.d \\
\hline Te & 0,0294 & 0,0765 & 0,0226 & 0,0266 & 0,0529 & 0,0218 & 0,0597 & 0,0741 & 0,0780 & b.1.d & b.1.d \\
\hline $\mathbf{S b}$ & 0,0724 & 0,0165 & 0,0041 & b.1.d & b.1.d & 0,0811 & b.1.d & 0,2081 & b.1.d & 0,0810 & b.1.d \\
\hline Sn & 0,0344 & 0,0303 & b.1.d & b.l.d & b.1.d & 0,0419 & b.1.d & 0,0454 & 0,0810 & b.l.d & 0,0063 \\
\hline In & b.1.d & 0,0299 & b.1.d & 0,0711 & b.1.d & b.1.d & 0,0166 & 0,0141 & b.1.d & b.1.d & 0,0034 \\
\hline Cd & b.1.d & 0,0548 & b.1.d & b.1.d & 0,0090 & 0,0098 & 0,0263 & b.1.d & 0,0598 & b.1.d & 0,0195 \\
\hline Ag & b.1.d & 0,0640 & b.1.d & 0,0515 & b.1.d & b.1.d & b.1.d & b.1.d & 0,0499 & 0,0293 & 0,0497 \\
\hline Se & 0,0371 & 0,0273 & 0,0425 & 0,0152 & 0,0015 & b.1.d & 0,0249 & b.1.d & b.1.d & 0,0029 & 0,0357 \\
\hline As & b.l.d & b.1.d & b.1.d & 1,0785 & 1,4247 & 3,3861 & b.1.d & 4,5580 & 2,4026 & b.1.d & b.l.d \\
\hline Ge & b.1.d & b.1.d & b.1.d & b.1.d & b.1.d & b.1.d & b.1.d & b.1.d & b.1.d & b.1.d & b.1.d \\
\hline Ga & b.1.d & b.1.d & b.1.d & b.1.d & b.1.d & b.l.d & b.1.d & 0,0264 & b.1.d & b.1.d & b.1.d \\
\hline Zn & 0,0189 & 0,0024 & b.1.d & b.1.d & b.1.d & 0,0029 & b.1.d & 0,0311 & 0,0308 & b.1.d & b.1.d \\
\hline $\mathbf{C u}$ & 0,0040 & 0,0016 & 0,0302 & 0,0134 & 0,0194 & b.1.d & 0,0218 & 0,0547 & 0,0817 & 0,0155 & b.1.d \\
\hline $\mathbf{N i}$ & 0,0561 & 0,0432 & 0,0453 & 0,0006 & 0,0013 & 0,0028 & 0,0076 & 0,0034 & b.1.d & b.1.d & 0,0146 \\
\hline Co & b.1.d & b.1.d & b.l.d & b.1.d & b.1.d & b.1.d & b.l.d & b.1.d & b.1.d & b.1.d & b.1.d \\
\hline $\mathbf{F e}$ & 48,9125 & 48,6289 & 48,5109 & 47,7737 & 48,1334 & 46,8145 & 48,7065 & 44,8135 & 46,5941 & 46,9224 & 47,3272 \\
\hline $\mathbf{T i}$ & 0,0226 & b.1.d & b.1.d & b.1.d & 0,0006 & b.1.d & b.l.d & b.1.d & b.l.d & 0,0003 & b.l.d \\
\hline $\mathbf{S}$ & 49,9513 & 49,6436 & 49,8046 & 49,2957 & 49,1564 & 49,8661 & 51,5255 & 49,2936 & 47,9981 & 52,1619 & 51,9886 \\
\hline TOTAL & 99,6664 & 99,0482 & 98,9496 & 99,1428 & 99,5855 & 100,9958 & 100,7936 & 99,9302 & 98,6959 & 99,4902 & 99,9098 \\
\hline
\end{tabular}

b.l.d. = bajo el límite de detección 
Análisis de SULFUROS por microsonda electrónica en MINERALIZACIONES VETIFORMES

\begin{tabular}{|c|c|c|c|c|c|c|c|c|c|c|c|}
\hline \multirow{3}{*}{$\begin{array}{c}\text { Mina } \rightarrow \\
\text { Muestra } \rightarrow \\
\text { Mineral } \rightarrow\end{array}$} & \multicolumn{11}{|c|}{ San Eduardo } \\
\hline & 15024 & & & & & & & & & & \\
\hline & Pirita & Pirita & Pirita & Pirita & Pirita & Pirita & Pirita & Pirita & Pirita & Pirita & Pirita \\
\hline$\%$ en peso & 14 & 15 & 16 & 17 & 18 & 19 & 20 & 21 & 22 & 23 & 24 \\
\hline $\mathbf{B i}$ & b.1.d & b.1.d & 0,0705 & 0,0453 & 0,0556 & 0,0556 & b.l.d & 0,2302 & b.l.d & 0,1235 & 0,1816 \\
\hline $\mathbf{P b}$ & 0,5073 & 0,4964 & 0,2391 & 0,4491 & 0,2496 & 0,1896 & 0,4356 & 1,0593 & 0,1800 & 0,2989 & 0,1593 \\
\hline $\mathbf{T l}$ & 0,0105 & b.1.d & b.1.d & b.1.d & b.1.d & b.1.d & b.1.d & b.1.d & b.1.d & b.1.d & b.1.d \\
\hline Hg & b.1.d & 0,0804 & b.1.d & 0,0941 & b.1.d & b.1.d & b.1.d & 0,0608 & 0,0550 & 0,1461 & 0,0816 \\
\hline $\mathbf{A u}$ & b.1.d & 0,0581 & 0,0524 & b.1.d & 0,1118 & b.1.d & b.1.d & 0,0108 & 0,0408 & 0,0517 & 0,0551 \\
\hline $\mathbf{W}$ & 0,0401 & b.1.d & 0,0690 & 0,0037 & b.1.d & 0,0383 & b.1.d & 0,0019 & b.1.d & b.1.d & 0,0168 \\
\hline Te & b.l.d & 0,0398 & b.1.d & 0,0245 & b.1.d & b.1.d & 0,0826 & 0,0441 & 0,0976 & b.1.d & 0,0259 \\
\hline $\mathbf{S b}$ & 0,0182 & b.1.d & b.1.d & 0,0089 & 0,0093 & 0,0654 & b.1.d & 0,0372 & 0,0421 & 0,0450 & b.1.d \\
\hline Sn & 0,0214 & 0,0169 & b.1.d & b.1.d & 0,0148 & 0,0593 & b.1.d & b.l.d & 0,0348 & b.1.d & 0,0236 \\
\hline In & b.1.d & b.1.d & b.1.d & 0,0201 & b.1.d & 0,0227 & b.1.d & b.l.d & b.1.d & b.1.d & b.1.d \\
\hline Cd & 0,0571 & b.1.d & 0,0195 & 0,0017 & 0,0423 & 0,0452 & b.1.d & b.1.d & b.1.d & b.1.d & 0,0058 \\
\hline Ag & b.1.d & 0,0141 & b.1.d & b.1.d & b.1.d & 0,0399 & 0,0679 & 0,1903 & 0,0731 & 0,0731 & 0,0089 \\
\hline Se & 0,0473 & 0,0469 & 0,0223 & 0,0312 & 0,0256 & 0,0567 & 0,0315 & b.1.d & 0,0169 & 0,0200 & 0,0473 \\
\hline As & b.l.d & b.1.d & b.1.d & 0,4553 & b.1.d & b.1.d & b.1.d & b.1.d & 0,5422 & 0,0964 & 0,0737 \\
\hline Ge & b.1.d & b.1.d & b.1.d & b.1.d & b.1.d & b.1.d & b.1.d & b.1.d & b.1.d & b.1.d & b.1.d \\
\hline Ga & 0,0110 & b.1.d & b.1.d & b.l.d & b.1.d & b.1.d & b.1.d & b.1.d & b.1.d & 0,0269 & b.1.d \\
\hline Zn & 0,0065 & b.1.d & 0,0107 & 0,0148 & b.1.d & 0,0177 & 0,0067 & b.1.d & b.1.d & 0,0052 & b.1.d \\
\hline $\mathbf{C u}$ & 0,0139 & 0,0167 & b.1.d & 0,0115 & 0,0279 & 0,0155 & 0,0250 & 0,0281 & b.1.d & 0,0072 & b.1.d \\
\hline $\mathbf{N i}$ & b.1.d & 0,0051 & 0,0155 & 0,0145 & 0,0127 & 0,0117 & 0,0003 & 0,0066 & b.1.d & 0,0098 & 0,0041 \\
\hline Co & b.1.d & b.l.d & b.l.d & b.1.d & b.1.d & b.1.d & b.l.d & b.1.d & b.1.d & b.1.d & b.l.d \\
\hline $\mathbf{F e}$ & 46,8832 & 47,0784 & 47,4486 & 47,6327 & 47,4639 & 48,0182 & 47,8960 & 48,4003 & 46,8766 & 47,3778 & 47,3858 \\
\hline $\mathbf{T i}$ & 0,0066 & 0,0119 & 0,0233 & 0,0086 & b.1.d & b.1.d & 0,0114 & 0,0387 & b.l.d & 0,0102 & b.l.d \\
\hline $\mathbf{S}$ & 51,4212 & 51,4860 & 51,6288 & 51,2294 & 51,7080 & 52,2781 & 52,8504 & 51,7038 & 52,5274 & 52,0684 & 52,5677 \\
\hline TOTAL & 99,0443 & 99,3507 & 99,5997 & 100,0454 & 99,7215 & 100,9139 & 101,4074 & 101,8121 & 100,4865 & 100,3602 & 100,6372 \\
\hline
\end{tabular}

b.l.d. = bajo el límite de detección 
Análisis de SULFUROS por microsonda electrónica en MINERALIZACIONES VETIFORMES

\begin{tabular}{|c|c|c|c|c|c|c|c|c|c|c|c|}
\hline \multirow{3}{*}{$\begin{array}{c}\text { Mina } \rightarrow \\
\text { Muestra } \rightarrow \\
\text { Mineral } \rightarrow\end{array}$} & \multicolumn{11}{|c|}{ San Eduardo } \\
\hline & 15024 & & & & & & & & & & \\
\hline & Pirita & Pirita & Pirita & Pirita & Pirita & Pirita & Pirita & Pirita & Pirita & Pirita & Galena \\
\hline$\%$ en peso & 25 & 26 & 27 & 28 & 29 & 30 & 31 & 32 & 33 & 34 & 1 \\
\hline $\mathbf{B i}$ & 0,4588 & b.1.d & 0,0025 & 0,0578 & 0,0429 & 0,1715 & 0,3505 & b.1.d & b.1.d & b.l.d & 0,5448 \\
\hline $\mathbf{P b}$ & 0,3988 & 0,3690 & 0,2589 & 0,4176 & 0,1495 & 0,2490 & 0,2694 & 0,2177 & 0,2391 & 0,1790 & 86,4648 \\
\hline $\mathbf{T l}$ & 0,1372 & b.1.d & b.1.d & b.1.d & b.1.d & b.1.d & b.1.d & b.1.d & b.1.d & b.1.d & b.1.d \\
\hline Hg & 0,0875 & b.1.d & b.1.d & 0,0954 & 0,0645 & b.1.d & 0,0236 & 0,0842 & 0,0075 & b.1.d & b.1.d \\
\hline $\mathbf{A u}$ & 0,0649 & b.1.d & b.1.d & 0,0364 & b.1.d & b.1.d & 0,0328 & 0,0299 & 0,0450 & b.1.d & 0,0084 \\
\hline $\mathbf{W}$ & 0,0737 & b.1.d & 0,0028 & 0,0372 & 0,0056 & 0,0121 & b.1.d & 0,0222 & b.1.d & b.1.d & 0,1465 \\
\hline Te & 0,0117 & 0,0002 & 0,0681 & b.l.d & 0,1202 & b.1.d & b.1.d & 0,0444 & 0,0382 & b.l.d & b.l.d \\
\hline $\mathbf{S b}$ & b.1.d & 0,0175 & b.l.d & 0,0289 & b.1.d & b.l.d & 0,0045 & b.1.d & b.l.d & 0,0468 & 0,1263 \\
\hline Sn & 0,0388 & 0,0903 & b.1.d & b.l.d & 0,0265 & 0,0112 & b.1.d & b.1.d & b.1.d & 0,0497 & 0,0008 \\
\hline In & b.1.d & b.1.d & b.1.d & b.l.d & b.1.d & b.1.d & b.1.d & b.1.d & b.l.d & b.1.d & 0,0020 \\
\hline Cd & 0,0315 & b.1.d & 0,0083 & b.1.d & b.1.d & b.1.d & 0,0456 & 0,0853 & b.1.d & 0,0174 & b.1.d \\
\hline Ag & 0,0806 & b.1.d & 0,0337 & b.1.d & 0,0400 & b.1.d & 0,0817 & 0,0768 & 0,0249 & b.1.d & 0,1058 \\
\hline Se & 0,0288 & 0,0284 & 0,0179 & 0,0331 & 0,0456 & 0,0036 & 0,0128 & 0,0087 & 0,0292 & 0,0091 & 0,0139 \\
\hline As & 0,1718 & 0,0548 & 0,1132 & 0,4215 & b.1.d & 0,1020 & 0,2912 & 0,0652 & 0,1705 & 0,0126 & b.1.d \\
\hline Ge & b.1.d & b.1.d & b.1.d & b.l.d & b.1.d & b.1.d & b.1.d & b.1.d & b.1.d & b.1.d & b.1.d \\
\hline Ga & b.1.d & b.1.d & b.1.d & b.1.d & b.1.d & b.1.d & b.1.d & b.1.d & 0,0018 & b.1.d & b.1.d \\
\hline $\mathbf{Z n}$ & b.1.d & b.1.d & 0,0208 & 0,0301 & b.1.d & 0,0007 & b.1.d & b.1.d & 0,0307 & 0,0269 & b.1.d \\
\hline $\mathrm{Cu}$ & 0,0112 & 0,0216 & 0,0255 & 0,0254 & 0,0136 & 0,0363 & 0,0223 & b.1.d & b.1.d & 0,0171 & 0,0117 \\
\hline $\mathbf{N i}$ & 0,0067 & b.1.d & 0,0101 & 0,0161 & b.1.d & 0,0038 & b.1.d & 0,0019 & b.1.d & b.1.d & b.1.d \\
\hline Co & b.l.d & b.1.d & b.1.d & b.l.d & b.1.d & b.1.d & b.1.d & b.l.d & b.1.d & b.l.d & b.l.d \\
\hline $\mathbf{F e}$ & 47,6284 & 46,9460 & 47,7104 & 46,8273 & 46,9846 & 47,1798 & 47,4763 & 46,2792 & 47,0714 & 47,5064 & b.1.d \\
\hline $\mathbf{T i}$ & 0,0022 & 0,0020 & 0,0193 & b.1.d & 0,0066 & b.1.d & 0,0205 & 0,0035 & b.1.d & b.1.d & b.1.d \\
\hline $\mathbf{S}$ & 51,9943 & 52,4475 & 52,4178 & 52,1320 & 52,6014 & 52,5284 & 52,2669 & 51,0874 & 52,1443 & 52,6688 & 11,1835 \\
\hline TOTAL & 101,2269 & 99,9773 & 100,7093 & 100,1588 & 100,1010 & 100,2984 & 100,8981 & 98,0064 & 99,8026 & 100,5338 & 98,6085 \\
\hline
\end{tabular}

b.1.d. = bajo el límite de detección 
Análisis de SULFUROS por microsonda electrónica en MINERALIZACIONES VETIFORMES

\begin{tabular}{|c|c|c|c|c|c|c|c|c|c|c|c|}
\hline \multirow{3}{*}{$\begin{array}{c}\text { Mina } \rightarrow \\
\text { Muestra } \rightarrow \\
\text { Mineral } \rightarrow\end{array}$} & \multicolumn{11}{|c|}{ San Eduardo } \\
\hline & 15024 & & & & & & & & & & \\
\hline & Galena & Galena & Galena & Galena & Galena & Galena & Calcopirita & Calcopirita & Calcopirita & Calcopirita & Calcopirita \\
\hline \% en peso & 2 & 3 & 4 & 5 & 6 & 7 & 1 & 2 & 3 & 4 & 5 \\
\hline $\mathbf{B i}$ & 0,7707 & 0,3873 & 0,5186 & 0,8136 & 0,2541 & 0,8197 & b.1.d & 0,0219 & b.1.d & 0,2250 & 0,3000 \\
\hline $\mathbf{P b}$ & 86,6702 & 87,2078 & 86,9913 & 87,1009 & 87,0815 & 86,7595 & 1,0290 & 1,0107 & 0,8794 & 1,0021 & 1,4235 \\
\hline $\mathbf{T l}$ & b.1.d & b.1.d & b.1.d & b.1.d & 0,0582 & b.l.d & b.1.d & b.l.d & 0,2433 & b.1.d & b.1.d \\
\hline Hg & 0,0582 & b.1.d & 0,0804 & b.1.d & 0,0377 & 0,0095 & 0,0955 & b.1.d & 0,0063 & b.1.d & b.1.d \\
\hline Au & b.1.d & 0,0039 & 0,0590 & 0,0059 & b.1.d & b.1.d & b.1.d & b.1.d & b.1.d & b.1.d & 0,0868 \\
\hline $\mathbf{W}$ & b.1.d & 0,0450 & b.1.d & 0,0500 & b.1.d & b.l.d & b.l.d & b.1.d & b.l.d & 0,0461 & 0,0009 \\
\hline Te & 0,0369 & b.1.d & 0,0098 & 0,0409 & 0,0728 & 0,0249 & 0,0244 & b.1.d & 0,0375 & b.1.d & 0,0146 \\
\hline $\mathbf{S b}$ & 0,2951 & 0,1065 & 0,1127 & 0,0494 & 0,0063 & 0,3250 & 0,1835 & 0,8717 & 1,1043 & 1,0894 & 1,7144 \\
\hline Sn & b.1.d & 0,0005 & b.1.d & 0,0132 & b.1.d & b.1.d & 0,0114 & 0,0615 & b.1.d & 0,0003 & 0,0734 \\
\hline In & b.l.d & b.l.d & b.l.d & b.l.d & 0,0258 & b.l.d & b.1.d & b.l.d & 0,0072 & b.l.d & 0,0268 \\
\hline Cd & b.1.d & b.1.d & b.1.d & b.1.d & b.1.d & b.1.d & b.1.d & b.1.d & 0,0686 & 0,0359 & 0,0489 \\
\hline Ag & b.1.d & 0,1360 & b.1.d & 0,0507 & 0,0173 & 0,0501 & 0,0367 & b.1.d & 0,1557 & 0,0909 & 0,1135 \\
\hline Se & 0,0010 & 0,0045 & 0,0222 & 0,0076 & 0,0174 & 0,0056 & 0,0037 & b.1.d & 0,0144 & 0,0261 & 0,0219 \\
\hline As & b.1.d & b.1.d & b.1.d & b.1.d & b.1.d & b.l.d & 1,0675 & 1,1786 & 1,2502 & 0,9936 & 1,2064 \\
\hline Ge & b.1.d & b.1.d & b.1.d & b.1.d & b.1.d & b.1.d & 0,0240 & 0,0150 & 0,0251 & 0,0265 & 0,0106 \\
\hline Ga & 0,0096 & 0,0022 & b.1.d & b.1.d & b.1.d & 0,0063 & b.1.d & b.1.d & b.1.d & b.1.d & b.1.d \\
\hline $\mathbf{Z n}$ & b.1.d & 0,0052 & 0,0105 & 0,0137 & b.1.d & 0,0102 & 0,0034 & 0,0068 & 0,0311 & b.1.d & 0,0859 \\
\hline $\mathbf{C u}$ & 0,0198 & 0,0308 & b.1.d & 0,0531 & 0,0244 & 0,0347 & 35,4613 & 34,6088 & 34,0346 & 34,6283 & 35,3116 \\
\hline $\mathbf{N i}$ & b.l.d & 0,0145 & 0,0008 & 0,0044 & 0,0092 & b.1.d & 0,0115 & 0,0024 & 0,0050 & 0,0133 & 0,0372 \\
\hline Co & 0,0086 & b.l.d & b.l.d & b.l.d & b.1.d & 0,0061 & b.l.d & b.l.d & b.1.d & b.1.d & b.1.d \\
\hline $\mathrm{Fe}$ & b.l.d & 0,0077 & b.1.d & 0,0048 & 0,0121 & b.1.d & 28,8277 & 27,5366 & 26,9558 & 27,4777 & 27,2212 \\
\hline $\mathbf{T i}$ & 0,0108 & b.1.d & b.1.d & b.l.d & b.1.d & b.1.d & b.l.d & b.l.d & b.l.d & b.l.d & b.1.d \\
\hline $\mathbf{S}$ & 11,2015 & 10,2592 & 11,1781 & 12,4692 & 12,5884 & 12,8298 & 34,3478 & 34,2731 & 34,0346 & 34,6312 & 32,3857 \\
\hline TOTAL & 99,0824 & 98,2111 & 98,9834 & 100,6774 & 100,2052 & 100,8814 & 101,1274 & 99,5871 & 98,8531 & 100,2864 & 100,0833 \\
\hline
\end{tabular}

b.l.d. = bajo el límite de detección 


\section{Análisis de SULFUROS por microsonda electrónica en MINERALIZACIONES VETIFORMES}

\begin{tabular}{|c|c|c|c|c|c|c|c|c|c|c|c|}
\hline \multirow{3}{*}{$\begin{array}{c}\text { Mina } \rightarrow \\
\text { Muestra } \rightarrow \\
\text { Mineral } \rightarrow\end{array}$} & \multicolumn{11}{|c|}{ San Eduardo } \\
\hline & 15024 & & & & & & & & & & \\
\hline & Calcopirita & Esfalerita & Esfalerita & Esfalerita & Esfalerita & Esfalerita & Esfalerita & Esfalerita & Esfalerita & Esfalerita & Esfalerita \\
\hline$\%$ en peso & 6 & 1 & 2 & 3 & 4 & 5 & 6 & 7 & 8 & 9 & 10 \\
\hline $\mathbf{B i}$ & b.1.d & b.1.d & 0,0457 & 0,0073 & b.1.d & b.1.d & 0,1962 & b.1.d & b.1.d & 0,0895 & b.1.d \\
\hline $\mathbf{P b}$ & 1,1107 & b.l.d & 0,3007 & 0,1509 & 0,2209 & 0,1391 & 0,1395 & 0,3131 & 0,1042 & 0,1975 & b.1.d \\
\hline $\mathbf{T l}$ & b.1.d & b.1.d & b.1.d & 0,1151 & b.1.d & b.1.d & 0,0374 & b.1.d & 0,1148 & b.1.d & b.1.d \\
\hline Hg & b.1.d & b.1.d & b.1.d & b.1.d & b.1.d & b.1.d & b.1.d & b.1.d & b.1.d & b.1.d & b.1.d \\
\hline Au & 0,0405 & 0,5241 & 0,5200 & 0,3908 & 0,4016 & 0,4758 & 0,5353 & 0,3935 & 0,5657 & 0,5188 & 0,4471 \\
\hline $\mathbf{W}$ & 0,0282 & b.1.d & b.1.d & b.1.d & b.1.d & b.1.d & b.1.d & b.1.d & b.1.d & b.1.d & b.1.d \\
\hline Te & 0,0091 & 0,0184 & b.1.d & 0,0767 & b.1.d & b.1.d & b.1.d & 0,0286 & b.1.d & 0,0277 & b.1.d \\
\hline $\mathbf{S b}$ & 0,5252 & 0,0359 & 0,0087 & 0,0271 & b.1.d & b.1.d & b.1.d & b.1.d & b.1.d & 0,0167 & 0,0303 \\
\hline Sn & b.1.d & b.1.d & 0,0101 & 0,0044 & 0,0353 & b.1.d & b.1.d & 0,0084 & 0,0016 & b.1.d & 0,0102 \\
\hline In & 0,0277 & 0,0033 & b.1.d & b.1.d & b.1.d & b.1.d & b.1.d & b.1.d & b.1.d & b.1.d & b.1.d \\
\hline Cd & 0,0019 & 0,2296 & 0,7039 & 0,3221 & 0,7085 & 0,7111 & 0,2990 & 0,3846 & 0,2886 & 0,3757 & 0,7092 \\
\hline Ag & b.1.d & 0,0977 & 0,0463 & 0,0302 & 0,0172 & 0,1524 & 0,0268 & 0,0009 & b.1.d & 0,0121 & 0,0026 \\
\hline $\mathrm{Se}$ & 0,0263 & 0,0237 & 0,0363 & 0,0210 & 0,0323 & 0,0352 & 0,0590 & 0,0134 & 0,0624 & 0,0665 & 0,0397 \\
\hline As & 0,8870 & b.1.d & 0,0086 & 0,0366 & b.1.d & b.1.d & b.1.d & b.1.d & 0,0165 & b.1.d & b.1.d \\
\hline Ge & b.1.d & b.1.d & b.1.d & b.1.d & 0,0405 & b.1.d & 0,0577 & 0,0938 & b.1.d & 0,0190 & 0,0070 \\
\hline Ga & b.1.d & 0,0468 & 0,0288 & b.1.d & b.1.d & 0,0476 & b.1.d & 0,0158 & 0,0401 & b.1.d & 0,0252 \\
\hline Zn & 0,0171 & 63,6063 & 64,1640 & 63,1781 & 63,9350 & 61,9679 & 63,1776 & 62,6493 & 61,7619 & 63,0015 & 63,6266 \\
\hline $\mathbf{C u}$ & 35,9104 & 0,0550 & 0,0839 & 0,0475 & 0,1053 & 0,0095 & 0,0549 & 0,0325 & 0,0158 & 0,0549 & 0,0090 \\
\hline $\mathbf{N i}$ & 0,0523 & 0,0080 & 0,0069 & 0,0033 & 0,0076 & b.1.d & b.1.d & b.l.d & b.1.d & b.l.d & b.l.d \\
\hline Co & b.1.d & 0,0125 & b.l.d & b.l.d & 0,0082 & b.1.d & b.1.d & b.1.d & b.1.d & b.1.d & 0,0117 \\
\hline $\mathrm{Fe}$ & 28,6795 & 0,3892 & 0,2246 & 1,8410 & 0,4163 & 2,5064 & 1,5099 & 2,1396 & 3,5490 & 1,5909 & 1,0162 \\
\hline $\mathbf{T i}$ & b.l.d & b.1.d & 0,0028 & b.l.d & 0,0179 & b.1.d & b.l.d & b.1.d & 0,0037 & b.1.d & b.l.d \\
\hline $\mathbf{S}$ & 32,5378 & 33,1769 & 33,0498 & 33,0716 & 32,7138 & 32,8704 & 33,0076 & 32,9432 & 33,2712 & 32,7040 & 32,2858 \\
\hline TOTAL & $\mathbf{9 9 , 8 5 3 7}$ & 98,2274 & 99,2411 & 99,3237 & 98,6604 & 98,9154 & 99,1009 & 99,0167 & 99,7955 & 98,6748 & 98,2206 \\
\hline
\end{tabular}

b.1.d. = bajo el límite de detección 
Análisis de SULFUROS por microsonda electrónica en MINERALIZACIONES VETIFORMES

\begin{tabular}{|c|c|c|c|c|c|}
\hline \multirow{3}{*}{$\begin{array}{c}\text { Mina } \rightarrow \\
\text { Muestra } \rightarrow \\
\text { Mineral } \rightarrow \\
\end{array}$} & \multicolumn{5}{|c|}{ San Eduardo } \\
\hline & \multicolumn{5}{|l|}{15024} \\
\hline & Esfalerita & Esfalerita & Esfalerita & Esfalerita & Esfalerita \\
\hline$\%$ en peso & 11 & 12 & 13 & 14 & 15 \\
\hline Bi & b.l.d & 0,1623 & 0,1157 & 0,1595 & 0,0651 \\
\hline $\mathbf{P b}$ & b.l.d & 0,0932 & 0,2663 & 0,1734 & 0,3245 \\
\hline Tl & 0,0093 & b.1.d & b.1.d & b.1.d & b.l.d \\
\hline Hg & b.1.d & b.1.d & b.1.d & b.1.d & b.l.d \\
\hline $\mathbf{A u}$ & 0,4933 & 0,5236 & 0,5679 & 0,5679 & 0,4702 \\
\hline $\mathbf{W}$ & b.l.d & b.1.d & b.1.d & b.l.d & b.1.d \\
\hline Te & 0,0685 & 0,0072 & 0,0203 & 0,0346 & 0,1139 \\
\hline Sb & 0,0220 & 0,0316 & b.1.d & b.1.d & 0,0130 \\
\hline Sn & b.l.d & b.1.d & 0,0321 & 0,0718 & b.l.d \\
\hline In & b.l.d & b.l.d & b.1.d & 0,0041 & b.l.d \\
\hline Cd & 0,3283 & 0,5192 & 0,8239 & 0,2984 & 0,5909 \\
\hline Ag & 0,0026 & b.1.d & 0,0591 & b.l.d & 0,0756 \\
\hline Se & 0,0208 & 0,0065 & 0,0588 & 0,0357 & 0,0342 \\
\hline As & b.l.d & b.1.d & 0,0085 & b.1.d & b.l.d \\
\hline Ge & 0,0181 & 0,0330 & b.1.d & b.l.d & 0,0240 \\
\hline $\mathbf{G a}$ & 0,0128 & 0,0065 & b.1.d & 0,0709 & 0,0264 \\
\hline $\mathbf{Z n}$ & 62,5459 & 64,6243 & 62,9708 & 61,7934 & 63,8339 \\
\hline $\mathbf{C u}$ & 0,0594 & 0,0840 & 0,0679 & b.1.d & 0,1926 \\
\hline $\mathbf{N i}$ & b.l.d & b.l.d & 0,0197 & 0,0181 & b.l.d \\
\hline Co & b.l.d & 0,0069 & b.1.d & b.l.d & 0,0048 \\
\hline $\mathrm{Fe}$ & 2,4224 & 0,2761 & 1,6803 & 2,8899 & 0,1306 \\
\hline $\mathbf{T i}$ & b.1.d & 0,0072 & b.l.d & 0,0146 & 0,0070 \\
\hline $\mathbf{S}$ & 32,8436 & 32,9733 & 32,4593 & 33,3034 & 32,7490 \\
\hline TOTAL & 98,8470 & 99,3549 & 99,1506 & 99,4357 & 98,6557 \\
\hline
\end{tabular}

b.l.d. = bajo el límite de detección 


\section{ANEXO 5:}

Análisis de galena por microsonda electrónica 
Análisis de GALENA por microsonda electrónica en MINERALIZACIONES VETIFORMES

Mina $\rightarrow$

Julio César

\begin{tabular}{|c|c|c|c|c|c|c|c|c|c|c|c|c|}
\hline Muestra $\rightarrow$ & 19369 & & & & & & & & & & & \\
\hline$\%$ en peso & 1 & 2 & 3 & 4 & 5 & 6 & 7 & 8 & 9 & 10 & 11 & 12 \\
\hline $\mathbf{P b}$ & 86,0800 & 86,8900 & 86,8300 & 87,0100 & 87,7600 & 87,5000 & 86,6400 & 86,9700 & 88,0100 & 87,1400 & 86,8500 & 87,4100 \\
\hline Sb & 0,0368 & b.l.d & b.l.d & b.l.d & 0,0311 & b.l.d & 0,0517 & 0,0243 & b.l.d & 0,0070 & b.l.d & b.l.d \\
\hline Cd & b.l.d & b.l.d & 0,0151 & b.l.d & 0,0005 & 0,0128 & 0,0132 & 0,0140 & b.1.d & b.l.d & b.l.d & 0,0048 \\
\hline Ag & 0,1739 & 0,0557 & 0,0449 & b.l.d & b.l.d & 0,0051 & b.l.d & 0,0690 & 0,0393 & b.l.d & 0,0691 & 0,0398 \\
\hline As & b.l.d & 0,0098 & b.1.d & 0,0151 & 0,0053 & 0,0266 & b.1.d & 0,0248 & 0,0204 & b.l.d & 0,0106 & 0,0035 \\
\hline $\mathbf{Z n}$ & 0,0543 & 0,0079 & b.l.d & b.1.d & b.l.d & b.1.d & b.l.d & 0,0834 & 0,0860 & b.l.d & b.1.d & 0,0763 \\
\hline $\mathbf{C u}$ & 0,0390 & b.1.d & b.1.d & b.l.d & 0,0827 & b.l.d & b.l.d & b.l.d & 0,0405 & b.l.d & 0,0318 & b.l.d \\
\hline Co & b.l.d & 0,0027 & b.l.d & 0,0167 & 0,0075 & b.l.d & 0,0123 & b.l.d & 0,0226 & b.1.d & 0,0092 & 0,0176 \\
\hline Mn & b.l.d & b.1.d & b.1.d & b.l.d & b.l.d & b.1.d & 0,0774 & 0,0111 & b.l.d & 0,0070 & 0,0006 & 0,0082 \\
\hline $\mathrm{Fe}$ & 0,0089 & b.l.d & b.l.d & b.l.d & b.l.d & 0,0177 & 0,0092 & 0,0008 & b.l.d & b.l.d & 0,0292 & 0,0196 \\
\hline $\mathbf{S}$ & 13,4800 & 13,2800 & 13,2400 & 13,2400 & 13,1900 & 13,2100 & 13,3800 & 13,0700 & 13,2100 & 13,1800 & 13,1100 & 13,0400 \\
\hline TOTAL & 99,8729 & 100,2461 & 100,1300 & 100,2818 & 101,0771 & 100,7722 & 100,1838 & 100,2674 & 101,4288 & 100,3340 & 100,1105 & 100,6198 \\
\hline
\end{tabular}

b.l.d. = bajo el límite de detección

\section{Análisis de GALENA por microsonda electrónica en MINERALIZACIONES VETIFORMES}

Mina $\rightarrow$

Julio César

\begin{tabular}{|c|c|c|c|c|c|c|c|c|c|c|c|c|}
\hline Muestra $\rightarrow$ & 19369 & & & & & & & & & & & \\
\hline$\%$ en peso & 13 & 14 & 15 & 16 & 17 & 18 & 19 & 20 & 21 & 22 & 23 & 24 \\
\hline $\mathbf{P b}$ & 88,1000 & 87,0700 & 86,4700 & 86,6200 & 86,1900 & 87,1400 & 85,7600 & 87,4600 & 86,5500 & 86,9500 & 86,8100 & 86,4100 \\
\hline $\mathbf{S b}$ & 0,0613 & b.1.d & b.1.d & 0,1000 & 0,0272 & 0,0725 & 0,0054 & b.l.d & 0,0719 & b.1.d & 0,0266 & b.l.d \\
\hline Cd & 0,0125 & b.l.d & b.1.d & b.1.d & 0,0160 & 0,0249 & 0,0541 & b.l.d & 0,0050 & b.l.d & 0,0613 & b.l.d \\
\hline Ag & b.1.d & 0,0280 & 0,0248 & 0,0334 & b.1.d & b.1.d & 0,0166 & b.1.d & 0,1152 & b.l.d & 0,1040 & 0,1375 \\
\hline As & 0,0106 & b.l.d & 0,0035 & 0,0204 & 0,0053 & 0,0141 & 0,0195 & 0,0062 & b.1.d & 0,0469 & 0,0531 & 0,0159 \\
\hline $\mathbf{Z n}$ & b.l.d & 0,0377 & 0,1465 & 0,0991 & 0,0140 & b.l.d & 0,0675 & 0,0377 & b.1.d & 0,0333 & b.1.d & 0,0946 \\
\hline $\mathrm{Cu}$ & b.l.d & b.l.d & b.l.d & b.l.d & b.l.d & 0,0202 & 0,0723 & 0,0195 & b.1.d & b.1.d & 0,0044 & b.l.d \\
\hline Co & 0,0225 & b.1.d & b.l.d & 0,0284 & b.l.d & 0,0236 & b.l.d & b.l.d & b.1.d & b.l.d & 0,0134 & 0,0240 \\
\hline Mn & 0,0076 & 0,0011 & b.l.d & 0,0140 & 0,0011 & 0,0017 & 0,0362 & 0,0333 & 0,0164 & 0,0321 & b.l.d & b.l.d \\
\hline $\mathrm{Fe}$ & b.1.d & b.l.d & 0,0178 & 0,0182 & b.1.d & 0,0375 & 0,0004 & b.1.d & b.1.d & b.1.d & 0,0242 & 0,0195 \\
\hline $\mathbf{S}$ & 13,2900 & 13,3800 & 13,1600 & 13,1400 & 13,1300 & 13,3300 & 13,1100 & 13,0700 & 13,0800 & 13,0900 & 13,0700 & 12,8500 \\
\hline TOTAL & 101,5045 & 100,5168 & 99,8226 & 100,0735 & 99,3836 & 100,6645 & 99,1420 & 100,6267 & 99,8385 & 100,1523 & 100,1670 & 99,5515 \\
\hline
\end{tabular}

b.l.d. = bajo el límite de detección 
Análisis de GALENA por microsonda electrónica en MINERALIZACIONES VETIFORMES

Mina $\rightarrow$

Julio César

\begin{tabular}{|c|c|c|c|c|c|c|c|c|c|c|c|c|}
\hline Muestra $\rightarrow$ & 19369 & & & & & & & & & & & \\
\hline$\%$ en peso & 25 & 26 & 27 & 28 & 29 & 30 & 31 & 32 & 33 & 34 & 35 & 36 \\
\hline $\mathbf{P b}$ & 87,5600 & 87,3000 & 88,1100 & 85,5700 & 86,4100 & 86,3900 & 87,1200 & 86,2700 & 86,9600 & 87,4300 & 86,7800 & 86,6100 \\
\hline Sb & b.1.d & 0,0149 & 0,0003 & b.l.d & b.1.d & 0,0046 & b.1.d & b.1.d & b.1.d & b.1.d & b.1.d & 0,0476 \\
\hline Cd & b.l.d & b.l.d & b.l.d & b.1.d & 0,0681 & b.1.d & b.l.d & 0,0039 & 0,0628 & b.l.d & b.l.d & b.l.d \\
\hline Ag & 0,2144 & b.l.d & b.l.d & b.1.d & b.l.d & 0,1147 & 0,0410 & 0,0866 & b.l.d & b.l.d & b.l.d & b.l.d \\
\hline As & b.l.d & b.l.d & 0,0576 & b.l.d & b.1.d & b.l.d & b.1.d & b.1.d & 0,0151 & 0,0593 & b.l.d & 0,0284 \\
\hline Zn & 0,1515 & b.1.d & b.l.d & 0,0052 & b.1.d & 0,0562 & 0,0254 & 0,0798 & b.l.d & b.l.d & 0,0070 & 0,0648 \\
\hline $\mathrm{Cu}$ & b.1.d & b.1.d & b.l.d & b.l.d & 0,0375 & b.l.d & 0,0115 & 0,0188 & b.l.d & 0,0180 & 0,0918 & b.l.d \\
\hline Co & 0,0027 & b.1.d & 0,0476 & 0,0493 & b.l.d & b.1.d & 0,0134 & b.l.d & b.l.d & b.l.d & b.1.d & b.l.d \\
\hline Mn & b.1.d & b.1.d & 0,0298 & b.l.d & b.l.d & 0,0035 & b.1.d & b.l.d & 0,0275 & 0,0338 & b.l.d & b.1.d \\
\hline $\mathrm{Fe}$ & b.l.d & 0,0215 & b.l.d & b.l.d & 0,0172 & b.l.d & 0,0215 & b.1.d & b.1.d & 0,0231 & b.1.d & b.l.d \\
\hline $\mathbf{S}$ & 12,8300 & 13,1200 & 12,9600 & 13,0000 & 12,8300 & 13,2300 & 13,1000 & 12,9000 & 13,2200 & 12,8000 & 13,0900 & 12,8900 \\
\hline TOTAL & 100,7586 & 100,4564 & 101,2053 & 98,6245 & 99,3628 & 99,7990 & 100,3328 & 99,3591 & 100,2854 & 100,3642 & 99,9688 & 99,6408 \\
\hline
\end{tabular}

b.l.d. = bajo el límite de detección

\section{Análisis de GALENA por microsonda electrónica en MINERALIZACIONES VETIFORMES}

Mina $\rightarrow$

Julio César

\begin{tabular}{|c|c|c|c|c|c|c|c|c|c|c|c|c|}
\hline Muestra $\rightarrow$ & 19369 & & & & & & & & & & & \\
\hline \% en peso & 37 & 38 & 39 & 40 & 41 & 42 & 43 & 44 & 45 & 46 & 47 & 48 \\
\hline $\mathbf{P b}$ & 86,8800 & 87,3100 & 88,2200 & 87,7300 & 86,4700 & 86,7400 & 87,4000 & 87,9800 & 86,0800 & 88,2300 & 87,4400 & 86,7000 \\
\hline $\mathbf{S b}$ & b.1.d & b.1.d & 0,0270 & b.1.d & 0,0009 & 0,0041 & b.l.d & b.l.d & 0,0677 & b.l.d & b.l.d & b.l.d \\
\hline Cd & b.l.d & 0,0655 & 0,0745 & b.1.d & 0,0151 & 0,0474 & 0,0572 & 0,0109 & b.1.d & b.1.d & b.l.d & 0,0673 \\
\hline Ag & 0,1602 & 0,1302 & 0,0547 & b.1.d & 0,0484 & 0,1041 & b.l.d & b.l.d & 0,0013 & 0,1133 & 0,0313 & b.l.d \\
\hline As & b.l.d & b.l.d & 0,0230 & 0,0177 & 0,0239 & b.l.d & 0,0124 & 0,0266 & b.l.d & 0,0124 & 0,0088 & b.l.d \\
\hline $\mathbf{Z n}$ & 0,1615 & b.1.d & b.l.d & 0,0455 & b.l.d & b.l.d & 0,0787 & b.l.d & 0,0948 & b.1.d & b.1.d & 0,0666 \\
\hline $\mathrm{Cu}$ & b.l.d & 0,0339 & b.1.d & 0,0375 & 0,0687 & b.l.d & 0,0483 & b.l.d & b.1.d & b.l.d & b.l.d & b.l.d \\
\hline Co & b.1.d & b.1.d & b.1.d & b.1.d & 0,0375 & b.l.d & 0,0032 & b.l.d & b.1.d & b.l.d & b.1.d & 0,0022 \\
\hline Mn & 0,0041 & 0,0006 & b.l.d & b.1.d & 0,0064 & 0,0619 & b.l.d & b.1.d & b.l.d & 0,0583 & 0,0076 & b.l.d \\
\hline $\mathrm{Fe}$ & 0,0423 & b.l.d & 0,0064 & b.l.d & b.l.d & 0,0355 & 0,0051 & b.l.d & 0,0240 & 0,0093 & 0,0108 & b.l.d \\
\hline $\mathbf{S}$ & 13,1100 & 12,9800 & 12,9600 & 12,8500 & 13,1800 & 12,9700 & 13,1300 & 13,1600 & 13,0500 & 12,9000 & 12,8200 & 12,9800 \\
\hline TOTAL & 100,3581 & 100,5202 & 101,3656 & 100,6807 & 99,8509 & 99,9630 & 100,7349 & 101,1775 & 99,3178 & 101,3233 & 100,3185 & 99,8161 \\
\hline
\end{tabular}

b.l.d. = bajo el límite de detección 
Análisis de GALENA por microsonda electrónica en MINERALIZACIONES VETIFORMES

Mina $\rightarrow$

Julio César

\begin{tabular}{|c|c|c|c|c|c|c|c|c|c|c|c|c|}
\hline Muestra $\rightarrow$ & 19369 & & & & & & & & & & & \\
\hline$\%$ en peso & 49 & 50 & 51 & 52 & 53 & 54 & 55 & 56 & 57 & 58 & 59 & 60 \\
\hline $\mathbf{P b}$ & 86,8000 & 86,9400 & 86,4500 & 87,4100 & 87,5300 & 86,2600 & 86,1900 & 86,8800 & 86,7200 & 85,9800 & 87,2000 & 86,4900 \\
\hline Sb & b.l.d & b.l.d & b.l.d & b.l.d & 0,0111 & b.l.d & 0,0585 & 0,0021 & b.l.d & b.l.d & b.l.d & 0,0155 \\
\hline Cd & 0,0691 & b.l.d & b.1.d & 0,0202 & b.l.d & b.l.d & 0,0355 & 0,0335 & b.l.d & 0,0264 & b.l.d & 0,0148 \\
\hline Ag & 0,0502 & b.1.d & 0,0502 & 0,0252 & 0,0621 & 0,0402 & b.l.d & b.l.d & b.l.d & 0,1112 & b.l.d & 0,0387 \\
\hline As & 0,0522 & b.l.d & 0,0611 & 0,0018 & 0,0115 & 0,0594 & 0,0124 & 0,0115 & b.l.d & 0,0088 & 0,0141 & b.l.d \\
\hline $\mathbf{Z n}$ & 0,0596 & 0,0796 & 0,0140 & b.1.d & 0,0865 & 0,1042 & 0,1228 & b.l.d & 0,0166 & 0,0061 & 0,0813 & 0,0105 \\
\hline $\mathrm{Cu}$ & b.1.d & b.1.d & b.l.d & 0,0484 & b.1.d & b.1.d & b.1.d & 0,0007 & b.l.d & b.1.d & b.1.d & b.l.d \\
\hline Co & 0,0081 & b.l.d & 0,0396 & b.1.d & b.l.d & 0,0343 & 0,0262 & 0,0112 & 0,0225 & b.l.d & 0,0299 & b.l.d \\
\hline Mn & 0,0140 & b.l.d & b.l.d & b.1.d & b.l.d & 0,0053 & 0,0128 & 0,0134 & 0,0163 & 0,0088 & 0,0017 & 0,0327 \\
\hline $\mathrm{Fe}$ & b.l.d & 0,0433 & b.1.d & 0,0297 & b.l.d & b.l.d & 0,0044 & 0,0249 & b.1.d & b.l.d & b.1.d & 0,0039 \\
\hline $\mathbf{S}$ & 13,2000 & 12,8300 & 12,6400 & 12,9000 & 12,7900 & 12,8100 & 13,0400 & 12,5700 & 12,9600 & 13,1100 & 12,7200 & 12,8000 \\
\hline TOTAL & 100,2532 & 99,8929 & 99,2549 & 100,4353 & 100,4912 & 99,3134 & 99,5026 & 99,5473 & 99,7354 & 99,2513 & 100,0470 & 99,4061 \\
\hline
\end{tabular}

b.l.d. = bajo el límite de detección

\section{Análisis de GALENA por microsonda electrónica en MINERALIZACIONES VETIFORMES}

Mina $\rightarrow$

Julio César

\begin{tabular}{|c|c|c|c|c|c|c|c|c|c|c|c|c|}
\hline Muestra $\rightarrow$ & 19369 & & & & & & & & & & & \\
\hline$\%$ en peso & 61 & 62 & 63 & 64 & 65 & 66 & 67 & 68 & 69 & 70 & 71 & 72 \\
\hline $\mathbf{P b}$ & 86,6200 & 86,7200 & 87,0000 & 86,9900 & 87,0100 & 87,9100 & 87,3500 & 86,7600 & 87,1900 & 87,1400 & 87,6100 & 86,3500 \\
\hline $\mathbf{S b}$ & b.l.d & b.1.d & b.l.d & b.l.d & b.l.d & b.1.d & b.l.d & 0,1011 & 0,0097 & 0,0638 & 0,0441 & 0,0314 \\
\hline Cd & 0,0892 & 0,0693 & b.1.d & b.l.d & 0,0057 & 0,0502 & 0,0048 & b.1.d & b.1.d & b.1.d & b.l.d & 0,0431 \\
\hline Ag & 0,0746 & b.l.d & 0,1034 & 0,0151 & b.l.d & b.1.d & b.l.d & b.l.d & b.1.d & b.l.d & b.l.d & 0,0941 \\
\hline As & 0,0195 & 0,0106 & b.l.d & b.l.d & b.l.d & b.l.d & 0,0080 & 0,0610 & 0,0460 & 0,0168 & 0,0584 & b.1.d \\
\hline $\mathbf{Z n}$ & b.l.d & b.l.d & b.1.d & b.l.d & 0,0604 & 0,1162 & b.l.d & b.1.d & 0,0192 & 0,0525 & 0,0061 & b.1.d \\
\hline $\mathrm{Cu}$ & b.l.d & b.l.d & b.l.d & 0,0802 & 0,0043 & 0,0137 & b.1.d & b.1.d & b.l.d & 0,0224 & b.l.d & b.l.d \\
\hline Co & b.1.d & 0,0198 & b.1.d & b.l.d & b.l.d & b.1.d & b.l.d & b.l.d & 0,0358 & 0,0070 & 0,0016 & b.1.d \\
\hline Mn & b.l.d & b.1.d & 0,0094 & b.l.d & b.1.d & b.1.d & 0,0082 & b.1.d & 0,0029 & b.1.d & b.1.d & 0,0105 \\
\hline $\mathrm{Fe}$ & b.l.d & 0,0389 & 0,0066 & b.l.d & 0,0053 & 0,0290 & b.l.d & 0,0211 & b.1.d & b.l.d & 0,0569 & b.l.d \\
\hline $\mathbf{S}$ & 12,8800 & 12,9200 & 13,0100 & 13,2500 & 12,7900 & 12,7500 & 13,0400 & 13,0800 & 12,9400 & 12,9200 & 13,1600 & 12,6500 \\
\hline TOTAL & 99,6833 & 99,7786 & 100,1294 & 100,3353 & 99,8757 & 100,8691 & 100,4110 & 100,0232 & 100,2436 & 100,2225 & 100,9371 & 99,1791 \\
\hline
\end{tabular}

b.l.d. = bajo el límite de detección 
Análisis de GALENA por microsonda electrónica en MINERALIZACIONES VETIFORMES

Mina $\rightarrow$

Julio César

\begin{tabular}{|c|c|c|c|c|c|c|c|c|c|c|c|c|}
\hline Muestra $\rightarrow$ & 19369 & & & & & & & & & & & \\
\hline$\%$ en peso & 73 & 74 & 75 & 76 & 77 & 78 & 79 & 80 & 81 & 82 & 83 & 84 \\
\hline $\mathbf{P b}$ & 87,0700 & 86,3200 & 86,9800 & 86,5600 & 87,0600 & 88,1400 & 86,7600 & 86,9900 & 87,2800 & 87,5500 & 85,4800 & 86,5100 \\
\hline $\mathbf{S b}$ & 0,0400 & 0,0130 & 0,0774 & b.l.d & 0,1270 & 0,0200 & 0,0036 & b.l.d & b.l.d & 0,0144 & b.l.d & b.l.d \\
\hline Cd & b.1.d & b.1.d & b.1.d & b.1.d & b.1.d & 0,0241 & b.1.d & b.l.d & 0,0207 & b.l.d & 0,0158 & b.l.d \\
\hline Ag & b.l.d & 0,1858 & b.l.d & 0,1125 & b.1.d & b.1.d & b.l.d & b.l.d & b.l.d & 0,0134 & b.l.d & b.1.d \\
\hline As & 0,0486 & 0,0195 & 0,0328 & b.l.d & 0,0018 & 0,0434 & 0,0177 & 0,0257 & b.l.d & 0,0222 & 0,0451 & 0,0203 \\
\hline Zn & b.l.d & 0,0044 & b.l.d & b.l.d & b.l.d & 0,0227 & b.l.d & 0,0298 & b.l.d & 0,1340 & 0,0166 & b.l.d \\
\hline $\mathrm{Cu}$ & b.l.d & 0,0564 & 0,0403 & b.l.d & 0,0318 & 0,0541 & b.l.d & 0,0448 & 0,0535 & 0,0332 & b.l.d & b.1.d \\
\hline Co & b.1.d & 0,0032 & 0,0287 & b.1.d & 0,0262 & b.1.d & 0,0011 & b.l.d & 0,0022 & 0,0193 & b.l.d & b.1.d \\
\hline Mn & b.l.d & b.1.d & 0,0396 & b.l.d & b.l.d & 0,0321 & b.1.d & b.l.d & 0,0339 & 0,0035 & 0,0117 & 0,0053 \\
\hline $\mathbf{F e}$ & 0,0088 & b.l.d & b.1.d & 0,0175 & 0,0056 & 0,0006 & b.l.d & 0,0054 & 0,0215 & b.l.d & 0,0003 & b.l.d \\
\hline $\mathbf{S}$ & 12,8500 & 12,8300 & 12,8000 & 12,7300 & 12,9400 & 12,7900 & 12,9900 & 12,9400 & 13,0700 & 12,9600 & 13,0800 & 12,8900 \\
\hline TOTAL & 100,0174 & 99,4323 & 99,9988 & 99,4200 & 100,1924 & 101,1270 & 99,7724 & 100,0357 & 100,4818 & 100,7500 & 98,6495 & 99,4256 \\
\hline
\end{tabular}

b.l.d. = bajo el límite de detección

\section{Análisis de GALENA por microsonda electrónica en MINERALIZACIONES VETIFORMES}

Mina $\rightarrow$

Julio César

\begin{tabular}{|c|c|c|c|c|c|c|c|c|c|c|c|c|}
\hline Muestra $\rightarrow$ & 19369 & & & & & & & & & & 19373 & \\
\hline$\%$ en peso & 85 & 86 & 87 & 88 & 89 & 90 & 91 & 92 & 93 & 94 & 1 & 2 \\
\hline $\mathbf{P b}$ & 86,9500 & 88,5200 & 87,6300 & 87,0200 & 87,0200 & 87,0000 & 87,3200 & 87,4700 & 87,7200 & 87,4600 & 86,9500 & 86,4200 \\
\hline Sb & 0,0360 & 0,0695 & b.1.d & b.1.d & 0,0030 & b.1.d & b.l.d & b.1.d & b.1.d & b.1.d & b.1.d & 0,0379 \\
\hline Cd & b.l.d & 0,0369 & b.1.d & 0,0744 & b.l.d & b.l.d & b.1.d & 0,0027 & b.l.d & 0,0047 & 0,0986 & b.1.d \\
\hline Ag & 0,1178 & b.l.d & 0,0489 & 0,0207 & b.1.d & 0,0343 & b.1.d & b.1.d & b.l.d & 0,0262 & b.1.d & b.1.d \\
\hline As & 0,0044 & 0,0186 & b.l.d & b.l.d & b.l.d & 0,0540 & b.l.d & b.l.d & b.l.d & b.l.d & 0,0665 & b.1.d \\
\hline $\mathbf{Z n}$ & 0,0131 & b.1.d & b.1.d & 0,0245 & b.l.d & 0,0202 & b.1.d & 0,0622 & b.l.d & 0,0867 & b.l.d & b.l.d \\
\hline $\mathrm{Cu}$ & b.l.d & b.l.d & b.l.d & 0,0411 & 0,0281 & b.l.d & b.1.d & 0,0289 & b.1.d & b.l.d & b.l.d & 0,0383 \\
\hline Co & 0,0396 & b.1.d & b.l.d & b.l.d & 0,0139 & 0,0037 & b.l.d & 0,0316 & b.l.d & b.l.d & b.1.d & b.l.d \\
\hline Mn & 0,0321 & b.l.d & 0,0053 & b.l.d & 0,0099 & 0,0398 & 0,0146 & 0,0099 & 0,0070 & 0,0233 & b.1.d & 0,0339 \\
\hline $\mathrm{Fe}$ & 0,0441 & b.1.d & b.1.d & b.1.d & 0,0011 & b.1.d & 0,0016 & b.l.d & b.1.d & 0,0075 & 0,0075 & 0,0038 \\
\hline $\mathbf{S}$ & 12,7500 & 13,0500 & 12,8700 & 12,6900 & 12,6600 & 13,0400 & 13,0100 & 12,7000 & 12,5400 & 12,6400 & 13,1800 & 12,8500 \\
\hline TOTAL & 99,9871 & 101,6950 & 100,5542 & 99,8707 & 99,7360 & 100,1920 & 100,3462 & 100,3053 & 100,2670 & 100,2484 & 100,3026 & 99,3839 \\
\hline
\end{tabular}

b.l.d. = bajo el límite de detección 
Análisis de GALENA por microsonda electrónica en MINERALIZACIONES VETIFORMES

Mina $\rightarrow$

Julio César

\begin{tabular}{|c|c|c|c|c|c|c|c|c|c|c|c|c|}
\hline Muestra $\rightarrow$ & 19373 & & & & & & & & & & & \\
\hline$\%$ en peso & 3 & 4 & 5 & 6 & 7 & 8 & 9 & 10 & 11 & 12 & 13 & 14 \\
\hline $\mathrm{Pb}$ & 87,1700 & 86,7400 & 87,0600 & 87,6000 & 86,1000 & 86,7500 & 87,5600 & 87,0100 & 87,3000 & 87,3700 & 87,6400 & 87,5000 \\
\hline $\mathbf{S b}$ & 0,0497 & b.1.d & b.1.d & b.1.d & b.1.d & b.1.d & 0,0174 & b.l.d & b.1.d & b.1.d & 0,0130 & b.l.d \\
\hline Cd & b.l.d & 0,0303 & b.1.d & b.l.d & b.l.d & b.l.d & b.l.d & 0,0610 & b.1.d & b.l.d & b.l.d & b.l.d \\
\hline Ag & b.l.d & 0,1538 & b.1.d & 0,0920 & b.1.d & b.l.d & b.l.d & b.1.d & b.l.d & b.l.d & b.l.d & b.l.d \\
\hline As & b.l.d & b.1.d & 0,0443 & b.1.d & b.l.d & 0,0302 & 0,0470 & 0,0089 & 0,0213 & b.l.d & b.1.d & 0,0142 \\
\hline Zn & 0,0745 & b.l.d & b.l.d & 0,0263 & b.l.d & b.1.d & b.l.d & 0,0964 & 0,1542 & b.l.d & b.l.d & b.l.d \\
\hline $\mathrm{Cu}$ & b.1.d & b.1.d & b.1.d & b.1.d & b.1.d & b.l.d & 0,0224 & b.1.d & b.1.d & b.l.d & 0,0036 & b.1.d \\
\hline Co & b.l.d & 0,0053 & b.l.d & 0,0284 & 0,0011 & 0,0316 & b.l.d & b.l.d & b.l.d & b.l.d & b.l.d & 0,0294 \\
\hline Mn & 0,0292 & b.l.d & 0,0292 & b.l.d & 0,0152 & b.l.d & b.l.d & 0,0181 & 0,0023 & 0,0088 & b.l.d & b.l.d \\
\hline $\mathrm{Fe}$ & 0,0347 & 0,0584 & 0,0027 & 0,0217 & b.1.d & 0,0528 & 0,0229 & 0,0275 & 0,0251 & 0,0120 & 0,0121 & 0,0035 \\
\hline $\mathbf{S}$ & 12,8500 & 13,0500 & 12,8900 & 12,8100 & 12,8500 & 13,0100 & 12,8300 & 12,8800 & 12,7000 & 13,0900 & 12,8500 & 12,9800 \\
\hline TOTAL & 100,2081 & 100,0378 & 100,0262 & 100,5784 & 98,9663 & 99,8746 & 100,4997 & 100,1019 & 100,2029 & 100,4808 & 100,5187 & 100,5271 \\
\hline
\end{tabular}

b.l.d. = bajo el límite de detección

\section{Análisis de GALENA por microsonda electrónica en MINERALIZACIONES VETIFORMES}

Mina $\rightarrow$

Julio César

\begin{tabular}{|c|c|c|c|c|c|c|c|c|c|c|c|c|}
\hline Muestra $\rightarrow$ & 19373 & & & & & & & & & & & \\
\hline$\%$ en peso & 15 & 16 & 17 & 18 & 19 & 20 & 21 & 22 & 23 & 24 & 25 & 26 \\
\hline $\mathbf{P b}$ & 86,9600 & 86,6200 & 87,0300 & 87,0500 & 86,6200 & 86,3100 & 86,5500 & 87,3000 & 87,7200 & 87,0200 & 87,7600 & 87,2200 \\
\hline $\mathbf{S b}$ & b.l.d & b.l.d & b.l.d & 0,0194 & 0,0225 & b.l.d & b.l.d & b.l.d & 0,0099 & b.l.d & b.l.d & b.l.d \\
\hline Cd & 0,0337 & 0,0071 & 0,0373 & b.1.d & 0,0090 & b.1.d & 0,0074 & 0,0171 & b.1.d & b.l.d & 0,0767 & b.l.d \\
\hline Ag & 0,0087 & b.l.d & 0,1233 & 0,1328 & 0,0157 & b.1.d & b.l.d & b.l.d & b.1.d & 0,0390 & 0,0218 & b.l.d \\
\hline As & b.l.d & b.l.d & b.l.d & b.1.d & 0,0328 & b.l.d & 0,0275 & b.1.d & 0,0035 & 0,0470 & b.l.d & b.l.d \\
\hline Zn & b.1.d & 0,1157 & b.1.d & 0,0202 & b.l.d & 0,0474 & b.l.d & b.l.d & b.l.d & 0,0877 & 0,0912 & b.l.d \\
\hline $\mathrm{Cu}$ & b.l.d & 0,0427 & b.l.d & b.l.d & 0,0051 & b.l.d & 0,0536 & 0,0738 & 0,0131 & b.l.d & b.l.d & b.l.d \\
\hline Co & b.l.d & b.1.d & 0,0241 & 0,0160 & 0,0466 & 0,0011 & 0,0263 & 0,0209 & b.l.d & 0,0107 & b.l.d & 0,0257 \\
\hline Mn & b.1.d & b.l.d & 0,0368 & 0,0392 & b.1.d & 0,0035 & 0,0685 & 0,0134 & 0,0497 & 0,0088 & b.1.d & 0,0017 \\
\hline $\mathrm{Fe}$ & b.l.d & 0,0192 & 0,0412 & b.1.d & b.1.d & b.l.d & b.l.d & 0,0022 & 0,0546 & 0,0141 & b.l.d & 0,0073 \\
\hline $\mathbf{S}$ & 12,9500 & 12,9100 & 12,9700 & 12,8200 & 12,8200 & 13,0100 & 13,0700 & 13,0700 & 13,1700 & 12,9300 & 12,8400 & 12,9600 \\
\hline TOTAL & 99,9524 & 99,7147 & 100,2627 & 100,0976 & 99,5717 & $\mathbf{9 9 , 3 7 2 0}$ & $\mathbf{9 9 , 8 0 3 3}$ & 100,4974 & 101,0208 & 100,1573 & 100,7897 & 100,2147 \\
\hline
\end{tabular}

b.l.d. = bajo el límite de detección 
Análisis de GALENA por microsonda electrónica en MINERALIZACIONES VETIFORMES

Mina $\rightarrow$

Julio César

\begin{tabular}{|c|c|c|c|c|c|c|c|c|c|c|c|c|}
\hline Muestra $\rightarrow$ & 19373 & & & & & & & & & & & \\
\hline$\%$ en peso & 27 & 28 & 29 & 30 & 31 & 32 & 33 & 34 & 35 & 36 & 37 & 38 \\
\hline $\mathbf{P b}$ & 87,2400 & 86,9700 & 85,6900 & 87,1800 & 86,3500 & 87,4500 & 87,2400 & 86,0500 & 85,3700 & 86,5700 & 87,2300 & 86,0800 \\
\hline Sb & b.l.d & b.l.d & b.1.d & b.l.d & b.1.d & b.1.d & 0,0105 & 0,0079 & b.1.d & b.l.d & b.1.d & b.l.d \\
\hline Cd & b.l.d & b.l.d & b.l.d & 0,0155 & b.l.d & b.l.d & b.l.d & b.l.d & 0,0109 & b.l.d & b.l.d & b.l.d \\
\hline Ag & b.1.d & 0,0274 & b.l.d & b.l.d & 0,0966 & 0,0225 & b.l.d & b.l.d & b.l.d & 0,1149 & 0,0151 & b.l.d \\
\hline As & b.l.d & 0,0044 & 0,0301 & b.l.d & b.l.d & 0,0106 & b.l.d & 0,0018 & 0,0213 & b.l.d & b.1.d & b.l.d \\
\hline $\mathbf{Z n}$ & 0,1465 & 0,0456 & b.l.d & 0,0562 & b.l.d & 0,0298 & 0,0254 & b.l.d & b.l.d & 0,0966 & b.l.d & b.1.d \\
\hline $\mathbf{C u}$ & b.l.d & b.1.d & b.l.d & 0,0485 & b.l.d & b.1.d & 0,0340 & 0,0073 & b.1.d & b.l.d & b.l.d & b.l.d \\
\hline Co & b.l.d & 0,0161 & b.l.d & 0,0349 & b.l.d & 0,0268 & 0,0230 & 0,0032 & b.1.d & b.l.d & 0,0402 & b.l.d \\
\hline Mn & 0,0088 & 0,0251 & b.l.d & 0,0298 & b.1.d & 0,0164 & b.l.d & b.l.d & b.1.d & b.l.d & 0,0310 & b.1.d \\
\hline $\mathbf{F e}$ & b.l.d & 0,0434 & 0,0274 & b.l.d & 0,0313 & 0,0468 & 0,0125 & b.l.d & b.1.d & b.l.d & 0,0422 & 0,0270 \\
\hline $\mathbf{S}$ & 12,8500 & 13,0000 & 12,8800 & 12,9900 & 12,9300 & 13,0000 & 13,0400 & 13,0600 & 12,9300 & 13,0000 & 12,8800 & 12,8100 \\
\hline TOTAL & 100,2453 & 100,1320 & 98,6275 & 100,3549 & 99,4079 & 100,6029 & 100,3854 & 99,1302 & 98,3322 & 99,7815 & 100,2385 & 98,9170 \\
\hline
\end{tabular}

b.l.d. = bajo el límite de detección

\section{Análisis de GALENA por microsonda electrónica en MINERALIZACIONES VETIFORMES}

Mina $\rightarrow$

Julio César

b.l.d. = bajo el límite de detección 
Análisis de GALENA por microsonda electrónica en MINERALIZACIONES VETIFORMES

Mina $\rightarrow$

Julio César

\begin{tabular}{|c|c|c|c|c|c|c|c|c|c|c|c|c|}
\hline Muestra $\rightarrow$ & 19373 & & & & & & & & & & & \\
\hline$\%$ en peso & 51 & 52 & 53 & 54 & 55 & 56 & 57 & 58 & 59 & 60 & 61 & 62 \\
\hline $\mathbf{P b}$ & 85,2400 & 87,0100 & 85,7800 & 86,8200 & 88,3900 & 87,5500 & 86,4000 & 86,1500 & 87,3700 & 88,2000 & 87,6500 & 86,9900 \\
\hline Sb & b.1.d & b.1.d & b.l.d & 0,0566 & b.1.d & b.l.d & b.1.d & b.l.d & b.l.d & 0,0691 & b.1.d & b.l.d \\
\hline Cd & b.l.d & 0,0277 & b.l.d & b.l.d & 0,0024 & 0,0167 & b.l.d & b.l.d & b.l.d & b.l.d & b.l.d & b.l.d \\
\hline Ag & b.l.d & b.1.d & b.l.d & b.l.d & 0,0120 & 0,1750 & b.l.d & b.l.d & b.l.d & 0,0542 & b.l.d & 0,0358 \\
\hline As & 0,0248 & 0,0710 & 0,0098 & b.l.d & b.l.d & b.l.d & b.l.d & 0,0550 & b.l.d & 0,0275 & 0,0035 & b.l.d \\
\hline $\mathbf{Z n}$ & 0,1609 & 0,0781 & 0,0888 & b.l.d & 0,0869 & 0,1030 & 0,0615 & 0,0114 & 0,0070 & 0,0887 & 0,0123 & 0,0931 \\
\hline $\mathrm{Cu}$ & b.1.d & b.1.d & b.1.d & b.l.d & b.1.d & 0,0181 & 0,0261 & 0,0152 & b.1.d & 0,0174 & b.l.d & b.l.d \\
\hline Co & b.l.d & b.l.d & 0,0220 & 0,0348 & b.l.d & b.l.d & 0,0360 & 0,0022 & b.l.d & 0,0016 & 0,0317 & b.l.d \\
\hline Mn & 0,0023 & b.1.d & 0,0035 & 0,0409 & 0,0088 & b.1.d & 0,0252 & b.l.d & 0,0762 & b.l.d & 0,0017 & b.l.d \\
\hline $\mathbf{F e}$ & b.l.d & 0,0063 & 0,0239 & b.l.d & b.l.d & 0,0628 & b.l.d & b.l.d & b.l.d & 0,0294 & b.l.d & 0,0053 \\
\hline $\mathbf{S}$ & 13,0000 & 12,8800 & 12,9800 & 12,8200 & 13,0900 & 13,3400 & 12,9600 & 12,9400 & 13,2500 & 13,0600 & 12,9700 & 13,0400 \\
\hline TOTAL & 98,4280 & 100,0731 & 98,9080 & 99,7723 & 101,5901 & 101,2656 & 99,5088 & 99,1738 & 100,7032 & 101,5479 & 100,6692 & 100,1642 \\
\hline
\end{tabular}

b.l.d. = bajo el límite de detección

\section{Análisis de GALENA por microsonda electrónica en MINERALIZACIONES VETIFORMES}

Mina $\rightarrow$

Julio César

\begin{tabular}{|c|c|c|c|c|c|c|c|c|c|c|c|c|}
\hline Muestra $\rightarrow$ & 19373 & & & & & & & & & & & \\
\hline$\%$ en peso & 63 & 64 & 65 & 66 & 67 & 68 & 69 & 70 & 71 & 72 & 73 & 74 \\
\hline $\mathbf{P b}$ & 85,6400 & 86,1000 & 85,8700 & 87,0000 & 85,8700 & 85,5200 & 87,4400 & 86,7800 & 86,6100 & 87,2600 & 86,9500 & 86,3500 \\
\hline $\mathbf{S b}$ & b.1.d & b.1.d & b.1.d & b.1.d & b.1.d & b.l.d & 0,0081 & b.1.d & b.1.d & 0,0080 & b.1.d & b.1.d \\
\hline Cd & 0,0189 & 0,0521 & 0,0331 & 0,0399 & 0,0372 & 0,0290 & b.1.d & b.1.d & b.1.d & b.1.d & b.l.d & b.1.d \\
\hline Ag & b.1.d & b.l.d & b.l.d & 0,0023 & b.l.d & 0,1087 & 0,0052 & b.l.d & b.1.d & b.l.d & b.l.d & b.l.d \\
\hline As & 0,0009 & b.1.d & b.l.d & 0,0177 & 0,0267 & 0,0053 & b.l.d & 0,0319 & 0,0115 & b.1.d & 0,0319 & b.1.d \\
\hline $\mathbf{Z n}$ & b.1.d & b.1.d & b.1.d & b.l.d & 0,0968 & b.l.d & 0,0351 & 0,0357 & b.l.d & b.l.d & b.l.d & 0,0175 \\
\hline $\mathrm{Cu}$ & 0,0203 & b.l.d & b.l.d & 0,0072 & 0,0094 & b.1.d & b.l.d & b.l.d & 0,0361 & 0,0609 & b.1.d & 0,0022 \\
\hline Co & b.1.d & 0,0102 & b.l.d & b.1.d & 0,0500 & b.1.d & b.1.d & 0,0375 & b.1.d & 0,0451 & b.1.d & b.1.d \\
\hline Mn & b.l.d & 0,0621 & 0,0369 & b.l.d & 0,0146 & 0,0106 & 0,0322 & 0,0480 & 0,0170 & b.1.d & b.l.d & b.l.d \\
\hline $\mathbf{F e}$ & b.l.d & b.1.d & b.l.d & 0,0064 & 0,0393 & 0,0261 & 0,0457 & 0,0405 & 0,0308 & b.l.d & 0,0053 & b.l.d \\
\hline $\mathbf{S}$ & 12,7900 & 12,8300 & 12,8700 & 12,9900 & 13,1100 & 12,8200 & 12,9400 & 13,0400 & 12,8700 & 13,1800 & 12,8500 & 12,8300 \\
\hline TOTAL & 98,4701 & 99,0544 & 98,8100 & 100,0635 & 99,2540 & 98,5197 & 100,5063 & 100,0136 & 99,5754 & 100,5540 & 99,8372 & 99,1997 \\
\hline
\end{tabular}

b.l.d. = bajo el límite de detección 
Análisis de GALENA por microsonda electrónica en MINERALIZACIONES VETIFORMES

Mina $\rightarrow$

Julio César

\begin{tabular}{|c|c|c|c|c|c|c|c|c|c|c|c|c|}
\hline Auestra $\rightarrow$ & 19373 & & & & & & & & & & & \\
\hline$\%$ en peso & 75 & 76 & 77 & 78 & 79 & 80 & 81 & 82 & 83 & 84 & 85 & 86 \\
\hline $\mathbf{P b}$ & 86,2700 & 86,8200 & 87,3800 & 87,6800 & 87,3700 & 86,9000 & 87,4500 & 87,5100 & 86,3900 & 86,6400 & 86,5400 & 85,9900 \\
\hline Sb & b.l.d & b.l.d & 0,0366 & b.1.d & 0,0072 & b.l.d & 0,0003 & b.1.d & b.l.d & 0,0318 & b.1.d & 0,0397 \\
\hline Cd & b.l.d & b.l.d & b.1.d & b.1.d & b.1.d & 0,0203 & b.l.d & 0,0285 & 0,0474 & b.l.d & 0,0113 & 0,0385 \\
\hline Ag & 0,1031 & 0,1084 & b.1.d & b.1.d & 0,0378 & b.1.d & b.1.d & 0,0021 & b.1.d & b.l.d & b.1.d & b.l.d \\
\hline As & b.l.d & 0,0204 & b.l.d & b.l.d & 0,0142 & 0,0364 & b.l.d & 0,0062 & 0,0275 & 0,0470 & b.l.d & 0,0310 \\
\hline Zn & 0,1141 & b.l.d & b.l.d & 0,0562 & 0,0501 & 0,0052 & 0,0940 & 0,0175 & b.1.d & b.l.d & b.l.d & 0,0088 \\
\hline $\mathrm{Cu}$ & b.l.d & b.l.d & b.l.d & b.l.d & b.l.d & b.l.d & b.1.d & b.1.d & b.l.d & b.l.d & 0,0528 & b.l.d \\
\hline Co & b.1.d & 0,0171 & 0,0543 & b.l.d & 0,0225 & 0,0236 & 0,0032 & 0,0252 & 0,0151 & 0,0097 & 0,0123 & b.l.d \\
\hline Mn & b.l.d & 0,0363 & b.l.d & 0,0199 & 0,0070 & 0,0228 & 0,0281 & 0,0105 & 0,0129 & b.l.d & b.l.d & b.l.d \\
\hline $\mathbf{F e}$ & 0,0185 & 0,0288 & b.1.d & 0,0036 & b.1.d & 0,0398 & 0,0606 & 0,0112 & 0,0082 & b.l.d & b.1.d & b.l.d \\
\hline $\mathbf{S}$ & 12,8400 & 12,9700 & 13,1300 & 13,1300 & 13,0900 & 13,0100 & 12,9700 & 13,0600 & 13,0800 & 13,1700 & 12,7700 & 13,0200 \\
\hline TOTAL & 99,3457 & 100,0010 & 100,6009 & 100,8897 & 100,5988 & 100,0581 & 100,6062 & 100,6712 & 99,5811 & 99,8985 & 99,3864 & 99,1280 \\
\hline
\end{tabular}

b.l.d. = bajo el límite de detección

\section{Análisis de GALENA por microsonda electrónica en MINERALIZACIONES VETIFORMES}

Mina $\rightarrow$

Julio César

\begin{tabular}{|c|c|c|c|c|c|c|c|c|c|c|c|c|}
\hline Muestra $\rightarrow$ & 19373 & & & & & & & & & & & \\
\hline$\%$ en peso & 87 & 88 & 89 & 90 & 91 & 92 & 93 & 94 & 95 & 96 & 97 & 98 \\
\hline $\mathbf{P b}$ & 86,9900 & 86,3000 & 86,8400 & 86,0600 & 86,1600 & 86,1700 & 86,2400 & 86,6600 & 87,5400 & 86,3600 & 85,8700 & 88,3200 \\
\hline Sb & b.l.d & b.l.d & b.l.d & b.l.d & 0,0541 & b.l.d & b.l.d & b.l.d & b.l.d & b.l.d & b.1.d & b.l.d \\
\hline Cd & 0,0124 & b.l.d & 0,0011 & b.l.d & b.1.d & b.l.d & b.l.d & 0,0347 & 0,0264 & b.l.d & b.l.d & b.l.d \\
\hline Ag & 0,1280 & b.l.d & 0,0087 & b.l.d & 0,0381 & b.l.d & b.l.d & b.l.d & b.1.d & b.l.d & 0,0425 & b.l.d \\
\hline As & 0,0436 & 0,0151 & 0,0231 & b.1.d & b.1.d & 0,0275 & 0,0728 & 0,0018 & b.l.d & b.1.d & 0,0223 & 0,0045 \\
\hline $\mathbf{Z n}$ & 0,0967 & b.l.d & 0,0299 & b.1.d & b.l.d & b.l.d & b.l.d & b.1.d & 0,0307 & 0,0950 & 0,1723 & 0,0281 \\
\hline $\mathbf{C u}$ & b.l.d & 0,0986 & 0,0276 & b.l.d & b.l.d & b.l.d & 0,0870 & b.l.d & b.l.d & b.1.d & b.l.d & b.l.d \\
\hline Co & 0,0043 & 0,0252 & 0,0172 & b.l.d & 0,0048 & b.1.d & b.1.d & b.l.d & 0,0215 & 0,0247 & 0,0623 & 0,0134 \\
\hline Mn & b.1.d & 0,0305 & 0,0094 & 0,0193 & 0,0463 & b.l.d & 0,0041 & b.1.d & 0,0240 & b.1.d & 0,0351 & b.l.d \\
\hline $\mathrm{Fe}$ & 0,0479 & 0,0263 & 0,0274 & 0,0162 & b.1.d & b.l.d & b.l.d & 0,0034 & 0,0698 & b.1.d & 0,0061 & 0,0168 \\
\hline $\mathbf{S}$ & 12,8800 & 12,9900 & 13,1400 & 12,9700 & 12,9300 & 12,8000 & 13,1700 & 12,9500 & 12,9400 & 12,9400 & 12,7700 & 12,9400 \\
\hline TOTAL & 100,2029 & 99,4857 & 100,1244 & 99,0655 & 99,2333 & 98,9975 & 99,5739 & 99,6499 & 100,6524 & 99,4197 & 98,9806 & 101,3228 \\
\hline
\end{tabular}

b.l.d. = bajo el límite de detección 
Análisis de GALENA por microsonda electrónica en MINERALIZACIONES VETIFORMES Mina $\rightarrow \quad$ Julio César

\begin{tabular}{|c|c|c|c|c|c|c|}
\hline Muestra $\rightarrow$ & 19373 & & & & & \\
\hline$\%$ en peso & 99 & 100 & 101 & 102 & 103 & 104 \\
\hline $\mathbf{P b}$ & 87,3000 & 86,9800 & 86,7200 & 87,0000 & 86,0800 & 86,4700 \\
\hline Sb & b.1.d & 0,0049 & b.l.d & b.1.d & 0,0527 & b.l.d \\
\hline Cd & b.1.d & 0,0555 & b.1.d & 0,0319 & b.l.d & 0,1043 \\
\hline Ag & b.l.d & b.l.d & b.l.d & b.l.d & b.1.d & 0,0594 \\
\hline As & 0,0275 & 0,0115 & 0,0062 & 0,0230 & b.1.d & 0,0621 \\
\hline Zn & b.l.d & b.l.d & b.l.d & 0,0484 & b.l.d & 0,0035 \\
\hline $\mathrm{Cu}$ & 0,0768 & 0,0782 & 0,0029 & b.l.d & 0,0552 & b.l.d \\
\hline Co & b.l.d & b.l.d & b.l.d & b.l.d & 0,0048 & 0,0366 \\
\hline Mn & b.l.d & 0,0387 & 0,0023 & b.1.d & b.l.d & b.l.d \\
\hline $\mathrm{Fe}$ & 0,0139 & 0,0121 & b.l.d & b.l.d & b.1.d & 0,0039 \\
\hline $\mathbf{S}$ & 13,0800 & 13,0800 & 13,2200 & 13,2500 & 13,1800 & 13,0900 \\
\hline TOTAL & 100,4982 & 100,2609 & 99,9514 & 100,3533 & 99,3727 & 99,8298 \\
\hline
\end{tabular}

b.l.d. = bajo el límite de detección 


\section{ANEXO 6:}

Análisis de magnetita por microsonda electrónica 
Análisis de MAGNETITA por microsonda electrónica de ROCAS ÍGNEAS y MINERALIZACIONES

\begin{tabular}{|c|c|c|c|c|c|c|c|c|c|c|c|}
\hline \multicolumn{12}{|c|}{ Muestra $\rightarrow 21827$ (cerro Los Bueyes) } \\
\hline$\%$ en peso & 1 & 2 & 3 & 4 & 6 & 7 & 8 & 9 & 10 & 11 & 12 \\
\hline $\mathrm{SiO}_{2}$ & 0,19 & 0,06 & 0,07 & 0,06 & 0,01 & 0,07 & 0,02 & 0,05 & 0,50 & 0,12 & 0,46 \\
\hline $\mathrm{TiO}_{2}$ & 2,95 & 3,30 & 3,58 & 3,65 & 3,37 & 3,67 & 3,01 & 2,95 & 3,47 & 3,37 & 3,51 \\
\hline $\mathrm{Sc}_{2} \mathrm{O}_{3}$ & bl.d & bl.d & 0,02 & bl.d & bl.d & 0,01 & bl.d & 0,01 & 0,03 & bl.d & bl.d \\
\hline $\mathrm{Al}_{2} \mathbf{O}_{3}$ & 1,09 & 1,23 & 1,67 & 1,86 & 1,48 & 1,56 & 1,16 & 1,03 & 1,58 & 2,29 & 2,00 \\
\hline $\mathrm{Cr}_{2} \mathrm{O}_{3}$ & 0,04 & 0,03 & 0,01 & 0,04 & 0,04 & 0,02 & 0,05 & 0,04 & 0,03 & 0,03 & 0,02 \\
\hline $\mathbf{V}_{2} \mathbf{O}_{3}$ & 0,31 & 0,34 & 0,26 & 0,22 & 0,44 & 0,29 & 0,29 & 0,36 & 0,44 & 0,48 & 0,32 \\
\hline $\mathrm{Fe}_{2} \mathrm{O}_{3} *$ & 60,74 & 61,01 & 59,66 & 59,72 & 60,78 & 60,09 & 61,52 & 62,00 & 58,48 & 60,10 & 59,81 \\
\hline FeO* & 32,18 & 31,76 & 31,41 & 31,81 & 31,48 & 32,48 & 31,08 & 32,51 & 32,64 & 31,66 & 32,61 \\
\hline MnO & 1,51 & 1,60 & 1,84 & 1,63 & 1,36 & 1,08 & 1,87 & 0,81 & 1,44 & 1,36 & 1,41 \\
\hline $\mathrm{NiO}$ & bl.d & bl.d & bl.d & bl.d & bl.d & bl.d & bl.d & bl.d & bl.d & bl.d & bl.d \\
\hline MgO & 0,09 & 0,48 & 0,73 & 0,72 & 0,78 & 0,64 & 0,44 & 0,43 & 0,45 & 1,09 & 0,96 \\
\hline $\mathrm{CaO}$ & bl.d & bl.d & bl.d & bl.d & bl.d & bl.d & bl.d & bl.d & bl.d & bl.d & bl.d \\
\hline $\mathrm{CoO}$ & bl.d & bl.d & bl.d & bl.d & 0,25 & bl.d & bl.d & bl.d & bl.d & bl.d & bl.d \\
\hline ZnO & 0,18 & 0,22 & 0,22 & 0,23 & 0,18 & 0,33 & 0,31 & 0,19 & 0,25 & 0,30 & 0,18 \\
\hline $\mathrm{Na}_{2} \mathrm{O}$ & bl.d & bl.d & bl.d & bl.d & bl.d & bl.d & bl.d & bl.d & bl.d & bl.d & bl.d \\
\hline $\mathbf{K}_{2} \mathbf{O}$ & bl.d & 0,03 & bl.d & 0,02 & 0,01 & 0,02 & 0,02 & bl.d & bl.d & bl.d & bl.d \\
\hline $\mathbf{P}_{2} \mathbf{O}_{5}$ & bl.d & bl.d & bl.d & bl.d & bl.d & bl.d & bl.d & bl.d & bl.d & bl.d & bl.d \\
\hline TOTAL & 99,27 & 100,05 & 99,47 & 99,96 & 100,18 & 100,26 & 99,76 & 100,37 & 99,30 & 100,81 & 101,28 \\
\hline
\end{tabular}

* = $\mathrm{Fe}_{2} \mathrm{O}_{3}$ y FeO discriminado estequiométricamente según Droop 1987; b.l.d. = bajo el límite de detección 
Posiciones $\mathrm{R}^{+2}$

Muestra $\rightarrow 21827$ (cerro Los Bueyes)

\begin{tabular}{|c|c|c|c|c|c|c|c|c|c|c|c|}
\hline c.p.u.f. & 1 & 2 & 3 & 4 & 6 & 7 & 8 & 9 & 10 & 11 & 12 \\
\hline $\mathrm{Fe}^{2+}$ & 8,2666 & 8,0668 & 7,9878 & 8,0405 & 7,9573 & 8,2074 & 7,9270 & 8,2485 & 8,3198 & 7,8969 & 8,1024 \\
\hline Mn & 0,3921 & 0,4108 & 0,4739 & 0,4179 & 0,3482 & 0,2774 & 0,4820 & 0,2084 & 0,3723 & 0,3436 & 0,3541 \\
\hline Mg & 0,0389 & 0,2191 & 0,3323 & 0,3236 & 0,3506 & 0,2869 & 0,1982 & 0,1922 & 0,2058 & 0,4833 & 0,4257 \\
\hline $\mathrm{Ca}$ & 0,0000 & 0,0000 & 0,0000 & 0,0000 & 0,0000 & 0,0000 & 0,0000 & 0,0000 & 0,0000 & 0,0000 & 0,0000 \\
\hline Co & 0,0000 & 0,0000 & 0,0000 & 0,0000 & 0,0608 & 0,0000 & 0,0000 & 0,0000 & 0,0000 & 0,0000 & 0,0000 \\
\hline $\mathrm{Ni}$ & 0,0000 & 0,0000 & 0,0000 & 0,0000 & 0,0000 & 0,0000 & 0,0000 & 0,0000 & 0,0000 & 0,0000 & 0,0000 \\
\hline Zn & 0,0413 & 0,0482 & 0,0498 & 0,0509 & 0,0406 & 0,0727 & 0,0705 & 0,0423 & 0,0551 & 0,0670 & 0,0402 \\
\hline $\mathbf{K}$ & 0,0000 & 0,0128 & 0,0000 & 0,0073 & 0,0054 & 0,0058 & 0,0089 & 0,0000 & 0,0000 & 0,0000 & 0,0000 \\
\hline Suma & 8,7389 & 8,7578 & $\mathbf{8 , 8 4 3 7}$ & 8,8401 & 8,7630 & 8,8502 & 8,6866 & 8,6914 & 8,9531 & 8,7907 & 8,9224 \\
\hline
\end{tabular}

Posiciones $\mathrm{M}^{+3}$

\begin{tabular}{|c|c|c|c|c|c|c|c|c|c|c|c|}
\hline $\mathrm{Fe}^{3+}$ & 14,0411 & 13,9429 & 13,6498 & 13,5845 & 13,8259 & 13,6626 & 14,1187 & 14,1532 & 13,4121 & 13,4898 & 13,3721 \\
\hline Al & 0,3957 & 0,4385 & 0,5985 & 0,6634 & 0,5273 & 0,5562 & 0,4159 & 0,3672 & 0,5679 & 0,8057 & 0,7018 \\
\hline $\mathrm{Cr}$ & 0,0100 & 0,0079 & 0,0019 & 0,0103 & 0,0100 & 0,0053 & 0,0116 & 0,0084 & 0,0060 & 0,0080 & 0,0052 \\
\hline Sc & 0,0001 & 0,0000 & 0,0025 & 0,0000 & 0,0000 & 0,0014 & 0,0000 & 0,0012 & 0,0035 & 0,0000 & 0,0000 \\
\hline $\mathbf{V}$ & 0,0754 & 0,0823 & 0,0624 & 0,0543 & 0,1054 & 0,0698 & 0,0716 & 0,0883 & 0,1078 & 0,1150 & 0,0762 \\
\hline Suma & 14,5223 & 14,4716 & 14,3151 & 14,3124 & 14,4687 & 14,2953 & 14,6178 & 14,6183 & 14,0973 & 14,4185 & 14,1553 \\
\hline
\end{tabular}

\begin{tabular}{|c|c|c|c|c|c|c|c|c|c|c|c|}
\hline & siciones $\mathbf{T}^{+}$ & & & & & & & & & & \\
\hline $\mathbf{S i}$ & 0,0581 & 0,0176 & 0,0222 & 0,0166 & 0,0030 & 0,0202 & 0,0058 & 0,0164 & 0,1536 & 0,0358 & 0,1370 \\
\hline $\mathbf{T i}$ & 0,6807 & 0,7530 & 0,8190 & 0,8308 & 0,7653 & 0,8343 & 0,6898 & 0,6739 & 0,7960 & 0,7549 & 0,7854 \\
\hline Suma & 0,7388 & 0,7706 & 0,8412 & 0,8475 & 0,7684 & 0,8545 & 0,6956 & 0,6903 & 0,9496 & 0,7907 & 0,9224 \\
\hline TOTAL & 24,0000 & 24,0000 & 24,0000 & 24,0000 & 24,0000 & 24,0000 & 24,0000 & 24,0000 & 24,0000 & 24,0000 & 24,0000 \\
\hline
\end{tabular}

Proporciones moleculares de los componentes finales*

\begin{tabular}{crrrrrrrrrrr}
\hline Espinela & 2,74 & 3,05 & 4,20 & 4,65 & 3,67 & 3,91 & 2,86 & 2,53 & 4,06 & 5,63 & 4,98 \\
Magnetita & 97,19 & 96,90 & 95,79 & 95,28 & 96,26 & 96,05 & 97,06 & 97,41 & 95,90 & 94,31 & 94,98 \\
Cromita & 0,07 & 0,06 & 0,01 & 0,07 & 0,07 & 0,04 & 0,08 & 0,06 & 0,04 & 0,06 & 0,04 \\
\hline TOTAL & $\mathbf{1 0 0 , 0 0}$ & $\mathbf{1 0 0 , 0 0}$ & $\mathbf{1 0 0 , 0 0}$ & $\mathbf{1 0 0 , 0 0}$ & $\mathbf{1 0 0 , 0 0}$ & $\mathbf{1 0 0 , 0 0}$ & $\mathbf{1 0 0 , 0 0}$ & $\mathbf{1 0 0 , 0 0}$ & $\mathbf{1 0 0 , 0 0}$ & $\mathbf{1 0 0 , 0 0}$ & $\mathbf{1 0 0 , 0 0}$ \\
\hline * & & & &
\end{tabular}

*= según Deer et al. 1992 
Análisis de MAGNETITA por microsonda electrónica de ROCAS ÍGNEAS y MINERALIZACIONES

\begin{tabular}{|c|c|c|c|c|c|c|c|c|c|c|c|}
\hline \multicolumn{12}{|c|}{ Muestra $\rightarrow 21827$ (cerro Los Bueyes) } \\
\hline$\%$ en peso & 13 & 14 & 15 & 16 & 17 & 18 & 19 & 20 & 21 & 22 & 23 \\
\hline $\mathrm{SiO}_{2}$ & 0,96 & 0,85 & 0,90 & 0,07 & 0,47 & 0,13 & 0,08 & 0,05 & 0,04 & 0,05 & 0,17 \\
\hline $\mathrm{TiO}_{2}$ & 3,39 & 3,38 & 3,26 & 3,67 & 3,55 & 3,84 & 3,30 & 3,53 & 3,45 & 3,01 & 3,27 \\
\hline $\mathrm{Sc}_{2} \mathrm{O}_{3}$ & bl.d & 0,01 & 0,01 & bl.d & 0,01 & bl.d & 0,01 & 0,01 & 0,03 & 0,01 & bl.d \\
\hline $\mathbf{A l}_{2} \mathbf{O}_{3}$ & 2,45 & 2,39 & 2,49 & 1,66 & 1,73 & 1,87 & 1,42 & 2,02 & 1,32 & 1,43 & 3,20 \\
\hline $\mathrm{Cr}_{2} \mathrm{O}_{3}$ & 0,04 & 0,03 & 0,02 & 0,02 & 0,04 & 0,03 & bl.d & 0,01 & 0,09 & 0,04 & 0,01 \\
\hline $\mathbf{V}_{2} \mathbf{O}_{3}$ & 0,39 & 0,28 & 0,42 & 0,30 & 0,30 & 0,40 & 0,41 & 0,42 & 0,24 & 0,49 & 0,22 \\
\hline $\mathrm{Fe}_{2} \mathrm{O}_{3} *$ & 57,89 & 58,19 & 58,54 & 60,70 & 59,12 & 59,45 & 60,68 & 60,30 & 60,85 & 60,77 & 59,56 \\
\hline FeO* & 33,18 & 32,34 & 33,23 & 31,98 & 31,54 & 31,49 & 33,93 & 31,82 & 32,94 & 32,30 & 31,72 \\
\hline MnO & 1,42 & 1,94 & 0,96 & 1,54 & 1,86 & 1,98 & 0,29 & 1,49 & 1,09 & 0,96 & 1,58 \\
\hline NiO & bl.d & bl.d & 0,03 & bl.d & bl.d & bl.d & 0,02 & bl.d & bl.d & bl.d & bl.d \\
\hline MgO & 0,84 & 0,94 & 0,96 & 0,87 & 0,89 & 0,82 & 0,13 & 1,01 & 0,37 & 0,29 & 0,97 \\
\hline $\mathrm{CaO}$ & bl.d & bl.d & bl.d & bl.d & bl.d & bl.d & bl.d & bl.d & bl.d & bl.d & bl.d \\
\hline $\mathrm{CoO}$ & bl.d & bl.d & bl.d & bl.d & bl.d & 0,05 & bl.d & bl.d & bl.d & bl.d & bl.d \\
\hline $\mathrm{ZnO}$ & 0,26 & 0,18 & 0,24 & 0,29 & 0,49 & 0,44 & 0,18 & 0,05 & 0,12 & 0,32 & 0,41 \\
\hline $\mathrm{Na}_{2} \mathrm{O}$ & bl.d & bl.d & bl.d & bl.d & bl.d & bl.d & bl.d & bl.d & bl.d & bl.d & bl.d \\
\hline $\mathbf{K}_{2} \mathbf{O}$ & bl.d & bl.d & 0,05 & 0,02 & 0,02 & 0,02 & bl.d & 0,02 & bl.d & 0,02 & 0,01 \\
\hline $\mathbf{P}_{2} \mathbf{O}_{5}$ & bl.d & bl.d & bl.d & bl.d & bl.d & bl.d & bl.d & bl.d & bl.d & bl.d & bl.d \\
\hline TOTAL & 100,81 & 100,54 & 101,11 & 101,12 & 100,01 & 100,50 & 100,45 & 100,73 & 100,55 & 99,68 & 101,10 \\
\hline
\end{tabular}

* $=\mathrm{Fe}_{2} \mathrm{O}_{3}$ y $\mathrm{FeO}$ discriminado estequiométricamente según Droop 1987; b.l.d. = bajo el límite de detección 
Posiciones $\mathbf{R}^{+2}$

Muestra $\rightarrow 21827$ (cerro Los Bueyes)

\begin{tabular}{|c|c|c|c|c|c|c|c|c|c|c|c|}
\hline c.p.u.f. & 13 & 14 & 15 & 16 & 17 & 18 & 19 & 20 & 21 & 22 & 23 \\
\hline $\mathrm{Fe}^{2+}$ & 8,2535 & 8,0672 & 8,2353 & 7,9945 & 7,9527 & 7,9078 & 8,5993 & 7,9592 & 8,3288 & 8,2404 & 7,8574 \\
\hline Mn & 0,3587 & 0,4896 & 0,2414 & 0,3886 & 0,4750 & 0,5042 & 0,0744 & 0,3762 & 0,2797 & 0,2483 & 0,3959 \\
\hline Mg & 0,3729 & 0,4157 & 0,4250 & 0,3863 & 0,3996 & 0,3680 & 0,0605 & 0,4490 & 0,1677 & 0,1337 & 0,4275 \\
\hline $\mathbf{C a}$ & 0,0000 & 0,0000 & 0,0000 & 0,0000 & 0,0000 & 0,0000 & 0,0000 & 0,0000 & 0,0000 & 0,0000 & 0,0000 \\
\hline Co & 0,0000 & 0,0000 & 0,0000 & 0,0000 & 0,0000 & 0,0120 & 0,0000 & 0,0000 & 0,0000 & 0,0000 & 0,0000 \\
\hline $\mathbf{N i}$ & 0,0000 & 0,0000 & 0,0069 & 0,0000 & 0,0000 & 0,0000 & 0,0044 & 0,0000 & 0,0000 & 0,0000 & 0,0000 \\
\hline $\mathbf{Z n}$ & 0,0573 & 0,0403 & 0,0530 & 0,0647 & 0,1082 & 0,0982 & 0,0394 & 0,0108 & 0,0261 & 0,0719 & 0,0892 \\
\hline $\mathbf{K}$ & 0,0000 & 0,0000 & 0,0170 & 0,0061 & 0,0062 & 0,0073 & 0,0000 & 0,0076 & 0,0000 & 0,0062 & 0,0042 \\
\hline Suma & 9,0425 & 9,0127 & 8,9786 & 8,8402 & 8,9417 & 8,8975 & 8,7781 & $\mathbf{8 , 8 0 2 7}$ & 8,8023 & 8,7004 & 8,7743 \\
\hline
\end{tabular}

Posiciones $\mathrm{M}^{+3}$

\begin{tabular}{|c|c|c|c|c|c|c|c|c|c|c|c|}
\hline $\mathrm{Fe}^{3+}$ & 12,9556 & 13,0586 & 13,0526 & 13,6519 & 13,4125 & 13,4343 & 13,8384 & 13,5712 & 13,8442 & 13,9489 & 13,2767 \\
\hline Al & 0,8592 & 0,8415 & 0,8692 & 0,5840 & 0,6162 & 0,6612 & 0,5061 & 0,7123 & 0,4704 & 0,5145 & 1,1158 \\
\hline $\mathrm{Cr}$ & 0,0085 & 0,0071 & 0,0047 & 0,0057 & 0,0091 & 0,0064 & 0,0000 & 0,0019 & 0,0220 & 0,0092 & 0,0030 \\
\hline Sc & 0,0000 & 0,0016 & 0,0006 & 0,0000 & 0,0016 & 0,0003 & 0,0016 & 0,0007 & 0,0042 & 0,0007 & 0,0000 \\
\hline $\mathbf{V}$ & 0,0918 & 0,0674 & 0,0993 & 0,0719 & 0,0728 & 0,0958 & 0,0994 & 0,1014 & 0,0589 & 0,1203 & 0,0518 \\
\hline Suma & 13,9151 & 13,9762 & 14,0265 & 14,3135 & 14,1121 & 14,1980 & 14,4454 & 14,3875 & 14,3996 & 14,5936 & 14,4473 \\
\hline
\end{tabular}

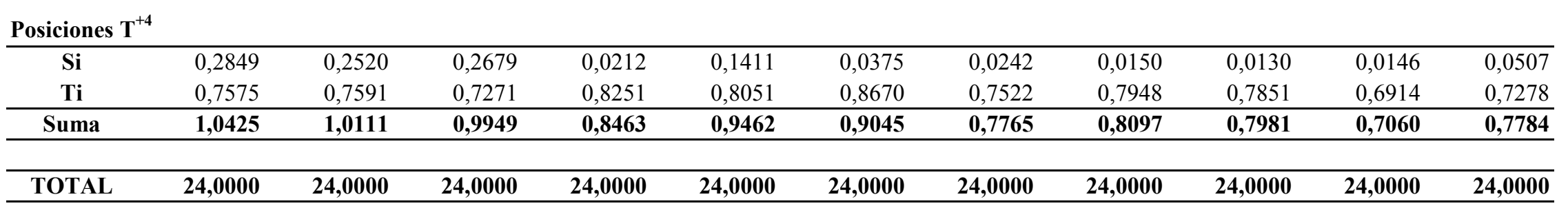

Proporciones moleculares de los componentes finales*

\begin{tabular}{|c|c|c|c|c|c|c|c|c|c|c|c|}
\hline Espinela & 6,22 & 6,05 & 6,24 & 4,10 & 4,39 & 4,69 & 3,53 & 4,99 & 3,28 & 3,55 & 7,75 \\
\hline Magnetita & 93,72 & 93,90 & 93,72 & 95,86 & 95,55 & 95,27 & 96,47 & 95,00 & 96,57 & 96,38 & 92,23 \\
\hline Cromita & 0,06 & 0,05 & 0,03 & 0,04 & 0,06 & 0,05 & 0,00 & 0,01 & 0,15 & 0,06 & 0,02 \\
\hline TOTAL & 100,00 & 100,00 & 100,00 & 100,00 & 100,00 & 100,00 & 100,00 & 100,00 & 100,00 & 100,00 & 100,00 \\
\hline
\end{tabular}

*= según Deer et al. 1992 
Análisis de MAGNETITA por microsonda electrónica de ROCAS ÍGNEAS y MINERALIZACIONES

\begin{tabular}{|c|c|c|c|c|c|c|c|c|c|c|c|}
\hline \multicolumn{6}{|c|}{ Muestra $\rightarrow 21827$ (cerro Los Bueyes) } & \multicolumn{6}{|c|}{21824 (cerro Los Bueyes) } \\
\hline$\%$ en peso & 24 & 25 & 26 & 27 & 28 & 29 & 30 & 1 & 2 & 3 & 4 \\
\hline $\mathrm{SiO}_{2}$ & bl.d & 0,31 & 0,02 & 0,08 & 0,11 & 0,05 & 0,05 & 0,74 & 1,14 & 0,14 & 0,22 \\
\hline $\mathrm{TiO}_{2}$ & 3,39 & 3,52 & 3,80 & 3,14 & 3,71 & 3,50 & 3,26 & 3,16 & 3,79 & 3,58 & 3,49 \\
\hline $\mathrm{Sc}_{2} \mathrm{O}_{3}$ & 0,01 & bl.d & bl.d & 0,01 & 0,02 & bl.d & bl.d & bl.d & bl.d & bl.d & bl.d \\
\hline $\mathbf{A l}_{2} \mathbf{O}_{3}$ & 2,14 & 1,44 & 1,60 & 1,99 & 1,84 & 1,90 & 1,54 & 2,74 & 2,63 & 2,14 & 2,26 \\
\hline $\mathrm{Cr}_{2} \mathrm{O}_{3}$ & bl.d & 0,01 & bl.d & 0,08 & 0,03 & 0,04 & 0,03 & 0,04 & 0,03 & 0,06 & 0,07 \\
\hline $\mathbf{V}_{2} \mathbf{O}_{3}$ & 0,36 & 0,36 & 0,44 & 0,35 & 0,39 & 0,23 & 0,29 & 0,26 & 0,43 & 0,27 & 0,33 \\
\hline $\mathrm{Fe}_{2} \mathrm{O}_{3} *$ & 60,99 & 60,04 & 60,26 & 60,76 & 60,34 & 60,02 & 60,70 & 57,82 & 56,35 & 60,03 & 59,63 \\
\hline FeO* & 31,89 & 32,42 & 32,29 & 32,76 & 31,64 & 31,70 & 31,31 & 31,83 & 33,30 & 32,37 & 32,10 \\
\hline MnO & 1,29 & 1,57 & 1,63 & 0,92 & 1,87 & 1,53 & 1,87 & 2,01 & 1,58 & 1,56 & 1,62 \\
\hline $\mathrm{NiO}$ & bl.d & bl.d & bl.d & bl.d & bl.d & bl.d & bl.d & bl.d & bl.d & bl.d & bl.d \\
\hline MgO & 1,08 & 0,62 & 0,72 & 0,49 & 1,04 & 0,82 & 0,68 & 0,75 & 0,64 & 0,74 & 0,83 \\
\hline $\mathrm{CaO}$ & bl.d & bl.d & bl.d & bl.d & bl.d & bl.d & bl.d & bl.d & bl.d & bl.d & bl.d \\
\hline $\mathrm{CoO}$ & bl.d & bl.d & bl.d & bl.d & bl.d & bl.d & bl.d & bl.d & 0,59 & bl.d & bl.d \\
\hline $\mathrm{ZnO}$ & 0,10 & 0,20 & 0,13 & 0,25 & 0,26 & 0,20 & 0,14 & 0,27 & 0,23 & 0,20 & 0,24 \\
\hline $\mathrm{Na}_{2} \mathrm{O}$ & bl.d & bl.d & bl.d & bl.d & bl.d & bl.d & bl.d & bl.d & bl.d & bl.d & bl.d \\
\hline $\mathbf{K}_{2} \mathbf{O}$ & bl.d & bl.d & bl.d & bl.d & bl.d & bl.d & bl.d & 0,02 & 0,04 & bl.d & bl.d \\
\hline $\mathbf{P}_{\mathbf{2}} \mathbf{O}_{\mathbf{5}}$ & bl.d & bl.d & bl.d & bl.d & bl.d & bl.d & bl.d & bl.d & bl.d & bl.d & bl.d \\
\hline TOTAL & 101,24 & 100,49 & 100,89 & 100,81 & 101,24 & 99,99 & 99,88 & 99,63 & 100,73 & 101,08 & 100,79 \\
\hline
\end{tabular}


Posiciones $\mathbf{R}^{+2}$

Muestra $\rightarrow 21827$ (cerro Los Bueyes)

\begin{tabular}{|c|c|c|c|c|c|c|c|c|c|c|c|}
\hline \multicolumn{6}{|c|}{ Muestra $\rightarrow 21827$ (cerro Los Bueyes) } & \multicolumn{6}{|c|}{21824 (cerro Los Bueyes) } \\
\hline c.p.u.f. & 24 & 25 & 26 & 27 & 28 & 29 & 30 & 1 & 2 & 3 & 4 \\
\hline $\mathrm{Fe}^{2+}$ & 7,9308 & 8,1699 & 8,0999 & 8,2246 & 7,8781 & 8,0054 & 7,9403 & 8,0109 & 8,2850 & 8,0772 & 8,0207 \\
\hline Mn & 0,3239 & 0,4002 & 0,4136 & 0,2329 & 0,4709 & 0,3908 & 0,4805 & 0,5113 & 0,3973 & 0,3938 & 0,4100 \\
\hline Mg & 0,4801 & 0,2781 & 0,3202 & 0,2207 & 0,4599 & 0,3687 & 0,3083 & 0,3360 & 0,2829 & 0,3301 & 0,3684 \\
\hline $\mathrm{Ca}$ & 0,0000 & 0,0000 & 0,0000 & 0,0000 & 0,0000 & 0,0000 & 0,0000 & 0,0000 & 0,0000 & 0,0000 & 0,0000 \\
\hline Co & 0,0000 & 0,0000 & 0,0000 & 0,0000 & 0,0000 & 0,0000 & 0,0000 & 0,0000 & 0,1410 & 0,0000 & 0,0000 \\
\hline $\mathbf{N i}$ & 0,0000 & 0,0000 & 0,0000 & 0,0000 & 0,0000 & 0,0000 & 0,0000 & 0,0000 & 0,0000 & 0,0000 & 0,0000 \\
\hline Zn & 0,0209 & 0,0443 & 0,0288 & 0,0550 & 0,0574 & 0,0444 & 0,0307 & 0,0609 & 0,0494 & 0,0432 & 0,0525 \\
\hline $\mathbf{K}$ & 0,0011 & 0,0000 & 0,0000 & 0,0000 & 0,0000 & 0,0000 & 0,0000 & 0,0092 & 0,0159 & 0,0000 & 0,0000 \\
\hline Suma & 8,7568 & 8,8924 & 8,8624 & 8,7332 & 8,8663 & 8,8093 & 8,7598 & 8,9283 & 9,1716 & 8,8443 & 8,8515 \\
\hline
\end{tabular}

Posiciones $\mathrm{M}^{+3}$

\begin{tabular}{|c|c|c|c|c|c|c|c|c|c|c|c|}
\hline $\mathrm{Fe}^{3+}$ & 13,6484 & 13,6125 & 13,6021 & 13,7278 & 13,5205 & 13,6395 & 13,8499 & 13,0927 & 12,6125 & 13,4797 & 13,4063 \\
\hline Al & 0,7500 & 0,5128 & 0,5670 & 0,7045 & 0,6461 & 0,6773 & 0,5514 & 0,9704 & 0,9210 & 0,7537 & 0,7941 \\
\hline $\mathrm{Cr}$ & 0,0000 & 0,0019 & 0,0000 & 0,0183 & 0,0078 & 0,0091 & 0,0079 & 0,0093 & 0,0061 & 0,0137 & 0,0168 \\
\hline Sc & 0,0008 & 0,0000 & 0,0000 & 0,0008 & 0,0030 & 0,0000 & 0,0000 & 0,0000 & 0,0000 & 0,0000 & 0,0003 \\
\hline $\mathbf{V}$ & 0,0868 & 0,0879 & 0,1061 & 0,0830 & 0,0931 & 0,0557 & 0,0712 & 0,0618 & 0,1014 & 0,0644 & 0,0798 \\
\hline Suma & 14,4860 & 14,2152 & 14,2751 & 14,5344 & 14,2705 & 14,3815 & 14,4805 & 14,1341 & 13,6409 & 14,3114 & 14,2972 \\
\hline
\end{tabular}

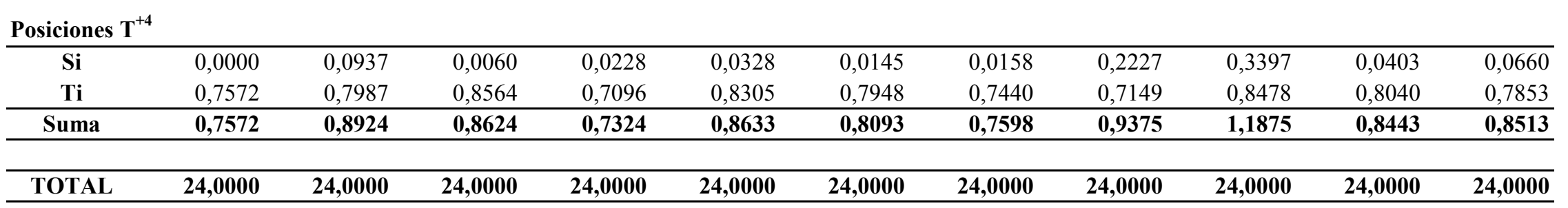

Proporciones moleculares de los componentes finales*

\begin{tabular}{|c|c|c|c|c|c|c|c|c|c|c|c|}
\hline Espinela & 5,21 & 3,63 & 4,00 & 4,88 & 4,56 & 4,73 & 3,83 & 6,90 & 6,80 & 5,29 & $\overline{5,59}$ \\
\hline Magnetita & 94,79 & 96,36 & 96,00 & 95,00 & 95,39 & 95,21 & 96,12 & 93,04 & 93,15 & 94,61 & 94,30 \\
\hline Cromita & 0,00 & 0,01 & 0,00 & 0,13 & 0,05 & 0,06 & 0,05 & 0,07 & 0,05 & 0,10 & 0,12 \\
\hline TOTAL & 100,00 & 100,00 & 100,00 & 100,00 & 100,00 & 100,00 & 100,00 & 100,00 & 100,00 & 100,00 & 100,00 \\
\hline
\end{tabular}


Análisis de MAGNETITA por microsonda electrónica de ROCAS ÍGNEAS y MINERALIZACIONES

\begin{tabular}{|c|c|c|c|c|c|c|c|c|c|c|c|}
\hline \% en peso & 5 & 6 & 7 & 8 & 9 & 10 & 11 & 12 & 13 & 14 & 15 \\
\hline $\mathrm{SiO}_{2}$ & 0,33 & 0,11 & 1,86 & 1,33 & 0,06 & 0,02 & 0,06 & 0,02 & 0,31 & 0,05 & 0,03 \\
\hline $\mathrm{TiO}_{2}$ & 3,55 & 3,34 & 3,48 & 3,66 & 3,80 & 3,60 & 3,39 & 3,55 & 2,98 & 3,57 & 3,61 \\
\hline $\mathrm{Sc}_{2} \mathrm{O}_{3}$ & bl.d & bl.d & 0,00 & 0,00 & 0,02 & bl.d & bl.d & 0,02 & 0,02 & bl.d & bl.d \\
\hline $\mathbf{A l}_{2} \mathbf{O}_{3}$ & 3,17 & 1,80 & 3,43 & 2,56 & 1,59 & 1,83 & 1,57 & 1,60 & 3,83 & 1,99 & 1,72 \\
\hline $\mathrm{Cr}_{2} \mathrm{O}_{3}$ & 0,02 & 0,03 & 0,04 & 0,04 & 0,03 & 0,03 & 0,02 & 0,03 & 0,03 & 0,03 & 0,05 \\
\hline $\mathbf{V}_{2} \mathbf{O}_{3}$ & 0,22 & 0,27 & 0,33 & 0,31 & 0,43 & 0,31 & 0,28 & 0,18 & 0,37 & 0,33 & 0,42 \\
\hline $\mathrm{Fe}_{2} \mathrm{O}_{3} *$ & 57,76 & 60,50 & 54,13 & 55,89 & 59,92 & 60,22 & 60,79 & 60,15 & 57,69 & 60,34 & 60,59 \\
\hline FeO* & 31,76 & 31,79 & 34,42 & 33,35 & 32,84 & 31,94 & 32,78 & 33,44 & 31,61 & 33,64 & 31,77 \\
\hline MnO & 1,98 & 1,70 & 1,54 & 1,82 & 1,54 & 2,02 & 1,31 & 0,85 & 2,03 & 0,99 & 2,19 \\
\hline $\mathrm{NiO}$ & bl.d & bl.d & bl.d & bl.d & bl.d & bl.d & bl.d & bl.d & bl.d & bl.d & 0,03 \\
\hline MgO & 0,81 & 0,61 & 0,70 & 0,90 & 0,38 & 0,55 & 0,31 & 0,19 & 0,63 & 0,21 & 0,63 \\
\hline $\mathrm{CaO}$ & bl.d & bl.d & bl.d & bl.d & bl.d & bl.d & bl.d & bl.d & bl.d & bl.d & bl.d \\
\hline $\mathrm{CoO}$ & bl.d & bl.d & bl.d & bl.d & bl.d & bl.d & bl.d & bl.d & bl.d & bl.d & bl.d \\
\hline ZnO & 0,20 & 0,33 & 0,27 & 0,11 & 0,23 & 0,10 & 0,20 & 0,11 & 0,20 & 0,27 & 0,16 \\
\hline $\mathbf{K}_{2} \mathbf{O}$ & 0,03 & bl.d & 0,05 & bl.d & 0,01 & bl.d & bl.d & bl.d & bl.d & bl.d & bl.d \\
\hline $\mathbf{P}_{\mathbf{2}} \mathbf{O}_{5}$ & bl.d & bl.d & bl.d & bl.d & bl.d & bl.d & bl.d & bl.d & bl.d & bl.d & bl.d \\
\hline TOTAL & 99,83 & 100,48 & 100,26 & 99,98 & 100,84 & 100,61 & 100,70 & 100,14 & 99,70 & 101,42 & 101,20 \\
\hline
\end{tabular}

* $=\mathrm{Fe}_{2} \mathrm{O}_{3}$ y $\mathrm{FeO}$ discriminado estequiométricamente según Droop 1987; b.l.d. = bajo el límite de detección 
Posiciones $\mathbf{R}^{+2}$

\section{Muestra $\rightarrow 21824$ (cerro Los Bueyes)}

\begin{tabular}{|c|c|c|c|c|c|c|c|c|c|c|c|}
\hline c.p.u.f. & 5 & 6 & 7 & 8 & 9 & 10 & 11 & 12 & 13 & 14 & 15 \\
\hline $\mathrm{Fe}^{2+}$ & 7,9649 & 8,0067 & 8,5347 & 8,3351 & 8,2617 & 8,0350 & 8,2687 & 8,4891 & 7,9263 & 8,4131 & 7,9463 \\
\hline Mn & 0,5027 & 0,4334 & 0,3870 & 0,4602 & 0,3935 & 0,5149 & 0,3347 & 0,2190 & 0,5142 & 0,2515 & 0,5545 \\
\hline Mg & 0,3639 & 0,2734 & 0,3103 & 0,4014 & 0,1700 & 0,2484 & 0,1394 & 0,0873 & 0,2825 & 0,0936 & 0,2804 \\
\hline $\mathrm{Ca}$ & 0,0000 & 0,0000 & 0,0000 & 0,0000 & 0,0000 & 0,0000 & 0,0000 & 0,0000 & 0,0000 & 0,0000 & 0,0000 \\
\hline Co & 0,0000 & 0,0000 & 0,0000 & 0,0000 & 0,0000 & 0,0000 & 0,0000 & 0,0000 & 0,0000 & 0,0000 & 0,0000 \\
\hline $\mathbf{N i}$ & 0,0000 & 0,0000 & 0,0000 & 0,0000 & 0,0000 & 0,0000 & 0,0000 & 0,0000 & 0,0000 & 0,0000 & 0,0063 \\
\hline Zn & 0,0434 & 0,0738 & 0,0595 & 0,0252 & 0,0500 & 0,0211 & 0,0434 & 0,0240 & 0,0449 & 0,0596 & 0,0353 \\
\hline $\mathbf{K}$ & 0,0119 & 0,0000 & 0,0182 & 0,0000 & 0,0023 & 0,0000 & 0,0000 & 0,0000 & 0,0000 & 0,0000 & 0,0000 \\
\hline Suma & 8,8868 & 8,7874 & 9,3096 & 9,2218 & $\mathbf{8 , 8 7 7 5}$ & 8,8194 & 8,7862 & 8,8195 & 8,7680 & 8,8178 & 8,8228 \\
\hline
\end{tabular}

Posiciones $\mathrm{M}^{+3}$

\begin{tabular}{|c|c|c|c|c|c|c|c|c|c|c|c|}
\hline $\mathrm{Fe}^{3+}$ & 13,0360 & 13,7126 & 12,0759 & 12,5692 & 13,5664 & 13,6310 & 13,7969 & 13,7381 & 13,0160 & 13,5776 & 13,6345 \\
\hline Al & 1,1201 & 0,6400 & 1,1985 & 0,9031 & 0,5652 & 0,6477 & 0,5574 & 0,5724 & 1,3523 & 0,7024 & 0,6066 \\
\hline $\mathrm{Cr}$ & 0,0045 & 0,0079 & 0,0101 & 0,0099 & 0,0078 & 0,0069 & 0,0052 & 0,0070 & 0,0064 & 0,0061 & 0,0121 \\
\hline Sc & 0,0000 & 0,0000 & 0,0003 & 0,0004 & 0,0025 & 0,0000 & 0,0000 & 0,0029 & 0,0027 & 0,0000 & 0,0000 \\
\hline $\mathbf{V}$ & 0,0539 & 0,0647 & 0,0782 & 0,0740 & 0,1032 & 0,0755 & 0,0680 & 0,0436 & 0,0894 & 0,0782 & 0,1012 \\
\hline Suma & 14,2145 & 14,4252 & 13,3629 & 13,5567 & 14,2452 & 14,3611 & 14,4275 & 14,3639 & 14,4668 & 14,3643 & 14,3543 \\
\hline
\end{tabular}

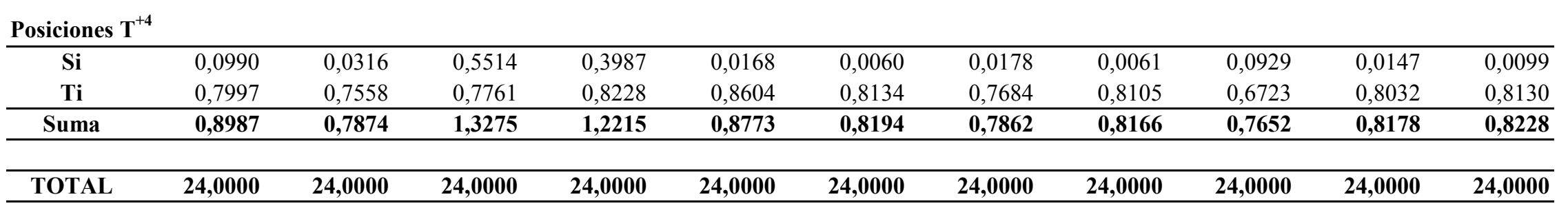

Proporciones moleculares de los componentes finales*

\begin{tabular}{|c|c|c|c|c|c|c|c|c|c|c|c|}
\hline Espinela & 7,91 & 4,46 & 9,02 & 6,70 & 4,00 & 4,53 & 3,88 & 4,00 & 9,41 & 4,92 & 4,26 \\
\hline Magnetita & 92,06 & 95,49 & 90,90 & 93,23 & 95,95 & 95,42 & 96,08 & 95,95 & 90,55 & 95,04 & 95,66 \\
\hline Cromita & 0,03 & 0,05 & 0,08 & 0,07 & 0,06 & 0,05 & 0,04 & 0,05 & 0,04 & 0,04 & 0,08 \\
\hline TOTAL & 100,00 & 100,00 & 100,00 & 100,00 & 100,00 & 100,00 & 100,00 & 100,00 & 100,00 & 100,00 & 100,00 \\
\hline
\end{tabular}

*= según Deer et al. 1992 
Análisis de MAGNETITA por microsonda electrónica de ROCAS ÍGNEAS y MINERALIZACIONES

\begin{tabular}{|c|c|c|c|c|c|c|c|c|c|c|c|}
\hline \multicolumn{10}{|c|}{ Muestra $\rightarrow 21824$ (cerro Los Bueyes) } & \multicolumn{2}{|c|}{19334 E (c Naunauco) } \\
\hline$\%$ en peso & 16 & 17 & 18 & 19 & 20 & 21 & 22 & 23 & 24 & 1 & 2 \\
\hline $\mathrm{SiO}_{2}$ & 0,11 & 0,03 & 0,11 & 0,04 & 0,04 & 0,03 & 0,03 & 0,01 & 0,05 & bl.d & bl.d \\
\hline $\mathrm{TiO}_{2}$ & 3,44 & 3,25 & 3,60 & 3,09 & 3,00 & 3,34 & 3,82 & 3,30 & 3,17 & 0,36 & 0,33 \\
\hline $\mathrm{Sc}_{2} \mathrm{O}_{3}$ & bl.d & 0,01 & bl.d & bl.d & bl.d & bl.d & bl.d & 0,01 & bl.d & 0,02 & 0,01 \\
\hline $\mathbf{A l}_{2} \mathbf{O}_{3}$ & 2,41 & 2,01 & 2,54 & 2,04 & 2,14 & 2,17 & 2,05 & 2,03 & 1,81 & 1,33 & 1,34 \\
\hline $\mathrm{Cr}_{2} \mathrm{O}_{3}$ & 0,03 & 0,01 & bl.d & 0,00 & 0,08 & 0,03 & 0,06 & 0,04 & 0,03 & bl.d & bl.d \\
\hline $\mathbf{V}_{2} \mathbf{O}_{3}$ & 0,32 & 0,36 & 0,16 & 0,33 & 0,35 & 0,34 & 0,33 & 0,34 & 0,26 & bl.d & 0,02 \\
\hline $\mathrm{Fe}_{2} \mathrm{O}_{3} *$ & 59,65 & 60,92 & 59,62 & 61,17 & 60,97 & 60,34 & 59,53 & 60,56 & 61,23 & 68,80 & 69,31 \\
\hline FeO* & 32,11 & 31,35 & 31,96 & 31,53 & 31,41 & 32,53 & 31,74 & 31,45 & 31,32 & 26,31 & 25,42 \\
\hline MnO & 1,32 & 1,93 & 1,82 & 1,55 & 1,66 & 1,17 & 2,01 & 1,84 & 2,00 & 0,17 & 0,16 \\
\hline $\mathrm{NiO}$ & 0,02 & bl.d & bl.d & bl.d & bl.d & bl.d & bl.d & bl.d & bl.d & bl.d & 0,02 \\
\hline MgO & 0,78 & 0,84 & 0,74 & 0,85 & 0,66 & 0,62 & 0,81 & 0,75 & 0,75 & 3,23 & 3,91 \\
\hline $\mathrm{CaO}$ & bl.d & bl.d & bl.d & bl.d & bl.d & bl.d & bl.d & bl.d & bl.d & bl.d & bl.d \\
\hline $\mathrm{CoO}$ & bl.d & bl.d & bl.d & bl.d & bl.d & bl.d & bl.d & bl.d & bl.d & 0,17 & 0,20 \\
\hline $\mathrm{ZnO}$ & 0,17 & 0,17 & 0,35 & 0,15 & 0,28 & 0,13 & 0,15 & 0,20 & 0,12 & 0,17 & bl.d \\
\hline $\mathbf{K}_{2} \mathbf{O}$ & 0,04 & bl.d & bl.d & bl.d & 0,02 & bl.d & bl.d & bl.d & bl.d & bl.d & bl.d \\
\hline $\mathbf{P}_{2} \mathbf{O}_{5}$ & bl.d & bl.d & bl.d & bl.d & bl.d & bl.d & bl.d & bl.d & bl.d & bl.d & bl.d \\
\hline TOTAL & 100,42 & 100,87 & 100,91 & 100,75 & 100,60 & 100,70 & 100,51 & 100,52 & 100,74 & 100,56 & 100,71 \\
\hline
\end{tabular}

* $=\mathrm{Fe}_{2} \mathrm{O}_{3}$ y $\mathrm{FeO}$ discriminado estequiométricamente según Droop 1987; b.l.d. = bajo el límite de detección 
Posiciones $\mathbf{R}^{+2}$

Muestra $\rightarrow 21824$ (cerro Los Bueyes)

\begin{tabular}{|c|c|c|c|c|c|c|c|c|c|c|c|}
\hline \multicolumn{10}{|c|}{ Muestra $\rightarrow 21824$ (cerro Los Bueyes) } & \multicolumn{2}{|c|}{19334 E (c Naunauco) } \\
\hline c.p.u.f. & 16 & 17 & 18 & 19 & 20 & 21 & 22 & 23 & 24 & 1 & 2 \\
\hline $\mathrm{Fe}^{2+}$ & 8,0517 & 7,8443 & 7,9733 & 7,8985 & 7,8884 & 8,1588 & 7,9662 & 7,9026 & 7,8600 & 6,5312 & 6,2670 \\
\hline Mn & 0,3355 & 0,4879 & 0,4604 & 0,3938 & 0,4227 & 0,2982 & 0,5097 & 0,4672 & 0,5074 & 0,0424 & 0,0397 \\
\hline Mg & 0,3486 & 0,3729 & 0,3305 & 0,3809 & 0,2972 & 0,2772 & 0,3610 & 0,3359 & 0,3365 & 1,4294 & 1,7184 \\
\hline $\mathbf{C a}$ & 0,0000 & 0,0000 & 0,0000 & 0,0000 & 0,0000 & 0,0000 & 0,0000 & 0,0000 & 0,0000 & 0,0000 & 0,0000 \\
\hline Co & 0,0000 & 0,0000 & 0,0000 & 0,0000 & 0,0000 & 0,0000 & 0,0000 & 0,0000 & 0,0000 & 0,0412 & 0,0464 \\
\hline $\mathbf{N i}$ & 0,0051 & 0,0000 & 0,0000 & 0,0000 & 0,0000 & 0,0000 & 0,0000 & 0,0000 & 0,0000 & 0,0000 & 0,0042 \\
\hline Zn & 0,0383 & 0,0376 & 0,0775 & 0,0338 & 0,0614 & 0,0297 & 0,0326 & 0,0441 & 0,0268 & 0,0367 & 0,0000 \\
\hline $\mathbf{K}$ & 0,0153 & 0,0000 & 0,0000 & 0,0000 & 0,0092 & 0,0000 & 0,0000 & 0,0000 & 0,0000 & 0,0007 & 0,0012 \\
\hline Suma & 8,7945 & 8,7426 & 8,8418 & 8,7070 & 8,6789 & 8,7640 & 8,8695 & 8,7498 & 8,7307 & 8,0815 & 8,0769 \\
\hline
\end{tabular}

Posiciones $\mathrm{M}^{+3}$

\begin{tabular}{|c|c|c|c|c|c|c|c|c|c|c|c|}
\hline $\mathrm{Fe}^{3+}$ & 13,4590 & 13,7167 & 13,3854 & 13,7886 & 13,7754 & 13,6180 & 13,4450 & 13,6909 & 13,8293 & 15,3696 & 15,3767 \\
\hline Al & 0,8530 & 0,7092 & 0,8928 & 0,7184 & 0,7563 & 0,7657 & 0,7240 & 0,7195 & 0,6385 & 0,4667 & 0,4650 \\
\hline $\mathrm{Cr}$ & 0,0069 & 0,0031 & 0,0000 & 0,0007 & 0,0183 & 0,0069 & 0,0135 & 0,0083 & 0,0078 & 0,0000 & 0,0000 \\
\hline Sc & 0,0000 & 0,0012 & 0,0000 & 0,0000 & 0,0000 & 0,0000 & 0,0000 & 0,0007 & 0,0000 & 0,0029 & 0,0007 \\
\hline $\mathbf{V}$ & 0,0769 & 0,0859 & 0,0383 & 0,0783 & 0,0831 & 0,0815 & 0,0784 & 0,0817 & 0,0630 & 0,0000 & 0,0058 \\
\hline Suma & 14,3958 & 14,5160 & 14,3164 & 14,5860 & 14,6330 & 14,4721 & 14,2609 & 14,5010 & 14,5387 & 15,8392 & 15,8482 \\
\hline
\end{tabular}

\begin{tabular}{|c|c|c|c|c|c|c|c|c|c|c|c|}
\hline $\mathbf{S i}$ & 0,0333 & 0,0102 & 0,0334 & 0,0117 & 0,0105 & 0,0102 & 0,0081 & 0,0030 & 0,0159 & 0,0000 & 0,0000 \\
\hline $\mathbf{T i}$ & 0,7765 & 0,7312 & 0,8084 & 0,6953 & 0,6776 & 0,7538 & 0,8614 & 0,7462 & 0,7147 & 0,0793 & 0,0726 \\
\hline Suma & 0,8098 & 0,7414 & 0,8418 & $\mathbf{0 , 7 0 7 0}$ & 0,6881 & 0,7640 & $\mathbf{0 , 8 6 9 5}$ & 0,7492 & $\mathbf{0 , 7 3 0 7}$ & $\mathbf{0 , 0 7 9 3}$ & 0,0726 \\
\hline TOTAL & 24,0000 & 24,0000 & 24,0000 & 24,0000 & 24,0000 & 24,0000 & 24,0000 & 24,0000 & 24,0000 & 24,0000 & 23,9976 \\
\hline
\end{tabular}

Proporciones moleculares de los componentes finales*

\begin{tabular}{|c|c|c|c|c|c|c|c|c|c|c|c|}
\hline Espinela & 5,96 & 4,91 & 6,25 & 4,95 & 5,20 & 5,32 & 5,11 & 4,99 & 4,41 & 2,95 & 2,94 \\
\hline Magnetita & 93,99 & 95,06 & 93,75 & 95,04 & 94,68 & 94,63 & 94,80 & 94,95 & 95,54 & 97,05 & 97,06 \\
\hline Cromita & 0,05 & 0,02 & 0,00 & 0,00 & 0,13 & 0,05 & 0,10 & 0,06 & 0,05 & 0,00 & 0,00 \\
\hline TOTAL & 100,00 & 100,00 & 100,00 & 100,00 & 100,00 & 100,00 & 100,00 & 100,00 & 100,00 & 100,00 & 100,00 \\
\hline
\end{tabular}

*= según Deer et al. 1992 
Análisis de MAGNETITA por microsonda electrónica de ROCAS ÍGNEAS y MINERALIZACIONES

\begin{tabular}{|c|c|c|c|c|c|c|c|c|c|c|c|}
\hline Muestra $\rightarrow$ & $19334 \mathrm{I}$ & erro Nau & co) & & & & & & & & \\
\hline$\%$ en peso & 3 & 4 & 5 & 6 & 7 & 8 & 9 & 10 & 11 & 12 & 13 \\
\hline $\mathrm{SiO}_{2}$ & 0,01 & 0,03 & bl.d & bl.d & bl.d & bl.d & 0,02 & bl.d & 0,03 & bl.d & 0,15 \\
\hline $\mathrm{TiO}_{2}$ & 0,24 & 0,22 & 0,38 & 0,28 & 0,33 & 0,38 & 0,34 & 0,47 & 0,27 & 0,16 & 0,19 \\
\hline $\mathrm{Sc}_{2} \mathrm{O}_{3}$ & 0,01 & bl.d & bl.d & bl.d & bl.d & 0,04 & bl.d & bl.d & bl.d & 0,01 & 0,03 \\
\hline $\mathbf{A l}_{2} \mathbf{O}_{3}$ & 0,57 & 0,55 & 0,84 & 1,35 & 1,39 & 1,12 & 1,37 & 1,33 & 1,30 & 0,59 & 0,51 \\
\hline $\mathrm{Cr}_{2} \mathrm{O}_{3}$ & bl.d & bl.d & bl.d & bl.d & 0,04 & bl.d & bl.d & 0,01 & bl.d & bl.d & bl.d \\
\hline $\mathbf{V}_{2} \mathbf{O}_{3}$ & bl.d & bl.d & bl.d & bl.d & bl.d & 0,12 & 0,17 & bl.d & 0,01 & 0,02 & bl.d \\
\hline $\mathrm{Fe}_{2} \mathrm{O}_{3} *$ & 69,43 & 68,45 & 68,78 & 69,20 & 69,32 & 69,15 & 69,00 & 68,82 & 68,95 & 69,41 & 68,22 \\
\hline FeO* & 26,76 & 26,53 & 26,55 & 26,01 & 26,17 & 25,89 & 26,12 & 26,71 & 26,16 & 26,59 & 26,63 \\
\hline MnO & 0,07 & 0,08 & 0,17 & 0,13 & 0,11 & 0,19 & 0,14 & 0,08 & 0,13 & 0,11 & 0,12 \\
\hline $\mathrm{NiO}$ & bl.d & 0,03 & bl.d & bl.d & bl.d & bl.d & bl.d & bl.d & bl.d & bl.d & bl.d \\
\hline MgO & 2,91 & 2,74 & 2,95 & 3,52 & 3,54 & 3,57 & 3,53 & 3,24 & 3,42 & 2,90 & 2,71 \\
\hline $\mathrm{CaO}$ & 0,07 & 0,02 & 0,01 & bl.d & 0,01 & bl.d & 0,01 & bl.d & bl.d & 0,01 & 0,04 \\
\hline $\mathrm{CoO}$ & 0,15 & 0,12 & 0,13 & 0,15 & 0,18 & 0,17 & 0,20 & 0,21 & 0,19 & 0,12 & 0,12 \\
\hline ZnO & bl.d & 0,01 & 0,08 & 0,05 & bl.d & bl.d & 0,02 & bl.d & 0,01 & bl.d & 0,03 \\
\hline $\mathbf{K}_{2} \mathbf{O}$ & bl.d & bl.d & 0,01 & bl.d & bl.d & 0,03 & bl.d & bl.d & 0,01 & bl.d & bl.d \\
\hline $\mathbf{P}_{2} \mathbf{O}_{5}$ & bl.d & bl.d & bl.d & bl.d & bl.d & bl.d & bl.d & bl.d & bl.d & bl.d & bl.d \\
\hline TOTAL & 100,22 & 98,79 & 99,89 & 100,69 & 101,08 & 100,65 & 100,93 & 100,86 & 100,49 & 99,92 & 98,75 \\
\hline
\end{tabular}

*= $\mathrm{Fe}_{2} \mathrm{O}_{3}$ y $\mathrm{FeO}$ discriminado estequiométricamente según Droop 1987; b.l.d. = bajo el límite de detección 
Posiciones $\mathbf{R}^{+2}$

Muestra $\rightarrow \quad 19334$ E (cerro Naunauco)

\begin{tabular}{|c|c|c|c|c|c|c|c|c|c|c|c|}
\hline & & & & & & & & & & & \\
\hline c.p.u.ı. & 3 & 4 & 3 & 0 & 1 & 8 & 9 & 10 & 11 & 12 & 13 \\
\hline $\mathrm{Fe}^{2+}$ & 6,7045 & 6,7533 & 6,6648 & 6,4342 & 6,4450 & 6,4106 & 6,4420 & 6,6082 & 6,4864 & 6,6845 & 6,7824 \\
\hline Mn & 0,0168 & 0,0217 & 0,0420 & 0,0316 & 0,0272 & 0,0474 & 0,0351 & 0,0200 & 0,0315 & 0,0292 & 0,0313 \\
\hline Mg & 1,2995 & 1,2431 & 1,3201 & 1,5520 & 1,5543 & 1,5757 & 1,5520 & 1,4291 & 1,5114 & 1,2996 & 1,2302 \\
\hline $\mathbf{C a}$ & 0,0209 & 0,0077 & 0,0033 & 0,0000 & 0,0029 & 0,0000 & 0,0040 & 0,0000 & 0,0000 & 0,0030 & 0,0129 \\
\hline Co & 0,0370 & 0,0285 & 0,0304 & 0,0360 & 0,0414 & 0,0407 & 0,0481 & 0,0495 & 0,0461 & 0,0282 & 0,0283 \\
\hline $\mathbf{N i}$ & 0,0000 & 0,0069 & 0,0000 & 0,0000 & 0,0000 & 0,0000 & 0,0000 & 0,0000 & 0,0000 & 0,0000 & 0,0000 \\
\hline Zn & 0,0000 & 0,0020 & 0,0184 & 0,0117 & 0,0000 & 0,0000 & 0,0035 & 0,0000 & 0,0027 & 0,0000 & 0,0070 \\
\hline $\mathbf{K}$ & 0,0000 & 0,0003 & 0,0036 & 0,0000 & 0,0008 & 0,0105 & 0,0000 & 0,0000 & 0,0055 & 0,0000 & 0,0000 \\
\hline Suma & 8,0788 & 8,0635 & 8,0825 & 8,0656 & 8,0715 & 8,0848 & 8,0847 & 8,1068 & 8,0836 & 8,0445 & 8,0921 \\
\hline
\end{tabular}

Posiciones $\mathrm{M}^{+3}$

\begin{tabular}{|c|c|c|c|c|c|c|c|c|c|c|c|}
\hline $\mathrm{Fe}^{3+}$ & 15,6520 & 15,6769 & 15,5360 & 15,4009 & 15,3627 & 15,4053 & 15,3140 & 15,3227 & 15,3824 & 15,7018 & 15,6332 \\
\hline Al & 0,2001 & 0,1975 & 0,2955 & 0,4694 & 0,4840 & 0,3894 & 0,4778 & 0,4630 & 0,4531 & 0,2075 & 0,1826 \\
\hline $\mathrm{Cr}$ & 0,0000 & 0,0000 & 0,0000 & 0,0000 & 0,0095 & 0,0000 & 0,0000 & 0,0023 & 0,0000 & 0,0000 & 0,0000 \\
\hline Sc & 0,0013 & 0,0000 & 0,0000 & 0,0000 & 0,0000 & 0,0055 & 0,0000 & 0,0000 & 0,0002 & 0,0007 & 0,0035 \\
\hline $\mathbf{V}$ & 0,0000 & 0,0000 & 0,0000 & 0,0000 & 0,0000 & 0,0275 & 0,0404 & 0,0000 & 0,0014 & 0,0059 & 0,0000 \\
\hline Suma & 15,8534 & 15,8744 & 15,8315 & 15,8703 & 15,8562 & 15,8277 & 15,8322 & 15,7879 & 15,8372 & 15,9158 & 15,8193 \\
\hline
\end{tabular}

\begin{tabular}{|c|c|c|c|c|c|c|c|c|c|c|c|}
\hline $\mathbf{S i}$ & 0,0036 & 0,0095 & 0,0000 & 0,0003 & 0,0000 & 0,0000 & 0,0050 & 0,0000 & 0,0094 & 0,0000 & 0,0461 \\
\hline $\mathbf{T i}$ & 0,0544 & 0,0510 & 0,0860 & 0,0622 & 0,0723 & 0,0851 & 0,0765 & 0,1036 & 0,0602 & 0,0357 & 0,0425 \\
\hline Suma & $\mathbf{0 , 0 5 8 0}$ & 0,0604 & 0,0860 & 0,0624 & 0,0723 & $\mathbf{0 , 0 8 5 1}$ & 0,0815 & 0,1036 & 0,0696 & $\mathbf{0 , 0 3 5 7}$ & 0,0886 \\
\hline TOTAL & 23,9903 & 23,9983 & 24,0000 & 23,9984 & 24,0000 & 23,9976 & 23,9984 & 23,9984 & 23,9904 & 23,9959 & 24,0000 \\
\hline
\end{tabular}

Proporciones moleculares de los componentes finales*

\begin{tabular}{lrrrrrrrrrrr}
\hline Espinela & 1,26 & 1,24 & 1,87 & 2,96 & 3,05 & 2,47 & 3,03 & 2,93 & 2,86 & 1,30 & 1,15 \\
Magnetita & 98,74 & 98,76 & 98,13 & 97,04 & 96,89 & 97,53 & 96,97 & 97,05 & 97,14 & 98,70 & 98,85 \\
Cromita & 0,00 & 0,00 & 0,00 & 0,00 & 0,06 & 0,00 & 0,00 & 0,01 & 0,00 & 0,00 & 0,00 \\
\hline TOTAL & $\mathbf{1 0 0 , 0 0}$ & $\mathbf{1 0 0 , 0 0}$ & $\mathbf{1 0 0 , 0 0}$ & $\mathbf{1 0 0 , 0 0}$ & $\mathbf{1 0 0 , 0 0}$ & $\mathbf{1 0 0 , 0 0}$ & $\mathbf{1 0 0 , 0 0}$ & $\mathbf{1 0 0 , 0 0}$ & $\mathbf{1 0 0 , 0 0}$ & $\mathbf{1 0 0 , 0 0}$ & $\mathbf{1 0 0 , 0 0}$ \\
\hline * = según Deer et al & 1992 & & & & & & &
\end{tabular}

*= según Deer et al. 1992 
Análisis de MAGNETITA por microsonda electrónica de ROCAS ÍGNEAS y MINERALIZACIONES

\begin{tabular}{|c|c|c|c|c|c|c|c|c|c|c|c|}
\hline \multirow{2}{*}{$\begin{array}{c}\text { Muestra } \rightarrow \\
\% \text { en peso } \\
\end{array}$} & \multicolumn{11}{|c|}{19334 E (cerro Naunauco) } \\
\hline & 14 & 15 & 16 & 17 & 18 & 19 & 20 & 21 & 22 & 23 & 24 \\
\hline $\mathrm{SiO}_{2}$ & bl.d & 0,36 & bl.d & 0,04 & bl.d & bl.d & bl.d & 0,02 & 0,03 & bl.d & 0,01 \\
\hline $\mathrm{TiO}_{2}$ & 0,31 & 0,20 & 0,19 & 0,19 & 0,18 & 0,43 & 0,24 & 0,20 & 0,15 & 0,32 & 0,36 \\
\hline $\mathrm{Sc}_{2} \mathrm{O}_{3}$ & 0,00 & bl.d & 0,01 & 0,01 & bl.d & 0,03 & 0,03 & bl.d & 0,03 & bl.d & 0,03 \\
\hline $\mathbf{A l}_{2} \mathbf{O}_{3}$ & 0,40 & 1,00 & 0,63 & 0,67 & 0,26 & 0,67 & 0,77 & 0,66 & 0,39 & 0,41 & 0,71 \\
\hline $\mathrm{Cr}_{2} \mathrm{O}_{3}$ & bl.d & bl.d & 0,01 & bl.d & bl.d & 0,04 & 0,01 & bl.d & 0,04 & 0,01 & bl.d \\
\hline $\mathbf{V}_{2} \mathbf{O}_{3}$ & 0,07 & bl.d & 0,04 & 0,01 & 0,08 & bl.d & bl.d & bl.d & bl.d & bl.d & bl.d \\
\hline $\mathrm{Fe}_{2} \mathrm{O}_{3} *$ & 69,37 & 68,46 & 69,13 & 69,09 & 69,79 & 68,99 & 69,31 & 68,88 & 68,87 & 69,49 & 69,42 \\
\hline FeO* & 27,13 & 26,86 & 27,15 & 26,39 & 26,88 & 26,53 & 26,77 & 26,49 & 26,31 & 26,50 & 26,25 \\
\hline MnO & 0,08 & 0,06 & 0,11 & 0,10 & 0,06 & 0,05 & 0,10 & 0,10 & 0,10 & 0,08 & 0,07 \\
\hline $\mathrm{NiO}$ & 0,01 & bl.d & bl.d & bl.d & bl.d & bl.d & bl.d & bl.d & bl.d & bl.d & 0,01 \\
\hline MgO & 2,61 & 3,01 & 2,57 & 2,94 & 2,62 & 2,98 & 2,78 & 2,81 & 2,74 & 2,94 & 3,24 \\
\hline $\mathrm{CaO}$ & bl.d & 0,11 & bl.d & 0,06 & 0,11 & 0,24 & 0,08 & 0,13 & 0,18 & 0,12 & 0,13 \\
\hline $\mathrm{CoO}$ & 0,15 & 0,19 & 0,15 & 0,21 & 0,18 & 0,14 & 0,15 & 0,21 & 0,12 & 0,16 & 0,17 \\
\hline $\mathrm{ZnO}$ & 0,08 & 0,05 & 0,11 & 0,06 & bl.d & bl.d & 0,12 & bl.d & bl.d & bl.d & bl.d \\
\hline $\mathrm{Na}_{2} \mathrm{O}$ & bl.d & bl.d & bl.d & bl.d & bl.d & bl.d & bl.d & bl.d & bl.d & bl.d & bl.d \\
\hline $\mathbf{K}_{2} \mathbf{O}$ & bl.d & 0,02 & bl.d & bl.d & 0,01 & bl.d & bl.d & bl.d & bl.d & bl.d & bl.d \\
\hline $\mathbf{P}_{2} \mathbf{O}_{5}$ & bl.d & bl.d & bl.d & bl.d & bl.d & bl.d & bl.d & bl.d & bl.d & bl.d & bl.d \\
\hline TOTAL & 100,19 & 100,31 & 100,10 & 99,78 & 100,17 & 100,11 & 100,37 & 99,50 & $\mathbf{9 8 , 9 7}$ & 100,03 & 100,40 \\
\hline
\end{tabular}

* = $\mathrm{Fe}_{2} \mathrm{O}_{3}$ y FeO discriminado estequiométricamente según Droop 1987; b.l.d. = bajo el límite de detección 
Posiciones $\mathbf{R}^{+2}$

Muestra $\rightarrow \quad 19334$ E (cerro Naunauco)

\begin{tabular}{|c|c|c|c|c|c|c|c|c|c|c|c|}
\hline c.n.f. & 14 & 15 & & 17 & 18 & 19 & 20 & 21 & 22 & & \\
\hline $\mathrm{Fe}^{2+}$ & 6,8253 & 6,6945 & 6,8269 & 6,6371 & 6,7668 & 6,6460 & 6,7008 & 6.6847 & 6.6887 & 6.6568 & 65443 \\
\hline Mn & 0,0198 & 0,0144 & 0,0282 & 0,0263 & 0,0145 & 0,0132 & 0,0262 & 0,0259 & 0,0268 & 0,0212 & 0,0174 \\
\hline Mg & 1,1705 & 1,3372 & 1,1518 & 1,3179 & 1,1757 & 1,3308 & 1,2403 & 1,2640 & 1,2419 & 1,3166 & 1,4400 \\
\hline Ca & 0,0000 & 0,0349 & 0,0000 & 0,0200 & 0,0341 & 0,0766 & 0,0245 & 0,0405 & 0,0576 & 0,0390 & 0,0419 \\
\hline Co & 0,0356 & 0,0452 & 0,0367 & 0,0510 & 0,0442 & 0,0341 & 0,0361 & 0,0497 & 0,0303 & 0,0376 & 0,0415 \\
\hline $\mathbf{N i}$ & 0,0015 & 0,0000 & 0,0000 & 0,0000 & 0,0000 & 0,0000 & 0,0000 & 0,0000 & 0,0000 & 0,0000 & 0,0027 \\
\hline Zn & 0,0170 & 0,0104 & 0,0239 & 0,0139 & 0,0000 & 0,0000 & 0,0266 & 0,0000 & 0,0000 & 0,0000 & 0,0000 \\
\hline K & 0,0000 & 0,0075 & 0,0014 & 0,0000 & 0,0024 & 0,0000 & 0,0017 & 0,0000 & 0,0007 & 0,0000 & 0,0000 \\
\hline Suma & 8,0696 & 8,1442 & 8,0689 & 8,0662 & 8,0376 & 8,1008 & 8,0561 & 8,0648 & 8,0460 & 8,0712 & 8,0879 \\
\hline
\end{tabular}

Posiciones $\mathrm{M}^{+3}$

\begin{tabular}{|c|c|c|c|c|c|c|c|c|c|c|c|}
\hline $\mathrm{Fe}^{3+}$ & 15,7036 & 15,3518 & 15,6396 & 15,6336 & 15,8085 & 15,5525 & 15,6094 & 15,6402 & 15,7577 & 15,7096 & 15,5738 \\
\hline Al & 0,1403 & 0,3523 & 0,2234 & 0,2360 & 0,0933 & 0,2355 & 0,2731 & 0,2360 & 0,1397 & 0,1454 & 0,2503 \\
\hline $\mathrm{Cr}$ & 0,0008 & 0,0000 & 0,0013 & 0,0000 & 0,0000 & 0,0104 & 0,0035 & 0,0000 & 0,0099 & 0,0025 & 0,0000 \\
\hline Sc & 0,0004 & 0,0000 & 0,0009 & 0,0018 & 0,0002 & 0,0045 & 0,0035 & 0,0005 & 0,0046 & 0,0000 & 0,0035 \\
\hline $\mathbf{V}$ & 0,0161 & 0,0000 & 0,0088 & 0,0029 & 0,0205 & 0,0000 & 0,0000 & 0,0000 & 0,0000 & 0,0000 & 0,0000 \\
\hline Suma & 15,8612 & 15,7041 & 15,8739 & 15,8743 & 15,9225 & 15,8028 & 15,8895 & 15,8766 & 15,9119 & 15,8575 & 15,8276 \\
\hline
\end{tabular}

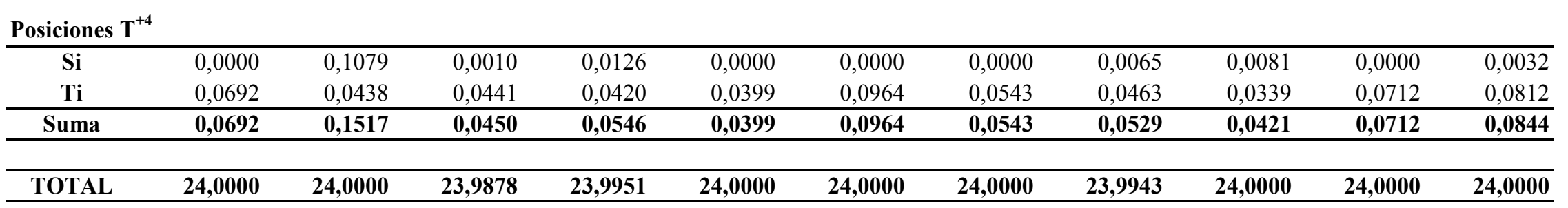

Proporciones moleculares de los componentes finales*

\begin{tabular}{crrrrrrrrrrr}
\hline Espinela & 0,89 & 2,24 & 1,41 & 1,49 & 0,59 & 1,49 & 1,72 & 1,49 & 0,88 & 0,92 & 1,58 \\
Magnetita & 99,11 & 97,76 & 98,58 & 98,51 & 99,41 & 98,44 & 98,26 & 98,51 & 99,06 & 99,07 & 98,42 \\
Cromita & 0,01 & 0,00 & 0,01 & 0,00 & 0,00 & 0,07 & 0,02 & 0,00 & 0,06 & 0,02 & 0,00 \\
\hline TOTAL & $\mathbf{1 0 0 , 0 0}$ & $\mathbf{1 0 0 , 0 0}$ & $\mathbf{1 0 0 , 0 0}$ & $\mathbf{1 0 0 , 0 0}$ & $\mathbf{1 0 0 , 0 0}$ & $\mathbf{1 0 0 , 0 0}$ & $\mathbf{1 0 0 , 0 0}$ & $\mathbf{1 0 0 , 0 0}$ & $\mathbf{1 0 0 , 0 0}$ & $\mathbf{1 0 0 , 0 0}$ & $\mathbf{1 0 0 , 0 0}$ \\
\hline * & & & &
\end{tabular}

*= según Deer et al. 1992 
Análisis de MAGNETITA por microsonda electrónica de ROCAS ÍGNEAS y MINERALIZACIONES

\begin{tabular}{|c|c|c|c|c|c|c|c|c|c|c|c|}
\hline \multicolumn{12}{|c|}{ Muestra $\rightarrow$ mina Augusta } \\
\hline$\%$ en peso & 1 & 2 & 3 & 4 & 5 & 6 & 7 & 8 & 9 & 10 & 11 \\
\hline $\mathrm{SiO}_{2}$ & 1,89 & bl.d & 0,81 & 0,01 & 0,05 & 0,08 & 0,24 & 0,02 & 0,02 & 0,03 & 0,06 \\
\hline $\mathrm{TiO}_{2}$ & bl.d & bl.d & bl.d & 0,06 & 0,02 & bl.d & 0,06 & 0,04 & 0,02 & bl.d & 0,06 \\
\hline $\mathrm{Sc}_{2} \mathrm{O}_{3}$ & 0,01 & 0,04 & 0,02 & bl.d & bl.d & bl.d & 0,02 & bl.d & 0,03 & 0,03 & 0,01 \\
\hline $\mathbf{A l}_{2} \mathbf{O}_{3}$ & 0,15 & 0,08 & 0,08 & 0,06 & 0,19 & 0,24 & 0,22 & 0,09 & 0,12 & 0,08 & 0,06 \\
\hline $\mathrm{Cr}_{2} \mathrm{O}_{3}$ & bl.d & bl.d & bl.d & bl.d & 0,02 & bl.d & bl.d & 0,01 & 0,02 & 0,01 & bl.d \\
\hline $\mathbf{V}_{2} \mathbf{O}_{3}$ & 0,03 & 0,12 & bl.d & bl.d & 0,04 & 0,01 & 0,07 & bl.d & bl.d & 0,07 & 0,11 \\
\hline $\mathrm{Fe}_{2} \mathrm{O}_{3} *$ & 64,10 & 68,30 & 65,97 & 68,49 & 68,30 & 68,50 & 67,95 & 68,08 & 68,59 & 68,71 & 68,58 \\
\hline FeO* & 32,07 & 30,56 & 30,80 & 30,70 & 30,82 & 30,71 & 31,13 & 30,45 & 30,61 & 30,89 & 31,05 \\
\hline MnO & 0,02 & 0,05 & 0,04 & 0,08 & 0,15 & 0,16 & 0,08 & 0,09 & 0,09 & 0,07 & 0,07 \\
\hline $\mathrm{NiO}$ & bl.d & bl.d & 0,01 & 0,02 & bl.d & bl.d & bl.d & bl.d & bl.d & bl.d & 0,02 \\
\hline MgO & 0,16 & 0,01 & 0,14 & 0,04 & bl.d & 0,03 & bl.d & 0,01 & bl.d & bl.d & 0,01 \\
\hline $\mathrm{CaO}$ & 0,47 & 0,04 & 0,23 & bl.d & 0,01 & 0,08 & 0,06 & 0,05 & 0,03 & bl.d & bl.d \\
\hline $\mathrm{CoO}$ & 0,15 & 0,16 & 0,14 & 0,19 & 0,14 & 0,14 & 0,22 & 0,19 & 0,18 & 0,15 & 0,17 \\
\hline ZnO & 0,14 & 0,03 & 0,09 & bl.d & bl.d & bl.d & bl.d & bl.d & 0,02 & bl.d & bl.d \\
\hline $\mathrm{Na}_{2} \mathrm{O}$ & bl.d & bl.d & bl.d & bl.d & bl.d & bl.d & bl.d & bl.d & bl.d & bl.d & bl.d \\
\hline $\mathrm{K}_{2} \mathrm{O}$ & 0,09 & 0,01 & 0,04 & bl.d & 0,01 & 0,02 & 0,01 & bl.d & 0,03 & bl.d & bl.d \\
\hline $\mathbf{P}_{2} \mathbf{O}_{5}$ & bl.d & bl.d & bl.d & bl.d & bl.d & bl.d & bl.d & bl.d & bl.d & bl.d & bl.d \\
\hline TOTAL & 99,28 & 99,39 & 98,37 & 99,64 & 99,76 & 99,96 & 100,07 & 99,04 & 99,75 & 100,04 & 100,21 \\
\hline
\end{tabular}

* = $\mathrm{Fe}_{2} \mathrm{O}_{3}$ y FeO discriminado estequiométricamente según Droop 1987; b.l.d. = bajo el límite de detección 
Posiciones $\mathbf{R}^{+2}$

Muestra $\rightarrow$ mina Augusta

\begin{tabular}{|c|c|c|c|c|c|c|c|c|c|c|c|}
\hline c.p.u.f. & 1 & 2 & 3 & 4 & 5 & 6 & 7 & 8 & 9 & 10 & 11 \\
\hline $\mathrm{Fe}^{2+}$ & 8,2226 & 7,9238 & 8,0213 & 7,9349 & 7,9510 & 7,9033 & 7,9969 & 7,9207 & 7,9066 & 7,9566 & 7,9782 \\
\hline Mn & 0,0049 & 0,0119 & 0,0107 & 0,0209 & 0,0401 & 0,0425 & 0,0213 & 0,0243 & 0,0227 & 0,0177 & 0,0184 \\
\hline Mg & 0,0735 & 0,0048 & 0,0663 & 0,0168 & 0,0011 & 0,0120 & 0,0011 & 0,0053 & 0,0000 & 0,0000 & 0,0063 \\
\hline $\mathbf{C a}$ & 0,1531 & 0,0131 & 0,0753 & 0,0012 & 0,0043 & 0,0267 & 0,0193 & 0,0168 & 0,0087 & 0,0016 & 0,0007 \\
\hline Co & 0,0367 & 0,0401 & 0,0353 & 0,0477 & 0,0345 & 0,0335 & 0,0548 & 0,0477 & 0,0451 & 0,0369 & 0,0419 \\
\hline $\mathbf{N i}$ & 0,0000 & 0,0000 & 0,0021 & 0,0041 & 0,0000 & 0,0000 & 0,0000 & 0,0000 & 0,0000 & 0,0000 & 0,0056 \\
\hline $\mathbf{Z n}$ & 0,0318 & 0,0074 & 0,0206 & 0,0000 & 0,0000 & 0,0000 & 0,0000 & 0,0000 & 0,0035 & 0,0000 & 0,0000 \\
\hline $\mathbf{K}$ & 0,0366 & 0,0021 & 0,0163 & 0,0000 & 0,0034 & 0,0064 & 0,0043 & 0,0000 & 0,0137 & 0,0000 & 0,0000 \\
\hline Suma & 8,5592 & 8,0032 & 8,2480 & 8,0257 & 8,0343 & 8,0243 & 8,0976 & 8,0149 & 8,0003 & 8,0127 & 8,0511 \\
\hline
\end{tabular}

Posiciones $\mathrm{M}^{+3}$

\begin{tabular}{|c|c|c|c|c|c|c|c|c|c|c|c|}
\hline $\mathrm{Fe}^{3+}$ & 14,7895 & 15,9336 & 15,4628 & 15,9312 & 15,8525 & 15,8594 & 15,7065 & 15,9342 & 15,9392 & 15,9261 & 15,8582 \\
\hline Al & 0,0546 & 0,0280 & 0,0299 & 0,0225 & 0,0689 & 0,0859 & 0,0812 & 0,0332 & 0,0420 & 0,0286 & 0,0221 \\
\hline $\mathrm{Cr}$ & 0,0000 & 0,0000 & 0,0000 & 0,0000 & 0,0044 & 0,0000 & 0,0000 & 0,0028 & 0,0044 & 0,0021 & 0,0000 \\
\hline Sc & 0,0019 & 0,0054 & 0,0022 & 0,0000 & 0,0000 & 0,0000 & 0,0025 & 0,0000 & 0,0041 & 0,0037 & 0,0011 \\
\hline $\mathbf{V}$ & 0,0074 & 0,0298 & 0,0000 & 0,0000 & 0,0104 & 0,0030 & 0,0178 & 0,0000 & 0,0000 & 0,0178 & 0,0266 \\
\hline Suma & 14,8534 & 15,9968 & 15,4950 & 15,9537 & 15,9363 & 15,9483 & 15,8079 & 15,9703 & 15,9897 & 15,9783 & 15,9079 \\
\hline
\end{tabular}

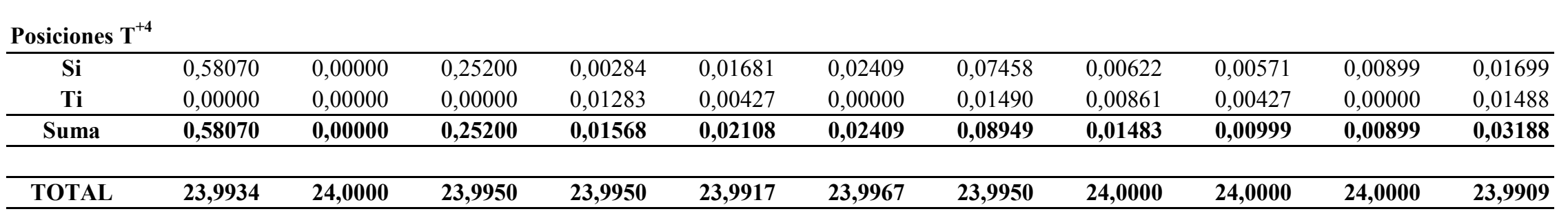

Proporciones moleculares de los componentes finales*

\begin{tabular}{lrrrrrrrrrrr}
\hline Espinela & 0,37 & 0,18 & 0,19 & 0,14 & 0,43 & 0,54 & 0,51 & 0,21 & 0,26 & 0,18 & 0,14 \\
Magnetita & 99,63 & 99,82 & 99,81 & 99,86 & 99,54 & 99,46 & 99,49 & 99,77 & 99,71 & 99,81 & 99,86 \\
Cromita & 0,00 & 0,00 & 0,00 & 0,00 & 0,03 & 0,00 & 0,00 & 0,02 & 0,03 & 0,01 & 0,00 \\
\hline TOTAL & $\mathbf{1 0 0 , 0 0}$ & $\mathbf{1 0 0 , 0 0}$ & $\mathbf{1 0 0 , 0 0}$ & $\mathbf{1 0 0 , 0 0}$ & $\mathbf{1 0 0 , 0 0}$ & $\mathbf{1 0 0 , 0 0}$ & $\mathbf{1 0 0 , 0 0}$ & $\mathbf{1 0 0 , 0 0}$ & $\mathbf{1 0 0 , 0 0}$ & $\mathbf{1 0 0 , 0 0}$ & $\mathbf{1 0 0 , 0 0}$ \\
\hline * = según Deer et al & 1992 & & & & & & & &
\end{tabular}

*= según Deer et al. 1992 
Análisis de MAGNETITA por microsonda electrónica de ROCAS ÍGNEAS y MINERALIZACIONES

\begin{tabular}{|c|c|c|c|c|c|c|c|c|c|c|c|}
\hline \multicolumn{12}{|c|}{ Muestra $\rightarrow$ mina Augusta } \\
\hline$\%$ en peso & 12 & 13 & 1 & 2 & 3 & 4 & 5 & 6 & 7 & 8 & 9 \\
\hline $\mathrm{SiO}_{2}$ & 0,12 & 1,37 & bl.d & 1,87 & 0,05 & 0,02 & 3,01 & 0,93 & 0,22 & 1,52 & 1,53 \\
\hline $\mathrm{TiO}_{2}$ & bl.d & bl.d & bl.d & bl.d & bl.d & bl.d & 0,05 & 0,06 & bl.d & 0,10 & 0,03 \\
\hline $\mathrm{Sc}_{2} \mathrm{O}_{3}$ & 0,03 & bl.d & bl.d & bl.d & 0,01 & bl.d & bl.d & bl.d & 0,01 & bl.d & bl.d \\
\hline $\mathbf{A l}_{2} \mathbf{O}_{3}$ & 0,05 & 0,08 & 0,05 & 0,29 & 0,03 & 0,02 & 0,55 & 0,07 & 0,10 & 0,15 & 0,03 \\
\hline $\mathrm{Cr}_{2} \mathrm{O}_{3}$ & 0,03 & 0,01 & 0,04 & bl.d & bl.d & 0,02 & bl.d & bl.d & bl.d & bl.d & 0,01 \\
\hline $\mathbf{V}_{2} \mathbf{O}_{3}$ & 0,03 & 0,02 & bl.d & 0,10 & 0,10 & bl.d & 0,02 & bl.d & 0,02 & bl.d & 0,05 \\
\hline $\mathrm{Fe}_{2} \mathrm{O}_{3} *$ & 68,58 & 64,92 & 69,05 & 64,38 & 68,73 & 68,85 & 60,91 & 65,49 & 68,09 & 64,56 & 64,79 \\
\hline FeO* & 30,98 & 31,65 & 30,68 & 31,89 & 30,58 & 30,58 & 32,94 & 30,85 & 30,84 & 32,16 & 31,59 \\
\hline MnO & 0,07 & 0,04 & 0,12 & 0,10 & 0,06 & 0,10 & 0,05 & 0,05 & 0,07 & 0,07 & 0,02 \\
\hline $\mathrm{NiO}$ & bl.d & bl.d & bl.d & bl.d & bl.d & bl.d & bl.d & bl.d & 0,01 & bl.d & bl.d \\
\hline MgO & 0,06 & 0,16 & 0,03 & 0,25 & 0,05 & 0,06 & 0,43 & 0,07 & bl.d & 0,10 & 0,13 \\
\hline $\mathrm{CaO}$ & bl.d & 0,24 & bl.d & 0,71 & 0,09 & 0,02 & 0,67 & 0,53 & 0,03 & 0,22 & 0,59 \\
\hline $\mathrm{CoO}$ & 0,15 & 0,20 & 0,20 & 0,14 & 0,18 & 0,15 & 0,12 & 0,16 & 0,14 & 0,23 & 0,17 \\
\hline ZnO & bl.d & bl.d & 0,09 & bl.d & 0,11 & 0,10 & 0,03 & bl.d & 0,06 & 0,07 & 0,06 \\
\hline $\mathrm{Na}_{2} \mathrm{O}$ & bl.d & bl.d & bl.d & bl.d & bl.d & bl.d & bl.d & bl.d & bl.d & bl.d & bl.d \\
\hline $\mathrm{K}_{2} \mathrm{O}$ & bl.d & 0,02 & bl.d & 0,06 & bl.d & bl.d & 0,08 & 0,04 & 0,02 & bl.d & 0,02 \\
\hline $\mathbf{P}_{2} \mathbf{O}_{5}$ & bl.d & bl.d & bl.d & bl.d & bl.d & bl.d & bl.d & bl.d & bl.d & bl.d & bl.d \\
\hline TOTAL & 100,10 & 98,71 & 100,25 & 99,79 & 100,00 & 99,92 & 98,87 & 98,23 & 99,61 & 99,18 & 99,01 \\
\hline
\end{tabular}

* = $\mathrm{Fe}_{2} \mathrm{O}_{3}$ y FeO discriminado estequiométricamente según Droop 1987; b.l.d. = bajo el límite de detección 
Posiciones $\mathbf{R}^{+2}$

Muestra $\rightarrow$ mina Augusta

\begin{tabular}{|c|c|c|c|c|c|c|c|c|c|c|c|}
\hline c.p.u.f. & 12 & 13 & 1 & 2 & 3 & 4 & 5 & 6 & 7 & 8 & 9 \\
\hline $\mathrm{Fe}^{2+}$ & 7,9680 & 8,1939 & 7,8865 & 8,1201 & 7,8770 & 7,8869 & 8,3993 & 8,0371 & 7,9688 & 8,2821 & 8,1454 \\
\hline Mn & 0,0194 & 0,0099 & 0,0310 & 0,0249 & 0,0157 & 0,0264 & 0,0137 & 0,0125 & 0,0190 & 0,0188 & 0,0062 \\
\hline Mg & 0,0256 & 0,0736 & 0,0142 & 0,1138 & 0,0215 & 0,0257 & 0,1964 & 0,0310 & 0,0000 & 0,0462 & 0,0603 \\
\hline $\mathbf{C a}$ & 0,0000 & 0,0812 & 0,0000 & 0,2328 & 0,0308 & 0,0071 & 0,2199 & 0,1763 & 0,0114 & 0,0719 & 0,1942 \\
\hline Co & 0,0380 & 0,0504 & 0,0482 & 0,0347 & 0,0438 & 0,0363 & 0,0305 & 0,0389 & 0,0355 & 0,0560 & 0,0431 \\
\hline $\mathbf{N i}$ & 0,0000 & 0,0000 & 0,0000 & 0,0000 & 0,0000 & 0,0000 & 0,0000 & 0,0000 & 0,0023 & 0,0000 & 0,0000 \\
\hline Zn & 0,0000 & 0,0011 & 0,0201 & 0,0000 & 0,0257 & 0,0229 & 0,0077 & 0,0000 & 0,0136 & 0,0159 & 0,0133 \\
\hline $\mathbf{K}$ & 0,0000 & 0,0074 & 0,0000 & 0,0250 & 0,0015 & 0,0000 & 0,0305 & 0,0145 & 0,0088 & 0,0000 & 0,0071 \\
\hline Suma & 8,0510 & 8,4175 & 8,0000 & 8,5513 & 8,0160 & 8,0052 & 8,8979 & 8,3102 & 8,0593 & 8,4909 & 8,4695 \\
\hline
\end{tabular}

Posiciones $\mathrm{M}^{+3}$

\begin{tabular}{|c|c|c|c|c|c|c|c|c|c|c|c|}
\hline $\mathrm{Fe}^{3+}$ & 15,8704 & 15,1233 & 15,9734 & 14,7488 & 15,9290 & 15,9765 & 13,9726 & 15,3500 & 15,8332 & 14,9634 & 15,0298 \\
\hline Al & 0,0188 & 0,0278 & 0,0176 & 0,1032 & 0,0122 & 0,0081 & 0,1966 & 0,0261 & 0,0349 & 0,0548 & 0,0100 \\
\hline $\mathrm{Cr}$ & 0,0063 & 0,0028 & 0,0091 & 0,0000 & 0,0000 & 0,0049 & 0,0000 & 0,0000 & 0,0000 & 0,0000 & 0,0021 \\
\hline Sc & 0,0039 & 0,0000 & 0,0000 & 0,0000 & 0,0016 & 0,0000 & 0,0000 & 0,0000 & 0,0014 & 0,0001 & 0,0000 \\
\hline $\mathbf{V}$ & 0,0074 & 0,0045 & 0,0000 & 0,0238 & 0,0252 & 0,0000 & 0,0045 & 0,0000 & 0,0045 & 0,0000 & 0,0120 \\
\hline Suma & 15,9068 & 15,1584 & 16,0000 & 14,8758 & 15,9681 & 15,9895 & 14,1738 & 15,3761 & 15,8740 & 15,0184 & 15,0539 \\
\hline
\end{tabular}

\begin{tabular}{|c|c|c|c|c|c|c|c|c|c|c|c|}
\hline $\mathbf{S i}$ & 0,0372 & 0,4233 & 0,0000 & 0,5697 & 0,0159 & 0,0052 & 0,9176 & 0,2898 & 0,0666 & 0,4671 & 0,4702 \\
\hline $\mathbf{T i}$ & 0,0000 & 0,0000 & 0,0000 & 0,0000 & 0,0000 & 0,0000 & 0,0107 & 0,0130 & 0,0000 & 0,0236 & 0,0064 \\
\hline Suma & 0,0372 & 0,4233 & 0,0000 & $\mathbf{0 , 5 6 9 7}$ & 0,0159 & $\mathbf{0 , 0 0 5 2}$ & 0,9283 & 0,3028 & 0,0666 & $\mathbf{0 , 4 9 0 7}$ & 0,4766 \\
\hline TOTAL & 23,9950 & 23,9992 & 24,0000 & 23,9967 & 24,0000 & 24,0000 & 24,0000 & 23,9891 & 24,0000 & 24,0000 & 24,0000 \\
\hline
\end{tabular}

Proporciones moleculares de los componentes finales*

\begin{tabular}{lrrrrrrrrrrr}
\hline Espinela & 0,12 & 0,18 & 0,11 & 0,69 & 0,08 & 0,05 & 1,39 & 0,17 & 0,22 & 0,36 & 0,07 \\
Magnetita & 99,84 & 99,80 & 99,83 & 99,31 & 99,92 & 99,92 & 98,61 & 99,83 & 99,78 & 99,64 & 99,92 \\
Cromita & 0,04 & 0,02 & 0,06 & 0,00 & 0,00 & 0,03 & 0,00 & 0,00 & 0,00 & 0,00 & 0,01 \\
\hline TOTAL & $\mathbf{1 0 0 , 0 0}$ & $\mathbf{1 0 0 , 0 0}$ & $\mathbf{1 0 0 , 0 0}$ & $\mathbf{1 0 0 , 0 0}$ & $\mathbf{1 0 0 , 0 0}$ & $\mathbf{1 0 0 , 0 0}$ & $\mathbf{1 0 0 , 0 0}$ & $\mathbf{1 0 0 , 0 0}$ & $\mathbf{1 0 0 , 0 0}$ & $\mathbf{1 0 0 , 0 0}$ & $\mathbf{1 0 0 , 0 0}$ \\
\hline * = según Deer et al & 1992 & & & & & & & &
\end{tabular}

*= según Deer et al. 1992 
Análisis de MAGNETITA por microsonda electrónica de ROCAS ÍGNEAS y MINERALIZACIONES

\begin{tabular}{|c|c|c|c|}
\hline \multicolumn{4}{|c|}{ Muestra $\rightarrow$ mina Augusta } \\
\hline$\%$ en peso & 10 & 11 & 12 \\
\hline $\mathrm{SiO}_{2}$ & 2,35 & 0,96 & 0,46 \\
\hline $\mathrm{TiO}_{2}$ & bl.d & bl.d & bl.d \\
\hline $\mathrm{Sc}_{2} \mathrm{O}_{3}$ & bl.d & bl.d & bl.d \\
\hline $\mathbf{A l}_{2} \mathbf{O}_{3}$ & 0,33 & 0,07 & 0,08 \\
\hline $\mathrm{Cr}_{2} \mathrm{O}_{3}$ & 0,02 & bl.d & bl.d \\
\hline $\mathbf{V}_{2} \mathbf{O}_{3}$ & bl.d & 0,04 & bl.d \\
\hline $\mathrm{Fe}_{2} \mathrm{O}_{3} *$ & 62,07 & 66,45 & 66,98 \\
\hline $\mathrm{FeO}^{*}$ & 32,16 & 31,81 & 30,73 \\
\hline MnO & 0,05 & 0,08 & 0,05 \\
\hline $\mathrm{NiO}$ & bl.d & 0,02 & bl.d \\
\hline MgO & 0,36 & 0,04 & 0,06 \\
\hline $\mathrm{CaO}$ & 0,49 & 0,14 & 0,15 \\
\hline $\mathrm{CoO}$ & 0,18 & 0,21 & 0,20 \\
\hline $\mathrm{ZnO}$ & bl.d & bl.d & bl.d \\
\hline $\mathrm{Na}_{2} \mathrm{O}$ & bl.d & bl.d & bl.d \\
\hline $\mathbf{K}_{2} \mathbf{O}$ & 0,06 & bl.d & 0,01 \\
\hline $\mathbf{P}_{\mathbf{2}} \mathbf{O}_{5}$ & bl.d & bl.d & bl.d \\
\hline TOTAL & 98,06 & 99,82 & 98,74 \\
\hline
\end{tabular}

* $=\mathrm{Fe}_{2} \mathrm{O}_{3}$ y FeO discriminado estequiométricamente según Droop 1987; b.l.d. = bajo el límite de detección 
Posiciones $\mathbf{R}^{+2}$

Muestra $\rightarrow$ mina Augusta

\begin{tabular}{cccc} 
Muestra $\rightarrow$ mina Augusta & & \\
\hline c.p.u.f. & 10 & 11 & 12 \\
\hline $\mathbf{F e}^{\mathbf{2 +}}$ & 8,3086 & 8,1675 & 7,9947 \\
$\mathbf{M n}$ & 0,0136 & 0,0218 & 0,0142 \\
$\mathbf{M g}$ & 0,1648 & 0,0192 & 0,0295 \\
$\mathbf{C a}$ & 0,1616 & 0,0477 & 0,0513 \\
$\mathbf{C o}$ & 0,0450 & 0,0511 & 0,0508 \\
$\mathbf{N i}$ & 0,0000 & 0,0044 & 0,0000 \\
$\mathbf{Z n}$ & 0,0000 & 0,0000 & 0,0000 \\
$\mathbf{K}$ & 0,0220 & 0,0000 & 0,0031 \\
\hline Suma & $\mathbf{8 , 7 1 5 6}$ & $\mathbf{8 , 3 1 1 7}$ & $\mathbf{8 , 1 4 3 7}$
\end{tabular}

\begin{tabular}{crrr} 
Posiciones $\mathbf{M}^{+\mathbf{3}}$ & & & \\
\hline $\mathbf{F e}^{\mathbf{3 +}}$ & 14,4278 & 15,3507 & 15,6815 \\
$\mathbf{A l}$ & 0,1193 & 0,0260 & 0,0297 \\
$\mathbf{C r}$ & 0,0054 & 0,0000 & 0,0000 \\
$\mathbf{S c}$ & 0,0000 & 0,0001 & 0,0000 \\
$\mathbf{V}$ & 0,0000 & 0,0089 & 0,0000 \\
\hline Suma & $\mathbf{1 4 , 5 5 2 6}$ & $\mathbf{1 5 , 3 8 5 7}$ & $\mathbf{1 5 , 7 1 1 1}$ \\
\hline
\end{tabular}

\begin{tabular}{cccc} 
Posiciones $^{+\mathbf{4}}$ & & & \\
\hline Si & 0,7259 & 0,2935 & 0,1435 \\
Ti & 0,0000 & 0,0000 & 0,0000 \\
\hline Suma & $\mathbf{0 , 7 2 5 9}$ & $\mathbf{0 , 2 9 3 5}$ & $\mathbf{0 , 1 4 3 5}$ \\
\hline & & & \\
\hline TOTAL & $\mathbf{2 3 , 9 9 4 1}$ & $\mathbf{2 3 , 9 9 0 9}$ & $\mathbf{2 3 , 9 9 8 3}$
\end{tabular}

Proporciones moleculares de los componentes finales*

\begin{tabular}{crrr}
\hline Espinela & 0,82 & 0,17 & 0,19 \\
Magnetita & 99,14 & 99,83 & 99,81 \\
Cromita & 0,04 & 0,00 & 0,00 \\
\hline TOTAL & $\mathbf{1 0 0 , 0 0}$ & $\mathbf{1 0 0 , 0 0}$ & $\mathbf{1 0 0 , 0 0}$ \\
\hline
\end{tabular}

*= según Deer et al. 1992 
Lic. Melisa A. Salvioli

Tesista doctoral

Dra. Mabel E. Lanfranchini Directora
Dr. Raúl E. de Barrio Director 